\title{
Peter Deutschmann
}

\section{Allegorien des Politischen}

Zeitgeschichtliche Implikationen des tschechischen historischen Dramas

(1810-1935)

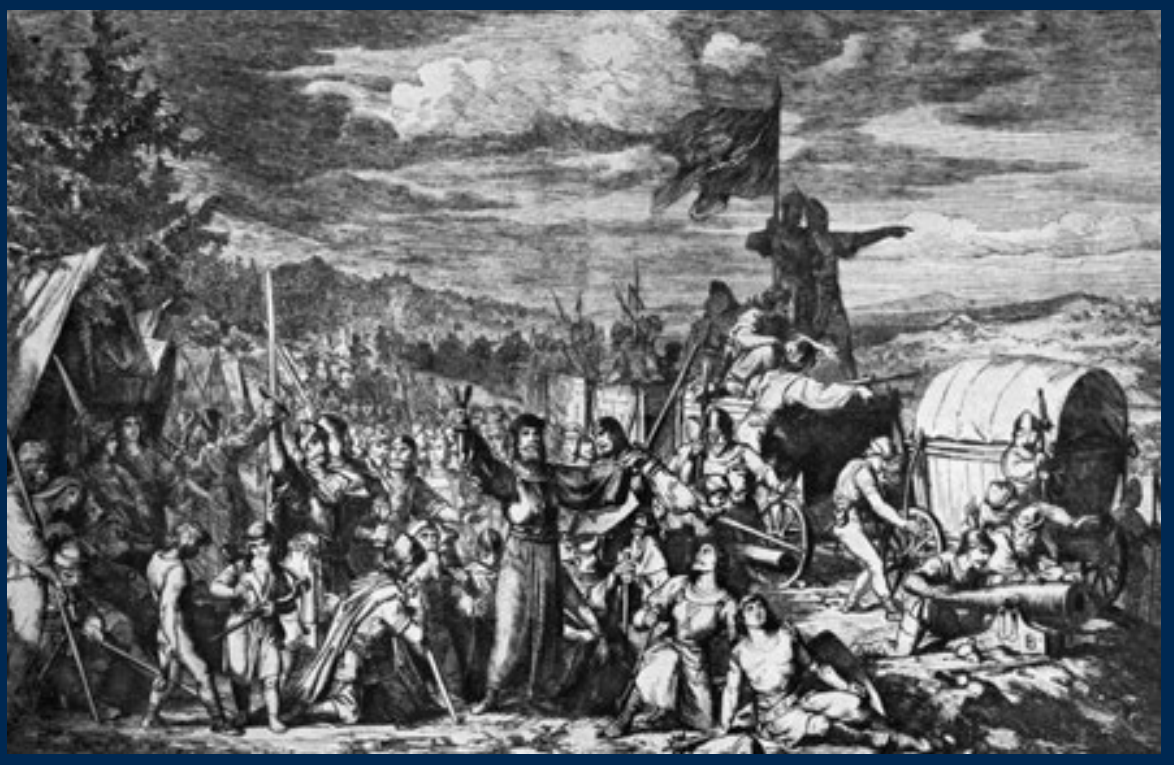


BAUSTEINE ZUR SLAVISCHEN PHILOLOGIE UND KULTURGESCHICHTE

NEUE FOLGE

Begründet von

HANS-BERND HARDER $(\dagger)$

und

HANS ROTHE

Herausgegeben von

DANIEL BUNČIĆ, ROLAND MARTI, PETER THIERGEN, LUDGER UDOLPH und BODO ZELINSKY

\author{
Reihe A: \\ SLAVISTISCHE FORSCHUNGEN
}

Begründet von

REINHOLD OLESCH $(\dagger)$

Band 83 



\section{Allegorien des Politischen}

Zeitgeschichtliche Implikationen des tschechischen historischen Dramas

(1810-1935)

von

Peter Deutschmann

2017

BÖHLAU VERLAG KÖLN WEIMAR WIEN 


\section{Veröffentlicht mit der Unterstützung des Austrian Science Fund (FWF): PUB 252-V23

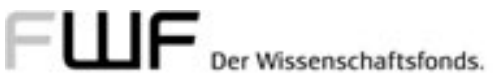

Peter Deutschmann ist Professor für Slawische Literaturund Kulturwissenschaft an der Universität Salzburg.

Bibliografische Information der Deutschen Nationalbibliothek: Die Deutsche Nationalbibliothek verzeichnet diese Publikation in der Deutschen Nationalbibliografie; detaillierte bibliografische Daten sind im Internet über http://portal.dnb.de abrufbar.

Umschlagabbildung:

P. Maixner: Hussitenlager vor dem Kampf (Tableau vivant, 1869), entnommen aus: Dějiny českého divadla. Sv. 3. Činohra 1848-1918. Hrsg. von František Černý und Ljuba Klosová. Praha: Academia 1977, S. 79.

() 2017 by Böhlau Verlag GmbH \& Cie, Köln Weimar Wien Ursulaplatz 1, D-50668 Köln, www.boehlau-verlag.com

Alle Rechte vorbehalten. Dieses Werk ist urheberrechtlich geschützt.

Jede Verwertung außerhalb der engen Grenzen des

Urheberrechtsgesetzes ist unzulässig.

Korrektorat: Josef Schiffer, Graz

Druck und Bindung: Prime Rate, Budapest

Gedruckt auf chlor- und säurefreiem Papier

Printed in the EU

ISBN 978-3-412-22510-0 
Politika vytvárela základni horizont, jemuž podléhala - prímo či neprímo - celá sféra kultury. (Brabec 2006, 16)

[Die Politik bildete den grundlegenden Rahmen, dem die gesamte Kultur - direkt oder indirekt - entsprach.] 



\section{Vorbemerkung}

Die vorliegende Arbeit entstand aus der persönlichen Einschätzung ihres Verfassers, dass die große Epoche von Drama und Theater, die für die europäischen Kulturen von der Aufklärung bis zu den Medieninnovationen des 20. Jahrhunderts von allergrößter Bedeutung war, abgeschlossen ist und dass einige ihrer Erscheinungen aus heutiger Sicht bereits erratisch anmuten. Aus der aktuellen Situation - Hans-Thies Lehmann hat sie mit großem Nachdruck als postdramatische beschrieben - ist gerade die enge Verbindung zwischen der Institution Theater und der Formierung von Nationalkulturen nicht mehr selbstverständlich. Dies mag unter anderem auch in dem Umstand begründet liegen, dass aus einer post factum-Perspektive, in der die politische wie kulturelle Bedeutung des Nationalen schon wieder im Schwinden begriffen ist, die einstige Entwicklung zur Nation nur mehr abstrakt als Voraussetzung gesehen wird. Die Umstände der Entwicklung sind der Erfahrung nicht mehr konkret gegeben, sie können allenfalls partiell rekonstruiert werden.

Die Geschichte der tschechischen Kultur während der vergangenen beiden Jahrhunderte kann insofern als Erfolgsgeschichte betrachtet werden, als das Tschechische vom Zustand einer kommunikativ nicht ausreichend funktionalen und soziolinguistisch von einer vom einfachen Volk in den Städten und in ländlichen Gebieten verwendeten Sprache zu einer voll ausgebauten, standardisierten Nationalsprache geworden ist. Daneben erfolgte die politische Emanzipation: aus einer größeren Ethnie im Verband der Habsburger Monarchie wurde 1918 im Verband mit den Slowaken eine tschechische „Staatsnation“.

Dass Theater und Drama bei diesen Veränderungen eine eminente Rolle gespielt haben, mag aus der Sicht heutiger Medienverhältnisse verwundern; mit der Errichtung des Nationaltheaters in Prag verbanden die Tschechen jedenfalls ihre Konsolidierung als nationale Gemeinschaft. Bezeichnend ist hierfür die Dialektik von Idee und Manifestation, von Gebäude und kulturell gefasster Ethnie. Denn gegenüber der stets abstrakten Idee von Volk, Nation, Kultur etc. weist ein als „Kathedrale der Nation" apostrophiertes Gebäude jene Konkretheit auf, an der es der Idee mangelt. In der berühmten Widmung über der Bühne des Tschechischen Nationaltheaters Národ sobé - ist daher auch ein performatives Moment zu erkennen, durch welches Kultur erst entsteht bzw. als gemachte erscheint. Der Dativus commodi von Národ sobé kann so verstanden werden, dass nicht allein das Theatergebäude Gegenstand der Nutznießung durch das tschechische „Volk“ ist, sondern dass sich das Volk seiner selbst erst vermittels des Nationaltheaters inne wird.

Diese Publikation beschäftigt sich freilich nicht in erster Linie mit den kulturgeschichtlichen Aspekten des tschechischen Nationaltheaters, sondern mit einer literarischen (Sub-)gattung, für die das Nationaltheater den gemäßen Rahmen abgibt. Das historische Drama als Genre ist stärker als alle anderen theatralen Gattun- 
gen mit den Prozessen der Nationswerdung verbunden, stellt es doch Momente der Geschichte vor Augen, die als bedeutsam für die Geschicke der jeweiligen Nation angesehen werden. Die nationalkulturellen Implikationen dieser Geschichtsrepräsentation sowie die darin erkennbaren politischen Ideen stehen im Zentrum dieser Arbeit.

Diese wurde in ihren Anfängen als kontrastive Arbeit konzipiert: zwei unterschiedliche politische Kontexte - im Fall der tschechischen Kultur deren Eingebundenheit in die supranationale Habsburgermonarchie, im Fall der russischen Kultur deren Eigenstaatlichkeit - sollten den Hintergrund für den Vergleich historischer Dramen tschechischer und russischer Provenienz liefern. Nach einigen Vorarbeiten zeigte sich freilich, dass eine solche Themenstellung den Rahmen einer monographischen Darstellung überschreitet, sodass nunmehr allein das tschechische historische Drama im Mittelpunkt steht und vergleichende Arbeiten in anderem Zusammenhang als Aufsätze publiziert wurden.

In der ursprünglichen Fassung wurde diese Monographie im Februar 2012 als Habilitationsschrift an der Universität Graz eingereicht und im Oktober 2012 approbiert. In dieser Form ist sie auch online auf www.academia.edu zugänglich gemacht worden. Die vom Fond Wissenschaftlicher Forschung (FWF) geförderte Publikation der Arbeit im Rahmen der Bausteine zur Slavischen Philologie und Kulturgeschichte. Reibe A. Slavistische Forschungen machte eine Ergänzung um relevante neuere Publikationen erforderlich. Im Zuge der Publikationsvorbereitung wurden auch Korrekturen und geringfügige Veränderungen am Text vorgenommen, die allerdings den Aussagegehalt nicht wesentlich verändert haben.

Ich möchte allen Personen herzlich danken, die in verschiedenen Stadien der Arbeit mit Rat und Tat zum Entstehen dieses Buches beigetragen haben: Vorrangig gilt mein Dank Prof. Wolfgang Eismann (Univ. Graz) für seine langährige Unterstützung und geduldige Beratung. Während eines Forschungsaufenthalts in Prag zu Beginn der Arbeit, der durch das mittlerweile leider nicht mehr existierende Programm MOEL-plus der Österreichischen Forschungsgemeinschaft (ÖFG) ermöglicht wurde, erhielt ich wichtige Hinweise von Prof. Dalibor Tureček (Univ. České Budějovice), Univ. Doz. Dr. Jiří Brabec (Ústav pro českou literaturu, Prag), Dr. Barbara Topolová (Divadelní ústav Prag) sowie Prof. Jiř́ Holý (Karlova univerzita, Prag). Für Gutachtermeinungen danke ich des Weiteren Prof. Anja Tippner (Univ. Hamburg) und Prof. Andreas Leben (Univ. Graz) sowie Prof. Ludger Udolph (TU Dresden). Letzterem sei auch herzlich für die Aufnahme in die Reihe Bausteine zur Slavischen Philologie und Kulturgeschichte. Reibe A. Slavistische Forschungen des Böhlau Verlags gedankt, dessen Programmleiter Johannes van Ooyen ein umsichtiger Berater bei Publikationsfragen ist. Die sprachliche und technische Redaktion wurde durch tatkräftige Mithilfe von Zahra Mani (englische Übersetzung der Überblicksdarstellung), Mgr. Patrik Varga (Übersetzung des Überblicks 
ins Tschechische sowie Redaktion tschechischsprachiger Textteile), Herrn Mag. Josef Schiffer (Lektorat, Korrektorat), Herrn Dr. Emmerich Kelih (technische Assistenz), Frau Vera Flasch (Register) sowie Frau MMag. Marie Brunová (Korrektorat) erleichtert. Hilfreich bei der Fertigstellung waren auch die StudienassistentInnen Karin Ramsauer, Lukas Meingaßner und Thomas Schroll vom Salzburger Fachbereich Slawistik. Immer noch vorhandene Unzulänglichkeiten in der vorliegenden Publikation verantworte ich freilich ausschließlich selbst. 



\section{Inhalt}

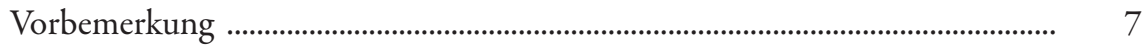

Einleitung: Themenstellung - Relevanz - Ergebnisse ........................................... 15

Differenzierung zu Theaterwissenschaft und Theatergeschichte ......................... 16

Zeitbezüge im historischen Drama ....................................................................... 17

Analysefokus und Korpus ................................................................................... 18

Skizzierung der Ergebnisse ..................................................................................... 19

Aufbau und Gliederung ...................................................................................... 20

A. Allgemeiner Teil: Zur Spezifik der Gattung „,historisches Drama“ ...... 21

I. Historische Dramen: Aktualität und (Re-)Konstruktion .............................. 23

I.1. Historisches Drama und kulturelles Gedächtnis .................................. 27

I.2. Eine systemtheoretische Beschreibung von kulturellem Gedächtnis 32

I.3. Zur Repräsentation von Geschichte im dramatischen Text ................ 35

I.4. Repräsentation und dramatische Handlung (mythos) ......................... 38

I.5. Historisches Drama und Geschichtsschreibung als

Repräsentationen ................................................................................. 40

I.6. Dramatische Re-/De-präsentation........................................................... 48

I.7. Die Allegorie zwischen Repräsentation und Depräsentation ............ $\quad 52$

I.8. Die Repräsentationsleistung des Dramas in der Ästhetik Hegels....... 56

I.9. Die Nation in Hegels Ästhetik und das historische Drama ................ 69

II. Kommunikationstheoretische Implikationen der Gattung Drama ............. 73

II.1. Zur Fokussierung der Analyse................................................................... $\quad 75$

II.2. Text und Lebenswelt ............................................................................. $\quad 76$

II.3. Die ideologische Bewertung eines Dramas ............................................. $\quad 80$

II.4. Dialogizität und Drama ............................................................................ 86

II.5. Eine Frage der Perspektive? ................................................................... 90

II.6. Die Position des Dritten als methodische Konsequenz aus

Bachtins Polyphoniekonzept .................................................................. 92

II.7. Theoretische Bestimmung des Analysestandpunktes............................ 99

II.8. Die Positionen des Dritten ..................................................................... 101

II.9. Was beobachtet das (Lese-)Publikum?................................................. 102

III.Erläuterungen und Überleitung zum analytischen Teil ................................... 107

III.1. Zur Gattungsdefinition und Korpuswahl ............................................ 107

III.2. Erläuterungen zur Schreibweise von Eigennamen und zu

Pluralformen mit generischer Bedeutung ........................................... 111

III.3. Erläuterungen zur ideologischen Analyse.............................................. 112

III.4. Legende zu den Figurenkonstellationen ............................................. 114 


\section{B. Analytischer Teil: Das tschechische historische Drama im} soziokulturellen Kontext

IV. (Historisches) Drama und Gesellschaft

IV.1. Aufriss der Gattungstradition

IV.2. Der kulturgeschichtliche Kontext des tschechischen Dramas 124

IV.3. Tschechisches Theater vor 1848 130

IV.3.1. Exkurs: Kurze Bemerkung zur Zensurpraxis 142

IV.4. Ideologische Analysen historischer Dramen des obrození 146

IV.4.1. Jan Nepomuk Štěpánek: Břetislav Proní, Český Achylles, aneb: Vitèzsstvi u Domažlic. Vlastenská puivodní cinohraz jedenáctého stoletív péti jednánich (1812)

IV.4.2. Josef Linda: Jaroslav Šternberg v boji proti Tatariom. Divadelni hra (1823)

IV.4.3. Václav Kliment Klicpera: Soběslav, selský kniže. Truchlohra ve čtveru dèjství (1826)

IV.4.4. Šebestián Hněvkovský: Jaromir. Smutnohra v pateru jednání (1835)

IV.4.5. Karel Hynek Máchas Bemühungen um historische Dramen (1830-33)

IV.4.6. Josef Kajetán Tyl: Čestmír. Dramatická báseñ ve dvou oddélenich (1835)

IV.4.7. Václav Vojáček: Ludmila. Drama ve tréch dèjstvích (1843)...

IV.4.8. Simeon Karel Macháček: Záviš Vitkovic, pán z Rưže anebo Pokuta za zradu. Smutnohra v pateru jednáni (1846)

IV.4.9. Josef Jiří Kolár: Monika. Tragédie ve trech jednánich (1846)....

IV.4.10.Ferdinand Břetislav Mikovec: Zábuba rodu Premyslovského. Tragédie ve čtyřech jednánich (1848)

IV.4.11.Josef Kajetán Tyl: Krvavý soud aneb Kutnohorsttí havirí. Cinohra v pèti jednánich (1847)

IV.4.12.Josef Kajetán Tyl: Jan Hus. Dramatická báseñ v 5 oddèlenich (1848)

IV.5. Synopsis: Themen und Tendenzen des historischen Dramas von 1812 bis 1848

IV.6. Das historische Drama in der zweiten Hälfte des 19. Jahrhunderts...

IV.6.1. Exkurs zur Geschichte des Nationaltheaters

IV.6.2. Josef Václav Frič: Svatopluk a Rastislav. Truchlohra v pateru dějstvích $z$ dèjin moravských (1857).

IV.6.3. Exkurs zum Dramenwettbewerb für historische Dramen aus der slawischen Geschichte 
IV.6.4. Vítězslav Hálek: Závišz z Falkenštejna. Tragedie v pèti jednánich (1860)

IV.6.5. Vítězslav Hálek: Král Vukašín. Tragedie v pèti jednáních (1862) 270

IV.6.6. Vítězslav Hálek: Sergius Catilina. Tragedie v pěti jednáních (1863)

IV.6.7. Josef Václav Frič: Ivan Mazepa. Tragedie v 5 dèjstvích (1865)

IV.6.8. Emanuel Bozděch: Baron Goertz. Truchlohra v péti dèjstvich (1867)

IV.6.9. František Zákrejs: Král svého lidu. Truchlohra v pèti dèjstvich (1879)

IV.6.10.Václav Vlček: Lipany. Truchlohra v péti jednánich (1881).... 303

IV.6.11.Ladislav Stroupežnický: Panímincmistrová. Aktovka (1885)

IV.6.12.Julius Zeyer: Neklan. Tragedie o péti jednáních (1893)......... 316

IV. 7. Das historische Drama im ersten Drittel des 20. Jahrhunderts ........ 324

IV.7.1. Alois Jirásek: Jan Žižka. Historická hra o péti jednáních (1903)

IV.7.2. Jaroslav Hilbert: Falkenštejn. Hra o pèti dèjstvích (1903) .......

IV.7.3. Ein Vergleich der Usurpationsdramen um Záviš von Falkenštejn und Otokar Fischers Premyslovci. Hra o pèti dèjstvich (1918)

IV.7.4. Jaroslav Hilbert: Česká komedie. Válečná episoda z roku 1866 o jednom dèjstvi (1908)

IV.7.5. Viktor Dyk: Posel. Drama o třech déjstvich (1907) und Revolućni trilogie (1908-1917)

IV.7.6. Arnošt Dvořák: Král Václav IV. Drama o pěti dèjstvích (1910)

IV.7.7. Arnošt Dvořák: Husité. Tragedie národa o pěti dèjstvích (1919)

IV.8. Diachroner Überblick über Dramen um den hl. Václav/Wenzel....... 365

IV.8.1. Josef Kajetán Tyl: Krvavé křtiny, čili, Drahomira a její synové: Romantický obraz z dávných dèjin českých ve čtyřch oddělenich (1849)

IV.8.2. Jan Dvorský: Drahomíra. Dramatický obraz z českých dějin v trech jednánich (1859).

IV.8.3. Jaroslav Vrchlický: Česká trilogie (1882-1903). 376

IV.8.4. František Langer: Svatý Václav. Tragédie ve třech dèjstvich (1912) 
IV.8.5. František Zavřel: Boleslav Ukrutný. Tragoedie o trech dèjstvich (1919)

IV.8.6. Jaroslav Durych: Svatý Václav. Kvas na Boleslavi. Hra o třech dèjstvich (1924)

IV.8.7. Gabriela Preissová: Svatý Václav. Hra o pèti dèjstvích (1929) 406

IV.8.8. Stanislav Lom: Svatý Václav. Tragická hra z českých déjin (1935)

IV.9. Zusammenfassung des diachronen Überblicks über die Dramatik um sv. Václav

V. Zusammenfassender Überblick über die analysierten Dramen 426

V.1. Methodische Vorbemerkung 426

V.2. Erörterungen zu diversen Synopsen 430

V.3. Schlussbemerkung 444

VI. Brief Overview of the Study 448

VII. Stručná charakteristika díla 455

VIII. Literaturverzeichnis 461

VIII.1. Abkürzungen und Siglen

VIII.2. Primärliteratur 461

VIII.3. Sekundärliteratur 463

IX. Namens- und Werkregister. 473 


\section{Einleitung: Themenstellung - Relevanz - Ergebnisse}

Die vorliegende Abhandlung untersucht in einem diachronen Überblick, wie sich der politisch-ideologische Gehalt in den historischen Dramen der tschechischen Literatur zwischen 1810 und 1935 - vom Beginn der Dramatik des obrozeni ${ }^{1}$ bis zu den Millenniumsfeiern des Václav/Wenzel-Jubiläums der tschechoslowakischen Republik - gewandelt hat. Für die Gattung des historischen Dramas kann gelten, dass die politische bzw. ideologische Funktion in der Regel über die anderen Funktionen des Sprachkunstwerks dominiert. Die Leitidee der Untersuchung ist, dass den historischen Dramen eine allegorische Struktur zugrunde liegt, die über bloße Geschichtsdarstellung oder "Geschichtsdeutung" (vgl. Neubuhr 1980, 3f) hinausgeht: Neben der Darstellung historischer oder pseudohistorischer Ereignisse haben die tschechischen Dramen einen allegorischen Bezug auf politische Fragen ihrer Entstehungszeit. Neben der Funktion, die nationale Existenz in einer möglichst fernen Vergangenheit nachzuweisen, ${ }^{2}$ haben die Dramen auch eine ideologische Aussage, die mehr oder weniger offensichtlich im Text bzw. im Handlungszusammenhang manifest ist.

Die Analyse von ca. 40 Dramen aus einem Zeitraum von 125 Jahren zeichnet nach, wie sich der zeitaktuelle politische Gehalt der Dramen verändert hat und auf welche Weise die zeitgleich erfolgenden Ereignisse bzw. Veränderungen (Erstarken der Nationalbewegung, Revolution von 1848, Beginn des Parlamentarismus, Österreichisch-Ungarischer Ausgleich, Nationalitätenkonflikt, Erster Weltkrieg und Zerfall der Monarchie, tschechoslowakische Eigenstaatlichkeit) reflektiert werden.

Mit dieser Fragestellung wird zugleich ein geschichtlicher Überblick über die Entwicklung einer Gattung gegeben, der einerseits in der Kultur- und Theatergeschichte vieler europäischer Völker - namentlich der Tschechen - eine große Bedeutung beigemessen wurde, die aber andererseits wohl aufgrund ihrer starken ideologischen Funktion in der literaturwissenschaftlichen Forschung eher wenig Aufmerksamkeit gefunden hat. Zwar gibt es nicht wenige Einzelanalysen von historischen Dramen sowie Darstellungen des dramatischen Schaffens einzelner Autoren

1 Mit dem Zeitrahmen 1810-1935 handelt es sich um eine annalistische Rundung, denn im Jahr 1810 gab es - aufgrund des Krieges gegen das napoleonische Heer - überhaupt keine Theateraufführungen in Prag. Die patriotischen Schauspiele von Jan Nepomuk Štěpánek, die als historische Dramen gelten können, wurden ab dem Jahr 1812 im Prager Ständetheater aufgeführt (vgl. Laiske 1974, I/89f; Haman 2007, 78).

2 Vgl. die Funktionsbestimmung Walter Puchners, der auch auf die Vielgestaltigkeit des historischen Dramas hinweist: „Erweckung und Kultivierung des nationalen Selbstbewusstseins, das die Unterschiede zu anderen Völkern hervorhebt und das Eigenständige unterstreicht, das geltende oder entstehende Wir-Bilder und Fremdbilder in der (fernen) Vergangenheit wiedererstehen läßt und dem Zuschauer zur Identifikation anbietet“" (Puchner 1994, 77). 
oder bestimmter Epochen, ein zusammenhängender größerer Überblick über die Entwicklung der historischen Dramatik in der tschechischen Literatur des 19. oder der ersten Hälfte des 20. Jahrhunderts liegt jedoch nicht vor. Aufgrund der Menge an Dramen mit historischen Stoffen, die in der untersuchten Periode entstanden sind, kann der im Folgenden gegebene Überblick nur einen Ausschnitt darstellen, verbunden ist damit allerdings die Hoffnung, dass dieser Ausschnitt eine synekdochische Relation auf das Totum hat, also einigermaßen repräsentativ ist. Die Fokussierung auf den politischen bzw. ideologischen Gehalt der Dramen gründet in einem kulturgeschichtlichen Interesse, das idealiter der politischen bzw. ideologischen Funktion der historischen Dramen besser entsprechen sollte als eine rein literaturwissenschaftliche dramenanalytische Perspektive.

\section{Differenzierung zu Theaterwissenschaft und Theatergeschichte}

Vor der Verbreitung der technischen Medien war das Theater, für das die historischen Dramen ja konzipiert waren, die wichtigste Institution für die Formierung von Öffentlichkeit; es erreichte breitere Gesellschaftsschichten und behandelte oft andere Themen als die traditionellen Printmedien. Die Dissemination von Geschichtsbildern wie auch die Reaktualisierung der Geschichte in der damaligen Gegenwart konnten von der Gattung des historischen Dramas ideal umgesetzt werden.

Die tschechische Nationaltheaterbewegung, deren Vorboten ins späte 18. Jahrhundert zurückreichen ${ }^{3}$ und die noch vor 1848 Gestalt annahm, aber im europäischen Vergleich erst relativ spät mit der Eröffnung des Národní divadlo 1881 bzw. 1883 ihr Ziel erreichte, ist in ihrer Relevanz für die Konsolidierung der tschechischen Nation schon vielfach beschrieben worden. Philipp Ther $(2006,260)$ sieht die Entstehungsgeschichte des Národní divadlo nicht nur als ,zentrale[n] Bestandteil der tschechischen Nationalgeschichte, sondern zugleich [als] ein Lehrstück für die europäische Geschichte“. Den Theaterstücken, die in diesem Zentralbau der Nationalbewegung aufgeführt werden sollen, wird metonymisch eine ähnliche Bedeutung zugeschrieben. So erklärt Pavla Buzková (vgl. 1932, 27), dass das tschechische Drama eng mit dem Schicksal der "wiedergeborenen“ Nation verbunden sei und aufgrund seines „blutigen Ernstes“ Anklänge an die griechische Schicksalstragödie der Antike erkennen lasse. ${ }^{4}$

Während die theatergeschichtlichen Aspekte schon in enzyklopädischer Breite untersucht worden sind - die vierbändige Darstellung der Déjiny českého divadla

3 Prokop Šedivý fügte seiner Übersetzung von Schillers Vortrag „Die Schaubühne als eine moralische Anstalt betrachtet“ die Bemerkung hinzu: „Wenn wir endlich ein festes tschechisches Theater hätten, dann wären wir auch ein Volk" - (zit. nach Císař 2004, 32f).

4 Die dem tschechischen Theater zugemessene Bedeutung erkennt man auch an der großen theaterwissenschaftlichen Tradition, die sogar den Wechsel der politischen Regimes im 20. Jahrhundert einigermaßen gut überstanden hat. 
(1968-1983) ist trotz ihrer ideologischen Imprägnierung nach wie vor ein unverzichtbares Standardwerk -, gibt es bislang keine vergleichbare jüngere Untersuchung, die eine Geschichte der Gattung Drama oder der Subgattung historisches Drama in der tschechischen Literatur beschreibt. Das Drama, das bevorzugt Stoffe aus der eigenen Geschichte behandelt, galt - zumindest im 19. Jahrhundert - als prestigereiches Genre im kulturellen Wettbewerb der Nationen. Es stand in der Hierarchie der Gattungen weit oben - davon zeugen so unterschiedliche kunst- bzw. literaturtheoretische Schriften wie etwa Hegels Vorlesungen zur Ästhetik und Josef Jungmanns Slovesnost sowie der von Ferdinand Fingerhut (Náprstek) ausgelobte Preis für die Schaffung eines Dramas mit einem Stoff aus der slawischen Geschichte, der in den späten 1850er Jahren die tschechische Dramatik auf ein internationales Niveau heben sollte. ${ }^{5}$ Um die kulturpolitische Wichtigkeit dieser Gattung pointiert hervorzuheben: Wenn das Národní divadlo als die nötige „Hardware“ für die tschechische Kultur angesehen werden kann, so ist das historische Drama die entsprechende „Software“ - eine Art nationalpolitisches „Programm“. Entsprechend wurden zu den Eröffnungen des Národní divadlo (1881) sowie auch des Prozatímní divadlo (1862), das gleichsam die Ensembles wie auch die Öffentlichkeit auf das Nationaltheater vorbereiten sollte, historische Dramen aufgeführt. ${ }^{6}$

Allerdings zeigt ein Rückblick auf die Theatergeschichte, dass historische Dramen nur in Ausnahmefällen größere Popularität beim Publikum genossen, das in der Regel zeitgenössische Stoffe und weniger gravitätische Gattungen wie Komödien, Sing- und Zauberspiele oder Schwänke bevorzugte. ${ }^{7}$

\section{Zeitbezüge im historischen Drama}

Der doppelte Zeitbezug des historischen Dramas lässt sich mit dem für diese Arbeit geprägten Begriffspaar „Repräsentation“ und „Depräsentation“ gut erfassen. Der dramatische Text holt einerseits Ereignisse der Vergangenheit in die jeweilige Gegenwart der Produktion/Rezeption („Repräsentation“), andererseits wird die Auswahl von Stoffen und ihre dramatische Gestaltung von Ereignissen der Gegenwart mitbestimmt, gegenwärtig Aktuelles wird in die Vergangenheit projiziert, was metaphorisch als „Depräsentation“ bezeichnet werden kann. Für diesen doppelten

$5 \mathrm{Vgl}$. Zprávy soudců o dramatech $z$ dèjin slovanských, ježto $k$ dosažení premie, Pražským měštanem, panem Ferdinandem Fingerbutem ustanovené, v letech 1859 a 1860 byly zaslány, Praha: Rivnáč 1860.

6 Vítězslav Háleks Král Vukašn eröffnete 1862 das Prozatímní divadlo, Václav Vlčeks Lipany 1881 das Národní divadlo. Freilich ist das Drama Vlčeks weniger prominent als Smetanas Oper Libuše, die als zentrales Eröffnungswerk in Auftrag gegeben wurde.

7 Der tschechische Theaterhistoriker František Černý (vgl. 2005b, 63) erklärt diesen Umstand damit, dass die gravitätischen Konnotationen der großen Tragödie nicht dem eher komödiantischen tschechischen Nationalcharakter entsprächen. 
Zeitbezug, der beim historischen Drama besonders auffällig ist (vgl. Lindenberger 1975, 5), aber auch für die Geschichtsschreibung generell angesetzt werden kann (insofern die historiographische Darstellung der Vergangenheit von aktuellen Interessen geleitet wird), hat es schon verschiedene Charakterisierungen gegeben: Walter Benjamin (Benjamin 1977, 259) spricht vom „Tigersprung ins Vergangene“, die Systemtheorie (vgl. Luhmann 2002, 102) oder die kulturwissenschaftliche Gedächtnisforschung (vgl. Assmann 1992, 41f) akzentuieren gleichermaßen das Primat der Aktualität für die Rekonstruktion der Vergangenheit.

Obschon den historischen Dramen in der Regel Geschichtsdarstellungen zugrunde liegen (bevorzugt etwa die Dalimil-Chronik oder die Chronik des Václav Hájek z Libočan, später František Palackýs Geschichte von Böhmen), wird in dieser Untersuchung jedoch von einem detaillierten Vergleich zwischen Referenzwerk(en) und dem einzelnen historischen Drama abgesehen, da die ideologische Tendenz des Dramas auch ohne einen solchen Vergleich (der überdies die Menge an Primärtexten irritierend vergrößern würde) klar bestimmt werden kann. Stattdessen wird der Dramentext als doppelt hybrider Text betrachtet. Hybrid ist nicht allein die Verquickung von Vergangenheit und Gegenwart, sondern auch die Zwischenstellung von dramatischem Pseudo-„Ereignis“ und textlicher Repräsentation. Der Dramatiker bringt ja gewissermaßen mit seinem Schreiben eine (pseudo-)historische Welt hervor, in der bestimmte Ereignisse passieren. Zugleich aber sind die dramatischen Ereignisse Texte, also nicht historische res gestae. Die Analyse des Dramentextes erfolgt anhand der von Hayden White in Metahistory beschriebenen Strata Ereignisse - Chronik - Fabel - Erklärung, wobei in den Text der Untersuchung nur die „Fabel“ (qua knapper Nacherzählung der Dramenhandlung) und die „Erklärung" eingehen. Die „Erklärung “ liefert dabei die wichtigsten Anhaltspunkte für die in den Dramen eingeschlossenen politischen Ideen der Dramatiker.

\section{Analysefokus und Korpus}

Die Analyse der historischen Dramen erfolgt auf der Grundlage von deren Textausgaben und nicht auf der Basis von Theateraufführungen, die ja ihrerseits ein plurimedialer Text sind. Im Unterschied zu Inszenierungen können Dramentexte einfach tradiert, gelesen und auf ihre politischen Implikationen hin analysiert werden. Drameninszenierungen und deren Rezeption durch Publikum, Kritiker etc. liefern allenfalls Hintergrundinformationen für die Untersuchung. Entsprechend liegt der Fokus auch nicht auf der tatsächlich erfolgten Kommunikation zwischen Autor und Publikum, sondern auf einer Bestimmung der ideologischen Tendenzen, die durch die Analyse der Mitteilung (des Dramentextes) gewonnen wird. Niemals aufgeführte historische Dramen, die nur in Bibliotheken gesammelt und in biobibliographischen Lexika verzeichnet sind, werden ebenso sorgfältig auf die in ihnen implizierten politischen Ideen untersucht wie erfolgreiche Bühnenstücke (etwa die 
Dramen von Josef Kajetán Tyl, Ladislav Stroupežnický, Jaroslav Hilbert u.a.). Bei der Zusammenstellung des Korpus galt das Prinzip einer Streuung: daher werden nicht ausschließlich bekannte Autoren oder Stücke berücksichtigt; nicht sämtliche historische Dramen eines Autors oder einer Epoche werden analysiert, ${ }^{8}$ die historischen Stoffe können ebenfalls unterschiedlicher Natur sein und von einer strikten Trennung zwischen historischen und pseudohistorischen Bezügen wurde abgesehen. So wurden Dramen, die Stoffe aus den berühmten gefälschten Handschriften (der sogenannten Königinhofer und der Grünberger Handschrift) aufgreifen, ebenso jene, die fiktive Personen in einer ansonsten präzise gezeichneten historischen Situation zeigen, gleichberechtigt in das Korpus aufgenommen. Auch in diesen Dramen ist ja eine politisch-ideologische Aussage zu erkennen, vielleicht sogar deutlicher, weil die Autoren weniger Rücksicht auf historisch beglaubigte und dem Publikum bekannte Handlungsentwicklungen nehmen mussten.

\section{Skizzierung der Ergebnisse}

Der Umfang des Korpus und das Ziel einer synoptischen Sicht auf politische Implikationen und Tendenzen machen einen gliedernden Überblick erforderlich. Dieser kann am ehesten anhand eines Stoffes gewonnen werden, der im untersuchten Zeitraum immer wieder behandelt wurde. Anhand von acht Dramen um den hl. Wenzel/sv. Václav, den böhmischen Nationalpatron, ${ }^{9}$ wird deutlich, dass jene Dramen, die vor 1918 entstanden sind, die christliche Ethik Václavs als politisches Modell in Zweifel ziehen, während die Stücke nach 1918 Václav als positives Ideal darstellen, das nur wegen seiner sehr negativ gezeichneten Antagonisten scheitert.

Die Václav-Thematik schließt an die Dramen des obrozeni an, in denen jene Themenkomplexe tangiert werden, die auch in der Folgezeit die Dramatiker immer wieder beschäftigen: das Problem der nationalen Einigkeit der Tschechen und die Frage, welche Politik eine solche Einigkeit und Stärke gegenüber einer Bedrohung von „außen“ zu erzielen imstande sei (Štěpánek, Linda, Klicpera, Mikovec, Vojáček, Kolárs Monika, Tyls Krvavé křtiny), die Legitimation von politischer Macht (Štěpánek, Klicpera, Hněvkovský, Tyls Čestmír, Macháček), das Verhältnis von Einzelperson und Gemeinschaft (Tyls Čestmír, bei Vojáček und Kolár). In der zweiten Hälfte des 19. Jahrhunderts wird in Háleks Catilina und Bozděchs Baron Goertz die Einführung des beschränkten Parlamentarismus 1861 reflektiert. Ebenso ist zu dieser Zeit eine „Internationalisierung“ der Allegorie zu beobachten, da nämlich zunehmend auch Stoffe aus der Geschichte anderer Völker gewählt werden (Háleks

8 Barbara Topolová: České obrozenecké a poobrozenecké drama, Diss. Praha: Karlova univerzita, Katedra divadelní vědy 1996.

9 Es handelt sich um die Václav-Dramen von Tyl, Dvorský, Vrchlický, Langer, Zavřel, Preissová, Durych und Lom. 
Král Vukašin, Fričs Ivan Mazepa, Zeyers Doňa Šanca). Die Verschärfung des tschechisch-deutschen Antagonismus gegen Ende des 19. Jahrhunderts erkennt man bei Zákrejs, Hilbert und Jirásek (meist im Zusammenhang mit der Frage nach dem nationalen Zusammenhalt, der bevorzugt auf der religiös-konfessionellen Ebene mit dem Gegensatz Utraquismus bzw. Protestantismus versus Katholizismus vorgeführt wird - eine Alternative dazu vertritt Dvořák mit Král Václav IV.). Nach der Gründung der Tschechoslowakei 1918 ist anhand der ausgewählten Stücke ein Funktionswandel des historischen Dramas festzustellen: Die Dramatik zielt weniger auf eine Analyse geschichtlicher Vorgänge ab, die die Schwierigkeiten des nationalpolitischen Handelns vorführen, stattdessen wird in den Dramen um den hl. Wenzel/sv. Václav ein Idealbild gezeichnet, das wohl eine Vorbildfunktion haben sollte.

\section{Aufbau und Gliederung}

Diese Untersuchung ist in zwei Teile gegliedert. Im ersten Teil (A) werden dramentheoretische sowie kulturwissenschaftliche Fragen erörtert, die für das Genre des historischen Dramas relevant sind. Dieser Teil ist nicht sprachspezifisch konzipiert; er kann auch ohne besonderes Interesse für die tschechische Dramenproduktion gelesen werden. Er bietet Beiträge zu Aspekten der historischen Dramatik, die in der Fachliteratur nicht immer eine hinreichende Beachtung gefunden haben (wie etwa die Frage nach der Gedächtnisfunktion des historischen Dramas und seinem allegorischen Potenzial) oder die von andauernder Brisanz für die Dramentheorie sind (wie die Fragen der dramatischen Kommunikation bzw. der Interpretation von dramatischen Texten).

Der zweite Teil (B) ist kulturspezifisch ausgerichtet. Er behandelt das tschechische historische Drama vor dem Hintergrund der theatergeschichtlichen Entwicklung, die mit der Eröffnung des Nationaltheaters in den 1880er Jahren ihren institutionellen Höhepunkt findet. Der dramenanalytische Abschnitt ist dreigeteilt: Er umfasst die Epoche des obrozeni (hier im Wesentlichen als die erste Hälfte des 19. Jahrhunderts verstanden), die zweite Jahrhunderthälfte des 19. sowie das erste Drittel des 20. Jahrhunderts. Den Abschluss findet die Einzelanalyse mit einer synoptischen Betrachtung der Dramen um den Heiligen Václav/Wenzel, weil ein und derselbe historische Stoff eine ideale Vergleichsgrundlage bietet. Die Zusammenfassung am Ende der Arbeit begegnet der Schwierigkeit, alle in der Arbeit analysierten Dramen vor dem zeitgeschichtlichen Hintergrund vergleichend zu erfassen, mittels graphischer Veranschaulichungen. Somit kann trotz der Verschiedenheit der in den Dramen behandelten Stoffe gezeigt werden, dass die historischen Dramen einen deutlichen politischen Bezug auf ihre Entstehungszeit haben. 
A.

Allgemeiner Teil: Zur Spezifik der Gattung „historisches Drama“" 



\title{
I. Historische Dramen: Aktualität und (Re-)Konstruktion
}

Am 27. Oktober 1938, anlässlich des 20. Jahrestages der Proklamation der Unabhängigkeit der Tschechoslowakei und einen Monat nach dem Münchner Abkommen, welches eben diesen Staat demolierte, wurde im Prager Ständetheater (Stavovské divadlo) Jaroslav Hilberts Stück Falkenštejn aufgeführt, welches 1903 seine Uraufführung erlebt hatte. Diese vierte Inszenierung wurde vom Kritiker A. M. Píša mit folgenden Worten kommentiert:

\begin{abstract}
Napsána již počátkem století [...] uchvacuje dnes Hilbertova hra o ctižádostivém Vítkovici Falkenštejn jako málokteré naše drama soudobé. Jak se v ní rýsuje a střetá dvojí politická koncepce národního osudu, jak biskup Dobeš usiluje tu mělkou kotlinu Čech všemi prostředky začlenit do mocenského prostoru německého, kdežto Falkenštejn toužebně sní o češství obrozeném a sebevědomém - tot̀ zní, jako by Hilbertova dramatická báseň vyvřela teprve včera z citu a otázek nejsoučasnějších [...] Č́m vysvětlit tento časově nadčasový účin kusu, od jehož premiéry míjí letos pětatřicet let? Především štastným citem a hmatem rozeného dramatika, jenž, neulpívaje na liteře dějin, uměl v historii posledních Přemyslovců postihnout podstatné, trvalé, vždy znovu se obnovující prvky naší národní sudby a státní problematiky. Ale nadto znal dávné děje a mrtvé postavy živě napojit vzněty novodobého češství a žilobitím moderního lidství, z jehož ovzduší na sklonku minulého století vyvážil a k politickému, ideovému konfliktu hry přidružil i motiv vášnivé a temné pudovosti. ${ }^{10}$ (A. M. Píša 1967, 18f)
\end{abstract}

Dieser Kommentar des Kritikers betont die Aktualität von Hilberts Falkenštejn, die auch 1992, zweieinhalb Jahre nach der samtenen Revolution 1989, zu einer weiteren Inszenierung Anlass gab. Hilbert hat um 1900 einen Stoff des 13. Jahr-

10 „Das bereits Anfang des Jahrhunderts [...] geschriebene frühe Stück Hilberts vom ehrgeizigen Witigonen Falkenštejn fesselt heute wie kaum ein zeitgenössisches Stück. Wie in diesem zwei Konzeptionen vom Schicksal des Volks im Widerstreit gezeichnet werden, wie der Bischof Dobeš mit allen Mitteln versucht, diesen kleinen böhmischen Kessel in den deutschen imperialen Raum einzugliedern, während Falkenštejn sehnlich von einem wieder erstarkten und selbstbewussten Tschechentum träumt, das klingt, als wäre Hilberts dramatisches Gedicht erst gestern aus den alleraktuellesten Empfindungen und Problemen entstanden. [...] Wie lässt sich diese von Zeit zu Zeit überzeitliche Wirkung des Stücks erklären, seit dessen Premiere heuer 35 Jahre vergangen sind? Vor allem mit dem glücklichen Gefühl und der glücklichen Hand des geborenen Dramatikers, der nicht am Buchstaben der Geschichte festhält und in der Geschichte der letzten Přemysliden die wesentlichen, dauernden, immer wieder sich erneuernden Elemente unseres nationalen Schicksals und unserer staatlichen Problematik erfasst. Darüber hinaus wusste er, die weit zurückliegenden Ereignisse und die längst toten Figuren mit Impulsen des neuzeitlichen Tschechentums und mit dem Pulsschlag der modernen Menschheit zu beleben, dessen fin-de-siècle-Atmosphäre er mit dem Motiv leidenschaftlicher und dunkler Triebhaftigkeit verknüpfte, die er dem politischen, ideellen Konflikt beifügte.“ 
hunderts aufgegriffen, der bereits von mehreren - vorwiegend tschechischen und deutschen - Dramatikern bearbeitet wurde. Die von Hilbert vorgenommene Verbindung zeitgenössischer Fragen mit dem historischen Stoff ergab jedoch nicht bloß ein Stück, das in der kulturellen Situation der Tschechen in den letzten Jahren der österreichisch-ungarischen Monarchie Aktualität besaß, sondern auch in den Jahren 1938 und 1947 (Inszenierung in Brno), im Frühjahr 1968, als es in Olomouc aufgeführt wurde (damit wurde das Quasi-Aufführungsverbot von Werken Hilberts durchbrochen, das sich mit dem Februarumsturz 1948 etabliert hatte) sowie 1992, drei Jahre nach der Wende und kurz vor der Teilung der Tschechoslowakei in zwei unabhängige Staaten (vgl. Král 1992a, 11).

Die diesem Stück immer wieder zugeschriebene zeitgenössische Relevanz hat ihren Grund gewiss nicht in prophetischen Fähigkeiten seines Autors, sondern verdankt sich einer bestimmten Rezeptionshaltung gegenüber Texten, die als Literatur ausgewiesen sind bzw. von Autoren, Verlagen etc. als künstlerische Literatur präsentiert werden. Demgemäß werden historische Dramen nicht allein als Texte aufgefasst, die auf historische Ereignisse referieren; in ihnen wird ein allgemeines Modell gesucht, das Referenzbezüge auf unterschiedliche historische Situationen einer als nationales Kollektiv imaginierten Gemeinschaft erlaubt.

Das neueste Handbuch zur Gattungstheorie (Lamping/Poppe 2009) definiert das historische Drama als „eine Untergattung des Dramas, in dessen Mittelpunkt - unter Rückgriff auf historische Konstellationen und Personen - die Rekonstruktion und die Konstruktion von Geschichte steht." (Reitz 2009, 370) Ereignisse werden als Rekonstruktion oder Konstruktion in einem Theatertext präsentiert, dessen handelnde Figuren (personae dramatis) vor allem historische Personen sind. Beim historischen Drama kommt es weniger - das Konstruktionsmoment in der Definition weist darauf hin - auf den Versuch von „historischer Wahrheit“ qua Korrespondenz zu wirklichen Ereignissen an, sondern darauf, dass ein Bezug zur Geschichte behauptet bzw. von den Adressaten geglaubt wird. Historische bzw. quasi-historische Vorgänge werden einem Publikum „live“ vor Augen geführt. Diesen Aspekt haben schon Goethe und Schiller in ihrer gemeinsamen Reflexion „Über epische und dramatische Dichtung" akzentuiert, wo sie die Epik mit der Vergangenheit assozieren, während in der Dramatik die Begebenheiten als ,vollkommen gegenwärtig" dargestellt werden (vgl. Goethe/Schiller 1999, 108). Die Vergangenheit wird in der Gegenwart der Aufführung in einer Version repräsentiert, die sich von historiographischen Erzählungen bzw. Versionen dieser Vergangenheit mehr oder weniger deutlich unterscheiden kann. Was Schiller über die Tragödie schreibt, gilt auch für das historische Drama und gewinnt dabei besondere Brisanz:

[Die Tragödie] ist zuerst - Nachahmung einer Handlung. Der Begriff der Nachahmung unterscheidet sie von den übrigen Gattungen der Dichtkunst, welche bloß erzählen oder beschreiben. In Tragödien werden die einzelnen Begebenheiten im Augenblick ihres Ge- 
schehens, als gegenwärtig, vor die Einbildungskraft oder vor die Sinne gestellt; unmittelbar, ohne Einmischung eines Dritten. Die Epopöe, der Roman, die einfache Erzählung rücken die Handlung, schon ihrer Form nach, in die Ferne, weil sie zwischen den Leser und die handelnden Personen den Erzähler einschieben. Das Entfernte, das Vergangene schwächt aber, wie bekannt ist, den Eindruck und den teilnehmenden Affekt; das Gegenwärtige verstärkt ihn. Alle erzählenden Formen machen das Gegenwärtige zum Vergangenen; alle dramatischen machen das Vergangene gegenwärtig. (Schiller 1962, 164f)

Eine Gattungsdefinition, die das historische Drama mit der Historiographie konfrontiert, führt zwangsläufig bald zur Problematisierung des Verhältnisses von faktographischer Rekonstruktion und fiktionaler Konstruktion im dramatischen Text; die Gattungsgeschichte des historischen Dramas im 19. und 20. Jahrhundert ist durch einen ständigen Vergleich von Dramen und historiographischen Darstellungen dominiert. Während das Drama in der Antike, im Mittelalter, in Renaissance, Barock und Klassizismus in der dramatischen Thematisierung von historischen Begebenheiten in der Regel kein Problem sah (wobei sich die kulturellen Gründe für das Ausbleiben einer Differenzierung von historischer Realität und Fiktion in den jeweiligen Epochen freilich unterschieden), führte die Ausdifferenzierung von Literatur in Historiographie und Belletristik im 19. Jahrhundert zu einem Kompetenzstreit, in dem die nun selbstbewusst auftretende Historiographie ihr Monopol auf wahrhaftige Geschichtsdarstellung proklamierte und in literarischen Geschichtsdarstellungen Konkurrenten ausmachte, die nur insofern akzeptiert wurden, als sie von den historiographischen Aussagen über die Vergangenheit nicht allzu weit abwichen. Die in den voraufgegangenen Epochen verbreitete Lässigkeit der licentia poetica war in historischer Prosa und Dramatik nicht mehr selbstverständlich, wenn die Geschichtsschreibung ihre Deutungshoheit über die Geschichte verteidigen wollte.

Erst die Auffassung, dass auch die Historiographie nicht allein von ihren Forschungsgegenständen, sondern zugleich auch von der Subjektivität ihrer Autoren bzw. von Gattungskonventionen und Erzählmustern gekennzeichnet ist, rehabilitierte die genuin literarische Darstellung von Geschichte und reaktivierte das Spannungsverhältnis von Literatur und Historiographie, ohne dass dabei die historische Belletristik auf eine reine Illustrationsfunktion für die Geschichtsschreibung reduziert wurde.

Nun mag zwar die im 19. Jahrhundert etablierte Hierarchie von Geschichtsschreibung und belletristischer Geschichtsdarstellung relativiert worden sein (auch weil die Ausdifferenzierung von Wissenschaft und Literatur selbstverständlich geworden ist); das Spannungsverhältnis bzw. die mediale Konkurrenz bleiben noch immer aufrecht, wenn man die Texte selbst betrachtet und Historiographie und historisches Drama miteinander vergleicht. Der Grund dafür liegt darin, dass die Definition des historischen Dramas im Handbuch der literarischen Gattungen ein 
Moment nicht entsprechend berücksichtigt, welches für das historische Drama in höherem Maß kennzeichnend ist als für die historische Prosa oder für die Historiographie: Es ist das Moment der referenziellen Bezugnahme auf die jeweilige Gegenwart der Entstehungszeit bzw. der Aufführungszeit, das in der historischen Dramatik von besonderer Signifikanz ist. Auf dieses verweist schon Lindenberger in der bislang umsichtigsten Monographie über das historische Drama:

It has long been a commonplace that historical plays are at least as much a comment on the playwright's own times as on the periods about which they are ostensibly written. (Lindenberger 1975, 6)

Nur die Berücksichtigung der Produktions- bzw. auch der Rezeptionssituation erklärt ja die wiederholte Aktualität von Hilberts Falkenštejn, auf die A. M. Píša im einleitenden Zitat aufmerksam machte. Diese bedeutet zugleich auch einen Unterschied zur Geschichtsschreibung, der zumindest graduell besteht. Geschichtsschreibung referiert primär auf die thematisierten Ereignisse in der Vergangenheit, wobei freilich das Erkenntnisinteresse des Historiographen in seiner Gegenwart, in seiner Situation, gründet. Von dieser Vermitteltheit von Geschichte und Gegenwart in der Historiographie hebt sich das historische Drama medial und sprachlich schon dadurch ab, dass es die Vorgänge der Vergangenheit als gegenwärtige vor Augen führt, wofür die innere Form des Begriffs »Repräsentation « ein signifikanter Ausdruck ist (vgl. Werber 2003, 264): Repräsentation als ,erneut-präsent-Machen von Absentem, im Falle des historischen Dramas von Vorgängen, die in der Vergangenheit liegen, aktualisiert die Vergangenheit und stellt somit eine Verbindung von Vergangenheit und Gegenwart her. In diesem Gegenwartsbezug jedoch wohnt das Moment der Rekonstruktivität, das die Vergangenheit an das Interesse und die Belange der jeweiligen Gegenwart bindet und dem somit ein konstruktivistischer Aspekt zukommt: „Das Gedächtnis verfährt also rekonstruktiv. Die Vergangenheit vermag sich in ihm nicht als solche zu bewahren. Sie wird fortwährend von den sich wandelnden Bezugsrahmen der fortschreitenden Gegenwart her reorganisiert " (Assmann 1992, 41f).

Angesichts der engen Verbindung gibt es nun zwei unterschiedliche Betrachtungsweisen, die das Verhältnis von Vergangenheit und Gegenwart in dieser Gattung jeweils anders akzentuieren. Die traditionelle Betrachtungsweise, die auch im gattungsgeschichtlichen Rückblick von Reitz (2009) breiter erörtert wird, sieht historische Dramen in Relation zur Vergangenheit bzw. zu historiographischen Darstellungen derselben. Historiographie und historisches Drama werden dann unter dem Gesichtspunkt der Rekonstruktion von Geschichte miteinander verglichen, wobei eben die erwähnten Kompetenzstreitigkeiten zwischen Literatur und Geschichtsschreibung unvermeidlich sind. Der andere Zugang, der konzeptuell dieser Arbeit zugrunde liegt, betrachtet das historische Drama im Verhältnis zur Situation 
seines Entstehens sowie als Konstruktion von Geschichte. ${ }^{11}$ Der damit fokussierte Bezug auf die Entstehungssituation des historischen Dramas erlaubt es, die Funktion von Geschichtsrepräsentation für Gegenwart und Zukunft besser zu erfassen. Diese erschöpft sich nicht in der von Puchner (vgl. 1994, 77) festgestellten Projektion nationaler Existenz.

Der seit gut zwei Jahrzehnten in den Sozial- und Kulturwissenschaften thematisierte Begriff vom kulturellen Gedächtnis findet damit in der Gattung des historischen Dramas ein nahezu paradigmatisches Untersuchungsobjekt. Bezieht man Jan Assmanns (vgl. 1992, 16) Aspekte des kulturellen Gedächtnisses auf diese Gattung, so dienten die historischen Dramen der Erinnerung, indem sie für die tschechische Gesellschaft des 19. und 20. Jahrhunderts besondere Bezüge zur Vergangenheit herstellten. Sie stifteten damit eine kollektive Identität und bedienten die politische Imagination, die auf der kulturellen Kontinuierung oder Traditionsbildung kulturelle und politische Programme aufbaute. Das historische Drama als Gattung, das auf eine Aufführung vor einem sprachkulturell einigermaßen einheitlichen Publikum hin konzipiert ist, sollte mit der Darstellung vergangener Ereignisse Bezugspunkte für die sich neu formierende tschechische Nation schaffen. Gerade im Hinblick auf die kollektive Rezeption im Rahmen der Theateraufführung kommt dem historischen Drama eine zentrale Bedeutung in Rahmen der Herausbildung von Nationalliteratur zu (vgl. Höhne 2000, 44).

\section{I.1. Historisches Drama und kulturelles Gedächtnis}

Als grundlegende Hypothese der neueren interdisziplinären Gedächtnisforschung gilt die Auffassung, dass Gedächtnis „nicht als Zugriff auf gespeicherte Daten“, sondern als Prozess gedacht wird, ,der wenig mit Archivausgabe, erheblich aber mehr mit gestaltendem Erzählen zu tun hat" (Hejl 1996, 36 u. 37). Dies bedeutet nichts anderes, als dass Gedächtnis nicht als bloßes Aufzeichnungs- und Ablagesystem, sondern als „aktuelle Sinnproduktion im Zusammenhang jetzt wahrgenommener oder empfundener Handlungsnotwendigkeiten“ (ebd.) konzipiert wird. Diese für den individuellen Organismus postulierte Hypothese erfährt bei ihrer Übertra-

11 Die konstruktivistische Betrachtung ist freilich auch gegenüber der Historiographie angemessen, nur ist diese in vorliegender Arbeit nicht das Thema: „Traditionelle historiographische Konzepte gehen davon aus, daß Geschichtsschreibung ein Akt der Rekonstruktion von Vergangenem ist, der sich zur Korrektur und Objektivierung seiner Rekonstruktionen auf archivierte Dokumente stützen kann. Diese Vorstellung muß im Lichte dessen, was bisher über Gedächtnis und Erinnerung gesagt worden ist, revidiert werden. Historiographie kann danach nur als Konstruktion von Geschichte angesehen werden, die den Handlungsbedingungen und Interessen der Historiographen sowie den Machtverteilungen in ihren soziopolitischen Handlungssituationen korrespondiert. Auch noch so volle Archive ändern daran nichts; denn die Dokumente sprechen nicht für sich." (Schmidt 1996b, 48) 
gung auf das „kulturelle Gedächtnis“, also auf überindividuelle Gedächtnisphänomene in Gruppen, Kollektiven, Gesellschaften, nur insofern eine Modifikation, als in der Kultur zum einen meist Institutionen eingerichtet sind, die mittels externer Speichermedien die Funktionen des kulturellen Gedächtnisses - nämlich für die Gesellschaft einen synchronen und diachronen Zusammenhalt herzustellen (vgl. Assmann 1992, 16-18) - leisten. Zum anderen wird in Kulturen die „Sinnproduktion" verteilt, die Mitglieder einer Kultur partizipieren nicht alle zu gleichen Teilen an der Produktion und Konstruktion von Gedächtnis. Geht man aber mit Maurice Halbwachs (vgl. Halbwachs 1985, 19-23) davon aus, dass das individuelle Gedächtnis eines sozialen Rahmens bedarf, um sich auszubilden, lässt sich eine deutliche Interdependenz von individuellem und Gruppengedächtnis postulieren: Das erstere entwickelt sich im Zusammenhang mit der Kommunikation, wobei aufgrund der Partizipation in verschiedenen gesellschaftlichen Gruppierungen das einzelne Gedächtnis von verschiedenen Kommunikationszusammenhängen formiert wird; das Sozium, das kein allgemein verbindliches kollektives Gedächtnis hat, verteilt die kollektive Gedächtnisleistung auf seine Mitglieder (vgl. Assmann 1992, 37). Das kollektive Gedächtnis stützt sich dabei in der Regel auf die Tradierung von Texten, ${ }^{12}$ womit Texte im weitesten Sinn gemeint sind, also auch Artefakte.

Unter dem Begriff des kulturellen Gedächtnisses fassen wir den jeder Gesellschaft und jeder Epoche eigentümlichen Bestand an Wiedergebrauchs-Texten, -Bildern und -Riten zusammen, in deren „Pflege“ sie ihr Selbstbild stabilisiert und vermittelt, ein kollektiv geteiltes Wissen vorzugsweise (aber nicht ausschließlich) über die Vergangenheit, auf das eine Gruppe ihr Bewußtsein von Einheit und Eigenart stützt. (Assmann 1988, 15)

Einem Kollektiv bzw. „sozialem System“ als Menge von Individuen ermöglicht das kulturelle Gedächtnis die „gemeinsame Wirklichkeitsfestlegung und -konstruktion" sowie die darauf bezogene Interaktion (Hejl 1996, 303).

Bezieht man die von Jan Assmann in einem programmatischen Aufsatz (Assmann 1988) zusammengefassten charakteristischen Momente des kulturellen Gedächtnisses auf die historische Dramatik der tschechischen Literatur, die in dieser Arbeit untersucht wird, lassen sich ohne große Modifikationen folgende Feststellungen treffen:

12 Diese Postulate zum kulturellen Gedächtnis rekurrieren auf die Thesen der Kultursemiotik der Moskau-Tartuer-Schule, derzufolge Kultur als „nicht-erblich vermitteltes Gedächtnis eines menschlichen Kollektivs" begriffen wird (vgl. Lotman/Uspenskij 1986, 856). 
1) Die historische Dramatik sollte zur Identitätsstiftung bzw. zur Stärkung einer tschechischen Sprachnation beitragen: Dies gilt insbesondere für die Zeit des obrozeni13 ${ }^{13}$, als die tschechischsprachige Kultur ein wesentlich geringeres Prestige besaß als die deutschsprachige und allein schon der Umstand bedeutungsvoll war, dass man in tschechischer Sprache anspruchsvolle Belletristik - und historische Tragödien wurden als Höhepunkt der dramatischer Gattung angesehen - zu schreiben versuchte. Wie jede „Renaissance“-Periode ist auch die Epoche des obrozeni durch den Rückgriff auf die Vergangenheit gekennzeichnet (vgl. Assmann 1992, 32). Zusätzlich zu der mittels der gewählten Sprache des dramatischen Textes erfolgenden Identifikation trug der in den Dramen selbst repräsentierte Inhalt zu Identitätskonstruktionen bei: Diese beruhten meist auf ziemlich einfachen Wertzuschreibungen von der Art, dass die positiv gezeichneten Figuren eher mit ,tschechisch“ konnotiert wurden und die negativ gezeichneten Figuren eher „nicht-tschechischer" Herkunft waren; keineswegs aber war eine solche Identitätsstiftung immer zentrales Thema der Dramen. Elementare dramatische Regeln verlangen ja auch, dass simple Freund-Feind-Schemata differenziert werden müssen. Mit der Konsolidierung der tschechischen Nation im letzten Drittel des 19. Jahrhunderts, die zugleich bei der deutschsprachigen Bevölkerung in Böhmen und Mähren Sorge um den drohenden Verlust von Privilegien und Status hervorrief, verlor die identitätsstiftende Funktion der historischen Dramatik aber keineswegs an Relevanz, bis in die 1930er Jahre hinein waren Fragen von nationaler Zugehörigkeit und Differenz zumindest im Hintergrund der repräsentierten Konflikte virulent.

2) Das Moment der Rekonstruktivität wird, wie gesagt, bei der Betrachtung von historischen Dramen oft übersehen. Meist erschöpft sich die Reflexion darauf in Vergleichen von Dramentexten mit historiographischen Vorlagen. Die tschechische Theaterwissenschaft hat hingegen - wohl aufgrund ihrer sozialhistorischen bzw. marxistischen Basis, die bis in die 1920er Jahre zurückreicht - immer wieder auf die Bezüge zur Entstehungszeit von historischen Dramen hingewiesen. Der Rückgriff auf die Hussitenthematik durch Josef Kajetán Tyl in den Jahren 1848/49 und durch Alois Jirásek nach 1900 wurde etwa umgehend mit der aktuellen Situation der Tschechen assoziiert. Die in den Dramen entworfenen Geschichtsbilder haben weniger mit den historischen Begebenheiten als mit ideologischen Szenarien der damaligen Gegenwart gemeinsam, was nicht zuletzt im freien Umgang mit geschichtlichen Stoffen erkennbar ist.

3) Assmanns Moment der Geformtheit ist für die historische Dramatik in zweierlei Hinsicht zu spezifizieren: Damit das identifikatorische Potenzial des historischen Stoffes für die Gegenwart aktualisiert werden kann, reicht die bloße Textfassung eines Dramas nicht aus: Das historische Drama als „Software“ bedarf gleichsam eines Theaters als „Hardware“, um die entsprechende Erinnerungsfunktion leisten zu können. Der Dramatiker

13 Mit der Bezeichnung obrození ist im Rahmen dieser Arbeit die Zeit des ausgehenden 18. Jahrhunderts sowie die erste Hälfte des 19. Jahrhunderts gemeint, was der in der zeitgenössischen Bohemistik dominanten Epochenbestimmung entspricht (vgl. Haman 2007, 22-26). 
sinnt auf die theatralische Aufführung, welche als massenmediale Kommunikation auf „kognitive Parallelität und Homogenität“ (Hejl 1996, 39) von Geschichtsvorstellungen abzielt. Die langen, Anfang der 1880er Jahre letztlich erfolgreichen Bemühungen um ein tschechisches Nationaltheater - zumal es ja noch keinen Film oder keine elektronischen Medien wie Radio oder Fernsehen gab, kann ein Nationaltheater als Massenmedium sui generis gelten, dem zudem hoher symbolischer bzw. repräsentativer Wert zugeschrieben wurde ${ }^{14}$ - entsprechen in ihrer Funktion für die Formung des kulturellen Gedächtnisses den Bestrebungen Josef Jungmanns, zur Herausbildung einer Literatur beizutragen, die den internationalen Vergleich nicht zu scheuen brauchte oder den Förderungsbemühungen von Ferdinand Fingerhut/Náprstek, der mit der Auslobung eines Preises die Produktion historischer Dramen stimulieren wollte. Die medialen Formen des historischen Dramas - Text oder in einer Aufführung realisierter Text - sind auf unterschiedliche Weise für das kulturelle Gedächtnis relevant: die Schriftform, die meist ja selbst auf anderen - historiographischen - Schriften basiert, soll die längere Speicherung ermöglichen, welche aber zugleich auch das Risiko des Entschwindens aus dem aktiven Gedächtnis der Mitglieder einer Kultur birgt; die Theaterform dagegen ist stärker dem Ritus und der Wiederholung verwandt: als kollektive Produktion (vgl. Pfister 2001, 29) und Rezeption stellt sie Gemeinschaften her, ${ }^{15}$ die Wiederholungen von Aufführungen oder die Neuinszenierung eines Stücks schaffen ebenfalls so etwas Ähnliches wie „rituelle Kohärenz“ (vgl. Assmann 1992, 17). ${ }^{16}$ Erfolgreiche, d.h. mehrfach gespielte oder inszenierte historische Dramen leisten also nicht allein die Funktion der Repräsentation, die

14 So hat etwa Graf Stadion 1848 keinen besseren Weg gewusst, um das Versprechen, eine Verfassung zu erlassen, der Öffentlichkeit mitzuteilen, als ins Ständetheater zu fahren, die Aufführung unterbrechen zu lassen und von seiner Loge aus die Nachricht zu verkünden (vgl. McCord 1993, 40; Ježková/Ludvová 2013, 81). Gute 80 Jahre früher, 1767, hat der Direktor des ersten deutschen „Nationaltheaters“ (der Hamburger Enterprise) dessen propagatorische Funktion erkannt: „Welch ein vortreffliches Hülfsmittel könnten sie [die Schauspiele] der Regierung seyn, wenn es darauf ankäme, die Veränderung eines Gesetzes, oder die Abschaffung eines Gebrauchs vorzubereiten“ (zit. nach Schramm 1990, 232).

15 „Die Tränen, welche der Redner oder Schauspieldichter sie [die Zuschauer] für einen verleumdeten Unschuldigen, für einen in den Tod gehenden Helden zu vergießen nötigt, befreunden, verbrüdern sie alle. Es ist unglaublich, welche verstärkende Kraft die sichtbare Gemeinschaft vieler für ein inniges Gefühl hat [...]“"(Schlegel 1966, 36f).

16 Dieser Unterschied lässt sich anhand von Texten des der Arbeit zugrunde liegenden Dramenkorpus konkretisieren: während Dramen wie Hilberts Falkenštejn oder Tyls Krvavé kŕtiny immer wieder gespielt werden und einem theaterinteressierten tschechischen Publikum aufgrund der zahlreichen Inszenierungen durchaus geläufig sind, sind andere Dramen entweder gar nicht oder nur zu wenigen Aufführungen oder Inszenierungen gekommen. Sie können damit keinesfalls irgendwie mit Ritualität in Zusammenhang gebracht werden; zumal sie aber in verschriftlichter Form in Bibliotheken oder Archiven aufbewahrt werden, sind sie zwar noch Teil des externalisierten, auf Schrift und Institutionalisierung basierenden Gedächtnisses, aber aus dem aktiven Gedächtnis der Kulturgemeinschaft verschwunden. Da sich die Fragestellung dieser Arbeit aber auf die Entstehungszeit historischer Dramen bezieht, verdienen 
Assmann der Schrift generell zuschreibt, sie sind in der inszenierten Form stärker gemeinschaftsstiftend als in der bloßen Textform.

4) Das unter (3) Angeführte gilt teilweise auch für die Organisiertheit des kulturellen Gedächtnisses: Die mit der Nationsbildung geschaffenen Institutionen waren bei den Tschechen stark historisch ausgerichtet. Zu nennen ist hier etwa die 1818 gegründete Museums-Gesellschaft oder der Stellenwert der Geschichtsschreibung, der mit František Palackýs Geschichte von Böhmen (1836-1867, in erweiterter tschechischer Fassung als Déjiny národu českého v Čechách a v Moravè, 1848-67) auf ein neues Niveau gehoben wurde. Die Anstrengungen um regelmäßige tschechischsprachige Theateraufführungen in Prag gipfelten 1848 in der Forderung nach einem Nationaltheater. 1850 wurde ein Verein unter Palackýs Vorsitz zur Schaffung eines Nationaltheaters gegründet. Mit der Vollendung des Národni divadlo 1881 bzw. 1883 verband die tschechische Nationalbewegung die endgültige Konsolidierung der Tschechen als Nation (vgl. Schamschula 1996, 139-141), also einen Grad von Organisiertheit, der vordem noch nicht erreicht war.

5) Das Charakteristikum der Verbindlichkeit des kulturellen Gedächtnisses steht in Zusammenhang mit dem Wert und der Relevanz, die einem Text bzw. Artefakt zugeschrieben werden. Viele historische Dramen repräsentieren Episoden der tschechischen Geschichte, die auch heute noch als Schlüsselereignisse aufgefasst werden und somit als „Erinnerungsfiguren“ (Assmann 1992, 38) gelten können. So variieren die Dramatiker im gesamten hier untersuchten Zeitraum immer wieder den Stoff um den hl. Wenzel/ sv. Václav, den Nationalheiligen Böhmens; in der Mitte des 19. Jahrhunderts entdeckt man die Hussitenzeit als nationalen Bezugspunkt. Der dritte Stoffkreis, der in historischen Dramen gerne behandelt wird, ist die Zeit nach der Niederschlagung des Ständeaufstands, die im 19. und 20. Jahrhundert von den Tschechen als Unterdrückung der eigenen Kultur aufgefasst wurde und daher als negativer Bezugspunkt thematisiert wird. Aufgrund der Tatsache, dass das kulturelle Gedächtnis der Tschechen sich über 60 Jahre lang von den Handschriftenfälschungen hat beeindrucken lassen, fanden die in den Handschriften fingierten pseudohistorischen Ereignisse Eingang in verschiedene Gattungen; auch historische Dramen rekurrieren bisweilen auf Ereignisse, die in den sog. Handschriften (der Grünberger und Königinhofer Handschrift) behandelt wurden.

6) Betrachtet man den Umstand, dass Dramen in der Regel die Interaktion von Individuen vor Augen führen, dann erweist sich Assmanns Charakteristikum der Reflexivität als überaus wichtig für das Drama. Der Leser bzw. Zuschauer ist in Beobachterposition, er kann aus dem fiktionalen Dramengeschehen auf reale Interaktion zurückschließen, zehrt doch das „subjektive Vermögen der Reflexion [...] von den Potentialen und Prozessen der Reflexion, die in Darstellungen, in Texten, Aufführungen und Bildern gespeichert sind. [...] [D]ie Reflexivität des Darstellens [...] gilt ebenso für die poetischen Texte“ (C. Menke 1996, 67).

diese vergessenen Dramen keine geringere Aufmerksamkeit als die der tschechischen Kulturgemeinschaft besser bekannten historischen Dramen. 
Bezogen auf die in dieser Arbeit behandelte historische Dramatik bedeutet Reflexivität darüber hinaus: Mit der Vorführung historischer Stoffe auf der Bühne oder im Dramentext soll ja vielfach eine Besinnung auf die Gegenwart, auf die aktuelle Situation erreicht werden. Aus den repräsentierten Ereignissen können unmittelbar - Assmann nennt es „praxis-reflexiv“ - Folgerungen für politisches Handeln gezogen werden (verwiesen sei hier etwa auf Josef Lindas Jaroslav Šternberg v boji proti Tatarüm, ein Drama mit vielseitigem - auch kryptischem - Bezug auf die Handschriftenfälschungen, auf Josef Kajetán Tyls Jan Hus oder Jaroslav Hilberts Falkenštejn); die historischen Dramen sind zugleich aber auch insofern „selbst-reflexiv“ und „Selbstbild-reflexiv“, als sie mit Rückgriff auf die Geschichte zum Nachdenken über den aktuellen Zustand verleiten wollen bzw. mittels der Vorführung von „typischen“ Nationalcharakteren zu einer Selbstthematisierung und Kritik von rekurrenten Verhaltensmustern anregen (etwa Viktor Dyks Posel, der vorführt, wie eine mit der Idee von radikaler christlicher Nächstenliebe und Gewaltlosigkeit verbundene Haltung zu nationaler Passivität führt, womit Dyk auf Tomáš G. Masaryks Entwurf einer ,positiven“ Nationalideologie reagiert).

\section{I.2. Eine systemtheoretische Beschreibung von kulturellem Gedächtnis}

Als Gedächtnistexte stehen die historischen Dramen aus der tschechischen Geschichte mit der Gegenwart ihrer Entstehungszeit in doppelter Hinsicht in Verbindung: Zum einen gehören die repräsentierten Ereignisse der Vergangenheit an, sie sind ein „Kettenglied“ der imaginierten historischen Kette, die Geschichte und Gegenwart verbindet, zum anderen erinnert sich die jeweilige Gegenwart selektiv der Vergangenheit, sie wählt aus der eigenen Geschichte diejenigen Momente, die für die Gegenwart von Relevanz sind: „In der Erinnerung wird Vergangenheit rekonstruiert" (vgl. Assmann 1992, 31). Für die erste Form der Verbindung von Geschichte und Gegenwart hat Hegel bereits eine genaue Bestimmung gegeben: „Das Geschichtliche ist nur dann das Unsrige, [...] wenn wir die Gegenwart überhaupt als eine Folge derjenigen Begebenheiten ansehen können, in deren Kette die dargestellten Charaktere oder Taten ein wesentliches Glied ausmachen." (Hegel XIII/352) Zumal die zweite Verbindung, die mit dem Ausgang von der jeweiligen Gegenwart die Selektivität des Erinnerns betont, eine wichtige theoretische Basis für die hier vorgenommene Betrachtung historischer Dramen abgibt, ist es angebracht, ausführlicher auf die konzeptuelle Grundidee dieses konstruktivistischen Gedächtniskonzepts einzugehen. Den hier interessierenden Zusammenhang von Gesellschaft und Gedächtnis hat Peter M. Hejl in einem grundlegenden Beitrag des von Siegfried J. Schmidt herausgegebenen Sammelbandes zum Gedächtnis (Schmidt 1996a) systematisch dargestellt (Hejl 1996).

Hejl geht von einfachen Grundüberlegungen aus: ein soziales System besteht aus seinen Komponenten (den Individuen) und der Organisation, die sich zwischen 
den Komponenten etabliert: „Ein soziales System liegt dann vor, wenn eine Menge von Individuen eine gemeinsame Wirklichkeitsfestlegung oder -konstruktion ausgebildet (oder übernommen) hat und mit Bezug auf sie direkt oder indirekt interagiert" (ebd., 303). Die Interaktion schafft die Wirklichkeitskonstrukte des Soziums; Synreferenzialität ist notwendig, um die Interaktionen zwischen den Komponenten zu ermöglichen, also das soziale System zu bilden. Eine wichtige und - meiner Ansicht nach - auch praxisrelevante Überlegung betrifft die Komponenten und deren Eingebundensein in Systeme. Eine einzelne Komponente ist in der Regel in mehrere Systeme gleichzeitig integriert: ein Individuum ist ja beispielsweise Familienvater, Universitätslehrer, Mitglied der Freiwilligen Feuerwehr und Obmann eines Basketballvereins. Diese verschiedenen Organisationen und die in diesen Systemen anfallenden Aufgaben verlangen unterschiedliches Verhalten vom Einzelnen, dennoch kommt es trotz aller relativen Geschlossenheit der einzelnen Systeme zu Interaktionen zwischen ihnen - eben aufgrund der „Personalunion“, die nicht einfach dispensiert werden kann. Innerhalb eines Systems gibt es meist „eingespielte“ Interaktionsmuster zwischen den Komponenten, wodurch die relative Stabilität des Systems gegenüber Einflüssen und auch gegenüber dem Handlungspotenzial der einzelnen Komponenten - diese haben ja trotz ihrer Eingebundenheit in Systeme eine relative Eigendynamik - erreicht wird.

Die Reaktionen auf Veränderungen - egal, ob diese jetzt durch die Eigendynamik der Komponenten innerhalb des Systems oder durch Umwelteinflüsse entstehen - sind mitbedingt durch die Interaktionen, die sich bereits zuvor im System etabliert haben (Hejl nennt diese Bahnungen „Konnektivitäten“). Macht eine Gesellschaft eine „Erfahrung“ (trifft sie ein bestimmtes Ereignis, etwa ein Naturereignis oder ist sie in einen Krieg involviert), so heißt das konkret, dass natürlich die Individuen qua Komponenten des Gesellschaftssystems die Erfahrung machen: aus den Veränderungen, die daraus entstehen, können sich aufgrund der Konnektivitäten neue Beziehungen innerhalb des Systems ergeben. „Erinnern“ hingegen unterscheidet sich vom „Erfahrungen machen" insofern, als sich die Komponenten an etwas erinnern, wozu sie bereits Verbindungen mit anderen Komponenten aufgebaut haben (vgl. Hejl 1996, 321). Der aktuelle Erinnerungsprozess rührt also an vergangene Konnektivitäten, er führt möglicherweise zu einer Veränderung derselben, zu einer Neuordnung des Systems. Erinnerung ist somit keine getreue bzw. authentische Wiedergabe von Vergangenem, sondern eher eine Beschäftigung, die an die vergangenen Zustände rührt:

Als Ergebnis [von Erinnerungsprozessen] kann es sich dann zeigen, daß die den Ereignissen zugeordneten kognitiven Konstrukte und Handlungen unangemessen sind, sei es, daß das aktualisierte Wissen sich weiterentwickelt hat und deshalb nicht mehr "paßt“, sei es, daß es gerade deshalb zu Problemen kommt, weil die Weiterentwicklung nicht schnell genug oder nicht in der richtigen Richtung erfolgte. [...] Daß in solchen [Erinnerungsprozessen der Gesellschaft] 
nicht Abbildungen der ursprünglichen Ereignisse reproduziert werden, sollte [...] deutlich werden. Dies kann schon deshalb nicht der Fall sein, weil aufgrund der Mehrfachmitgliedschaften von Komponenten in mehreren Sozialsystemen gleichzeitig oder/und auch nacheinander, es natürlich zu den bereits angesprochenen intersystemischen Einflüssen kommt, die Modifikationen [von Erinnerungen] erzwingen. (Hejl 1996, 322; kursiv von mir, PD)

Diese systemtheoretische Theorie von Gedächtnis, die Hejl „Produktionsmodell“ nennt, hat den Vorteil, dass ihre Prinzipien - Systeme bestehen aus Komponenten mit Eigendynamik und der veränderlichen Organisation zwischen den Komponenten - zum einen für Systeme ganz unterschiedlicher Größenordnung und Komplexität anwendbar sind und dass zum anderen diese Theorie gänzlich ohne die Vorstellung von Speicherung - also Ablage und Wiederfinden des Abgelegten am bestimmten Speicherort - auskommen kann. Im Produktionsmodell haben die einzelnen Komponenten eines Systems eine Geschichte („Konnektivität“, „Spur“), auf welche die neuen Leistungen bezogen werden, die vom System erbracht werden müssen. Wahrnehmungen bzw. Erfahrungen tangieren die Komponenten und ihre Konnektivitäten und modifizieren sie gegebenenfalls. Es wird kein Speicherort aufgesucht, um an diesem die dort abgelegten „Einträge“ zu reaktivieren (so das Speichermodell), sondern das Produktionsmodell unterscheidet nicht zwischen „Hardware“ (Speicher, Prozessoren etc.) und „Software“ (Einträgen), weil es Gedächtnis als Veränderung der Hardware-Systems und seiner Organisation versteht (vgl. Hejl 1996, 326). ${ }^{17}$ Diese Modellierung gibt auch eine überzeugende Erklärung des Zusammenspiels von Wahrnehmung und Erinnern: die neue Wahrnehmung trifft auf die historisch etablierten Konnektivitäten (qua Erinnerungen) und führt zu deren Modifikation.

Wird »Gedächtnis « verstanden als erfahrungsbedingte Modifikation eines Systems, das (unter anderem) Wahrnehmungen erzeugt, dann ist es naheliegend, daß Wahrnehmung ein Prozeß ist, der vielfältigen Einflüssen unterliegt. Die Konzeption von Erinnertem als immer aktuell produzierter Wahrnehmung aufgrund eines historisch modifizierten Produktionssystems legt nicht mehr den Gedanken nahe, Erinnerung sei - oder sollte sein - getreue Reproduktion früherer Wahrnehmungen. Die im Speichermodell angelegte Tendenz zu einer objektivistischen Epistemologie wird also konzeptuell vermieden. (Hejl 1996, 326f)

Überträgt man dieses theoretische Modell von Erinnerung auf das historische Drama, so gibt es Aufschluss über die oben erwähnten beiden Richtungen des Be-

17 Dass beim Speichermodell von „Hardware“ und „Software“, beim Produktionsmodell aber nur von „Hardware“ gesprochen wird, bedeutet jedoch nicht, dass das Produktionsmodell Bewusstsein bzw. Phänomenalität ausklammert oder auf die Hardware Gehirn reduziert. Hejl (vgl. 1996, 329, Fn. 46) gesteht ein, dass auch das Produktionsmodell das Bewusstseinsproblem nicht gelöst hat. 
zugs zwischen Vergangenheit und Gegenwart: zum einen haben ja die historischen Erfahrungen eine Gesellschaft betroffen und diese nachhaltig verändert. Diese Veränderungen werden in den Komponenten und deren Organisation im weiteren Verlauf der Geschichte konserviert. Eine neue Situation für die Gesellschaft in der jeweiligen Gegenwart tangiert nun auch die konservierte Organisation, sie rührt also an diese und „reaktiviert" die Erfahrungen der Vergangenheit. Aufgrund der Reaktivierung der Vergangenheit, die in der Gegenwart gründet, kann es also nicht zu deren „ursprünglichen“ Wiederherstellung in der Erinnerung kommen, vielmehr ist das Erinnerte beeinflusst von der aktuellen Gegenwart. Dass es in der tschechischen Kultur des 19. Jahrhunderts unter anderem auch zu einer durch literaturpolitische Initiativen wie diejenige von Ferdinand Fingerhut/Náprstek angeregten Produktion von historischen Dramen gekommen ist, hat also mehrfache Gründe: Zum einen bewirkte die gesellschaftlich-kulturelle Situation der Tschechen die intensivierte Beschäftigung mit der Vergangenheit, zum anderen brachte es die (Kultur-) Geschichte der Tschechen mit sich, dass die Gattung des historischen Dramas eine Form darstellte, mit der auf aktuelle Fragen der tschechischen Gesellschaft reagiert werden konnte. ${ }^{18}$ Der Rückgriff auf die Geschichte im Medium des historischen Dramas diente dazu, das Theater bzw. Lese-Publikum an die Geschichte zu erinnern und das Bewusstsein von der tschechischen Nation in Gegenwart und Vergangenheit zu schaffen. Immerhin war die tschechische Gesellschaft im 19. Jahrhundert schon so komplex, dass die Beschäftigung mit der Vergangenheit für ihre Mitglieder keineswegs mehr als für die breite Allgemeinheit selbstverständlich gelten konnte, sondern distinguierten bzw. „ausdifferenzierten“ Spezialisten übertragen war, deren (historiographische oder literarische) Texte der interessierten Öffentlichkeit dienen sollten. Die Repräsentation von Geschichte stand im 19. Jahrhundert ,auf der Tagesordnung", was nichts anderes bedeutet, als dass die aktuelle Situation die Erinnerung aktivierte und damit entscheidend beeinflusste: nicht die Vergangenheit ,in nuce" wurde reaktiviert, sondern die Schriften über die Vergangenheit - geschichtswissenschaftliche ebenso wie belletristische - dienten als historische Konstruktionen aktuellen politischen Zwecken.

\section{I.3. Zur Repräsentation von Geschichte im dramatischen Text}

Die oben angestellten Überlegungen thematisieren die Hypothese, dass Texte über die Vergangenheit ihren „Ort“, also den Ausgangspunkt ihrer Genese und den Grund ihrer Emergenz in der jeweiligen Gegenwart haben. Aus der ,inneren Form“ des polyse-

18 Die kulturgeschichtliche Entwicklung in Europa im Lauf des 20. Jahrhunderts hat es mit sich gebracht, dass zum gegenwärtigen Zeitpunkt - 2015 - auf gegenwärtige Situationen nicht mehr mit historischen Dramen reagiert wird. Die Gattung ist zwar nach wie vor „produktiv“, sie ist freilich formal stark modifiziert und steht in Konkurrenz zu anderen Medien, die sich mit Geschichte befassen (vgl. Düsing 1998; Reitz 2009, 376-378). 
men Ausdruckes „Repräsentation“ wurde eben das Moment der Präsenz, der Gegenwartsbezogenheit bzw. der Aktualität präpariert, weil das „Erkenntnisinteresse“ bei der Analyse der historischen Dramen in der vorliegenden Arbeit auf dieses ausgerichtet ist. Im Folgenden sollen die ästhetischen und semiotischen Modi von dramatischer Repräsentation und auch historiographischer Darstellung genauer herausgearbeitet werden, um die Relevanz des historischen Dramas als repräsentierende (und in der Gattungshierarchie des 19. Jahrhunderts „repräsentative“) Gattung zu erklären.

Für Wolfgang Iser ist Repräsentation deswegen ein „performativer Akt" - so der Titel seiner Überlegungen (Iser 1989), weil Rezipienten in ihrer Imagination etwas erschaffen, das ohne diese darstellende Imagination nicht vorhanden war, wenngleich die Repräsentation und die ihr entsprechende Imagination auf außertextliche Bereiche verweisen. Mit der Repräsentation entstehen Doppelungen, eine „simultaneity of the mutually exclusive" (Iser 1989, 239) - gemeint sind mit den Doppelungen das Zugleich von künstlerischem Text und Weltausschnitten, die durch diesen Text repräsentiert werden, das Zugleich von Anwesendem und Abwesendem innerhalb des Textes (bzw. deren Interdependenz) wie auch dasjenige von Fiktionalität und „Wahrheit“, das mit den Repräsentationen verbunden ist. Die künstlerische Fiktion weist ihre Fiktionalität ja aus und verbirgt sie nicht etwa (vgl. ebd., 236239). Repräsentation erscheint bei Iser als anthropologische Notwendigkeit, um diejenigen großen existenziellen Fragen vor Augen zu führen, die der menschlichen Erkenntnis verborgen sind und für welche Ideologien nur oberflächliche Lösungen bieten. Künstlerische Darstellung bzw. Repräsentation - Iser verwendet diese Ausdrücke synonym und grenzt sie von der Mimesis als bloßer Nachahmung ab - hat somit ihre ontologische Domäne in einem Bereich des Menschseins, der von der Erkenntnis nicht erfasst werden kann. Bei der Überführung in den künstlerischen Text wird die außertextuelle Welt durch die Selektions- und Kombinationsverfahren deformiert und verzerrt, wodurch die Domäne des Ästhetischen erzeugt wird (vgl. ebd. 238). Dieser in Bezug auf die Welt „deformierende“ Aspekt, der in der europäischen Ästhetik schon früh thematisiert worden ist (vgl. Werber 2003, 270272), muss auch für eine so mimetische Gattung wie das historische Drama angesetzt werden, das eben repräsentierender künstlerischer Text und nicht historische Wirklichkeit ist - wenngleich freilich meist nicht die großen existenziellen Fragen in ihm repräsentiert sind, wohl aber wichtige Momente politischen Handelns. ${ }^{19}$

19 Dass es zwischen der Themenwahl und dem kulturellen Gedächtnis einen Zusammenhang gibt, hat schon Hegel angemerkt. In Hinblick auf die enge Relation zwischen Dramentext und Publikum bei der Aufführung heißt es: „Im allgemeinen läßt sich daher behaupten, daß ein dramatisches Werk, je mehr es, statt substantiell-menschliche Interessen zu behandeln, sich ganz spezifische Charaktere und Leidenschaften, wie sie nur durch bestimmte nationale Zeitrichtungen bedingt sind, zum Inhalt erwählt, bei aller sonstigen Vortrefflichkeit um desto vergänglicher sein werde“ (Hegel XV/499). 
Die Bühne als Medium bzw. Ort von Repräsentationen ${ }^{20}$ fungiert ebenso bei Iser als wichtiges Demonstrationsobjekt seiner Auffassung, dass Repräsentation keineswegs mit dem Repräsentierten verwechselt werden darf (was aber aufgrund der Ähnlichkeit von Darstellendem und Dargestellten oft passiert), aber zugleich auch nicht ohne das absente Repräsentierte sein kann: „Whatever takes place on the stage is in the service of something absent which makes itself felt through what is present" (vgl. ebd. 246). Iser setzt die Repräsentationstradition der europäische Ästhetik insofern fort, als er der Repräsentation einen - zumindest ästhetischen - Vorrang gegenüber dem Repräsentierten (der Welt) einräumt, anstelle des Anspruchs aber, dass die Repräsentation etwas wie „Wahrheit“ vor Augen führe, sieht Iser die großen Fragen des Menschseins repräsentiert. Umgelegt auf den Fall des historischen Dramas bzw. dessen Bühnen- oder „Lese“-Präsenz heißt das nun, dass nicht allein die ephemeren Ereignisse der Vergangenheit repräsentiert werden; ist doch das Zusammenspiel von Präsenz und Absenz immer mehr als eine Aufzeichnung des Vergangenen. Bei der Repräsentation spielen diejenigen Momente hinein, die zu dieser künstlerischen Darstellung bewegen und die in einer bloßen Fixierung der Ereignisse - etwa durch eine Überwachungskamera - fehlen. Isers Insistieren auf dem Ästhetischen als besonderer Aussageform - jenseits von Alltagsdiskurs, Wissenschaft oder Ideologie - lässt aufgrund der akzentuierten Doppelungen und Simultaneitäten mithin gleichfalls erkennen, dass eine Gattung wie das historische Drama nicht allein von der absenten Vergangenheit, sondern zugleich auch von der präsenten Gegenwart bestimmt ist: gemeint ist mit dem Gegenwartsbezug - über den Zeitpunkt von Produktion oder Rezeption hinausgehend - auch das „Begehren, die Widersprüche des Menschseins“ zu thematisieren, das in den Text einfließt. Gibt der Text eine Erklärung dieser Widersprüche, ähnelt er Ideologien und wird wie diese relativ kurzlebig sein. Ein Text kann aber freilich das Begehren selbst vorführen, ohne eine Antwort auf die großen existenziellen Fragen zu geben. Übernimmt man Isers Dichotomie von wahrer Literatur einerseits und ideologischen Antworten auf eigentlich unlösbare Fragen andererseits und appliziert man sie auf das Textkorpus der tschechischen historischen Dramen, wird man wohl einräumen müssen, dass diese eher als Ideologie einzustufen sind: Sie behandeln wichtige Aspekte der nationalen Geschichte, sie stellen mit dem Bezug auf die Vergangenheit eine Reflexionsebene für das politische Handeln dar, sie haben aber in der Regel wenig Relevanz außerhalb des nationalen bzw. politischen Rahmens, wie im Abschnitt B gezeigt werden wird.

20 Zur Repräsentation im theatrum mundi der Renaissance und des französischen Klassizismus und zu ihrer sozialen Funktion vgl. Werber (2003, 267f). 


\section{I.4. Repräsentation und dramatische Handlung (mythos)}

Im Zusammenhang mit der Frage der dramatischen Repräsentation im historischen Drama muss die trivial anmutende Feststellung stehen, dass die Handlung selbst bedeutungstragend ist. Seit Aristoteles (vgl. Kap. 6 seiner Poetik) gilt Handlung als zentral für die dramatische Gattung (vgl. Asmuth 1994, 4-8). Handlung ist als Handlungsgefüge auch Resultat von Imagination und Kombination, das auf diese Momente hin analysierbar ist. In Entsprechung zu Isers Feststellung, dass Repräsentationen in die außertextliche Welt eingreifen und dabei die Zusammenhänge der Welt zwangsläufig ästhetisch „deformieren“, kann ein Dramentext aus strukturalistischer Perspektive als Selektion und Kombination von Ereignissequenzen betrachtet werden. Ausgewählt wird aus einer offenen Menge von Ereignisketten; die ausgewählten Ereignisse werden dann linear zum Dramentext kombiniert. Nimmt man als kleinste Einheit der Selektion (bzw. als deren Resultat) die Szene an, so ist das Drama ein Syntagma von Szenen, das einen Handlungs- bzw. Ereigniszusammenhang vorführt. ${ }^{21}$

Mit diesem Rückgriff auf strukturalistische Texttheorie soll nicht mehr gesagt sein, als dass ein Drama als Text eine Informationsstruktur darstellt, die im Vergleich zur außertextuellen Welt eine reduzierte Komplexität aufweist und gerade deswegen leichter analysierbar ist. Während die außertextuelle Welt als eine unendliche Menge an Information angesehen werden kann, ist die von einem »Text « repräsentierte Welt „ärmer an Information“. Diese Informationsdifferenz bzw. -reduktion zwischen Welt und »Text « ist selbstverständlich bei jeder medialen Repräsentation zu beobachten und gewiss kein Spezifikum des Dramas. Die Informationsdifferenz wird hier nur deshalb ins Spiel gebracht, weil die Subgattung „,historisches Drama“ schon in ihrem Namen einen genretypischen Bezug auf geschichtliche Ereignisse anzeigt, der gerade hinsichtlich des Begriffs der Handlung wichtige Bestimmungen möglich macht.

21 Angemerkt sei hierzu, dass sich diese Fragestellung in analoger Form auch in der Blütezeit der Filmsemiotik abgezeichnet hat, da das Medium Film noch deutlicher als die Kunstformen Schauspiel/Drama sein Material von der „Wirklichkeit“ selbst nimmt. Das etwas scholastische Problem der Filmsemiotiker bestand nun darin, die Grenzen der einzelnen Zeichen zu bestimmen, aus denen sich die „Sprache“ Film zusammensetzt. Während Christian Metz die einzelne Einstellung als narratives Grundelement betrachtete (gleichsam als einen Satz), schlug Pier Paolo Pasolini den Begriff Kinem vor, um die unaufösliche Verbindung von auBerfilmischer gefilmter Wirklichkeit und Filmbild zu benennen und die Inferenzen aus der strukturalistischen Sprachtheorie einzudämmen. Im Film wird demnach die Welt selbst zum Zeichen. Über das historische Drama könnte gesagt werden, dass schlechthin alles an ihm - Handlungen, Nebentext, Sprechhandlungen - Zeichen ist, aber vom „naiven“ Betrachter fälschlich als die Wirklichkeit selbst angesehen wird. Richtet man ähnlich wie Metz den Blick auf die Handlung bzw. die Syntagmatik der Szenen, wird das Verhältnis zur Wirklichkeit zweitrangig. 
Die Konzentration auf Sujetentwicklung im Drama bedingt eine klare chronologische Verkettung von Handlungen ${ }^{22}$ und Ereignissen, die den Konflikt ausmachen. Der vorgeführte Handlungszusammenhang erlaubt eine ziemlich eindeutige Analyse, bei der Verantwortlichkeiten für Handlungen und Gründe für diese festgelegt werden können. Der große Stellenwert der Handlung im Drama wurde ja schon in der antiken Dramentheorie thematisiert, er setzt sich in der Dramentheorie Schillers und Hegels fort (vgl. Lehmann 2013, 90): Aristoteles versteht unter mythos die Zusammensetzung der Geschehnisse und hält diesen für das „Fundament und gewissermaßen die Seele der Tragödie“ (Aristoteles 1994, 23); auch die kathartische Wirkung wird an bestimmte Handlungsverläufe gebunden, sie stellt sich nicht bei jedem Handlungsverlauf ein (vgl. ebd., Kap. 6 u. 13). Ungeachtet des Umstandes, dass Dramenhandlungen nur im Idealfall eine von der Autorintention bestimmte Wirkung auf den „Dritten“ (das Publikum, den Betrachter) haben, können sie dennoch unter Absehen von der konkreten Rezeptionssituation auf Zusammenhänge hin analysiert werden. Wie unten mit Rückgriff auf Hayden Whites Analyse der Historiographie (White 1973) gezeigt wird, ist der Handlungszusammenhang ein im »Text « bzw. in den Repräsentationen hergestellter; dies gilt gleichermaßen für das Geschichtswerk wie für das Drama.

Die „Einheit der Handlung“ im Drama legt Zusammenhänge selbst dann nahe, wenn die Handlung nicht in der klassischen Form ausgeführt ist, sondern diskontinuierliche Szenen im Text zusammengefügt sind - die Erwartungshaltung des Rezipienten stellt mehr oder weniger bestimmte Verbindungen zwischen den vorgeführten Szenen her, während bei ähnlicher Disparatheit in der historischen Wirklichkeit anzunehmen ist, dass diese als unverbunden erscheinen. Jede textuelle Repräsentation, die immer auch eine Komplexitätsreduktion gegenüber der historischen Wirklichkeit ist, „generiert“ bei der Rezeption Zusammenhänge zwischen ihren Elementen. ${ }^{23}$

Für die Gattung Drama ist weiters Unmittelbarkeit ein wichtiges Kennzeichen: Die Handlungen und Sprechakte der Figuren erschaffen keine fiktionale Welt, wie das für die Erzählerrede in der Epik charakteristisch ist, vielmehr sind sie selbst schon Teil der repräsentierten Welt. Figurenhandlungen verändern die Sachverhalte in der repräsentierten Welt, mit welcher das Theaterpublikum bzw. der Leser

22 Handlung im engeren Sinn will als (bewusste) Tat verstanden werden, sie impliziert also ein handelndes - meist menschliches bzw. allenfalls anthropomorphes - Subjekt. Demgegenüber ist die Urheberschaft von Ereignissen nicht so deutlich gegeben: Ereignisse haben entweder keinen erkennbaren Urheber oder die ineinandergreifenden bzw. parallel erfolgenden Handlungen vieler Handelnder führen zu einem Ereignis.

23 Ähnlich wie in der Lebenswelt der Zusammenhang von Szenen, die keine gemeinsamen „Protagonisten" haben und an gänzlich unterschiedlichen Orten stattfinden, vielfach unter Rekurs auf die „Atmosphäre“ bzw. den Zeitgeist hergestellt wird, erfolgt dies bei Dramen mit „offener“ Form, etwa bei Karl Kraus' Die letzten Tage der Menschheit. 
in der Regel unmittelbar - ohne Vermittlung eines epischen Erzählers - konfrontiert werden.

Der Charakter dieser Unmittelbarkeit ist gattungslogischer, nicht ästhetischer Natur (vgl. Schlegels Bestimmung „Der dramatische Dichter stellt uns zwar auch, wie der epische, äußerliche Vorfälle dar, aber als wirklich und gegenwärtig. Er nimmt unsre Teilnahme in Anspruch, aber nicht so genügsam wie der lyrische Dichter, sondern weit unmittelbarer als dieser will er uns erfreuen und betrüben" (Schlegel 1966, 40f). Er hängt nicht von der Illusionswirkung ab, ${ }^{24}$ die darin besteht, dass die Rezipienten die ontologische Differenz zwischen ihrer Situation und der repräsentierten fiktionalen Situation überbrücken und die fiktionale Welt quasi als reale Welt akzeptieren. Vielmehr besteht die Unmittelbarkeit in der Konfrontation des Rezipienten mit Vorgängen in der repräsentierten Welt; von den extratextuellen Rahmenbedingungen des Mediums (ob das Drama als Lesetext oder als Theateraufführung rezipiert wird) kann abstrahiert werden, wenn man sich auf die Welt selbst konzentriert. Das vorgeführte Geschehen in dieser Welt ist als (quasi-) reales Geschehen - natürlich in Relation auf die vom Text repräsentierte Welt - zu charakterisieren; keine erzählende oder reflektierende Instanz vermittelt zwischen der vorgeführten Welt und dem Rezipienten.

\section{I.5. Historisches Drama und Geschichtsschreibung als Repräsentationen}

Welche Handlungen und Ereignisse führen zu „historischer“ Veränderung? Kann man die unendliche Menge der Handlungen und Ereignisse in der Welt kategorisieren und klassifizieren, um - etwa in einer Unterscheidung von historisch relevanten und irrelevanten Handlungen und Ereignissen - auf diese Frage eine Antwort zu geben? Neben den theoretischen Antworten auf diese ständig aktuelle Kernfrage der Historiographie, welche etwa Lev Tolstoj im geschichtsphilosophischen Anhang zu Vojna $i$ mir erörtert hat, bestehen praktische Lösungen in Gestalt von historiographischen »Texten «, die jeweils eine bestimmte Version von Geschichte liefern. Diese Darstellungen von Geschichte stellen als »Texte « nur eine Auswahl der Ereignisse in der Welt dar, darin unterscheiden sie sich nicht von anderen Repräsentationen bzw. anderen »Texten«, wie etwa historischen Dramen. Letztere schöpfen ihren historischen Gehalt zwar meist nicht aus historischem Quellen-

24 Die Illusion ist ein kontingentes Rezeptionsphänomen, das sich in der rezeptiven Auseinandersetzung mit welterzeugenden Texten einstellen mag oder auch nicht. Tatsächlich kann sich in einer konkreten Rezeptionssituation die Illusionswirkung einstellen, sie kann nur teilweise funktionieren oder gar gänzlich ausbleiben. Wenn die Texte selbst (der Dramentext oder der Text einer konkreten Inszenierung) Illusionsdurchbrechungen aufweisen, handelt es sich natürlich nicht mehr um eine kontingente Eigenschaft der Rezeption, sondern um eine Eigenschaft des Textes. 
material, sondern schon aus historiographischen Texten, dennoch können sie als Texte selbstständig, d.h. ohne Kenntnis der historiographischen Prätexte rezipiert werden. Somit müssen sie als eigenständige bzw. gattungsspezifische Version von Geschichtsdarstellung gelten (und nicht etwa als subalterne Versionen der ihnen zugrunde liegenden historiographischen Texte).

Die angesprochenen Spezifika der dramatischen Gattung - Unmittelbarkeit, Publikumsbezug, die eingeschränkten Möglichkeiten von Dramentext bzw. Bühne, ein umfangreicheres Bild der repräsentierten Welt zu liefern, die damit verbundene Reduktion der Mittel und die Bindung der Handlung an die dramatis personae etc. - haben ihren Effekt auf die Darstellung von Geschichte in den Dramen. Diese unterscheidet sich markant von Darstellungsmodi in geschichtswissenschaftlichen Genres.

Die explizit von Ansgar Nünning $(1995,92)$ konstatierte Hybridität des historischen Romans zwischen historischem Bezug und literarischer Fiktion findet eine diskursgeschichtliche Entsprechung im Umstand, dass im 19. Jahrhundert viele Autoren historischer Belletristik auch als Verfasser geschichtlicher Werke wirkten, Literatur und Geschichtsschreibung bei ihnen also in Personalunion verbunden war. ${ }^{25}$ Auch nach der Ausdifferenzierung von Historiographie und Belletristik, die relativ spät erfolgte (vgl. Hüttmann 2001, 15-18) bilden in der Regel immer noch historiographische Texte die Grundlage für das literarische Geschichtsdrama. Mithin kann in Anschluss an Nünning die Hybridität auch für die historische Dramatik reklamiert werden (vgl. ebd., 35).

Hayden White unterscheidet in Metahistory (1973) mehrere Strata im Textaufbau historiographischer Werke. Auf einer elementaren Ebene ist dies die Umwandlung der Chronik (chronicle) in eine Fabel (story), nachdem schon zuvor eine Auswahl bestimmter Ereignisse als für eine Chronik relevanter erfolgt sein muss. Nach White (vgl. ebd. 19-21) stellt die Fabel, die aus einer Chronik entstanden ist, eine einfach nacherzählte Geschichte dar, deren Anfang und Ende deutlich markiert ist. Aus der Fabel modelliert der Historiker dann eine Geschichte, die bedeutungsvoll ist und Erklärungen für die erzählten Ereignisse liefert. In diese Erklärungen fließen in rudimentärer Form literarische Gattungsschemata bzw. diesen entsprechende Deutungsmuster ein. ${ }^{26}$ Neben den literarisch-historiographischen „Gattungen“ gibt

25 Dem im Zuge des obrození geweckten Interesse für die tschechische Kultur und Geschichte wurde mit František Palackýs Geschichte von Böhmen (1836-1867) begegnet; Palacký versuchte sich in seiner Jugend auch als Dichter und steht somit in einer Reihe von Persönlichkeiten der tschechischen bzw. slowakischen Kulturgeschichte, die Literatur und Wissenschaft in ihrem Schaffen verbanden. Zu nennen wären neben Palacký Pavel Josef Šafařík, František Čelakovský, Jan Nebeský, Jan Kollár, Josef Václav Sládek, Jaroslav Vrchlický, Jaroslav Goll, František Xaver Šalda, Arne Novák, Otokar Fischer (vgl. Schamschula 1996, 35f).

26 Whites These von der Affinität der Historiographie zur Belletristik ist keineswegs ganz neu, schon Hegel hat in seinen Vorlesungen zur Ästhetik die Geschichtsschreibung, die er pro- 
es in Geschichtswerken freilich auch noch explizitere Erklärungsmuster (z.B. nomologisch-deduktive und diskursive). Überdies können sich Historiker nicht von ihren ideologischen Standpunkten freimachen, nolens volens manifestieren sich diese auch in den von ihnen verfassten historiographischen Texten.

Wenn der Geschichtsschreibung wie auch dem historischen Drama die Thematisierung von tatsächlichen Ereignissen gemeinsam ist, gilt es dennoch, die unterschiedlichen Modi dieser Thematisierung durch die beiden Gattungen zu betrachten. Fasst man die oben mit White beschriebenen Strata eines historiographischen Textes chronologisch auf, so ergibt dies die Reihe (außertextuelle) Ereignisse -> Chronik -> Fabel -> historiographisches Werk; die Genese eines Geschichtsdramas hingegen verläuft - vereinfacht gesehen - umgekehrt: es nimmt seinen Ausgang meist von einem historiographischen Text, in welchem die von White beschriebenen Faktoren enthalten sind, um daraus wieder „dramatische“ Ereignisse zu machen, die im Medium Text oder auf einer Bühne den Rezipienten vorgeführt werden.

Aufgrund dieses Transformationsprozesses - selbst wenn dieser hier nur theoretisch-abstrakt beschrieben ist, kann gelten, dass konkrete historische Dramen auf einem vergleichbaren Weg zustande kommen - hat man es mit zwei grundsätzlich differenten „historischen Ereignissen“ zu tun: den realen außertextlichen Ereignissen qua res gestae, welche für die Geschichtsschreibung die Grundlage für textuelle Transformationsprozesse darstellen, und den vom Dramentext repräsentierten und ggf. in eine Inzenierung mündenden Ereignissen, deren ontologischer Status von den realen Ereignissen natürlich kategorial verschieden ist, handelt es sich doch um virtuelle bzw. um Quasi-Ereignisse, um Repräsentationen, deren Rezeption historische Vergangenheit gegenwärtig macht bzw. aktualisiert.

Die Eigentümlichkeit von Repräsentationen - historische Dramen, aber natürlich auch andere Genres und Darstellungen können als solche gelten - besteht darin, dass sie im Unterschied zu Aussagen über reale Sachverhalte bzw. Ereignisse komplexer organisiert sind. Ankersmit (vgl. 2002, 18f) erläutert dies am Beispiel

saisch nennt, im Vergleich zur „Poesie“ (heute würde man stattdessen „Belletristik“ sagen) diskutiert und abzugrenzen versucht. Was Hegel dabei über die „Kunst“ der antiken Historiker schreibt, ähnelt doch Whites Überlegungen: „[...] und wie sehr der Historiker auch bemüht sein muß, das wirklich Geschehene wiederzugeben, so hat er doch diesen bunten Inhalt der Begebnisse und Charaktere in die Vorstellung aufzunehmen und aus dem Geiste her für die Vorstellung wiederzuschaffen und darzustellen. Bei solcher Reproduktion darf er sich ferner nicht mit der bloßen Richtigkeit des einzelnen begnügen, sondern muß zugleich das Aufgefaßte ordnen, bilden und die einzelnen Züge, Vorfälle, Taten so zusammenfassen und gruppieren, daß uns aus ihnen einerseits ein deutliches Bild der Nation, der Zeit, der äußeren Umstände und inneren Größe oder Schwäche der handelnden Individuen in charaktervoller Lebendigkeit entgegenspringt, andererseits aus allen Teilen ihr Zusammenhang hervorgeht, in welchem sie zu der inneren geschichtlichen Bedeutung eines Volks, einer Begebenheit usf. stehen." (Hegel XV/257f) 
eines Fotos einer schwarzen Katze. Bei einem Foto kann nicht mehr streng zwischen referenzieller Bezugnahme auf ein Subjekt und einer Prädikation unterschieden werden. Während angesichts einer realen Katze über diese eine De-re-Aussage bzw. Prädikation gemacht werden kann (z.B. „Die Katze ist müde“), greifen bei einer Repräsentation Referenz und Prädikation ineinander und werden ununterscheidbar. Analog verhält es sich, wie Ankersmit $(2002,15)$ zeigt, mit historiographischen Darstellungen: eine neue Studie über die Renaissance ist nicht etwa eine neue Aussage über ein klar abgegrenztes Thema bzw. ein Referenzobjekt, sie hat vielmehr das Potenzial, den Gegenstand selbst in der Vorstellung der Rezipienten signifikant zu verändern. Laut Ankersmit können in geschichtswissenschaftlichen Darstellungen - z.B. über die Epoche der Renaissance - Aussagen de dicto nicht klar von Aussagen de re unterschieden werden. Meiner Auffassung nach kann dies umso mehr für die Repräsentation von Geschichte gelten, die in historischen Dramen erfolgt. Angesichts einer Studie über ein bestimmtes Thema der Geschichtswissenschaft ist man vielleicht eher geneigt, zu meinen, der Historiker beziehe sich auf klar abgegrenzte reale Ereignisse, insofern man nämlich der Auffassung ist, dass mehr oder weniger korrekte De-re-Aussagen über diese möglich sind. Angesichts eines Dramas oder eines Spielfilms über den Spartakus-Aufstand etwa wird man aber sagen, das Drama bzw. der Film handle von diesem Ereignis; man beginge einen ontologischen Fehler, diese Repräsentation für eine wahre oder falsche Aussage über die Realität zu halten, und sei die Machart auch noch so „realistisch“. Mit Texten der Geschichtswissenschaft verhält es sich - so zumindest die Auffassung Ankersmits - ähnlich: Entgegen der weit verbreiteten Ansicht, die Historiographie treffe wahre oder falsche Tatsachenaussagen, postuliert er, dass historiographische Texte mehr oder weniger "Ähnlichkeit“ mit der historischen Realität haben, von der sie handeln, nicht aber selbstverständlich als Sachverhaltsdarstellungen mit Wahrheitswerten aufgefasst werden sollen. ${ }^{27}$

Zumal für Ankersmit die Historiographie wie auch die Literatur Repräsentationen der außersprachlichen Realität liefern, sind sie - was ihren Realitätsbezug betrifft - nur graduell voneinander verschieden. Abgesehen von der skizzierten Genealogie historischer Belletristik (ihre meist text-quellengeschichtlich nachweisbare Verschränktheit mit historiographischen Texten, die als Vorlage dienten) gibt es also auch sprachtheoretische Gemeinsamkeiten zwischen diesen beiden Arten, Geschichte darzustellen, womit etwa der Umstand besser verständlich wird, warum es überhaupt diachrone Veränderungen in den repräsentierenden Genres Geschichtsschreibung bzw. historisches Drama geben kann. Denn hätte man es mit „einfachen“ referenziellen Bezügen

27 Die mehr oder weniger große Ähnlichkeit der Repräsentationen unterscheidet sich von Wahrheitsaussagen dadurch, dass Wahrheitsaussagen binär - wahr/falsch - kodiert sind, während Repräsentationen nicht auf diese Weise, sondern nach Ähnlichkeitsgraden betrachtet werden. 
und Prädikationen zu tun, ließen sich wahre von falschen Aussagen über geschichtliche Ereignisse leichter unterscheiden, und es gäbe weniger Vielstimmigkeit und stattdessen mehr Konsens über Texte mit geschichtlicher Thematik. So aber spielen in die Repräsentationen die unterschiedlichsten Faktoren hinein und induzieren unterschiedliche Bilder von historischen Gegenstandsbereichen (Epochen, Ereignissen etc.), auf welche die diversen Texte keineswegs „starr“" (im Sinne Kripkes) referieren.

In literaturwissenschaftlichen Arbeiten zu historischer Belletristik - gleichgültig, ob es sich um Drama, Lyrik oder Epik handelt - wird sehr oft auf das Verhältnis dieser Texte zu ihren historiographischen Prätexten bzw. Quellen abgehoben, um die spezifischen Unterschiede des literarischen Textes - den „Mehrwert“, welchen dieser gegenüber seinen Vorlagen schafft - zu bestimmen. Eine solche vergleichende Analyse liefert tatsächlich meist gute Einsichten in das „Pathos" des belletristischen Textes, dessen Darstellung eines historischen Ereignisses in entscheidenden Punkten von den geschichtswissenschaftlichen Prätexten abweichen und damit eine andere Erklärung sowie eine andere ideologische Position implizieren kann.

Zugleich jedoch schränkt eine solche Untersuchung die Analysemöglichkeiten deswegen ein, weil die Berücksichtigung intertextueller Bezüge und Differenzen zwar bei einigen wenigen Texten durchführbar ist, mit dem Anwachsen der Zahl literarischer Primärtexte jedoch zu umfangreich und komplex wird, gilt es doch, mögliche Prätexte von verschiedenen „manifesten“ literarischen Texten zu betrachten, um zu Schlüssen über den Primärtext zu kommen. Abgesehen von der Schwierigkeit, eine größere Anzahl literarischer und geschichtswissenschaftlicher Texte synoptisch zu vergleichen, ist vor allem aber die qualitative Besonderheit literarischer gegenüber historiographischer Repräsentation zu beachten. Beide „handeln von“ "etwas, beide „stellen“ etwas „dar“ (in ihrem Repräsentationscharakter besteht laut Ankersmit ihre Gemeinsamkeit); während aber die Geschichtsschreibung die realen Ereignisse mit den Strata Chronik, Fabel, Erklärung überformt und dabei den Eindruck vermittelt, eine Beschreibung von Ereignissen zu liefern, produziert namentlich das historische Drama Ereignisse zweiter Ordnung in einem theatralischen Raum, wobei dem dramatischen Text zumindest die „White'schen“ Strata Fabel und Erklärung für die vorgeführten Ereignisse zu fehlen scheinen.

Für das historische Drama als Repräsentation gilt dennoch dasselbe wie für alle anderen Repräsentationen: aufgrund der Informationsreduktion des repräsentierenden Textes (gegenüber der historischen Wirklichkeit) gehorcht das Drama bestimmten gattungsimmanenten Gesetzen - man könnte diese allgemein textlinguistisch als Gesetze der Kohärenz, Extension und Konsistenz bezeichnen - welche für die historische, nicht textuell repräsentierte Wirklichkeit selbstverständlich nicht gelten (vgl. Ankersmit 2002, 22f). Dementsprechend können mit diesen Ereignissen zweiter Ordnung, die vom dramatischen Text repräsentiert werden, die Strata Chronik, Fabel und Erklärung auf eine ähnliche Weise verbunden werden, wie dies in der Geschichtsschreibung funktioniert. Repräsentiert ein historisches 
Drama also geschichtliche Ereignisse, sind in den Text - gleichsam eine Partitur der szenischen Ereignisse - „Fabel“ und „Erklärung“ als Strata historiographischer Repräsentationen „eingefaltet“, sie können bei der Analyse des dramatischen Textes dementsprechend wieder „ausgefaltet“ werden, ohne dass dafür auf die historiographischen Prätexte zurückgegriffen werden müsste. Das historische Drama ist demnach als Text sui generis zu betrachten, der Ereignisse zweiter Ordnung - szenische Ereignisse - als Repräsentation produziert und - anders als die realen historischen Ereignisse erster Ordnung - die historiographischen Strata Fabel und Erklärung eingefaltet enthält. Man betrachte die hypothetische Kette:

Ereignisse erster Ordnung [= reale Ereignisse bzw. res gestae $] \rightarrow$ Chronik $_{1} \rightarrow>$ Fabel $_{1} \rightarrow>$ historiographische Erklärung ${ }_{1} \rightarrow>$ (historisches Drama qua Partitur $\rightarrow>$ Ereignisse zweiter Ordnung [=repräsentierte Ereignisse]) $->$ Chronik $_{2}->$ Fabel $_{2}->$ historiographische Erklä$\operatorname{rung}_{2} \ldots$

Sie macht ersichtlich, dass die (historiographischen) Erklärungen auf Ereignisse reale oder repräsentierte - „folgen“ und dass es unterschiedliche Betrachtungsweisen dieser Kette gibt.

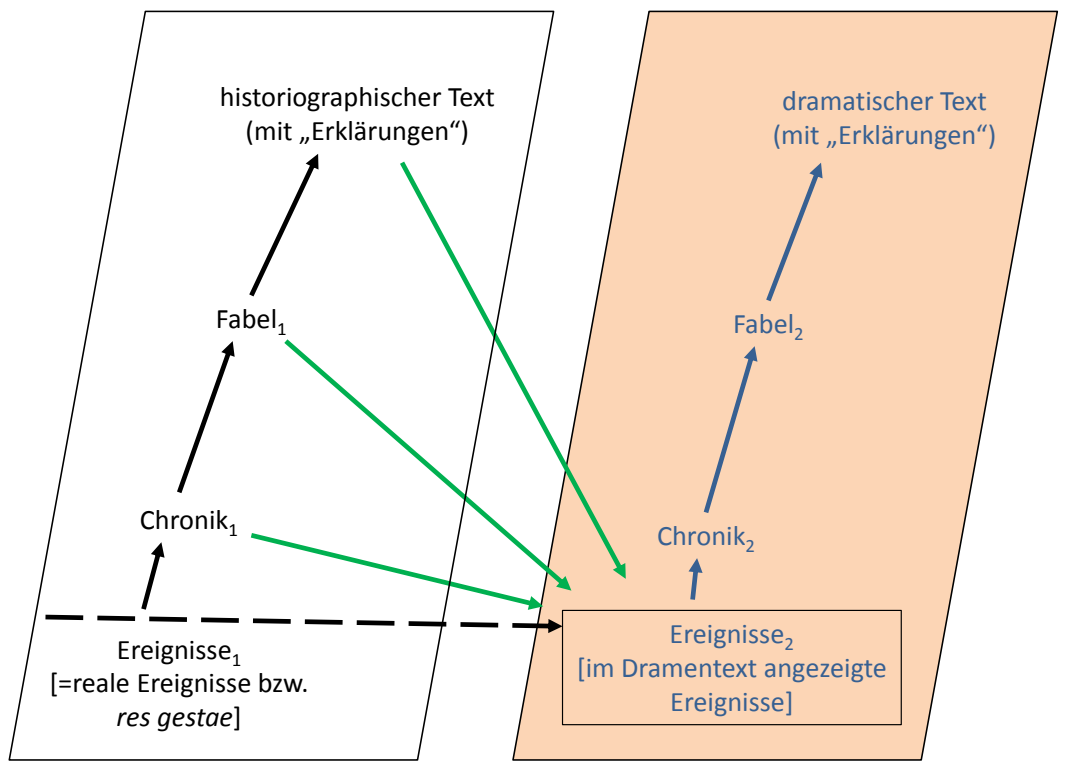

Graphik 1-Geschichtsschreibung und historisches Drama

In der Graphik werden Nähe und Differenz von Geschichtsschreibung und historischem Drama dargestellt. Zwischen den beiden Gattungen, die meist in einer chronologischen Dependenz stehen (die Geschichtsschreibung stellt die textuelle 
Basis für die Dramatiker her), besteht ein wichtiger Unterschied darin, dass Ereignisse Thema der Historiographie sind, dass aber ein Drama als Text aufzufassen ist, der die dramatischen (Pseudo-)Ereignisse repräsentiert. Spätestens die Aufführung „dissimuliert“ den Textcharakter des Dramas (im Schema soll diese Dissimulation dadurch angedeutet werden, dass die strichlierte Pfeillinie, die links die Bereiche von Welt und Text auseinanderhält, dem historischen Drama insofern nicht entspricht, als dieses „sekundäre" bzw. Pseudo-Ereignisse enthält, die zwischen Text und Bühnen-Ereignis schwanken). Die Analyse der Dramen kann mithin auf ähnliche Weise erfolgen wie die von White beschriebenen Etappen in der Erstellung eines historiographischen Textes, ein wichtiger Unterschied ist aber durch den Textcharakter des Dramas bedingt, der im Vergleich zur Welt bereits ärmer an „Information“ (im informationstheoretischen Sinn) ist, da ja das Drama nicht die gesamte „Welt" mit ihren unendlichen Sachverhalten ausmacht, sondern nur einen Ausschnitt der Welt repräsentiert. ${ }^{28}$ Dieser Ausschnitt ist schon - wenngleich bzw. weil er die Welt erfassen soll - präpariert, der Autor hat nach seinem Vorverständnis die Ereignisse so arrangiert, dass ihr Zusammenhang einfach erfasst werden kann (siehe dazu unten S. 102).

Während (zumindest ihrem orthodoxen Selbstverständnis nach) Historiker primär „reale Ereignisse“ mit Darstellungen und Erklärungen bedenken, thematisieren Kultur- oder Literaturwissenschaften unterschiedliche Aspekte der Kette, sie beschäftigen sich aber weniger mit einer Erklärung der Ereignisse erster Ordnung. Ihr Interesse kann darin bestehen, die Repräsentationen zweiter Ordnung mit historiographischen Repräsentationen zu vergleichen (was eben ein oft gewählter Ansatz bei der Analyse von historischen Dramen ist), so analysiert die White'sche „Metahistory“ etwa bevorzugt die Historiographie selbst, oder die Kultur- und Literaturwissenschaften fokussieren gesondert auf die literarischen Repräsentationen von Geschichte: Letzteres erfolgt natürlich auch in dieser Arbeit, die Veränderungen des historischen Dramas in einem Zeitraum von ca. 125 Jahren untersucht. Die Konzentration auf die dramatischen Texte und die an diese anschließbaren Strata zweiter Ordnung impliziert eine Abstandnahme von sowohl den realen Ereignissen selbst wie auch von den an diese angeschlossenen Strata erster Ordnung in der historiographischen Darstellung. Immerhin trägt sie dabei aber dem Umstand Rechnung, dass diese literarischen Repräsentationen von Geschichte eigenen gattungs-

28 Jurij M. Lotman (vgl. 1972, 300-305) verbindet ja gerade mit der Beschränkung des Kunstwerks durch einen Rahmen dessen Potenzial, keine singulären Referenzen auf einen einzelnen Sachverhalt zu leisten, sondern prinzipiell auf unendlich viele - und dabei auch verschiedene - Situationen beziehbar zu sein. Diesem Potenzial zu vielfacher Referenz des künstlerischen Texts stehen die historischen Genres insofern entgegen, als sie in der Regel die Handlung zeitlich genau lokalisieren. Die „Re-/De-präsentation“ - der in dieser Arbeit thematisierte Bezug auf die jeweils aktuelle Gegenwart - muss gleichsam diese historische „Barriere“ überwinden. 
spezifischen Regeln folgen, die weder in den repräsentierten Ereignissen selbst noch in den historiographischen Prätexten ihren Grund haben.

Die doppelt hybride Struktur des historischen Dramas (neben der bereits von Nünning festgestellten Mischung von Facta und Ficta ist der schriftliche Dramentext eine „Partitur“ von Bühnenereignissen wie auch Repräsentation von geschichtlichen Ereignissen) gestattet es, aus ihm die Fabel 2 zu extrapolieren, um in dieser die eingefalteten „Erklärungen “ auszumachen, welche den Ablauf der Ereignisse verständlich machen sollen (Die Indexzahl 2 verweist auf die obige Skizze bzw. darauf, dass es sich um Strata des historischen Dramas handelt).

Der praktische Gang der einzelnen Dramenanalysen in dieser Arbeit erfolgte tatsächlich ähnlich wie im obigen Modell: während der Lektüre wurden in einem ersten Schritt die einzelnen Szenen beschrieben, was dem Stratum der „Chronik “ entspricht. Über den so beschriebenen Szenen (deren Beschreibung, die „Chronik $_{2}$ “, wird den Lesern hier aus dem Grund vorenthalten, als sie allzu „roh“ anmutet) entsteht die Fabel 2 als Verbindung der Szenen, als Beschreibung der dramatischen Handlung. Diese Fabel 2 nun wird dem Leser dieser Dramenanalysen in der Arbeit sehr wohl präsentiert, sie enthält dabei auch schon eingefaltete „Erklärungen“.

Die Fabel ${ }_{2}$ ist de facto natürlich nichts anderes als eine einigermaßen genaue Inhaltsangabe der historischen Dramen; diese ist aus zweierlei Gründen unumgänglich: Zum einen kann die Bekanntschaft mit den Dramentexten keineswegs vorausgesetzt werden, in der Regel sind diese sogar ausgewiesenen Bohemisten nicht sonderlich bekannt, weil sie nicht zu den kanonischen Texten der tschechischen Literaturgeschichte zählen (wenngleich einige Autoren - etwa Tyl, Mácha, Hálek, Vrchlický, Zeyer, Dyk, Langer - als durchaus bedeutende Persönlichkeiten der tschechischen Literatur gelten), eine einigermaßen detaillierte Nacherzählung in Form einer Fabel ${ }_{2}$ ist daher durchaus angebracht. Und zum anderen - und das ist der weitaus gewichtigere Umstand - ist die Fabel ${ }_{2}$ bzw. die Inhaltsangabe als Nacherzählung der Dramenhandlung zentral für die Analyse des Dramas, die auf den in dieses eingefalteten ideologischen Gehalt und dessen Zeitbezug abzielt. Die Handlung des Dramas selbst ist keineswegs ein Ereignis in seiner bloßen Faktizität, sondern eine durch den Dramentext und den ihm zugrunde liegenden Kriterien geschaffene Repräsentation, die nicht allein die Vorstellung von der Vergangenheit verändern kann, sondern über diese auch ein entsprechendes Muster für die Interpretation zeitgenössischer Ereignisse abgibt.

Dass die Inhaltsangaben der Dramen als eine Form von Fabel ${ }_{2}$ mit Erklärungen analog zur der von White beschriebenen Praxis der Geschichtsschreibung stehen, heißt natürlich auch, dass für sie im Prinzip die Problematik der Historiographie gilt, deren narrative Verfahren Ereignisse zu Texten transformieren. Aus thematischen Gründen - die Arbeit zielt auf einen Überblick über Entwicklungen des historischen Dramas bei den Tschechen ab und soll keine theoretische Diskussion historiographischer Praktiken sein - muss auf eine Reflexion der Verfahren, mit denen 
die Inhaltsangabe die „Ereignisse “ ${ }_{2}$ des Dramentextes in eine Erzählung verwandelt, verzichtet werden. Verwiesen sei aber auf einige Beiträge - vor allem diejenigen von Weinrich, Stierle, Borst - im Sammelband Geschichte - Ereignis und Erzäblung (Koselleck/Stempel 1973). Am historischen Drama lässt sich die in der Narratologie erst allmählich etablierte Erkenntnis leicht veranschaulichen, dass die Ebene des Geschehens bereits Teil des Textes ist (vgl. Stierle 1973, 531; W. Schmid 2008, 2-11), weil ja das Geschehen bzw. die Ereignisse ${ }_{2}$ die Ergebnisse einer auktorialen Gestaltung sind.

Unter „Erklärungen“ subsumiert White verschiedene Modi, die mehr oder weniger explizit die Verbindungen von Ereignissen herstellen. Im Fall des historischen Dramas, wo sowohl eine ausformulierte Fabel wie auch eine entsprechende Erklärung an der Textoberfläche fehlen, latent bzw. eingefaltet aber vorhanden sind, liefert die extrapolierte Fabel, also die detaillierte Inhaltsangabe die zentrale Grundlage für die Erklärung. Die gattungsspezifische Kohärenz des Dramas - die Einheit der „Handlung“, welche als die wichtigere im Vergleich zu den meist freier ausgeführten Einheiten Zeit und Ort gelten kann (vgl. Asmuth 1994, 192f) - lässt nämlich Handlungsketten und Zusammenhänge deutlich werden, während andere explizite Erklärungsmuster in den Hintergrund treten. In die vom dramatischen Text dargestellten Handlungsketten fließen verschiedenartige Faktoren ein, die bei der Analyse des Textes zu berücksichtigen sind, wenn dem kulturellen bzw. ideologischen Gehalt von Dramen und der gattungsspezifischen szenischen Repräsentation geschichtlicher Vorgänge nachgespürt werden soll.

Angesichts der Anzahl der im Laufe von eineinviertel Jahrhunderten entstandenen historischen Dramen ist es vonnöten, vom jeweiligen historischen Gehalt der exemplarisch ausgewählten Texte möglichst zu abstrahieren, da sie auf der Ebene der repräsentierten Ereignisse wenig Gemeinsamkeiten aufweisen. Anders gesagt, sie sind auf dieser Ebene der historischen Ereignisse oft inkommensurabel, insofern sie unterschiedliche Ereignisse thematisieren. Eine Untersuchung dessen, welche Veränderungen das historische Drama zwischen 1810 und 1935 erfahren hat, muss vielmehr auf das Stratum der "Erklärungen“ abzielen, das in den Dramen eingefaltet ist und an die Fabel des Dramas anschließt. Diese „Erklärungen“ ergeben sich in der Betrachtung der verschiedenen Faktoren, die den Verlauf der repräsentierten Ereignisse bestimmen und die in der Fabel am besten ausgemacht werden können.

\section{I.6. Dramatische Re-/De-präsentation}

Die in den einzelnen historischen Dramen erkennbare Version von Geschichte steht mit historiographischen, literarischen und politischen Faktoren im Zusammenhang: Bei der Transformation des historischen Stoffs in ein Drama wird das historiographische „Material“ den Konventionen von Dramen- und Theaterpraxis 
angepasst. Geschichtliche Vorgänge, die in verschiedenen Quellen und Überlieferungen ihre erste Fixierung und Darstellung gefunden haben und in der Folge in historiographische Schriften eingegangen sind, werden somit im buchstäblichen wie auch übertragenen Sinne „dramatisiert", d.h. in eine Form gebracht, die ihrerseits eine eigene Geschichte hat, welche mit den Erwartungen des Publikums und dessen Apperzeptionsfähigkeit in Relation steht. Der "Spannungsbogen“ des „klassischen“ Dramas beispielsweise ist zum einen historisch bedingt, zum anderen findet die Antizipation psychologischer Dispositionen des Publikums ihren produktionsästhetischen Niederschlag in der Konzeption des Dramas. Je strenger die Gesetze der Form im Drama eingehalten werden müssen, desto größer ist beim historischen Drama der sog. „Widerstand des Materials“ - so erlaubt etwa historisches Material, insbesondere solches, das dem Publikum gut bekannt ist, keine große Veränderung, um in ein Drama eingehen zu können (vgl. Lindenberger 1975, 1-4). „Das ist eben die große Schwierigkeit des historischen Dramas, daß es zugleich ein gedrängter Auszug und eine lebendige Entfaltung der Geschichte sein muß", konstatierte schon Schlegel $(1967,181)$.

Wenn Dramen auf das Interesse des Publikums stoßen wollen, müssen sie nicht allein mit dessen ästhetischen Prädispositionen und Erfahrungen rechnen, sondern auch mit ideologischen Einstellungen und politischen Interessen (vgl. Lindenberger 1975, 10-12). Der Hinblick auf Publikumsinteresse und zeitgemäße Relevanz moduliert somit auch die Auseinandersetzung mit einem historischen Stoff. Dieser mündet nicht allein als Repräsentation vergangener Ereignisse für die Gegenwart in das Drama, sondern die aktuelle Situation, die künstlerischen und politischen Einstellungen und Erwartungshaltungen von Autor und Publikum werden im historischen Stoff de-präsentiert. Eine ganz offensichtliche Form der Depräsentation sind Anachronismen, wenn also Erscheinungen späterer Zeiten in historischem "Gewande“ auftauchen. Depräsentationen können in stratifikatorisch organisierten Gesellschaften unmittelbar politische Gründe haben, etwa wenn aufgrund von äußerer Einflussnahme auf die literarische Produktion die Diskussion zeitaktueller Probleme nur in äsopischer Form, also beispielsweise in Gestalt eines historischen Stoffes, möglich erscheint. ${ }^{29}$

Unter Berücksichtigung des Einflusses der genannten literarischen und außerliterarischen Faktoren wird die Sonderstellung des historischen Dramas als literarische Subgattung deutlicher. Das Drama ist von der Historiographie darin verschieden, dass es den theatralischen Formen und Konventionen entsprechen muss; sein direkterer Publikumsbezug bedingt auch die Depräsentation der Gegenwart im Kleid der Vergangenheit bzw. die aktualisierende Repräsentation von Vergangen-

29 Dass freilich auch die Kommunikation mit dem Publikum über diesen Umweg erschwert sein kann, zeigt die Rezeptionsgeschichte von Puškins Boris Godunov, die nur über die 1831 gedruckte Variante erfolgen konnte (vgl. Neuhäuser 1986, 51-53). 


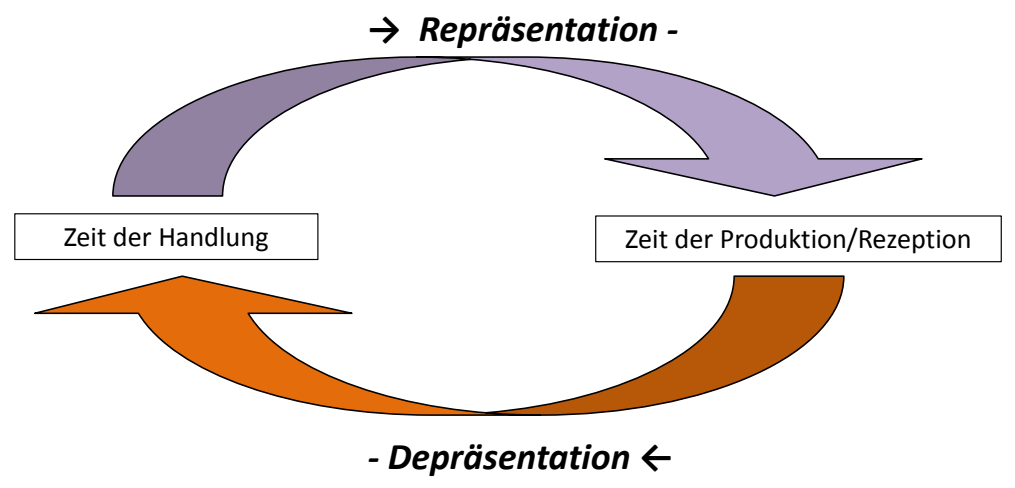

Graphik 2 - Dramatische Re/De-präsentation

heit, welche zwar gleichfalls auch im historiographischen Diskurs stattfindet, dort aber - oft unter dem Mantel „geschichtswissenschaftlicher Objektivität" - weniger deutlich bleibt. An der Darstellung vergangener Ereignisse in geschichtswissenschaftlichen Werken ist wohl auch meist ihre Entstehungszeit erkennbar, doch können in diesen die Gegenwartsbezüge auf die Entstehungszeit weniger leicht ausgemacht werden als im Fall von historischen Dramen, die bei aller Geschichtlichkeit zeitaktuell bleiben wollen. Nun kann zwar nicht pauschal für historische Dramen gelten, dass diese an der Vergangenheit nur um der Gegenwart willen interessiert sind, denn natürlich erheben sie vielfach auch Anspruch auf eine Darstellung der Vergangenheit, doch ist das Verhältnis von Repräsentation und Depräsentation in ihnen ein anderes als in der Historiographie. Unter der Voraussetzung der Relativität apriorisch anmutender typologischer Unterscheidung kann behauptet werden, dass in historischen Dramen die Depräsentation gegenüber der Repräsentation einen größeren Stellenwert hat, bei der Historiographie ist dies umgekehrt.

Der Stellenwert, den der Bezug zur Gegenwart der Entstehungszeit der historischen Dramen hat, verleitet zu einer rhetorisch-mnemotechnischen Zusammenfassung als figura etymologica: Die Situation der tschechischen Gesellschaft im 19. Jahrhundert führte zu mannigfaltigen Erinnerungsprozessen; neben vielen anderen Erscheinungen der tschechischen Kultur des 19. Jahrhunderts kann das historische Drama als ein Produkt dieser Erinnerungsprozesse gelten. Es wählt aus der Geschichte „repräsentative “Stoffe, repräsentiert diese in Text- oder in Aufführungsform, wobei schon früh an ein für die tschechische Nation repräsentativ erscheinendes Nationaltheater gedacht wurde, das schließlich mit einiger Verzögerung als Národní divadlo auch seine Realisierung fand. Im Text der die Vergangenheit reprä- 
sentierenden Dramen findet sich die Situation des 19. und frühen 20. Jahrhunderts depräsentiert, weil der Text als repräsentatives Produkt seiner Zeit und nicht etwa der repräsentierten historischen Vergangenheit angesehen werden muss.

Das Prager Národní divadlo, das so lange ein Desiderat war, um welches sich die Tschechen fast 40 Jahre bemüht haben, wurde auch als „Chrám znovurozeni“", also als „Kathedrale der tschechischen Wiedergeburt" - so der Titel einer bezeichnenderweise 1918 erschienenen Monographie František Žákavecs über das Nationaltheater - bezeichnet. Die sakrale Metaphorik liefert einen Hinweis auf das „Theater der Repräsentation“, das mit diesem - wie mit dem Theater überhaupt verbunden ist. Mit diesem Ausdruck beschreibt Jacques Derrida einen weiteren Bedeutungsaspekt des Ausdrucks Repräsentation, der über den bislang erörterten - im Zusammenhang mit dieser Arbeit ist ja die „innere Form“, das „Präsent-Machen" von Vergangenem bedeutsam - hinausgreift und allgemein auf die letztlich transzendente Voraussetzung des traditionellen europäischen Theaters hinweist. Die tschechischen historischen Dramen entsprechen tatsächlich diesen allgemeinen Voraussetzungen:

Die Szene ${ }^{30}$ ist theologisch, sofern sie durch die Sprache, durch einen Willen zur Sprache, durch das Ziel eines ersten Logos beherrscht wird, der dem theatralischen Ort nicht angehörend, ihn von ferne beherrscht. Die Szene ist solange theologisch, als sie, der ganzen Tradition gemäß, folgende Elemente enthält: einen Autor-Schöpfer, der abwesend und aus der Ferne, mit einem Text bewaffnet, die Zeit oder den Sinn der Repräsentation überwacht, versammelt und lenkt, und der er das Repräsentieren seiner selbst in dem, was man den Inhalt seiner Gedanken, seiner Absichten und seiner Ideen zu nennen pflegt, überläßt. Repräsentieren mittels Repräsentanten, Regisseure [sic!] oder Schauspieler [sic!], unterjochte Interpreten, die Personen repräsentieren, die in dem was sie sagen, zunächst mehr oder weniger die Gedanken des „Schöpfers“ repräsentieren. (Derrida 1966, 355f)

Der Logozentrismus, den Derrida im Anschluss an Artaud im Theater konstatiert, ist für die in dieser Arbeit thematisierten Dramen generell charakteristisch. Es sind Wortdramen in dem Sinn, dass sie einen „Text, ein verbales Gewebe, einen Logos" repräsentieren, der von den Autoren verfasst wurde, um die Nation in der Geschichte (und über diese indirekt auch in der Gegenwart) darzustellen. Das Národní divadlo war für dieses Unterfangen gleichsam der ideale Repräsentationsort: vor seiner Bespielbarkeit implizierte das schiere Vorhandensein von historischen Dramen in der tschechischen Theaterliteratur dessen Vorwegnahme; die Idee eines tschechischen Nationaltheaters war für die Vertreter des öffentlichen Lebens und der nationalen Wiedergeburt eine zutiefst politische (vgl. Štěpán 2006, 11). Als

30 Wahrscheinlich ist der Doppelsinn von ,Bühne‘ und ,Dramenabschnitt` im franz. Text wie auch in dessen Übersetzung beabsichtigt. 
das Národní divadlo errichtet worden war und bespielt werden konnte, galt es als repräsentativ genug, um die erfolgreiche Entwicklung der tschechischen Nation und deren Sakralität anzuzeigen. Für die gleichsam mythische Aufladung des Národní divadlo spielte auch der Umstand eine wichtige Rolle, dass von den Anfängen der Idee eines repräsentativen Nationaltheaters, wie sie von der Aufklärung und der deutschen frühromantischen Theaterbewegung inspiriert war, bis zur tatsächlichen Eröffnung eines für die tschechische Nation repräsentativen Theatergebäudes gut einhundert Jahre verstrichen, in denen sich die tschechische Kultur auch sehr stark über das Medium Theater zu konstituieren begann (vgl. Císař 2011, 6-8).

\section{I.7. Die Allegorie zwischen Repräsentation und Depräsentation}

Dass in einem historischen Drama zum einen erinnerungswürdige Ereignisse der Vergangenheit repräsentiert, zum anderen aktuelle Situationen der Gegenwart im Gewand der Vergangenheit depräsentiert erscheinen, hat sein rhetorisch-figuratives Gegenstück in der Allegorie als zwei- bzw. hintersinnigem Text. Zuerst einmal und nicht unbedingt bloß „vordergründig“ repräsentiert das Drama historische Ereignisse aus der eigenen Geschichte oder aus der Geschichte anderer Völker, bei genauerem Hinsehen freilich lassen sich Bezugnahmen auf die Gegenwart der Entstehungszeit bzw. der Rezeption ausmachen. Die oben diskutierte Gedächtniskonzeption, derzufolge Erinnerung nicht etwas Abgespeichertes ist, das bei Gelegenheit abgerufen wird, sondern vielmehr ein Prozess, der ausgehend von der Gegenwart immer eine Re-konstruktion der Vergangenheit vornimmt, liefert die theoretische Grundlage für die Erklärung der Genese dieser allegorischen Doppelsinnigkeit. Wenn kulturelles Gedächtnis vermittels der Produktion eines Textes geschaffen wird, kommt es zu allegorischen Textstrukturen, da ja die jeweilige Produktionssituation nicht vom Resultat der Produktion isoliert werden kann. Dementsprechend ist sogar die Historiographie zumindest soweit „allegorisch“, als der geschaffene Text seine Herstellungszeit reflektiert.

Walter Benjamin hat bekanntlich in Urspung des deutschen Trauerspiels (1928) die Allegorie zur zentralen Figur des Barockzeitalters und - weitaus ambitionierter - auch zur Methode einer spekulativen geschichtsphilosophischen Wahrheitsfindung erklärt. Die verspätete Benjamin-Rezeption hat das Ihre dazu beigetragen, die Allegorie sowohl als Trope wie auch als spezielle Denkfigur wieder stärker zu thematisieren (die klassizistische Ästhetik, mit der Benjamin polemisiert, stellte die Allegorie dem als „organisch“ gedachten Symbol gegenüber und behandelte sie geringschätzig). Benjamins programmatisch polyseme Verwendung des Allegoriebegriffs in seinem Trauerspielbuch (vgl. B. Menke 2010, 53f) soll hier nur insofern weiter beschäftigen, als einerseits das historische Drama diese doppelte Lesart impliziert und es sich andererseits als Gattung der tschechischen Literatur, die sich in einem Konkurrenzverhältnis zu anderen Nationalliteraturen sieht und dabei ihren Beitrag 
zum ideologischen Aufbau einer Nation leisten möchte, von der verwandten, aber in mehrerlei Hinsicht doch verschiedenen Gattung Trauerspiel unterscheidet, die Benjamin in der deutschen, spanischen, englischen Barockliteratur untersucht hat, deren historisch-politischer Kontext wenig Gemeinsamkeiten mit der tschechischen Literatur des 19. und beginnenden 20. Jahrhunderts hat. Für Benjamin ist das barocke Trauerspiel bereits eine ,Allegorie‘ der Tragödie der klassischen Antike, denn obzwar die Poetik der deutschen Barockautoren die Bezeichnung Trauerspiel bloß als Lehnübersetzung des Ausdrucks Tragödie verstanden haben wollte, sind die barocken Erzeugnisse doch sehr verschieden vom Tragödienbegriff, den Benjamin von der klassischen Antike zeichnet.

Während die Allegorie im Trauerspiel für Benjamin vor allem die Vergänglichkeit („Vergängnis“ - Benjamin 1974, 353) bedeutet, die Geschichte im Gegensatz zur Natur im Barock kennzeichnet, prägt die historische Dramatik der Tschechen eine optimistische Allegorie. Die doppelte Bedeutung des dramatischen Texts drückt nicht die Vergänglichkeit von Geschichte, sondern deren Gegenteil, die Wiederholung, aus, deren Sinn in historischer Legitimierung sowie in der gemeinschaftsstiftenden Affirmation der repräsentierten Ereignisse besteht.

Die Allegorie des barocken Trauerspiels basiert auf der Grundlage des Todes: Wie das Leben, „vom Tode her betrachtet“, die Leiche produziert (so Benjamin 1974, 392) ist die Figur der Allegorie als paradigmatisch für jedes Zeichen, jede Repräsentation zu sehen: es bleibt ein „toter Rest“ des Zeichens, des Repräsentierenden erhalten, das eben nicht ganz transparent wird auf das Repräsentierte. Und im Bedeuten selbst, in der Signifikation, ist für Benjamin insofern der „Grund der Traurigkeit“ zu sehen, als die Signifikation einerseits nicht abschließbar und damit vergeblich erscheint, und andererseits die Kluft zwischen dem materiellen Sprachzeichen (dem Zeichen qua Signifikanten) und dem Signifikat unüberbrückbar bleibt (vgl. B. Menke 2010, 195-201). Das Trauerspiel erinnert allegorisch daran, dass vom Leben letztlich der Leichnam übrigbleibt und es führt vor, dass die Zeichen einerseits etwas repräsentieren, andererseits aber auch eben tote Materie sind und als solche nichts bedeuten. „Ist aber die Natur von jeher todverfallen, so ist sie auch allegorisch von jeher. Bedeutung und Tod sind so gezeitigt in historischer Entfaltung wie sie im gnadelosen Sündenstand der Kreatur als Keime enge ineinandergreifen" (Benjamin 1974, 343).

Demgegenüber will das historische Drama allegorisch so verstanden werden, dass sich die Bedeutsamkeit des Repräsentierten nicht im Tod und der Vergänglichkeit erschöpft hat, sondern in Gegenwart und Zukunft weiterhin gilt. ${ }^{31}$ Damit

31 Zumal ja auch Benjamin wiederholt auf die Theologie als letzten Begriffsrahmen verweist (vgl. Benjamin 1974, 390f), sei zur Unterscheidung von Trauerspiel und nationalem historischen Drama auf zwei Betrachtungen der Passion Christi verwiesen: Für die Agnostiker ist der Tod Christi das Ende seines Lebens, für die Gläubigen ist die Passion das Opfer, das die gesamte Menschheit rettet. Übertragen auf die Implikationen der Allegorie, könnte man vom 
ist das tschechische historische Drama maximal weit vom Trauerspiel entfernt, es ist kein „Spiel vor Traurigen“ (vgl. Benjamin 1974, 298), sondern ermunterndes Spiel für „Erwachende“ bzw. für die erweckte Nation, die aus einem Blick auf die Geschichte für gegenwärtiges und zukünftiges Handeln profitieren sollen. Während die emblematische Allegorie das Bild bzw. den sensus litteralis zugunsten des sensus allegoricus abwertet bzw. gerade die Differenz zwischen diesen hervorkehrt (vgl. Benjamin 1974, 391; Haverkamp/Menke 2000, 74f), entspricht die im historischen Drama enthaltene Allegorie eher der Bedeutungspotenzialität des künstlerischen Texts als Welt-Modell: Das historische Drama als Kunstform repräsentiert zum einen vergangene Ereignisse, als künstlerischer Text hat es zudem das Potenzial, über die repräsentierte Situation hinausgehend auch auf andere Situationen zu referieren, wodurch es sich von der Geschichtsschreibung unterscheidet, die bloß eine Repräsentation der Vergangenheit vornimmt, aber über die Repräsentation keine anderen Wirklichkeitsausschnitte darzustellen bestrebt ist als den jeweils ausgewählten: „Der aristotelische Satz, daß die Dichtung philosophischer sei als die Geschichte, hat in dem allegorischen, das heißt das Allgemeine im Einzelnen vergegenständlichenden Charakter fiktionaler Texte seinen Grund" (Stierle 1973, 533; kursiv von mir, PD). Jurij Lotman behauptet für das künstlerische Werk eine unendliche polyvalente Referenz, womit die Repräsentation eines Weltausschnitts mit der ganzen Welt in Verbindung gebracht werden kann - dieser Bedeutungsüberschuss des künstlerischen „Modells“ ist eben darin dem sensus allegoricus ähnlich, dass er gleichfalls vor allem etwas anderes bedeutet bzw. auf andere Situationen referiert als der sensus litteralis; vom sensus allegoricus ist er freilich darin verschieden, dass er keine so singuläre und konventionell bestimmte Bedeutung hat. In seinen Überlegungen zu Kunstwerk und Rahmen unterscheidet Lotman den mythologischen Aspekt der Kunst, der auf unendlich viele Situationen bezogen werden kann, und den Aspekt der „Fabel“, der bloß die ausgewählte bzw. im Text repräsentierte Wirklichkeit betrifft (vgl. Lotman 1972, 303f).32

historischen Drama sagen, dass die repräsentierten Ereignisse „überaus bedeutsam“ für das spätere Leben der nationalen Gemeinschaft sind, womit der Unterschied zur „melancholischen" Allegoriekonzeption des barocken Trauerspiels bzw. Benjamins deutlich wird.

32 Was Lotman Mythos und Fabel nennt, lässt sich übertragen auf das Paar sensus allegoricus und sensus litteralis. Die historischen Dramen haben eine Doppelstruktur des Bedeutens, die in der Repräsentation historischer Ereignisse - dem sensus litteralis - zum einen und der depräsentierenden Bezugnahme auf aktuelle Situationen qua sensus allegoricus zum anderen besteht. Diese Doppelstruktur wäre wohl der Allegorie zu subsumieren, allerdings jedoch übergeht eine allzu betuliche Begriffsgeschichtsschreibung der Allegorie (Haverkamp/Menke 2000) diesen Aspekt von künstlerischen Texten. Denn Haverkamp/Menke beschreiben zwar detailliert alle möglichen Diskussionen in der Begriffsgeschichte und stellen mitunter kraus anmutende Zusammenhänge her - die „strukturelle“ bzw. „begriffliche“ Nähe der Allegorie zur Polyreferenz von künstlerischen Texten kommt dabei aber seltsamerweise zu kurz, wird sie doch nur indirekt angesprochen, etwa dann, wenn die in der begriffsgeschichtlichen Dar- 
Wenn Peter Szondi apodiktisch von der Absolutheit des Dramas spricht, so wird bei dieser an eine phänomenologische epoché erinnernden Isolierung eines bestimmten Dramentyps all dasjenige ausgeblendet, was über den Dramentext hinausgeht und dessen multiple Referenz bedingt: Für Szondi entwickelt sich das neuzeitliche Drama aus dem interaktiven Handeln und dem zwischenmenschlichen Dialog. Dementsprechend ist weder die Verbindung von Drama zu Autor oder Zuschauer wichtig; die Guckkastenbühne, die unvermittelt das Publikum zum Zeugen der sich entwickelten Handlung macht, ist der „Absolutheit des Dramas als einzige adäquat" (Szondi 1978, 18). Und der Schauspieler soll restlos in seiner Rolle aufgehen, um einen dramatischen Menschen zu schaffen. Szondis Absolutheit kontrastiert zu allen Formen des Dramas und Theaters, die auf die Bedingtheit (uslovnost'), die Gemachtheit oder die Tradition der Gattung oder Institution hinweisen oder sonstwie die theatralische Illusion der fiktionalen dramatischen Welt durchbrechen. Keine Beachtung findet auch das Verhältnis zwischen dem absolutisierten Drama und dem in ihm repräsentierten fiktiven inneren Kommunikationssystem einerseits und dem äußeren Kommunikationssystem bzw. der Rezeptionsleistung des Publikums andererseits. Lotmans Rede vom Modellcharakter behandelt ja gerade dieses Verhältnis: das innere Kommunikationssystem wird auf das äußere bezogen, ohne dass diese Bezugnahme immer von einer intentio auctoris vorhergesehen wäre. Hier kann von einer allegoretischen Doppelung gesprochen werden. Beziehen die im äußeren Kommunikationssystem Beteiligten die repräsentierte Kommunikation auf eine andere Situation - etwa ihre aktuelle - so realisieren sie das im künstlerischen Text als Modell angelegte referenzielle Potenzial: Die „Fabel“ des Dramas weist dann über den vorgeführten Rahmen hinausgehend auf eine „mythologische“ - Lotman will mit dem Ausdruck wohl auf die Allgemeinheit bzw. Polyreferenzialität hinweisen Situation hin.

Da das „historische Drama“, Szondi nennt es leicht despektierlich „historisches Spiel“ Bezug auf etwas Äußeres nimmt, nämlich auf die geschichtlichen Ereignisse, gilt es ihm gleich als „allemal undramatisch“ (Szondi 1978, 18). Die Komplexität historischer Vorgänge ließe sich darüber hinaus nur schwerlich aus zwischenmenschlichen Aktionen nur weniger Akteure entwickeln, daher könnten epochale Veränderungen - Szondi nennt als Beispiel die Reformation - nicht dramatisiert werden.

Mit dem Ausschluss aus dem Bereich des wesentlich Dramatischen durch Szondi wird die Sonderstellung des historischen Dramas ersichtlich, die es mit anderen

stellung diskutierten Autoren rhetorischer und ästhetischer Konzeptionen davon handeln. So spricht etwa Schlegel von der Allegorie als pars pro toto der künstlerischen Ausdrucksformen oder de Man proklamiert: „All representational poetry is always also allegorical, whether it be aware of it or not" (vgl. ebd. 90 u. 93), ohne dass diesen Überlegungen anders nachgegangen würde als in der Akkumulation weiterer Zitate und dazwischengepropfter Zwischenbemerkungen. 
dramatischen Subgattungen (Passionsspiel, epische Dramenformen etc.) teilt, die auf irgendeine Weise illusionsdurchbrechend oder repräsentierend vorgehen. Das historische Drama macht vor allem aufgrund seines Stoffes zwangsläufig auf seine Gemachtheit aufmerksam, darauf, dass das vorgeführte Geschehen zwar historisch ist, aber repräsentierte Geschichte, nicht reale Geschichte als res gestae. Es ist eben die von Szondi verworfene Darstellung von etwas Primärem, den geschichtlichen Ereignissen. Selbst bei einer ganz auf Illusionserzeugung abzielenden Inszenierung ist das Bewusstsein der Nachzeitigkeit der Rezeption dafür hinreichend, dass das Publikum zum Vorgeführten eine reflexive Haltung einnimmt, also die Aufführung als Repräsentation von Ereignissen ansieht, zu denen es einen zeitlichen Abstand hat. Die dramatische Repräsentation von Geschichte aktualisiert diese für die Gegenwart, das Lese- oder Theater-Publikum wird zu einer Reflexion über Geschichte bewogen. Das historische Drama kann damit als ebenso „ostentativ" gelten wie das barocke Trauerspiel, dessen Spielcharakter Walter Benjamin hervorgehoben hat (vgl. Benjamin 1974, 298f).

Das historische Drama als Kunstform repräsentiert zum einen vergangene Ereignisse, als künstlerischer Text hat es zum anderen aber zugleich das Potenzial, über die repräsentierte Situation hinausgehend auf andere Situationen zu referieren, wodurch es sich von der Geschichtsschreibung unterscheidet, die bloß eine Repräsentation der Vergangenheit vornimmt, aber über diese keine anderen Wirklichkeitsausschnitte zu erfassen bestrebt ist als den jeweils ausgewählten.

Der Dramentext bzw. seine Inszenierung haben eben eine Doppelstruktur, deren Bedeutungspotenzial vom Publikum realisiert werden kann oder auch nicht. Die reale Zeit der Rezeption und die fiktive bzw. dargestellte Zeit laufen parallel nebeneinander her, woraus sich die scheinbar unmittelbare "Gegenwärtigkeit des dargestellten Geschehens" ergibt, die in der "Gleichzeitigkeit des Dargestellten mit der Darstellung und dem Vorgang der Rezeption" (Pfister 2001,23) besteht. Das historische Drama unterstreicht aufgrund der Vergangenheit der repräsentierten Ereignisse das besondere Zeitverhältnis des Dramas, die unmittelbare Gegenwärtigkeit des dargestellten Geschehens gewinnt damit eine besondere Paradoxie, aus der das modellierende Bedeutungspozential dieser dramatischen Subgattung gewonnen wird.

\section{I.8. Die Repräsentationsleistung des Dramas in der Ästhetik Hegels}

Insofern Repräsentation und Depräsentation eine Verschränkung von zwei Zeitabschnitten implizieren und dabei die jeweilige Gegenwart die „Initiative“ setzt, welche die Repräsentationsleistungen des kulturellen Gedächtnisses auslöst, können in Hegels geschichtsphilosophischer Konzeption von dramatischer Kunst Parallelen erkannt werden. Das Drama erzeugt als Kunstform höchste Gegenwärtigkeit, wenn es für den Zuschauer aktuelle Inhalte auf die Bühne bringt und allgemeines, „substanzielles" Geschehen mit individuellen, aber geschichtsrelevanten Momenten 
verbindet (vgl. Tschopp 2002, 372). Für Hegel ist die Entwicklung der Kunst mit dem geschichtlichen Wirken des „Geistes“ verbunden, allerdings bleibt die Kunst gewissermaßen „retardiert“: in ihr wird ein geschichtliches Entwicklungsstadium konserviert, das der tatsächliche Gang der „Weltgeschichte“ in der vom Großphilosophen erzählten Version hinter sich gelassen hat. Das Kunstwerk aber „repräsentiert" dieses bereits überwundene Stadium geschichtlicher Entwicklung, womit aber kein defizitärer, sondern eher ein „glücklicher" Zustand dem modernen Menschen vor Augen geführt wird. Das Drama repräsentiert für Hegel die wesentlichen Aspekte des menschlichen Seins: subjektives Handeln in seinem Widerstreit, das die geschichtliche Dynamik ausmacht.

\begin{abstract}
Was wir deshalb [im Drama] vor uns sehen, sind die zu lebendigen Charakteren und konfliktreichen Situationen individualisierten Zwecke, in ihrem Sichzeigen und -behaupten, Einwirken und Bestimmen gegeneinander - alles in Augenblicklichkeit wechselseitiger Äußerung - sowie das in sich selbst begründete Endresultat dieses ganzen sich bewegt durchkreuzenden und dennoch zur Ruhe lösenden menschlichen Getriebes in Wollen und Vollbringen. (Hegel $\mathrm{XV} / 475 f)$
\end{abstract}

Hegels philosophische Konzeption, wohl die bedeutendste „Meistererzählung“ der neuzeitlichen Geistesgeschichte, unternimmt eine breite spekulative Integration aller Aspekte der Menschheitsgeschichte: Philosophie- und Religionsgeschichte, Logik und Biologie, Geist, Kunst und Staat werden in ihr zusammengedacht, um das angestrebte systematisch kohärente System der diachronen Entwicklung des Geistes darzustellen. Hegel zufolge kulminiert die geschichtliche Entwicklung des menschlichen Geistes in der Realisierung eines aufgeklärten Staats, der zugleich auch die Grundlage für die Selbsterkenntnis des „absoluten Geistes“ darstellt, welche nichts Geringeres als der sich selbst, die Welt und ihre Geschichte vollständig erkennende Mensch ist.

Sieht man von der anvisierten Totalität dieses „absoluten Geistes“ als teleologischem Fluchtpunkt der Menschheitsgeschichte ab, stellt die hegelsche Philosophie ein Angebot auch für das wesentlich bescheidenere Interesse dar, die in der Geschichte von Drama und Theater rekurrenten Bezüge auf Gemeinschaft, Nation und Staat in Hinblick auf das historische Drama zusammen zu denken. Tschopp vertritt die Auffassung, dass Hegels Vorstellungen vom Drama, wie sie ausführlich in den Vorlesungen über die Ästhetik entwickelt wurden, in engem Zusammenhang mit Hegels spekulativem Geschichtsverständnis stehen. ${ }^{33}$ Dieses Geschichtsver-

33 Die Metaphorik im folgenden Zitat liefert hierfür ein bezeichnendes Indiz: „Der Geist ist aber auf dem Theater, auf dem wir ihn betrachten, in der Weltgeschichte, in seiner konkretesten Wirklichkeit; dessenungeachtet aber, oder vielmehr um von dieser Weise seiner konkreten Wirklichkeit auch das Allgemeine zu fassen, müssen wir von der Natur des Geistes zuvörderst einige abstrakte Bestimmungen vorausschicken." (Hegel XII/29) Diese Passage aus den 
ständnis lasse sich zum einen in der Ästhetik Hegels erkennen, die zumindest in der deutschsprachigen Tradition stark auf die Valorisierung der literarischen Gattungen im 19. Jahrhundert eingewirkt hat. Zum anderen sieht Tschopp überhaupt die Gattung des historischen Dramas in einer engen begrifflichen Verbindung mit Hegels Dramenkonzeption, die zumindest in der deutschen Literaturgeschichte die Geschichtsdramen allzu lange als Ideal präfiguriert hätte; episierende Tendenzen, die andere Vorstellungen von geschichtlichen Vorgängen implizieren, wären aus diesem Grund verworfen worden, sodass sich das historische Drama langfristig als eine ästhetisch und geschichtsphilosophisch wenig avancierte Gattung erwiesen habe (vgl. Tschopp 2002, 383-385).

Nun ist zwar die Philosophie Hegels nur verspätet und meist wenig enthusiatisch von den Tschechen rezipiert worden, sie wird also wohl kaum den Grund für die hohe Valorisierung und die damit zusammenhängende Produktion historischer Dramen auch bei ihnen ausgemacht haben. ${ }^{34}$ Die Patrioten der - nach Miroslav Hrochs Periodisierung (vgl. Hroch 2005, 41-47) - zweiten Phase des obrození, die von Hegel Kunde hatten, äußerten sich weitgehend ablehnend über deren abstrakte Begrifflichkeit, so etwa Josef Jungmann in einem Brief an den obrozeni-Philosophen Antonín Marek (vgl. Fajfr 1934, 434f). Wenn die vorliegende Arbeit dennoch auf Hegels Ästhetik rekurriert, hat dies seinen Grund darin, dass in dieser das Drama eine so prominente Position einnimmt und zudem mit geschichtsphilosophischen Überlegungen in Zusammenhang gebracht wird, welche das Pathos erkennen lassen, das dem heute wenig produktiven Genre „historisches Drama“ von Hegel zugeschrieben wurde. Ob die in dieser Arbeit analysierten Dramen nun stärker der von ihm favorisierten Charaktertragödie oder eher der offeneren epischen Form vom Typus der Shakespeare'schen Historien entsprechen, bleibt nachrangig angesichts des Umstandes, dass die Ästhetik Hegels das Drama als diejenige Gattung beschreibt, die idealerweise die für eine Gemeinschaft wichtigen historischen Ereignisse in einer aktualisierten, an der jeweiligen Gegenwart orientierten Form repräsentiert.

Vorlesungen zur Philosophie der Geschichte handelt doch überhaupt nicht vom Theater, dieses firmiert nur als Bildspender für die Weltgeschichte und das Auftreten des Geistes, es lässt mithin diese beiden abstrakten Begriffe Hegels anschaulich werden.

34 Seinen Beitrag zur tschechischen Rezeption Hegels beginnt František Fajfr mit den Worten: „Hegels Einfluß auf das čechische kulturelle Schaffen war schwach. Es besteht keine Möglichkeit, eine selbständigere Fortführung der Ideen Hegels oder wenigstens eine interessantere Verarbeitung derselben auf böhmischem Boden vorzuweisen." (Fajfr 1934, 413) Haman allerdings deutet an, dass es mit Vincenc Zahradník, Ignác Jan Hanuš, Augustin Smetana und Karel Boleslav Štorch ein paar hegelianisch gestimmte Geister gegeben habe, er gibt aber leider keine genauere Angabe über deren Interessen als den Hinweis darauf, dass Zahradník 1818 in der Zeitschrift Hlasatel [český?] einen Artikel veröffentlicht hat, der „Rozjímání o některých stránkách politické filosofie“ [Überlegungen über einige Aspekte der politischen Philosophie] hieß (vgl. Haman 2007, 50). 
In der Architektonik Hegels machen nämlich sowohl der aufgeklärt organisierte Staat wie auch das Drama jeweils Endpunkte einer Entwicklung aus, die den menschlichen Geist zur Selbsterkenntnis führt. Während der Staat die höchste Verkörperung der „Sittlichkeit“ ist (vgl. Taylor 1978, 496), ist das Drama „die höchste Stufe der Poesie und der Kunst überhaupt" (Hegel XV/474). Dass diese beiden End- bzw. Höhepunkte des Geistes untereinander nicht unverbunden sind, sollen die folgenden Ausführungen kurz andeuten. Aus pragmatischen Gründen kann dabei nicht auf die Fülle einschlägiger Sekundärliteratur der Hegel-Philologie zu dessen Ästhetik und Geschichtsphilosophie eingegangen werden, stattdessen muss ich mich auf eine Darstellung, die vorwiegend auf eigener Lektüre und ausgewählten Hegel-Interpreten beruht, beschränken.

Hegels dynamisches System basiert auf der spekulativen Grundannahme, dass die Welt im weitesten Sinne Verkörperung des Geistes ist, also in Materie verkörperter Geist. Die Entwicklung von Kosmos und Leben wird aus der Diskrepanz zwischen dem Geist, der seine Verkörperung braucht, und der Mangelhaftigkeit dieser Verkörperung erklärt. Mit dem Erscheinen des Menschen gewinnt diese Entwicklung an Dynamik, denn aufgrund seines Selbstbewusstseins ist der im Menschen verkörperte Geist imstande, die von ihm bewohnte Welt umzugestalten und zu verändern. Der Mensch muss Hegel zufolge seinen Willen in der äußeren Welt realisieren, wobei ein gemeinsames Streben aller Willensträger nach einem höheren, allgemeinen Prinzip ausgerichtet sein soll, um individuellen Einzelwillen und daraus unvermeidlich entstehende Konflikte in diesem supraindividuellen Streben nach einem gänzlich vernünftig organisierten Staat aufzulösen.

Von dem Menschen als einem Träger des rationalen Willens wird gefordert, daß er in einer Gemeinschaft lebe, die die Vernunft verkörpert, die der erfüllte Zweck der Vernunft ist. Das heißt: Was in dem Begriff des Menschen als Vermittler des rationalen Willens enthalten ist, wird nur in einer solchen Gemeinschaft vollkommen verwirklicht. (Taylor 1978, 564)

Diese Forderung mutet zwar wie die Unterwerfung des Einzelnen unter ein Kollektiv an, doch soll damit keineswegs eine Beschränkung individueller Freiheit begründet werden; im Gegenteil, Hegel möchte mit dieser Lösung die Freiheit des Einzelnen erst ermöglichen - selbst wenn diese darin besteht, ein überindividuelles Vernunftprinzip anzuerkennen, das vom Menschen mitgetragen und in der Welt realisiert werden muss. Als Teil der Welt, als Handelnder innerhalb einer bestimmten Gesellschaft hat der Mensch die Möglichkeit und die moralische Verpflichtung (die Hegel als Ausdruck der menschlichen Freiheit begreift), aktiv an der Formung und Gestaltung des gemeinschaftlichen Lebens gemäß den Prinzipien der Vernunft teilzunehmen. Hegel nennt diese Teilhabe am gesellschaftlichen bzw. politischen Leben „Sittlichkeit“. Diese Einheit von „Substantiellem“ und „Individualität“ bezeich- 
net also den Umstand, dass der Mensch in einer Gemeinschaft lebt, zu welcher er beiträgt und welche ihrerseits den Menschen und sein geschichtliches Sein betrifft.

Die erste ideale Realisierung von Sittlichkeit in der Weltgeschichte erfolgte für Hegel - wie für viele seiner Zeitgenossen - in der griechischen Polis, in der sich der einzelne Mensch als Teil der Allgemeinheit des Stadtstaates begriff, mit der er sich vollständig identifizierte. ${ }^{35}$ "Sittlichkeit" ist begrifflich mit dem Kunstschönen verbunden, denn dieses führt in der sinnlichen Anschauung das Absolute vor, das Kunstschöne kann „Inneres und Äußeres, Geistiges und Sinnliches“ als Momente integrieren, was in der Weltgeschichte dem Griechentum in der Polisgesellschaft gelungen ist. Ein ethisches Moment spielt also insofern in die Kunst hinein, als es um die Integration disparater Momente geht, die gleichermaßen in der Kunst wie auch im politischen Leben erfolgen soll (vgl. C. Menke 1996, 46-48).

Diese erste geglückte Realisierung der Sittlichkeit war aber partikulär, indem die Bürgerrechte nur einem Teil der Einwohner der Polis zugesprochen waren, weil die verschiedenen Poleis voneinander getrennt waren und sich gegenüber „Barbaren“ demarkierten.

In diesem geschichtsphilosophischen Entwurf folgt auf die partikuläre Sittlichkeit der Polis die Entfremdung der Menschen im großen Imperium des Römischen Reichs, wo die Menschen nicht mehr unmittelbar am politischen Prozess teilnehmen konnten, sondern sich der Willkür der Führungselite ausgesetzt sahen. Immerhin aber entwickelten sich in Rom allgemeine Rechtsvorstellungen vom Recht der Persönlichkeit, die Hegel zufolge erst mit dem Untergang des Römischen Reiches soweit in historische Wirklichkeit umgesetzt wurden, als sich Vorstellungen individueller Freiheit allmählich mit diesen universalen Rechtsvorstellungen verbanden und so die Grundlage für einen modernen, vernünftigen Staat schufen. ${ }^{36}$ Zumal der moderne Staat wesentlich komplexere Beziehungen zwischen den einzelnen Vertretern hat und überdies im Unterschied zur Polisgesellschaft keiner so großen Zahl seiner Bewohner die Bürgerrechte verwehrt sind, gibt es keine einfache Identifikation von Bürgern mit dem modernen Staat, vielmehr verstehen sich die Bürger zugleich als „Mensch schlechthin“, als Vertreter einer bestimmten Klasse (eines bestimmten „Standes") und ihre Identität kann genauso wenig auf eine rein nationale oder politische Identität reduziert werden, wie sich auch nicht alle Bürger am Gemeinwesen

35 Die religionsgeschichtliche Entsprechung für diese in der konkreten Welt realisierte Subjektivität der Griechen besteht für Hegel darin, dass die griechische Götterwelt zutiefst menschliche Züge hatte. Die jüdische Religion begriff demgegenüber Gott als eine bloß transzendente Kraft, die von Mensch und Welt radikal entfernt war.

36 Die mit dem Christentum erfolgende Innovation besteht für Hegel darin, dass für die Christen im Irdisch-Werden des Göttlichen in Gestalt Jesu, seiner Transfiguration und Rückkehr im Heiligen Geist die Inzidenz geschaffen worden sei, in der christlichen Gemeinschaft die göttliche Vernunft zu erkennen, die sich in der Geschichte realisieren müsse. 
in gleichem Ausmaß engagieren, sondern unterschiedlich ihre Privatsphäre von den Angelegenheiten des öffentlichen Lebens abgrenzen.

Nach Hegels Version von Weltgeschichte ist diese nach Reformation, Aufklärung und Französischer Revolution zu weit fortgeschritten, um jemals wieder die Sittlichkeit der Polisgesellschaft erreichen zu können, in der die Menschen zugleich die Bürger der Polis waren und alle Angelegenheiten derselben sie auch persönlich betrafen. Wenngleich also die neuzeitliche Gesellschaft für eine solche Identifikation von öffentlichen und privaten Angelegenheiten als zu komplex angesehen wird, geht Hegel nicht von der für ihn kennzeichnenden Korrelation ab, dass der Mensch nicht als individuelle Einzelperson, sondern als Gemeinwesen - bzw. in weiterer Folge als Medium des Geistes - zu sehen ist. Mit dieser ontologischen Auffassung wendet sich Hegel gegen die politische Philosophie der Aufklärung, da diese beim Individuum ihren Ausgang nimmt und soziale Entscheidungen entweder utilitaristisch (als Kalkulation über die addierten Willensäußerungen der Einzelnen und deren Effekte) oder kollektivistisch (als Ausdruck des "Gemeinwillens“) konfiguriert. Letzteres (die Freiheit der Entscheidung darf von keiner Heteronomie beschränkt werden; alle Entscheidungen müssen daher kollektiv gefällt werden) ist aber praktisch nur in kleinen sozialen Einheiten möglich, da in modernen Gesellschaften Interessenskonflikte unvermeidlich sind. Eine Identifikation des Einzelnen mit einem Gemeinwesen - einer Volksgruppe, einer Nation, einem Staat - ist demnach selbstverständlich; dass Hegel dennoch den zu seinen Lebzeiten emergierenden deutschen Nationalismus ablehnte, liegt für Taylor (vgl. 1978, 551-555) in dessen Rationalitätskonzeption begründet, der zufolge der bloße Appell an Gefühle bzw. die „Einheit“ des Volkes unzureichend intellektuell fundiert war. Die Wirklichkeit des modernen Staates hat den Einzelnen in ein Gemeinwesen eingebunden, dem gegenüber sich der Einzelne entfremdet fühlen kann, wenn er nicht erkennen will, dass dieses Gemeinwesen vernünftig ist.

Im wahren Staate gelten die Gesetze, Gewohnheiten, Rechte, insofern sie die allgemeinen, vernünftigen Bestimmungen der Freiheit ausmachen, nun auch in dieser ihrer Allgemeinheit und Abstraktion und sind nicht mehr vom dem Zufall des Beliebens und der partikulären Eigentümlichkeit bedingt. Wie das Bewußtsein sich die Vorschriften und Gesetze in ihrer Allgemeinheit vor sich gebracht hat, so sind sie auch äußerlich wirklich als dieses Allgemeine, das für sich seinen ordnungsmäßigen Gang geht und öffentliche Gewalt und Macht über die Individuen hat, wenn sie ihre Willkür dem Gesetz auf verletzende Weise entgegenzustellen unternehmen. (Hegel XIII/239)

Diese Entwicklung des Allgemeinen, das den Einzelmenschen überformt, überfordert mitunter auch seine Vorstellungskraft. Daher führen dem Einzelnen, der in „ausgebildeten Staaten“ nur eine „untergeordnete Stellung“ einnimmt (ebd. 241), Kunst und Literatur vor Augen, wie das Gemeinwesen als Objektivation des in den 
Subjekten wirkenden Geistes gesehen werden kann. Hegels Vorlesungen über die Ästhetik enthalten im Abschnitt „Die Idee des Kunstschönen oder das Ideal“ eine lange Darstellung des Verhältnisses von geschichtlicher Entwicklung und Kunst. Letztere ist für Hegel dazu angetan, die wesentlichen Momente des Geistes zu erfassen und darzustellen. In dieser Hinsicht ist die Kunst sinnlicher als die in der Geschichte entfaltete Wirklichkeit des Geistes, da diese bereits eine solche Komplexität erreicht habe, dass sie vom einzelnen Menschen nicht mehr überblickt werden kann. Die Kunst ist somit genauso wie die Realität Ausdruck des Geistes bzw. des „Ideals“, nur dass in der Kunst die Idealität besser zu erkennen ist als in der historischen Wirklichkeit, die im Zustand der Moderne bereits von „Entfremdung“ des Subjekts vom Substantiellen des Geistes gekennzeichnet ist (vgl. Pillau 1981, 13). Dass der Mensch als Subjekt Vermittler des Ideals (des „Objektiven“) ist, dass seine Freiheit dazu beiträgt, das Ideal in die Wirklichkeit umzusetzen, sei in der Kunst erfahrbar; in der historischen Wirklichkeit hingegen erscheinen die Menschen oft als vom Ideal getrennt. „Das ideale Individuum muß in sich beschlossen, das Objektive muß noch das Seinige sein und sich nicht losgelöst von der Individualität der Subjekte für sich bewegen und vollbringen, weil sonst das Subjekt gegen die für sich schon fertige Welt als das bloß Untergeordnete zurücktritt" (Hegel XIII/238). - Mit dem in diesem Zitat angesprochenen „Objektiven“ ist die Welt als geschichtliche gemeint, die in der Kunst eben als noch vom einzelnen Subjekt veränderbare erscheinen soll.

Die historische Wirklichkeit hat sich für Hegel soweit entwickelt, dass der vernünftige Staat als höhere Realisation des Geistes gilt als die Subjektivität eines Einzelnen, denn im von der menschlichen Freiheit gewollten Staat sind die Gesetze begründet, gesichert und allgemein verbindlich, ein Verstoß gegen diese erscheint bloß als Willkür des Individuums, das eine vernünftige allgemeine Regel übertritt.

Die einzelnen Individuen erhalten dadurch im Staate die Stellung, daß sie sich dieser Ordnung und deren vorhandener Festigkeit anschließen und sich ihr unterordnen müssen, da sie nicht mehr mit ihrem Charakter und Gemüt die einzige Existenz der sittlichen Mächte sind, sondern im Gegenteil, wie es in wahrhaften Staaten der Fall ist, ihre gesamte Partikularität der Sinnesweise, subjektiven Meinung und Empfindung von dieser Gesetzlichkeit regeln zu lassen und mit ihr in Einklang zu bringen haben. (Hegel XIII/240)

Das einzelne Individuum ist in der entwickelten Gesellschaft nur Teil eines Ganzen, des Allgemeinen, das als historische Realisierung des Geistes gilt. Die wesentlichste Manifestation dieses Allgemeinen ist der Staat mit seinen allgemeinen, von der Vernunft hervorgebrachten Gesetzen. Dieses Allgemeine ist künstlerisch aber nicht mehr darstellbar, die Kunst muss also auf Einzelpersonen („Heroen“) zurückgreifen, um das Allgemeine anschaulich werden zu lassen. Die großartigen Individuen bzw. Heroen der Kunst sind somit die Repräsentanten des Allgemeinen: „Wie nun 
der idealere Weltzustand bestimmten Zeitaltern vorzugsweise entspricht, so wählt die Kunst auch für die Gestalten, welche sie in demselben auftreten läßt, vorzugsweise einen bestimmten Stand - den Stand der Fürsten “ (Hegel XIII/251).

Die Unterordnung des Einzelnen unter ein im Staat vernünftig organisiertes Allgemeines muss nicht zwangsläufig als Entfremdung aufgefasst werden, denn eine solche läge nur dann vor, wenn der Staat nicht auf einer vernünftigen, sondern auf einer despotischen Ordnung aufgebaut ist, mit der sich das aufgeklärte Individuum nicht identifizieren kann. Diese Unterordnung kann ebenso aus der Einsicht in die historische Notwendigkeit einer solchen Entwicklung des Staates erfolgen, doch auch in diesem Fall ist das Individuum nur mehr Teil eines größeren Ganzen und nicht mehr Gestalter desselben (als anschauliches Beispiel führt Hegel an, dass Gerechtigkeit eine Angelegenheit des Staates geworden ist, womit die Ausübung von Rache durch Einzelpersonen obsolet geworden ist - vgl. Hegel XIII/241 bzw. Posner 1998, 23).

Während also die geschichtliche Entwicklung dazu geführt hat, dass das Individuum nur mehr Teil eines komplex organisierten Staates ist, das „Objektive“ also von vielen Subjekten und Institutionen abhängt, können bzw. „sollen“"37 in der Kunst die Verhältnisse „idealer“ dargestellt werden, nämlich die Welt (das „Objektive“) als „Funktion“ der Subjekte:

\footnotetext{
Wir haben es hier nur mit dem Ideal der Kunst zu tun, und für die Kunst muß die Scheidung von Allgemeinheit und Individualität noch nicht in der angegebenen Weise heraustreten, wie sehr dieser Unterschied auch für die sonstige Wirklichkeit des geistigen Daseins notwendig ist. Denn die Kunst und ihr Ideal ist eben das Allgemeine, insofern es für die Anschauung gestaltet und deshalb mit der Partikularität und deren Lebendigkeit noch in unmittelbarer Einheit ist. (Hegel XIII/243)
}

In Abwandlung eines Terminus von Freud kann man in der Kunst folglich von der „Rücksicht auf Darstellbarkeit“ sprechen: Die Komplexität gesellschaftlicher Wirklichkeit kann nicht überschaubar erfasst werden, die Kunst vereinfacht das Bild, indem sie die Wirklichkeit immer noch als vom einzelnen Menschen wesentlich mit-

37 In den Vorlesungen zur Ästhetik wie überhaupt in der ganzen Gestaltung des hegelschen Systems ist der Übergang zwischen abstrakten metaphysischen Überlegungen, der Beschreibung historischer Umstände und der präskriptiven Darlegung von „regelhaften“ Abfolgen stets ein fließender. Im Zusammenhang dieser Arbeit, die ja nicht den Zweck verfolgt, Gewichtiges zur Hegel-Philologie beizutragen, sondern einige ihrer Grundzüge referierend darstellt, um auf die Überschneidungen von Politik und Literatur im historischen Drama aufmerksam zu machen, wird der historisch gewordene Text Hegels als Beleg für diesen Umstand verwendet. Es ist daher auch nicht notwendig, explizit alternative Betrachtungsweisen des Zusammenwirkens von Kunst und Gesellschaft ins Treffen zu führen, wenn es um die Darstellung des von Hegel gedachten Zusammenhanges geht. 
geprägte begreift. Die Vereinfachung enthält damit noch immer für Hegel genug „Wahrheit“, weil ja auch die komplexe historische Wirklichkeit als vom Menschen geschaffene anzusehen ist und deren Vorstufen den in der Kunst dargestellten Verhältnissen der „Heroenzeit“ ähnlich sind, in der sich „Substantielles“ (also die wesentlichen Manifestationen des Geistes in der Welt) und Individuelles noch nicht auseinanderentwickelt haben. Die heroische Idealität ist idealer, „weil sie sich nicht in der formellen Freiheit und Unendlichkeit in sich genügt, sondern mit allem Substantiellen der geistigen Verhältnisse, welche sie zu lebendiger Wirklichkeit bringt, in steter unmittelbarer Identität zusammengeschlossen bleibt. Das Substantielle ist in ihr unmittelbar individuell und das Individuum dadurch in sich selber substantiell“ (Hegel XIII/248). Hingegen ist die Gegenwart in einer aufgeklärten Monarchie nicht anschaulich genug:

Sehen wir nun in allen diesen bisher angedeuteten Beziehungen auf die Gegenwart unseres heutigen Weltzustandes und seiner ausgebildeten rechtlichen, moralischen und politischen Verhältnisse, so ist in der jetzigen Wirklichkeit der Kreis für ideale Gestaltungen nur sehr begrenzter Art. (Hegel XIII/253)

(Dramatische) Kunst als „ideale Gestaltung“ des Verhältnisses von Mensch und Welt ist demnach Folge der geschichtlichen Entwicklung: Je weiter diese voranschreitet und dabei der von Hegel hoch valorisierte objektive Gang der Geschichte die Komplexität steigert, desto dringender bedarf es der „idealen Gestaltungen“, um sich des historischen Potenzials des Menschseins inne zu werden. In der Kunst gibt es also gleichfalls ein Rekonstruktionsmoment, denn die vereinfachende Repräsentation der Vergangenheit ist nichts anderes als die Funktion der Komplexität der Gegenwart. ${ }^{38}$ In den heroischen Figuren wird geschichtsmächtiges Handeln sichtbar: „Historical drama, insofar as it deals with issues of power and larger forces in conflict with one another, provides a natural arena in which the heroic impulse can manifest itself" (Lindenberger 1975, 56).

Berücksichtigt man diese Unterschiede der Entwicklung des „Geistes“ in Geschichte und Kunst - die Kunst als Medium größerer Idealität, das die Verhältnisse

38 Ohne die große geschichtsphilosophische Einbettung hat auch A. W. Schlegel als kennzeichnend für die dramatische Gattung deren Überschaubarkeit relativ zur außerliterarischen Wirklichkeit bzw. „Natur“ angesetzt. „Wodurch wird nun ein Drama poetisch? Unstreitig eben dadurch, wodurch es auch Werke anderer Gattungen werden. Zuerst soll es ein zusammenhängendes, in sich geschlossenes befriedigendes Ganzes sein. Allein dieses ist nur die negative Bedingung der Form eines Kunstwerkes, wodurch es von den ineinander verfließenden und nie ganz für sich bestehenden Erscheinungen der Natur ausgesondert wird“" (Schlegel 1966, 34). - In dieser Bestimmung ist deutlich der Bezug auf die Rezeptionssituation erkennbar, den wir mit dem vieldeutigen Begriff der Repräsentation markiert haben. 
deutlicher darstellt, weil die Wirklichkeit sich bereits zu großer Komplexitität auseinanderentwickelt hat - , erscheint das historische Drama als literarische Subgattung, die in Hegels impliziter Valorisierung der Künste einen überaus prominenten Rang einnimmt. Lindenberger folgte Hegel in dessen Überlegungen von der Darstellungsfunktion des historischen Dramas in Zeiten, in denen der geschichtsträchtige Heroismus einzelner passé geworden ist:

One could perhaps speak of a principle of compensation in great drama whereby the historical process assumes a heroic role to compensate for the loss, or impossibility, of conventional heroism; it is as though the human imagination demands a sense of greatness whether this greatness is located in the individual will or in processes beyond human grasp. (Lindenberger $1975,64 f)$

Die Positionierung von „Poesie“ (epischer, lyrischer und dramatischer) an der Spitze des literarischen Gattungssystems, welches seinerseits in der Hierarchie der ästhetischen Konzeption Hegels die höchste Position einnimmt und damit die Kunst überschreitet (vgl. C. Menke 1996, 45), verdankt sich der im Drama vorhandenen Verbindung von Rede und Handlung in den Personen. Insofern jede Person ihre "Zwecke" und Interessen verfolgt und diese verbal oder handelnd zum Ausdruck bringt, sieht Hegel in der dramatischen Darstellung des Zusammenwirkens und des Konflikts der Interessen die Entsprechung zum Wirken des Geistes in der Weltgeschichte, für den Individuen und ihre Handlungen nur Momente eines größeren Zusammenhanges sind, der in der Realisierung des Göttlichen bzw. Absoluten in der Weltgeschichte besteht.

Der wahrhafte Inhalt, das eigentlich Hindurchwirkende sind daher wohl die ewigen Mächte, das an und für sich Sittliche, die Götter der lebendigen Wirklichkeit, überhaupt das Göttliche und Wahre - aber nicht in seiner ruhenden Macht, in welcher die unbewegten Götter, statt zu handeln, als stille Skulpturbilder selig in sich versunken bleiben, sondern das Göttliche in seiner Gemeinde als Inhalt und Zweck der menschlichen Individualität, als konkretes Dasein zur Existenz gebracht und zur Handlung aufgeboten und in Bewegung gesetzt. (Hegel $\mathrm{XV} / 480)$

In diesem Zitat ist der entscheidende Unterschied zwischen den Kunstformen Skulptur und Drama enthalten: das „stille Skulpturbild“ als prototypisches Kunstschönes stellt zwar das verkörperte Ideal vor die Sinne, weil es das Innere (Willen und Intentionalität) und das Äußere (den Körper) in der menschlichen Gestalt verbunden darstellt; es gibt allerdings dabei keine Bewegung, weil zwischen den Idealbildern keinerlei Konflikte auftreten können, die sich entwickeln. Dies bleibt der Zeitkunst Drama vorbehalten, dessen Vorzug eben darin besteht, dass es das Interagieren der in den Figuren verkörperten Ideale zeigt. 
Dass insbesondere die Tragödie in Hegels geschichtsphilosophischem System einen Übergang markiert und die bloß glückliche Sittlichkeit der griechischen Polis entscheidend transformiert, ist die zentrale These in der Hegel-Interpretation Christoph Menkes. Ihm zufolge ist in der griechischen Tragödie insofern eine Darstellung des Tragischen vorgeführt, weil verschiedene Auffassungen von Sittlichkeit - man denke an Hegels Antigone-Interpretation, die sowohl den Standpunkt Antigones wie denjenigen Kreons als gerechtfertigt darstellt - in Konflikt geraten. Im Zustand der schönen Sittlichkeit, der für die griechische Polis charakteristisch ist, sind sich die einzelnen Subjekte noch nicht der Freiheit des subjektiven Geistes bewusst, wenngleich bereits in der Gattung der Tragödie ein Fortschreiten zur Subjektivität zu erkennen sei, was sich zum einen in der Form der Tragödie (Individuen sprechen sich aus, sie äußern ihre Subjektivität), zum anderen in der Aufführungspraxis (ein Schauspieler ist notwendig für die Verkörperung der Rolle, wenngleich er von dieser immer verschieden bleibt) abzeichnet. Mit der Erschaffung einer zweiten, dramatischen Welt sind nach Menkes Hegel-Interpretation (vgl. 1996, 56-68) sowohl rezeptionsästhetische als auch geschichtsphilosophische Implikationen verbunden: Denn indem der Dramatiker Figuren gestaltet, die als Handelnde auftreten, führt er Reflexivität und Subjektivität ein, was im System der hegelschen Geschichtsphilosophie letztendlich die präsubjektive Einheit der Sittlichkeit, wie sie idealerweise in der Polisgesellschaft vorhanden war, auflöst. Der dramatische Dichter wie auch der Schauspieler bringt etwas hervor - ein Drama, das eine Einheit bildet, in der eine Vielzahl einzelner Stimmen aufgelöst ist bzw. eine Figur, bei der sich Schauspieler und Maske unterscheiden lassen - und die „Konsequenz poetischer Performanz ist ethische Emanzipation [eben das mit dem Drama Deutlich-Werden des Subjekts als Vermittler des Substantiellen]“ (C. Menke 1996,63). Angesichts des Dramas, könnte man pathetisch meinen, wird sich der Mensch seiner Subjektivität, seiner Handlungsfähigkeit bewusst.

Denn „höher“ [...] ist die Tragödiensprache nicht, weil sie das Wahre oder Richtige sagt. Sondern weil sie eine andere, eine (Selbst-)Erfahrung des Sprechens oder Sagens enthält. So ist die Tragödie gegenüber dem Epos eine Erfahrung der Performanz des Sagens: der Performanz des Ausgesagten durchs Sagen. Allein darin, nicht in ihrem Inhalt, sondern in ihrer Reflexivität besteht der Vorrang der Tragödie: daß sie den Akt des Sagens oder Darstellens nicht in der Präsenz des Ausgesagten oder Dargestellten „verschwinden“ läßt. Das bedeutet, daß die Tragödie eine „höhere“ Form der Darstellung ist, weil in ihr explizit wird, was dem gewöhnlichen Darstellen ebenso zugrunde liegt, wie es in ihm verstellt ist. In der Tragödie tritt die Reflexivität - die Erfahrung der (Selbst-)Tätigkeit des Darstellens - hervor, die auch im gewöhnlichen Darstellen schon enthalten ist. (C. Menke 1996, 66)

Mit der griechischen Tragödie löst Reflexivität die unreflektierte naiv-glückliche Sittlichkeit der Polis auf: Im vorgeführten dramatischen Sprechen wird die aktive Tätigkeit des Subjekts erfahrbar, Subjekte erscheinen auf der Bühne, die jeweils un- 
terschiedliche Zwecke verfolgen und miteinander in Konflikt geraten. ${ }^{39}$ Dichter, Schauspieler und Publikum erfahren dieses reflexive Moment anhand des Dramas, das somit gleichsam als ein Katalysator moderner reflexiver Subjektivität angesehen werden kann. Dass die Reflexivität nur in der Tragödie bzw. dem Drama, nicht aber in der Epik erscheint, verdankt sich dem „Echtzeit“- bzw. Performanz-Charakter der Aufführung oder des Sprechens: Man erfährt unmittelbar die Verbindung zwischen dem Subjekt und der von ihm hervorgebrachten (Sprech-)Handlung, während die Epik nur die Resultate der Sprechtätigkeit zeigt. ${ }^{40}$

Hegel räumt dem Drama zudem die Möglichkeit der Versöhnung, nämlich die Aufhebung der Gegensätze ein - zumal in der Tragödie gehe „das ewig Substantielle in versöhnender Weise siegend hervor" (Hegel XV/527). Diese Versöhnung der widerstreitenden Ideen in der Tragödie wird von modernen Hegel-Interpreten allerdings in Abrede gestellt: Zumindest gilt sie nicht mehr für die nachgriechische Zeit: der freien Subjektivität steht die zur Norm, zum Gesetz gewordene Allgemeinheit gegenüber, beide können nicht mehr - wie im präreflexiven Zustand der Sittlichkeit - zur Deckung gebracht werden „[...] zwischen den verschiedenen Gestalten sittlich-schöner Versöhnung ist eine sittlich-schöne Versöhnung nicht mehr möglich“ (C. Menke 1996, 50). Es gibt für Menke eine zu große Mannigfaltigkeit von Widersprüchen, von denen jeder für sich den Anspruch erheben kann, notwendig zu sein, sodass keine begründete Versöhnung stattfinden kann.

Das Drama stellt das Interagieren wesentlicher "Zwecke“, die in den dramatis personae individualisiert sind, insofern „ökonomisch“ dar, als es sowohl objektive Verhältnisse der dargestellten Welt wie auch die subjektiven Bestrebungen („Zwecke“) erfasst und weder „epische“ Breite (also eine umfassende Repräsentation der Welt) noch bloß die Subjektivität eines lyrischen Ichs allein vorgeführt werden, sondern Objektivität und Subjektivität im „selbstbewussten und tätigen“ Individuum zusammengefasst sind. Schon die Dialektik der Gattungstrias bezieht Hegel auf geschichtliche Entwicklung: Das Drama „ist das Produkt eines schon in sich ausgebildeten nationalen Lebens" (Hegel XV/476) - Hegel verknüpft Heldenepik mit der Frühzeit eines Volkes; die Subjektivität markanter Einzelpersönlichkeiten sieht er erst danach in die Literaturgeschichte eintreten, weil das Drama von der Person ausgeht und deren Handeln in der Welt vorführt (wobei es sich auf die bestimmten Zwecke der Person und nicht auf eine breite Darstellung von deren Charakter konzentriert). Insgesamt aber ist das Drama ein Medium, in dem das „Göttliche“

39 In den Vorlesungen über die Philosophie der Geschichte heißt es entsprechend, dass die Dramen von Aischylos, Sophokles und Euripides zwar zur Blütezeit Athens entstanden sind, aber im Unterschied zur Skulptur „nicht mehr denselben plastischen sittlichen Charakter an sich tragen“, weil sich „schon mehr das Prinzip des Verderbens [der rein sittlichen, noch nicht subjektiv fundierten Lebensart] zu erkennen gibt" (Hegel XII/318).

40 Allenfalls kann - gerade in der antiken Vortragspraxis - die Erzählhandlung des Rezitators „live“ erfahren werden. 
in seinem geschichtlichen Wirken, in der Entwicklung aus dem Widerstreit von Zwecken und Interessen vorgeführt wird. Das Publikum sieht sich somit in einer Position, von der aus es die Konflikte übersieht, in welchen die in den handelnden Figuren personifizierten Zwecke nur partikulär und Teil einer dramatischen Finalität sind, die über die einzelnen Zwecke hinausgeht.

Diese Konzeption des Dramas als Handlungszusammenhang, der in einem oder mehreren Konflikten besteht, charakterisiert Hegels ästhetische Theorie als Teilprojekt seiner Philosophie des Geistes. Diese Theorie, so umfassend und systematisch sie auch anmutet, beschreibt freilich nicht die gesamte geschichtliche Entwicklung der dramatischen Gattung in der europäischen Tradition, Hans-Thies Lehmann zufolge ist das Konfliktmodell des Dramas bzw. der Tragödie nur für die europäische Neuzeit bis zum Anbruch der Moderne gültig, es gelte weder für die „prädramatische“ Antike noch für die postdramatische Moderne und Postmoderne (vgl. Lehmann 2013, 74-99). Jedenfalls aber können alle der in dieser Arbeit diskutierten historischen Dramen diesem Konfliktmodell zugerechnet werden: Das für das Konfliktmodell charakteristische Moment der Repräsentation von Handlung kommt offenbar dem Bedürfnis entgegen, Geschichte als Verkettung von Handlungen zu konfigurieren und anschaulich zu machen.

Hegel bevorzugt das Drama also wegen dessen Tendenz zur Abstraktion und seiner Affinität zum logozentrischen Geist, der sich in (Sprech-)handlungen manifestiert. Das Drama ist den wesentlichen Momenten der hegelschen Geschichtsphilosophie affin: es sieht von der realen Mannigfaltigkeit der Welt ab und konzentriert sich auf „Substantielles“, also auf die Realisierung des göttlichen Geistes in der menschlichen Geschichte, welche nur über Subjekte in einem konkreten Handlungszusammenhang erfolgen kann. Entsprechend unterscheidet Hegel „subjektives" und „objektives“ Pathos und präferiert letzteres wegen seiner Nähe zu geschichtlichen Entwicklungen; bloße Subjektivität, die nur die Leidenschaften eines Individuums betrifft, aber keine weiteren Zwecke in der Welt verfolgt, erscheint ihm als minderwertig bzw. als Thema der Komödie.

\footnotetext{
Wenn nun in der Tragödie das ewig Substantielle in versöhnender Weise siegend hervorgeht, indem es von der streitenden Individualität nur die falsche Einseitigkeit abstreift, das Positive aber, was sie gewollt, in seiner nicht mehr zwiespaltigen, affirmativen Vermittlung als das zu Erhaltende darstellt, so ist es in der Komödie umgekehrt die Subjektivität, welche in ihrer unendlichen Sicherheit die Oberhand behält. (Hegel XV/427)
}

In der Tragödie mögen die Individuen zwar untergehen, die von ihnen metonymisch verkörperte Idee als Teil des "Substantiellen“ kann dabei jedoch bestehen bleiben und weiterwirken. Die Komödie - von Hegel gleichsam als Kehrseite der Tragödie abgewertet - bleibt beim Unwesentlichen: die Subjektivität vermag sich in ihrem Sein zu behaupten, allfällige Ideen erscheinen in der Komödie lächerlich. 


\section{I.9. Die Nation in Hegels Ästhetik und das historische Drama}

Diese kursorische Darstellung von Hegels Vorstellungen von geschichtlicher Entwicklung, Staat, Kunst allgemein und Drama im Speziellen können in Hinblick auf die Themenstellung dieser Arbeit bündig wie folgt zusammengefasst werden:

Das Drama ist eine „ideale“ Kunstform, weil die handelnden Figuren in ihm gleichsam metonymisch für allgemeine Vorstellungen stehen, die im dramatischen Sujet in Konflikt geraten und einer Auflösung des Konflikts zugeführt werden. Die dargestellten Handlungen sind - wenigstens in der Tragödie - „substantiell“, das heißt, sie betreffen das geschichtliche Sein des Menschen, das durch dessen Aktivität verändert wird. Hegel (vgl. XV/537) führt als Beispiel für substantielle Zwecke „Vaterland, Familie, Krone und Reich“ an, worin man den Philosophen des reformorientierten preußischen Staates erkennen kann. In der dramatischen Rede spricht gleichsam der geschichtliche „Logos“ in seinen verschiedenen „wirklichen“ Manifestationen, deren Interaktion den Gang der Geschichte befördert. Sowenig die „heroischen" dramatischen Figuren private Einzelpersonen sind, sondern gewichtige Zwecke verfolgen, deren Auswirkungen die Allgemeinheit tangieren, sowenig sind die historischen Dramen Darstellungen von singulären geschichtlichen Begebenheiten; mit diesen sind vielmehr Momente verbunden, die für Geschichte und Gegenwart der Nation von Belang sind. Das historische Drama ist damit diejenige Subgattung, in der die wesentlichen Ereignisse nationalen Lebens repräsentiert werden.

Wenngleich Hegel in seiner politischen Philosophie nicht ausdrücklich „Nation“ als Bezugsgröße thematisiert, in der sich die Sittlichkeit realisiert, weil sich das einzelne Subjekt hier mit einem transsubjektiven Allgemeinen identifizieren könnte, scheint die „Nation“ in den Vorlesungen zur Ästhetik immer wieder als Bezugpunkt durch.

[...] das echt Poetische aber ist das konkret Geistige in individueller Gestalt; und das Epos, indem es zum Gegenstande hat, was ist, erhält das Geschehen einer Handlung zum Objekte, die in ihrer ganzen Breite der Umstände und Verhältnisse als reiche Begebenheit im Zusammenhange mit der in sich totalen Welt einer Nation und Zeit zur Anschauung gelangen muß. (Hegel XV/330)

Epik und Dramatik werden explizit auf die „Nationalwirklichkeit“ (vgl. Hegel XV/479) bezogen, wobei das Drama insofern „Produkt eines schon in sich ausgebildeten nationalen Lebens“ (vgl. ebd. 476) ist, als eine „Nation“ sich als geschichtliche Entität herausgebildet hat und erst post factum die dramatische Darstellung eines Kampfes möglich ist. ${ }^{41}$ Mit anderen Worten bedeutet dies, dass die Bildung einer

41 Schon in der Phänomenologie des Geistes spricht Hegel vom Volksgeist bzw. von der Nation als erstem Allgemeinen, einer Voraussetzung für den allgemeinen Staat, die noch stark in der unmittelbaren „Sittlichkeit“ verhaftet ist. „Volksgeist“ und „Nation“ basieren auch schon bei 
„Nation“ als Bezugspunkt von Sittlichkeit die Voraussetzung für das Entstehen der epischen und der dramatischen Gattung ist. Hegel behauptet eine unterschiedliche Eignung der beiden Gattungen für die Darstellung von Konflikten: Während die auf der einfachen natürlichen Sittlichkeit aufsetzende Epik das Gesamte einer Nation vornehmlich anhand von Kriegen zwischen Völkern erfasst (aus diesem Gedanken sollte Lukács seine für den Sozialistischen Realismus maßgebliche Theorie der Epopöe entwickeln [vgl. Lauer 2000, 702-705]), eignen sich Konflikte innerhalb der Nation - paradigmatisch personifiziert in streitenden Brüdern - deshalb besser für das Drama, weil dieses das individuelle Wollen, die subjektive Besonderheit am deutlichsten vor dem Hintergrund der Gemeinsamkeit (der Familienbande, der Nation) hervortreten lässt und im Widerstreit der Besonderen die Notwendigkeit der Subjektivierung wie auch von deren Verschwinden zeigt (vgl. Hegel XV/351f).

Akzeptiert man diese hegelsche Überlegung, muss das historische Drama als verspätete Nationalbewegung erscheinen, durch welche die bereits herausgebildete Nation noch weiter in ihrem Nationalbewusstsein bestärkt wird.

Die Frage nach dem historischen Gehalt von Hegels spekulativer Philosophie ist im Zusammenhang dieser theoretischen Erörterung weniger wichtig als seine Auffassung, dass unter den Künsten speziell das Drama mit politischen und kulturhistorischen Veränderungen verbunden wird; konkreter: dass in Hegels Philosophie Subjektivität und Substantiell-Allgemeines mit der dramatischen Gattung verschränkt sind. Aus der Perspektive Hegels kommen im Drama diejenigen Momente zum Vorschein, die das „Wesen“ des Menschen betreffen, aus „Rücksicht auf die Darstellbarkeit" dieses immer historisch zu denkenden Wesens freilich auf eine unhistorische Art und Weise: das Drama kann nicht mehr die komplexe Realisierung des Geistes im modernen Staat repräsentieren, wohl aber die wesentlichen Momente des Wirkens des Geistes, die in der Verschränktheit von Subjektivität und Allgemeinheit liegen (vgl. Pillau 1981, 13).

Das Drama repräsentiert dem Menschen also die Idee seiner Möglichkeiten, wobei es insofern anachronistisch ist, als sich die repräsentierte Welt von der im Gang der Geschichte befindlichen Welt seiner Autoren und seines Publikums unterscheidet. Hegel hatte jedoch keinerlei Vorbehalte gegenüber Anachronismen, im Gegenteil, er hielt diese sogar für höchst notwendig, um zu einer deutlichen künstlerischen Repräsentation zu finden:

Zur wirklichen Existenz einer Handlung oder eines Charakters gehören viele geringfügige vermittelnde Umstände und Bedingungen, mannigfach einzelnes Geschehen und Tun, während in dem Bilde der Erinnerung alle diese Zufälligkeiten verlöscht sind. In dieser Befreiung

Hegel im Wesentlichen auf der Sprache (vgl. Hegel III/529-531). Herders Vorstellungen vom diachronen Wandel des Volks als natürlicher Größe bilden dabei wohl die konzeptuelle Vorlage von Hegels Denken. 
von der Zufälligkeit des Äußeren erhält der Künstler, wenn die Taten, Geschichten, Charaktere alten Zeiten angehören, in betreff auf das Partikuläre und Individuelle freie Hand für seine künstlerische Gestaltungsweise. (Hegel XIII/249)

Die künstlerische Freiheit ist der Gegenwart des Künstlers bzw. der Gegenwart des Publikums verpflichtet, nicht der Vergangenheit als solcher. Hegel entbindet das Drama vom Zeitrahmen der repräsentierten Zeit; ähnlich wie Halbwachs und Assmann kulturelle Gedächtnisprozesse um die Gegenwart des Erinnernden zentrieren, lokalisiert Hegel die Orientierung und Wirkkraft des Dramas in der Gegenwart der literarischen Kommunikation.

Werden daher fremde dramatische Werke in Szene gesetzt, so hat jedes Volk ein Recht, Umarbeitungen zu verlangen. Auch das Vortrefflichste bedarf in dieser Rücksicht einer Umarbeitung. Man könnte zwar sagen, das eigentlich Vortreffliche müsse für alle Zeiten vortrefflich sein, aber das Kunstwerk hat auch eine zeitliche, sterbliche Seite, und diese ist es, mit welcher eine Änderung vorzunehmen ist. Denn das Schöne erscheint für andere, und diejenigen, für welche es zur Erscheinung gebracht wird, müssen in dieser äußeren Seite der Erscheinung zu Hause sein können. In dieser Aneignung nun findet alles dasjenige seinen Grund und seine Entschuldigung, was man in der Kunst Anachronismen zu nennen und den Künstlern gewöhnlich als einen großen Fehler anzurechnen pflegt. (Hegel XIII/358)

Was Hegel über Tragödie und Drama allgemein sagt, gilt gleichfalls auch für das historische Drama, dieses ist geschichtsphilosophisch deswegen interessant, weil es im Zustand entwickelter Staatlichkeit - im allgemeinen Sinn, nicht im Sinn von Nationalstaatlichkeit, die ja bei den Tschechen im 19. Jahrhundert fehlte - eine idealisierte Darstellung politischen Handelns liefert. Dabei muss für ihn ein metonymischer Bezug zwischen Vergangenheit und Gegenwart insofern bestehen, als das gegenwärtige Publikum in der repräsentierten Vergangenheit seine eigene Vorgeschichte zu erkennen vermeint. Insofern das historische Drama Ereignisse aus der Vorgeschichte desjenigen Volkes zeigt, welches als vorgestellter Adressat des Textes gilt, kann gesagt werden, dass der aktuelle Zustand der Nation (des Publikums) als - nähere oder fernere - Folge der vorgeführten Handlungen gelten kann. Der zeitliche Abstand impliziert, könnte man Hegel weiterdenken, auch bereits eine höhere Entwicklung, sodass das Ende eines historischen Dramas, in dem sich die Konflikte und Kollisionen der Dramenhandlung weitgehend aufösen, eine historische Vorstufe der geschichtlichen Entwicklung zum aktuellen Zustand des Publikums bedeutet, der vermittels des idealisierenden Vergangenheitsbezugs indirekt ebenfalls in den idealen Gang der Weltgeschichte eingebunden wird:

Auch dies Geschichtliche ist wohl, aber es ist gewesen, und wenn es mit der Gegenwart des Lebens keinen Zusammenhang mehr hat, so ist es, mögen wir es noch so gut und genau ken- 
nen, nicht das Unsrige; für das Vorübergegangene aber haben wir nicht aus dem bloßen Grunde schon, daß es einmal dagewesen ist, Interesse. Das Geschichtliche ist nur dann das Unsrige, wenn es der Nation angehört, der wir angehören, oder wenn wir die Gegenwart überhaupt als eine Folge derjenigen Begebenheiten ansehen können, in deren Kette die dargestellten Charaktere oder Taten ein wesentliches Glied ausmachen. Denn auch der bloße Zusammenhang des gleichen Bodens und Volks reicht nicht letztlich aus, sondern die Vergangenheit des eigenen Volks muß in näherer Beziehung zu unserem Zustand, Leben und Dasein stehen. (Hegel XIII/352f)

Betont man den historischen Aspekt des Dramas, indem man eben auf die Bedeutung des Dargestellten für die Geschichte und deren weiteren Verlauf verweist, hat man es mit einer achronen Kurzschließung von Ereignissen in der Vergangenheit mit der Gegenwart des Publikums zu tun, das Dargestellte hat demnach metonymischen Bezug zum aktuellen Zustand der Nation, insofern die historischen Ereignisse zeitlich vorauf gingen und somit die Bedingungen für weitere Ereignisse bis hin zur Gegenwart geschaffen haben. Freilich ist diese Metonymie performativer oder rhetorischer Effekt, der in der Attribuierung eines Theaterstücks als „historisches Drama" gründet, denn erst das Attribut stellt diesen Bezug auf die Wirklichkeit her, während Dramen ohne ein solches Attribut wohl nur metaphorisch - per analogiam - mit der geschichtlichen Wirklichkeit des Publikums verbunden sind. Eine solche Betrachtung, die eben das Dargestellte nicht als zeitlich der Gegenwart des Publikums voraufgehend auffasst, sondern als Darstellung eines allgemeinen Konflikts, ist freilich auch gegenüber historischen Dramen möglich.

Berücksichtigt man die drei bislang thematisierten Momente des historischen Dramas - Gegenwartsorientiertheit, Idealisierung und Reflexivität/Performanz mag verständlicher werden, warum die Gattung den Proponenten des tschechischen obrození attraktiv erschienen ist. Die repräsentierte Historie gewinnt in der Aufführung Aktualität, die Idealisierung der repräsentierten Ereignisse ermöglicht die Konzentration auf das Wesentliche des - vorwiegend politischen - Handelns, das die Reflexivität beim Publikum „induzieren“ kann. In ihrem Zusammenwirken lassen diese drei Momente erwarten, dass das Publikum vom historischen Drama affiziert wird und sich selbst als geschichtlich handelndes kollektives Subjekt begreift. Das Drama wird bei Hegel zur konzentriertesten literarischen Gattung, die das „Ideal“ des menschlichen Subjekts in seinen wesentlichen Aspekten - Reflexivität, Aktivität und Agentivität (ich bezeichne damit die Rolle als Vermittler des Geistes) - repräsentiert. Seine Ästhetik liefert damit einen theoretischen - keinen historischen - Bezugsrahmen für historische Dramen, die in diesem Rahmen an Bedeutsamkeit gewinnen. Das historische Drama wird in dieser Arbeit auf ähnliche Weise als Sonderfall angesehen: Es ist eben nicht bloße Darstellung historischer Zusammenhänge, sondern es ,idealisiert" vergangene Ereignisse in dem Sinn, dass diese repräsentativ für das Schicksal des tschechischen Volkes - auch in seiner jeweils gegenwärtigen Situation - gelten sollen. 


\section{Kommunikationstheoretische Implikationen der Gattung Drama}

Die allgemeine Potenzialität von künstlerischer Literatur, immer neue Referenzen zu ermöglichen, gilt für alle literarischen Gattungen und Genres, wohl aber in unterschiedlichem Maße. Nur kursorisch kann hier auf ein semiotisches Modell unterschiedlicher Referenzierbarkeit eingegangen werden, welches das semantische Potenzial der Poesie anders einstuft als dasjenige der Prosa (Revzina 1994/95): Die erzählende Prosa entwirft fiktionale Welten; die nur nach den allgemeinen sprachlichen Regeln kombinierten Signifikanten eines prosaischen Textes verweisen auf Signifikate bzw. Referenzobjekte in dieser fiktionalen Welt. Hingegen sind im formal überstrukturierten poetischen Text die Signifikanten nicht allein aufgrund ihrer semantisch-referenziellen Verweisfunktion auf fiktionale oder tatsächliche Welten ausgewählt, sondern auch aufgrund ihrer phonetischen bzw. graphischen Qualität. Dieser materielle Aspekt des poetischen Textes dominiert gegenüber dem referenziellen Aspekt - in der Ausdrucksweise Jakobsons (vgl. 1960): die poetische Funktion ist anderen Sprachfunktionen vorgeordnet - diese größere Eigenwertigkeit des poetischen Textes hat nach dieser idealtypischen Konzeption zur Folge, dass poetische Texte nicht zuerst auf eine bestimmte fiktionale Welt bezogen werden, sondern gleichsam multipel referierbar sind. Die Aussage des lyrischen Ichs ist demnach keine Aussage eines einzelnen Individuums, das auf eine singuläre Situation referiert, sondern sie hat das Potenzial, von jedem Rezipienten auf seine jeweils individuellen Situationen bezogen zu werden. Diese polyvalente Referenzierbarkeit kann natürlich einem prosaischen Text nicht generell abgesprochen werden, aber im Vergleich zum poetischen Text erscheint diese als sekundär gegenüber der primären Referenz auf die fiktionale Welt. ${ }^{42}$

Diese semiotische Differenzierung von poetischem und prosaischem Text bedarf einer Erweiterung, wenn die Gattung Drama auf ihrer Grundlage beschrieben werden soll. Diese Erweiterung kann nur in der Berücksichtigung der besonderen Kommunikationssituation des Dramas bestehen. Diese besteht zum einen im Fehlen einer Vermittlungsinstanz zwischen dargestelltem Geschehen und Rezipienten, zum anderen in der Kollektivität der theatralischen Rezeption. Das in Analogie zu erzähltheoretischen Überlegungen entworfene Kommunikationsmodell für drama-

42 Lotman (vgl. 1972, 300-311) postuliert generell die multiple Referenzierbarkeit von künstlerischen Texten und führt sie auf den Rahmen, also ihre Beschränkung, zurück. Dabei bleibt aber unklar, welche Unterschiede zu nicht-künstlerischen Texten bestehen, schließlich sind diese ja gleichfalls nicht unendlich, sondern haben einen Anfang und ein Ende. Revzinas Beitrag differenziert aber zuerst zwischen den Redeformen Prosa und Poesie und ordnet diesen ein unterschiedliches Referenzpotenzial zu. Ihre Konzeption ließe sich in diejenige Lotmans integrieren, die allerdings im entscheidenden Punkt - nämlich der Bestimmung unterschiedlicher Rahmen von künstlerischem und nicht-künstlerischem Text - unbestimmt bleibt. 
tische Texte weist mit den Einklammerungen auf das Fehlen einer vermittelnden Erzählerfigur (bzw. deren Korrelat, einer fiktiven Empfängerfigur) hin:

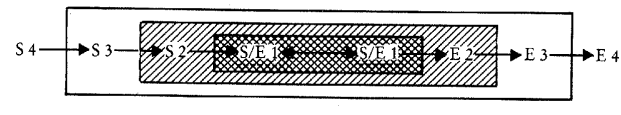

Graphik 3 - Kommunikationsmodell für dramatische

Texte (entnommen aus Pfister 2001,21)

Der doppelt schraffierte Bereich, das „innere Kommunikationsmodell“ besteht aus der verbalen und nonverbalen Interaktion der dramatischen Figuren. Auf die räumliche Theatersituation umgelegt entspricht dieser Bereich der Bühne, die zugleich der markierte Raum für die Interaktion der von den Schauspielern repräsentierten Figuren ist wie auch das Medium der Interaktion zwischen den verschiedenen Produktionsinstanzen (Autor, Regisseur, Bühnenbildner ...) und dem Publikum.

Beide spezifischen Merkmale von Drama und Theater haben Auswirkungen auf den Text des Dramas. So bedingt das Fehlen des Erzählers als Vermittlungsinstanz, dass zeitliche Diskontinuitäten in der dramatischen Diegese weitaus schwerer zu realisieren sind als in der Erzählprosa, zugleich aber ermöglicht es - in der Situation des Theaters - den Zusammenfall von Darstellung, Dargestelltem und Rezeption. Die kollektive Rezeptionssituation wiederum impliziert unter der Forderung der Publikumswirksamkeit auch textliche Eigenschaften: etwa eine größere Eindringlichkeit und Verständlichkeit, mehr Redundanzen in der Informationsvergabe etc. (vgl. Pfister 2001, 19-23 u. 62-64).

Diese kontextuellen Spezifika des Dramas, die sich aus der Kommunikationssituation erschließen lassen, können um eine weniger offensichtliche, in dramenästhetischen Überlegungen (vornehmlich denjenigen, die in der Tradition von Hegels Ästhetik stehen) aber öfter thematisierte Eigenschaft erweitert werden. Dieser zufolge wäre nicht allein die Rezeption eine kollektive, sondern schon der Inhalt des Vorgeführten sei von allgemeiner Relevanz, und nicht etwa bloß die Repräsentation eines einzelnen bestimmten Handlungszusammenhangs.

Der Zuschauer des Dramas ist nicht zufällig anwesend bei irgendeiner zufälligen privaten Begebenheit des Lebens, er belauscht nicht durch ein vergrößertes Schlüsselloch das Privatleben seiner Mitmenschen, sondern das, was ihm dargeboten wird, muß seinem innersten Gehalt, seiner wesentlichen Form nach ein öffentliches Ereignis sein (vgl. Lukács 1965, 162).

Demnach beansprucht schlechthin jeglicher dramatische Text allgemeine Relevanz. ${ }^{43}$ Mit dieser Feststellung stehen die beiden Interessen in Zusammenhang,

43 Gegen diese Generalisierung könnten sicherlich Einwände erhoben werden und mit etwas Mühe ließen sich womöglich auch Ausnahmen finden, doch sollte dabei beachtet werden, dass dem Duktus bzw. der Semantik solcher Sätze der philosophischen Ästhetik schlecht mit 
welche diese Arbeit leiten: einerseits das Interesse von Autoren, Dramaturgen, Regisseuren, Publikum an der Gattung des historischen Dramas im 19. und beginnenden 20. Jahrhundert, andererseits das Meta-Interesse, das sich auf dieses primäre Interesse richtet. Die Fragestellung lautet: Worin bestand die Attraktivität der Gattung historisches Drama für das Publikum dieses Zeitraums?

In diesem Zusammenhang wären die zuvor thematisierten Unterschiede der Redeformen Prosa und Poesie, die beide in der Gattung Drama vorkommen (neben der Prosarede der Figuren gibt es ja auch die Versdramen), in der dramatischen Gattung zu relativieren: Welche Redeform das Drama auch aufweisen mag, es geht weniger um eine singuläre Referenz auf eine historische oder fiktionale Welt wie in der Prosa, noch induziert die Versrede der Figuren sofort multiple Referenzierbarkeit für das Publikum, stattdessen impliziert die Gattung Drama, dass das im Text oder auf der Bühne Repräsentierte von öffentlichem Interesse für das intendierte Publikum ist.

\section{II.1. Zur Fokussierung der Analyse}

Zwischen den Vorgängen auf der Bühne/im dramatischem Text und der Welt der Produzenten bzw. Rezipienten besteht ein ontologischer Unterschied, welcher insbesondere in der Welt des Theaters vielerlei schon oft beschriebene Phänomene ermöglicht. So sind beispielsweise die Interaktionen von Schauspieler und Publikum, die Überlagerungen zwischen der Person des Schauspielers und der fiktionalen Figur, Möglichkeiten von Bühnen- und Theaterarchitektur kennzeichnend für die Welt des Theaters, die in vorliegender Arbeit nur im Rahmen einer allgemeinen Charakterisierung des kulturgeschichtlichen Hintergrunds tangiert werden kann.

Aufgrund der Konzentration auf die Texte des historischen Dramas werden hier die konkreten Lebensumstände von Autoren, ihre ideologischen bzw. politischen Auffassungen oder die überlieferten Berichte von ihren Handlungen als reale Personen des öffentlichen Lebens, Kritiken und Berichte von Theateraufführungen nur am Rande berücksichtigt. Die Ausführungen in dieser Arbeit haben also Bezug auf die „theoretischen“ Instanzen „,idealer Autor" bzw. ,idealer Leser" (S3 und E3); ihre „Idealität" ist freilich keine platonisch-universale, sondern sie gründet in den Befunden des Verfassers (dessen spezifische Rezeption der Stücke (E4) das konkrete Gegenstück zur ,idealen“ Instanz E3 ist) zu den diversen dramatischen Texten. Die

dem Werkzeug der Prädikatenlogik beizukommen ist - es sind dies unterschiedliche Sprachspiele mit unterschiedlichen Regeln. Ihre Plausibilität beruht auf den Anteilen von empirischer Betrachtung ausgewählter Beispiele, der Autorität des Beobachters, auf Rhetorik, Intertextualität (Lukács verweist im Zusammenhang dieser Feststellung auf andere Autoritäten, die ähnliche Gedanken äußern) und performativer Kraft: Indem Georg Lukács dies („Das Dargebotene muss ein öffentliches Ereignis sein“) behauptet, hat die Aussage bereits eine gewisse Gültigkeit. 
von der Literaturtheorie erarbeiteten Instanzen des ,implizierten idealen Autors“ (S3) bzw. des „impliziten idealen Rezipienten“ (E3) gehören - wie schon in ihren Bezeichnungen indiziert ist - wiederum einer anderen ontologischen Kategorie an, die bei aller Idealität in zwei Richtungen vermittelt bzw. repräsentiert: Geht der reale Rezipient E4 vom Text aus, ergibt sich aus dessen Interpretation eine Vorstellung vom Autor (S3), die nichts mit der Kommunikationsabsicht des realen Autors S4 gemein haben muss. Der reale Autor $\$ 4$ bedenkt seinerseits einen idealen Rezipientenkreis, der nichts mit den realen Rezipienten E4 von dramatischen Aufführungen zu tun hat. Die Thematisierung der realen Rezipienten, also empirischer Personen wie Autoren und Publikum der Aufführungen bzw. allfällige Kritikermeinungen, erfolgt in dieser Arbeit allenfalls als vertiefende Hintergrundinformation.

Um die Arbeit lesbar zu halten und Lektüre nicht durch eine Terminologie zu erschweren, die nur einer in literaturwissenschaftlicher Methode versierten Leserschaft zugänglich wäre, wird jedoch auf das Attribut „ideal“ verzichtet - der Verfasser wünscht sich hiermit - es sei explizit und zugleich paradox gesagt - „ideale“ Leser, die zwischen empirischen und idealen Instanzen zu unterscheiden wissen. Sofern allerdings der Kontext eine Spezifizierung - realer Autor (S4) oder idealer Autor qua Funktion der Textrezeption (S3) - nahelegt, wird eine solche erfolgen.

\section{II.2. Text und Lebenswelt}

Michail Bachtin verbindet das ästhetische Problem literarischer Gattungen und Genres mit Fragen nach dem Verhältnis zwischen Autor und geschaffener Figur, welches dabei stets mit lebensweltlicher Intersubjektivität bzw. Alterität verglichen wird. Der Autor eines Romans erschafft seine Figuren und nimmt diesen gegenüber eine objektivierende Haltung ein, da er sie ja in ihrer fiktionalen Umgebung zeigt und charakterisiert. Eine solche Objektivierung von anderen Menschen erfolgt auf ähnliche Weise auch im alltäglichen Leben; anderen Subjekten werden beispielsweise mentale oder charakterliche Eigenschaften auf der Grundlage eines nur flüchtigen Umgangs zugeschrieben. Die Subjektivität der anderen wird dabei annihiliert, aus anderen Subjekten werden Objekte für ein urteilendes Subjekt. In der Lebenswelt freilich behauptet sich die Subjektivität der anderen etwa in dem Umstand, dass ich als Subjekt erfahre, vom anderen Subjekt objektiviert zu werden (etwa indem ich vom anderen angeblickt werde oder sonst wie "thematisiert“ werde) und entsprechend auf diese Objektivierung reagieren kann.

Die Anstrengung Bachtins bestand nun darin, den Wechsel von Objektivierung und Subjektivierung - der andere als Objekt, der eigentlich Subjekt ist - auf die Literatur zu übertragen: bekanntlich sah er vor allem in der Erzählprosa Dostoevskijs die Möglichkeit verwirklicht, dass sich der fiktionale Held von seinem Objektstatus löst und zum gleichberechtigten Gegenüber des Autors wird. Bachtin sieht in Dostoevskijs Poetik den realen Autor mit den von ihm geschaffenen fiktiven Figu- 
ren in einen „Dialog“"44 treten; die Figuren geraten gleichsam auf eine Ebene mit dem Autor, der sie dabei nicht mehr definitiv gestaltet, ${ }^{45}$ weil das neue Verhältnis zu ihnen einem lebensweltlichen Verhältnis entspricht. In einem solchen ist ein anderes Subjekt für das Subjekt irreduzibel anders, die andere Subjektivität kann ontologisch nicht dauerhaft auf einen Objektstatus zurückgeführt werden. In Dostoevskijs Werken seien die erzählten Figuren aufgewertet, sie konkurrieren für Bachtin auf einer Ebene mit dem Autor bzw. dem Erzähler:

Слово героя о себе самом и о мире так же полновесно, как обычное авторское слово; оно не подчинено объектному образу героя как одна из его характеристик, но и не служит рупором авторского голоса. Ему принадлежит искцючительная самостоятельность в структуре произведения, оно звучит как бы рядом с авторским словом и особым образом сочетается с ним и с полноценными же голосами Аругих героев. ${ }^{46}$ (Bachtin 2000, 11)

Bachtin sieht im Wesentlichen drei Alternativen des Verhältnisses von Autor und von ihm geschaffener Figur, dabei wohl einräumend, dass es sich um Idealtypen handelt, die in literarischen Werken auch in gemischter Weise realisiert sein können: zum einen das Subjekt-Objekt-Verhältnis, in welchem die Figuren völlig vom Autor bestimmt sind, zum anderen das Verhältnis, dass ein Autor bestimmte Figu-

44 Schmid (vgl. W. Schmid 1984) hat den Versuch unternommen, die allzu euphorische Rezeption bachtinscher Konzepte kritisch zu beleuchten, indem er auf die gewagte Metaphorizität des Ausdrucks „Dialog“ hinwies, wenn dieser auf das Verhältnis Autor - Figur bzw. Autor Leser bezogen wird. Da dieses Verhältnis keineswegs Merkmale eines lebensweltlichen Dialogs hat, wird in der vorliegenden Arbeit der „Dialog“ unter Anführungszeichen gesetzt, wenn es sich um dieses von Bachtin thematisierte literaturästhetische Verhältnis handelt.

45 „Geroj ideologičeski avtoriteten i samostojatelen, on vosprinimaetsja kak avtor sobstvennoj polnovesnoj ideologičeskoj koncepcii, a ne kak ob"ekt zaveršajuščaja chudožestvennogo videnija Dostoevskogo [...] kak esli by geroj byl ne ob"ektom avtorskogo slova, a polnocennym i polnopravnym nositelem sobstvennogo slova““ (Bachtin 2000, 9) - „Die Figur ist ideologisch autoritativ und selbstständig, sie wird als Schöpferin ihrer eigenen vollwertigen ideologischen Konzeption wahrgenommen und nicht etwa als Objekt, das die künstlerische Perspektive Dostoevskijs vollendet.“ - Die Übersetzung der Bachtin-Zitate hier und in der Folge, stammt, sofern nicht anders gekennzeichnet, immer von mir, PD. (Das russische Wort geroj wird hier und in der Folge nicht als „Held“ übersetzt, sondern mit dem neutraleren Begriff „Figur“, der in der modernen Erzähltheorie üblicher ist. Im Haupttext wird sowohl Figur als auch Held synonym verwendet.)

46 „Die Rede der Figur über sich selbst und über die Welt ist genauso gewichtig, wie die gewöhnliche Rede des Autors; sie ist dem Objektbild der Figur nicht als eines ihrer Charakteristiken untergeordnet, sie ist aber auch kein Sprachrohr der Stimme des Autors. Dieser Rede ist eine besondere Selbstständigkeit in der Struktur des Werks eigen, sie ertönt gleichsam neben der Rede des Autors, sie verbindet sich auf besondere Weise mit dieser und mit den vollwertigen Stimmen der anderen Figuren." 
ren als sein Sprachrohr gebraucht, schließlich drittens das seiner Ansicht nach von Dostoevskij erstmals realisierte Verhältnis der Gleichrangigkeit, in welchem die Figuren selbst zu Subjekten, zu einem „Dialogpartner“ des Autors werden.

Das erste und das zweite Verhältnis steht in Relation zu den faktischen Bedingungen literarischer Kommunikation: Immerhin kreiert ja der Autor die Figuren, was einem Subjekt-Objekt-Verhältnis entspricht und die Auffassung plausibel macht, dass die Figuren finite Objekte auktorialen Willens sind. ${ }^{47}$ Als solche können sie auch zum Sprachrohr für ideologische Überzeugungen des Autors werden. Selbst wenn der Autor dies vermeiden möchte und keine Figur als porte-parole gestaltet, könnte aus der Rezipientenperspektive, die ihrerseits ja eine Objektbeziehung zum Text konstituiert, immer auf eine ideologische Aussage des Autors geschlossen werden; auch bei Dostoevskijs Texten wäre dies prinzipiell möglich. ${ }^{48}$ Der Unterschied zwischen der offensichtlichen Instrumentalisierung einer Figur als „Sprachröhre“ des Autors und der „dialogischen“ Poetik Dostoevskijs besteht demnach wohl nur im Grad der Raffinesse, mit welchem ideologische Standpunkte des Autors in den Text einfließen.

Das dritte Verhältnis - die Gleichrangigkeit von Autor und Figuren - resultiert aus einem Perspektivenwechsel, dem zufolge die beiden ontologisch differenten Ebenen von Autor und Figur plötzlich als ineinander verschoben erscheinen. Man beachte die bachtinschen Formulierungen „[slovo geroja] zvučit kak by rjadom s avtorskim slovom“, „množestvennost' ravnopravnych sozdanij s ich mirami“ - „[k miru] polnopravnych sub"ektov, a ne ob"ektov “49 (2000, 11f, kursiv immer von mir, PD), um zu erkennen, dass ein Autor hier keineswegs als Schöpfer differenter und logisch von ihm dependenter fiktiver Charaktere mehr gilt, sondern als Erzeuger

47 Die spekulative Umkehrung des Verhältnisses, nämlich dass der Autor Funktion des Textes ist, mithin also gewissermaßen dessen Objekt, kann in zweierlei Hinsicht Plausibilität beanspruchen. Sie ist gewissermaßen aus der Rezipientenperspektive richtig, nämlich dass - wie oben angedeutet - die Gesamtmerkmale des Textes auf einen impliziten bzw. idealen Autor schließen lassen, der sich ontologisch vom realen Autor unterscheidet. Andererseits entspricht auch die Dialektik von Subjektivität I -> Entäußerung bzw. Objektivierung der Subjektivität in einem „Werk“ -> Subjektivität II dieser Umkehrung: man kann nicht Autor sein, solange man kein „literarisches“ Objekt hervorgebracht hat, die Entäußerung bzw. Objektivierung in einen Text macht mithin rückwirkend einen schreibenden Menschen zum Autor.

48 Auf die Monologizität hinter der „Dialogizität“ bei Dostoevskij weisen etwa Wellek (1980) und Schmid (1984) hin. Freise (vgl. 1993, 279-281) meint, dass Bachtin in Dostoevskij den Konflikt von Autorrede und Figurenrede sowie die Bindung von Ideologie an bestimmte Personen sieht, nicht aber den Umstand, dass Dostoevskij vorführt, wie die Ideenträger scheitern und gerade darin die menschliche Würde hervortreten lassen, die Dostoevskijs Lieblingsidee war.

49 „[die Rede der Figur] ertönt gleichsam neben der Rede des Autors“, „die Mannigfaltigkeit von gleichberechtigten Schöpfungen und von deren Welten“ - „[zur Welt] vollberechtigter Subjekte, nicht etwa Objekte“. 
multipler gleichrangiger Diskurse, gegenüber welchen seine Stimme angeblich keinerlei Dominanz mehr besitzt.

Wenn nun gemäß dem ersten Verhältnis die geschaffenen Figuren sui generis Objekte für Autor und Leser sind, wäre zu fragen, wie dieser Status überhaupt verlassen werden kann, damit die Figuren mit Autor und Leser gleichrangig werden? Bachtin selbst hat zwar immer wieder behauptet, dass es zu einer solchen Gleichrangigkeit kommt; an seinen Belegen, die vor allem auf die sogenannte "personale“ Erzählsituation, auf die langen Monologe der dostoevskijschen Helden angesichts eines Gegenübers hinweisen, wurden aus erzähltheoretischer Sicht jedoch Zweifel angemeldet. Eine personale Erzählsituation bzw. die erlebte Rede ist keineswegs „dialogisch“, sondern in ihr kommen lediglich Aussagen vor, deren Zuordnung zu den differenten Bewusstseins- bzw. Sprecherinstanzen - des Erzählers bzw. der erzählten Figur - nicht eindeutig erfolgen kann (vgl. W. Schmid 1984, 72f; Martinez/Scheffel 1999, 52f).

Nach Freises dezidiert hermeneutischer Bachtin-Exegese gäbe es allerdings zwei von Bachtin nicht beachtete Momente im ästhetischen Umgang mit der durch Vielstimmigkeit (raznorečie) gekennzeichneten Erzählprosa, welche die Subjekt-Objekt-Hierarchie zwischen Autor/Leser und erzählter Figur überwinden können (vgl. Freise 1993, 254-261). Zum einen wäre dies die „Einfühlung“ in die Figur des Helden, welche als spontane, unwillkürliche und wohl nur partielle Identifikation von Autor bzw. Leser mit dem Helden zu denken ist (die dem Autor/Leser eigene Subjektivität wird dabei auf die Figur übertragen), zum anderen die ästhetische Vollendung (zaveršenie) qua sinnliche und nicht begriffliche Einstellung zu den erzählten Figuren, welche diesen eine „Form“ verleiht (vgl. ebd. 269). Zaveršenie sei für die ästhetische Einstellung zum Mitmenschen charakteristisch, die bloße „Einfühlung“ in eine Figur werde um eine sinnliche und zugleich nicht-objektivierende Distanznahme erweitert. ${ }^{50}$ Zaveršenie wäre somit für Freise die Lösung für die Alternative zwischen Objektivierung, die ein anderes Subjekt auf ein Objekt reduziert, und subjektiver Einfühlung, bei der die eigene Subjektivität auf einen

50 In der beständig auf lebensweltliche Zusammenhänge ausgerichteten ästhetischen Theorie Bachtins ist die zaveršenie einer Figur durch den Autor der Hingabe eines Tänzers an den Tanz vergleichbar - der Tänzer entspricht insofern dem Helden, als er nicht selbst die Musik schafft, sondern sich in diese einlässt, sein Tanz verbindet Aktivität und Passivität (vgl. Bachtin 2003, 205). - Dass der Vergleich an mehreren Stellen hinkt, hat vor allem damit zu tun, dass Bachtin eben geschaffene Figuren ständig so betrachtet, als ob sie Subjektivität hätten. Freise setzt diese verwirrende Konzeption, in der die ontologisch distinkten Bereiche Lebenswelt und literarisches Kunstwerk ineinander verschoben werden, fort: „Was aber macht die Form mit mir, dem Helden? Sie überantwortet mich meinem Rhythmus. Das mag sich äußerlich nicht vom selbstvergessenen Tanz unterscheiden, doch der entscheidende Unterschied liegt darin, daß dieser Rhythmus erschaut wird: ich tanze unter dem Blick des sehenden Autors." (Freise 1993, 265f, kursiv im Orig.) 
Anderen - einen wirklichen Anderen oder eine fiktive Figur - übertragen wird. Die Einfühlung werde dabei „aufgehoben“ - bewahrt und abgelöst -, aus der ontologischen vnenachodimost' von Autor/Leser gegenüber einer Figur werde deren ästhetische Vollendung. Freises Umdeutung von Bachtins Ideen ist aber weitgehend allgemein; was über Einfühlung und ästhetische Vollendung gesagt wird, könnte wohl für jede fiktionale Figur gelten. Eine Differenzierung der Genres bzw. Gattungen, an der Bachtin offenbar gelegen war, ist auf diese Weise nicht mehr möglich.

\section{II.3. Die ideologische Bewertung eines Dramas}

Die Kommunikationssituation Theateraufführung impliziert, dass dem Publikum Szenen vor Augen geführt werden, denen die Vermittlung durch eine Erzählerfigur in der Regel abgeht. Intradiegetische Rede und Gegenrede, dramatische Handlungen werden von einem Publikum betrachtet und können von diesem bewertet werden. Die Konfrontation Publikum - Theateraufführung ist unmittelbar, das Publikum ist leibhaftig zugegen und verfolgt eine Handlungsentwicklung, auf welche es spontan reagieren kann, insofern es sie mit seinen Sinnen wahrnimmt. Dieser dem Medium Theateraufführung eigene Publikumsbezug ist den Dramen, der textlichen Grundlage von Stücken, als Potenzialität eingeschrieben: Da die Texte für die Wirkung auf ein Theaterpublikum bestimmt sind, haben sie Eigentümlichkeiten, die anderen Texten - die nicht für die kollektive Rezeption in einer „Live“-Aufführung vorgesehen sind - fehlen. Das Fehlen einer Vermittlungsinstanz, das die Unmittelbarkeit der dramatischen Rede bedingt, sieht A. W. Schlegel in der Theateraufführung durch die Konkretheit der Schauspielerarbeit und durch die Bühne kompensiert, sodass er die dramatische Gattung in Relation auf das Medium Theater hin betrachtet, für welches das Drama geschrieben ist (vgl. Schlegel 1966, 28-30).

Für sich als Text genommen, mithin nicht als Surrogat einer Theateraufführung verstanden, kann die Gattung Drama darin als logozentrisch gelten, dass nicht bloß die Dialoge bzw. Repliken der Figuren als Sprechhandlungen angesehen werden können, sondern gleichfalls die nonverbale Handlung und die gesamte außersprachliche Situation, in der die Figuren handeln, sprachlich konstituiert sind (vgl. Veltruský 1999, 16-19). Der Logozentrismus gilt im Besonderen für das „Wortdrama“, also das traditionelle klassische Drama von seinen Anfängen im antiken Griechenland bis zum Ende des 19. Jahrhunderts, als Herta Schmid zufolge in den europäischen Literaturen allmählich ein Übergang zum „Dingdrama“ erfolgte, den Schmid in Čechovs Werk paradigmatisch lokalisiert. Während bei Letzterem die dargestellten Figuren gleichsam wie „Dinge“ behandelt werden, es also zu einer „Emanzipation der dinglichen Struktur der Bühne gegenüber der Wortbedeutung kommt" (H. Schmid 1992, 39), ist das Wortdrama dadurch gekennzeichnet, dass in der verbalen Kommunikation eine „absolute Wahrheit“ über die dargestellte Welt ausgemacht werden 
kann, also eine für diese Welt definitiv gültige Aussage des Autors, die dem Leser bzw. Publikum mehr oder weniger vermittelt mitgeteilt wird (vgl. ebd. 46).

\begin{abstract}
Während es im antiken Drama die Helden selber sind, die ihr Innerstes [ihre Wahrheit, ihre eigentlichen Motive] aufdecken [...], ist es im klassizistischen Drama der Andere, der als Inkarnation des Dritten im dialogischen Verhalten des Helden die sowohl vor den Handlungspartnern wie vor sich selbst verborgen gehaltenen Emotionen und Gedanken aufdeckt. Einen Höhepunkt dieser Psychologisierung der verbalen Äußerung stellt dann das Drama Čechovs dar, worin das „letzte“, auf das Innerste der Person gerichtete Wort nicht mehr gesprochen wird und damit dann auch nicht mehr ins Bewußtsein der Personen vordringen kann. Die Funktion des Dritten [der die Wahrheit offenbart] übernimmt hier der Autor und mit ihm das Publikum, insofern dieser durch nichtdiskursive Mittel der Dialogorganisation jenem einen ,Blick' ins Innere der Person freilegt, zu welchem die Person selber und keine der übrigen Personen der Stücke mehr fähig sind. (H. Schmid 1992, 46)
\end{abstract}

Die meisten der in dieser Arbeit analysierten historischen Dramen sind gleichfalls unter dem Typus „Wortdrama“ zu subsumieren: Der Aufbau des Dramas lässt in der Regel keine Zweifel über die Motive der Personen und die Verkettung der Handlung weist in der Regel wenig „Unbestimmtheitsstellen“ auf, die heterogene oder gar konträre Rezipientenhypothesen ermöglichen würden. Damit kommunizieren die historischen Dramen eine bestimmte Auffassung von Geschichte und Ideologie, die vom Publikum (bzw. dem „idealen“ Empfänger E3) nur entsprechend entdeckt werden muss. Auf die Freilegung und Diskussion dieser in dramatischer Kommunikation mitgeteilten ideologischen Auffassung der Geschichte bzw. der repräsentierten Ereignisse zielt die vorliegende Arbeit ab.

Möglicherweise aber bedingt der für das Drama grundlegende Repräsentationsmodus, der oben in seinen Ausformungen der Gegenwartsorientiertheit, Idealisierung und Reflexivität konstatiert wurde, durch die Unmittelbarkeit der dramatischen Kommunikation den Umstand, dass angesichts der repräsentierten Vielstimmigkeit nicht immer gleich die Stimme des Autors, die mit der dramatischen Kommunikation verbundene Aussage ausgemacht werden kann.

Die Doppelung der dramatischen Kommunikation in Makro- und Mikrokommunikation, in ein äußeres und ein inneres Kommunikationssystem (vgl. Pfister 2001,20-22) besagt, dass Sprechhandlungen der Figuren nicht allein für das innere Kommunikationssystem - dasjenige der Figuren (im Schema oben S. 59 schraffiert) - gelten, sondern dass Publikum bzw. Leser anhand dieses über die Intentionen des Dramatikers mutmaßen bzw. somit den ,idealen“ Autor als Subjekt des Werkganzen im äußeren Kommunikationssystem konstruieren. ${ }^{51}$ Die über die ver-

51 Dies ist freilich ein idealisiertes Modell literarischer Kommunikation. Faktisch konstituiert sich die Rezeption eines literarischen Werks natürlich aus der offenen Menge paratextueller 
schiedenen Figuren hergestellte Polyperspektivität im inneren Kommunikationssystem ist folglich von der Monoperspektivität des äußeren Kommunikationssystems überlagert; die Person des realen Autors teilt sich über die fiktionale Figurenkommunikation seinem Publikum mit. Damit wird, wie es Jiř́ Veltruský aus strukturalistischer Perspektive formuliert hat, die Dialogstruktur eines Dramas kompliziert, weil sich über dem dramatischen Dialog der Figuren die Makrokommunikation des Autors mit seinem Publikum vollzieht. ${ }^{52}$

Diese theoretische Überlegung verknüpft mit der Autorschaft ein singuläres, für das Werkganze verantwortliches Subjekt, welches seine persönliche Perspektive über die Personen des Dramas und ihre Interaktionen mitteilt. Einer solchen ,monologisierenden' Betrachtung wäre der Gemeinplatz marxistischer Literaturtheorie entgegenzuhalten, dass die Gattung Drama vor allem in gesellschaftlichen Umbruchszeiten produktiv und innovativ sei, eine Auffassung, die sich auch mit $\mathrm{He}-$ gels Konzeption verträgt, der zufolge das Drama die ideale Gattung ist, um das vom Menschen vermittelte weltgeschichtliche Wirken des Geistes darzustellen. Lukács formuliert die Sensibilität der dramatischen Gattung auf Geschichte wie folgt:

Es kann im allgemeinen als unbestritten betrachtet werden, daß das Drama die Kollision gesellschaftlicher Kräfte auf ihrem extremsten, am meisten zugespitzten Punkt zum zentralen Vorwurf hat. Und es gehört kein besonderer Scharfsinn dazu, um die Beziehung von gesellschaftlicher Kollision in extremer Form und gesellschaftlicher Umwälzung, Revolution zu sehen. Jede echte, tiefe Theorie des Tragischen betont als Wesenszeichen der Kollision einerseits die Notwendigkeit des Handelns auf beiden Seiten der kämpfenden Kräfte und andererseits die Notwendigkeit der gewaltsamen Austragung dieser Kollision. (Lukács 1965, 117)

bzw. allgemein kultureller Kommunikation und Wissensbeständen, ein Bottom-up-Prozess (aus den Merkmalen des literarischen Textes hervorgehend) interagiert dabei immer mit einem Top-down-Prozess (historische, textexterne Informationen werden gleichfalls aktualisiert).

52 „Bylo-li řečeno, že podoba významové jednotky v dialogu je výsledkem aktů všech účastníků, v dramatickém dialogu je poměr obrácený: všechny tyto akty jsou pouhými významy, které vznikají na základě podoby oné jednotky [básníka jako mluvč́́ho]. Významová jednotka je totiž v dramatickém dialogu dána aktem jediným, ale básník, který je subjektem tohoto aktu, má na mysli kontexty všech účastníků a formuje jednotku tak, aby v čtenářově mysli vyvolala příslušné akty všech účastníků jakožto významy.“ (Veltruský 1999, 20) „Wenn gesagt wurde, dass die Art des semantischen Zusammenhalts im [nicht-literarischen] Dialog das Resultat von [Sprech-]Akten aller [Dialog]teilnehmer ist, so gilt für den dramatischen Dialog das umgekehrte Verhältnis: All die [Sprech]Akte sind nur Bedeutungen, die auf der Basis jener Einheit [des Dichters als Sprecher] entstehen. Der semantische Zusammenhalt ist nämlich im dramatischen Dialog durch einen einzigen Akt gegeben; nur stellt sich der Dichter als Subjekt dieses Akts die entsprechenden Kontexte aller Teilnehmer am Dialog in der Imagination vor und gestaltet die Einheit so, dass in der Vorstellung des Lesers die entsprechenden Akte als [eigenständige] Bedeutungen erscheinen." 
Autoren nehmen als historische Personen an gesellschaftlichen Auseinandersetzungen teil; dass sie dabei, wie Bachtin es postuliert hat, nolens volens eine „Lebensideologie" (žitejskaja ideologija) vertreten und dementsprechend andere Ideologien ausschließen oder ablehnen, muss freilich nicht auch implizieren, dass ihre Lebensideologie immer deutlich bestimmt ist; sie kann ja auch schwanken, in sich widersprüchlich sein, ohne dass diese Widersprüche als existenzielle Paradoxa wahrgenommen werden.

Die ideologische Vielstimmigkeit realer sozialer Kommunikation findet ihre strukturelle Entsprechung in jener dramatischer Figurenrede. Die Person des Autors könnte unter dieser Perspektive wie ein Transformator realer textexterner in fiktionale textinterne Vielstimmigkeit betrachtet werden. Die beschworene Affinität von Drama und gesellschaftlicher Umbruchszeit wäre also mit der Vielstimmigkeit gesellschaftlicher Diskurse zu verbinden, die zwar in der Person eines realen Autors gebündelt, dabei nicht aber unbedingt auch gleich auf einen einzigen Standpunkt reduziert wird, um sodann in die Vielstimmigkeit eines dramatischen Textes einzugehen.

Die beiden extremen Möglichkeiten von (literarischer) Kommunikation wären einerseits eine einfache monologische Äußerung eines Sprechers/Autors, die seinen ideologischen Standpunkt zu einer Frage wiedergibt, andererseits aber die von Szondi skizzierte Möglichkeit des absoluten Dramas, in welchem allein die unterschiedlichen ideologischen Positionen von Figuren vorgeführt werden, ohne dass eine deutliche Präferenz durch den Autor erkennbar wäre, da dieser auch nicht einmal in Relation zu einem Stellvertreter (z.B. einem fiktiven Erzähler) gebracht werden kann. Hinsichtlich der Loslösung des inszenierten Textes vom Autor beschreibt Szondi die Auseinandersetzung des Zuschauers mit der Inszenierung eines dramatischen Textes als interpretatives Schockerlebnis:

Die gleiche Absolutheit weist das Drama dem Zuschauer gegenüber auf. Sowenig die dramatische Replik Aussage des Autors ist, sowenig ist sie Anrede an den Zuschauer. Dieser wohnt vielmehr der dramatischen Aussprache bei: schweigend, mit zurückgebundenen Händen, gelähmt vom Eindruck einer zweiten Welt. Seine totale Passivität hat aber (darauf beruht das dramatische Erlebnis) in eine irrationale Aktivität umzuschlagen: der Zuschauer war, wird in das dramatische Spiel gerissen, wird selber Sprechender (wohlverstanden durch den Mund aller Personen). (Szondi 1978, 17)

Wenngleich der Umschlag von rezeptiver Passivität zu ,irrationaler Aktivität“ in dieser Passage unvermittelt anmutet (so wird nicht deutlich, ob er generell postuliert wird oder ob er nur unter spezifischen Bedingungen - Inszenierungsfaktoren, Rezeptionsdispositionen - erfolgen kann bzw. soll), scheint Szondi besonderen Nachdruck auf die ästhetische Illusion zu legen. Seiner Ansicht nach bewirke diese, dass der Betrachter mit fiktiven dramatischen Personen zu sprechen beginne; aus 
dem Publikum werde so das Gegenüber der dargestellten Figuren, was freilich einer „irrationalen“ Verletzung der ontologischen Grenzen gleichkomme (vergleichbar den Metalepsen in der Erzählliteratur).

Die Klammerbemerkung Szondis, derzufolge der aktivierte Zuschauer „durch“ den Mund aller Personen spricht, ist erratisch: liest man sie so, dass ein Drama ein Text ist, dessen Polyphonie vom Zuschauer/Leser übernommen, der also auch nicht monologisiert wird, so entspräche dieses ,irrationale“ polyphone Sprechen der im Autor gebündelten Polyphonie, welche dieser auf die einzelnen Figuren verteilt.

Eine schematische Darstellung der Genese und Abfolge dramatischer Kommunikation, welche auch Monologisierung und Dialogisierung erfasst, sähe demnach wie folgt aus:

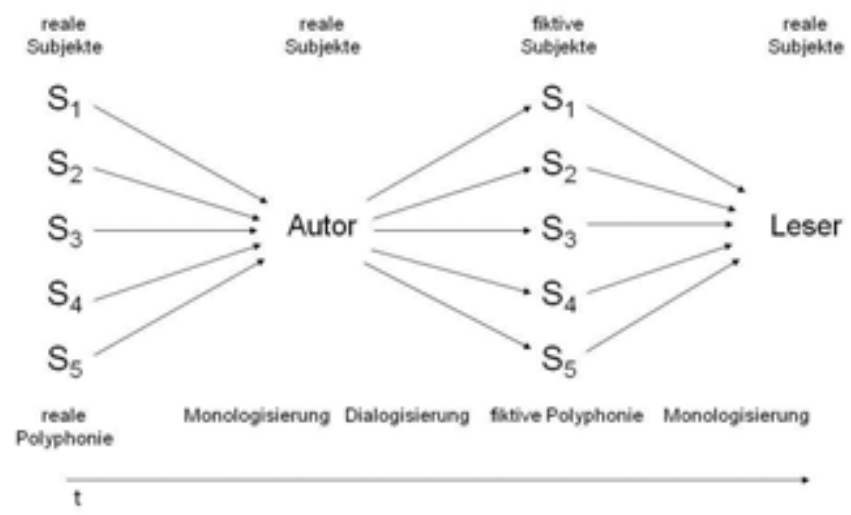

Graphik 4 - Schema der Genese dramatischer Kommunikation

Der im Schema dargestellte Wechsel von vielen Sprechern zu einem Sprecher (Autor oder Leser) kann demnach unterschiedlich ausgelegt werden. In Bezug auf den Leser/Rezipienten lässt die unklare Formulierung Szondis zwei Auffassungen zu, nämlich dass es bei einer Polyphonie bleibt oder dass sich in der „aktiven“ Auseinandersetzung mit den Figuren erst die ideologische Position des Lesers herausbildet. Letztere wäre dann keineswegs mehr als „polyphone“, vielmehr als prozessuale Entwicklung einer monologischen Perspektive aufzufassen, die der Leser gegenüber den Personen des Dramas bzw. dem Gesamttext einnimmt (im Schema hier als Monologisierung des Lesers angesichts der fiktiven Kommunikation bezeichnet). Entsprechend oszilliert auch die Auffassung von der Instanz des Autors zwischen einer monologischen Position, die auf seine Individualität als Person bezogen ist (im Schema als „Monologisierung“ bezeichnet), und einer dialogischen Position, die sich aus dem Zurücktreten der Person des Autors hinter eine Menge verschiedener fiktiver Stimmen ergibt. Das Schema deutet an, dass die für die dramatische Gattung charakteristische Vielstimmigkeit fiktiver Stimmen mit dem Moment der 
Monologisierung verbunden ist, die diese organisiert. Die Verbundenheit von Vielstimmigkeit und monologischer Position ist freilich schon wiederholt in der Gattungstheorie thematisiert worden.

So wird etwa in der system- bzw. kommunikationstheoretischen Beschreibung von Peter Fuchs die im Schema oben (S. 69) angezeigte Alternative von Monologisierung und Polyphonie eindeutig zugunsten ersterer entschieden: In der dramatischen Kommunikation gibt es demnach keine wirkliche „Dialogizität“ und daher allenfalls nur den Anschein einer Polyphonie - in der systemtheoretischen Perspektive heißt das: es gibt nicht zwei Systeme, die interagieren, sondern das Drama führt bloß das Resultat einer projizierten Interaktion vor, in die Projektion sind bereits Verstehensleistungen (des Autors) eingeflossen, der Leser/das Publikum kann diese Verstehensleistungen beobachten, während „echte“ Kommunikation nicht „direkt“ beobachtbar ist, sondern bloß eine weitere Kommunikation ist, die an die voraufgegangene anschließt und diese damit - gleichsam retroaktiv - bestimmt (vgl. Fuchs 1992a, 223f).

Das obige Schema lässt die Sequenzialität der textexternen und textinternen Kommunikationen gut erkennen, die - wie in den uns interessierenden Fällen etwa auch zu historischen Dramen als „Kommunikaten“ führen. Diese sind demnach Kommunikationen, die an andere Kommunikationen anschließen; diese unmittelbar voraufgehende Vergangenheit, die „gerade noch“ Gegenwart war, ist der eigentliche Kommunikationsanlass, es sind dies nicht etwa die „buchstäblich“ im Drama vorgeführten historischen Ereignisse.

Das Schema verdeutlicht aber darüber hinaus den Wechsel zwischen Monologisierung und Dialogisierung an der Grenze von textexternem und textinternem Bereich: Beim Vergleich von realer und fiktiver Polyphonie ist zu beachten - was im Schema nicht deutlich genug dargestellt ist - dass die fiktive Polyphonie als Repräsentation eine „akzentuierte“ Polyphonie ist: Sie führt dem Leser/Publikum intensiviert die Vielstimmigkeit und die in dieser enthaltenen ideologischen Widersprüche bzw. Konflikte vor Augen, die angesichts „alltäglicher“ bzw. realer Vielstimmigkeit nicht immer deutlich auszumachen ist. Im Idealfall wird erst die Repräsentation das Publikum zum „Sprechen“ bringen - im obigen Zitat Szondis ist der Umstand nur kryptisch angedeutet, dass die repräsentierte fiktive Polyphonie das Publikum zu einer Positionierung - einer Subjektivierung, Monologisierung im wahrsten bzw. etymologischen Sinn des Wortes - provoziert.

Mit dieser schematischen Darstellung und den für sie verwendeten Begriffen erfolgt eine Annäherung an die literarische Ästhetik von Michail Bachtin, ohne dass freilich die oben verwendeten Ausdrücke wie „Monologisierung“, „Dialogisierung“ schon als bachtinsche Termini zu verstehen wären. Die Bedeutung der Ausdrücke ergibt sich vielmehr aus dem von der Bachtin-Rezeption mitgeprägten literaturwissenschaftlichen Jargon sowie aus dem Kontext der obigen Überlegungen; Bachtin selbst hat ja die Fragen des Verhältnisses von Autor und Figur, von Monologizität 
und Dialogizität sehr extensiv, jedoch auf nicht völlig einheitliche und schlüssige Weise behandelt (vgl. Freise 1993, 247; Grübel 2001, 111).

Wenngleich die vorliegende Arbeit keineswegs den Anspruch erhebt, der Bachtin-Exegese einen substanziell neuen Beitrag hinzuzufügen, ist es dennoch vonnöten, das Verhältnis von realem Autor bzw. realem Leser und geschaffener Figur eingehender zu betrachten. Damit nämlich wird die wichtigste Verbindung zwischen literarischem Text (im Zusammenhang dieser Arbeit gehört dieser zur Gattung des historischen Dramas) und textexterner Wirklichkeit thematisiert. Erst nach Diskussion dieser Problematik kann die Frage nach dem ideologischen Gehalt eines bestimmten historischen Dramas einigermaßen reflektiert erörtert werden.

\section{II.4. Dialogizität und Drama}

Zumal der Dialog als konstitutives Kennzeichen der Gattung Drama angesehen werden kann - Sonderfälle wie Monodramen oder genresprengende Formen brauchen hier nicht zu interessieren -, liegt die Frage nahe, ob das Drama eine gattungsmäßige Prädisposition für die „Dialogizität“ im Sinne Bachtins hat. Bachtin räumt dem Drama eine solche aber nur in intertextueller bzw. kultureller Hinsicht ein: „niedere" dramatische Gattungen wie z.B. Satyrspiele, Karnevalsszenen, Komödien etc. befinden sich demnach im relativierenden Dialog mit würdevollen hohen dramatischen Genres oder kulturellen Inszenierungen (vgl. Carlson 1992, 314-316; H. Schmid 1992, 37f).

Wenngleich wie gesagt Bachtins Schlüsselkonzept keinem lebensweltlichen Dialog entspricht - mit literarischer „Dialogizität" ist bei ihm ja das Ausbleiben einer expliziten definitiven Beurteilung der Figuren durch den Autor/Erzähler sowie die Relativierung der Autorposition in Bezug auf die erzählten Figuren gemeint -, wäre zu fragen, ob ein Drama wenigstens auf Ebene des inneren Kommunikationssystems „dialogisch“ sein kann.

Der bloße Wechsel von Repliken zweier differenter Subjekte gilt Bachtin keineswegs als Indiz für Dialogizität: Als Pseudo-Dialog wird mit Bezugnahme auf die Autorintention abgetan, wenn die monologische Position rein formal auf unterschiedliche Sprecher aufgeteilt ist, um letztlich die Position eines Sprechers als korrekte, eine andere als falsche zu werten. Insofern dabei ein einziges Bewusstsein argumentativ oder ethisch dominiert, handle es sich um keinen echten Dialog (vgl. Grübel 1979, 39 u. 45). Gerade das Drama würde demnach den Anschein von Dialogizität erwecken, dahinter aber sei oft die als monologisch zu denkende Position eines Autors erkennbar. ${ }^{53} \mathrm{~W}$ ie das nachfolgende Zitat erkennen lässt, konzipiert

53 Veltruský (vgl. 1999, 24-33) weist anhand des Umstandes, dass die Personen eines Dramas auf ein und denselben Sachverhalt markant unterschiedlich referieren, nach, dass mit der Akzentuierung der Differenzen auf Ebene des Dramas eben die Einheit des Dramas auf der 
Bachtin das Verhältnis von Drama und Autor als Projektionsverhältnis in dem Sinn, dass ein Autor seine monologische Intention in die kompakte fiktionale Welt eines Stücks projiziert (im obigen Schema wurde das zu veranschaulichen versucht).

[...] Араматический Аиалог в драме и драматизованный диалог в повествоватемьных формах всегда обрамлены прочной и незыблемой монологической оправой. В Араме эта монологическая оправа не находит, конечно, непосредственно словесного выражения, но именно в драме она особенно монолитна. Реплики драматического диалога не разрывают изображаемого мира, не делают его многопканным; напротив, чтобы быть подлинно Араматическими, они нуждаются в монолитнейшем единстве этого мира. В Араме он Аолжен быть сделан из одного куска. Всякое ослабление этой монолитности приводит к ослаблению драматизма. Герои диалогически сходятся в еАином кругозоре автора, режиссера, зрителя на четком фоне односоставного мира. Концепция драматического действия, разрешающего все диалогические противостояния, - чисто монологическая. Подлинная многопланность разрушима бы драму, ибо драматическое Аействие, опирающееся на единство мира, не могло бы уже связать и разрешить ее. В Араме невозможно сочетание целостных кругозоров в надкругозорном единстве, ибо драматическое построение не Аает опоры Аһя такого еАинства. Поэтому в полифоническом романе Аостоевского подиинно драматический диалог может играть иишь весьма второстепенную ромь. ${ }^{54}$ (Bachtin 2000, 23; kursiv von mir, PD)

\section{Ähnlich wie später Veltruský hält Bachtin das Drama, das auf der Ebene der Figu- ren dialogisch ist, auf der Ebene des Autors für monologisch, da in der dominanten übergeordneten auktorialen Perspektive die monologische Perspektive die fiktio-}

Ebene des Autors verbunden ist: der Autor schafft Kontraste, der dramatische Text kann also auf diesen Kontrasten aufgebaut sein.

54 „Dramatische Dialoge im Drama sowie der dramatische Modus des Dialogs in narrativen Formen stehen immer in einem festen und unerschütterlichen monologischen Rahmen. Im Drama findet dieser monologische Rahmen selbstverständlich keinen direkten verbalen Ausdruck, doch ist er gerade im Drama besonders monolithisch. Die Repliken des dramatischen Dialogs durchbrechen nicht die dargestellte Welt, sie verschaffen dieser keine Vielschichtigkeit; im Gegenteil, um wirklich dramatisch zu sein, benötigen sie die größtmögliche Monolithhaftigkeit dieser Welt. Im Drama muss diese aus einem Stück geschaffen sein. Jedwede Schwächung der Monolithhaftigkeit führt zur Schwächung der dramatischen Wirkung. Die Figuren treffen sich unter der einheitlichen Perspektive des Autors, Regisseurs oder Zuschauers vor dem Hintergrund einer einseitigen Welt. Die Konzeption dramatischer Handlung, die alle dialogischen Kontrapositionen auflöst - ist klar monologisch. Eine wirkliche Vielfalt würde das Drama auflösen, denn die dramatische Handlung, die auf der Einheitlichkeit der Welt basiert, könnte sie nicht bündeln und aufösen. Im Drama ist die Kombination eigenständiger Horizonte in einer transhorizontalen Einheit unmöglich, weil der Aufbau eines dramatischen Werks keine solche Einheit ermöglicht. Daher kann im polyphonen Roman Dostoevskijs ein wirklich dramatischer Dialog nur von nachrangiger Bedeutung sein.“ 
nale Dialogizität aufhebt. Im obigen Zitat ist jedoch auf die apodiktische Formulierung der ersten beiden Sätze hinzuweisen, mit welcher Bachtin ausgerechnet die herausragende Eigenschaft des Dramas, nämlich dessen Tendenz zur szondischen Absolutheit - den Rückzug des Autors aus dem Text - relativiert: Weil es im Drama keine wörtliche Entsprechung für die monologische Fassung bzw. Vision der Welt gibt, sei gerade dieses besonders monologisch bzw. monolithisch..$^{55}$

Selbst wenn man von der faktischen Ungenauigkeit dieser Formulierung absieht - immerhin kann ja der Nebentext eines Dramas tatsächlich als direkter Ausdruck/ „neposredstvennoe vyraženie“ einer monologischen auktorialen „Vision“ gelten, Bachtin thematisiert dies aber überhaupt nicht -, bedarf es einer gesonderten Erörterung, um zu verstehen, warum das Fehlen einer Vermittlerinstanz zwischen fiktionaler Welt und Welt des Adressaten mit einer monologischen Perspektive verbunden wird. Bachtin postuliert pauschal, dass ein Drama einen homogenen Handlungsraum voraussetzt, innerhalb dessen die einzelnen Figuren interagieren; ohne diesen umgreifenden gemeinsamen Boden könnte es nicht zu einem dramatischen Konflikt kommen. Laut Bachtin sichert der Handlungsraum die Homogenität der fiktionalen Welt: diese sei für den dramatischen Konflikt unabdingbar, während die „dialogische“ Einstellung zu erzählten Figuren diese gleichsam zu Personen werden lässt, die ähnlich einem monologischen Autor Sinn produzieren, damit aber zu sinnstiftenden Konkurrenten des realen Autors werden (vgl. Freise 1993, 288).

Die von Bachtin insinuierte Dialogizität von Figuren und Autor in der Erzählprosa impliziert, dass ontologisch differente Sphären - nämlich die des realen Autors und die der erzählten fiktionalen Figuren - in einem homogenen „Handlungsraum “ aufgehen, erst damit wäre die Aufgabe auktorialer Souveränität verwirklicht. Explizit beschreibt Bachtin diesen Rückzug des Autors in der Prosa als Zerstörung der fiktionalen Welt; untersucht man dies aber genauer, so ist damit nichts anderes gemeint als die Aufösung einer Hierarchie zwischen ontologisch distinkten Sphären. Die ideologische Position des realen Autors wäre damit nur eine unter anderen Positionen im Sprech-Handlungsraum. Sophistisch gewendet ließe sich dasselbe gerade aber auch für den Fall des von Bachtin offenbar verachteten Tendenzdramas konstatieren, wenn in dessen Handlungsraum eine Figur als Sprachrohr des Autors fungiert: Warum sollte dieser eine größere Autorität beigemessen werden als einem Autor, der sich mit seinen Figuren auf „Augenhöhe" befindet? Beide, die Figur wie auch der reale Autor, repräsentieren ideologische Positionen in Auseinandersetzung mit anderen ideologischen Positionen - dass die „Sprachrohrfunktion“ dominanter erscheint als die eines Autors wie Dostoevskij, der in Bachtins Meinung neben

55 In Analogie zum Begriffsapparat des Strukturalismus könnte man das Fehlen einer monologischen Einrahmung im Drama als „Nullphänomen“ bezeichnen. Wie ein „Nullmorphem“ keinen positiv gegebenen Signifikanten hat, sondern nur ex negativo die Zugehörigkeit zu einem Paradigma indiziert wird, zählt für Bachtin das Drama zu den monologischen Gattungen: ein explizites Merkmal für den Monologismus fehlt, dennoch wird er postuliert. 
seine Figuren treten möchte, liegt möglicherweise also nicht primär im „Handlungsraum“ begründet - ein solcher lässt sich nämlich überall entfalten -, sondern eher in anderen Faktoren: etwa darin, wie andere Figuren gestaltet sind, wie sie zur Entwicklung der Handlung beitragen etc., wie das Handeln der Figuren ideologisch und moralisch zu bewerten ist.

Abgesehen vom Handlungsraum, dessen Kompaktheit verschiedene Positionen in einer einheitlichen, vom Autor „monologisch“ konzipierten Welt vorstellt, sind die Chancen der dramatischen Gattung, von Bachtin als dialogisch angesehen zu werden, in noch anderer Hinsicht geschmälert. Indem nämlich der Autor sämtliche Rede an die Figuren delegiert und selbst sich nur im Nebentext „äußert“, wird er zur transzendenten, für die Figuren wie für den Leser unzugänglichen Instanz, gegenüber welcher sich kein intersubjektives Verhältnis aufbauen lässt. Leser und Held können den Autor nicht objektivieren, weil sich dieser ihnen entzieht (vgl. Freise 1993, 256).

Die Dialogizität Dostoevskijs gründe zwar auch in der singulären Autorinstanz, diese umgreife die einzelnen Figuren, ohne sie dabei aber aufzuheben oder sie mit dem „letzten Wort“ definitiv zu bestimmen. Diese Ausnahmeposition Dostoevskijs erscheint dabei wunderbar, was sich in der paradoxalen Verbindung „sočetanie celostnych krugozorov v nadkrugozornom edinstve" 56 äußert. Um die räumliche bzw. topologische Metaphorik Bachtins in diesem Zusammenhang aufzugreifen: Es erscheint zwar durchaus möglich, dass einzelne Horizonte (die man sich als Kreise oder Sphären vorstellen könnte) von einem umfassenden Kreis bzw. einer umfassenden Sphäre umschlossen werden, aber gilt dasselbe nicht auch in ähnlicher Form für das Drama? Die übergeordnete Einheit - das Autorbewusstsein - äußert sich nur in Nebentexten, die Positionen der Figuren werden durch die übergeordnete Instanz nicht explizit beeinträchtigt bzw. „deformiert“. Objektivierungen mittels des „letzten Worts“, also Reduktionen unendlicher Subjektivität und Freiheit auf finite Bestimmungen, ${ }^{57}$ finden allenfalls im Nebentext statt, in der Regel sind diese auf Beschreibungen des Äußeren einer Figur beschränkt. Die umgreifende Vereinheitlichung durch das kreative Bewusstsein des dramatischen Autors weist also keine expliziten Werturteile auf, implizit ergibt sich jedoch beim Drama ein Bild, welches ähnlich dem projizierten Bild eines monologisierenden Autors eine Perspektive des Autors bzw. dessen ideologische Präferenzen erkennen lässt, die auch den Rezipienten übermittelt werden sollen. Für Bachtin bleibt nun gerade dies bei Dostoevskij aus:

56 Etwa: „umfassende bzw. ganzheitliche Sinnhorizonte innerhalb einer Einheit, die sich jenseits der einzelnen Sinnhorizonte konstituiert."

57 Bachtin (2000, 68f) verweist auf die intertextuelle Kritik, die Dostoevskij über seine Figur Makar Devuškin an Gogol's Darstellung von Akakij Akakievič übt - (siehe auch die Notiz in Bachtin 2002, 311). 
Роман не только не дает никакой устойчивой опоры вне диалогического разрыва Аля третьего монологически объемляющего сознания, наоборот, все в нем строится так, чтобы сделать диалогическое противостояние безысходным. С точки зрения безучастного «третьего» не строится ни один эмемент произведения. ${ }^{58}$ (Bachtin 2000, 24)

Die einem solchen Rückzug des übergeordneten auktorialen Bewusstseins, des nicht teilnehmenden „Dritten“, entsprechenden Erzählhaltungen bzw. „Erzählsituationen“ wären zum einen der äußere oder der innere Monolog erzählter Figuren, zum anderen die personale Erzählsituation, gemäß welcher die erzählte Welt in Bezug auf das Bewusstsein des Helden präsentiert wird. Der Autor tritt dabei in den Hintergrund, das Bewusstsein der erzählten Figuren dominiert in der fiktionalen Welt. Zumal dasselbe jedoch auch für die Gattung Drama gilt, muss der für Bachtin entscheidende Unterschied zwischen der Gattung Drama und dem polyphonen Roman undeutlich bleiben. Entweder impliziert die Polyphonie Dostoevskijs keine wirkliche Dialogizität, wie die Kritiker Bachtins meinen, oder Gattungen wie dem Drama muss eine solche „Dialogizität“ zugeschrieben werden.

\section{II.5. Eine Frage der Perspektive?}

Unter Rekurs auf die Dostoevskij-Interpretation von Albert Camus hält Freise (vgl. 1993, 278-281) die Figuren Dostoevskijs für Emanationen der inneren Konflikte des Autors selbst; was Dostoevskij beschäftigt habe, sei via Projektion in die erzählten Figuren eingegangen. Das oben (S. 69) gezeichnete allgemeine Schema soll mit den Tendenzen der Monologisierung bzw. Dialogisierung diese beiden Sichtweisen auf die Figur des Autors erfassen: einerseits ist ein Autor der einzelne monologische Sprecher, andererseits sieht er sich ähnlich wie jeder sozialisierte Mensch in dialogischer Auseinandersetzung unterschiedlichen Stimmen gegenüber, welche er als Autor in verschiedene fiktionale Figuren transformieren kann, ohne immer eine souverän transzendente und objektivierende Position einzunehmen.

Bachtins dichotomische Unterscheidung von monologischen und dialogischen Gattungen bzw. Poetiken hat wohl gerade aufgrund des Insistierens Bachtins die literaturwissenschaftliche Zunft beschäftigt, ihre Anwendung bei der Analyse von literarischen Werken lässt bald ihre Problematik deutlich werden. Aus rezeptionsästhetischer Perspektive lassen sich divergierende Meinungen über ein und dasselbe Werk erwarten; ob es eher als monologisch oder als dialogisch eingestuft werden

58 „Der Roman bietet nun für ein drittes monologisch umfassendes Bewusstsein überhaupt keinen festen Anhaltspunkt außerhalb des dialogischen Risses, im Gegenteil, alles in ihm ist so aufgebaut, dass die dialogische Gegenüberstellung keine Lösung findet. Kein einziges Element des Werks wird aus der Sicht eines teilnahmslosen Dritten geschaffen." 
könnte, hängt wohl auch davon ab, inwieweit die Person des realen Autors überhaupt berücksichtigt wird; denn dem abstrakten Autor als hypostasiertem Bedeutungsorganisator des Textes wird per definitionem eine Position zugeschrieben, die das Werk als Ganzes (und mit ihm die Figuren) transzendiert, und diese Position wäre mithin nicht anders als monologisch zu bezeichnen. Zumal aus produktionsästhetischer Sicht die Instanz des Autors einen größeren Stellenwert hat denn aus rezeptionsästhetischer, erscheinen die fiktionalen Figuren in Relation zu dieser vorgängigen Autorinstanz. Rezeptionsästhetisch steht das Werk im Zentrum der Aufmerksamkeit, folglich wird den Figuren eine größere Bedeutung zugemessen, was die Konturen der Abgrenzung von Monologizität und Dialogizität unscharf werden lässt. Man darf daher annehmen, dass Rezipienten dazu tendieren, Werke als dialogisch zu klassifizieren, weil sie Interaktionen von Figuren wahrnehmen und in diesen nicht sofort deutliche Dominanzverhältnisse konstatierbar sind (diese sind eher in folkloristischen bzw. trivialen Genres vorhanden). Werden aber produktionsästhetisch ideologische Positionen des Autors berücksichtigt, so ergeben sich aus dem Vergleich von literarischem Text und Lebenstext eher andere Kriterien für die Bestimmung des Verhältnisses von Autor und Figuren als monologisch oder dialogisch. Bachtins Unterscheidung von monologischem und dialogischem Schreiben und seine mit ihr verbundene Gattungstypologie, der zufolge das Drama so monologisch organisiert sei wie ein Großteil der Erzählprosa, scheint nicht distinktiv genug zu sein: konzentriert man sich in der Interpretation auf die Interaktion von Figuren, entsteht bald einmal der Eindruck von Dialogizität (auch beim Drama), berücksichtigt man die ideologische Position des Autors, werden viele Werke auch diejenigen Dostoevskijs - als monologisch erscheinen.

Der Unterschied zwischen dem polyphonen Roman Dostoevskijs und „monologischen" Konzeptionen ist wohl kein kategorischer, mithin wird freilich auch die von Bachtin mit Verve versuchte, aber nicht wirklich überzeugende Abgrenzung zwischen Dialogizität/Polyphonie einerseits und Monologizität andererseits hinfällig. ${ }^{59}$ Sie könnte überführt werden in eine Skala, welche die Komplexität literarischer Texte erfasst. Als Wertungskategorie ist Komplexität ja bereits in Bachtins Gegenüberstellung von Monologizität und Dialogizität impliziert; die dialogische Rede in der Prosa ist insofern komplizierter, als sie deutliche Spuren fremder Rede enthält. Zwar ist Komplexität gewiss ein problematischer Begriff, der auf keiner exakten Definition beruht und in Anbetracht der soziokulturellen Bedingungen von ästhetischer Kommunikation auch nicht hinreichend genau definiert werden kann. In Bezug auf die Gattung Drama kann jedoch auf textzentrierte Konzeptionen verwiesen werden, die einen Begriffsrahmen für eine typologische Beschreibung von

59 Bachtin (vgl. 1996, 314) selbst hat angedeutet, dass literarische Texte eo ipso dialogisch sind, die dichotomische Gegenüberstellung von monologischen und dialogischen Genres also nicht gut aufrechterhalten werden kann. 
Dramentexten aufspannen, etwa auf Klotz' (1969) Unterscheidung von „offener“ und „geschlossener" Form des Dramas. In deren Fortführung weist etwa Pfister darauf hin, dass ein Drama mit "geschlossener" Form als ideelles Ganzes konzipiert wird, dessen deduktives Grundprinzip die einzelne Szene dem Gesamtkonzept unterordnet, während die weniger schematische offene Form von der Szene ausgehend induktiv zu einer Gesamtbedeutung hinführt (vgl. Pfister 2001, 320-326). Die geschlossene Form mutet wohl deshalb als Entsprechung zu Bachtins Monologismus an, weil sie als Gesamtheit konzipiert ist und weil im Rezeptionsprozess die Fügung einzelner Elemente des Dramas in das Gesamtbild erfolgen soll, andernfalls die kompositionelle Einheit nicht erfahren wird: die offene Form - die Klotz offenbar in Anlehnung an Umberto Ecos erste große theoretische Schrift Opera aperta (1962) bestimmt hatte - entspricht nicht etwa einem lebensweltlichem Dialogismus, sie lässt aber den Rezipienten weitaus mehr Freiheiten in der Interpretation des Textes und der Herstellung von Bezügen im dramatischen Text.

\section{II.6. Die Position des Dritten als methodische Konsequenz aus Bachtins Polyphoniekonzept}

Beim unablässigen Versuch, die missverständliche, dabei aber umso stärker diskutierte Metapher der Dialogizität in Bezug auf literarische Texte zu präzisieren, hat Bachtin gleichwohl Bestimmungen vorgeschlagen, welche bei ihrer Übertragung auf die Wortkunst eine bessere Differenzierung von Gattungen erlauben. Solche sind meiner Ansicht nach der mit der Objektivierung einer erzählten Figur gleichgesetzte Begriff des „letzten Worts“ sowie der damit im Zusammenhang stehende, bereits oben kurz erwähnte Begriff des „Dritten“ bzw. des monologischen umrahmenden Bewusstseins. Bachtin legt in seiner Diskussion des „letzten Worts" darauf Wert, dass Aussagen über die erzählten Figuren in letzter Instanz nicht vom Autor bzw. Erzähler stammen, der damit kraft seiner erzähllogischen Dominanz eine definitive Bestimmung der Figur abgibt, sondern dass die erzählte Figur selbst über sich befindet. ${ }^{60}$ Wiederum ist dieses "letzte Wort" in Analogie zur Lebenswelt konzipiert; ein Subjekt hat dabei immer wieder die Freiheit, das über es Ausgesagte, in welchem es sich objektiviert sieht, zurückzuweisen und über den Haufen zu werfen. In der Erzählliteratur entspricht dem die Dominanz von Figuren- über Erzählerrede, dennoch meint Bachtin, dass es sich nicht um das kompositionelle Problem

$60 \ll$ «едь то, что Аолжно быть раскрыто и охарактеризовано, является не определенным бытием героя, не его твердым образом, но последним итогом его сознания и самосознания, в конце концов последним словом героя о себе самом и о своем мире.» (Bachtin 1963, 56f) „Das, was entdeckt und beschrieben werden soll, ist nicht etwa ein bestimmtes Sein der Figur, kein festes Bild, sondern die abschließende Bilanz ihres Bewusstseins und Selbstbewusstseins, letztendlich das letzte Wort der Figur über sich selbst und über ihre Welt." 
von Erzählerfiguren dreht: Ein Ich-Erzähler wie Grinëv in Kapitanskaja dočka sei keineswegs ein hinreichendes Indiz für das Fehlen eines monologischen objektivierenden Rahmens (vgl. Bachtin 2000, 67), die Figurenrede der Zapiski iz podpolja, in der sich die Rede des Erzählers/Autors auf die knappen Rahmenbemerkungen der Herausgeberfunktion reduziert, stelle hingegen eine Innovation dar, weil kein obraz, sondern die Rede (slovo) dargestellt werde.

Diese Differenzierung zwischen zwei Ich-Erzählern hat assertorischen Charakter, ist doch aus produktionslogischer Sicht die Figurenrede nur eine indirekte Form, eine Figur zu kreieren - anstelle einer definitiven objektiven Beschreibung „gewährt" der Autor Figurenrede. ${ }^{61}$ Der entscheidende Unterschied zwischen dem Ich-Erzähler Grinëv und Dostoevskijs Menschen aus dem Untergrund liegt auf einer anderen Ebene: Grinëv ist als homodiegetischer Erzähler auch zentraler Aktant in der Sujetentwicklung, während in den Zapiski iz podpolja ein Sujet nur mehr rudimentär vorhanden ist. In den Vordergrund rückt - und Bachtin wertet dies als kategorialen Unterschied - die Figurenrede, Erzählelemente erscheinen demgegenüber sekundär.

Betrachtet man diese narratologische Frage aus allgemeiner Perspektive, wird eine Erzählung durch personalisierte bzw. homodiegetische Erzählerfiguren komplexer: Gegenüber Figurenrede bzw. der Rede eines homodiegetischen Ich-Erzählers kann theoretisch immer wieder Zweifel erhoben werden, während indikativische Aussagen eines heterodiegetischen Erzählers „welterzeugend“ bzw. definitiv sind (vgl. Martinez/Scheffel 1999, 97). „Fictional texts can carry out the function of authentication precisely because they are exempt from truth-valuation; they are performative speech acts." (Doležel 1998, 146) Fiktionserzeugende Aussagen eines heterodiegetischen Erzählers werden gemeinhin nicht angezweifelt oder widerlegt - ein Grund dafür, dass in der Regel unzuverlässiges Erzählen nur homodiegetischen Erzählern "gestattet" ist (vgl. Jahn 1998, 83-85; dazu kritisch Deutschmann 2005, 37f).

Hinsichtlich dieser narrativ-ontologischen Unterschiede könnte man Bachtins Rede vom "letzten Wort" damit verdeutlichen, dass nur in einer heterodiegetischen Erzählung das „letzte Wort“ gesprochen werden kann, während eine homodiegetische Erzählung immer Unsicherheiten über die Wahrheitswerte der Aussage des Erzählers in Bezug auf die fiktionale Welt hat und somit ein definitiv „letztes“, vereindeutigendes Wort nicht erfolgen kann.

Überträgt man die bachtinsche Idee vom letzten Wort auf die Gattung Drama, so läge es aufgrund des Fehlens auktorialer Rede bzw. deren Beschränkung auf den

61 «Он [автор] строит героя не из чужих Аля него слов, не из нейтральных определений, он строит не характер, не тип, не темперамент, вообще не объектный образ героя, а именно слово героя о себе самом и о своем мире» (Bachtin 2000, 63). „Er [der Autor] schafft die Figur nicht aus Worten, die dieser fremd sind, nicht aus neutralen Attributen, er schafft keinen Charakter, keinen Typus, kein Temperament, überhaupt kein objektiviertes Bild der Figur, sondern vielmehr das Wort der Figur über sich selbst und über ihre Welt." 
Nebentext nahe zu meinen, dass die Figuren im Drama das „letzte Wort“ haben, weil infratextuell keine ontologisch übergeordnete Instanz - andere Figuren sind ja gleichrangig (Sonderformen wie das „epische Theater" stellen diesbezüglich freilich eine Ausnahme dar) - diese mit einer definitiven Bestimmung objektiviert. Es obliege allein den extratextuellen Instanzen Autor/Leser/Publikum, ein Urteil über die Figuren zu fällen. Bachtins Pointe besteht aber darin, dass er im Fall der Beurteilung der Figur durch diese transzendenten Instanzen vom Monologizität spricht: das letzte Wort habe eben nicht die Figur, sondern Autor/Leser/Publikum, aufgrund von deren Transzendenz habe die Figur nicht die Möglichkeit, gegen dieses „letzte Wort“"Einspruch zu erheben (vgl. Bachtin 2000, 82f).

Erneut tritt hier Bachtins Kategorienfehler zu Tage, dessen Grund eben in der Übertragung intersubjektiver Verhältnisse der Lebenswelt auf den Bereich der Kunst liegt, in welchem es nun einmal logische Dependenzverhältnisse zwischen Autor/Leser und Werk bzw. Autor/Leser und Figur gibt, die nur unter Verlusten als ein dialogisches Verhältnis begriffen werden können. In diesem Dependenzverhältnis sind die Figuren - im Drama wie im Roman - Kreationen des Autors und sie können immer von einer Metaposition aus betrachtet und bewertet werden. Auch der Mensch aus dem Untergrund kann sich nicht kritisch zu den Objektivierungen äußern, welche die Interpretationsgemeinschaft an ihm vornimmt.

Bachtin scheint sich immerhin der Schwierigkeiten bewusst zu sein, die mit seiner Differenzierung des "großen Dialogs“ bei Dostoevskij von der Monologizität - Tolstoj fungiert bei Bachtin bekanntlich als Kontrastfolie zu Dostoevskij - verbunden sind und erklärt einen Sinnüberschuss (smyslovoj izbytok, vgl. Bachtin 2000, 83-88) der Autorposition gegenüber den Helden als für eine monologische Position kennzeichnend. Bei Dostoevskij gäbe es einen solchen Überschuss bzw. eine solche Privilegierung einer die Welt der Helden transzendierenden Position nicht, verschiedene mögliche Objektivierungen wären schon im Bewusstsein der Figuren selbst vorhanden. Dass in der „Bewusstseinsprosa“ Dostoevskijs eine derartige Massierung und wechselseitige Spiegelung von ideologischen Positionen festzustellen ist, sei hier nicht in Abrede gestellt. Hingegen wäre aber zu fragen, ob dieser quantitative Aspekt in eine spezifische Qualität umschlägt und somit den Roman als Gattung von anderen Gattungen unterschieden macht und ob dies insbesondere für die Romane Dostoevskijs charakteristisch ist. Unverständlich erscheint überhaupt Bachtins Auffassung, dass bei einem "großen Dialog" keine Metaposition von Autor/Leser mehr möglich sei, eine solche ist schlicht eine erzähllogische Gegebenheit: über Figuren von Dostoevskij urteilen die Rezipienten in keinem anderen Modus als über Figuren aus einem Theaterstück, und sei dieses von Tolstoj.

Bachtins Rede vom smyslovoj izbytok könnte narratologisch präziser gefasst werden als authentication (Beglaubigung) von Aussagen. Diese steht mit der Erzählerfigur in engerem Zusammenhang: Wie oben gezeigt wurde, werden Aussagen eines heterodiegetischen Erzählers in der Regel nicht auf ihre Wahrheitswerte für 
die fiktionale Welt befragt; sie gelten vielmehr als für diese notwendig wahr. Anders ist dies bei Aussagen eines homodiegetischen Erzählers, die auch falsch sein können (was sich etwa durch Kontrastierung mit anderen Aussagen oder durch Ungereimtheiten erweist). Angesichts eines homodiegetischen Erzählers können immer leise Zweifel erhoben werden, was auch die Ähnlichkeit zum lebensweltlichen Erzählen ausmacht: bei diesem sind ja immer Zweifel möglich und es kommt niemals zu einer absoluten Gewissheit des Gegenübers in Bezug auf das Erzählte/Ausgesagte und auf das sprechende Subjekt. Angesichts der énoncé des Erzählers wird man immer zweifeln können; dieser selbst hat die Möglichkeit, jede Objektivierung, die über ihn gemacht wird, zurückzuweisen.

Und bei der Transponierung dieser erzähltheoretischen Überlegung auf das Drama wird nun die von Bachtin behauptete Differenzierung etwas klarer: Zwar fehlt im Drama die transzendente Vermittlungsinstanz, zwar sprechen die dramatis personae so „unmittelbar“ wie nur Ich-Erzähler, insgesamt aber heißt dies nun nicht, dass das Publikum angesichts dramatischer Rede und Handelns in fundamentalem Zweifel verharren muss: Vielmehr ist es ihm durchaus möglich, eine kohärente und „richtige“ Version des Geschehens zu erstellen, die beglaubigt werden kann und über die es wenig Zweifel gibt. Dies impliziert zugleich, dass es wenig Auffassungsunterschiede über die vorgeführte Welt gibt, sondern dass das Publikum konform gehen kann in seiner Interpretation des Stücks: von der dramatischen Repräsentation wird es zur Univozität provoziert (was wohl Bachtins Rede von monologičeskaja oprava entspricht). ${ }^{62} 63$

62 Dies gilt natürlich nicht pauschal für die gesamte dramatische Gattung, sondern vor allem für das traditionelle „Wort-Drama“, auf dessen Techniken der "Wahrheits“-Offenbarung Herta Schmid hingewiesen hat. Die Univozität gilt wohl nicht mehr für das moderne Drama, das Schmid Ding-Drama nennt, weil die wahrheitsoffenbarende Rede verschwindet und die dramatis personae damit anderen Elementen des Dramen- bzw. Theatertextes äquivalent werden.

63 In diesem Zusammenhang muss doch auf den Unterschied von Dramentext und Inszenierungstext verwiesen werden (letzterer ist wie gesagt nicht Thema dieser Arbeit): Es handelt sich meinem Dafürhalten nach um zwei unterschiedliche Texte, wobei der Inszenierungsbzw. Aufführungstext auf dem Dramentext basiert. Nun könnte man einwenden, dass gerade dieser Umstand ein Argument gegen die behauptete Tendenz zur Univozität und Eindeutigkeit nahe legt: zumal von den Bühnenklassikern gebe es durch die wiederholten Inszenierungen immer wieder neue Interpretationen, keinesfalls aber Univozität in Bezug auf die Ereignisse in der repräsentierten Welt. Die Differenz der unterschiedlichen Inszenierungstexte gebe ich gerne zu, es wäre absurd, zu meinen, dass alle Inszenierungen im Wesentlichen gleich sind. Doch sei auf zwei Dinge hingewiesen: Zum einen kann man angesichts jeder Inszenierung von einem Appell zur Univozität sprechen (das Publikum einer bestimmten Inszenierung wird über viele repräsentierte Sachverhalte gleicher Auffassung sein), zum anderen aber gründet die Differenz oft in Veränderungen, die Regisseure und Dramaturgen am Dramentext selbst vornehmen (und damit gleichsam einen neuen Text schaffen). Man könnte hier von unterschiedlichen Phänotexten ein und desselben Genotextes sprechen: angesichts des 
Gemäß dieser monologischen Rahmung bringen Autoren eine Welt hervor, welche von den dramatis personae "bewohnt" wird, deren Interaktion ihrerseits wiederum verschiedene Sprechhandlungen einschließt. Dies sind freilich Sprechhandlungen zweiter Ordnung gegenüber der fundierenden, welt-konstruierenden Sprechhandlung des Autors. ${ }^{64}$ Die semantischen bzw. ontologischen Unterschiede zwischen den beiden Redeformen im dramatischen Text lassen sich in Anlehnung an das narratologische Modell (vgl. Doležel 1998, 149) wie folgt definieren: Entitäten der fiktionalen Welt, die in den Nebentexten eingeführt werden, sind eo ipso als fiktionale Fakten beglaubigt [,authenticated“ in Doležels Worten], diejenigen Entitäten, die von den Sprechhandlungen der Figuren eingeführt werden, sind nicht selbstverständlich fiktionale Fakten. Dies bedeutet im Detail Folgendes:

1. Die dargestellten Sachverhalte und Vorgänge in der Welt des Textes bzw. innerhalb der Konvention des Bühnenraums sind „nicht negierbar", innerhalb des Rahmens der Konvention stellen sie Fakten dar und können in diesem Sinn natürlich nur in Bezug auf die dargestellte Welt - als „real“ begriffen werden. Um unnötige Komplikationen zu vermeiden, wird in der Folge jedoch nicht von „realer Handlung“, „realem Geschehen“, „realen“ oder „tatsächlichen“ Zuständen usw. gesprochen, wenn es sich um Ereignisse der in Dramen repräsentierten Welt handelt, sondern präziser von „repräsentierten“ Handlungen, Ereignissen oder Zuständen. Im Terminus „Repräsentation“ ist jenes Moment der Unmittelbarkeit enthalten, das für die dramatische Wirkung ja so entscheidend ist. Die Diskussion dieser in künstlerischer Literatur repräsentierten Ereignisse steht im Vordergrund der Arbeit; wenn hingegen im Vergleich zur künstlerischen Repräsentation auf Ereignisse bzw. Personen Bezug genommen wird, die von der historischen Forschung thematisiert werden, lautet zur Unterscheidung das Attribut entsprechend „historisch“, „historisch belegt" oder ähnlich. ${ }^{65}$

2. Die Sprechhandlungen der Figuren - in den meisten Dramentexten immerhin der Großteil des vom Autor verfassten Textes - sind als Handlungen einerseits „repräsentierte“ Ereignisse, der propositionale Gehalt der Aussagen der Figuren

Letzteren gibt es hinsichtlich der repräsentierten Ereignisse - die auch nacherzählbar sind Univozität.

64 Die diversen Nebentexte des Dramas sind diese Performative, die die fiktionale Welt erster Ordnung hervorbringen, die aufgrund des ihr meist eigenen Charakters der Unmittelbarkeit als „real“ erscheint. Die Sprechakte der Charaktere dieser Welt können so verschieden sein wie die Sprechakte in der außertextuellen Welt, sollte etwa ein Performativ darunter sein (etwa: „Hiermit übergebe ich die Königswürde an meinen Sohn und Nachfolger“, geäußert von einem König in der fiktionalen Welt), so unterscheidet sich dieses kategorisch von dem Performativ erster Ordnung (den Nebentexten des realen Autors).

65 Insofern es sich um die Gattung historisches Drama handelt, hätte deren Qualifizierung als „fiktional“ allzu unhistorische Konnotationen, wenngleich „fiktional“ als Attribut besser anzeigt, dass es sich um vom Dramatiker konstruierte Welten handelt. 
ist aber andererseits keineswegs immer „wahr“ (auf die gleiche Weise „notwendig wahr" wie die Propositionen des Nebentextes, die eindeutige Ereignisse des Textes beschreiben). Zum einen transportieren die Reden referenzielle Sachverhaltsdarstellungen, deren propositionaler Gehalt wahr ist, weil er „Fakten“ über die fiktionale Welt berichtet (Paradebeispiel ist dafür der „Botenbericht“, in dem tatsächliche bzw. „wahre" Ereignisse der „Welt des Textes“ referiert werden), zum anderen sind andere als die referenzielle Sprachfunktion in den Reden enthalten, die Aussagen sind damit eher figurenbezogen als weltbezogen: Die Sprachhandlungen der Figuren konturieren in diesem Fall die Figuren selbst, verleihen ihnen ein „ideologisches“ Profil. ${ }^{66}$ Aus der Warte des „Dritten“ kommt den Sprechhandlungen eine andere Bedeutung zu als in Bezug auf die illokutive Absicht der sprechenden Figur: wenn etwa eine Figur eine andere zu täuschen versucht, muss das Publikum diese Täuschung entsprechend erkennen und bewerten (ist die Täuschung gerechtfertigt, eine nötige List, ein verwerflicher Betrug etc.?). Gegenüber dem dramatischen Konflikt, der zwischen den „ideologisch“ heterogenen Figuren entsteht und sich mittels der Sprechhandlungen entwickelt, nehmen Leser/Publikum als „Dritte“ eine Metaposition ein, die die reflektierte Betrachtung der Handlungen und Sprechakte voraussetzt, um in eine bestimmte Hypothese über die Kommunikationsabsicht des dramatischen Autors zu führen.

3. Da nun zumindest im "Wortdrama“ (nach H. Schmid) in der Figurenrede nicht einfach zwischen dem referenziellen Bezug auf die repräsentierte Welt und anderen Sprachfunktionen unterschieden werden kann, weil in den Sprechhandlungen Sprache, Person und Welt eng miteinander verschränkt sind, kann aus der Perspektive des Dritten, aus welcher bzw. für welche Bachtin zufolge diese Wortdramen geschrieben sind, eine reduzierende Abstraktion der Handlungsebene vorgenommen werden. Denn gerade die Subjektgebundenheit der Handlungen (verbaler Handlungen und res gestae), die sich auf Ebene des Sujets in der Interaktion vieler unterschiedlicher Subjekte entfaltet, soll sich letztendlich auf der Metaebene des Dritten als „monolithische“ Handlungseinheit erweisen. Und diese Handlungseinheit ist hinsichtlich ihrer chronologisch-kausalen bzw. handlungsfunktionalen Verkettung analysierbar.

So etwa spricht Pfister von drei idealtypischen Modellen einer Perspektivenstruktur, welche die Rezipientenhaltung zur Dramenhandlung beeinflusst (Pfister 2001, 100-103): Bei der geschlossenen Perspektivenstruktur, der praktisch alle hier analysierten Dramen entsprechen, soll die vom Autor intendierte Rezeptionsperspektive

66 Das (sozio-)linguistische Profil der handelnden Personen hingegen ist in der historischen Perspektive weniger ausgeprägt: Man bedenke die Stilkonventionen des klassischen Dramas, von denen sich allmählich die „Realismus“-Tendenzen unter der Losung der vraisemblance bzw. der situations- und charakteradäquaten Rede emanzipierten. 
aus dem inneren Kommunikationssystem (bzw. dem fiktionsimmanenten Handeln der Figuren) eines Theatertextes hervorgehen, ohne dass eine Figur die intendierte Perspektive proklamiert. Diese intendierte Rezeptionsperspektive soll im äußeren Kommunikationssystem (zwischen Autor und Publikum) vermittelt werden; sie kommt der Beurteilung einer dramatischen Handlung bzw. von deren Aktanten/ Komponenten durch Autor/Leser gleich. Aus Bachtins Sicht handelt es sich dabei wie gesagt um eine monologisch-monolithische Position, da die Perspektive von Autor/Publikum diejenige der Figuren übersteigt und diese in der dramatischen Handlung zu bloßen Funktionen einer transzendenten ideologischen Einstellung macht.

[...] Арама по природе своей чужда подиинной полифонии; драма может быть многопцанной, но не может быть многомирной, она допускает только одну, а не несколько систем отсчёта. ${ }^{67}$ (Bachtin 2000, 43)

Diese auf einem Bezugssystem (systema otsč̈ta) beruhende transzendente ideologische Einstellung ist derjenige Punkt, auf welchen die Dramenanalysen in dieser Arbeit zustreben. Es ist die Position des „Dritten“, die der dialogischen Gegenüberstellung zweier Subjekte (bzw. eines „Ich“ und eines „Du“) übergeordnet ist (vgl. H. Schmid 1992, 48). Insofern Dramen einen Weltausschnitt repräsentieren, soll in der vorliegenden Arbeit dieser Weltausschnitt darauf hin betrachtet werden, welchen Standpunkt sein Autor zu ihm einnimmt und wie dieser Standpunkt mit dem historischen Kontext des Autors vermittelt werden könnte. Die Relevanz von Bachtin in dieser Arbeit besteht also darin, dass er auf jene übergeordnete Instanz des Dritten hingewiesen und sie vor allem als für das Drama und den monologischen Roman charakteristisch reklamiert hat. Im Unterschied zu Bachtin allerdings bin ich der Auffassung, dass diese Instanz im Prinzip jedem Text - also auch jeder literarischen Gattung, den polyphonen Roman eingeschlossen - zugeordnet werden kann, weil sie sowohl produktionslogisch vorausgesetzt - ein Autor gestaltet mehr oder weniger komplexe Texte - wie auch rezeptionsästhetischer Bezugspunkt ist: Rezipienten bilden über dem Text sowie aufgrund von Vorstellungen vom Autor verschiedene Hypothesen über die Mitteilungsabsicht bzw. sie objektivieren und reduzieren in ihrer Interpretation Aussagen von Figuren auf eine bestimmte Bedeutung. Im „Wortdrama“ - das für das Korpus dieser Arbeit charakteristisch ist - soll sich eine solche Objektivation mit der intendierten Rezeptionsperspektive treffen, im Drama mit offener Perspektivenstruktur (vgl. Pfister 2001, 102f) sowie in stärker auf Dialogizität hin ausgerichteten Erzähltexten kann es mehrere

67 „[...] dem Drama ist seiner Natur nach eine echte Polyphonie fremd; das Drama kann vielschichtig sein, es kann aber nicht mehrere Welten erfassen, es lässt nur ein einziges, nicht aber mehrere Bezugssysteme zu.“ 
unterschiedliche Auffassungen von den erzählten Sachverhalten bzw. den erzählten Figuren geben, ohne dass eine bestimmte Auffassung größere Plausibilität für sich reklamieren kann.

\section{II.7. Theoretische Bestimmung des Analysestandpunktes}

Wenn nun dieser Standpunkt des „Dritten“ bestimmt werden soll, der von den Autoren historischer Dramen mit geschlossener Perspektivenstruktur eingenommen bzw. als impliziter Adressat imaginiert wird, so ergeben sich daraus Implikationen für das methodische Vorgehen dieser Arbeit: Ausgangspunkt und Zentrum der Analyse sind die Dramentexte, die in einem ersten Schritt ausgewählt werden. Aus ihnen sollte auf möglichst plausible Weise eine ideologische Interpretation extrapoliert werden, die gleichsam dem monologischen Blick des Autors qua Drittem auf die im Stück entwickelte Problematik entspricht. Sodann werden die ideologischen Interpretationen auf die historischen Zeitumstände der Autoren bezogen, um die Aktualität von historischen Dramen, d.h. ihre Referenz auf ihre Entstehungszeit, untersuchen zu können, die den De- bzw. Repräsentationsfunktionen der Gattung entspricht.

Dieses knapp formulierte methodologische Programm bedarf eines erweiterten Kommentars. Die im ersten Schritt unternommene Textauswahl erfolgt vorwiegend nach dem Gesichtspunkt der Vergleichbarkeit von Dramentexten sowie nach dem Gesichtspunkt von deren erwartetem zeitaktuellen Bezug. Literaturhistorische Bewertungen, rezeptionsgeschichtliche Aspekte sowie die hier nicht diskutierte Frage ästhetischen Gelingens spielen dabei nur eine untergeordnete Rolle. Die Vergleichbarkeit von historischen Dramen ist vorwiegend unter zweierlei Aspekt von Interesse. Einerseits gibt es aufgrund eines gemeinsamen Stoffs, eines gemeinsamen Sujets Vergleichbarkeit auf thematischer Ebene, an der recht deutlich Unterschiede zwischen einzelnen Versionen eines Stoffes deutlich werden. Andererseits können Stoffe, die verschiedene historische Ereignisse behandeln, auf ideologischer Ebene vergleichbar sein, in solchen Fällen ist aber eine größere Abstraktion vom jeweiligen Dramensujet erforderlich.

Wenngleich die Berücksichtigung historischer Zeitumstände erst nach ideologischer Interpretation der Dramen erfolgen soll, ist sie in eingeschränktem Maß auch schon bei der Stückauswahl relevant, denn die von Lukács behauptete Affinität der Gattung Drama zu gesellschaftlichen Umbruchsituationen lässt erwarten, dass historische Dramen, deren Entstehungszeit um historische „Großereignisse“ liegt, besonders deutliche zeitaktuelle Spuren haben werden. In diesem Vorgriff auf mögliche Ergebnisse ein methodisches Problem zu sehen, wäre übertrieben, zumal ja erst die Textanalyse die wichtigsten Anhaltspunkte für die historische Verortung der Dramen liefert.

Die für die ideologische Interpretation der Dramen fundierende Analyse erfolgt in Anlehnung an die von Hayden White postulierten Strata der Historiographie. 
Wie oben (S. 45) gezeigt wurde, repräsentiert das Geschichtsdrama Pseudo-Ereignisse, über die die Strata Chronik, Fabel, Erklärung errichtet werden können. Die Chronik-Ebene bildet zwar den Hintergrund der Analyse, da sie aber nur protokollartig die Ereignisse in den einzelnen Szenen festhält, geht sie nicht explizit in den Text dieser Arbeit ein. Sehr wohl aber ist die auf der Chronik-Ebene aufbauende Fabel-Ebene im Text ausgeführt, weil sie die Grundlage der ideologischen Analyse darstellt. Die Darstellung der repräsentierten Ereignisse als Fabel gibt nicht allein einen überschaubaren Überblick über die Dramen (zumal die meisten hier analysierten Dramen wenig bekannt sind, ist freilich auch dieser Aspekt von praktischem Nutzen), die nacherzählte bzw. „episierte“ Fabel ist diejenige Ebene, die von Autor bzw. (Lese-)Publikum als gemeinsamer Hintergrund aller Figuren und ihrer Handlungen anzusehen ist. Die Fabelebene verschafft dem Drama jene Monolithhaftigkeit, von der Bachtin im obigen Zitat (S. 71) gesprochen hat. Sie bietet sich dem Blick des Dritten als überschaubar dar.

Dass die hier skizzierte Methode auf das Bewusstsein des abstrakten, keinesfalls des realen historischen Autors abzielt, mag aus dem bisher Ausgeführten im obigen Abschnitt deutlich geworden sein, wo die zentrale Rolle des literarischen Textes betont wird. Die Untersuchungsrichtung - vom künstlerischen (fiktionalen) Text zur historischen Wirklichkeit seiner Entstehung - nimmt die einzelnen Texte eines literarischen Genres zum Ausgangspunkt, um von deren Interpretationen aus Schnittpunkte mit historiographischen Texten - der allgemeinen Geschichtsoder der Literaturgeschichtsschreibung im engeren Sinn - zu bestimmen. Somit wird im günstigsten Fall eine vergleichende Betrachtung zwischen den Resultaten dieser Interpretationsarbeit und den bestehenden literaturgeschichtlichen Texten möglich, zumindest wird aber die Gefahr vermieden, rein deduktiv vom aktuellen Forschungsstand der (Literatur-)Geschichtsschreibung auch die Gattung des historischen Dramas zu erfassen. Per analogiam zu verfahren, hieße nichts anderes, als dass man etablierte literaturhistorische Meinungen über Epochen und Perioden auf das historische Drama überträgt, zumal diese Subgattung noch nicht entsprechend aufgearbeitet wurde. Zwar sollen die etablierten Meinungen hier nicht gleich pauschal verworfen werden, die stärker induktive Richtung dieser Arbeit soll aber zumindest potenziell die Möglichkeit bieten, geläufige Auffassungen von der Literatur einer Epoche als Folie zu betrachten, von der sich die Einzeltexte auch abheben können. Zugleich wird damit auch der spezifischen gattungsimmanenten (Pseudo-) Polyphonie des Dramas Rechnung getragen, welche ja immer mehrere Figuren und Standpunkte vorführt und dem Leser eine Beurteilung dieser Vielstimmigkeit auferlegt. Erinnert sei in diesem Zusammenhang an das obige Schema (S. 69), welches einerseits die reale Vielstimmigkeit der Welt und die reale Einstimmigkeit des Dritten (eines Autor- bzw. Lesersubjekts) mit fiktionaler Vielstimmigkeit andererseits zu vermitteln sucht, aber keine binäre Alternative zwischen Dialogizität und Monologizität als Resultat der Textinterpretation anstrebt. Würde man die Dramen- 
analyse deduktiv im Ausgang vom bestehenden Forschungsstand zu Epochen bzw. Autoren betreiben, entspräche dies einer Applikation von etablierten Meinungen auf die analysierten Dramen. Dass sich aus der Spannung von allgemeinem Forschungstand und konkreten Einzeltexten Modifikationen des Forschungsstandes ergeben können, ist zwar durchaus möglich, die fiktionale Vielstimmigkeit des Dramas gestattet aber darüber hinaus die Berücksichtigung von Aspekten, welche mit der Übernahme etablierter Meinungen von einer Epoche und deren Literatur oft ausgeblendet bleiben.

\section{II.8. Die Positionen des Dritten}

Das äußere Kommunikationssystem des Dramas ist dem inneren übergeordnet, demnach können wie gesagt die Positionen des Autors bzw. des Publikums als Positionen eines Dritten relativ zum inneren Kommunikationssystem angesehen werden. Hier von einem Dritten in Bezug auf die handelnden Personen zu sprechen, ist insofern berechtigt, als die Aussagen der dramatis personae aussagenlogisch untergeordnet sind, also nicht als direkte Aussagen des Autors aufgefasst werden dürfen; erst im Zusammenhang mit dem Stückganzen, das Leser/Publikum berücksichtigen, nehmen sie Bedeutung an. ${ }^{68}$ Die einzelnen Repliken und Elemente des Dramentextes beziehen sich auf diese Instanz, die im Text selbst eben nicht direkt gegeben ist.

Die Position des Autors und des Publikums/der Leser sind zwar beide Positionen des Dritten, freilich sind sie nicht identisch: Die Mitteilungsabsicht des Autors unterscheidet sich zwangsläufig von den diversen Rezeptionsleistungen von Lesern/ Publikum. Das Drama als „Kommunikat“ dieses äußeren Kommunikationssystems verbindet die Positionen von Autor und Leser/Publikum; jede Interpretation eines Dramas kann in eine Hypothese über das „Autorbewusstsein im Text“ münden, die textbasiert die hypothetische Frage nach der Mitteilungsabsicht/der Intention des Autors ist. Diese Hypothese produziert den Autor als Dritten damit, dass sie eine bestimmte Bedeutung des Dramas und eine bestimmte Mitteilungsabsicht produziert. Umgekehrt kann produktionsästhetisch postuliert werden, dass mit der Wahl dieser dramatischen Subgattung nicht allein ein größeres, kollektiv versammeltes Publikum (wie beim Medium Theater generell), sondern die „Nation“ schlechthin adressiert wird, also ein Dritter als Kollektivsubjekt, dem mittels der dramatischen Kommunikation eine literarisch komplexe Mitteilung über seine Geschichte bzw. seine Politik gemacht wird. De facto werden freilich nicht alle Mitglieder dieser

68 Erinnert sei in diesem Zusammenhang an Szondis apodiktisch-blumige Formulierung: „Die gleiche Absolutheit weist das Drama dem Zuschauer gegenüber auf. Sowenig die dramatische Replik Aussage des Autors ist, sowenig ist sie Anrede an den Zuschauer. Dieser wohnt vielmehr der dramatischen Aussprache bei: schweigend, mit zurückgebundenen Händen, gelähmt vom Eindruck einer zweiten Welt." (Szondi 1978, 17) 
„Nation" erreicht, sondern meist nur Vertreter der bildungsbürgerlichen Schicht, die sich für Drama und Theater interessieren.

Diese soziopolitischen, kommunikativen Aspekte der Gattung gelten für jedes einzelne Drama, mithin ist es für seine Analyse gleichgültig, ob ein historisches Drama inszeniert wird und also ein Publikum erreicht oder ob es ein Lesedrama bleibt: das historische Drama als Gattung ist eine Kommunikation mit dem Dritten als Sprachnation.

Der Begriff des Dritten kommt im vorgehenden Absatz in drei Zusammenhängen vor, die noch einmal differenziert werden müssen, um unnötige Verwirrungen zu vermeiden: erstens ist der Autor als Schöpfer des Dramas den geschaffenen Figuren übergeordnet. Dass der Autor Dritter in Relation zu den dramatis personae ist, hängt zweitens rezeptionsseitig mit den Interpretationsleistungen des Publikums zusammen. Aus dem Text des Dramas, aus der Interaktion der Figuren im inneren Kommunikationssystem, entsteht eine Hypothese über die Mitteilungsabsicht des Autors bzw. eine Hypothese über seine ideologische Position, die sich aus dem Werk ergibt. Insofern entspricht der Dritte in diesem Sinn dem narratologischen „Autorbewusstsein im Text“ bzw. dem „abstrakten Autor“, er ist nicht mehr (und nicht weniger) als Funktion jedes Rezeptions- bzw. Sinnbildungsaktes durch Leser/ Publikum.

Und drittens ist ein historisches Drama für bestimmte intendierte Adressaten geschrieben; darüber hinaus tangiert es aber ein wesentlich größeres Publikum: in der attischen Tragödie betraf das Drama beispielsweise die Polis, in der in dieser Arbeit thematisierten Epoche etwa die Nation als imagined community (Anderson 2005). Letztere ist schon dadurch angesprochen, dass das historische Drama bevorzugt Stoffe aus der Geschichte der jeweiligen Nation wählt, womit so etwas wie ein metonymisches Verhältnis zwischen der repräsentierten Handlung und dem zeitgenössischen Publikum - die dargestellten Vorgänge sollen vom Publikum als dem aktuellen Zustand zeitlich vorausgehende gesehen werden - hergestellt wird.

\section{II.9. Was beobachtet das (Lese-)Publikum?}

Als Mischform bzw. „hybride Gattung“ besetzt das historische Drama die Schwelle zwischen der Sphäre der Fiktion und der Sphäre der Wirklichkeit, da es produktions- wie rezeptionsästhetisch mit der historischen Wirklichkeit in Verbindung gebracht wird. Eine Unterscheidung zwischen „world-constructing-texts“ und „world-imaging-texts" (vgl. Doležel 1998, 24-28), also zwischen Fiktion und Wirklichkeitsdarstellung ist beim historischen Drama keineswegs einfach. Es sinnt zwar auf „world-imaging" (und wird entsprechend rezipiert), aber häufig sind in viele historische Dramen fiktionale Elemente - frei Erfundenes (Personen, Ereignisse) - integriert. Dieser besonderen Stellung im „Gattungssystem“ verdanken sich zwei wichtige Möglichkeiten des historischen Dramas: Zum einen wird so 
die „Beobachtung“ von geschichtlichen Vorgängen (in ihrem jeweiligen Werden) möglich, zum anderen aber haben die dargestellten Vorgänge einen stärkeren Bezug zum Publikum als bloß fiktive Stoffe: die Beobachtungsposition, die schon in der Antike mit dem in der Katharsis kulminierenden Miterleben verknüpft ist, wird auf geschichtliche Vorgänge ausgerichtet, repräsentierte Vorgänge der Geschichte und die Beobachtung von komplexem Handeln konvergieren, wofür man eventuell auch Begriffe wie Simulation oder virtuelle Realität finden könnte, die allerdings allzu starke Konnotationen mit stärker technikgestützten Medien haben und insofern für die Gattung Drama - noch dazu in seiner Textform, auf die in dieser Arbeit der Fokus gerichtet ist - etwas überzogen wirken würden.

Dass die Verbindung von innerem und äußerem Kommunikationssystem eine für das Medium Theater/Drama und andere mimetische Medien charakteristische Form der Beobachtung impliziert, hat Peter Fuchs in einer systemtheoretischen Skizze über Theater und Drama zu zeigen versucht. Kulturgeschichtlicher Anstoß zu dieser Beschäftigung ist die Vermutung, dass die verstärkte Emergenz von Drama und Theater in der Frühen Neuzeit, die auf die eher spärlichen mittelalterlichen Theaterformen wie Fasnachts- oder Passionsspiele folgt, in einem synchronen $\mathrm{Zu}-$ sammenhang stehen könnte: Für das Mittelalter gab es eine einfache, christlich fundierte Ordnung, die nicht weiter hinterfragt wurde und zu der keine Alternativen ernsthaft erwogen wurden. Gewissermaßen „beobachteten“ die Menschen des Mittelalters auf einfache Weise; sie unterschieden und bezeichneten die „Welt“ bzw. die Entitäten und Ereignisse in dieser. Die systemtheoretische Vorstellung von Beobachtung als „Unterscheidung-mit-Bezeichnung“ (Fuchs 1992a, 55) geht davon aus, dass sich diese Beobachtung selbst nicht beobachten kann; es bleibt immer ein blinder Fleck, erst eine „Beobachtung zweiter Ordnung“ kann die Beobachtung erster Ordnung thematisieren:

[Werden ...] Beobachter beobachtet und wird beobachtet, daß die so entstehende Welt den Beobachter so einschließt, daß auch er beobachtet werden kann, dann liegen die Dinge vielfach, dann ist die Welt polykontextural, genau dann wird die Vorstellung eines Meta-Beobachters (der ein unbeobachteter Beobachter wäre) obsolet. (Fuchs 1992a, 57)

Fuchs legt mit seinen Überlegungen zum Theater nahe, dass dessen Boom in der Renaissance mit der Reflexion über Beobachtung zusammenhängt, damit, dass die Welt "polykontextural“ geworden ist und die „Beobachtungen“ auf der Basis des transzendenten christlichen Sinnsystems ihren Monopolcharakter verloren haben (vgl. Fuchs 1992a, 43-64).

Fuchs erklärt die medial repräsentierten Formen von Figureninteraktion und -kommunikation zu Pseudo-Kommunikation: „Echte“ Kommunikation beruht nicht auf einem „fixiertem Gedächtnis“ (einem Prä-Skript, einem vorgegebenen Text), sie ist vielmehr „doppelt kontingent" und stellt für die Kommunikations- 
teilnehmer („Beobachter erster Ordnung“) eine besondere Herausforderung dar: gemeint ist mit doppelter Kontingenz bei „echter", nicht theatralischer Kommunikation, dass sowohl die „Mitteilung“ (dass überhaupt gesprochen/geschrieben wird etc.) wie auch die „Information“ (das Mitgeteilte selbst) Selektionen aus Möglichkeiten sind und beim „Verstehen“ durch den „Beobachter erster Ordnung“ aufeinander bezogen werden müssen. Was Fuchs in getreuer Anwendung des von Niklas Luhmann vertretenen systemtheoretischen Kommunikationsmodells „Information" und „Mitteilung" nennt (vgl. Fuchs 1992b, 113 u. 117), entspricht in der Sprechakttheorie den Begriffen „propositionaler Gehalt“ bzw. „wörtliche Semantik“ einerseits und „Illokution“ andererseits. Auf den Satz „Ich bin verkühlt“ kann in der einen Situation z.B. mit dem Schließen des Fensters, in der anderen mit Erkundigungen über den Grund der Verkühlung reagiert werden: Der propositionale Gehalt des Satzes, seine semantische Information ist in beiden Fällen dieselbe, die Mitteilung bzw. Illokution ist eine andere, im einen Fall eine (indirekte) Bitte, das Fenster zu schließen, im anderen etwa die Bemühung darum, Aufmerksamkeit oder Mitleid hervorzurufen. Das Verstehen/die Perlokution ist in beiden Fällen verschieden, einmal wird mit dem Schließen des Fensters, das andere Mal mit Rückfragen zum Gesundheitszustand etc. reagiert. Der Hörer als „Beobachter erster Ordnung“ vergleicht den propositionalen Gehalt der Äußerung und die "Mitteilung" (die in die Situation „eingelassen“ ist) und er reagiert je verschieden. Die Verbindung von „Mitteilung“" „Information“ und „Verstehen“ ist keineswegs starr, sie lässt unterschiedliche Verlaufsformen der Kommunikation zu (vgl. Fuchs 1992a, 26-33).

Dramatische Repliken sind aber bereits vorgegeben und in der Regel nicht offen für alternative Handlungen/Reaktionen. Die dramatische Kommunikation ist insofern Illusion oder Simulation von Kommunikation, als bei ihr bereits - vom Autor des dramatischen Textes - eine "Unterscheidung von Information und Mitteilung“ vollzogen wurde: „Der Beobachter [zweiter Ordnung, das Publikum bzw. der Leser eines Dramas] [...] versteht, was im Drama schon einmal (durch die Projektion einer solchen Unterscheidung) als verstanden markiert worden ist" (Fuchs 1992b, 125). Dies bedeutet mit anderen Worten, dass die Repliken im dramatischen Dialog bzw. die Sprachhandlungsverknüpfungen im Drama generell so aussehen wie eine „echte" Kommunikationskette, aber eben keine solche sind (sie geben allenfalls eine gut gelungene, ,authentisch“ anmutende Imitation einer solchen ab), weil der Autor des Dramas bereits beim Verfassen eines Dramas eine Unterscheidung getroffen hat, die die Grundlage für den dramatischen Text abgibt. Das Publikum bzw. der Leser qua Beobachter zweiter Ordnung beobachtet also eine reduzierte Form von Kommunikation, gleichsam deren Simulation, dies hat jedoch den Vorzug, dass es/er dabei die Verknüpfungen erkennt, die vom Autor geschaffen wurden. Während „echte“ Kommunikation für die Systemtheorie der Luhmann-Schule ein autopoietisches System darstellt (weil sie keine fundierende Basis hat, auf die sich die Kommunikationspartner verlässlich beziehen könnten, sondern bloß aus in- 
teragierenden geschlossenen Systemen besteht), ist die Kommunikation im inneren Kommunikationssystem ein „allopoietisches System“, das von der transzendenten Autorinstanz geschaffen wurde. Der Text des Dramas ist offen für einen Beobachter zweiter Ordnung, der als Außenstehender nur sprachliche Äußerungen verfolgt (die vom Autor entsprechend arrangiert wurden), ohne dass Bewusstsein als zweites System im beobachteten drameninternen Kommunikationssystem als Korrektiv involviert wäre:

Wie immer psychische Mitlauf- und Anschlussoperationen im Blick auf jene theatralischen Ereignisse beschaffen sein mögen, die Kommunikation darüber (ob Foyergespräche, Kritikerrezensionen oder literaturwissschaftliche Arbeiten) kann nicht Anderes als Metakommunikation (als mindestens Beobachtung von Kommunikation auf der Beobachtungsebene zweiter bis n-ter Ordnung) sein, also Beobachtung von Kommunikation, die dadurch ermöglicht, ja erzwungen wird, daß dort oben, da unten, da vorne in einem genauen Sinn Kommunikation nicht stattfindet. (Fuchs 1992b, 126)

Das Publikum/der Leser als Beobachter zweiter Ordnung kann eben tatsächlich genau die drameninterne, vom Autor projizierte Pseudo-Kommunikation verfolgen und von einer übergeordneten Warte aus Zusammenhänge beobachten, die in der wirklichen Kommunikation nicht beobachtbar sind. ${ }^{69}$

Die im Drama beobachtete Pseudo-Kommunikation unterscheidet sich aufgrund der in ihr bereits vom Autor vorgenommenen Verkettungen von Pseudo-Ereignissen (nicht-sprachlichen Ereignissen, Sprechereignissen, Reaktionen auf diese Ereignisse) von der „echten“ ungesteuerten Kommunikation, die immer Bewusstseine mit Kommunikation verbindet, ohne dass das Ergebnis dieser Verbindung vorhersehbar wäre. Beobachtbar sind da nur die kommunikativen Antworten auf die Kommunikationen, nicht die Wirkungen auf die Bewusstseine. Die „Pseudo-Kommunikation“ im Drama wird aus der Metaposition des Autors bzw. des Publikums aber überblickbar, sie ermöglicht den Eindruck, Zusammenhänge und

69 „Dies macht einen Unterschied zu gewöhnlichen Beobachtungen (,Es wird dunkel', ,Ein Gegenstand fällt vom Schreibtisch') aus, bei der Kommunikation bleibt immer etwas unbeobachtbar, nämlich die Semantik, die ein anderes System mit der Kommunikation (bzw. den Signifikanten) verbindet. „Die Weise, wie wir Kommunikation vorgestellt haben, als elementare Einheit von sich autopoietisch konstituierenden Sozialsystemen, erzwingt den Schluß, daß Kommunikationen sich nicht ,direkt ' beobachten lassen. Wenn Kommunikation Kommunikation beobachtet, tut sie das (natürlich) nur als Kommunikation und mit deren Mitteln, und das heißt (unter anderem): immer zu spät. Sie beobachtet (mit einer Folgekommunikation und ihrer beobachtungsleitenden Unterscheidung), was gerade (oder vor langer Zeit) geschehen ist, und das, was sie dann als ,geschehen' bezeichnet, ist das, was geschehen ist. Kommunikation - mit anderen Worten - erzeugt laufend ihre eigene Realität, und wenn sie sich darauf kapriziert zu beobachten, wie sie das macht und warum sie das macht, erzeugt sie eine weitere Realität: mehr desselben." (Fuchs 1992a, 225) 
Wechselwirkungen zu erkennen, die in der gesellschaftlichen Wirklichkeit einfach nicht beobachtbar sind. In diesem Umstand liegt das ideologische Potenzial des Dramas begründet, es ,simuliert“ Kommunikation und den Ablauf von (geschichtlichen) Handlungen. Mit dieser systemtheoretischen Begründung wird Bachtins Qualifizierung des Monologismus plausibler, dieser entspricht eben dem Umstand, dass es sich in der dramatischen Binnenkommunikation um Pseudokommunikation handelt, die eben schon einmal „verstanden“ wurde (vom Autor). ${ }^{70} \mathrm{Da}$ es unserer Auffassung nach aber keinen textinternen „Dialogismus“ im literarischen Text gibt, kann dieser Begriff weder sinnvoll verwendet werden, noch entspricht ihm der systemtheoretische Kommunikationsbegriff. Der bachtinsche Dialogismus und der systemtheoretische Kommunikationsbegriff haben allerdings in der Kontingenz und Unbestimmbarkeit von „Intersubjektivität“ ein Gemeinsames: Der bachtinsche Ausgangsgedanke, dass Menschen zwar aufeinander bezogen sind, ihre jeweiligen Subjektivitäten aber vom anderen nicht erfasst werden können, sodass Alterität irreduzibel ist, findet sein Gegenstück in der Systemtheorie, die nicht nur das jeweilige Bewusstein als abgeschlossenes System sieht, sondern zwischen den Bewusstseinen noch das eigene System Kommunikation ansetzt, das aber keineswegs einen „Austausch“" von subjektiven Zuständen (Gedanken, Gefühlen etc.) ermöglicht, sondern nur eine sehr labile Verbindung zwischen den selbstständig operierenden Bewusstseinssystemen darstellt. Das System Kommunikation hat aber sehr wenig mit der Gattung Drama zu tun, weil deren textinterne Kommunikation keine echte ist, wiewohl sie komplex ist. Die Komplexität der dramatischen Kommunikation ist nicht genuin kontingent und „offen“, sondern analysierbar auf die Verknüpfungen, mit denen der Autor die (Sprach-)Handlungen zu einer Bedeutungseinheit verbindet. Dramatische „Kommunikation“ (die Anführungszeichen zeigen den Pseudo-Charakter der Binnenkommunikation im Drama an) kann als bündiger gelten, aufgrund der in ihr vom Autor vorgenommenen Verknüpfungen von Repliken (die nach seinem „Verstehen“ erfolgt) kommt das Verstehen eines Dramas durch das Publikum einem Verstehen des „Verstehens“ gleich, es ähnelt damit dem Auflösen eines Rätsels (der Repliken und Handlungen qua „Phänotext") in Richtung auf einen "Genotext", den der Autor als Dritter „verstanden“ hat.

70 Wie das Verstehen der dramatischen Pseudo-Kommunikation erfolgt, wird von Fuchs gar nicht einmal weiter ausgeführt; dass es sich um eine ganz andere Form von Verstehen als das Verstehen von echter Kommunikation handelt, wird aber etwa aus Pfisters Beschreibungen dramatischer Kommunikation (vgl. Pfister 2001, 149-219) deutlich. 


\section{Erläuterungen und Überleitung zum analytischen Teil}

\section{III.1.Zur Gattungsdefinition und Korpuswahl}

Hinsichtlich der Frage, ob das historische Drama als Subgattung von allen Dramen, die nicht als historische Dramen zu kategorisieren wären, deutlich unterschieden werden kann, besteht in der Forschung wenig Einmütigkeit. Zwar gibt es verständliche Bestrebungen, eine größere Bestimmtheit darin zu erzielen, was als historisches Drama gelten kann (aus der Fülle von dramentheoretischen und poetologischen Überlegungen verdienen die Arbeiten Sengles [1969] und Neubuhrs [1980] gröBere Beachtung, weil sie sich explizit dem Gattungsproblem stellen), doch sind die Vorschläge meist zu wenig präzise, um wirklich eine überzeugende Kategorisierung von Dramen vornehmen zu können. So wie Sengle zwischen historischem Drama und einem Drama mit historischen Stoffen differenziert, will Neubuhr Geschichtsdramen von historischen Dramen aufgrund des Kriteriums abscheiden, dass die Geschichtsdramen den Zweck haben, Geschichte $z u$ deuten, während die historischen Dramen bloß historische Stoffe verwenden (vgl. Neubuhr 1980, 3-5). Mit dem Kriterium des Zwecks wird allerdings ein textexternes Merkmal, das in der Autorintention zu bestimmen wäre, ausgewählt, und dies führt vom dramatischen Text zu nicht-literarischen Texten und deren Interpretation. Auch wenn damit der Kreis der Geschichtsdramen gegenüber demjenigen der „bloß historischen Dramen“ eingeschränkt wird, was ja Neubuhr erreichen möchte, ist diese Bestimmtheit nur auf der Grundlage extraliterarischer Bezüge möglich. Weiters muss man fragen, ob das Kriterium der Geschichtsdeutung von der Rezeptionsseite her gesehen nicht generell in historischen Dramen ausgemacht werden kann, ohne dass die Autoren dies expliziert reflektiert haben.

Als historische Dramen im engeren Sinn sollen für eine Reihe von Autoren nur diejenigen Dramen gelten, die "Geschichte zum Thema machen“ (Düsing 1998, 3), also nicht bloß vor historischem Hintergrund spielen. Ob das Kriterium „Geschichte zum Thema zu machen“ zum einen überhaupt konkret genug ist, um als Differenzierungsmerkmal zu funktionieren, mag bezweifelt werden, zum anderen wäre zu überlegen, ob damit etwa geschichtliche Implikationen von Dramen übersehen werden, die zwar unthematisch, aber dennoch vorhanden sind. Wie wenig handhabbar solche gattungstheoretischen Beschreibungen sind, lässt sich oft bereits an deren sprachlichem Duktus erkennen, man vergleiche etwa Tetzeli von Rosadors Definition des historischen Dramas:

[Unter historischem Drama] wird ein Drama verstanden, in dem eine Geschichtsauffassung eine aus geschichtlichem Stoff entwickelte Fiktion der Historizität formt, wobei $\mathrm{Pu}$ blikumskenntnis und Publikumserwartung an dieser Historisierung mitwirken und somit 
zu berücksichtigen sind, beziehungsweise ein Drama, das mittels dieser Elemente eine Geschichtsauffassung ausdrückt. Die Geschichtsauffassung legitimiert hierbei die Art der Geschichtlichkeit des Stoffes, der Stoff konkretisiert die Geschichtsauffassung: Die Beziehung zwischen beiden ist die der wechselseitigen Erläuterung. Die Fiktion der Historizität aber ist Folge und Korrelat der dramatischen Gestaltung, eben die Weise, in der der Stoff ästhetisch vermittelt wird und wirkt. (Tetzeli von Rosador 1976, 43)

Hier ist insbesondere das Kriterium der "Geschichtsauffassung“ eigentümlich, welches das Geschichtsdrama vom Drama mit historischem Stoff unterscheiden soll. Tetzeli von Rosador nennt als die drei Möglichkeiten von Geschichtsbewegungen die zyklische, fortschreitende oder christliche Bewegung (ebd. 41); eine dieser Möglichkeiten sei in den „echten“ Geschichtsdramen angelegt. Auch hier wäre zu fragen, ob dieses Kriterium nicht zu einschränkend ist und die tatsächliche Mannigfaltigkeit historischer Dramen reduziert.

Hegels Beschreibung der Spezifika der Dichtung und ihrer Differenz von der Geschichtsschreibung, die stark an Aristoteles erinnert, ist als Kriterium für die Bestimmung historischer Dramen weniger brauchbar denn als Beleg dafür, dass Hegel die Dichtung als literarisches Pendant zu seinem geschichtsphilosophischen Denken ansah:

[Die Dichtung hat] den innersten Kern und Sinn einer Begebenheit, Handlung, eines nationalen Charakters, einer hervorragenden historischen Individualität herauszufinden, die umherspielenden Zufälligkeiten aber und gleichgültigen Beiwerke des Geschehens, die nur relativen Umstände und Charakterzüge abzustreifen und dafür solche an die Stelle zu setzen, durch welche die innere Substanz der Sache klar herausscheinen kann, so daß dieselbe in dieser umgewandelten Außengestalt so sehr ihr gemäßes Dasein findet, daß sich nun erst das an und für sich Vernünftige in seiner ihm an und für sich entsprechenden Wirklichkeit entwickelt und offenbar macht. (Hegel XV/266f)

Hegels Bestimmung mag von ästhetischer Relevanz sein, für eine Korpuserstellung ist sie als Kriterium aber schon deswegen unbrauchbar, weil sie außerliterarische philosophische Unterscheidungen (was ist „substanziell“, was ist „vernünftig“ und was nicht?) voraussetzt.

Anstelle von zwar um größere Bestimmtheit bemühten, dabei aber doch auch vage oder spekulativ bleibenden Versuchen, die Gattung historisches Drama intensional zu bestimmen, pflichte ich im Zusammenhang dieser Arbeit eher Hüttmann bei, die lapidar konstatiert, dass das historische Drama als hybride Gattung in Abhängigkeit auch von der Entwicklung des historiographischen Diskurses gesehen werden muss (vgl. Hüttmann 2001, 35f). Sie folgt darin Lukács, der als Hegelianer zwar auch das historische Drama geschichtsphilosophisch beschreibt, aber keine scharfe Grenze zum Drama allgemein bestimmen möchte (vgl. Lukács 1965, 90-95). 
Für eine Korpuserstellung, die den formalen wie inhaltlichen Wandel von Dramen über einen Zeitraum von ca. 125 Jahren untersucht, erscheint es geraten, keine allzu kategorische Gattungsdefinition als Richtschnur zu nehmen, sondern besser mit einem minimalen Katalog an Merkmalen zu arbeiten, anhand dessen die Auswahl der Dramen erfolgen kann. Zumal diese Arbeit sich nicht als gattungstheoretische versteht, sondern zeitgeschichtliche Bezüge und politische Ideen in Dramen zu erkennen versucht, gibt es vor allem eine pragmatische Notwendigkeit, die Auswahl der Dramen für das Korpus zu reflektieren, dabei aber keine allzu starke Verengung des Korpus vorzunehmen, die überdies noch auf theoretisch wenig präzisen Bestimmungen beruhen würde. Zum Herausgreifen von „historischen Dramen“ aus der Menge an „Dramen schlechthin“ wird in der vorliegenden Arbeit die scheinbar lässige, praktisch aber brauchbare Bestimmung durch den historischen Stoff verwendet.

Eine historisch einigermaßen genau bestimmbare Zeit der Handlung, historische Personen als dramatis personae oder jede dramatische Repräsentation historischer Ereignisse schlechthin sind demnach hinreichend dafür, die entsprechenden Stücke in das Korpus von relevanten Dramen aufzunehmen. Im Grenzfall kann die Handlung also auch rein fiktiv sein, alle Figuren des Dramas können fiktive Personen sein, wenn aber wenigstens ein historisches Setting vorliegt, reicht dies als positives Kriterium für die Aufnahme in das Korpus mit tschechischen historischen Dramen aus. ${ }^{71}$ Diese „weiche“ Genredefinition, die eine deutlich in der Vergangenheit angesetzte Handlung als einzige conditio sine qua non veranschlagt, erlaubt es, einige interessante tschechische Dramen, die eigentlich eher Grenzfälle der Gattung sind, in Zusammenhang mit ihrem Bezug zur Entstehungszeit zu behandeln. So sind etwa Josef Jiř́ Kolárs Monika und Viktor Dyks Posel Dramen mit fiktiven Hauptpersonen, aufgrund ihres klar bestimmten historischen Settings jedoch sind sie im Korpus präsent. Ein anderer Grenzfall betrifft Dramen, die Stoffe aus den berühmten Handschriftenfälschungen übernehmen, wie etwa Josef Lindas Jaroslav Šternberg $v$ boji proti Tatarim oder Josef Kajetán Tyls Čestmír. Dass diese aufgenommen wurden und etwa Dramen aus der mythischen Frühgeschichte - etwa Stoffe um Praotec Čech, den Richter Krok, Libuše und Přemysl Oráč, den Krieg der Mädchen (Divči válka) - jedoch nicht, ist darin begründet, dass die mythischen Stoffe den Autoren des obrozeni schon eher als Mythen geläufig waren als die Stoffe der sogenannten Handschriften, die ja gemeinhin bis in die 1880er Jahre als authentisch galten. Josef Linda allerdings, der Autor von Jaroslav Sternberg v boji proti Tatarüm, steht unter dem schwerwiegenden Verdacht, gemeinsam mit Václav Hanka die Fälschungen produziert zu haben; er musste mithin davon Bewusstsein haben, dass die im Drama repräsentierten Begebenheiten fiktiv oder legendär sind. Mit

71 Solche Dramen entsprechen am ehesten der von Neubuhr aufgezeigten Möglichkeit, Geschichtsdeutung in Dramen mit unhistorischen Stoffen zu verbinden. 
der Aufnahme von Jaroslav Šternberg v boji proti Tatarüm, ein Stoff, der bereits vor den Handschriftenfälschungen kursierte, ist zwar eine weitere Ausnahme von der Grundregel gemacht worden, der brisante ideenpolitische bzw. strategische Gehalt des Drama wird dies aber wohl gerechtfertigt erscheinen lassen.

Auf der Grundlage des stofflichen Kriteriums ist die schwierige Abgrenzung zwischen einer Tragödie vor historischem Hintergrund und einem historischem Drama von nachrangiger Bedeutung, ${ }^{72}$ sie beruht meist entweder auf dem Vergleich mit historiographischen Quellen oder auf der Einschätzung, welche Aspekte des Dramas als dominant angesehen werden können, ob eher psychologische oder doch eher politische. Da nun die historischen Dramen in der Regel kaum ohne eine Liebesintrige auskommen und in der Tragödie vor historischem Hintergrund die Machtfrage anhand der Intrige um die Fürstenfigur erörtert wird, verzichte ich aus den angesprochenen pragmatischen Gründen auf eine kategorische Abgrenzung des historischen Dramas von der Tragödie.

Abgesehen von den angeführten Minimalkriterien erfolgte die Auswahl der Dramen für das Korpus ohne weitere große Einschränkungen. Um einen Überblick über die historische Entwicklung von eineinviertel Jahrhunderten bekommen zu können, schien es freilich notwendig, aus jedem Jahrzehnt mindestens ein bis zwei Dramen auszuwählen. Dass die Wahl und die Analyse gerade auf diese fiel, gründet in keiner bestimmten Regel: Es ging mir darum, ein möglichst breites Bild von existierenden historischen Dramen zu bekommen; demnach wählte ich nicht nur Dramen berühmterer AutorInnen aus, sondern auch Dramen von Autoren, die mittlerweile in Vergessenheit geraten sind oder die überhaupt niemals aufgeführt wurden. Da es mir ja nicht um eine Geschichte der theatralischen Kommunikation und Rezeption geht, sondern um eine Analyse von politischen Ideen, die in historischen Dramen erkannt werden können, erscheint diese Streuung gerechtfertigt. Freilich bemühte ich mich darum, historische Dramen von Autoren auszuwählen, die in den Literaturgeschichten als wichtige Figuren gelten, diese wurden gewissermaßen leicht „bevorzugt“ ausgewählt, zugunsten einer Breite des Korpus wurde aber darauf verzichtet, etwa alle historischen Dramen von Josef Kajetán Tyl, Josef Jiří Kolár, Vítězslav Hálek, Jaroslav Vrchlický oder Alois Jirásek zu analysieren. Ein weiteres Kriterium für die Auswahl war es, Dramen zu betrachten, deren Entstehungszeit mit wichtigen historischen Ereignissen zusammenfällt, womit der These von Lukács (der diese seinerseits von Engels übernommen hatte) gefolgt wurde, dass historische Dramen Indikatoren für gesellschaftliche Umbrüche seien (vgl. Lukács 1965, 116f).

72 Shakespeares Richard III. und Hamlet sind ja - um zwei prominente Beispiele der Dramenliteratur zu nennen - beide historisch verortet und könnten in einer offeneren Gattungsdefinition, die auch in dieser Arbeit zur Anwendung kommt, beide als historische Dramen bezeichnet werden, nur ist Hamlet weniger als historisches bzw. politisches Drama interessant, sondern vornehmlich als Charakter-Drama. 
Der angestrebten Streuung von Dramen bekannterer oder weniger bekannter Autoren bzw. von mehrfach gespielten Stücken oder unaufgeführten Texten entspricht auf inhaltlicher Ebene das Bestreben, unterschiedliche Stoffe aus verschiedenen Epochen der Geschichte zu betrachten, sich also nicht allein auf bestimmte Stoffe zu beschränken. Zum Ausgleich so entstandener Heterogenität, die den diachronen Vergleich zwar nicht unmöglich macht, aber erschwert, wurden zwei Themenkreise gewählt, die in mehreren Dramen behandelt wurden, nämlich zum einen die Geschichte um die Ermordung des Fürsten Václav durch seinen Bruder Boleslav und zum anderen der Stoff um den adeligen Usurpator Záviš von Falkenštejn. Anhand von Dramen, die diese Stoffe behandeln, werden diachrone „Achsen“ gebildet, an denen sich die Veränderungen im politisch-ideologischen Gehalt erweisen werden. Die Achsen dienen weiters zum Vergleich mit den Dramen, die ungefähr zeitgleich entstanden sind, aber andere Stoffe behandeln.

\section{III.2. Erläuterungen zur Schreibweise von Eigennamen und zu Pluralformen mit generischer Bedeutung}

Da sich die Arbeit als textnahe Analyse versteht, wurde bei der Schreibweise von Eigennamen grundsätzlich die in den Primärtexten verwendete Schreibung übernommen. Dies betrifft auch die Schreibung von Toponymen, es sei denn, diese tschechischen Toponyme haben eine ganz geläufige deutsche Entsprechung (wie Prag, Olmütz, Brünn etc.) oder ein geographisches Denotat, das außerhalb des Territoriums der böhmischen Länder liegt. Die Schreibweise wurde nur bei Dramenausgaben des obrození verändert, die noch vor den orthographischen Reformen der damaligen Zeit erschienen sind: in diesen Fällen wurde die Schreibweise der heute üblichen tschechischen Orthographie angepasst. Um die Lesbarkeit von direkten Zitaten aus solchen Dramenausgaben des obrození zu vergrößern, wurden auch die direkten Zitate der modernen Orthographie angeglichen.

Die historischen Dramen werden in der Arbeit primär als eigenständige Texte gelesen und nicht systematisch mit möglichen oder tatsächlichen Quellentexten verglichen, die von den Autoren verwendet wurden. Mitunter werden jedoch zur Erleichterung der historischen Orientierung in eckigen Klammern die in deutschsprachigen Geschichtsbüchern geläufigen Namensformen angegeben.

Der Verfasser ist sich der Genderproblematik in der Sprache bewusst und erklärt dazu Folgendes: Die historischen Dramen des Korpus wurden mit einer Ausnahme (Gabriela Preissová) alle von männlichen Autoren verfasst. Die Verwendung der maskulinen Pluralform bezeichnet wie in der traditionellen Schreibweise geschlechtsneutral sowohl männliche als auch weibliche Personen. Mitunter wird jedoch auch die geschlechtsneutrale Schreibweise mit dem Binnen-I verwendet, um auch formal zum Ausdruck zu bringen, dass die traditionelle Schreibweise als historisch angesehen werden kann und dass neben ihr auch eine andere Schreibung 
durchaus berechtigt ist. Die bewusst inkonsequente Verwendung beider Formen bei generischer Bedeutung wurde aus dreierlei Hinsicht durchgeführt: erstens soll die gute Lesbarkeit der Arbeit gewährleistet bleiben, zweitens wird der feministischen Kritik an sedimentierten patriarchalischen Sprachmustern durch die gelegentliche Verwendung der Schreibung mit Binnen-I Rechnung getragen, drittens soll kein Eindruck von verbiesterter Prinzipientreue erzeugt werden. Sprache befindet sich im Wandel und mitunter kann man diesen Sprachwandel auch gutheißen und mit dem eigenen Schreiben anzeigen.

\section{III.3. Erläuterungen zur ideologischen Analyse}

Das mit dieser Arbeit verfolgte Analyseinteresse ist auf die politischen Ideen gerichtet, die in historischen Dramen enthalten sind. Unter politischen Ideen bzw. unter Ideologie wird ganz allgemein eine Werthaltung verstanden, die sich auf die Welt bezieht, wobei es in unserem Zusammenhang vor allem politische und geschichtliche Aspekte sind, die Gegenstand ideologischen Denkens sind. Das ideologische Denken ist im Drama als ,ideologisches Zeichen“ (vgl. Vološinov 1975, 54-57) manifestiert.

Wie in Teil A diskutiert wurde, ist es aufgrund der indirekten Kommunikation der dramatischen Gattung gemeinhin schwer möglich, die Verbalisierung dieser Ideen dem Dramentext unmittelbar zu entnehmen, es sei denn, dass einzelne personae dramatis oder einzelne Repliken eine klare Sprachrohrfunktion haben. Aber selbst in diesem Fall ist zu bedenken, dass die personae dramatis in einen Handlungszusammenhang eingebunden sind, der auf den ideologischen Gehalt einzelner Repliken zu beziehen ist: Der Handlungszusammenhang kann diese Repliken konterkarieren, er kann sie unterstützen, er kann andere Aspekte hervorkehren und somit die verbalisierten ideologischen Vorstellungen erweitern. Der Handlungszusammenhang selbst ist als eine eigene Einheit zu verstehen, die in hohem Maße zur ideologischen Bedeutung des Dramas beiträgt. Die Auswahl und die Verkettung der Ereignisse im Drama sind ja bereits selbst bedeutungsgenerierende schriftstellerische Akte, durch sie wird zur "Sinnproduktion“ beigetragen bzw. hat die so geschaffene Dramenhandlung ideologischen Gehalt. ${ }^{73}$

Ein Handlungszusammenhang ist im Prinzip in allen traditionellen Dramenformen gegeben; gemäß der idealtypischen Unterscheidung von offener und geschlossener Form im Drama, die Klotz (1969) vorgenommen hat, ist der Handlungszu-

73 Hier muss auf den Unterschied zwischen den im Drama repräsentierten Ereignissen und den tatsächlichen Ereignissen in der Welt hingewiesen werden. Letztere werden zwar von den einzelnen Handelnden mit Sinn versehen; auch sind ja Handlungen als intentionale Akte des Handelnden sinnhaft. In der realen Welt freilich gibt es zum Unterschied vom historischen Drama keine Instanz, die eine Auswahl und Kombination der unendlich zahlreichen Ereignisse und Handlungen vornehmen würde und damit Sinn produziert. 
sammenhang in der geschlossenen Form deutlicher vorhanden als in der offenen Form, die zwischen einzelnen Szenen oft keine klaren Verkettungen von Handlungen erkennen lässt. In der Regel kann jedoch auch bei der offenen Form ein impliziter Zusammenhang festgestellt werden. Wenn man das narratologische Begriffspaar Fabel und Sujet auf das Drama anwendet, so kann man sagen, dass die Fabel dem Handlungszusammenhang entspricht: in der geschlossenen Form sind mehr Anteile der Fabel im Sujet (im Dramentext bzw. auf der Bühne) präsent als in der offenen Form, die den Handlungszusammenhang damit weniger eindeutig vorführt.

Die in dieser Arbeit vorgenommenen ideologischen Analysen sind nach dem folgenden Muster durchgeführt: nach einer meist kurz gehaltenen Einleitung, die knappe Informationen zum Autor, Produktionskontext und zur Rezeption gibt, wird der Handlungszusammenhang präsentiert, der praktisch eine Erzählung bzw. Nacherzählung der dramatischen Ereignisse ist, die dem Stratum der Fabel ${ }_{2}$ in Hayden Whites Meta-History (siehe dazu oben, S. 45ff) entspricht. Die Erzählung folgt im Wesentlichen der Dramenhandlung bzw. dem Sujet, erweitert dieses aber gegebenenfalls um implizite Zusammenhänge und um markante Sprechhandlungen bzw. Zitate von Repliken.

Dieser Handlungszusammenhang soll wie gesagt als Teil der ideologischen Analyse des Dramentexts gesehen werden. Freilich sind die in der Arbeit als Fabel ${ }_{2}$ präsentierten Handlungszusammenhänge Nach-Erzählungen des Verfassers dieser Arbeit und korrespondieren daher mit dessen Beobachterperspektive bzw. mit dessen Erkenntnisinteresse, sie sind aber sehr textnah gehalten und können also auf intersubjektive Zustimmung hoffen: LeserInnen der analysierten Dramen sollten den hier wiedergegebenen Handlungszusammenhang eigentlich als textadäquat bestimmen können. Das Augenmerk, das auf den Handlungszusammenhang gelegt wird, der im Prinzip intersubjektive Zustimmung finden sollte, unterscheidet diese Arbeit von frequenten Urteilen über Dramen, in denen meist nur sehr vage Qualitäten oder Mängel von Dramentexten festgestellt werden. So schreibt etwa Stanislav Lom pauschal, dass die Menge der historischen Dramen in der tschechischen Tradition zwar die tragische Bewegtheit der Geschichte spiegle, aber nicht dramatisch ausdrücke:

Nejlepší české historické hry [...] zůstávaly jen dramatizovanou národní i sociální historií nebo genrovými historickými obrazy, aniž se staly plnokrevnými dramaty historického námětu. ${ }^{74}$ (Lom 1942, 174)

Die in solchen Urteilen impliziten Wertungen - was ist "eine bloß dramatisierte Geschichtsschreibung oder ein historisches Genrebild“, wodurch unterscheiden

74 „Die besten historischen Schauspiele [...] blieben bloß eine dramatisierte nationale und soziale Geschichtsschreibung oder ein historisches Genrebild, aber keine vollblütigen Dramen mit historischer Vorlage." 
sich diese für Lom minderwertigen von „vollblütigen“ Dramenformen? - werden praktisch nie begründet oder relativiert. Eine solche Form der literarischen Kritik setzt sich meiner Ansicht nach auf vergleichbare Weise in ebenso vagen literaturwissenschaftlichen Unterscheidungen von „historischem Drama“ einerseits und „Geschichtsdrama" andererseits fort, auf die oben (vgl. oben, S. 108) kritisch hingewiesen wurde. Diesen Vagheiten der Literaturkritik, die einem Subjektivismus Vorschub leisten, soll mit der Analyse der Handlungszusammenhänge begegnet werden.

Zugleich wird mit der Erzählung des Handlungszusammenhangs dem Problem notdürftig Abhilfe geleistet, dass viele der analysierten Dramen sogar einem Fachpublikum nicht bekannt sein dürften.

Dem Bedarf nach einer nachvollziehbaren Darstellung der Dramenhandlung sollen auch die Figurenkonstellationen - siehe dazu die nachfolgenden Erläuterungen - begegnen, mit denen in der Regel die Darstellung des Handlungszusammenhangs abgeschlossen wird. In den Figurenkonstellationen werden die Relationen der wichtigeren personae dramatis zueinander in eine graphische Darstellung gebracht, wobei freilich nicht alle Aspekte des Handlungszusammenhangs berücksichtigt werden können, aber die handlungsentscheidenden Relationen und Ereignisse erfasst sind.

Im Anschluss an die Figurenkonstellationen erfolgt die explizite Analyse des ideologischen Gehalts, die auf dem dargestellten Handlungszusammenhang beruht; dabei werden markante Repliken und Zitate diskutiert, um zu einer ideologischen Interpretation des jeweiligen Dramas zu kommen.

\section{III.4. Legende zu den Figurenkonstellationen}

Zur optischen Verdeutlichung der Beziehungen zwischen den personae dramatis dienen die Figurenkonstellationen, die sowohl statische als auch dynamische Beziehungen zum Ausdruck bringen und die konfligierenden Parteien der zugrundeliegenden Fabel markieren.

—: Eine einfache Linie zwischen den Personen drückt eine weitgehend konfliktfreie Beziehung aus, wobei verwandtschaftliche Verhältnisse, sofern sie nicht durch Konflikte markiert sind, ebenfalls durch eine solche Linie ausgedrückt werden. Dasselbe gilt für Dienst- oder Loyalitätsverhältnisse.

[ ]: Eckige Klammern verbinden Personen, die zueinander in einem Liebesverhältnis oder Eheverhältnis stehen, das in der Handlung auf eine „Probe“ gestellt wird (etwa durch ein Liebesverhältnis eines der Partner mit einer dritten Person). Die eckigen Klammern sind dann zweifach vorhanden und umgeben die eine Person, die zu zwei anderen ein Liebesverhältnis hat.

$\longrightarrow$ : Ein einfach gerichteter Pfeil bezeichnet ein Verhältnis zwischen Gegnern, wobei der Pfeil von der aggressiven (meist auch tötenden oder mordenden, eine solche Tat zumindest wünschenden) Person ausgeht. Unterschiede in den Linienstär- 
ken sollen die Intensität der Aggression anzeigen. Je „dicker“ der Pfeil, desto größer die Aggression. In der Farbvariante (elektron. Ausgabe der Arbeit) bedeutet ein einfacher roter Pfeil, dass die Aggression in Tötung bzw. Ermordung gipfelt. Der Mord kann auch von einem abhängigen Diener ausgeführt werden, dieser ist aber dann nur Instrument einer sozial übergeordneten Person, die den Mord anstrebt oder anordnet.

$<->$ : Der Doppelpfeil bezeichnet ein deutliches antagonistisches Verhältnis zwischen Figuren an, ohne dass dieses in physischer Aggression bzw. Tötung endet.

勾食: flächige geschwungene Pfeile indizieren den Wechsel zwischen den Lagern, den eine Figur im Lauf der Handlung vollzieht. Häufig ist dieser Lagerwechsel auch noch durch einen Wechsel der Geschlechtsrollen (meist die Annahme einer männlichen Rolle durch Verkleidung) markiert.

Umgebungslinien (egal, welche Form, elliptisch, rechteckig oder als freie Form) fassen mehrere Personen zu Konfliktparteien zusammen, die einander gegenüberstehen. Die Parteien sind durch kursiv geschriebene Namen bezeichnet. Das Unterscheidungskriterium kann von Familie bzw. Sippe, Konfession, Nation, Stand oder territorialer Zugehörigkeit bestimmt sein.

-----: strichlierte Linien markieren mitunter zusätzlich derartige Lagergrenzen. Wichtigere Personen sind mit größerer Schrift angezeigt als zweitrangige oder Nebenfiguren. ( ): Runde Klammern zeigen Personen an, die zwar in der Fabel vorkommen und damit von Bedeutung für die repräsentierte Welt sind, die nicht aber im Sujet bzw. der szenischen Handlung ,ihren Auftritt“ haben. 

B.

Analytischer Teil: Das tschechische historische Drama im soziokulturellen Kontext 



\section{IV. (Historisches) Drama und Gesellschaft}

\section{IV.1. Aufriss der Gattungstradition}

Als Gattung ist das Drama sowohl in typologischer wie auch in historischer Hinsicht mit kollektiver Partizipation und Rezeption verbunden. Seine Wurzeln in kultischen Ritualen der Antike und in der sich daraus entwickelnden Tragödie finden ihren formalen Niederschlag noch in der traditionellen Einteilung in drei bzw. fünf Akte im Drama der Neuzeit; ihr Inhalt appelliert an das Interesse eines breiteren Rezipientenkreises, sei es nun religiös-mythischer oder säkularer Natur.

Beide Grundgattungen des antiken Dramas Griechenlands, Tragödie wie auch die jüngere Komödie, setzen die Teilnahme der versammelten freien Bürger an den Dionysien voraus, die zentraler Teil des im 6. Jahrhundert v. Chr. in Athen zum Staatskult erhobenen Dionysoskults wurden (vgl. Werner 1986, 219-221 u. 232; Kindermann 1966, 16). Insofern sich die Entwicklung der Tragödie vermutlich auf die Chorlyrik zurückführen lässt, ${ }^{75}$ ist auch offensichtlich, dass es sich um eine kollektive Kommunikation handelt, die strukturell weitgehend einer Autokommunikation (vgl. Lotman 1972, 22) entsprach: sowohl die Aufführenden wie auch das „Publikum" gehörten zu Polis, welche die Theateraufführungen mit einem dem Alltag enthobenen, rituell-religiösen Zwecken dienenden Fest verband. Diese entwicklungsgeschichtliche Bindung an heidnische oder - später - christliche Kulte um metaphysisch-spirituelles wie auch politisch-ökonomisches Heil (vgl. Huizinga 1956, 140-142) führt die dramatische Gattung bis in die Gegenwart als Konnotation mit. Wenngleich natürlich Drama und Theater der Neuzeit bisweilen weit von ihren Ursprüngen in der griechischen Antike entfernt sind, kann das Theater als dasjenige Medium mit der längsten Tradition in der abendländischen Geschichte gelten, das Selbstdarstellung und Selbstreflexion institutionalisiert ermöglicht: „Im Theater sieht sich die Gesellschaft selbst beim Handeln zu" (Fischer-Lichte 1990, 3f).

Bereits für diese erste große Periode abendländischen Theaters weist die Forschung auf die Parallelen zwischen der politischen Entwicklung der Polis und der Entfaltung der dramatischen Gattung hin. So sei die offizielle Förderung des Dionysoskults und der Dionysien eine Initiative des „Tyrannen“ Peisistratos (600-528 v. Chr.) gewesen, mittels derer er womöglich den Kreis der Untertanen, auf welche er sich stützte, bei Laune halten wollte. Die Agones, die im Rahmen von Dionysosfesten veranstalteten Tragödienwettbewerbe, haben in der demokratischen Zeit ab 510 v. Chr. ihre Blütezeit erlebt: Sie wurden vom höchsten Beamten der attischen Demokratie, dem árchon éponymos, geleitet, woraus sich schon ihr gesellschaftlicher Stellenwert erkennen lässt (vgl. Kindermann 1966, 13 u. 24-31; Seeck 2000, 60).

75 Eine ausführliche Diskussion der hier nicht weiter sonderlich relevanten genealogischen Fragen in Verbindung mit der Tragödie liefert Schadewaldt (1991, 34-46). 
Mithin war das Fest zu Ehren des Dionysos eine Veranstaltung, welche das Gemeinwesen der Polis bedeutsam stärkte und der "nationalen Selbstdarstellung “ (Fischer-Lichte 1990, 16) diente. ${ }^{76}$

Der weltgeschichtliche Sonderweg Athens zur Demokratie - die antiken Herrschaftsformen, die zur gleichen Zeit im Mittelmeerraum und in Asien bestanden haben, waren meist monarchisch oder aristokratisch ausgerichtet, das Territorium und die Gesellschaft stark hierarchisiert - bestand darin, dass eine relativ große Zahl von Bürgern angehalten war, sich in Angelegenheiten des Gemeinwesens zu engagieren, welches nach dem Sieg über die Perser erfolgreich sein Territorium vergrößerte und zur größten Macht im ägäischen Raum anwuchs (vgl. Kindermann 1966, 24-26).

Zwar wurden wirklich historische Stoffe in der griechischen Tragödie nur ausnahmsweise verwendet; dennoch kann den mythischen Stoffen im Gegenzug nicht zugleich der Charakter der Fiktionalität entschieden zugeschrieben werden. Während ein heutiges Publikum sie unumwunden als Fiktion kategorisieren würde, dürften die Menschen des antiken Griechenland die Heroen als „ferne, aber historische Gestalten“ angesehen haben, wenngleich für ihre Faktizität wahrscheinlich „kein Tragiker seine Hand [...] ins Feuer" hätte legen wollen (Seeck 2000, 167). Dies deutet darauf hin, dass das antike Publikum keine große Distanz gegenüber den vorgeführten Ereignissen verspürte und sich gut in die Handlung hineinversetzen konnte (explizit phantastische bzw. irreale Ereignisse wurden von den Tragödienschreibern ja vermieden), die ihnen keine historische, wohl aber eine „poetische Wahrheit“ präsentierte (vgl. ebd. 168). Die wenigen Stücke, die geschichtliche Ereignisse thematisierten, die den Zeitgenossen gut bekannt waren, waren große Ausnahmen von der Regel, den mythischen Stoffen weitaus größere Dignität beizumessen: Phrynichos' Die Einnahme von Milet (492) und dessen Phönikierinnen (476), dem vier Jahre später Aischylos' Drama Die Perser (472) folgte, welches als einziges mit historischem Stoff erhalten geblieben ist, stehen in engem Zusammenhang mit den Perserkriegen (490-479), der größten militärischen Herausforderung der damaligen Zeit. Insofern Die Einnabme von Milet (492) dem zeitgenössischen Publikum das nur zwei Jahre zuvor erfahrene Leid bei der Eroberung der mit Athen verbündeten Stadt Milet vorführte, erregte es dessen

76 Die mit der europäischen Klassik einsetzende Verklärung der Antike projizierte gerade in die griechische Hochkultur alle Imagination eines Frühlings der Menschheit, in der diese - nach Hegels Diktum - erstmals ganz bei sich war (Hegel XVIII/175). Die Resonanzen dieses verklärenden Interesses sind dank klassisch-humanistischer Bildung noch im beginnenden 21 . Jahrhundert nicht verhallt. Mittlerweile hat sich aber auch eine gewisse Skepsis gegenüber dem postklassischen Griechenlandbild eingestellt: Man vergleiche etwa Kindermanns fast hymnische Ausführungen über die Integration der Tragödie in die Kultur der Polis (Kindermann 1966, 25-31) mit dem Hinweis darauf, dass der historisch gesicherte Erkenntnisstand eigentlich keine solchen emphatischen Pauschalisierungen zulässt (Meier 1988, 54-61). 
Unmut so sehr, dass sein Autor eine Geldstrafe von 1.000 Drachmen zu entrichten hatte (vgl. Meier 1988, 76). Einigen Autoren gilt dieses erste historische Drama des abendländischen Theaters (vgl. Kindermann 1966, 22) überhaupt als Beginn des tragischen Theaters.

Diese frühe traditionsbegründende Theaterform ist mithin einerseits von ihrer Integration in die Kultur der Polis gekennzeichnet (vgl. Fischer-Lichte 1990, 19), andererseits dadurch, dass die vorgeführten dramatischen Stoffe in der Regel zeitlich keinen direkten Bezug zum Leben der Polis hatten, sehr wohl aber ihren Mitgliedern aufgrund von kultureller Überlieferung und Erzählungen gut bekannt gewesen sein dürften. Das sich mit der Entwicklung aus der Chorlyrik herausbildende typologische Spezifikum des Dramatischen - einzelne Handelnde stehen dem Chor oder später einander gegenüber - entspricht aus retrospektiver Sicht dem Wandel der griechischen Kultur vom mythologischen Denken zu stärkerer Immanenz. Während das Weltbild des Mythos den Menschen bloß als Teil eines von transzendenten Kräften gelenkten größeren Ganzen betrachtet, führt das Drama die Helden als Handelnde vor, die sich der Notwendigkeit des Handelns bewusst werden, aber erst im Nachhinein (im Moment der Anagnorisis) dessen Konsequenzen erkennen können und meist unter diesen zu leiden haben. ${ }^{77}$ Mit der Problematisierung des politischen Handelns in der attischen Polis, deren Bürger selbst oft vor schwierigen Entscheidungen standen (vgl. Meier 1988, 236), übernehmen für Kindermann Drama und Theater als „Systole“ und „Diastole“ „die Herzfunktion des abendländischen Kulturorganismus“ (Kindermann 1966, 18).

Doch auch ohne somatische Metaphorik kann Drama und Theater eine Sonderstellung eingeräumt werden, weil die dramatische Kommunikation das Publikum in die Rolle eines Beobachters versetzt, dem die gesamte Komplexität des Geschehens deutlich wird und der somit die partikuläre Perspektive der dramatis personae transzendiert. Das Drama als wesentlicher Teil des klassischen Theaters repräsentiert eine Welt, die in sich geschlossen ist und als solche vom Publikum vollständig überblickt werden kann. Aristoteles äußerte sich dezidiert in Kapitel 7 und 8 seiner Poetik über diesen Punkt; für ihn gilt, dass die Tragödie „Nachahmung einer in sich geschlossenen und ganzen Handlung ist, die eine bestimmte Größe hat; es gibt ja auch etwas Ganzes ohne nennenswerte Größe“ (Aristoteles 1994, 25).

In Bezug auf die Welt des Publikums ist die repräsentierte Welt des Dramas insofern natürlich eine Modell-Welt, die metaphorisch bzw. allegorisch auf reales Handeln bezogen werden kann und die synekdochisch-metonymisch mit der realen Welt verbunden ist (die Bühne/Szene ist ja Teil der Welt, die Figuren werden von Schauspielern dargestellt, die außerhalb des Dramas leben). Mit Theater und

77 Aristoteles weist im dritten Kapitel seiner Poetik (Aristoteles 1994) auf die Etymologie von „Drama“ hin: $\delta \rho \alpha \nu$ bezeichnet das Moment des Tuns in der Überwindung großen Widerstands bzw. im Augenblick der Entscheidung (vgl. Asmuth 1994, 4f). 
Drama als Institution der attischen Polis wurde ein Reflexionsmedium geschaffen, welches dem Publikum die Möglichkeiten des Handelns vor Augen führte. ${ }^{78}$ Auch der Chor dürfte diese Funktion einer stellvertretenden Reflexion bekommen haben, für Schlegel stellt er

[...] überhaupt und zuvörderst den nationalen Gemeingeist, dann die allgemein menschliche Teilnahme vor. Der Chor ist mit einem Worte der idealisierte Zuschauer. Er lindert den Eindruck einer tief erschütternden oder tief rührenden Darstellung, indem er dem wirklichen Zuschauer seine eignen Regungen schon lyrisch, also musikalisch ausgedrückt entgegenbringt und ihn in die Region der Betrachtung hinaufführt. (Schlegel 1966, 65)

Das metaphorisch-metonymische Repräsentationsverhältnis zwischen der Welt des Dramas und der Wirklichkeit erklärt auch die antike Präferenz für mythologische Stoffe: diese waren dem Publikum nicht nur bekannt, sie entsprachen auch besser dem Anspruch von Geschlossenheit, während gerade raumzeitliche Kontiguität die Stoffe aus der jüngeren Vergangenheit mit der eigenen Welt verband und den beobachtenden Überblick beeinträchtigte. Der mit dem Drama möglich gewordene Überblick über das vorgeführte Handeln und dessen möglicherweise tragische Implikationen dürfte angesichts des „distanzierten“ Mythos leichter zu gewinnen gewesen sein als angesichts von repräsentierten Vorgängen, wenn schon deren ontologische bzw. raumzeitliche Abgrenzung von der eigenen Welt Mühe machte (vgl. Meier 1988, 238).

Nach den geistlichen Spielen des Spätmittelalters wurde mit der Renaissance erneut eine Theaterform produktiv, die eine deutlichere Trennung von dramatischer Handlung und Publikum vorsah, aber die vom mittelalterlichen Drama die moralische Tendenz übernahm (vgl. Neubuhr 1980, 8f). Das elisabethanische Drama in England brachte mit der offenen Form auch verstärkt historische Stoffe in Dramenform auf die Bühne, es war Ausdruck und Funktion eines im Entstehen begriffenen englischen Nationalbewusstseins.

78 Der von Kindermann gleichsam als evolutionärer Sprung beschriebene Wandel von der Chorlyrik zur Tragödie, mit welchem menschliches Handeln vorgeführt und damit auch problematisiert wird, ließe sich in systemtheoretischer Fassung als re-entry bezeichnen, insofern Handeln bzw. Beobachten nun selbst unter Beobachtung gerät. „Einfaches“ Beobachten beobachtet nur einen Gegenstand, nicht aber den Unterschied zwischen Beobachtung und Gegenstand. Durch eine Beobachtung des Beobachtens bzw. Handelns aber wird dieser Unterschied beobachtet und ein „System“ entsteht, das sich selbst von einer Umwelt unterscheidet. Im Fall des Reflexiv-Werdens von Handeln mit der „Geburt der Tragödie“ heißt dies nicht weniger, als dass der Mensch als „System“ entsteht, das sich von seiner Umwelt durch seine Fähigkeit zu handeln und zu beobachten unterscheidet (vgl. Dieckmann 2004, 219-221 u. 232). Unter dieser hier nur notdürftig skizzierten systemtheoretischen Perspektive erscheint es verführerisch, auch die etwa zeitgleiche Emergenz vorsokratischer Philosophie mit dem re-entry, dem Reflexivwerden von Beobachtung, zu verbinden. 
Die Dramatiker erkannten die Zeichen der Zeit: das Historiendrama erschien hervorragend geeignet, das überall laut werdende Bedürfnis zu befriedigen, Englands nationale Größe gefeiert zu sehen und umgekehrt eindrucksvoll vor den Gefahren zu warnen, die der Nation aus Dünkel und Selbstgefälligkeit erwachsen könnten. Mit der Darstellung von Ereignissen aus der englischen Geschichte vermochte das Theater in jedem Fall, im Zuschauer ein Gefühl oder Bewußtsein für nationale Identität zu entwickeln oder es zu bestätigen oder zu fördern. (Fischer-Lichte 1990, 104)

Während die partizipativen Aufführungen geistlicher (Passions-)Spiele die immerwährende Aktualität der Leidensgeschichte Jesu Christi erreichen sollten, besaßen die historischen Stoffe den Charakter besonders großer Bedeutsamkeit, was schon in Aristoteles' Bestimmung, dass nur Personen mit hohen gesellschaftlichem Rang in der Tragödie statthaft sind, angelegt ist: „History, in short, magnifies, for it invests a subject within the eyes of its beholder with the illusion of its dignity, scope, and overriding importance." (Lindenberger 1975, 55)

Die Dramen und ihre Aufführungen stellten in den Theaterkulturen der Frühen Neuzeit ein Repräsentationspotenzial für unterschiedliche Gruppen dar: in Frankreich repräsentierte das Nationaltheater den an der Spitze der gesellschaftlichen Hierarchie stehenden Adel, in Spanien und England war das Theater schon auf ein breiteres und frühbürgerliches Publikum ausgerichtet (vgl. Fischer-Lichte 1990, 97f, 160-162, 191-195), wobei es nur im englischen und französischen Theater mehr oder weniger deutliche nationalpolitische Bezüge der Stoffe gab. Die Figur des Tyrannen im spanischen und deutschen Barockdrama wurde von Benjamin mit der Idee der Souveränität in Zusammenhang gebracht, derzufolge der Fürst die Ordnung herzustellen hat, um das Chaos abzuwehren. Der exzessive Machtmissbrauch des Tyrannen ist im Umstand begründet, dass somit der Widerspruch zwischen der faktischen Beschränktheit und Gebrechlichkeit der Person und der „absoluten“ Macht zum Ausdruck kommt, welche die Theorie der fürstlichen Souveränität ihm zuschreibt. Im Unterschied dazu kann die Darstellung des Fürsten als Märtyrer dafür gelten, dass er exemplarisch die Kontrolle und Würde vorführt, die seiner hierarischen bzw. souveränen Position entsprechen soll (vgl. Benjamin 1974, 60-66). Es geht mit der Darstellung des Tyrannen Benjamin zufolge nicht etwa um eine in Form eines Dramas ausgedrückte Kritik an konkreten historischen Fürsten oder an der Fürstenrolle generell, sondern eher darum, nur die negative Möglichkeit der Gestaltung der Souveränität zu zeigen, während die Darstellung des Märtyrers deren idealisierte Gestaltung ist.

Die auf die Renaissancetragödie aufbauende klassizistische Tragödie Racines und Corneilles stellt ein für das Drama in vielen europäischen Literaturen wichtiges formales Vorbild dar, doch war sie stark von den Interessen der höfischen Gesellschaft bestimmt, sodass nationalhistorische Momente noch wenig Bedeutung hatten. Der historische Hintergrund wird meist zugunsten von zwischenmenschlichen 
und psychischen Konflikten der Figuren abgeschwächt; der Kampf um die Macht, der in vielen Dramen der französischen Tragödie des Klassizismus eine zentrale Rolle spielt, ist auf die dramatis personae, nicht aber auf eine synekdochisch mitgemeinte bzw. in den Fürstenfiguren repräsentierte Nation bezogen. Dank deutscher Vermittlung kam es seit dem späten 18. Jahrhundert zu einer Durchmischung der Formen und einer Pluralisierung der Möglichkeiten der Gestaltung historischer Dramen; sowohl die strengere klassizistische Tragödie als auch das offenere englische Drama fanden in vielen europäischen Literaturen Verbreitung. Die historischen Dramen waren genealogisch mit der freieren englischen Form verbunden, doch die vor historischem Hintergrund spielende Tragödie war gleichfalls eine Option für die Dramatisierung geschichtlicher Ereignisse. Für das historische Drama der Deutschen und Tschechen waren weiters die meist als trivial eingestuften Ritterspiele von Bedeutung, die im 18. Jahrhundert auf den Volksbühnen gegeben wurden. Im deutschen Sprachraum diente der im 18. Jahrhundert etablierte Begriff des Nationaltheaters dann ja auch „bis zum Verschleiß als Kristallisationskern politischen Räsonnements" (Schramm 1990, 232), womit der ideelle Import nach Böhmen erleichtert wurde.

\section{IV.2. Der kulturgeschichtliche Kontext des tschechischen Dramas}

Der in die Gattung Drama eingeschriebene potenzielle Publikumsbezug manifestiert sich auf elementarer Ebene, etwa in der Wahl der Sprache, in welcher das Drama abgefasst ist. Die in der zweiten Hälfte des 18. Jahrhunderts beginnenden mannigfachen Bemühungen der tschechischen Patrioten um eine Neu- bzw. Wiedergeburt der tschechischen Kultur waren bekanntlich zuallererst auf eine Verbesserung der Stellung der tschechischen Sprache in Konkurrenz zu der damals auf dem Territorium der böhmischen Länder sprachpolitisch begünstigten deutschen Sprache ausgerichtet. Man bemühte sich, die primären und die sekundären modellbildenden Systeme, also die Sprache und die in dieser Sprache formulierten Texte, auf ein Niveau zu heben, das den gebildeten (und somit zwei bzw. mehrsprachigen) Proponenten der tschechischen nationalen Wiedergeburt als angemessen erschien. Im Gegensatz zur deutschen Sprache, die sich in der Folge der Niederschlagung des Ständeaufstandes 1620 und der »Verneuerten Landesordnung « von 1627 als Kultur- und Bildungssprache in den böhmischen Ländern etablierte, sank die tschechische Sprache im 17. und 18. Jahrhundert zur Sprache des einfachen Volkes ab, deren funktionale Möglichkeiten eingeschränkt waren (vgl. Hroch 1999, 132-135). Mit der Bildungspolitik von Maria Theresia und Joseph II. wurde Tschechisch zwar Schulsprache in den Volksschulen (um elementare Bildung zu vermitteln); höhere Schulausbildung erfolgte jedoch allein in deutscher - bzw. allenfalls in lateinischer - Sprache. Die Sprach- und Kulturpolitik des aufgeklärten Absolutismus strebte einerseits Deutsch als übernationale Verwaltungs- und Bildungssprache an, anderer- 
seits sollten die jeweiligen „Muttersprachen“ in den jeweiligen Territorien gefördert und ausgebaut werden, um zum Einen breiteren Schichten den Zugang zu höherer Bildung - die dann aber auf Deutsch erfolgte - zu ermöglichen und zum Anderen aber auch die Kommunikation zwischen dem Staatsapparat und der Bevölkerung in den jeweiligen Regionen zu verbessern (vgl. Bugge 1994, 16-18; Hroch 1999, 133137). ${ }^{79}$ Die beiden Sprachen Deutsch und Tschechisch hatten unterschiedliche gesellschaftliche Funktionen und eine dementsprechende kulturelle Konnotation, so konnotierte der Gebrauch des Deutschen „Kultur“ und „Kultiviertheit“, während das Tschechische mit dem ländlichen Raum, mit Bauerntum und mit „Natur“ assoziiert war. Dementsprechend wurde die Verwendung des Tschechischen im öffentlichen Raum durch die Patrioten bis in die 1830er Jahre als kulturell markiertes Benehmen wahrgenommen (vgl. Macura 1983, 123 u. 139f).

Die auf Ausbildung eines zeitgenössischen qualitativen Schrifttums abzielenden Bemühungen gewannen somit fundamentalen Charakter für die moderne tschechische Kultur. Die Literatursprache musste neu kodifiziert werden, um die heterogenen Entwicklungen auszugleichen, und es mussten zugleich Texte geschaffen werden, die das kulturelle Prestige des Tschechischen anzeigten. Diese ehrgeizigen Bestrebungen erforderten gleichsam ein „interdisziplinäres“ bzw. „synkretistisches“ Vorgehen, also Engagement nicht allein in Philologie, sondern auch in Belletristik, Publizistik, Literaturkritik, patriotischer Agitation etc. (vgl. Macura 1983, 16-23). ${ }^{80}$ Das Schaffen von Josef Jungmann zeigt am deutlichsten die „offensiven“ Bestrebungen des auf den Ausbau des Tschechischen bezogenen obrození, also derjenigen Epoche, in welcher die tschechische Kultur nach nationalen Prinzipien aufgebaut werden sollte. Wie sich paradigmatisch an Jungmanns Hauptwerk, dem 1834-39 erschienenen Slovnik česko-némecký zeigen lässt, inkludierte die Ausarbeitung eines primären Systems die Normierung der Literatursprache, die Aktualisierung und Erweiterung des Lexikons und die Ausarbeitung einer Fachterminologie für alle Bereiche der modernen Gesellschaft und der sozialen Kommunikation (vgl. Macura 1983, 56-58). Jungmann, der im Unterschied zu Josef Dobrovský, dem wichtigsten Vertreter der ersten, „defensiven“ Generation des obrozeni, seine Schriften bevorzugt auf Tschechisch verfasste, versuchte zuerst in den Dvojí rozmlouváni o jazyku českém (1806 in Jan Nejedlýs Hlasatel český veröffentlicht) mit der Gattung eines fiktiven Streitgesprächs aufzuzeigen, wie stark die tschechische Sprache der

79 Dementsprechend wurde in den 1750er Jahren der Tschechisch-Unterricht an der Militärakademie in Wiener Neustadt und an der Wiener Ingenieur-Akademie eingeführt; 1775 kam es zur Errichtung eines Lehrstuhls für Tschechisch an der Wiener Universität, 1791 an der Prager Universität (vgl. Hoensch 1992, 297-299).

80 Die Konzentration auf Sprache und Literatur manifestierte sich auch in der historiographischen Darstellungen der Zeit des tschechischen Vormärz, in denen nicht politische Entscheidungen, sondern philologische (Dobrovský, Jungmann, Šafařík) und historiographische Leistungen (Palacký) als prägend für die Epoche dargestellt wurden (vgl. Hlavačka 2005, 11f). 
Konkurrenz des Deutschen ausgesetzt sei - Jungmann setzte damit das Genre der in den siebziger Jahren des 18. Jahrhunderts begonnenen Verteidigung des Tschechischen fort, wobei die dialogische Form es ihm ermöglichte, die Standpunkte schärfer zu formulieren (vgl. Vodička 1960b, 235). ${ }^{81}$ Die Dvojí rozmlouváni o jazyku českém gelten dementsprechend als Einsatzpunkt eines sprachlich fundierten Kulturbegriffs bzw. als Grundstein für die Schaffung einer sprach- bzw. kulturzentrierten tschechischen Nationalideologie, welche im weiteren Verlauf des obrozeni den territorialen und damit transnationalen Landespatriotismus ablöst (vgl. Bugge 1994, 25f; Haman 2007, 45-47).

Im ersten Gespräch von Dvojí rozmlouváni o jazyku českém trifft der frühneuzeitliche Geschichtsschreiber und Förderer tschechischen Schriftums, Daniel Adam z Veleslavína (1546-1599) auf einen Tschechen des frühen 19. Jahrhunderts, der Tschechisch nur mehr mit deutschem Akzent spricht; ein nationalbewusster Deutscher bestärkt schließlich Daniel z Veleslavína in der Hoffnung, dass die tschechische Nation nicht gänzlich untergehen werde. Das zweite Gespräch zwischen den mit sprechenden Namen versehenen Dialogpartnern Slavomil und Protiva behandelt die politische Frage nach einer tschechischen Nation, die im Gegensatz zum territorialen Nationsbegriff der Aufklärung nun mittels der sprachlichen Zugehörigkeit definiert wird. Jungmann präsentiert in den »Gesprächen « seinen Sprachpatriotismus, den er gleichsam als fertiges Modell aus der deutschen Kultur übernimmt - in den Prvotiny pěkných uméní, der belletristischen Beilage zu den C.k. vídeňské noviny, übersetzte Jungmann 1813 in Auszügen Jahns Das deutsche Volkstum (vgl. Schamschula 1990, 359), im gleichen Jahr erschien dortselbst übrigens auch die Übersetzung von Herders geschichtsphilosophischer Spekulation über die Slawen (das Slawenkapitel aus den Ideen zur Philosophie der Geschichte der Menschheit, in dem die später so genannte „Taubentheorie“ formuliert wurde), die ebenfalls von Jungmann besorgt wurde (zu Jungmanns durchaus eigenwilliger Übersetzungspraxis vgl. Macura 1983, 75-77).

Insofern es im obrozeni nicht unmittelbar um politische, rechtliche oder institutionelle Anliegen der Patrioten ging, sondern überhaupt einmal erst um die Schaffung eines Nationalbewusstseins, welches erst in weiterer Folge mit gezielten politischen Forderungen verknüpft war, wird mit Recht von dessen „philologischer Prägung" (vgl. Macura 1983, 64) gesprochen. ${ }^{82}$ Mit Slovesnost aneb Sbirka príkladiu s krátkým pojednáním o slohu (1. Aufl. 1820) erarbeitete Jungmann eine ursprünglich für den Gymnasialunterricht vorgesehene Poetik, die an klassischen

81 Aufgrund der Zentralisierungsbemühungen Josefs II., die vorsahen, Deutsch als alleinige Verwaltungssprache durchzusetzen, war das Tschechische einem verstärkten politischen Druck ausgesetzt, konnte sich aber bereits auf Interessengruppen stützen, denen die Zentralisierung und sprachliche Vereinheitlichung von Wirtschaft und Verwaltung ungelegen kam.

82 Dies bemerkten aufmerksame Zeitgenossen wie Adam Mickiewicz, der von den Tschechen als „philologischer“ Nation gesprochen hat (vgl. Jungmann 1846, 29; Bugge 1994, 25). 
Mustern der Rede- und Stilkunde ausgerichtet war. Wie der Titel anzeigt, handelt das Werk nicht von belletristischer Literatur (Literatur im engeren Sinn), sondern von Schrifttum allgemein; es ging darum, Anleitungen zu geben, wie möglichst viele "Textsorten“, die in den europäischen Literaturen etabliert waren, auch in tschechischer Sprache verfasst werden können: „[...] tím, že to, což nejlepšího jest, vypodobňujeme, nabýváme schopnosti sami něco podobného vymýšleti“" ${ }^{\text {“83 }}$ (zitiert nach Vodička 1960b, 248). Slovesnost ist demnach als ehrgeiziges Kulturprogramm zu verstehen, mittels welchem eine vollwertige Kultur möglichst rasch geschaffen werden sollte. Das Werk setzt die seit der zweiten Hälfte des 18. Jahrhunderts vermehrten Aufforderungen fort, tschechischsprachige Texte zu produzieren, die dem „internationalen Vergleich“ standhalten könnten. Während die Verweise auf die Dramatik Shakespeares, Lessings, Schillers oder Goethes durch Autoren des späten 18. Jahrhunderts wie Karel Ignác Thám (dem ersten Übersetzer Shakespeares ins Tschechische, er übersetzte Macbeth von einer deutschen Vorlage - Drábek 2012, 94f) oder Prokop Šedivý aus dem Geist aufklärerischer Volkserziehung erfolgten und vor allem also den moralisch-erbaulichen Aspekt von Drama und Theater betonten, war die Motivation von Jungmann und seiner Umgebung eine dezidiert nationalsprachliche; es ging nicht in erster Linie um die Vermittlung entsprechender Inhalte an ein Publikum, sondern um das Medium der Vermittlung selbst: dieses sollte die tschechische Sprache sein, die damit ihre Leistungsfähigkeit bzw. den Grad der Kultiviertheit der tschechischen Nation demonstrieren sollte. ${ }^{84}$

Als einer der Hauptvertreter des obrození war Jungmann der Überzeugung, dass die tschechische Sprache in allen Gattungen erprobt und eingesetzt werden müsse, er trat für eine größere stilistische Freiheit und Elastizität der Sprache der Dichtung ein und erprobte dies selbst an Übersetzungen (in denen der Umstand, dass ins Tschechische übersetzt wurde, eine größere Bedeutung als der übersetzte Originaltext hatte, denn für Jungmann war der Inhalt des Übersetzten gleichsam ein „Wanderstoff“, der zwischen den Sprachen und Kulturen ausgetauscht wurde, während die Spezifik in der sprachlichen Form steckte). Somit erklärt er in der zweiten Auflage von Slovesnost im Zusammenhang mit Überlegungen den Nutzen

83 „[...] dadurch, dass wir dasjenige, was zum Besten zählt, nachahmen, erlangen wir die Fähigkeit, selbst etwas Ähnliches auszudenken.“

84 Macuras materialreicher Nachweis, dass die lingozentrische Kultur des obrozeni auf die Zeichenhaftigkeit (des Sprachzeichens) großen Wert gelegt habe, könnte um McLuhans Formeln vom (sprachlichen) Medium als „message“ bzw. „massage“ erweitert werden, um etwa die perlokutiven bzw. soziologischen Effekte dieser patriotischen Kommunikation zu erfassen: Tatsächlich beförderten bzw. stimulierten die tschechischsprachigen Texte die Ausweitung der Nationalbewegung. 
von Übersetzungsarbeit: „V jazyku naše národnost“85 (Jungmann 1846, 25; vgl. allgemein Hrabák/Jeřábek/Tichá 1976, 162f).

Die nach dem Muster zeitgenössischer psychologisierender ästhetischer Theorien (des Handbuchs der Aesthetik [1803] von Johann August Eberhard und der Aesthetik für gebildete Leser [1807] des Universalgelehrten Karl Heinrich Ludwig Pölitz) konzipierte Slovesnost präsentierte erstmals in der tschechischen Kulturgeschichte ein kategoriales System literarischer Gattungen und erlaubte somit Vergleiche zwischen dem entwickelten „Ideal“ und dem zeitgenössischen Zustand der tschechischen Literatur. Während František Palacký und Pavel Josef Šafařík in den Poćátkové ceského básnictví [Die Anfänge tschechischer Dichtung] bloß monierten, dass es an großen Werken in tschechischer Sprache fehle, gibt Jungmann u.a. mit Übersetzungen vor allem aus der englischen (Miltons Paradise Lost), französischen (Chateaubriands Atala) und deutschen (Goethes Hermann und Dorothea) Literatur Beispiele, die er tschechischen Autoren als Vorbild empfiehlt. ${ }^{86}$ Zwar wurde bereits von Literaten der Aufklärung die Nachahmung von Shakespeare, der klassischen Tragödie und Schiller zur moralischen Erbauung des Publikums angeregt, aber in der Slovesnost wurde das Fehlen des prestigereichen Genres Tragödie in der tschechischen Literatur aufgezeigt und in einen gesamtkulturellen Bezug gebracht.

Was nun die Darstellung des Dramas im ästhetischen System von Slovesnost betrifft, so unterscheidet Jungmann dieses von den anderen Gattungen Epik und Lyrik aufgrund des Umstandes, dass dem Publikum eine Handlung durch Sprache und Körperbewegungen vorgeführt, mithin also in der Gegenwart rezipiert wird (vgl. Jungmann 1820, LVIII). Entsprechend dem auf klassizistischen Vorstellungen beruhenden Gattungssystem der Slovesnost galt die Tragödie mehr als die Komödie, in welcher die ,niedrigeren Mächte' des Menschen vorgeführt werden. Die Tragödie (Jungmann übersetzt die Genrebezeichnung auch mit smutnohra - ,Trauerspiel') wurde entsprechend ihrem Inhalt und ihrer Wirkung definiert als ,dramatische Handlung, die selbst oder aufgrund ihrer Folgen Furcht und Schrecken hervorruft, bei der eine oder mehrere Personen mit einem von Leidenschaften oder Umständen bestimmten Schicksal kämpfen, was meist unglücklich endet' (vgl. Jungmann 1820, LX). Jungmann betont, dass von der moralischen bzw. sittlichen Größe des Tragödienhelden die Wirkung auf das Publikum abhängt, die nicht allein in Furcht und Mitleid, sondern auch in einer Hebung des Geistes bestehen soll. Seine Unterscheidung von alter und neuer Tragödie begründet er zum einen mit unterschiedlichen Heldentypen: in der alten Tragödie seien es Kriegerhelden gewesen, während die

85 „In der Sprache ist unser Volkstum.“

86 In die zweite (1845) und dritte (1846) Auflage der Slovesnost, welche gegenüber der Erstveröffentlichung stark überarbeitet wurden, fanden bereits immer mehr Beispiele aus der neueren tschechischen Literatur Aufnahme; der ursprüngliche Zweck - die Verbesserung der tschechischen Belletristik im internationalen Vergleich - erscheint somit erfüllt worden zu sein. 
neue Tragödie im gewöhnlichen Leben der Gegenwart angesetzt sei und Gefühle und Leidenschaften vorführe, die dem Publikum leichter zugänglich seien. Als Beispiel für schicksalsmächtige Gefühlsstrebungen führt Jungmann die Liebe zur Heimat noch vor Ehrgeiz, Liebe und Eifersucht an; solche Gefühle könne das Publikum eher teilen als physische Qualen alter Heroen (vgl. ebd. LXI f) ${ }^{87}$

Zwischen Tragödie und Komödie setzt Jungmann noch das Schauspiel („vlastní drama neb činohra“) an, das durch weniger extreme Motive und Handlungen eines eher gewöhnlichen Helden gekennzeichnet ist und nach dem Wechsel von Gefühlen und Stimmungen meist glücklich endet.

Der regelpoetische und didaktische Charakter der ersten Ausgabe von Slovesnost - vgl. dazu auch Haman (2007, 78f), wo der Vergleich zu der klassizistischen Lehre von den genera dicendi gezogen wird - lässt darauf schließen, dass die Gattungsbeschreibungen Jungmanns eher den „deduktiven“ Charakter eines idealen poetologischen Programms hatten als dass sie deskriptiv aus der tschechischen Literatur hervorgegangen wären. Jungmann legte mit Slovesnost gleichsam eine Anleitung zum Ausbau der tschechischen Nationalliteratur vor, um die tschechische Literatur an die europäischen Literaturen heranzuführen.

Vladimír Macura (vgl. 1983, 118-137) beschreibt die text- bzw. „kulturgenerierende" Praxis im obrození als Mystifikation und Spiel. Insofern nämlich die historische Realität ziemlich weit vom patriotischen Ideal einer breit ausgebauten Nationalkultur entfernt war und es für eine tschechische Hochkultur eine nur sehr schmale soziale Grundlage gab, simulierten die von den Nationalpatrioten produzierten Texte eher das Vorhandensein einer Hochkultur, als dass sie als verlässlicher Indikator für diese dienen konnten. Die Neukonzeption einer tschechischen Nationalsprache als „primäres modellbildendes System“ und die erwünschte Produktion von Texten, die in dieser Sprache verfasst waren, sollten entsprechend rasch das Ideal einer vollwertigen nationalsprachlichen Kultur näherbringen.

Macura ist dementsprechend der Meinung, dass den in Slovesnost charakterisierten idealen Gattungen der Tragödie und der Komödie nichts in der tatsächlichen tschechischen Theaterproduktion entsprochen habe. ${ }^{88}$ Er unterscheidet daher auch scharf zwischen der von Jungmann angeregten Dramenproduktion und dem realen Theater, wobei er im Wesentlichen die bereits von Vladimír Štěpánek vorgenommene Dichotomisierung von Drama und Theater übernimmt. Štěpánek selbst geht

87 Neben dem Chor, den Jungmann aus dramaturgischen Gründen ablehnt (er zerstöre das Miterleben und die Einheit der Handlung), missfällt ihm an den älteren Tragödien die Körperlichkeit des heroischen Leidens. Man fühle leichter bei unglücklicher Liebe und Eifersucht mit als etwa bei Gichtschmerzen (vgl. Jungmann 1820, LXII).

88 „Tato situace - pro jungmannovské kulturní úsilí typická- platí i pro drama, tj. texty dramatické, nemohla však platit pro divadlo“ (Macura 1995, 192). - „Diese Situation [gemeint ist die oben geschilderte] gilt auch für das Drama, also für dramatische Texte, sie konnte aber nicht für das Theater gelten." 
davon aus, dass es sehr wohl ein anspruchsvolles Drama vor der „reifen“ Dramatik von Josef Kajetán Tyl gegeben habe, nur habe dieses nicht in den Theaterbetrieb der damaligen Zeit gepasst. Die zeitgenössische dramatische Produktion orientierte sich stattdessen an den Bedürfnissen und Rezeptionsgewohnheiten des tschechischen Theaterpublikums und war dementsprechend nicht sonderlich anspruchsvoll (vgl. Štěpánek 1959, 9-13). Hingegen war das gehobene Drama, wie es Jungmann erwartet hat, eine elitäre Gattung, die in der „Hochzeit" des obrození, also in den zwanziger und dreißiger Jahren des 19. Jahrhunderts, kein reales Publikum finden konnte. Es war daher wohl eher auf die Rezeption durch Lektüre ausgerichtet.

Die von Slovesnost angeregte, tatsächlich produzierte Dramenliteratur konnte den hohen Ansprüchen zwar nicht ganz genügen, dennoch kann Slovesnost initialisierender Charakter zugeschrieben werden (vgl. Topolová 1996, 18): im Verlauf des 19. Jahrhunderts lassen sich die Bemühungen um eine große Tragödie in der Regel auf die in Slovesnost geäußerten Forderungen zurückführen. Rückblickend konstatiert der tschechische Theaterhistoriker František Černý (vgl. 2005a, 33), dass einerseits zwar das Theater eine unvergleichlich große Rolle im obrození gespielt habe, andererseits aber die ehrgeizigen Bemühungen des Jungmann-Kreises auf das damalige Theaterleben wenig Auswirkungen hatten: „Divadelní podněty mimodivadelní, které vycházely od vzdělanců Jungmannova okruhu, byly sice z delších vývojových

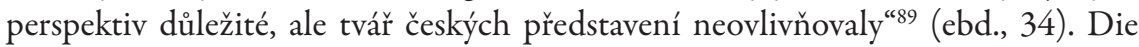
Bedeutung des „real existierenden“ Theaters bestand hingegen darin, dass es keine andere kulturelle Institution bzw. überhaupt keine andere öffentliche Institution gegeben hat, in welcher zur damaligen Zeit die tschechische Sprache in einem solchen Ausmaß öffentlich gesprochen bzw. in ihrer kommunikativen Leistung „vorgeführt“ wurde. Deswegen betrachteten die Nationalpatrioten es als wichtiges Medium für Agitationszwecke (vgl. Hroch 1999, 73).

\section{IV.3. Tschechisches Theater vor 1848}

Im Zusammenhang dieser auf das historische Drama ausgerichteten Arbeit kann unmöglich ein ausführlicher theatergeschichtlicher Überblick über einen Zeitraum von ca. 120 Jahren tschechischsprachigen Theaters gegeben werden, der überdies von berufener Seite auch schon umfassend geschaffen wurde. ${ }^{90}$ Zumal allerdings

89 „Die von außerhalb des Theaters stammenden Impulse, die von den Gebildeten des Kreises um Jungmann ausgingen, waren aus Sicht der weiteren Entwicklungsperspektive zwar wichtig, sie hatten aber keinen Einfluss auf die Gestalt der tschechischsprachigen Theateraufführungen."

90 An erster Stelle muss hier die im Zeitraum 1968-1983 veröffentlichte vierbändige Theatergeschichte Déjiny českého divadla I-IV (Hrsg. von František Černý, in der Folge wird mit der Sigle DčD auf sie verwiesen) erwähnt werden, die eine umfassende Darstellung liefert, deren Wert von der zeitbedingten Angleichung an die Vorgaben des realsozialistischen Machtappa- 
das Drama als literarische Gattung mit der gesellschaftlichen Institution Theater bzw. Theateraufführung in engem Zusammenhang steht, sollen als Hintergrundinformation in dieser Arbeit wenigstens skizzenhaft die Bedingungen des Theaterlebens verdeutlicht werden. Hierbei beschränke ich mich auf die Geschichte des tschechischen Theater bis zur Eröffnung des Národní divadlo, das als Symbol für die Konsolidierung der tschechischen Nation gilt; die Zeit danach, wiewohl theatergeschichtlich natürlich bedeutsam, ist für die nationalpolitischen Implikationen jedoch schon weniger relevant.

Wie oben festgestellt wurde, ließ sich der ideologische Plan der Patrioten des obrozeni nicht auf diejenige gesellschaftliche Wirklichkeit übertragen, die sich im Theaterleben (in der Organisation der Theater, in der Aufführungspraxis, in der Makrokommunikation zwischen Autor und Publikum) manifestierte. Štěpánek und Macura konstatierten, dass Drama und Theater zwei unterschiedliche Kommunikationspraktiken ausmachten. Die Vertreter des obrození wollten in ihren Kulturanstrengungen den Beweis schaffen, dass es eine tschechische Kultur gibt, die in allen relevanten Bereichen mit anderen Nationalkulturen konkurrieren kann, dementsprechend übernahmen sie den transnationalen klassischen Wertekanon, in welchem das Drama qua Tragödie eine so prominente Position in der kulturellen Wertehierarchie einnahm. Diese Bemühungen um eine voll ausgebaute nationale Kultur brachten in einem ersten Schritt Fiktionen hervor. ${ }^{91}$ Lebendiges Theater hingegen funktioniert unter Berücksichtigung des Publikums und dessen Rezeptionshorizonts; insofern also die Vertreter des obrození eine relativ kleine patriotische Avantgarde bildeten, entfernten sie sich in ihren nationalkulturellen Ansprüchen vom tschechischsprachigen Publikum, dessen Kommunikationserwartungen von der Tradition religiöser Theaterformen, von unterhaltendem Laien- und Wandertheater geprägt war und das im Theater vorwiegend ein Unterhaltungsmedium sah. Das tschechische Theater war folglich insgesamt "realer" und weniger „ideal“ bzw. abstrakt, es hatte ja - egal ob als semi-professionelles Theater wie in Prag oder als Laientheater in den Provinzstädten oder Dörfern - tatsächlich ein Publikum, dessen Erwartungshorizont mit der Theaterpraxis erreicht werden musste (vgl. Macura 1983, 123f). Im Hinblick auf die kulturelle Situation in Böhmen kann dem

rats kaum gemindert wird. Weniger extensiv, dafür aber besser fasslich, sind die Überblicksdarstellungen von Jan Vondráček (1956; 1957) und von Jan Císař (2004a; b). Für die Theatergeschichte bis zum Ende des 18. Jahrhunderts siehe Jakubcová/Pernerstorfer 2013. Die sich über zwei Jahrzehnte erstreckenden Aktivitäten des Prozatímní divadlo (Interimstheater, 1862-1883), der wichtigsten Vorstufe zum Národní divadlo, sind in einer voluminösen faktographischen Publikation verzeichnet: Štěpán/Trávníčková 2006.

91 Jungmanns zweisprachiges Wörterbuch wurde beispielsweise mittels Calquierungen, Übernahmen aus dem Polnischen und Wortneubildungen erstellt, um die Vollwertigkeit der Sprache und ihre Gleichrangigkeit mit dem Deutschen manifestieren zu können (vgl. Macura 1983, 58 f u.119). 
tschechischsprachigen Theater bis in die Mitte des 19. Jahrhunderts aber eher pauschal ein „subkultureller" Status zugeschrieben werden. Gerade weil es an einem „realen“ "tschechischen Publikum ausgerichtet war und dessen Interesse befriedigte, galt es als weniger anspruchsvoll und wurde von der Jungmann-Generation als minderwertig angesehen. ${ }^{22}$

Im praktisch zweisprachigen Prag, dessen Oberschicht nach der Niederschlagung des Ständeaufstands zusehends an der deutschsprachigen Kultur orientiert war, während die sozial niederen Schichten und die vom Land in die Stadt migrierten Bewohner Prags vorwiegend Tschechisch sprachen, ${ }^{93}$ waren am Ständetheater tschechischsprachige Aufführungen lange Zeit nur in eingeschränktem Maße möglich. Als institutioneller Vorläufer des Národní divadlo war das Ständetheater die dauerhafteste Bühne in der Hauptstadt Böhmens, es wurde 1781 auf Initiative des Grafen Nostitz gegründet (daher auch die für seine Frühzeit gebräuchliche Bezeichnung Gräfl. Nostitzsches Nationaltheater ${ }^{94}$ bzw. Nosticovo divadlo; adelige Familien übernahmen es 1798 nach dem Tod von Nostitz und die böhmischen Stände wurden rechtlich zum Träger des Theaters). Das 1783 mit Lessings Emilia Galotti eröffnete Theater sollte im Geist josefinischer Aufklärung von oben zur Bildung in deutscher wie auch in tschechischer Sprache (vgl. Wögerbauer 2015, 118) - des Volkes beitragen, daher wurde es auch gegenüber dem Karolinum, dem traditionsreichen Universitätsgebäude, errichtet. ${ }^{95} 1786$ erteilte Joseph II. die Spielerlaubnis für ein „utraquistisches ${ }^{496}$, dh. deutsches und tschechisches Theater. Dieses kurzlebige - es bestand nur bis 1789 - Vlastenské divadlo v Novém Městě, im Volksmund Bouda genannt, hatte einen Bühnenvorhang, auf welchem der Reichsadler abgebil-

$92 \mathrm{Ab}$ den 1860er Jahren wuchs die Laientheaterbewegung (sowohl die tschechische wie auch die deutsche) vor allem in den Kleinstädten deutlich an, was 1885 zur Gründung eines Zentralverbandes der Laien führte (vgl. Císař 2004b, 21).

93 Die soziolinguistischen Verhältnisse in Prag wurden bereits im obrození zentraler Gegenstand theatralischer Reflexion, so vor allem in Josef Kajetán Tyls populärem Schwank Fidlovacka aneb Žádný hnèv a žádná rvačka (vgl. dazu Osolsobě 1993).

94 Nach Ansicht von Philipp Ther war das Ständetheater in Prag das bedeutendste Adelstheater in Mitteleuropa: Graf Nostitz wollte mit dem Wiener Nationaltheater von Joseph II. konkurrieren, was ihm mit zwei Uraufführungen von Mozart-Opern (Don Giovanni, 1787, und La Clemenza di Tito, 1791) auch gelungen ist (vgl. Ther 2006, 78).

95 Noch vor dem Ständetheater gab es das Divadlo v Kotcích (1737-1783), das ein Zentrum mitteleuropäischen Theaterlebens war (u.a. wurden Schillers Räuber hier im Original bereits 1783 aufgeführt), im Verzeichnis Laiskes sind allerdings nur vier tschechische Aufführungen registriert. Unter dem aufgeklärten Absolutismus von Joseph II. kam es zu einer regelrechten „Theateroffensive“; in vielen Regionalzentren der Habsburgermonarchie (Baden, Graz, Salzburg, Innsbruck, Leoben, Lemberg, Kaschau, Hermannsstadt etc.) wurden Theatergebäude errichtet (vgl. Černý 2000, 14f).

96 Diesem Ausdruck aus der hussitischen Theologie des 15. Jahrhunderts begegnet man in der tschechischen Theatergeschichtsschreibung des Öfteren. 
det war: Unter dessen Flügeln stand der politisch programmatische Spruch „Sub umbra alarum tuarum vincit leo“ („Im Schatten deiner Flügel siegt der Löwe“), womit eine einträchtige Unterordnung des tschechischen „Löwen“ unter den Reichsverband ikonologisch postuliert wurde (vgl. Vodička 1960a, 94). Diese Darstellung braucht keineswegs als imaginäres politisches Ideal der österreichischen Regierung interpretiert zu werden, vielmehr schien ein „frühnationaler“ böhmischer Landespatriotismus damals - und für viele Tschechen sogar noch bis zum Ersten Weltkrieg - mit einer prinzipiellen Loyalität zum Kaiser als Repräsentanten des multinationalen Imperiums vereinbar (vgl. Hoensch 1992, 299f).${ }^{97}$ Das konventionalisierte Attribut der Aktivisten dieses ersten Theaters - „vlastencové z Boudy“ (,Patrioten aus der Bouda/Bude') - hatte somit noch keine anti-österreichische Konnotation.

Diese von Joseph II. erteilte Spielerlaubnis stellte als „Privilegium“ über 100 Jahre die rechtliche Grundlage für tschechischsprachiges Theater dar, das in quasi professioneller Form ab ca. 1785 existierte; davor gab es in der Zeit nach 1620 neben Theaterinszenierungen des Adels und jesuitischem Schultheater nur vorwiegend in oraler Tradition stehendes Volkstheater, Wanderbühnen bzw. vazierende Puppentheater (vgl. Černý 2005a, 32). Der Beginn eines tschechischsprachigen Theaters als nationale Institution, die sich auch entschieden von den als vulgär angesehenen Theaterformen absetzen wollte (vgl. Wögerbauer 2015, 74), ist also mit dem Ende des 18. Jahrhunderts anzusetzen (vgl. Císař 2004a, 29f). Prokop Šedivý, ein Autor und Schauspieler des Vlastenské divadlo übersetzte schon 1793 Schillers „Was kann eine gute stehende Schaubühne eigentlich wirken?" ${ }^{\text {988 }}$ unter dem Titel Krátké pojednání o užitku, který ustavičně stojici a dobře spoŕádané divadlo zprisobiti může ins Tschechische, wobei er Schillers Überzeugung, dass die Schaubühne letztendlich auch konstitutiv für die Nationsbildung sei („,...] wenn wir es erlebten, eine Nationalbühne zu haben, so würden wir auch eine Nation“ - Schiller 2005, 96), abschwächte zur Formulierung, dass die Nationsbildung durch ein „feststehendes Theater" („ustavičně stojící divadlo") befördert werde. Zumal ja das Vlastenské divadlo zu dieser Zeit bereits existierte, erscheint Schillers revolutionärer Anspruch an das Theater als Katalysator einer nachfeudalen nationalen Gemeinschaft bei Šedivý abgemildert (vgl. Císař

97 Gegen die traditionelle theatergeschichtliche Darstellung, in welcher die Bouda rein unter nationalemanzipatorischem Gesichtspunkt beschrieben wird - was auch belletristisch in Alois Jiráseks monumentalem Geschichtsroman F. L. Věk. Obraz z dob našeho národního probuzeni (1888-1906) Niederschlag gefunden hat -, wendet sich Peřina (2005), der auf den gerne marginalisierten Umstand hinweist, dass auch die Bouda eigentlich utraquistisch ausgerichtet war.

98 Die 1785 veröffentlichte Schrift geht auf einen Vortrag Schillers in Mannheim 1784 zurück; unter dem berühmteren Titel „Die Schaubühne als eine moralische Anstalt betrachtet“ veröffentlichte Schiller sie noch einmal nach Ergänzungen und Umarbeitungen 1802 in seinen kleineren prosaischen Schriften (vgl. Schiller 2005, 598). 
2004a, 32f; Hroch 1999, 72). Nach dem kurzen Erfolg der Bouda übersiedelte das tschechischsprachige Theater in die Bibliothek eines aufgelassenen Kapuzinerklosters U Hybernů (1789-1802) und von 1803-1811 auf die Prager Kleinseite (Malostranské divadlo v Ramannovském domě - vgl. Laiske 1974, 9).

Durch die 1810 unter Franz I./II. wieder verschärften Zensurbestimmungen (vgl. Wögerbauer 2015, 156-164) und die Napoleonischen Kriege wurden diese Anfänge einer professionellen tschechischen Theatertradition jedoch unterbrochen; die Zahl der tschechischsprachigen Aufführungen nahm zu Beginn des 19. Jahrhunderts ab.9 Aus der Zeit vor 1812 sind nur ganz wenige Stücke auch in textlicher Überlieferung - nicht allein nach dem Titel und ungefähren Inhaltsangaben - erhalten, da sie meist nur in handschriftlicher Form vorgelegen hatten. Bereits zu Beginn des obrození hatten diese Stücke Ereignisse aus der tschechischen Geschichte zum Inhalt. Diese wurden auch von deutschsprachigen Autoren zu Dramen mit historischen Stoffen verarbeitet (vgl. Jakubcová 2013, 22). Nach Aleš Haman (vgl. 2007, 41) sollte die historische Thematik den Anspruch auf Ernsthaftigkeit im Unterschied zu populären Gattungen markieren: das chronologisch erste tschechische Theaterstück dieser Epoche war Václav Tháms Břetislav a Jitka aneb Únos z kláštera [Břetislav und Jitka oder die Entführung aus dem Kloster, 1786], von Thám stammen auch Vlasta a Šárka aneb Divoč boj [Vlasta und Šárka oder Der Kampf der Mädchen] sowie Kutnohorský horníci nebo Kdo se vynasnaži, netrpi nouzi [Die Bergleute von Kutná Hora oder Wer sich anstrengt, leidet keine Not] und Švédská vojna v Čechách aneb Udatnost pražských měštanu a studentů [Der Schwedenkrieg in Böhmen oder Die Tapferkeit der Prager Bürger und Studenten, 1792]; die Stücke Josef Jakub Tandlers (1765-1826) hießen Libuše, první kněžna a rekyně $v$ Čechách [Libuše, Böhmens erste Fürstin und Heldin], Jan Žižka $z$ Trocnova (beide 1787), die von Maxmilián Štván Drahomira, ovdovělá kněžna česká, neb Krvavé boleslavské hody [Drahomíra, die verwitwete böhmische Fürstin oder Die blutige Feier in Boleslav, 1791], Jiř̀ z Podébrad (1792), Oldřich a Božena (vgl. Vodička 1960a, 94f). Diese Stücke sind nur ihrem Titel nach bekannt und als Dramentexte mithin nicht verfügbar.

Aufgrund ihrer Zweisprachigkeit fanden die gebildeteren Schichten tschechischer Herkunft mit den häufiger stattfindenden und besser ausgestatteten deutschsprachigen Aufführungen oft ihr kulturelles Auskommen - wie gesagt galt allein Deutsch als Sprache der Gebildeten (vgl. Hroch 1999, 135). Die Bühnen in den Städten von Böhmen und Mähren standen allesamt unter deutschsprachiger Leitung und boten nur sporadisch tschechischsprachige Gastspiele (vgl. Černý 1969,

99 Gegen die Verschärfung der Zensurbestimmungen halfen auch keine „Anbiederungen“ wie etwa antifranzösische Stücke, die bereits im Titel Loyalitätsbekundungen waren („Čechové, vlastně Rakušané “ [Die Tschechen, eigentlichen Österreicher], „Češi jsou praví vlastencové aneb krev a život za Františka, Karla a vlast “ [Die Tschechen sind die echten Patrioten, oder Blut und Leben für Franz, Karl und die Heimat] - vgl. Hroch 1999, 73). 
200). Am Ständetheater waren bis in die 1830er Jahre - vor allem bei Opernaufführungen und Musiktheater, aber auch im Sprechtheater - ein und dieselben Personen in deutsch- und tschechischsprachigen Aufführungen engagiert. Abgesehen von den drei Jahren 1809-1811, in denen aufgrund des Krieges gegen Napoleon überhaupt kein professionelles Theater auf Tschechisch gegeben wurde, erfolgten ab 1812 die Aufführungen in tschechischer Sprache meist unter Mitwirkung von Laienschauspielern. Diese unter der Leitung von Jan Nepomuk Štěpánek ab 1812 am Ständetheater organisierten Aufführungen, deren Erlös einem wohltätigen Zweck zugute kommen sollte, waren nicht sonderlich zahlreich - für die Jahre 1812-1823 führt Laiske (vgl. 1974, 89-102, vgl. Bartoš/Procházka 1969/DčD II, 200) gerade einmal 69 Vorstellungen im Ständetheater an. Gegeben wurden bevorzugt aus dem Deutschen (meist von Štěpánek selbst) übersetzte Ritterspiele und Komödien, Štěpáneks eigene patriotische Theaterstücke („vlastenecké původní činohry“) oder Stücke von Václav Kliment Klicpera, die als sprachlich und ästhetisch etwas anspruchsvoller galten. Aus dieser Zeit rühren auch die ersten Bemühungen um ein gänzlich eigenständiges tschechisches Theater - der Prager Bürger Mikuláš Müller wandte sich 1821 mit einem Gesuch um eine Bauerlaubnis an den Kaiser und begründete dies mit einer Notwendigkeit, die tschechische Sprache und das tschechische Volk zu unterstützen (vgl. V. Procházka 1969/DčD II, 98).

Neben dem seit Ende des 18. Jahrhunderts sich entwickelnden professionellen Theater in Prag kam der Laientheaterbewegung eine große Funktion in der nationalen Bewusstseinsbildung zu. Immerhin funktionierte hier Tschechisch gleichsam selbstverständlich als Bühnensprache, die auch dem Publikum verständlich war (und in diesem Zusammenhang auch nicht sozial markiert war). Das Laientheater war freilich keine rein tschechische Angelegenheit, auch die deutschsprachige Bevölkerung pflegte dieses, und so spielte um die Jahrhundertwende zum 19. Jahrhundert mitunter ein und dieselbe Truppe Aufführungen in beiden Landessprachen. Die Laientheaterbewegung entwickelte sich zu einer kulturell relevanten Bewegung vor allem in den regionalen Zentren, ${ }^{100}$ in Prag selbst ging es in erster Linie darum, das Niveau des tschechischen Theaters entsprechend zu sichern bzw. es an dasjenige des deutschsprachigen Theaters, das allein schon von der Aufführungszahl her dominierte, anzugleichen. In den Jahren 1818 bis 1824 gab es in Prag eine Laienbühne im Teisingrovo divadlo, dessen Repertoire ein wenig anspruchsvoller war, es führte u.a. Schillers Kabale und Liebe, Die Räuber und Stücke von Václav Kliment Klicpera auf (vgl. V. Procházka 1969/DčD II, 100; Laiske 1974, II/195-198), letztere wurden auch am Ständetheater gegeben.

100 Aufgrund der auch heutzutage noch großen Popularität des Puppentheaters in der tschechischen Kultur, einer Kunst, die von großem Einfluß auch auf die tschechische Trickfilmgeschichte war, tendierte man lange dazu, auch in der Geschichte des Puppentheaters nationalideologische Elemente sehen zu wollen, während dies heutzutage als Mythologie zurückgewiesen wird (vgl. Císař 2004a, 53). 
Jan Nepomuk Štěpánek leitete in den Jahren 1824 bis 1834 gemeinsam mit Josef Kainz und dem Schauspieler Ferdinand Polawský das Ständetheater; in seiner Ära kam es zu mehr als 300 Aufführungen in tschechischer Sprache: Diese Gesamtzahl ergibt sich aus übersetzten Dramen und Opern (Štěpánek hat selbst 13 Libretti übersetzt, wobei er sich des tonischen anstelle des bis dato im Tschechischen dominanten syllabischen Versprinzips bediente), Zauberspielen, ein Genre, das vom Wiener Theater übernommen wurde, Ritterspielen oder Possen. Als Theaterdirektor wollte Štěpánek vor allem die Nachfrage des tschechischen Publikums nach unterhaltender Bühnenkunst und Musiktheater befriedigen; dementsprechend selten kam es zu Aufführungen anspruchsvollerer Stücke in tschechischer Übersetzung; die zeitgenössische Theaterproduktion entsprach keineswegs den an hohen ästhetischen Modellen orientierten poetologischen Forderungen Jungmanns, sondern setzte wegen ihrer starken Publikumsbezogenheit auf ein unterhaltendes Repertoire, das wegen der engen Bindung von Josef Kainz an das Wiener Theaterleben stark von dessen Geschmack geprägt war. Wiener Theaterautoren bestimmten indirekt letztlich auch das tschechische Schaffen mit (vgl. Tureček 2001, 9). ${ }^{101}$

Sehr oft äußerten sich Vertreter der nationalbewussten tschechischen Intelligenz abfällig über die Aufführungen von populären Zauberspielen oder Possen wie etwa der Rezensent der tschechischen Version von Nestroys Der Affe und der Bräutigam (Opice a ženich):

Divadlo má být reflex života ve všech jeho rozmanitých a zaujímavých formách. Národ náš má zcela jiné potřeby. Národní život zcela jiným značen jest rázem, než aby individuální cizokrajné hry naň působiti a na větší vyvinování jeho mocí duševních nějakého vlivu míti mohly. ${ }^{102}$ (zit. nach Vondráček 1957, 389)

František Ladislav Čelakovský, der ebenfalls dem anspruchsvollen jungmannschen Programm anhing, schrieb in einem Privatbrief über Štěpáneks überaus erfolgreiche Inszenierung von Adolf Bäuerles Alina aneb Praha v jiném dilu svèta [Alína oder Prag in einem anderen Erdteil], das Štěpánek aus dem Wiener Milieu ins Prager Tschechische übertragen hatte (vgl. dazu Macura 1983, 209f):

101 Auch die deutschsprachigen Aufführungen am Ständetheater hatten in dieser Zeit eine starke Tendenz zu leichterer Unterhaltung. Zwar wurden in deutscher Sprache mitunter immerhin Klassiker der europäischen Dramenliteratur aufgeführt, wesentlich beliebter aber waren Possen und Zauberspiele.

102 „Das Theater soll das Leben in all seinen vielfältigen und interessanten Formen reflektieren. Unser Volk hat aber ganz andere Ansprüche. Das nationale Leben ist von ganz anderer Art geprägt, als dass einzelne fremdländische Spiele auf es wirken und irgendeinen Einfluss auf die Entwicklung seiner geistigen Kräfte nehmen könnten.“ 
Minulou neděli hráli Alínu, česky, člověče! To je ti hloupost vídeňácká. Kdyby to 14letý kluk skládal, zasloužil by pardousek. Zatím p. Bäuerle, redakteur novin divadelních - a p. Štěpánek to překládal. Ale lidu ti bylo, že by nikde moucha nepropadla. To dělá českému publiku hanbu. ${ }^{103}$ (František L. Čelakovský: Korespondence I. Praha 1907 zitiert nach Tureček 2001, 23)

In beiden Zitaten ist also nicht allein eine Abgrenzung gegenüber dem „Transfer“ von Wiener Zauberspielen oder Possen ins Tschechische zu vermerken, sondern gleichfalls eine scharfe Distanzierung der gebildeten nationalbewussten Elite vom einfachen tschechischen Volk, dessen Interessen sie besser zu verstehen vermeinen als dieses Volk selbst. Tureček spricht wohl zurecht von einer Kluft zwischen den Ansprüchen der an ausländischen Modellen kultureller Hierarchie orientierten Intelligenz und dem breiten Publikum, in dessen Rezeptionshorizont anspruchsvollere Dramen eigentlich nicht passten (vgl. Tureček 2001, 16).

Neben Operninszenierungen machten den überwiegenden Anteil an Štěpáneks ungefähr 320 Aufführungen Übersetzungen deutschsprachiger Stücke aus: Er favorisierte dabei vor allem August Kotzebue, von dem er nicht weniger als 13 Stücke inszenierte. ${ }^{104}$ Die große Menge an Übersetzungsliteratur hatte einen beträchtlichen Einfluss nicht allein auf das Theaterleben, sondern auch auf die Vorstellungen vom Drama generell, da mit der Übersetzerarbeit eine Verstärkung des verbalen Elements in Repliken und Nebentexten erfolgte und die für die damalige Zeit typische spontane Schauspielerarbeit allmählich reduziert wurde (vgl. Císař 2004a, 44). Wie wenig stark die tschechische Dramenliteratur in den Jahren 1824-1834 war, zeigt sich darin, dass Štěpánek mit Ausnahme von Josef Kajetán Tyls Dramenerstling Výhoň Dub [1832; der Titelheld ist dem Poem »Oldřich a Boleslav « der „Könighofer Handschrift" entnommen] und Simon Karel Macháčeks Ženichové [Die Bräutigame, 1824] nur Dramen von Václav Kliment Klicpera und aus seiner eigenen Feder im Repertoire hatte. Die tschechische Theatergeschichtsschreibung tendiert wegen dieser Inszenierungsbilanz dazu, die Aufführungspraxis des Sprechtheaters im ersten Drittels des 19. Jahrhunderts als „triviale Romantik“ oder "Präromantik“ zu bezeichnen; Štěpáneks Wirken im Ständetheater sei vor allem wegen seiner Bemühungen um Operninszenierungen und Musiktheater verdienstvoll,

103 „Vorige Woche, stell Dir vor, spielten sie Alina auf Tschechisch. Das ist vielleicht ein Wiener Blödsinn. Wenn das ein 14-jähriger Bub geschrieben hätte, verdiente er dafür ein paar Ohrfeigen. Herr Bäuerle aber, der Redakteur der Theaterzeitung - und Herr Štěpánek übersetzte es. Es waren so viele Leute im Theater, nicht einmal eine Fliege hätte mehr Platz gefunden. Eine Schande für das tschechische Publikum.“

104 In dieser Zeit wurden etwa Schillers Räuber (in der Übersetzung von K.I. Thám) nur einmal (1831) aufgeführt - Štěpánek hatte die Räuber bereits 1818 einmal inszeniert. 
meint etwa Procházka, der in den Opernlibretti sozial progressivere Inhalte als im tschechischen Drama feststellt (vgl. 1969/DčD II, 102 u. 107). ${ }^{105}$

Die mit der aufgeklärten Konzeption von Theater (bzw. „Schaubühne“) hervorgehobene bildende und erzieherische Funktion wurde im tschechischen Zusammenhang unterschiedlich aufgefasst. Wenn auf der einen Seite die Theaterpraktiker den Rezeptionshorizont des Publikums und darüber hinaus auch kommerzielle Aspekte des Theaterbetriebs beachten mussten, so bedeutet dies keineswegs, dass in den „banalen“ Produktionen keinerlei Augenmerk auf die ideologische Wirkung der Stücke gelegt worden wäre, wie dies etwa Štěpáneks patriotische Dramatik der 1810er Jahre zeigt, die immerhin eine Zeitlang gespielt wurde. Auf der anderen Seite erschien den nationalbewussten Gebildeten das Theater nicht entschlossen genug als Instrument der Volkserziehung eingesetzt, daher schwand im Kreis um Jungmann das Interesse am zeitgenössischen Theaterbetrieb, der eben vorwiegend auf die Unterhaltung seines Publikums ausgerichtet war (vgl. Císař 2004a, 40f).

Nach 1834, als Štěpánek nicht mehr Co-Direktor des Ständetheaters war, verloren tschechischsprachige Aufführungen dort weiter an Bedeutung; um eine Alternative zu finden, gründeten nationalbewusste Schriftsteller um Josef Kajetán Tyl das Kajetánské divadlo auf der Prager Kleinseite, das in den Jahren 1834-1837 versuchte, anspruchsvollere Stücke von Štěpánek, Klicpera und Tyl selbst (vgl. Ježková 2013c, 77) - zuerst allerdings ohne offizielle Spielerlaubnis und bei ungünstigen räumlichen Bedingungen - mit Laien zu inszenieren, letztlich aber am fehlenden Publikum und internen Zwistigkeiten scheiterte. ${ }^{106}$

Selbst noch Anfang der 1840er Jahre war in Prag die Nachfrage nach tschechischem Theater geringer als nach deutschsprachigem: deutschsprachige Inszenierungen wurden wesentlich öfter wiederholt als tschechische: Johann August Stöger, der 1834 die Leitung des Ständetheaters übernahm, eröffnete 1842 in der Růžová ulice ein neues Theater für unterhaltendes Repertoire, er verlagerte zeitweise auch tschechische Aufführungen dorthin, doch gab es für einen unverhältnismäßig großen Zuschauerraum zu wenig Publikum, sodass 1846 das Theater wieder schließen musste (vgl. Černý 1969/DčD II, 202f).

105 Auch im Königlichen Stadtheater der weitgehend Deutsch sprechenden Stadt Brünn gab es tschechischsprachige Aufführungen, diese waren aber noch weit weniger frequent als in Prag. Das deutsche Repertoire im Brünner Theater bestand vor allem aus Stücken von Kotzebue und Wiener Zauberspielen; (teilweise auch zweisprachige) Musiktheateraufführungen fanden wegen der höheren Produktionskosten nicht sehr oft statt (vgl. V. Procházka 1969/DčD II, 103-105). Ähnliches kann für Olmütz gelten (vgl. Černý 2005a, 33). Die Nationalbewegung der Tschechen war in Mähren generell weniger stark ausgeprägt und erfolgte später (vgl. Hroch 1999, 7).

106 Berühmt ist in diesem Zusammenhang der Streit zwischen Mácha und Tyl, der auch politische Implikationen hatte - siehe unten, S. 188. 
Die schwierige Situation des tschechischsprachigen Theaters wurde von der nationalbewussten Intelligenz immer wieder thematisiert: Tyl schreibt am 7. Jänner 1841 in den Květy: „Divadlo jest tak důležitou stránkou národního života, že majíce líčiti stav jaké také národnosti naší a neberouce ohled na divadlo, nedobře bychme účele svého dostihli." ${ }^{107}$ (zitiert nach Strejček 1932, 21f). Karel Havlíček Borovský ist in der Česká včela (2.10.1846) noch drastischer:

K čemu pak může dospěti naše české divadlo, na které Páni stavové království Českého nic nenakládají, které se beze vší pomoci, nemajíc ani obydlí ani výživy, jenom jako nějaké divoké zviře samo živiti musí tím, co kde užene! Pokavad naše divadlo v takovém nehodném stavu, v takovém podruží bude, nehodláme tedy žádných referátů o něm podávati, leč by se něco znamenitějš́ího přihodilo. ${ }^{108}$ (zitiert nach Strejček 1932, 78)

Havlíček Borovský schwebte bereits in den 1840er Jahren ein monumentales Theatergebäude vor, tatsächlich waren ja damals schon in fast allen Metropolen Europas Nationaltheater eröffnet worden oder in Bau befindlich. Im Vergleich mit diesen Tendenzen war die Situation für das tschechische Theater in Prag unbefriedigend, da tschechische Aufführungen schlechter dotiert waren als deutschsprachige und im Ständetheater deutsche Stücke klar dominierten. Einen Ausweg suchte man in Bestrebungen um ein eigenständiges tschechisches Theater, ${ }^{109}$ mittels einer Petition mit mehr als 130 Unterzeichnern - vorwiegend aufstrebende tschechische Unternehmer und Vertreter der Intelligenz - wollte man 1844 unter der Führung von František Ladislav Rieger die von Joseph II. erteilte Konzession für das Vlastenecké divadlo erneuert sehen und hatte damit zumindest beim vom tschechischen Adel dominierten Landtag Erfolg. Dieser genehmigte 1845 die Gründung einer tschechischen Theatertruppe, allerdings ohne dieser finanzielle Unterstützung zu gewähren. Im selben Jahr wurde auch ein Vorbereitungs-Komitee ins Leben gerufen, das eine Gesellschaft zur Finanzierung eines Nationaltheaters gründen wollte und sich

107 „Das Theater ist eine so wichtige Seite des nationalen Lebens, dass wir, wenn wir den Zustand einer Nation wie der unsrigen beschreiben müssen und dabei nicht das Theater berücksichtigen, unsere Aufgabe nicht gut erfüllen würden.“

108 „Was kann denn unser tschechisches Theater erreichen, für welches die edlen Stände des Königreichs Böhmen überhaupt nichts aufwenden, welches ohne jede Hilfe, ohne ein Zuhause und Futter zu haben, nur wie ein wildes Tier sich damit begnügen muss, was es sich erjagt. Solange unser Theater in einem so ungünstigen Zustand ist, solange es so untergeordnet ist, werden wir keine Berichterstattung über es geben, es sei denn, irgendetwas Außergewöhnliches geschieht."

109 Zumal der zweisprachige Theaterbetrieb im Ständetheater sich auf die Dauer als unbefriedigend erwies und man gezielt ein tschechisches Publikum erreichen wollte, wurde in den Jahren 1843-44 kurzfristig eine Bühne speziell für tschechische Aufführungen geschaffen. Diese - in der Růžová ulice - war jedoch kommerziell zu wenig erfolgreich, sodass die Direktion erst wieder zum „utraquistischen“ Betrieb zurückkehren musste. 
diesbezüglich an die Wiener Regierung wandte. Bei dieser ist das Gesuch aber wohl nicht angekommen, wie McCord (vgl. 1993, 90) vermutet. Die Regierung in Wien verhielt sich generell gegenüber der Gründung eines tschechischen Theatervereins (der Jednota pro divadlo české) ablehnend, womit einem Bauvorhaben auch die ökonomische Grundlage entzogen wurde. In diesem Zusammenhang wird jener politische Antagonismus zwischen Zentralregierung und Nationalbewegungen deutlich: Die Wiener Regierung hatte Gründe, nationalistische Tendenzen (die sich im Vormärz ja auch mit liberalen Bestrebungen vermischten) pauschal einzudämmen; im Ansuchen der tschechischen Patrioten wurde wohl nicht ganz zu Unrecht eine nationale Tendenz wahrgenommen, welche folglich unterdrückt werden musste:

Divadlo v dějinách našeho národa plnilo vždy politickou úlohu. Zápas o české divadlo v 19. století byl zápasem politickým. Konstituování českého divadla bylo chápáno jako konstituování národní svébytnosti nejenom ve sfére duchovní, ale především v oblasti politické. Vznik českého divadla byl významným politickým činem. Divadlo v Čechách nikdy nebylo pouze uměním pro umění. ${ }^{110}$ (Dvorský 1985, 9)

Als Tyl, der auch als Herausgeber und Autor mehrerer Zeitschriften, als Schauspieler, Übersetzer und Regisseur sehr aktiv war, 1846 zum Dramaturgen tschechischer Vorstellungen im Ständetheater ernannt wurde und als Autor von "Zeitbildern“ (obrazy ze života) und Zauberspielen (báchorky) auf originelle Weise populäre Gattungen des deutschsprachigen Volkstheaters auf tschechische Verhältnisse umlegte, konnte wieder ein breites Publikum für das Theater gewonnen werden. In Abgrenzung von der älteren tschechischen Bezeichnung „divadlo vlastenské“ (,Heimattheater bzw. patriotisches Theater ') führte Tyl auch den Begriff „divadlo národní“ ein, um die neue sprachkulturelle Ausrichtung seiner Theaterkonzeption entsprechend zu markieren (vgl. Bartoš/Procházka 1969/DčD II, 198):

Pro nás je divadlo ještě důležitější. Vedle poměrů jiných divadel - a sice hledem občanského, mravního a uměleckého stanoviště - dotýká se divadlo naše (mnohem více nežli které jiné) záležitostí národních [...] I jinde požadují sice, aby bylo divadlo výkvětem a výlevem národní bytosti, aby se z domácí krve rodilo a do krve domácí přecházelo, ale divadlo naše má vedle těchto stránek povolání svého ještě tu, že musí budit, že musí zahřívat a pěstovat, co jinde již probuzeno, zahřáto a vypěstováno a $\mathrm{v}$ uměleckých výtvorech jenom jako $\mathrm{v}$ čarovném zrcadle se zjevuje. Jinde - smím-li tak říci - chtějí spíše na divadle vidět, co v nich už je - u nás

110 „Das Theater erfüllte in der Geschichte unseres Volks stets eine politische Aufgabe. Der Kampf ums tschechische Theater im 19. Jahrhundert war ein politischer Kampf. Die Gründung eines tschechischen Theaters wurde als Gründung nationaler Souveränität nicht allein in der geistigen Welt, sondern vor allem im Bereich der Politik aufgefasst. Die Entstehung eines tschechischen Theaters war ein bedeutsamer politischer Akt. Das Theater war in Böhmen niemals bloß l'art pour l'art." 
musíme si přáti raděj vidět, co v nás býti má!111 (Josef Kajetán Tyl: „Cestující společnosti herecké" zit. nach Císař 2004a, 52)

Unter Tyls Leitung findet freilich auch die heterogene Rezeption tschechischer Aufführungen ihre Fortsetzung, wie sie zuvor unter Štěpánek konstatiert wurde. Die Nation wenigstens kulturell-ästhetisch zu einigen, stellte sich aufgrund des differenzierten Sozial- und Bildungsgefüges der tschechischsprachigen Bevölkerung immer deutlicher als illusorischer Wunsch heraus. Zwar war Tyl wesentlich stärker in nationalen Belangen engagiert als Štěpánek, doch wurden seine theatralischen Unternehmungen von der jüngeren Generation abgelehnt, weil sie dieser in ästhetischer und politischer Hinsicht missfielen.

Die Jahre 1845 bis 1850 gelten als eine Blütezeit des tschechischen Theaters, insofern nämlich diverse politische Anliegen wegen gelockerter Zensurmaßnahmen - die Texte mussten nur mehr dem Intendanten, nicht mehr der Behörde vorgelegt werden (vgl. Černý 1969/DčD II, 328) - auch auf der Bühne mehr oder weniger gut kaschiert Ausdruck finden konnten. 1848 fand der Wunsch nach einem eigenständigen tschechischen Theater erneut großen Zuspruch, Tyl brachte in seinem Artikel „Nebezpečný proslov“ die „Theaterfrage“, also die Schaffung eines Nationaltheaters als unerlässliche Bildungsinstitution, wieder auf die Tagesordnung:

My musíme ted' brzo na vlastní divadlo pomysliti: tak dobře jako pro nastávající pokolení dobré školy potřebujeme, potřebujeme i pro nynější generaci vedle jiných vzdělávacích prostředků i řádné divadlo, živé, plamenné slovo nadšených básníků a veřejné, umělecké osvědčení se před očima světa, kterýž bude ted' na nás pozornýma očima hleděti. ${ }^{112}$ (Tyl zitiert nach Černý 1969/DčD II, 331)

111 „Für uns [Tschechen] ist das Theater noch von allergrößter Bedeutung. Neben den Verhältnissen anderer Theater - und zwar von deren zivilen, sittlichen und künstlerischen Standpunkt aus - geht unser Theater (viel stärker als anderswo) das Volk an [...]. Zwar fordern sie auch anderswo, dass das Theater die Blüte und die Essenz des nationalen Seins sei, dass es aus heimischem Blut geboren werde und ins heimische Blut übergehe, unser Theater aber hat neben diesen Aspekten seiner Aufgabe auch noch diese, dass es wecken muss, dass es dasjenige anfachen und pflegen muss, was anderswo bereits erweckt, angefacht und gepflegt ist und in künstlerischen Schöpfungen nur wie in einem Zauberspiegel erscheint. Anderswo - wenn ich das sagen darf - wollen sie im Theater eher das sehen, was bei ihnen bereits ist, wir aber müssen eher das zu sehen wünschen, was bei uns erst sein soll!“

112 „Wir müssen nun bald an ein eigenes Theater denken: wie wir wohl für die kommende Generation gute Schulen benötigen, so benötigen wir auch für die jetzige Generation nebst anderen bildenden Medien auch ein ordentliches Theater, das lebendige, feurige Wort enthusiastischer Dichter und die öffentliche Bezeugung vor aller Welt, die auf uns mit aufmerksamen Augen blicken wird.“ 
Tyls Formulierung von der Gebundenheit des Theaters an das Volk ${ }^{113}$ erinnert frappant an die Begründung von Macht in den aufgeklärten demokratischen Verfassungstheorien und zeigt damit schon in der Wortwahl die nach wie vor aufrechte Verbundenheit des Theaters mit der res publica bzw. dem öffentlichen Leben, das schon die griechische und römische Antike kennzeichnete.

\section{IV.3.1. Exkurs: Kurze Bemerkung zur Zensurpraxis}

Die tschechische Nationalbewegung stand wie alle anderen Nationalbewegungen in der Habsburger Monarchie unter dem Pauschalverdacht, dass die nationale Agitation das multinationale Gefüge des Imperiums gefährden könnte. Die Wiener Regierung unterstützte zum einen zwar die kulturellen Aktivitäten der Nationalbewegungen, zum anderen beobachtete sie diese aufmerksam, um destabilisierende oder insbesondere regimekritische Momente auszumachen. Neben dieser repressiven Funktion von Zensur wäre auch deren aufklärerisch-progressive hervorzukehren, die darin bestand, dass die veröffentlichte Literatur qualitätsvoll zu sein hatte, wobei wissenschaftliche, moralisch-ethische wie auch künstlerische Kriterien ins Treffen geführt wurden, um zeittypische Bildungsvorstellungen zu verbreiten (vgl. Wellek 1963, 25f). Die Institution Zensur, die seit dem aufgeklärten Absolutismus Josephs II. nicht mehr von der Kirche, sondern von staatlichen Behörden ausgeführt wurde, bestand unter sich stark ändernden Bedingungen bis zum Ende der Monarchie, wobei im Gegensatz zum paternalistischen Typ der Präventivzensur ab der Verfassung von 1861 keine eigene Zensurbehörde, sondern die Zusammenarbeit von Legislative und Exekutive Druckerzeugnisse auf gesetzeswidrige oder unerwünschte Inhalte untersuchte. Dieses liberalere Modell der Zensur wurde im Prinzip in der ersten Tschechoslowakischen Republik weitergeführt, nur waren die damit verbundenen Zielsetzungen andere als in der durch das nationale Erwachen ihrer Völker destabilisierten Habsburgermonarchie.

Im Jahr 2015 wurde ein langjähriges Forschungsprojekt am Institut für tschechische Literatur an der Akademie der Wissenschaften in Prag mit einer voluminösen Studie abgeschlossen (Wögerbauer et al. 2015), die dem Bedarf nach einem Überblick über die Zensurgeschichte vom ausgehenden 18. Jahrhundert bis zum Ende des Sozialismus mit einer reflektierten Methodologie begegnet, wobei die Komplexität des Phänomens auf den verschiedenen Ebenen literarischer Kommunikation berücksichtigt und von einem allzu simplem Repressionsmodell abgegangen wird. ${ }^{114}$

113 „Naše divadlo musí býti dáno $\mathrm{v}$ srdce a ruce obecenstva, $\mathrm{v}$ interesy celého národu - a tak se mu povede dobře, k naší radosti a slávě (zit. nach Otruba/Kačer 1961, 350; „Unser Theater muss in die Herzen und die Hände der Bevölkerung gegeben werden, dem Interesse des ganzen Volks dienen - dann gedeiht es zu unserer Freude und unserem Ruhm.")

114 Während der Erstellung der Typoskriptvorlage dieser Arbeit (März bis Juli 2015) ist dieses umfangreiche Überblickswerk noch nicht erschienen, vom Projektverantwortlichen Dr. 
In Anbetracht der komplexen Rahmenbedingungen kann auf die Zensurpraxis in dieser Arbeit nur knapp hingewiesen werden. Die Themenstellung dieser Arbeit, die ja den Wandel von zeitgenössischen Einflüssen auf das historische Drama untersucht, würde ja auch vermuten lassen, dass das Genre des historischen Dramas von den Autoren deshalb gewählt wurde, um die Zensurbehörde bzw. die Exekutive vermittels des historischen Stoffs über die im Drama „versteckten“ kritischen Zeitbezüge hinwegzutäuschen. ${ }^{115}$ Wenngleich diese Überlegungen erste Hypothesen bei der Ausarbeitung der Themenstellung bildeten, hat die Beschäftigung mit den diversen Dramen gezeigt, dass die Auswirkungen der Institution Zensur auf die Dramen keineswegs leicht zu überprüfen sind. Einfacher ist dies nur in den nicht sonderlich zahlreichen Fällen, wo die Zensurmaßnahmen so deutlich waren, dass sie auch in der Theater- oder Literaturgeschichtsschreibung notiert bzw. in kritischen Werkausgaben ausgewiesen wurden, etwa für das Schaffen prominenter Dramatiker wie Josef Kajetán Tyl ${ }^{116}$ oder Jaroslav Hilbert. Bei den meisten Dramen aber sind keine solchen Eingriffe bekannt, was aber nicht heißt, dass die Institution Zensur produktionsästhetisch irrelevant wäre, immerhin kann sich die Zensur auch als schwer erkennbare Selbstzensur, als Zensur in der Verlags-, Vertriebs- oder Aufführungspraxis ausgewirkt haben, was aber nur mit sehr aufwändigen Recherchen - die dem thematischen Rahmen dieser Arbeit überhaupt nicht entsprechen - festzustellen wäre.

Die ausgewählten Dramentexte wurden in denjenigen Ausgaben gelesen, die dem Entstehungszeitraum möglichst nahestehen, es sei denn, dass es spätere repräsentativere Editionen des Dramentextes - etwa in (kritischen) Werkausgaben - gibt. Wenngleich die Zensurpraxis generell ziemlich strikt war und besonderes Augenmerk darauf gelegt wurde, ob in der Theaterliteratur und Aufführungspraxis Anspielungen auf zeitpolitische Verhältnisse zu erkennen sind, hat sich gezeigt, dass es für die Analyse der zeitpolitischen Implikationen keine großen Unterschiede macht, ob man eine

Michael Wögerbauer wie auch vom Mitautor Dr. Petr Piša wurden mir freundlicherweise Auszüge geschickt, die für die Drucklegung dieser Arbeit noch berücksichtigt werden konnten.

115 Solche Fälle sind teilweise auch dokumentiert. So hat etwa Josef Jiř́ Kolár 1848 eine Komödie mit dem Titel Čislo 67 (Die Zahl 67) verfasst, der deutlich auf ein damals bekanntes Dankschreiben von 67 Prager Bürgern an Fürst Windischgrätz anspielte. Im Schreiben dankten die Bürger für die Niederschlagung des Prager Pfingstaufstands. Auch wenn 1848 die Präventivzensur für Gedrucktes und für Theateraufführungen gefallen ist, waren die Theaterdirektoren gegenüber den Behörden verantwortlich für die in ihrem Haus gezeigten Aufführungen. Johann Hoffmann, der damalige Direktor des Ständetheaters, verlangte eine Änderung des Titels. Kolár machte aus Čislo 67 einen neuen Titel Čislo 76 anebo Praha pred sto lety (Die Zahl 76 oder Prag vor hundert Jahren) und verlegte die Handlung in die Vergangenheit (vgl. Pokorná 2015, 409).

116 Siehe dazu etwa das Kapitel zu den Zensurbedingungen für das Schaffen Tyls in Černý (2000, 51-57). 
kritische Werkausgabe mit Anmerkungsteil, in dem auf die Zensoreingriffe hingewiesen wird, oder eine Ausgabe aus der ersten Hälfte des 19. Jahrhundert verwendet, für die die Zensur generell als Institution im kulturpolitischen Hintergrund anzusetzen ist, die den gedruckten Text genehmigen musste (vgl. Píša 2015, 224). Ideologische Tendenzen werden ja aufgrund des Handlungszusammenhangs deutlich, auf die Streichung einiger Repliken, die der Zensurbehörde missfallen haben oder von der Exekutive inkriminiert wurden, kommt es dabei nicht unbedingt an. Anders formuliert: Die Relevanz der Zensur in produktionsästhetischer Hinsicht ist pauschal zwar als sehr hoch einzuschätzen, gerade aber aufgrund ihrer Ubiquität, die 1848 nur kurzfristig aufgehoben wurde, ist es für die Analyse unmöglich, eine Dramenproduktion zu imaginieren, die frei von Zensur wäre, in der es keinerlei Beschränkungen hinsichtlich der Möglichkeiten des Ausdrucks gibt. Diese Einsicht impliziert zugleich, dass die verfügbare Primär- und Sekundärliteratur in der Regel ausreichend ist, um die gewählte Fragestellung zu untersuchen, weil die Zensur als Institution generell als produktionsrelevant anzusetzen ist und damit die Entstehung eines jeden Textes beeinflusst hat. Dies zeigt sich etwa in der weitgehenden Absenz von Darstellungen von Österreichern oder Habsburgern in der historischen Belletristik allgemein, die Vladimíra Borová bemerkt hat: Die Deutsch sprechenden Österreicher werden oft den meist negativ dargestellten Deutschen subsumiert, womit die Texte wohl für die Zensurbehörde leichter annehmbar wurden (vgl. Borová 1995, 31).

Die Durchführung der Dramenanalysen auf der Grundlage der vorhandenen Literatur und ohne aufwändige Recherchearbeiten zur Produktionsgeschichte ist auch dadurch gerechtfertigt, dass die Zensurvorschriften im Fall von Inszenierungen strenger waren als bei Publikationen von Dramentexten. So kam es nicht selten vor, dass Dramen eine Druckerlaubnis erhielten, aber nicht zur Aufführung freigegeben wurden: Jan Roháć, der letzte Teil der Hussitentrilogie von Alois Jirásek nach Jan Žižka (1903) und Jan Hus (1911), durfte etwa 1914 gedruckt erscheinen, konnte jedoch erst knapp vor Ende des Ersten Weltkriegs aufgeführt werden (vgl. Obst 1977/DčD III, 314).

Was nun den allgemeinen institutionellen Rahmen der Zensur betrifft, so ist zu sagen, dass in den 1790er Jahren infolge der Französischen Revolution, deren Ausbreitung in Europa verhindert werden sollte, eine Vorzensur für alle Manuskripte, die in Druck gehen sollten, eingeführt wurde, außerdem unterzog man alle importierte Literatur einer Revision. Die Zensurvorschrift vom 22. Februar 1795 sah vor, dass zwischen den Autoren und den über die Schriften befindenden Stellen kein persönlicher Kontakt bestehen durfte; eine gewisse Zentralisierung der Zensuraufgaben in der Reichshauptstadt brachte es aber mit sich, dass beispielsweise in Prag nur drei Zensoren aktiv waren, die sich die Aufgaben teilten, diejenigen Schriften zu begutachten, die nicht nach Wien geschickt werden mussten (vgl. Píša 2015, 237). Dabei legte man auf eine Akkordierung Wert, um Divergenzen bei Beurteilungen in den Ländern der Habsburgermonarchie zu vermeiden. 
Im Vormärz hatten die Zensoren nicht allein politische Inhalte zu überwachen, sondern auch über den sittlichen, ästhetischen oder wissenschaftlichen Wert von Schriften zu befinden (vgl. Píša 2011, 179f). Wenngleich die Zensuraufgaben allgemein und übernational waren, wurden sie von den Aktivisten der tschechischen Nationalbewegung oft als national diskriminierend empfunden bzw. als solche dargestellt.

Im Fall von Dramen und Schauspielen ist wie gesagt zwischen der eigentlichen Theaterzensur sowie - wenn das Stück in Druck gehen sollte - der allgemeinen Präventivzensur zu unterscheiden. Während die Präventivzensur für Druckwerke 1862 in der Folge der Verfassungsbestimmungen 1861 abgeschafft wurde, blieb die sogenannte Theaterordnung vom November 1850, die eine Präventivzensur für alle Aufführungen vorsah, bis zum Ende der Monarchie gültig (vgl. Pokorná 2015, 410).

Für die Theaterzensur in Böhmen gibt es leider keine bündigen Überblicksdarstellungen. In einer Diplomarbeit über das Prager Ständetheater in der Zeit zwischen 1783 und 1861 (Zimmerhaklová 2005) wird etwa darauf hingewiesen, dass die Zensurbehörde den Kontakt mit den Theaterdirektoren suchte und sich mit diesen über die erlaubte Fassung von Stücken einigte: Improvisationen auf der Bühne waren damit untersagt, was offenbar auch von verdeckten Informanten überprüft wurde. Zimmerhaklová führt eine Reihe von Verboten an, die die Bühnenpraxis in der ersten Hälfte des 19. Jahrhunderts ziemlich stark reglementierten: so durften etwa keine Geistlichen vorgeführt werden, Erwähnungen der Kirche waren nicht erlaubt, jedwede österreichische Staatssymbolik wurde von der Bühne verbannt, sogar historische Stoffe wurden daraufhin geprüft, ob sie nicht allzu durchsichtige Anspielungen auf die Verhältnisse der Gegenwart enthielten (vgl. Zimmerhaklová 2005, 79-82). Mit Ausnahme der frühen Etappen der mittelalterlichen Geschichte (Anfänge der Přemyslidenherrschaft) waren viele Bereiche der böhmischen Geschichte tabuisiert. Das gilt insbesondere für die Hussitenperiode und für die Zeit des beginnenden Dreißigjährigen Kriegs bzw. des Ständeaufstands, aber sogar auch für die Repräsentation der Zeit von Karl IV. (vgl. Höhne 2000, 46).

Die Verbote veränderten sich allerdings auch in Abhängigkeit von den politischen Zielsetzungen und Befürchtungen der Regierung. So war unter Joseph II. mehr Kirchenkritik möglich als unter Franz I. bzw. war das Leibeigenenthema nicht immer tabuisiert. Unter dem eher als borniert geltenden Zensor Faustin Procházka wurden zu Beginn des 19. Jahrhunderts Aufführungen von Stücken Lessings oder Schillers (Emilia Galotti, Die Räuber, Maria Stuart, Don Carlos) verboten bzw. nur mit Coupierungen zugelassen, weil Herrscherfiguren in diesen Stücken nicht immer vorteilhaft gezeichnet sind (vgl. Vondráček 1956, 251f). ${ }^{117}$ Als Josef Kajetán Tyl 1842 anlässlich der Eröffnung des Stögrovo divadlo eine Eröffnungsansprache

117 Sogar noch um die Jahrhundertwende gab es Aufführungsverbote oder -beschränkungen für Dramen, die mittlerweile zum Kanon der Bühnenliteratur zählen, etwa für Gerhard Haupt- 
der Zensurbehörde zur Begutachtung vorlegte, beanstandete diese die Rede von „sny i přáni“" (,Träumen und Wünschen') sowie die Aufforderung „stůjte př́i nás“ (,steht zu uns'), weil dahinter ein politischer Sinn bzw. ein Aufruf zum Aufstand vermutet wurde (vgl. Zimmerhaklová 2005, 85).

1850 wurde die Zensur der Landesverwaltung (zemská politická správa) untergeordnet, die Theaterkonzessionen vergab und Listen mit verbotenen Stücken anfertigte. Die Erlaubnis für die einzelnen Aufführungen wurde jedoch in den Städten von der Polizeibehörde, am Land von der politischen Verwaltung (okresni politická správa) erteilt. Diese Regelung hatte bis zum Ende der Monarchie ihre Gültigkeit (vgl. Obst/DčD IV, 17).

Die konkrete Zensurpraxis war begreiflicherweise auch stark von den Veränderungen im politischen Klima und von den involvierten Persönlichkeiten bestimmt, sodass es spezieller Anstrengungen bedarf, um zu Generalisierungen auf der Basis von Einzelfällen zu gelangen. Im Folgenden kann nur im Zusammenhang mit einzelnen Dramen auf Zensureingriffe hingewiesen werden. Eine allgemeine „Poetik der Zensur" für das historische Drama ist nicht zu leisten, aus den angesprochenen Gründen - unterschiedliche Kriterien für Aufführungen und Drucklegungen, Ubiquität der Institution Zensur im kulturellen Feld, individuelle Dispositionen von Zensoren und Autoren - wäre sie vielleicht gar nicht einmal ein so großes Desiderat, zumindest nicht im Zusammenhang mit der in dieser Arbeit verfolgten Fragestellung.

\section{IV.4. Ideologische Analysen historischer Dramen des obrozeni}

(Die nachfolgenden Analysen sind nach den im Abschnitt III beschriebenen Prinzipien gestaltet.)

IV.4.1. Jan Nepomuk Štěpánek: Břetislav První, Český Achylles, aneb: Vitézstvi u Domažlic. Vlastenská pưvodni činohra z jedenáctého století v pèti jednánich (1812)

[Břetislav der Erste, der böhmische Achilles oder Der Triumph bei Domažlice. Originales patriotisches Schauspiel aus dem 11. Jahrhundert in fünf Akten; UA 22.12. 1812, publ. 1813]

Nach einer durch die Napoleonischen Kriege, die repressive antiaufklärerische Wende von Kaiser Franz II. (bzw. Franz I. von Österreich) und den Staatsbankrott von 1811 bedingten Krise des tschechischsprachigen Theaters - ab ca. 1807 scheint es überhaupt keine regulären Theateraufführungen in tschechischer Sprache mehr

manns Die Weber, die 1904 schließlich doch im Brünner Nationaltheater aufgeführt wurden (vgl. Obst 1977/DčD III, 427). 
gegeben zu haben (vgl. Kačer 1969, 70f; Topolová 1996, 21) - begann Jan Nepomuk Štěpánek ab 1812 die tschechische Laienschauspielergruppe am Ständetheater zu leiten, für die er auch „original patriotische Schauspiele“ („vlastenecké původní činohry“) - so lautete seine eigene Genrebezeichnung - schrieb. Diese patriotischen Stücke setzen offenbar die von Václav Thám, Maxmilián Štván, Josef Jakub Tandler und Antonín Josef Zíma begonnene Tradition fort, deren vollständige Textfassungen in der Regel nicht erhalten geblieben sind. Štěpánek, der in seiner Person die Aufgaben eines Dramatikers, Theaterdirektors (von 1824-34 führte er gemeinsam mit u.a. Josef Kainz das Ständetheater), Regisseurs, Schauspielers und Übersetzers vereinte, schuf gleichsam die Grundlage für den Aufschwung des tschechischen Theaters im 19. Jahrhundert (vgl. SIUD 500f). Von Zeitgenossen (u.a. Palacký, Čelakovský, Tyl) wurde Štěpánek wiederholt vorgeworfen, dem Publikum ein wenig anspruchsvolles Repertoire zu bieten bzw. vorwiegend Stücke und Übersetzungen aus eigener Feder zu inszenieren, doch musste er offensichtlich auf die eher an Unterhaltungs- und Musiktheater interessierte Prager Bevölkerung, auf die Möglichkeiten von Laienschauspielern sowie natürlich auch auf kommerzielle Interessen Rücksicht nehmen (vgl. Císař 2004a, 33-93; Ježková 2013a, 56). Neben Obleženi Prahy od Švejdì aneb Věrnost i udatnost česká [Die schwedische Belagerung Prags oder Böhmische Treue und Tapferkeit, UA 1812 $\left.{ }^{118}\right]$ und Osvobození vlasti aneb Korytanév Čechách [Die Befreiung der Heimat oder Die Kärntner in Böhmen, UA 1814] kann auch Bretislav Prvni (UA 1813) zu den Bemühungen gerechnet werden, mithilfe des Theaters die tschechische Bevölkerung für die Kriege gegen Napoleon zu mobilisieren.

Das Stück ist dem Fürsten Antonín Isidor z Lobkovic ${ }^{119}$ (1773-1819) gewidmet, in der Zueignung vollzieht Štěpánek einen panegyrischen Vergleich zwischen dem Widmungsträger und Břetislav, dem im Titel ja auch das Epitheton „český Achylles“ zugeschrieben ist. ${ }^{120}$ Mit Břetislav Prvni greift Štěpánek auf einen in der

118 Im Vorwort zur gedruckten Ausgabe dieses Stücks schreibt Štěpánek, dass er von der Vereinten Gesellschaft der wahren Patrioten (Sjednocená společnost pravých vlastenců) gebeten worden sei, Aufführungen in der heimatlichen Sprache („vlastenský jazyk“) zu geben. Nach Übersetzungen aus dem Deutschen habe er sich dann um ein originaltschechisches Werk bemüht; die Verteidigung Prags gegen die Schweden 1648 sei ein Stoff, der ideal die patriotischen Gefühle und die Ergebenheit gegenüber dem Herrscher erwirken könne. Dieses Stück sollte wie eine einzige Blume in der unermesslichen Wüste des tschechischen Theaters erscheinen (vgl. den Reprint des Vorworts in Ježková 2013a, 54f)

119 Der Widmungsträger war Kommandant des böhmischen Freicorps und fungierte nach seinem Rückzug aus dem militärischen Dienst als höchster Kammerherr des Königreichs Böhmen, daneben trat er in der Jednota prátel uméni als Förderer hervor (vgl. Ottův slovnik naučný, Díl 16. Praha 1900, 228).

120 „Ich habe mit schnellem Auge begierig in Gedanken die Ereignisse der Vergangenheit und die heutigen abgewogen, fand aber kein lebendigeres und erhabeneres Beispiel für meinen Břetislav, als Euch, erhabener Fürst." 
Kosmas-Chronik sowie bei Hájek z Libočan überlieferten Stoff aus der Přemysliden-Zeit zurück, in der Böhmen außenpolitisch in einer Dreieckskonstellation mit dem Heiligen Römischen Reich und Polen stand (vgl. Hoensch 1992, 50-56). Innenpolitisch stellt das Stück die Rivalität des herrschenden Přemysliden-Geschlechts mit dem Geschlecht der Vršovci [Wrschowetze] vor, wobei die Vršovci eindeutig - aber nicht pauschal - als heimtückische Halunken dargestellt sind.

Das Stück setzt nach dem Tod von Oldřich [Udalrich] ein, dem die Vršovci keine Träne nachtrauern. Vielmehr sehen sie mit dem nun nötigen Herrscherwechsel die Chance, das Fürstenamt usurpieren zu können, was sie schon immer mit abgefeimten Mitteln versucht haben. So wurde der nun verstorbene Oldřich einst von ihnen beeinflusst, seinen erstgeborenen Bruder Jaromír zu blenden und zu stürzen. Sie wollen das Vertrauen von Oldřichs Sohn Břetislav erwerben, um ihm dann in den Rücken zu fallen (I/6). Břetislav, der mit der Deutschen Jitka [Jutta] verheiratet ist, verspricht als Herrscher den Bedrängten zu helfen, den Unterdrückten beizustehen und unschuldigen Gefangenen die Freiheit zu schenken. Jaromírs Warnungen ${ }^{121}$ vor dem Geschlecht der Vršovci stellen den jungen Břetislav vor das Dilemma, ob er die lange Feindschaft zwischen den Geschlechtern einfach fortführen oder ob er die Loyalität der Adeligen nach Taten und Leistungen beurteilen soll. Am Ende des ersten Akts verkündigt Břetislav im Namen seines Vaters und an dessen Sarg seine patriarchalische Auffassung von Herrschaft: „Pro vás živu býti, pro vás i umřít bude mým heslem. [...] Vy jste všickní mé děti, Čechové! přijměte mne za svého otce." ${ }^{\text {“122 }}$ (I/9, S. 20f) Die Adressaten dieser „Regierungserklärung" werden mit Worten bestimmt, die nicht für das 11. Jahrhundert, wohl aber für den politischen Wortschatz des obrozeni charakteristisch sind: „Čechové! Vlastencové! Krajané!“123 (I/9, S. 20).

Diese Doublierung von innerem und äußerem Kommunikationssystem des Dramas, von der sich ein zeitgenössisches Publikum angesprochen fühlen sollte, wird zu Beginn des zweiten Akts auch auf dramaturgisch unplausible Weise fortgeführt: Břetislavs deutschstämmige Gattin Jitka sitzt am Fenster und sinniert angesichts der Herbstlandschaft über den kommenden Frühling - wenngleich sie sich schon länger in Böhmen aufhält (immerhin ist ihr Sohn Spytihněv schon sieben Jahre alt), spricht sie von der idyllischen Frühlingslandschaft so, als ob sie diese noch niemals gesehen habe: „Jaká to musí být pretěšená krajina!"124 (II/1, S. 22), worauf sie ein imaginäres idyllisches Bild des tschechischen Frühlings malt. ${ }^{125}$

121 Wie die Liste der dramatis personae zeigt, hat Štěpánek die Rolle des blinden Fürsten Jaromír in der Inszenierung seines eigenen Stücks selbst übernommen.

122 [Břetislav:] „Für euch zu leben, aber auch für euch zu sterben, wird meine Losung sein. Tschechen, ihr seid alle meine Kinder! Nehmt mich als euren Vater."

123 [Břetislav:] „Tschechen, Patrioten, Landsleute!“

124 [Jitka:] „Das muss eine trostreiche Landschaft sein!“

125 Macura (1999, 48-53) weist auf die enge Verschränkung von Literatur und Heimat- bzw. Landschaftslob im semiotischen Repertoire des 19. Jahrhunderts hin, was sogar bis zur 
Die selbstbewusste Wehrhaftigkeit Böhmens wird im zweiten Akt im privaten wie im politischen Bereich unterstrichen. So schmunzeln Břetislav und Jitka glücklich über ihren Sohn Spytihněv, der schon als siebenjähriger Knabe gerne das Schwert führen möchte. Als beim Landtag ein Gesandter des Kaisers dessen Tributforderungen vorbringt, kann Břetislav kaum seinen Zorn zurückhalten, obschon er den Kaiser als seinen Herrn anerkennt. „Jen tak dlouho jest národ samostatný, jak dlouho mu třeba není, kolena před jiným národem ohybovati." ${ }^{126}$ (II/11, S. 42) Dass die Zensurinstanzen in dieser Replik Břetislavs nicht den benjaminschen „Tigersprung ins Vergangene" ausgemacht haben, ist verwunderlich - immerhin lässt sich die politische Analogie bis ins Detail hinein verfolgen: denn Břetislavs Kundgebung, dass die Selbstständigkeit des Volkes nur so lange besteht, so lange es nicht vor einem anderen Volk sein Knie beugen muss, erfolgt ja unter der voraufgehenden Versicherung Břetislavs, dass er die Autorität des Kaisers anerkennt. ${ }^{127}$

Innenpolitisch möchte Břetislav mit strengem Kerker und dem Todesurteil für Kochan, der inzwischen Jaromír hat ermorden lassen, das Unkraut ausrotten, das andernfalls schöne Pflanzen erstickt. Břetislav ruft auch zum Feldzug gegen die Polen auf, mit dem er sein prosperierendes Land erweitern möchte (er begründet den Angriff dreifach: so will er für die Blendung seines Großvaters Rache nehmen, er will die Zerstörungen der Polen in Böhmen sühnen und weiteren Angriffen vorbeugen; von weniger gerechtfertigten Angriffskriegen gegen die Ungarn und die Bayern sieht er ab). Der Vršovec Drahouš allerdings versucht, unter den Adeligen gegen diese kriegerische Unternehmung eine Opposition zu bilden, er meint, das Schiff sei am wenigsten gefährdet, wenn es im Hafen bleibe (vgl. II/12, S. 45).

Die Verschränkung von Privatem und Politischen, und damit auch ein tragischer Konflikt von der Struktur einer tragischen Alternative (nach dem Muster „Geld oder Leben“, bei der jede Wahl eine Einbuße bedeutet), wird im dritten Akt entwickelt; der Vršovec Rohovín, der einerseits Břetislav seine Treue gelobt hat und diese auch persönlich halten möchte, liebt Milada, die Tochter des Vršovec' Drahouš, welche dieser nur um den Preis eines erfolgreichen Putsches gegen Břetislav hergeben möchte. Während Rohovín keinen Ausweg weiß, ergreift Milada die Initiative. Dem mit reicher Beute aus Polen zurückkehrenden Břetislav verrät sie die beabsichtigte Intrige der Vršovci, die den Papst gegen Břetislav mobilisieren

wechselseitigen semantischen Durchdringung dieser beiden Reihen führen kann; die tschechische Literatur wird dann mittels topographischer Metaphorik beschrieben: für Karolina Světlá ist 1863 Josef Kajetán Tyl eine frische Quelle und Karel Hynek Mácha natürlich ein "geheimnisvoller See“.

126 [Břetislav:] „Ein Volk ist nur so lange selbstständig, solange es nicht sein Knie vor einem anderen Volk beugen muss."

127 Derartige Repliken offenbar ignorierend, sieht Procházka (vgl. 1969/DčD II, 113) in Štěpánek einen Vertreter einer vorsichtigen bürgerlichen Ideologie, der alle Widersprüche glätten möchte, um nicht etwa durch allzu radikale Äußerungen aufzufallen. 
wollen. Břetislav, der in Polen bereits eine strenge Ordnung über seine Mitstreiter etabliert hat, zieht nun gegen die Burg der Vršovci, wohin auch der brutal seinen Willen durchsetzende Kochan nach dem Ausbruch aus dem Kerker geflüchtet ist. Drahouš hat eine Liste mit Unterschriften vieler tschechischer Ritter, mit welchen diese ihre Unzufriedenheit mit Břetislavs Herrschaft erklären, er berichtet, dass die Polen ob der von diesem angerichteten Schäden beim Kaiser Klage vorbringen, es sieht mithin so aus, als ob Břetislav von mehreren Seiten bedrängt sei. Die Vršovci entwaffnet Břetislav quasi im Alleingang und lässt sie nach Prag führen, wo ein Urteil über sie gesprochen werden soll. Ein solches fürchtet Milada, die ja ebenso wie Rohovín unter dem Zwiespalt zwischen Blutsverwandtschaft und ihrem Ehr- und Gerechtigkeitsgefühl zu leiden hat. Břetislav begnadigt die Vršovci bis auf Kochan, Drahouš verspricht nun auch Unterwerfung, laut Regieanweisung ist er dabei jedoch nicht aufrichtig. Gegenüber den Reichsständen des Kaiserreichs, die von ihm unter Kriegsandrohung die Abgabe der gesamten Beute aus Polen verlangen, bleibt Břetislav hart. Im Namen der Vernunft, die er als göttlichen Funken auffasst, lehnt er diese Forderung ab (IV/12; S. 99) und lässt gegen den bevorstehenden Angriff der deutschen Reichsstände mobilisieren.

Das Kampfgeschehen und die endgültige Überwältigung von Drahouš bestimmen den fünften Akt; die Bayern, wenngleich an Zahl überlegen, werden überwältigt, die Motivation ihrer Fürsten besteht vor allem in der in Aussicht gestellten Kriegsbeute. Břetislav schließt die Bayern in einer Schlucht ein, indem er Bäume fällen lässt, die die Schlucht unpassierbar machen. Als sein Gefolge angesichts der Übermacht zögert, den Befehl auszuführen, besteht Břetislav auf seinem Beschluss und erinnert die Tschechen an die Losung „Umřít anebo zvítězit!"128 (V/9; S. 125). Drahouš versucht ein letztes Mal eine Hinterlist, indem er Rohovín um den Preis von Milada auffordert, im Kampfesgetümmel Břetislav hinterrücks zu erdolchen. Für dieses Ansinnen wird er kurzerhand von einem Getreuen Břetislavs getötet, der dafür die Vorsehung preist. Břetislav versagt Drahouš die Beerdigung, die Beute teilt er seinen Rittern zu, er verkündet, dass mit dem heutigen Sieg alle gewarnt seien, die auf böhmisches Land begierig sind: „[...] pověst našich hrdinských činů roznese se daleko široko, a tím budeme strašlivi každému národu, kterýby našeho nábytku žádostiv, s námi zápasiti chtěl“129 (V/13, S. 133).

Der dem Drama Štěpáneks entnehmbare Aufruf zum wehrhaften Patriotismus wird mit einigen wenigen Verfahren erreicht: erstens sind mit den Vršovci die Hauptgegner des Titelhelden eindeutig negative Figuren, die vor keinem Verbrechen zurückschrecken, um ihre partikulären Familieninteressen durchzusetzen.

128 [Břetislav:] „Sterben oder siegen!“

129 [Břetislav:] „[...] die Legende unserer Heldentaten wird sich weithin verbreiten, damit werden wir jedem Volk Angst einjagen, das, gierig auf unser Eigentum, mit uns in den Kampf treten möchte." 
Břetislav hingegen wird deutlich als wehrhafter Fürst dargestellt, dem es um mehr geht als um private oder familiäre Interessen, der bedingungslos für Böhmen einsteht und somit ein perfektes Fürstenideal abgibt (so etwa lässt er seine Mitstreiter auf Gottesfurcht, Verbreitung des Glaubens, Nächstenliebe, Rechtschaffenheit und Gerechtigkeit schwören, vgl. III/11).

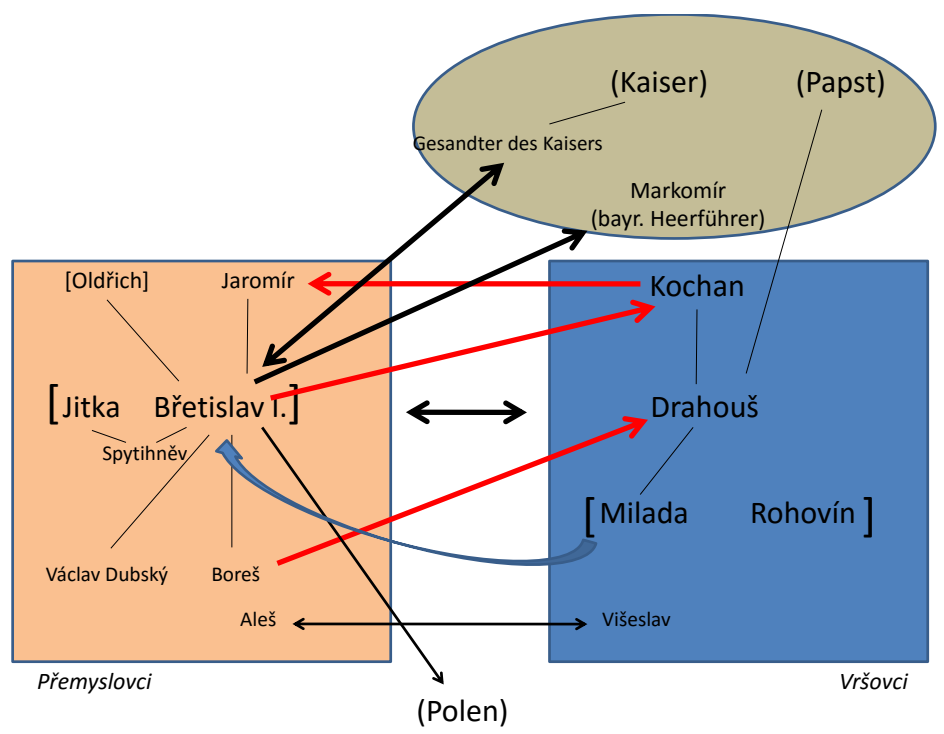

Graphik 5 - Jan Nepomuk Štěpánek: Břetislav Proní(1813)

Die außenpolitischen Gegner hingegen werden wenig profiliert dargestellt, dies gilt insbesondere für die Polen, gegen welche Břetislav einen in seinen Augen gerechtfertigten Angriffskrieg unternimmt. Die Deutschen scheinen vorwiegend an materiellen Gütern interessiert zu sein, wenn sie gegen den Polenfeldzug protestieren. Zweitens wird die geschlossene perspektivische Struktur von traditionellen semiotischen Zuordnungen wie der Dichotomisierung in Gut-Böse und Himmel-Hölle ${ }^{130}$ gestützt, welche dem Zuschauer eine militant patriotische Perspektive nahelegen. In dieser wird eine starke patriarchalische Fürstenmacht favorisiert - deren einzige Gegner sind die moralisch verwerflichen Vršovci Kochan und Drahouš. Dass es unter dem Adel noch andere Gegner der von Břetislav etablierten Zentralgewalt gibt, bleibt nur undeutlich erkennbar (Drahouš Unterschriften sind offenbar nicht alle gefälscht) und wird nicht weiter entwickelt.

130 So sind die Repliken der Vršovci reich an Flüchen mit „Höllen“-Semantik, die positive Figur Boreš erklärt, dass er nach dem Tod wohl kaum an demselben Ort wie Drahouš sein werde. 
Weiters sind alle privaten Angelegenheiten eng mit der Person des Fürsten verknüpft: In der bösen Intrige von Drahouš soll das Liebesgefühl des jungen Paares gegen Břetislav instrumentalisiert werden, dieser jedoch erst sichert dauerhaft das Glück von Milada und Rohovín. Die Idealität des Fürsten Břetislav ist im Drama von den Angriffen seiner Gegner bedroht, die ihr jedoch nichts effektiv anhaben können: denn letztlich obsiegt der ideale Fürst auch im Zweikampf oder in der militärischen Auseinandersetzung mit außenpolitischen Gegnern. Wenn die Vršovci ihre Intrigen spinnen (Drahouš erpresst Rohovín mit einem Double-bind) und Břetislav sich nicht aus eigener Kraft retten kann, stehen ihm seine Getreuen bei: Boreš ersticht Drahouš, zuvor schon verrät Milada den Plan von Drahouš, mittels gefälschter Unterschriften Břetislav die angebliche Unzufriedenheit der eigenen Adeligen vorzuhalten. Dass Milada überaus „mannhaft“ handelt, zeigt sich etwa auch in ihrer Verkleidung, denn in Ritterrüstung reitet sie zu Břetislav, um ihn von der Intrige zu informieren. Damit übertrifft Milada ihren Verehrer Rohovín, denn dieser lässt sich immer wieder in einen Double-bind drängen, womit er zum Werkzeug von Břetislavs Gegnern wird. Und Werkzeug wird er nur insofern, als er sein privates Glück - seine Liebe für Milada und sein Leben - nicht aufgeben möchte. Milada hingegen setzt sich hingegen so weit über ihr privates Glück hinweg, dass sie imstande ist, Břetislav zu warnen.

Břetislav präsentiert sich noch vor der Einsetzung in den Fürstenstand als gleichsam aufgeklärter Fürst, der allen Bewohnern beistehen und durch Wohltaten ihre Herzen gewinnen will (I/7; S. 14) seine Entscheidungen werden explizit als rationale Entscheidungen ausgewiesen, etwa die Zurückweisung der Tributforderungen der Reichsstände (IV/11) oder die rekurrente Aufforderung an seine Getreuen, nicht aus Rache und Hass über die Vršovci zu befinden, sondern den Tatbestand des Hoch- und Fürstenverrats zu beurteilen (IV/13). Dass Drahouš zuerst Gnade findet, obwohl er diese keineswegs verdient, ist nicht eigentlich Břetislavs Entscheidung, er gibt letztlich den Bitten von Milada und Rohovín nach, die von seiner Frau Jitka unterstützt werden. Doch diese Bitten sind auf keinem Gefühl begründet, sondern verdanken sich dem traditionellen Familiendenken, dem Milada nicht ganz entkommen kann, wenngleich ihr Einsatz für die in Břetislav verkörperte Allgemeinheit sie bereits zur mannhaften Aufgabe privaten Glücks bewogen hat.

Als Drahouš sich endgültig als unverbesserlich erweist und am Ende für seinen heimtückischen Attentatsplan getötet wird, preist Rohovín für diese letzte Wendung die Vorsehung (prozretelnost, V/12, S. 131). Dies ist wohl als eine Anrufung zu verstehen, die das äußere Kommunikationssystem betrifft, sie ist nämlich ein letzter Hinweis darauf, wie der Blick der Rezipienten auf das Drama justiert werden soll: auch die Vorsehung unterstützt die Apotheose einer starken Fürstenfigur, die keine politische Konkurrenz duldet, die für das Land das Beste leistet und deren Erfolge im Einzelkampf wie auch im Krieg dem Land nur förderlich sind. 
Die Überlagerung von nationaler Abwehrbereitschaft und panegyrischer Apotheose einer nahezu idealen Fürstenfigur stellt eine ziemlich komplizierte Struktur dar, womit die Bestimmung der kommunikativen Funktion des Stücks erschwert ist (vgl. V. Procházka 1969/DčD IIš, 99). Bei der hier vorgenommenen patriotischen Lesart stellt sich die Frage, ob es sich um einen territorial oder um einen national bzw. kulturell-sprachlich begründeten Patriotismus handelt: Zwar sind Jungmanns Rozmlouváni dvoje o jazyku českém, mit denen erstmals ein nationalsprachliches Programm formuliert wurde, schon sieben Jahre früher erschienen, ${ }^{131}$ doch ist Bretislav Proni wohl eher - man beachte auch den zeitlichen Zusammenhang der Kriege gegen Napoleon - landespatriotisch ausgerichtet und kein nationalpatriotischer Ausdruck der Ablehnung gegenüber der österreichischen („deutschen“) Souveränität über Böhmen (hierin unterscheidet sich das Stück praktisch nicht vom einzig erhaltenen Vorläufer aus dem 18. Jh., Zímas Oldřich a Božena). Den Einfall deutscher Truppen stellt Břetislav zwar als tödliche Bedrohung dar, womit er seine ob der Übermacht eingeschüchterten Mitstreiter zum Sieg mobilisieren kann, doch wird zugleich seine Ehe mit der deutschen Jitka (aus deren Mund ja auch die hoffnungsfrohen Worte über den Frühling in Böhmen kommen) als überaus glücklich dargestellt - nur die bösen Vršovci wollen ihn wegen der Ehe mit einer Deutschen anschwärzen. Wenn diese Ehe des tschechischen Fürsten mit einer Deutschen noch dazu einen sich so wehrhaft und kindlich-kriegerisch gebärdenden Sohn wie Spytihněv hervorbringt, soll wohl jeder Verdacht der Zensurbehörde, es könnte sich eine Tendenz gegen die „Deutschen“ qua Österreicher hinter dem Drama verbergen, ausgeräumt sein. Auch Vondráček (vgl. 1956, 370f) ist dieser Auffassung, er möchte die große patriotische Rhetorik hinter den bühnenwirksamen Elementen keinesfalls auf die Wiener Administration bezogen sehen, dem Stück wäre wohl keine Aufführungserlaubnis erteilt worden, hätte Štěpánek auf eine Kritik der österreichischen Herrschaft abgezielt. ${ }^{132}$

131 Císař (vgl. 2004a, 40) weist darauf hin, dass die Begriffe „národ“ und „vlast“ zur Zeit der Kriege gegen Napoleon im tschechischen Sprachraum noch durchaus mehrdeutig waren; erst nach dem Wiener Kongress erfuhr der sprachlich-kulturell begründete Nationsbegriff größere Verbreitung.

132 Dass aber die erfolgreiche Abwehr der Deutschen in Břetislav Prvni ein gewisses Risiko darstellt, von der Zensur inkriminiert zu werden, ist aber vielleicht im Umstand zu erkennen, dass Štěpánek während seiner Direktion erst wieder in den 1830er Jahren das Stück inszenierte, in den politisch etwas strengeren 1820er Jahren davon aber absah (vgl. V. Procházka 1969/DčD II, 101). Eine ähnliche Tendenz zum österreichischen Staatspatriotismus findet sich auch in den oben erwähnten anderen Stücken Štěpáneks, etwa in Obleženi Prahy od Švejdi̊ aneb Vèrnost a udatnost česká (1812), Osvobození vlasti aneb Korytané v Čechách (1814); anlässlich des Sieges über Napoleon in der Dreikaiserschlacht von Leipzig schreibt Štěpánek die Komödie Vlastenci aneb Zpráva o vitězství [Die Patrioten oder Die Nachricht vom Sieg, 1813], welche der freundlichen Verbundenheit der ländlichen Bevölkerung Böhmens dem Kaiser gegenüber Ausdruck verleiht (vgl. SluD 1988, 501). 
Břetislav steht verschiedenen Gegnern gegenüber und kann sich in jeder Auseinandersetzung behaupten. Seine Position als Fürst wird von den Vršovci angegriffen, Břetislav jedoch wehrt alle Angriffe ab. Die beiden semantischen bzw. ideologischen Räume, die im Drama einander gegenübergestellt sind - das Lager von Břetislav einerseits und dasjenige der Vršovci andererseits - lassen sich einfach nach einer Plus-Minus-Valorisierung von einander unterscheiden. Die Versuche, die Grenze zwischen den beiden Lagern zu überschreiten, um die Fürstenmacht für das eigene Lager zu gewinnen, gehen von den Vršovci aus, die als intrigante Handlungsträger gelten können. Für ihre Intrigen scheuen sie vor keinem Mittel zurück. Die angestrebte Machtübernahme scheitert freilich, da kein Mittel - nicht der Mord, nicht die gefälschte Petition von Unterschriften gegen Břetislav, nicht die Intrige bei Papst und Kaiser und der aufgrund dieser Intrige erwirkte Angriff der Bayern auf Böhmen - erfolgreich ist. Zwischen den beiden eindeutig gekennzeichneten Parteien steht mit Milada und Rohovín ein Liebespaar, welches die Vršovci für ihre Interessen einsetzen wollen. Beide wechseln aber ins andere Lager und desavouieren die erpresserischen Pläne ihrer Verwandten. Dabei ist Milada die in ihrem Handeln entschiedenere Figur, denn sie riskiert auch den Verlust von Rohovín, während sich dieser aus Angst vor dem Verlust von Milada beinahe erpressen lässt. Miladas Wechsel der Seiten wird von einem Geschlechterwechsel begleitet: deshalb tritt sie als Mann maskiert auf. Das Resultat des Dramas besteht in der völligen Bestätigung der Herrschaft von Břetislav, der Niederlage oder Vernichtung aller seiner Gegner und der Stabilisierung und Trennung der Lager. Die Widersacher des Fürsten sind geschlagen und moralisch besiegt, die positiv gezeichneten Figuren sind in das Lager des Fürsten übergewechselt.

\section{IV.4.2. Josef Linda: Jaroslav Šternberg v boji proti Tatarüm. Divadelní hra (1823)}

[Jaroslav Šternberg im Kampf gegen die Tataren. Schauspiel; unaufgef., publ. 1823]

Die mit Jungmanns Slovesnost vorgelegte Hierarchisierung und Kanonisierung literarischer Gattungen und Stile bewegte einige Autoren zum Verfassen entsprechender Texte, welche dieser theoretischen Vorgabe genügen sollten. Da von Jungmann die dramatische Gattung favorisiert wurde, entstanden einige Dramen à la Slovesnost, etwa Angelina von František Turinský (1821), ein Drama, das von patriotischen Zeitgenossen bestaunt wurde - Čelakovský bezeichnete es als die erste Tragödie der tschechischen Literatur, Simeon Karel Macháček übersetzte es ins Deutsche (vgl. V. Procházka 1969/DčD II, 137f) -, das aber aufgrund dramaturgischer Schwächen damals nicht aufgeführt wurde (Uraufführung erst 1897 im Národní divadlo). Ein weiteres Drama Turinskýs, Pražané v roku 1648 [Die Prager im Jahr 1648, 1824] griff den bereits von Václav Thám und Štěpánek für das Drama entdeckten historischen Stoff der Belagerung Prags durch die Schweden im Dreißigjährigen Krieg 
auf, die Zensurbehörde erlaubte wegen der nationalpatriotischen Tendenz bis 1849 keine Aufführung. Zu den Versuchen, ein anspruchsvolles ernstes Drama zu schreiben, wird auch Jan Erazim Vocels Harfa [Die Harfe, 1825/UA 1837) gerechnet, das seinen Stoff aus Legenden um den vorchristlichen Fürsten Neklan gewinnt, der auch noch gegen Ende des 19. Jahrhunderts durch Julius Zeyer eine dramatische Bearbeitung erfahren hat.

Der Umstand, dass diese Versuche, ein anspruchsvolles ernstes tschechisches Drama zu verfassen, in der Regel in Manuskriptform endeten und nicht aufgeführt wurden, wurde in marxistischer Tradition immer mit den soziopolitischen Bedingungen des obrozeni erklärt: Der Ehrgeiz nationalpatriotischer Intellektueller sei zu einer Zeit entstanden, in der die Gesellschaft noch nicht von scharfen Widersprüchen geprägt gewesen sei, die drameninterne Darstellung von Konflikten sei daher zu schwach ausgefallen. Bereits Procházka stellt diese schematische Erklärung mit dem Verweis auf die Blütezeit des deutschen Dramas in Frage, stattdessen führt er Kulturkonstanten an: Demnach sei in der tschechischen Kultur die von Jungmann gewünschte große Tragödie auch später nicht wirklich geschrieben worden, das tschechische Publikum hätte eben historische Dramen, Zauberspiele oder gesellschaftskritische Komödien lieber aufgeführt gesehen:

Dalo by se říci, že jak české národní umění, tak i český národní charakter se velkým tragickým vášním a patetickému gestu vyhýbají. Koturn byl cizí nejen básníkům, ale většinou se nedařil a nedaří ani našim hercům. ${ }^{133}$ (V. Procházka 1969/DčD II, 139)

Als dramaturgisch unglücklicher Versuch, ein großes nationales Drama vom Shakespearschen Typus zu schaffen, gilt Jaroslav Šternberg v boji proti Tatarüm von Josef Linda, der zur Entstehungszeit des Dramas auch begeistert Schiller übersetzt hat (vgl. Štěpánek 1959, 77) und sich zu Fragen der Dramatik Shakespeares in einzelnen Kommentaren äußerte (vgl. Drábek 2012, 111-114): in diesem Stück sind Momente von Liebestragödie, panegyrischem Herrscherlob und historischem Drama auf eine sehr schwerfällige Art zusammengefügt: Schon die Lektüre wird durch die gewundene Sprache aller Figuren sehr erschwert, auch für die Schauspieler war es wohl schwierig, einen solchen Text zu memorieren und genau wiederzugeben, und selbst wenn dies gelänge, wäre es dem Publikum bei einer rein akustischen

133 „Man kann sagen, dass sowohl die populäre tschechische Kunst wie auch der tschechische Nationalcharakter große tragische Leidenschaften und die pathetische Geste meiden. Der Kothurn war nicht allein den Dichtern fremd, er ist auch unseren Schauspielern meist nicht gelungen." 
Rezeption wohl unmöglich, dem Sinn der Repliken zu folgen. ${ }^{134}$ Dementsprechend erschien das Drama 1823 nur in gedruckter Form. ${ }^{135}$

Josef Linda gilt neben Václav Hanka als Zweitautor der ominösen tschechischen Handschriftenfälschungen. ${ }^{136}$ Das Theaterstück nimmt die Dichtung „Jaroslav“ aus der Königinhofer Handschrift (289 Verse) zur Vorlage, die insofern pseudohistorisch ist, als verschiedene Elemente unterschiedlicher Erzählungen von ihr tradiert bzw. zusammengefasst wurden (vgl. Mezník 1969, 167-176). Der legendenhafte Jaroslav-Stoff wurde schon vielfach vor den Handschriftenfälschungen dichterisch behandelt (vgl. Dobiáš/Novák 2014, 78f). Als „Text im Text“ enthält das Drama überdies 45 Verse der neutschechischen Version des Heldenliedes „Zábo“ aus der Königinhofer Handschrift.

Lindas Drama erweitert die Vorlage zu "Jaroslav" beträchtlich: Im Vorwort zum Drama schreibt er, dass ihn nach dem Erscheinen der längeren historischen Erzählung Záre nad pohanstvem [Abenddämmerung über dem Heidentum, 1818] Zeitgenossen gefragt hätten, woher dieser Text stamme. Um alles eindeutig zu halten, erklärt Linda, dass Záre nad pohanstvem und Jaroslav Šternberg $v$ boji proti Tatariom Originalarbeiten sind (,jsou práce mé vlastní původni“"), sollte er künftig noch etwas anderes veröffentlichen, werde deutlich gekennzeichnet sein, ob es sich um eine Übersetzung, eine Abschrift oder eine Kompilation handle. Diese seltsame Erklärung Lindas wurde bereits zum Gegenstand von Überlegungen zur Handschriftenfrage: durch genauen Textvergleich stellte etwa Dolanský (1972) fest, dass Josef Linda mit dieser Erklärung wohl versteckt zu verstehen gegeben hat, dass er der Autor des Heldenliedes „Záboj” sei, welches dann von Václav Hanka, dem Erstautor der Fälschungen ins „Alttschechische“ übertragen und in die Königinhofer Handschrift aufgenommen wurde, um letztendlich 1823 in Lindas „Urfassung“ im Dramentext von Jaroslav Šternberg zu erscheinen. Nimmt man Lindas Erklärung wörtlich, ließe sie freilich sogar die Vermutung zu, dass nicht bloß das Drama sein Originalwerk ist, sondern dass er auch maßgeblich zur Dichtung "Jaroslav" in der

134 Čelakovský schreibt in einem Privatbrief wohl zutreffend: „Tu hru, kdyby někdy dali v Praze, - všecko by usnulo“" („Wenn man dieses Stück einmal in Prag geben würde - das gesamte Publikum würde einschlafen.“ - zit. nach Procházka 1969/DčD II, 138).

135 Eine Anmerkung verdient der Umstand, dass anspruchsvolle Stücke und Stoffe im Volksund Puppentheater sehr oft modifiziert übernommen wurden und dabei durchaus populär werden konnten. Entsprechend wurde auch der Stoff von Jaroslav Šternberg v boji proti Tatarüm wahrscheinlich vom tschechischen Puppentheaterspieler Prokop Konopásek bearbeitet und mit einem Märchenstoff neu zu Mluvárna kombiniert (vgl. Bartoš/Procházka 1969/DčD II, 189).

136 Wie bereits von Masaryk 1886 festgestellt wurde, hat Lindas historische Erzählung Záre nad pohanstvem [Abenddämmerung über dem Heidentum, 1818 - im selben Jahr erschienen wie die „Entdeckung“ der „Grünberger Handschrift“] einige (sprachliche, motivische, ideologische etc.) Ähnlichkeiten mit Passagen aus den beiden Handschriften (vgl. Mezník 1969, insb. 127-138, zu Lindas Autorschaft 134-136). 
Königinhofer Handschrift beigetragen hat (dies vermutete bereits J. Hanuš im Jahre 1900, vgl. Mezník 1969, 136). ${ }^{137}$ Linda könnte zuerst sehr stark in die Fälschungspraxis von Václav Hanka und Václav Alois Svoboda involviert gewesen sein, aber sich bald womöglich durch den Einfluss von Bernard Bolzanos ethischen Auffassungen in einem Gewissenskonflikt befunden haben. So habe er sich in der Folge von Hanka und Svoboda distanziert und anderen Dingen gewidmet, dabei wiederholt mehr oder weniger deutlich auf die pia fraus der Handschriftenfälschungen angespielt (vgl. Loužil 1978, 234).

Im Drama muss sich Jaroslav von Šternberg, der Verteidiger von Olomouc, gegen die zahlenmäßige Übermacht der Tataren behaupten, die im Jahre 1241 die Stadt belagern. Unter seinen Heerführern wächst der Unmut über den Belagerungszustand; der Vladike Vneslav unternimmt auf eigene Initiative einen Ausfall mit entschlossenen Kämpfern, kommt dabei jedoch um. In den Diensten der Tataren steht der Herumtreiber Zatrán (seine Herkunft ist unklar, er präsentiert sich wortreich als wandlungsfähig, Soukup [2005] sieht in ihm eine frühe negative Darstellung eines Zigeuners), der sich, als er in Olomouc gefangen genommen wird, mit dem Angebot herauswindet, Geheimnisse der tatarischen Strategie an Jaroslav zu verraten. Zatrán gerät somit in die Rolle eines Doppelagenten, er dient beiden Kampfparteien, wie jedoch seine Monologe zeigen, strebt er dabei allein nach seinem Vorteil. Zatrán, der gleich beim ersten Auftritt als „Grenzgänger“, als Figur zwischen den beiden Lagern charakterisiert wird („nějaký zahraničník“138 - „Kde svět s peklem hraničí“ - I/1, S. 16), äußert sich in dieser Rolle als „Doppelagent“ entsprechend doppelzüngig („had zase plíží se do Olomouce mluvit dvojím jazykem“139 - IV/1, S. 134). Er versucht, die Verteidiger von Olomouc zu täuschen: um die stärksten und entschlossensten Kämpfer zu demotivieren, erzählt er ihnen, Jaroslav von Šternberg hätte die Flucht ergriffen und die Stadt im Stich gelassen.

Das Interessante am Drama besteht nun darin, dass die Strategie von Täuschung und Lüge nicht auf die negative Figur Zatrán beschränkt bleibt, sondern auf die Verteidiger der Stadt (und des christlichen Europa) übergreift und bei ihnen zum Erfolg führt, während die "geraden“ Ritter wie Vneslav oder Ronovín das Nachsehen haben (Vneslav fällt bei seinem kämpferischen Ausfall, Ronovín muss einsehen, dass Jaroslavs Kampf Erfolg gehabt hat). Die Täuschungsmanöver der „Patrioten“ („Co přinášíte, vlastencové?"140 - fragt Jaroslav seine Mitstreiter, I/2, S. 36) sind vielfältig: So täuscht Vestoň nicht allein die Tataren, sondern stößt auch seine Mitstreiter vor den Kopf, indem er sie in nahezu aussichtloser Lage dazu aufruft,

137 Die umfangreiche Darstellung der wissenschaftlichen Handschriftenrezeption bis in die 1880er Jahre fügt diesbezüglich nichts Neues hinzu (vgl. Dobiáš 2014, 51, Fn 87).

138 „Irgendein Ausländer [innere Form, von jenseits der Grenze “]“ - „Wo die Welt mit der Hölle zusammenstößt."

139 [Zatrán:] „Die Schlange kriecht wieder nach Olomouc, um mit doppelter Zunge zu reden““

140 [Jaroslav:] „Was bringt ihr mir, ihr Patrioten?“ 
doch den Kampf aufzugeben (V/1), mit der Täuschung gewinnt er aber wieder das Vertrauen der Recken und stärkt deren Einheit (V/2). Den Kampf entscheidet letzlich die große List Jaroslavs, der Zatrán folgendermaßen austrickst: Bludo, der nur augenscheinlich betrunkene Diener Jaroslavs, erzählt Zatrán, dass Jaroslav in der Nacht heimlich aus Olomouc ausrücken werde, um einerseits eine umzingelte Einheit zu retten und andererseits die Tataren von nachrückenden Truppen, die aus Böhmen kommen, ablenken zu können. Die Trunkenheit Bludos war nur vorgetäuscht; weil Zatrán ihr auf den Leim gegangen ist, können die Verteidiger trotz ihrer Unterzahl erfolgreich das Lager der Tataren angreifen (wobei sich ein Teil von ihnen als Tataren verkleidet, um schneller in das Lager einzudringen zu können). Auch in einer Nebenhandlung kommt es zu einer taktischen Täuschung: um die ohnmächtige Jaroslavna zu Bewusstsein zu bringen, flüstert ihre Erzieherin Alžběta, dass Vestoň am Leben sei (was Alžběta aber überhaupt nicht sicher weiß, es geht ihr nur darum, Jaroslavna zu ermuntern - IV/2).

Wenn sich das Sujet von Jaroslav Sternberg v boji proti Tatarüm wie eine martialische Variante des Kampfes von David gegen Goliath ausnimmt, so ist dies nicht zuletzt auch darauf zurückzuführen, dass sich auf Seiten der christlichen Verteidiger auch überirdische Hilfe einfindet: Regen bewahrt im entscheidenden Moment die umzingelte Einheit vorm Verdursten. Die Antagonisten Jaroslav und Zatrán werden in den Figurenreden und der Handlung einerseits mit einem Löwen und einer Schlange, andererseits mit einem gottähnlichen Streiter und dem Teufel verglichen. Jaroslav selbst erklärt sein Eintreten für Zatrán mit dem Gleichnis vom Löwen und der Schlange (III/2, S. 108-111): Nur durch Täuschung, also durch gespieltes Vertrauen kann der Anführer der Löwen die Schlangenbrut in eine Falle locken und endgültig vernichten. Die Durchsichtigkeit dieses depräsentativen Gleichnisses auf zeitgenössische nationalkulturelle Verhältnisse wird dadurch verstärkt, dass der Löwe das Wappentier Böhmens ist.

Als überlegener Führer wird Jaroslav von Šternberg im Stück von vielen Figuren als beinah schon übermenschliche Gestalt betrachtet: wenn Zatrán nach seiner Gefangennahme erstmals Jaroslav gegenübertritt, zittert er vor Schrecken; die Mitstreiter Jaroslavs verstehen dessen Befehle und Verhalten meist nicht, letztlich aber erweist sich alles Handeln als weitblickende Taktik Jaroslavs.

In Jaroslav findet gleichsam eine Apotheosierung der Führerfigur statt, die sich über alle Meinungen hinwegsetzen kann: Das Recht, dass sich der Anführer nicht den Entscheidungen seiner Mitstreiter fügen muss, lässt sich Jaroslav beim Erzählen des Gleichnisses vom Löwen und der Schlange bestätigen (vgl. S. 110), darüber hinaus setzt er sich auch über die Anordnung seines Herrn König Václav hinweg, wonach er Olomouc nicht verlassen dürfe.

Leitet man aus dem Handlungsverlauf des Dramas eine ideale gesellschaftliche Ordnung ab, die in der Lage ist, sich gegenüber einem starken Feind zu verteidigen, so besteht diese in einer starken, gleichsam zusammengeschweißten Einheit, die von 
einem umsichtigen und listenreichen Führer geleitet wird (vgl. die Beschreibung der Kriegsmaschine in V/3, S. 197-199). Gegenüber dessen Weitblick, der das Wohl der politischen Gemeinschaft umfasst, erscheinen andere Projekte ungeeignet. Unter den Hauptfiguren zeichnen sich ideelle Konflikte nur sehr schwach ab, weil sie immer der Apotheose des militärischen Führers untergeordnet sind: Jaroslavna stellt etwa sich gegen den Willen ihres Vaters Jaroslav und liebt in Vestoň einen anderen

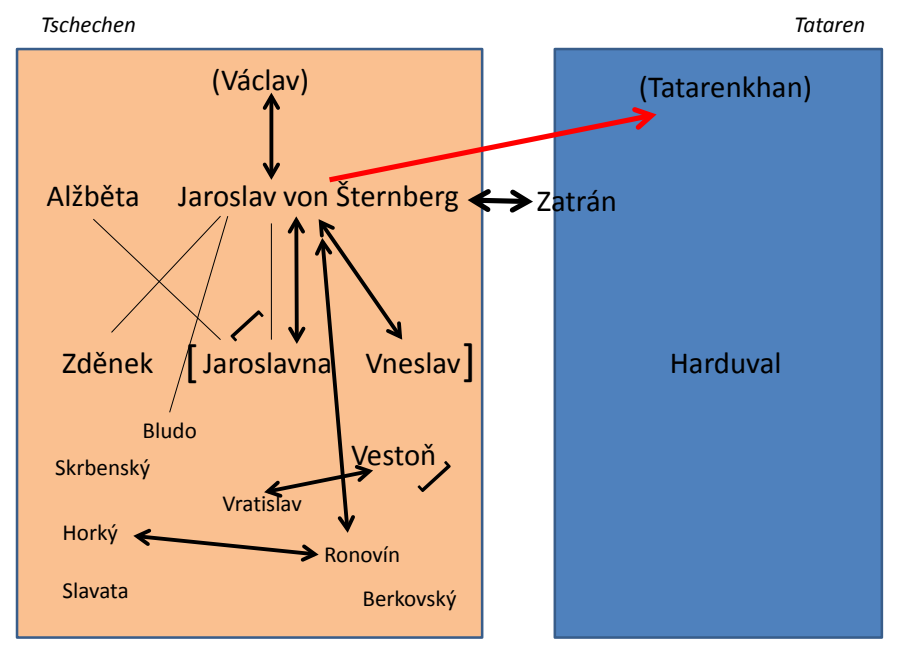

Graphik 6 - Josef Linda: Jaroslav Šternberg v boji proti Tatarüm (1823)

Mann als den für sie vorgesehenen Bräutigam Vneslav. Jaroslav möchte die Gefühle seiner Tochter übergehen, die meint, der mögliche Tod ihres Geliebten wäre ein zu hoher Preis für die Befreiung der Heimat vom Feind. Diesem Konflikt zwischen privatem Glück und dem Wohl der Gemeinschaft aber wird die dramatische Spitze dadurch genommen, dass zum einen der vom Vater vorbestimmte, aber nicht geliebte Bräutigam im Kampf fällt, zum anderen schließlich Jaroslavna selbst mit dem Schwert in der Hand und gleichsam überirdischen Kräften ihrem Vater zu Hilfe eilt. Auch ihr Geliebter Vestoň, der im dritten Akt noch vor die Alternative Vaterland oder Liebe gestellt wird, wird so zum todesmutigen Kämpfer, weil er ohne Liebe keinen Sinn mehr im Leben sieht (er trägt damit unwillkürlich ebenfalls zum Sieg bei). Wenn der Ritter Ronovín, der gegenüber den Siegeschancen angesichts tatarischer Übermacht skeptisch bleibt und sich gegen Jaroslav stellt, letztendlich mit seiner Entscheidung mehr oder weniger zufällig ebenfalls zum guten Ausgang der Schlacht beiträgt, kann dies gleichfalls als Indiz dafür gelten, dass Jaroslavs Handeln als richtig bestätigt wird.

Lindas Drama ist fehlende Dramazität vorgehalten worden, die darin besteht, dass entscheidende Ereignisse der Fabel meist nicht zwischen den Figuren selbst, 
sondern nur in Berichten oder im Off der Mauerschau geschehen (vgl. Štěpánek 1988, 100f). Diese „epische“ Tendenz sowie die äußerst komplizierte und gewundene Sprache schaffen den Eindruck eines Lesedramas: dass Linda womöglich tatsächlich eine Leserschaft und kein Theaterpublikum intendiert hat, könnte weiters auch in der Ausführung des Nebentextes erkannt werden. Denn in der 2. Szene des vierten Aufzugs wird im Nebentext Bludo als betrunken dargestellt („opilý přicházeje zpívá “ ${ }^{141}$ ), erst später aber erweist sich, dass er die Trunkenheit nur vorgespiegelt hat, um Zatrán auf eine falsche Fährte zu führen (gewissermaßen handelt es sich um das seltene Phänomen eines „unverlässlichen Nebentexts“, wodurch die Spannung des Lesers aufrechterhalten wird; dieser erkennt somit nicht, dass Bludo Zatrán in eine Falle lockt. Ähnlich ist es im Fall von Vestoňs Täuschung, der Leser glaubt, dass dieser tatsächlich kapitulieren möchte). ${ }^{142}$

Angesichts der offensichtlichen dramaturgischen Schwächen hat bereits Štěpánek (vgl. 1959, 82f) vorgeschlagen, Jaroslav Šternberg nicht als „Ideendrama“, also als Konflikt von unterschiedlichen Ideen zu lesen, sondern gewissermaßen als allegorische Darstellung einer Strategie bzw. Taktik, wie sich die tschechischen Nationalpatrioten in der gesellschaftlichen Situation verhalten sollten: Das Scheitern von Vneslavs militärischer Operation bzw. dessen Tod wie überhaupt die strategische Souveränität Jaroslavs lassen den Schluss zu, dass sich Linda zwar mit der Möglichkeit einer revolutionären Veränderung der politischen Verhältnisse beschäftigt, aber letztendlich doch eine andere Taktik favorisiert habe (vgl. Štěpánek 1959, 88f). Diese besteht ganz offensichtlich in der Täuschung, was Štěpánek allerdings nicht deutlich genug hervorhebt. Er spricht zwar davon, dass Linda Taktik, Überlegung und sogar Fälschung als patriotische Strategien favorisiert habe (gemeint ist damit Lindas Teilnahme an den Handschriftenfälschungen); für das Drama Jaroslav Šternberg v boji proti Tatarum hingegen betont Štěpánek (vgl. Štěpánek 1959, 90) allzu einseitig den Umstand der Ablehnung eines heroisch-radikalen Kampfes, wobei er die doch ziemlich eindeutige Apologie von Täuschung und Blendung im Drama übergeht.

Dabei ist es ja gerade das Mittel der Täuschung, welches als erfolgreiche und legitime Strategie vorgeführt wird, um Rettung aus einer ausweglos erscheinenden Situation zu finden. In der Rolle des „Opfers“ der Täuschungsmanöver steht im Drama einerseits der tatarische Feind, dessen Täuschung selbst durchbrochen wird, andererseits werden die Mitglieder der eigenen Gemeinschaft getäuscht, damit ihre Lebensgeister erwachen (wie im Fall der „todunglücklichen“ Jaroslavna) oder ihre Verteidigungsbereitschaft angestachelt wird (Vestoň gewinnt so das Vertrauen

141 „Der betrunkene [Bludo] kommt singend“

142 Das Duell der wechselseitigen Listen kann möglicherweise überhaupt besser von einem Leser als von einem Theaterzuschauer verfolgt werden: es beruht auf dem Wechsel der Unterscheidung von „wahrer" Aussage (konventionell im Monolog) und „falscher“ Aussage (Täuschungen in Dialogen). 
defätistischer Krieger und mobilisiert sie noch einmal). Das Täuschungsmotiv ist im Drama wesentlich deutlicher zu erkennen als der von Štěpánek (vgl. 1959, 77f) postulierte „dramatische“ Konflikt zwischen unterschiedlichen Kampfstrategien (das ungestüme Heldentum Vneslavs einerseits, Jaroslavs Berechnung andererseits), da alle einzelnen Verhaltensweisen letztlich ihren Platz in Jaroslavs Metastrategie haben. ${ }^{143}$

Es erscheint naheliegend, dieses Moment der Täuschung auch heterorefentiell zu lesen: nämlich als Hinweis darauf, dass die Mittel der Täuschung gerade in einer ausweglosen Situation die richtigen sind. Vladimír Macura hat für die Kultur des obrozeni deren Hang zu Spiel und Mystifikation hervorgekehrt: demnach ist die Praxis diverser Handschriftenfälschungen sowie die Vorspiegelung falscher Tatsachen - etwa die „Konstruktion“ bzw. mystifizierende „Fabrikation“ einer tschechischen Dichterin - im Zusammenhang damit zu sehen, dass es zur Blütezeit des obrozeni eigentlich noch keine tschechische Hochkultur gegeben hat (vgl. Macura 1983, 118-137). Die Vertreter des obrozeni haben große Mühen darauf verwendet, Texte zu schaffen, die einer ausgebauten Kultur entsprechen, wenngleich eine solche seit dem ersten Drittel des 17. Jahrhunderts faktisch nicht mehr vorhanden war, da die „hochkulturellen“ Bedürfnisse in deutscher Sprache befriedigt wurden. Auf diese Weise errichteten die Patrioten gleichsam potemkinsche Dörfer; diese hatten jedoch den Vorzug, dass sie sich mit Fortschreiten kultureller Aktivitäten allmählich mit Leben füllten und zu realen Dörfern wurden. Die Aktivisten des obrození gingen also ähnlich vor wie Jaroslav Šternberg bei der Verteidigung von Olomouc: sie suchten die passende Strategie, um ihre „Polis“ aus scheinbar aussichtsloser Lage zu retten. Jaroslav erklärt seine Strategie wie folgt:

[Jaroslav:] Čerty chytat nejlépe čertem. Nehanbi se, vlasti, že tvůj rek i padouchů spády prolezá. Co nebe, co peklo poskytuje - všecko pomahej - naše síla nedostačuje. ${ }^{144}$ (II/1, S. 58)

Wenn für den Zweck der Rettung der Heimat alle Mittel recht sind, also Jaroslav dieselben Tricks anwendet wie der „Teufel“ Zatrán, dann gelten strategische Aussagen des einen analog auch für den anderen. Zatrán erklärt seinem Diener, wie er es zuwege bringt, in die bestens befestigte Stadt Olomouc einzudringen:

[Zatrán:] Taškářství, podvod, lotrovství, a cokoliv takového, je Čechům cizozemské zboží, a proto, že ho neznají, nevědí také jak očima, nosem, ušima ani chmatem po něm pátrat; mezi

143 Štěpánek stellt dies - entgegen seiner These von der Dramatiziät des Konflikts - auch fest (vgl. Štěpánek 1959, 79 f u. Štěpánek 1988, 101).

144 [Jaroslav:] „Die Teufel fängt man am besten mit dem Teufel. Schäme dich nicht, Heimat, dass dein Held auch zu den Mitteln der Halunken greift. Was Himmel oder Hölle bereitstellen - alles soll helfen - unsere Kraft reicht nicht aus.“ 
ními taškář poctivě se uživí. Pak jejich svědomí - kterou pletichu ani neznám - je jim tak choulostivé, že co řeknou, na to můžeš svůj život nasadit. ${ }^{145}$ (IV/1, S. 133)

Wenngleich vordergründig die Bedeutung dieser Erklärung für das Publikum als Dritten in der patriotischen Behauptung besteht, dass die Tschechen so ehrlich und gutgläubig sind und Schelme und Betrüger somit leichtes Spiel mit ihnen haben, ist der Verdacht nicht ganz von der Hand zu weisen, dass Josef Linda hier eine „metastrategische" Aussage auch über die Handschriftenfälschungen macht, an denen er offenbar beteiligt war. Linda war ja der erste „Entdecker“ einer „Handschrift“, 1816 gab er vor, das angeblich aus dem 13. Jahrhundert stammende „Píseň vyšehradská" im Einband eines alten Buches gefunden zu haben (vgl. Schamschula 1990, 381); darüber hinaus schien er einen Hang dazu gehabt zu haben, mit den Mystifikationen zu spielen, also Andeutungen zu deren wahren Charakter zu machen (vgl. Macura 1983, 134 u. 232, Fn 26): 1823, im Erscheinungsjahr des Dramas, veröffentlicht Linda in der von ihm redigierten Zeitschrift »Vlastenský zvěstovatel « das Gedicht „Volmir, Nová starožitnost“, welches die sprachlichen und stilistischen Besonderheiten der Königinhofer Handschrift parodiert. Jaroslav Šternberg v boji proti Tatarim bezieht einen Teil seines Stoffes aus „Fragmenten“ der Königinhofer Handschrift; derjenige Anteil des Dramas, den Linda offenbar frei erdichtet hat, weil er weder in der Handschrift noch in anderen Erzählungen von einer angeblichen Tatarenschlacht bei Olomouc vorkommt, zeigt eigentlich den Zweikampf des „Löwen“ Jaroslav mit der „Schlange“ Zatrán, der vom Löwen deswegen gewonnen wird, weil er die Mittel der Schlange gegen diese selbst wendet.

Der Versuch, das Drama als metastrategische Aussage des tschechischen Patriotismus zu lesen, bedarf einer Klärung hinsichtlich des Feindbildes: Dieses ist nämlich weitgehend unbestimmt, als dramatis personae kommen Tataren gar nicht vor (allein Zatrán und sein Diener, die aber beide Tschechisch sprechen) repräsentieren sie. Der Gegner des Löwen (der als Wappentier Böhmens im Drama selbstverständlich allegorisch eingesetzt ist) bleibt die abstrakte Variable „Tatare“, ein expliziter Bezug auf die Deutschen als „Feinde“ fehlt. ${ }^{146}$ Jaroslav Šternberg $v$ boji proti Tatarüm wäre demnach ein Drama, das den patriotischen Kampf „theoretisch" entwirft: Die Ausgangslage der Patrioten erscheint auswegslos, doch mit

145 [Zatrán:] „Taschenspielertricks, Betrug, Halunkerei und dergleichen, ist für die Tschechen alles ausländische Ware, und weil sie diese nicht kennen, wissen sie auch nicht, wie sie mit Augen, Nase, Ohren oder Spürsinn diese ausmachen können; ein Taschenspieler kann gut unter ihnen sein Auskommen finden. Auch sind sie hinsichtlich ihres Gewissens - irgendwelche Hinterlist kennen sie nicht einmal - so empfindlich, dass man sein Leben darauf wetten kann, was sie sagen."

146 Die „Deutschen“ werden nur insofern erwähnt, als sie soeben eine große Schlacht gegen die Tataren verloren haben. Als Ronovín dies anführt, um vor der tatarischen Übermacht zu warnen, erhält er zur Antwort, dass die Verlierer aber keine Tschechen gewesen seien (IV/2, S. 138). 
den probaten Mitteln von Täuschung, Lüge und Trug kann ein kapitaler Sieg errungen werden.

Während Břetislav Pruni als Drama die moralische und politische Überlegenheit des legitim eingesetzten Fürsten und die Niedertracht seiner Gegner vor Augen führt, ${ }^{147}$ wird in Lindas Drama die strategische Souveränität der Titelfigur vorgeführt. Diese besteht in der Bereitschaft, in einer prekären Situation die Taktiken des Feindes zu übernehmen, um diesen zu täuschen. Wie bei Břetislav Prvni handelt es sich um die Verteidigung des eigenen Lagers: Břetislav muss seine Rolle als Fürst behaupten, Jaroslav Šternberg muss Olomouc vor den Tataren bewahren. Beide bleiben dabei erfolgreich, wenngleich ihre Mittel völlig verschieden sind: Břetislav ist ein vorbildlicher Fürst mit überlegtem Handeln, das dem Vorgehen seiner Widersacher weit überlegen ist. Jaroslav von Šternberg hingegen gewinnt seine Überlegenheit dadurch, dass er die gleichen Mittel wie der Gegner anwendet, womit dieser freilich nicht rechnet (im obigen Zitat meint der Gegner ja, dass die Tschechen nicht täuschen und betrügen: indem sie dies allerdings tun, wird der Gegner getäuscht). Das Sujet des Dramas besteht darin, dass Jaroslav die topologische Grenze zwischen den beiden Lagern damit überschreitet, dass er die Täuschungsstrategie seiner Gegner übernimmt - man kann sagen, dass er ins Lager der Gegner „wechselt" und aus diesem erfolgreich zurückkehrt. Mit seinem Erfolg ist der Konflikt gelöst, da das gegnerische Lager nicht mehr existiert. Břetislav První hingegen ist darin sujetlos, als die Titelfigur unbeweglich bleibt, die Handlungen gehen von seinen Gegnern aus, bleiben aber erfolglos, das Lager bzw. den semantischen Raum wechseln nur diejenigen Figuren, die allein aufgrund von Blutsbanden zuerst dem Lager der Gegner angehören, aber in dem Augenblick in das Lager des Fürsten wechseln, als sie diesem verraten, dass dessen Position angegriffen wird.

\section{IV.4.3. Václav Kliment Klicpera: Soběslav, selský kniže. Truchlohra ve čtveru dějství} (1826)

[Soběslav, der Bauernfürst. Trauerspiel in vier Akten; entst. 1824, publ. 1826, UA 6.1.1839 nach Bearbeitung durch J. K. Tyl]

Bei aller Verschiedenheit der Stoffe und handelnden Personen stellt Vladimír Štěpánek in seiner Studie über die Anfänge des tschechischen Nationaldramas zwischen den untersuchten Stücken einige Entsprechungen und Ähnlichkeiten fest.

147 Jan Nepomuk Štěpáneks letztes Theaterstück war übrigens gleichfalls eine dramatische Bearbeitung der legendären Belagerung von Olomouc. Sein Jaroslav Šternberg aneb porážka Tataru u Olomouce zeigt die Verteidiger von Olmütz in größter Not, jedoch entschlossen, bis zum letzten Mann und zum Tod zu kämpfen. Für die Inszenierung 1839 standen sogar echte Pferde auf der Bühne, das Stück ist aber bei der Kritik völlig durchgefallen (vgl. Procházka 1969/DčD II, 113f; Marinelli-König 2011, 565). 
Die größte Gemeinsamkeit zwischen František Turinskýs Angelina, Josef Lindas Jaroslav Šternberg v boji proti Tatarüm und Václav Kliment Klicperas Soběslav, selský kniže (1826) besteht für Štěpánek darin, dass alle drei Stücke große Konflikte nur in Ansätzen vorführen, letztendlich aber zu keinem dramatischen Wechselspiel der Widersprüche in der Lage seien. ${ }^{148}$ In allen drei Stücken konnten die von Jungmanns Slovesnost proklamierten poetologischen Erwartungen an hochstehende Dramenliteratur noch nicht erfüllt werden. ${ }^{149}$ Den Grund für diese dramaturgische Schwäche sieht Štěpánek nicht etwa in individuellen Unzulänglichkeiten der Autoren, sondern vielmehr in den soziohistorischen Rahmenbedingungen des obrození, unter dessen Proponenten eine optimistische Einschätzung der Chancen auf eine nationale Selbstbehauptung (wie im „taktischen“ Stück von Linda ausgedrückt) mit Rückzug in Resignation und Innerlichkeit (wie in Angelina) oder einer pessimistischen Sicht auf die Nationalbewegung (wie bei Klicpera) abwechseln konnten (vgl. Štěpánek 1959, 98).

Wie sieht im Vergleich zu dem Beispiel aus Jan Nepomuk Štěpáneks Dramenproduktion, die von den nationalbewussten Intellektuellen um Josef Jungmann negativ beurteilt wurde und dem eher als „Lesedrama“ konzipierten Jaroslav Šternberg ein Stück aus, welches mit einiger Verspätung 1839 aufgeführt wurde und auch weitgehend wohlwollend als ein erstes gelungenes tschechisches Trauerspiel (allerdings nicht von Jungmann selbst, der Vorbehalte äußerte) rezipiert worden war (vgl. Sajíc 1942, 28)? Neben seinem Hauptberuf als Gymnasialprofessor (in Hradec Králové und Prag) verfasste der sehr produktive Klicpera vorwiegend historische Erzählungen und mehr als 50 Theaterstücke, er war auch als Regisseur und Schauspieler an Laienbühnen beschäftigt (u.a. unter Štěpánek im Ständetheater); Klicpera ist vor allem mit seinen Komödien der am öftesten aufgeführte tschechische Autor des ersten Drittels des 19. Jahrhunderts.

Das in der zweiten Hälfte des 12. Jahrhunderts angesiedelte Stück - sein Beginn wird genau mit 1174 datiert - führt die Wirren um die Nachfolge des von Friedrich I. Barbarossa zum König erhobenen Vladislav vor Augen, der in seiner Herrschaftsperiode auch international sehr aktiv war, aber noch zu Lebzeiten abgetreten ist, um - gegen die vom historischen Břetislav I. festgelegte Senioratsregelung verstoßend - seinen Sohn Bedřich mit der Thronnachfolge bzw. Herzogsmacht zu betrauen (vgl. Hoensch 1997, 71-74). Im Titelhelden Soběslav findet Bedřich seinen vom Senioratsprinzip legitimierten Rivalen.

148 „Je nyní tedy také patrno, že Klicperův Soběslav má touž historickou motivaci jako Turinského Angelina a Lindův Soběslav [sic! es müsste Jaroslav heißen].“ („Es ist also mithin deutlich, dass Klicperas Sobèslav dieselbe historische Motivation wie Turinskýs Angelina und Lindas Soběslav [sic!] hat. - Štěpánek 1959, 96)

149 Für Slovesnost hatte Klicpera mit Fragmenten aus den Stücken Bratři und Svatislav zwei Muster für ernste Stücke bzw. Tragödien vorgelegt. 
In den ersten beiden Akten sind jedoch weder der passive und melancholische Bedřich noch der einst so energische, nun aber von der langjährigen Gefangenschaft geschwächte Soběslav willens, die Herrschergewalt über Böhmen zu ergreifen. Das Stück setzt ein mit der Ahnung des müden Vladislav vom Heraufziehen eines Unwetters über Böhmen. Die Ankunft Soběslavs wird gemeldet, den Vladislav aus der langen Haft, welche er über ihn verhängt hat, freigelassen hat. Soběslav kommt barfüßig, von den Jahren im Kerker gezeichnet. Bedřich, der währenddessen in einem schwarzen Mantel, in dunklen tiefen Gedanken stumm dabei gestanden hat, entlässt den Grafen Rosenberg aus seinen Diensten. Bedřich beklagt sich bei seinem Vater über seine mangelnde Akzeptanz bei Adeligen und bei den Bauern. Vladislav ermahnt ihn zu größerer Stärke und Gleichgültigkeit, der Fürst soll dem Abbild Gottes ähnlich werden. „Bys tomu tam nahoře obrazem / Podoben byl. Zpravuj kola svého / Světa, nic nedbaje na to, že tvůj / Déšt někoho rosí, jenžby právě / Jasné slunce mít chtěl. ${ }^{“ 150}$ (I/3, S. 69) Doch einen solchen starken politischen Willen, der sich selbst- und machtbewusst auch über die Untergebenen erhebt, haben weder Bedřich noch der erschöpfte Soběslav.

Der abdankende König Vladislav bereut im Alter sein Vergehen an Soběslav, weil dadurch die erfolgreiche Bilanz seiner Herrschaft getrübt wird. Die Versöhnung erfolgt auf der Basis von deren beider Erschöpfung: Sie haben nicht mehr die einstige Kraft, die sie zu Gegnern gemacht hat, als Personen aber - bar des Königsamtes bzw. im Fall von Soběslav, bar des Willens, die Erbfolgeregelung zu erzwingen und das Senioratsprinzip durchzusetzen - können sie einander begegnen. Angesichts der Altersschwachheit seines Vaters und seines Onkels Soběslav erklärt Bedřich, er werde jetzt seinen Willen und Ehrgeiz nicht mehr zurückhalten, sondern Taten setzen (vgl. I/4, S. 74).

Da Bedřich es ablehnt, Soběslav eine Burg in Böhmen abzutreten, fürchtet Vladislav Unruhen, die mit dem Tod Soběslavs beseitigt würden, auf welchen Bedřich offenbar sinnt (I/7). Soběslav wird von einem geheimnisvollen Ritter vor dem Anschlag auf sein Leben gewarnt und flüchtet. Von tschechischen Adeligen wird er als der rechtmäßige Fürst angesehen und mit allen Mitteln der Redekunst zu überzeugen versucht, als Fürst über sie zu herrschen und das Land zu stärken. Der geheimnisvolle Ritter meint, er werde sich erst zu erkennen geben, wenn Soběslav böhmischer Fürst sein würde (II/1 u. 2). Soběslav bleibt jedoch immer noch zögernd und meint, dass mit diesen Forderungen unweigerlich blutige Zwistigkeiten im Land eintreten würden. Sein anderer Bruder Oldřich fühlt sich ebenfalls zu schwach, um die Nachfolge anzutreten, beim Kaiser hat er aber für Soběslav ein Truppenaufgebot erhalten, mittels welchem Soběslav erfolgreich für sein Recht kämpfen könne. Somit erwacht

150 [Vladislav:] „Damit du im Bild dem da oben ähnlich bist. Verwalte den Lauf deiner Welt so, dass du darauf nicht achtest, wenn dein Regen jemanden nässt, der gerade eine klare Sonne haben möchte." 
zwar - mit Unterstützung des Kaisers und anderer Personen - endlich Soběslavs Wille zur Macht, doch er fühlt sich immer noch nicht in der Lage, das Fürstenamt zu übernehmen. Erst als sich der Ritter als seine Frau, die polnische Fürstin Eližběta, zu erkennen gibt, erwacht in Soběslav endlich der Wille, sich in Prag für die erfahrene Schmach zu rächen: Eližběta habe es verdient, Fürstin zu werden.

In Prag ist inzwischen Vladislav verstorben, man erwartet den Angriff von Soběslav; die Bedřich loyalen Adeligen Rosenberg und Vladota wollen ein Blutvergießen verhindern und außerdem Bedřich, dem die Herrschaft zu schwer geworden ist, vor der Rache Soběslavs retten, indem sie ihn heimlich entführen. Vladota hofft sogar auf einen Frieden zwischen den beiden Rivalen. Bedřich hat Gewissensbisse wegen des Versuchs, Soběslav blenden zu lassen, er ist müde von den Anstrengungen und Ansprüchen an seine Stellung, die ihm gefährdet erscheint. („s tichým srdcem / Nyní chtěl bych žezlo své složiti a odejíti / Tam, kde ni slávy, ni poddannosti / Není, ale i žádné tíže, žádného / Márného, líčeného lesku!"151 - II/8; S. 118). In einer Art von regressivem Todestrieb möchte Bedřich zu einem Käfer werden. Die Stimme des Vaters rät ihm zur Flucht nach Ungarn.

In den ersten beiden Akten werden - Štěpánek (vgl. 1959, 92f) hat darauf nachdrücklich hingewiesen - politische Figuren gezeigt, deren Schwäche und Passivität offensichtlich ist: der König Vladislav dankt nach zahlreichen Erfolgen ermüdet ab, sein Sohn Bedřich sieht wenig Chancen für seine Herrschaft, Soběslav ist nach dem Gefängnisaufenthalt zu erschöpft, um für seinen Anteil zu kämpfen; auch sein Bruder Oldřich wird mit allen Anzeichen von Schwäche geschildert (vgl. II/3). Diese vier „schwachen“ Männer im Vordergrund werden von Kräften im Hintergrund angetrieben, die sie zu Taten drängen. Neben dem Kaiser sind dies zum einen Adelige, die entweder Soběslav durchsetzen wollen oder - wie Rosenberg und Vladota - zu Bedřich halten, selbst wenn sie von diesem mit Undank bedacht werden. Entscheidend für Soběslavs Gemütswandel ist nun die Initiative seiner Frau, die, als kämpferischer Ritter verkleidet, Soběslav im richtigen Moment rettend beisteht und ihn schließlich dazu bringt, sein politisches Mandat auch anzunehmen.

Die Akte III und IV sind zwei Jahre später angesetzt, Soběslavs Herrschaft hat das Land in eine Krise gestürzt, er ist ständig in Kämpfe verwickelt, die er mit einem Bauernheer erfolgreich führt. Sein Bruder Oldřich beklagt sich über diese $\mathrm{Zu}$ stände, Kaiser Friedrich, der Soběslav zuerst ja unterstützt hatte, hat ihm den Krieg erklärt, seine Frau Eližběta, die den undisziplinierten Bauernsoldaten wenig Sympathien entgegenbringt, hofft auf eine andere Politik, die auch die Stände einbezieht; sie fühlt sich ebenfalls Soběslav entfremdet und meint, das von Gott geschaffene natürliche soziale Gefüge sei durcheinandergebracht worden (vgl. III/4, S. 134).

151 „mit ruhigem Herzen / Nun möchte ich das Eisen ablegen und fortgehen / Dahin, wo es weder Ruhm, noch Ergebenheit / Gibt, aber auch keine Schwere, keinerlei eitlen, falschen Glanz!“ 
Während der Abwesenheit von Soběslav vertritt sie ihn in den innenpolitischen Angelegenheiten und erfährt dabei von der Unzufriedenheit der Adeligen. Soběslav hingegen preist die Bauern für ihren selbstlosen Kampf und erklärt, sie keinesfalls aufgeben zu wollen. Ein Mann aus seinem Gefolge, Kuklovín, hat ein Auge auf Eližběta geworfen, diese ist über dessen Gegenwart zutiefst erschrocken.

Bedřich ist mit Truppen von Kaiser Friedrich ausgestattet worden, vor dem Einmarsch nach Böhmen zögert er jedoch: soll er, um den Fürstentitel kämpfend, tschechisches Blut vergießen? Er möchte umkehren, die Erscheinung des Geistes seines Vaters weist ihm aber weiter den Weg nach Osten. Bedřich fasst die Erscheinung als göttlichen Hinweis auf, wenngleich die Antwort offen bleibt, ob er im Kampf Gewalt anwenden soll. Eine Gesandtschaft von böhmischen Adeligen kommt zu Bedřich, darunter auch Zázyma, der Soběslav früher unterstützt hatte. Die Gesandtschaft, die ebenfalls göttliche Unterstützung auf ihrer Seite wähnt, beklagt sich über die in ihren Augen verkehrten sozialen Verhältnisse in Böhmen:

[Zázyma:] Ustav zemský, starý, jak lid, kořenem /Jest vyvrácený, zkácen, jak strom ladem / Leží, a ta divá zvěř, jenžto / Někdy pod snětvemi jeho krmila / Se hojnou úrodou, po jeho ted' / Leze životě a v čelo velevážné /Jemu šlape! ${ }^{152}$ (III/5, S. 146).

Im Lager Soběslavs gibt es Zwistigkeiten zwischen den Adeligen, deren Soldaten und den Bauern. Im Kampf treffen Soběslav und Bedřich aufeinander; Soběslav verschont aber den verwundeten Fürsten, dieser flüchtet. Da die erste Schlacht für Soběslav siegreich bleibt, erscheint der göttliche Beistand für Bedřich nicht erfolgt zu sein, und dieser fragt sich, ob die Lösung nicht etwa im Tod bestünde (vgl. III/18, S. 171). Bedřich findet weitere Unterstützung bei Konrad von Mähren und Leopold von Österreich; in der Schlacht vor Prag verlassen Soběslav die Bauern, auch die Ritter desertieren; Kuklovín, Soběslavs Stütze, erwartet im aussichtslosen Kampf den Tod.

Der letzte Akt zeigt den Untergang von Soběslav, der sich mit dem Rest seiner Getreuen in die schwer zugängliche Burg Veliká Skála zurückgezogen hat, Eližběta schlägt sich mit einigen Bauern - erneut als Mann verkleidet - in die Burg durch (wobei sie, um den Defätismus der Bauern zu brechen, einen von ihnen eigenhändig tötet - vgl. IV/4, S. 186). Sie möchte Soběslav dazu bringen, mit ihr nach Polen zu flüchten. Er aber beharrt unbedingt auf dem Fürstentitel, der ihm der Senioratsregel gemäß zusteht. Angesichts der Aussichtslosigkeit aufgrund der Belagerung möchte Elisabeth heimlich Friedensverhandlungen aufnehmen. Es kommt aber zu

152 [Zázyma:] „Die Ordnung im Land, so alt wie das Volk, ist mitsamt der Wurzeln / ausgerissen, gefällt wie ein Baum, sie liegt unbestellt da / und das wilde Tier, das / einst sich unter seinen Ästen reichlich nährte, / kriecht jetzt über seinen Leib und tritt ihm / auf die vornehme Stirn." 
einer langen Eifersuchtsszene wegen Kuklovín, der tödlich verwundet Eližběta um Verzeihung bittet dafür, dass er nach Böhmen geflohen ist, nachdem in Polen sein Werben um sie vergeblich war. Soběslav vermeint, Eližběta habe ihn während seiner Haft betrogen und wird rasend eifersüchtig.

Vor seinem Angriff auf die Burg Veliká Skála erfährt Bedřich von Rosenberg, dass dieser ihm einst - als Stimme des Vaters - geraten hat, nach Ungarn zu füchten; der Friede sei immer Rosenbergs einziges Interesse gewesen. Soběslav wird tödlich verwundet; er erwartet, dass Eližběta ihren Ehebruch beichtet, der ebenfalls sterbende Kuklovín schwört aber, dass sie Soběslav immer treu gewesen ist. Beide sterben. Soběslav bittet am Totenbett seine Frau um Vergebung. ${ }^{153}$ Bedřich sagt ihm nach, der mutigste der Přemysliden gewesen zu sein. Der ihr angebotenen Burg in Böhmen zieht Eližběta ihre Heimat Polen vor.

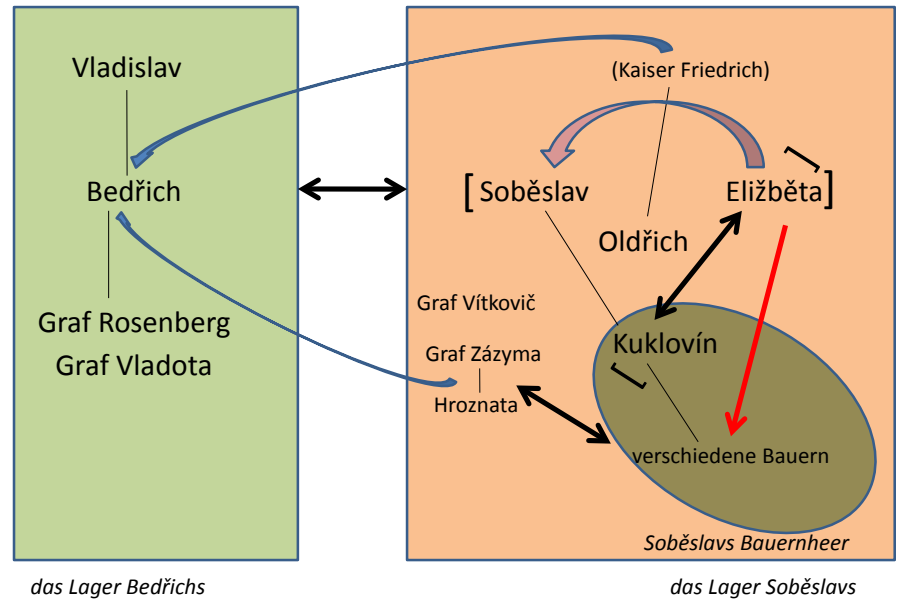

Graphik 7 - Václav Kliment Klicpera: Soběslav, selský kniže (1826)

Während die beiden ersten Akte von Klicperas Drama passive und unwillige politische Führer zeigen, treten im dritten und vierten Akt, die in der Fabel zwei Jahre später als die ersten beiden Akte angesetzt sind, Soběslav und sein Rivale Bedřich wesentlich aktiver auf. In Soběslav ist die Tatkraft erwacht, als er das Ausmaß von Eližbětas Einsatz erkennt und fühlt, dass er ihrer würdig sein müsse. Bedřichs Wille, wieder den Herzogstitel zurückzuerobern, hängt offenbar mit der Unterstützung

153 Die Eifersuchtstragödie, die zwischen Soběslav, Eližběta und Kuklovín entwickelt wird, soll Štěpánek (vgl. 1959, 100) zufolge die Attraktivität der Handlung steigern, welche der historischen Linie fehlt (letztere ist mit der Eifersuchtshandlung nur sehr schwach verbunden), eine ähnliche Funktion haben auch die mysteriösen Verkleidungen (von Eližběta, Kuklovín oder Rosenberg). 
zusammen, die ihm von Adeligen gewährt wird, welche einst Soběslav Waffenhilfe geleistet hatten. Darüber hinaus wähnt sich Bedřich von transzendenten Mächten unterstützt, womit ihm die Entscheidung praktisch abgenommen wird, da er sich auf die Vorsehung berufen kann: „Tak Bůh s námi, tak mluví s námi jeho / Svatá prozřetelnost “154 (III/5, S. 141) Zumal die darauf folgende Schlacht aber von Soběslav gewonnen wird, beginnen Zweifel an den transzendenten Fingerzeigen; der junge Hroznata, der in der Schlacht seinen Vater verloren hat, schließt daraus, dass der Triumph wohl im Tod liege. Seine Konsequenz besteht im Rückzug aus dem weltlichen Ritterleben, er möchte eine Kirche errichten.

Der politische Konflikt auf der Ebene der Fabel ist nicht sonderlich markant gezeichnet, er besteht vorwiegend darin, dass Vladislav die geltende Erbfolgeregel verletzt hat und der eingesetzte Bedřich wenig Unterstützung besitzt. Bei diesem Thronfolgekonflikt wird auf den Bruder- bzw. Bürgerkriegsaspekt hingewiesen (Soběslav ist ein Drama, in welchem kein tschechisch-deutscher Antagonismus thematisiert wird), die Rivalen zögern mit entschlossenem Handeln auch deswegen. Nachdem sich aber Soběslav mit seinem Bauernheer hatte durchsetzen können, erweist sich auch seine Herrschaft als fragwürdig, er verliert das Vertrauen seiner bisherigen Förderer. Als Fürst gebärdet sich Soběslav allzu bauernfreundlich als „selský kníže“ - sehr zum Leidwesen der Adeligen, welche die göttliche Ordnung gestört sehen - die Szenen aus Soběslavs Heer zeichnen fürwahr kein günstiges Bild der Bauern -, darüber hinaus spricht Eližběta, die einzige Hauptfigur mit vorwiegend positiven Eigenschaften, despektierlich von den undisziplinierten Bauernkriegern. Mithin zeigt sich, dass die Einhaltung der Erbfolgeregel allein keine Garantie dafür ist, dass das Land prosperiert, wie zuerst vermeint wurde: bis auf Vítkovič, dem Soběslav einst - mit scheinbar überirdischen Kräften - das Leben vor einem wütenden Wildschwein gerettet hat, werden alle zu Gegnern Soběslavs; Eližběta ist nur aufgrund ihrer ehelichen Bindung zu Soběslav gegenüber diesem loyal, sie rät jedoch inständig zu einer anderen Politik. Als sich Soběslav, aussichtslos eingeschlossen in der Burg Veliká Skála, hartnäckig weigert, aufzugeben und sich mit seiner Frau nach Polen zurückzuziehen, entschließt sich Eližběta zu Friedensverhandlungen hinter dem Rücken ihres fürstlichen Gemahls. Soběslav, der sich mit einem weidwunden Wildschwein vergleicht, stürzt sich in einen aussichtslosen Kampf, Eližběta hingegen hofft auf Gott, damit diese "Säule“ stehen bleibt (vgl. IV/9, S. 199). Ihre Bitte wird zwar nicht erhört, sie indiziert aber eine politische Klugheit, die sich deutlich von der blindwütigen Natur Soběslavs unterscheidet. Štěpánek (vgl. 1959, 94) hat auf dessen blindwütige Leidenschaft hingewiesen, die keine Rücksicht auf seine Umgebung und das von ihm vertretene Volk nimmt, ${ }^{155}$

154 [Bedřich:] „So ist Gott mit uns, so spricht mit uns / Seine heilige Vorsehung.“

155 Als Leser ist man versucht, angesichts des Verhaltens des Titelhelden den historischen Namen Soběslav zu resemantisieren (,derjenige, der vor allem sich selbst Ruhm sucht'). Allerdings gibt es dafür im Dramentext selbst keinen Anhaltspunkt. 
dabei aber die positive Figur seiner Frau und die von dieser vertretene Politik übersehen.

Ein Pendant zu Eližbětas Verhältnis zu Soběslav kann in Rosenberg gesehen werden, der sich loyal gegenüber Vladislav und seinem Sohn Bedřich verhält, auch wenn er von diesem ungerechtfertigt für zwei Jahre aus dessen Diensten suspendiert wird. Rosenberg bewertet die politische Situation nach der Einsetzung Bedřichs richtig, er weiß von der großen Unterstützung für Soběslav und möchte daher Bedřich retten: dessen heimliche Entführung sowie daran anschließende Friedensverhandlungen erscheinen jedoch als ein zu unsicheres Mittel, stattdessen gibt Rosenberg sich als nächtliche Erscheinung des verstorbenen Vaters aus und rät Bedřich zur Flucht nach Ungarn.

[Rosenberg:] Stál jste tady v nejistotě mrákotné / Boha, otce královského v radu volaje / Co Vám spasno podniknouti ... / Hlas ten, drahý vývodo, byl můj vlastní. ${ }^{156}$ (IV/3, S. 183)

An die Stelle des vermeintlichen Gottes, an die Stelle des verstorbenen königlichen Vaters tritt die Stimme des Beraters, der in der Verkleidung als König den entscheidungsschwachen Bedřich vor dem Untergang rettet. Wie bereits oben festgestellt wurde, geht in Sobéslav die politische Initiative nicht von den dargestellten politischen Hauptfiguren, sondern von Figuren aus deren Umfeld aus, die in der klassischen Dramenkonzeption eigentlich nicht handlungstragend sind (die Berater Bedřichs einerseits und andererseits Soběslavs Frau Eližběta). Štěpánek (vgl. 1959, 91f) hat die politische Passivität der Hauptfiguren bemerkt und sie als allgemeines Kennzeichen der formal ehrgeizig konzipierten Dramatik des obrozeni dargestellt, der es inhaltlich an großen Helden fehle, um zur wirklichen Tragödie zu werden:

Klicperův Soběslav je dalším faktem, který dokumentuje desiluzivni typ ideové inspirace dramatické tvorby [...] tato specifická ideová orientace dramatu nebyla nahodilá, nebyla dána prostě subjektivními zájmy autorů, nýbrž zákonitostí dramatu, ideovou podstatou této specifické formy, tím, že drama, jež mělo být dramatem nejvyšší úrovně, orientovalo se k tomu, co bylo v životě národní společnosti nejvyšším stupněm společenské konfliktnosti. ${ }^{157}$ (Štěpánek 1959, 97, kursiv im Orig.)

156 [Rosenberg:] Sie standen da in finsterer Unsicherheit / Gott, den königlichen Vater um Rat anrufend / Was Euch die Rettung bringen könnte ... / Diese Stimme, mein Herzog, war meine eigene."

157 „Klicperas Soběslav ist ein weiteres Faktum, das den desillusiven Typ der ideellen Inspiration des dramatischen Schaffens darstellt [...] diese spezifische ideelle Orientierung war nicht zufällig, sie wurde nicht einfach durch subjektive Interessen der Autoren bedingt, sondern man orientierte sich gemäß der dramatischen Gesetzmäßigkeit, gemäß des ideellen Wesens dieser spezifischen Form, gemäß des Umstandes, ein Drama von höchstem Niveau zu schaf- 
Unter dieser Optik erscheinen die dramaturgischen Mängel des Dramas folglich darin, dass aufgrund ihrer Schwäche die Hauptfiguren nicht wirklich zu Akteuren der dramatischen Handlung werden. Betrachtet man die beiden rivalisierenden Fürstengestalten Soběslav und Bedřich genauer, so erscheinen sie tatsächlich als politisch nicht sonderlich imposant. Soběslav weist mehrfach alle Ambitionen auf das ihm „gesetzlich“ zustehende Herzogsamt zurück, da ihn die lange Haft ausgezehrt hat, Bedřich hingegen ist unglücklich darüber, als Fürst designiert zu sein und dabei keine politische Unterstützung von den Adeligen zu erfahren. Sein Vater Vladislav bedauert seinen herrscherlichen Ehrgeiz, der als Last nun auf Bedřich übergeht: „Tamto stojí a ramenem / Silným drží sloup, který se zpouzí / Vývodský jeho stolec držeti!“158 (I/2, S. 66).

Aus der zutreffenden Beobachtung von der politischen Schwäche und „schwachen" dramaturgischen Motivationen bzw. Konventionen könnte allerdings auch eine andere Schlussfolgerung als Štěpáneks generalisierende Überlegung zur Literatur des obrození gezogen werden, welche unter der Perspektive des kulturellen Wettbewerbs den relativen Rückstand der tschechischen Literatur und Kultur im Vormärz einräumt, dabei aber die Mühen betont, zu den fremdkulturellen Modellen aufzuschließen. Der Passivität der Fürstenfiguren wäre die politische Aktivität des Adels bzw. die Klugheit von Eližběta gegenüberzustellen, womit Soběslav, selský kniže als Drama erscheint, das ein autokratisches Führungsmodell implizit kritisiert und die politische Partizipation von verantwortlich handelnden Personen die Bauern erscheinen im Stück nicht als solche ${ }^{159}$ - favorisiert. Diese ideologische Implikation, die sich daraus ableitet, dass die "geschichtsentscheidenden" und verantwortungsvollen Handlungen des Dramas nicht von den Hauptfiguren, sondern letztendlich von deren Umgebung ausgehen (von Eližběta, der Frau Soběslavs; von den Adeligen um Bedřich) wird von Štěpánek weitgehend übersehen.

Im Zusammenhang mit der politischen Funktion „nachrangiger" Figuren verdient die Untersuchung des Einflusses transzendenter Mächte in Soběslav besondere Aufmerksamkeit.

Im Drama gibt es nämlich zum einen quasi überirdischen Beistand (Hroznata erzählt, wie er bei einem nächtlichen Marsch einmal durch plötzliche Helligkeit

fen, daran, was im Leben der nationalen Gemeinschaft als höchster Ausdruck der Konflikthaftigkeit galt."

158 [Vladislav:] „Dort steht er [Bedřich] und stützt mit / starker Schulter die Säule, die sich weigert / seinen Herzogsthron zu tragen!“

159 In seiner Monographie über Klicpera betont Justl (vgl. 1960, 117) offenbar gemäß den Vorgaben marxistisch-leninistischer Kulturdoktrin einen in Soběslav manifesten „Demokratismus“, der sich in der sympathischen Darstellung der Bauern zeige. - Offenbar hat Justl nicht damit gerechnet, dass Soběslav noch von irgendjemandem gelesen wird, der diese Behauptung überprüfen würde: Sie ist schlichtweg falsch; die Bauernsoldaten werden als unzuverlässig und marodierend dargestellt. 
vor einem Sturz in eine Schlucht bewahrt worden war - vgl. III/7, S. 148), zum anderen bleibt dieser Beistand in Momenten aus, in welchen auf ihn gebaut wurde; die Figuren werden in ihrer Hoffnung auf überirdische Unterstützung enttäuscht (wie Bedřich, Zázyma und Hroznata hinsichtlich der bevorstehenden Schlacht, die anders ausgeht, als sie selbst vermutet haben - vgl. III. Akt). Eine dritte Variante des Bezugs auf Überirdisches besteht eben darin, dass dieses von jemandem nur vorgetäuscht wird, um ein gewünschtes Verhalten zu erreichen (Rosenberg bewegt Bedřich zur rettenden Flucht, indem er sich als Gespenst verkleidet). Eine in diesem Zusammenhang interessante Szene (II/5 u. 6) zeigt den „komischen“ Streit zweier Bürger darüber, ob der König Vladislav schon gestorben ist oder nicht. Der eine Bürger mit dem Namen Burian beharrt trotz Glockengeläut und Gerüchten darauf, dass der König noch immer lebe: Burian begründet diese Auffassung mit der Prophezeiung eines Weissagers, er werde so lange leben wie sein Fürst. Zumal er sich bester Gesundheit erfreut, kann auch König Vladislav nicht gestorben sein. „Náš král nesmí ještě umříti. Nechci tomu, nedám tomu, a kdybyste mi ukázali tělo jeho osvícené, řeknu, že to není on!“ - „Tu ho máte“160 (II/6, S. 112) - Die Replik „Tu ho máte" kann doppelsinnig gelesen werden, zum einen in der phraseologischen Bedeutung ,da haben wir's!' bzw. ,na so etwas' mit der wohl angedeutet wird, dass Burian seltsame Gedanken hat, zum anderen könnte auch eine buchstäbliche und dabei „tiefere“ politische Bedeutung aus dem Wortsinn herausgelesen werden - im Sinne von „hier ist der [politische] Körper des Königs!“ (mit deiktischer Referenz auf die politischen Subjekte der Königsherrschaft, die tatsächlich noch am Leben sind, auch wenn der König schon gestorben ist). In dieser Szene ist die mit dem „komischen“ Gedanken hergestellte Relation König - Bürger nicht zu übersehen: „Solange ich, der Bürger Burian, am Leben bin, lebt der König (qua Königsherrschaft) politisch weiter" - Wenngleich Burians Wahrsager also hinsichtlich der leiblichen Existenz des Königs Unrecht hat, kann seine Aussage bezüglich des Verhältnisses zwischen Repräsentant (König) und Repräsentiertem (der Bürger) zumindest ironisch eine gewisse Gültigkeit beanspruchen: der entsprechende „falsche" Syllogismus lautet: a) Der König repräsentiert/vertritt jeden einzelnen lebenden Untertan, b) Ich, Burian, lebe noch, c) Der König lebt noch.

Betrachtet man diese Aspekte des Dramas vor dem Hintergrund, dass die auf den verstorbenen König Vladislav folgenden Fürsten Bedřich und Soběslav beide nicht die volle Unterstützung der Stände erfahren, wird deutlicher, dass Sobéslav letztendlich auch von einer politischen Repräsentationskrise handelt. Der transzendente Bezug, die göttliche Legitimation und Stütze von Herrschaft funktioniert nicht mehr "problemlos" - hinter bzw. mit den Fürstenfiguren, die traditionell im

160 [Burian:] „Unser König darf noch nicht sterben. Ich möchte das nicht, ich lasse das nicht zu, selbst, wenn mir sein erlauchter Leib gezeigt werden würde, sage ich, dass er das nicht ist.“ [Baňka:] „Na so etwas!“ 
Handlungszentrum stehen, handeln andere verantwortungsvoller und umsichtiger als diese. Zuerst wird Soběslav als Fürst gewollt, weil er nach geltender Regel der legitime Nachfolger von Vladislav wäre, als er sich jedoch als unkluger Herrscher erweist, unterstützen die Adeligen Bedřich, dessen Handlungsinitiative dabei immer kleiner wird: gegen Ende des Stücks entfallen auf Bedřich kaum noch Repliken, in der letzten Szene spricht er einen Nachruf auf Soběslav aus und stellt dessen Witwe Eližběta ein Land in Böhmen zur Verfügung. Interessanterweise räumt er dabei Eližběta Herrschaftsgewalt ein: „Městem at vládne / Att i polem vládne vdova Soběslavova" ${ }^{\text {"161 }}$ (IV/12, S. 205). Wenngleich Eližběta dieses Angebot damit ausschlägt, nach Polen zurückgehen zu wollen, wird mit diesem Schluss die „fremde Frau" als Politikerin bestätigt, deren Urteilskraft größer war als die ihres Gatten und die somit ähnlich umsichtig wie die Grafen Rosenberg und Vladota in Bedřichs Reihen erscheint.

Angesichts der festgestellten Handlungsschwäche der politischen Rivalen Soběslav und Bedřich, die beide nur aufgrund von fremdem Willen die politische Führung übernehmen, wäre zu fragen, wo in diesem Drama die topologischen Grenzen verlaufen und ob es zu „Grenzverletzungen“ bzw. „Grenzübertretungen“ kommt. Soběslav und Bedřich, die politischen Rivalen um die Nachfolge Vladislavs, stehen zwar einander auch am Schluss antagonistisch gegenüber; dass die topologische Grenze dennoch nicht zwischen den beiden Lagern verläuft, erweist sich aber darin, dass etwa Adelige, die einst Soběslav unterstützt haben, nach einiger Zeit ins Lager von Bedřich übergewechselt sind (auch der als dramatis persona nicht präsente Kaiser vollzieht denselben Wechsel). Zumal sich dieser Wechsel der politischen Präferenzen im (historischen) Hintergrund des Dramas, nicht aber in der dramatischen Handlung abspielt, kann er nicht als sujetbildend aufgefasst werden. Motiviert ist dieser Wechsel durch Soběslavs Politik, die in einer Verkehrung der sozialen Strukturen besteht. Insofern Soběslav auf die Unterstützung seiner marodierenden Bauernkrieger baut, wird die traditionelle Verfassung des Fürstentums Böhmen umgestoßen (das Epitheton des Titelhelden [„selský kníže“] zeigt diese Aufösung sozialer Grenzen an). Soběslav verletzt also die ständischen Grenzen, die Verletzung jedoch wird „repariert“, ohne dass sie dabei dialektisch „aufgehoben“ bzw. für die Zukunft bewahrt wird. Entscheidenden Anteil an dieser Entwicklung hat Eližběta, Soběslavs Frau, welche neben der Titelfigur die zweite - und die wichtigere - Handlungsträgerin ist. Erstens hat sie eine - im Zusammenhang der Fabel nicht erklärte - Voraussicht, mit welcher sie - als Ritter verkleidet - Soběslav vor dem Geblendetwerden rettet, zweitens entschließt sich Soběslav erst wegen ihres Einsatzes dazu, den Fürstentitel einzufordern, und drittens korrigiert sie Soběslavs Politik, in dem sie hinter dem Rücken ihres Mannes zu vermitteln versucht und seine Fehler, so gut dies ihr möglich ist, ausbessert. Ihre Aktivität, die in Relation

161 [Bedřich:] „Möge die Witwe Soběslavs über die Stadt, möge sie über das Land herrschen!“ 
auf Soběslav auch die politisch klügere ist, wird denn auch als „männlich“ ausgewiesen, da sie zweimal in männlicher Verkleidung - zuerst als Ritter, im vierten Akt als Bauernsoldat - ihren Mann Soběslav zu retten versucht. Als dessen Frau ist sie funktional gesehen eigentlich der „starke Mann“, der Handlungsträger, der versucht, die Fehler Soběslavs zu korrigieren und ihn und das Land zu retten. Ihr Handeln erläutert sie selbst folgendermaßen:

\footnotetext{
Žena vás mužným slovem, žena mužným

Skutkem musila jsem zbrojiti. Každý

$Z$ vás byl svědkem očitým, duch s co jesti,

Bytby outlé, bytby tělo bylo nesmělé!

Můj jste vy sbor! Svým vás budu hlaholem

Svým vás budu ř́́diti praporem!

Za mnou! Za mnou!162 (IV/4, S. 186)
}

Einen Aspekt dieser Rettung stellt die Reparatur der verletzten ständischen Unterscheidung dar, die Bedřich vorzunehmen bereit ist. Bezeichnend für die politische Position des Stücks ist wohl, dass die Handlungen Bedřichs von seinen adeligen Beratern initiiert werden. Soběslav, selský kniže stellt die Macht der Fürstenfiguren als im Schwinden begriffen und als fragwürdig (da deren Entscheidungen nicht die klügsten sind) dar; das Drama lehnt allerdings das breite Volk als politische Machtbasis ab (damit erscheint es konservativ), aufgrund des affirmierten Einflusses, den Figuren in der Umgebung der politischen Repräsentationsfiguren haben, votiert es stattdessen für eine adelige Partizipation in politischen Entscheidungen.

\section{IV.4.4. Šebestián Hněvkovský: Jaromir. Smutnohra v pateru jednáni (1835)}

[Jaromír. Trauerspiel in fünf Akten; unaufgef., publ. 1835]

Dem „Trauerspiel in 5 Aufzügen“ schickt Šebestián Hněvkovský, der gemeinsam mit Antonín Puchmajer zu den ersten Dichtern des obrození gehörte, die auf Tschechisch schrieben und dabei die von Dobrovský vorgeschlagene Syllabotonik probierten (vgl. Schamschula 1990, 353; LčL 2/I, 211f) eine dramentheoretische Vorbemerkung voran. In dieser stellt er fest, dass sich die „heutigen“ Dramatiker meist nicht ganz streng an die aristotelischen Einheiten von Zeit, Ort und Handlung hielten, weil insbesondere die Einheiten von Zeit und Ort allzu große Einschränkungen

162 [Eližběta:] „Als Frau musste ich euch mit einem männlichen Wort, mit einer männlichen Tat / musste ich als Frau euch bewaffnen. Jeder / Von euch war Augenzeuge, wozu der Geist / Selbst wenn der Körper schwach, der Körper feige ist / Imstande ist! Ihr seid meine Mannschaft! Mit meinem Horn, / Mit meiner Fahne werde ich euch führen! / Mir nach! Mir nach!“ 
nach sich zögen - nur die Franzosen Corneille und Racine sowie Vittorio Alfieri in Italien bemühten sich um eine ganz klassische Form, während Shakespeare, Lope de Vega, Calderon de la Barca sowie Goethe und Schiller nur auf die Einheit der Handlung achteten. Es gebe noch bei vielen Völkern Uneinigkeit darüber, worauf der tragische Charakter eines Trauerspiels beruhe, es sei wohl wichtiger, dass das Schicksal der Hauptfigur Mitleid und Schrecken hervorrufe als dass immer ein Widerspruch zwischen derem selbstgewissen Handeln und dem Walten der Moiren auftreten müsse. Seinen Helden Jaromír charakterisiert Hněvkovský als nicht aktiv Handelnden, dennoch würde er - wie Agamemnon, Julius Cäsar oder Maria Stuart - tragisch wirken. Die aktive Person wäre Kochan (der vom Handlungstyp mit Klytemnestra und Brutus verglichen werden könne); Skřezislava, Jaromírs Frau, sei die edel Handelnde, die deshalb von vielen als Hauptfigur angesehen werde. Jaromírs Schicksal sei eines der traurigsten in der tschechischen Geschichte, das Unglück hätte diesen Fürsten seit der Wiege nicht verlassen. Hněvkovský schließt seine Vorbemerkungen mit einem Bescheidenheitstopos: Da er keine neuen Wege mit diesem Stück einschlage, lege er es gleichsam wie eine Prüfungsarbeit vor.

Das im frühen 11. Jahrhundert spielende Drama zeigt, welche Leiden Fürst Jaromír auf sich nehmen muss, weil die Vršovci um den intriganten Kochan den Fürstentitel begehren. Das Drama ist chronologisch um eine Generation früher angesiedelt als das oben analysierte Stück Štěpáneks Břetislav První, Český Achylles: Jaromír misstraut seiner Frau Skřezislava, sie würde ein zu enges Verhältnis mit Kochans Sohn Miloslav haben. Dieser wurde jedoch, wie Skřezislava selbst betont, von Jaromír selbst als Vertrauter herangezogen. Um das ungerechtfertigte Misstrauen ablegen zu können, solle Jaromír Miloslav doch zum polnischen König Boleslav schicken, dieser wäre somit nicht mehr in der Nähe von Skřezislava und könne bei den Polen diplomatische Aufgaben erledigen. Jaromír meint, sollte es wirklich zu Skřezislavas Untreue kommen, müsse sie ins Kloster und Miloslav mit seinem Leben bezahlen. Skřezislava erklärt, sie werde immer zu einem so guten und fürsorglichen Fürsten wie Jaromír stehen und ihm, der im Amt so viele Unbill zu erdulden habe, eine Stütze sein. Jaromír tendiert außenpolitisch eher zu einer Allianz mit den Deutschen, denen die Tschechen ihre Selbstständigkeit verdanken, als zu den Polen, die zu mächtig werden könnten. Der Vršovec Kochan versucht, Jaromír mit einer Erbstreitigkeit in eine Zwickmühle zu bringen: Kochan behauptet, er hätte die Unterstützung des deutschen Kaisers, um seinen Anspruch auf das Erbe seines verstorbenen Bruders gegen dessen Tochter durchzusetzen. Da Jaromír aber das geltende Erbrecht nicht zugunsten von Kochan ändern möchte, muss sich dieser letztendlich einverstanden zeigen. Jaromírs jüngerer Bruder Oldřich begehrt ebenfalls das Fürstenamt, er möchte seinen Sohn Břetislav, den er mit einer Frau aus dem einfachen Volk gezeugt hat, als Fürsten sehen, dieser habe das Potenzial zu einem starken Herrscher. Jaromír lehnt eine Teilung der Macht ab, da diese das Land destabilisiere. Er sieht sich mit verschiedenen schwierigen Problemen - den Thron- 
ansprüchen seines Bruders Oldřich, den Intrigen Kochans, dem Allianzangebot des Polen Boleslav, dem häuslichen Problem möglicher Untreue - konfrontiert und erklärt, dass die Herrscheraufgabe eine sehr schwere sei. Aus der nachzeitigen Perspektive der Geschichtsschreibung sei man immer klüger, in der Situation hingegen sei eine Lösung schwer zu erkennen (vgl. I/8). Der dramatische Konflikt entspinnt sich mit den Bitten Miloslavs, dass Skřezislava ihn erhören möge, denn sie habe doch für Jaromír nie Liebe empfunden. Skřezislava erkennt in den Reden Miloslavs einige dunkle Andeutungen; da sie Jaromír schützen möchte, ersinnt sie eine List, mit der sie Anschlagspläne auf Jaromír zu erfahren hofft: Sie gibt vor, Miloslav zu erhören, wenn er ihr etwas verraten werde. Jaromírs Berater Bosov belauscht dieses Zwiegespräch, er erkennt allerdings nicht die Verstellung von Skřezislava: Er tötet Miloslav und hält Skřezislava nicht nur für eine Ehebrecherin, sondern hält sie auch für am geplanten Attentat gegen Jaromír beteiligt.

Im zweiten Aufzug trifft Jaromír auf einen christlichen Einsiedler, der wunderbare Kräfte sowie die Gabe der Prophezeiung hat. Der Einsiedler möchte das teilweise noch im Heidentum befangene Land weiter christlich missionieren, er rät Jaromír inständig, die Fürstenmacht an seinen Bruder Oldřich abzutreten, da in den politisch stürmischen Zeiten eine starke Hand besser sei und Oldřich in der Lage wäre, die ungerechten Zahlungen ans Deutsche Reich einzustellen und Mähren zurückzuerobern. Jaromír widerstrebt dieser Rat, er möchte weiter die fürstliche Macht behalten, ob der Gefahr eines Bürgerkriegs und der damit verbundenen außenpolitischen Schwäche des Landes erklärt sich Jaromír letztendlich mit dem Vorschlag des Einsiedlers doch einverstanden, ohne dass es freilich zu dessen Umsetzung kommt: Oldřich soll sich gegen die Vršovci wehren, die alle Untertanen zu Sklaven machen wollen. Die Vršovci haben inzwischen Jaromír auf der Jagd gefangen genommen, Kochan möchte Jaromír und den ebenfalls gefangenen Bosov hinrichten lassen, durch eine List kann Bosov aber die Hinrichtung verzögern und Prager Truppen herbeilocken, die ihn und Jaromír im letzten Augenblick befreien.

Kochans Intrigen und Herrschaftsansprüche werden auch von seinem zweiten Sohn Protislav abgelehnt, der die Legitimität der Přemysliden nicht anzweifelt (Kochan meint, Libuše hätte - weil eine Frau - überhaupt nicht herrschen dürfen). Kochan kann der Gefangennahme entkommen, er sinnt auf Rache und möchte Oldřichs Interesse an der Fürstenmacht anstacheln. Oldřich hat mit Božena, einer Frau aus dem einfachen Volk, Břetislav gezeugt, der zum kampfesmutigen und zum Fürstenamt befähigten Mann herangewachsen ist. Oldřich sinnt auf einen Aufstand, den er gemeinsam mit Kochan durchführen möchte.

Neben dem Kampf um die Fürstenmacht vollzieht sich auch das private Drama Jaromírs. Er misstraut seiner Frau Skřezislava und schenkt deren Beteuerungen wenig Glauben. Zwar glaubt er nicht, dass Skřezislava wirklich den Anschlag gegen ihn mitgeplant hat; die Untreue mit Miloslav bleibt jedoch als Verdacht bestehen. Sie 
soll daher ins Kloster gehen. Zur ihrer Rechtfertigung wirft Skřezislava ihrem Mann vor, dass er ihr nicht Glauben schenke, die Männer seien mißtrauisch und verdächtigten bereits beim leisesten Verdacht ihre Frauen. Trotz ihrer Verstoßung würde sie auch in Zukunft zu Jaromír stehen.

Im vierten Akt droht ein großer Bürgerkrieg, da Oldřich - nach Bestärkung durch Kochan - für den Kampf gegen Jaromír mobilisiert. Dieser möchte einen Bruderkrieg vermeiden. Oldřichs Sohn Břetislav erweist sich als kampfentscheidend. Jaromírs Truppen unterliegen gegen Oldřich und Kochan. Letzterer lässt rachsüchtig Jaromír blenden, Oldřich hatte diesem Rachewunsch Kochans zugestimmt. Oldřich, als neuer Fürst begrüßt, verspricht eine Stärkung und Verbesserung des Landes, Jaromír habe, erklärt er, als Fürst zu nachsichtig gehandelt.

Der geblendete Jaromír hadert mit seinem traurigen Schicksal; in Anklang an den antiken Tragödien-Topos erklärt er, er wäre besser gar nicht geboren worden. Der Einsiedler, der Oldřich immer schon als Fürst empfohlen hat, versucht, tröstende Worte für Jaromír zu finden und das Unrecht zu relativieren. Oldřich hingegen verkündet, als Sieger alle Rechte zu haben, er werde Jaromír nötigenfalls sogar noch strenger bestrafen; Kochan würde diese Folter gerne ausführen. Die von Jaromír aus Eifersucht und falscher Einschätzung verstoßene Skřezislava erscheint verkleidet als Mann unter dem Namen Unislav, sie erklärt, dass Skřezislava unglücklich sei, als deren Bruder Unislav wolle er (eigentlich sie) Jaromír gerne beistehen. Jaromír bedauert seine Härte gegenüber Skřezislava und nimmt Unislav als Diener an.

Der fünfte Akt ist zeitlich etwas später angesetzt. Oldřich ist inzwischen nach wenig glücklicher Herrschaft verstorben: er war in deutscher Gefangenschaft und bereute dort sein Handeln gegen seinen Bruder Jaromír. Oldřichs Sohn Břetislav hingegen ist als Fürst bei der Ausweitung des böhmischen Territoriums sehr erfolgreich und möchte die Schuld Oldřichs an Jaromír durch Zahlungen und Reue wieder gutmachen. Kochan will immer noch den Přemysliden die Macht entreißen, er hat daher Anschläge auf Břetislav angeordnet, dieser wird allerdings von Jaromírs früherem Diener Hovora sehr gut beschützt. Kochans Sohn Protislav widerstrebt es zutiefst, den blinden Jaromír zu erstechen, der öffentlich gegen die Vršovci auftritt. Der als Pilger verkleidete Jaromír wandert mit Unislav bzw. Skřezislava zum Sázava-Kloster, sie treffen dort auf Kochan, der zuerst die beiden nicht erkennt, dann aber Jaromír ermordet. Dieser hatte zuvor noch von Skřezislava erfahren, dass sie wirklich unschuldig war, seinem Bruder Oldřich sieht er die Verbrechen nach, da Břetislav ein guter Fürst geworden ist und da Oldřich sich das Sázava-Kloster hatte bauen lassen.

Hněvkovskýs Drama kombiniert mehrere Konflikte: zentral für die Handlungsentwicklung ist der Konflikt der beiden rivalisierenden Geschlechter, der Přemysliden und der Vršovci, um die Fürstenmacht. An diesen Konflikt schließen weitere an; zunächst der Konflikt innerhalb der beiden Familien selbst: Oldřich entreißt seinem Bruder die Macht und willigt dabei sogar in dessen Blendung ein, bei den 
Vršovci kommt es zu Differenzen zwischen dem brutalen Vater Kochan und seinem Sohn Protislav, der ein so gewaltvolles Vorgehen gegen die Přemysliden ablehnt und kein willfähriges Werkzeug seines Vaters sein will. Die Rivalität der Familien um die politische Führung in Böhmen spielt in den tragischen privaten Konflikt zwischen Jaromír und seiner Frau Skřezislava hinein, da diese von ihm sogar verdächtigt wurde, im Bunde mit Kochans Sohn Miloslav einen Anschlag gegen ihn vorzubereiten. Jaromír verstößt deshalb seine Frau, die aber immer zu ihm hält und ihn in männlicher Verkleidung als Unislav beschützt.

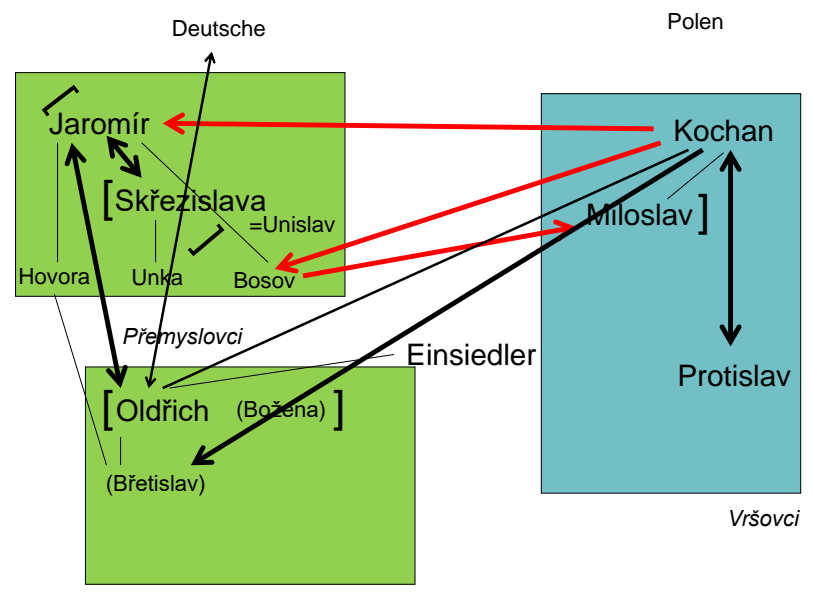

Graphik 8 - Šebestián Hněvkovský: Jaromír (1835)

Im Drama ist zwar der Vršovec Kochan eine rein negative Figur, der es nur um Macht geht und die dafür alle verwerflichen Mittel anwendet. Sein Opfer Jaromír ist aber keine fraglos positive Fürstenfigur, in mehrerlei Hinsicht zeigt sie Schwächen. Jaromír gilt vielen als politisch zu schwach: sein Bruder Oldřich meint, bessere Fähigkeiten zum Herrschen zu haben, der christliche Einsiedler ist ebenfalls dieser Auffassung. Die Schwäche Jaromírs zeigt sich vor allem aber auch gegenüber Skřezislava, die er zu Unrecht verstößt, obwohl sie ziemlich raffiniert vorgeht, um die Anschlagspläne der Vršovci gegen ihren Mann in Erfahrung zu bringen. Jaromír möchte zwar das Fürstenamt an Oldřich abtreten; doch noch ehe es dazu kommt, entreißt es ihm Oldřich mit Hilfe seines Sohnes Břetislav. Anders als sein Vater, der letztlich die Gewalt gegenüber Jaromír bereut, erscheint Břetislav als durchwegs positiver Herrscher, auch wenn seine rechtliche Legitimation - er entstammt der legendären Verbindung Oldřichs mit Božena, einer Frau aus dem einfachen Volk - schwach ist. Letztendlich preist ihn Jaromír, bevor er dem Anschlag Kochans zum Opfer fällt. 
Im Drama wird vom Einsiedler, der später der Gründer und erste Abt des Sázava-Klosters wird, zu einer Politik der Stärke geraten: diese sichere das Land nach außen hin, vor allem würden innere Zwiste und Bürgerkrieg durch sie vermieden, die Kirche profitiere von dieser gleichfalls, da sie dann umso besser gegenüber dem Heidentum und dem Doppelglauben vorgehen könne. Der christliche Einsiedler ist im vierten Akt (vgl. IV, Szene 11 u. 12) nahe daran, das Vorgehen Oldřichs mit dem Hinweis auf Gottes unerforschliche Pläne zu verteidigen, für seine Gewalt werde dieser dennoch bestraft werden, letztendlich aber scheint der Einsiedler die Herrschaft Oldřichs, zu der er ja schon vorher (vgl. II/2) geraten hat, zu billigen. Jaromír ist zwar Titelheld, aber keine politisch ideale Figur: eine solche ist allein Břetislav, der allerdings nur im Hintergrund anwesend ist, aber nicht als persona dramatis auftaucht (während er wie erwähnt in Štěpáneks Drama der idealisierte Titelheld ist). Mit der Repräsentation der Feindschaft der Adelsgeschlechter und der daraus folgenden Tragödie führt Jaromír also ex negativo die Notwendigkeit nationaler Einigkeit vor, mit seiner Fabel votiert das Drama zudem für die Legitimation durch Befähigung und politische Stärke und präsentiert in Skřezislava eine beherzt männlich handelnde - und entsprechend verkleidete - Frau, die ihrem Mann Jaromír überlegen ist. Dieser wird zwar durch einen Gewaltakt geblendet, bezeichnet sich selbst aber mehrfach als verblendet, als er sieht, dass er seiner Frau Unrecht getan hat.

Möchte man Jaromírs tragisches Schicksal allegorisch deuten, könnte man meinen, dass er allzu lange an seinem Recht festgehalten hat, Fürst zu sein. Hätte er früher den Rat befolgt, seinem politisch fähigeren Bruder Oldřich die Macht zu überlassen, wäre zum einen ein blutiger Kampf unter Brüdern vermieden und zum anderen er selbst wohl nicht geblendet worden. Die im Stück durch die Person des Einsiedlers vertretene christliche Position besteht darin, dass sie politischer Stärke das Wort redet. Damit würde nach Auffassung des Einsiedlers, der zuvor ein ruhmreicher Krieger war und später Abt des Sázava-Klosters wird, das Land zusammengehalten, es gäbe keinen Bürgerkrieg, Böhmen könnte die ungerechten Tributzahlungen an den deutschen Kaiser aufgeben und das Christentum würde an Stellenwert gewinnen.

Zieht man die Implikationen der Handlungsentwicklung in Betracht, entwirft Hněvkovský mit dem Drama eine Kritik an der traditionellen Rechtsordnung mit ihrer Thronfolgeregel, die mitunter die falschen Personen an die Macht bringt, was das Land entsprechend destabilisierte.

\section{IV.4.5. Karel Hynek Máchas Bemühungen um historische Dramen (1830-33)}

Schon aufgrund der bereits von Zeitgenossen beförderten und erst posthum breiter akklamierten Ausnahmestellung als romantisches Dichtergenie dürfen Karel Hynek Máchas Versuche, ein "großes“ historisches Drama zu schreiben, im Zusam- 
menhang dieser Arbeit nicht unbeachtet bleiben. Mácha, der mit Křivoklad auch historische Prosa schrieb, war laut seinem Freund Karel Sabina der Ansicht, dass sich die Tschechen, da bei ihnen die für andere Nationen selbstverständlichen kulturellen Institutionen fehlten oder nur schwach etabliert waren, mit ihrer Vergangenheit beschäftigen müssten (vgl. Vodička 1937, 137).

Die unvollendet gebliebenen Fragmente, die nach Meinung Vodičkas mehr als ein Indiz dafür sind, dass sie in ausgeführter Form - bezogen auf die dramatische Produktion im ersten Drittel des 19. Jahrhunderts - aufgrund ihrer sprachlichen Qualität markante Ereignisse in der tschechischen Dramatik gewesen wären, geben auch aus produktionästhetischer Sicht interessante Aufschlüsse. In Versen ausgeführte Szenen stehen neben kurzen Inhaltsangaben von Szenen oder Akten, zu denen kein weiterer ausgestalteter Text existiert.

So liegen etwa neben dem nur mit dem Prolog und einer Szene überlieferten Král Fridrich (um 1832-33) ein lyrischer Monolog aus dem vermutlich vor 1830 entstandenem Einakter Boleslav, einige Szenen eines auf die klassischen fünf Akte konzipierten Stücks mit dem Titel Bratrourah aneb Václav a Boleslav sowie die skizzierte Fabel von Bratři vor, in der Mácha den dramatischen Konflikt beschreibt (1832-33). Darin fasst er in knappen Worten den Kampf um die Herrschaft in Böhmen zusammen, der innerhalb der Familie der Přemysliden (zwischen Boleslav, Jaromír, Oldřich, Břetislav) unter Beteiligung des rivalisierenden Geschlechts der Vršovci für wechselvolle Ereignisse (Blendung, Kastration, Intrigen) sorgte. Es ist derselbe historische Stoffkreis, den Štěpánek in Břetislav Prvni (1813), Ferdinand B. Mikovec in Záhuba rodu Premyslovského (1848) und Jaroslav Vrchlický in Knižata (1903) behandelt haben.

Bratři beginnt damit, dass der Vršovec Herouš seinem Vater Kochán den wieder erstarkten Glanz der Přemysliden schildert, der wie die Sonne am Himmel erstrahle, während sich die Vršovci wie der Mond vorkommen müssten. Kochán entgegnet, dass der Mond schon auch einmal die Sonne unsichtbar machen könne. Einmal an der Macht, werde er wie der Mond erstrahlen, nachdem die Sonne untergegangen ist. Kochán erinnert Herouš an die Demütigung der Vršovci durch die Prager, als diese ihren Fürsten Jaromír, der schon gefangen war und getötet werden sollte, im letzten Augenblick befreiten und die Vršovci für den Anschlag auf Jaromír hart bestraften. ${ }^{163}$ Herouš ist nun sofort zur Rache bereit. Auf diese sinnt auch Kochán, der darauf hofft, dass der Pole Boleslav Chrabrý Oldřich und dessen Sohn Břetislav besiegen wird, sodass es dann ihm selbst leicht fallen wird, den böhmischen Thron zu besteigen. In der Vision von Herouš, Herrscher über Böhmen zu werden, finden sich

163 Bratři referiert hier auf die auch von Hněvkovský in Jaromir ausgeführte Szene, als Grundlage verwendeten Mácha und Hněvkovský die Kronika česká von Václav Hájek z Libočan aus dem 16. Jahrhundert, die noch den meisten Autoren des obrozeni als Quelle gedient hat. 
einige Klischees romantischer Landschaftsbeschreibung (z.B. ist entsprechend der epochenspezifischen Präferenz für Extreme Böhmen von hohen Bergen umgegeben, deren Stirn in Wolken gehüllt ist, der Herrscher gleicht einem Adler etc.). Der Bote Hovora bringt zur Enttäuschung von Vater und Sohn allerdings die Meldung, dass Oldřich die Polen besiegt hat; Kochán muss mithin anders vorgehen, um zum Ziel zu gelangen: Er versucht nun, die Brüder Jaromír und Oldřich gegeneinander aufzubringen, was ihm leicht gelingt. ${ }^{164}$ Jaromír lässt Oldřich, der mit Unterstützung des Kaisers ebenfalls Ansprüche auf den Thron erhebt, ins Gefängnis werfen. Herouš, der in Břetislav eine ideale Fürstenfigur sieht (nur möchte Herouš selbst der Herrscher über Böhmen sein) agitiert gegen Jaromír und erreicht, dass das Volk Oldřich aus dem Gefängnis befreit. Oldřich lässt nun seinerseits Jaromír festnehmen.

Im zweiten Akt - die bisherigen Ereignisse erfolgen alle zusammengedrängt im ersten Akt! - erwirkt Kochán beim machtgierigen Oldřich die Erlaubnis, den gefangenen Jaromír blenden zu dürfen. Das wiederholte Blendungsmotiv bzw. die von der Blendung bewirkte Blindheit wird in Máchas Skizze nicht nach der konventionellen Metaphorik mit fehlender moralischer oder sittlicher Kenntnis verbunden, sondern mit Ohnmacht und eingeschränktem Seh- bzw. Handlungsraum: als im zweiten Akt der ebenfalls geblendete greise Boleslav auf den blinden Jaromír trifft, erklärt er „Na krok vzdáleno (makaje okolo sebe) / co od tebe / už není pro tebe / tvůj svět tak ouzký, tak malý jest / nepotřebuje místa víc než ty. ${ }^{\text {"165 }}$ (III/3, S. 270) - Gegenüber dieser maximalen Reduktion des Gesichtskreises kontrastieren die „Visionen“ von Macht, die Herouš überkommen, als er aus dem Fenster sieht und die romantisch gezeichnete böhmische Landschaft erblickt (I/1, S. 262f u. 266). ${ }^{166}$ Im dritten Akt wird die Blindheit als Strafe für schwere Vergehen gedeutet; als der blinde Boleslav stirbt, hofft er auf Vergebung.

Im vierten Akt wirbt auch Herouš um Jitka, Břetislavs Frau. In finsterer Nacht, in der Oldřich heftige „romantische“ Unruhe, Gewissenbisse und Todesahnungen plagen, wird er von einem Pfeil Herouš getroffen und stirbt. Der fünfte Akt zeigt Břetislav am Grab der drei Herzöge (die Brüder Boleslav, Jaromír und Oldřich), die

164 [Kochán:] „Vlastní sílou má se vyhladiti jejich rod, bratra zlost' broditi v bratra krvi.“ (Mit eigener Kraft soll sich ihr Geschlecht auslöschen, die Bosheit des Bruders soll im Blut des Bruders waten) - Mácha hat das Motiv des Bruderzwists durch eine Abweichung vom historischen Quellentext verstärkt: während bei Hájek z Libočan der Vršovec Kochan der Anstifter zur Blendung von Boleslav III. in Polen ist, lässt bei Mácha Jaromír selbst seinen Bruder blenden.

165 [Boleslav:] „Was nur einen Schritt (tastend um sich greifend) von Dir entfernt ist / Ist schon nicht mehr für Dich / Deine Welt ist so eng, so klein / sie nimmt nicht mehr Raum als du selbst ein."

166 Diese Vision von Herouš eignet sich natürlich für beschreibendes lyrisches Sprechen, das Mácha aufgrund der Gattungsbeschränkungen notgedrungen in die Monologe legen musste (vgl. Vodička 1937, 139). 
einander durch Neid und Missgunst um die Herrschaft gebracht haben. Bratři sollte enden mit „Ať žije Břetislav, kníže český!“"167

In einer Skizze zu Bratři hat Mácha notiert: „Tak vládne Nemesis, nechavši nehodné vlády, aby sami mezi sebou se pohubili, vede nejhodnějšího vlády ku vládě. ${ }^{168}$ - Diese unredigierte Erläuterung dieser Shakespeare’schen „Grundidee “169 („hlavní idea") lässt bereits aufgrund der Rekurrenz des Wurzelmorphems vlad* darauf schließen, dass der Konflikt um Herrschaft das zentrale Thema des Dramas ist. Mácha versteht Geschichte einerseits als Verkettung von Zufällen, die zwingend aufeinander folgen; wenn er die Nemesis als Letztgrund für den Verlauf der Ereignisse angibt, so erscheint dies als eine bloß behelfsmäßige Evokation antiker Vorstellungen, gibt es doch in Bratrí selbst weder eine Personifikation noch eine Evokation von Nemesis; die konfligierenden Handlungen leidenschaftlicher Personen werden in den Figurenreden nicht explizit mit einem höheren Schicksal in Zusammenhang gebracht. In einer Variante hat Mácha dementsprechend auch die zentrale Idee anders beschrieben, nämlich dass die Absichten aller zunichte und die Ziele der einzelnen Personen nicht erreicht werden, Absicht stehe gegen Absicht, Gott allein verdiene „Ehre und Ruhm.. ${ }^{170}$ Dass Břetislav als der fähigste Herrscher, als welcher er in der Ideenskizze genannt wird, in den Fragmenten als Figur nicht ausgeführt wird, liegt nach Vodička in der Präferenz Máchas für zwiespältige bzw. extreme Figuren begründet, die einem verhängnisvollen Schicksal unterworfen sind, wie etwa der Vršovec Herouš, der auf Drängen seines intriganten Vaters morden muss, wenngleich er träumerisch veranlagt ist. Bei den dramatischen Versuchen sei Máchas Interesse für die Macht des Schickals bestimmend gewesen; die historischen Vorlagen jedoch standen dazu mitunter im Widerspruch, sodass sich Mácha gezwungen sah, unhistorische Begebenheiten zu schaffen. Die Figuren erscheinen dabei weniger als entschlossen handelnde, sondern eher als reflektierende Figuren, die in Monologen über das Verhältnis zwischen ihren Absichten und den Peripetien des Schicksals reflektieren. Die Dramenfragmente etwa auch die einzige Szene aus Boleslav - seien durch den lyrisch-epischen Monolog gekennzeichnet, der in der Lyrik einfacher und wirksamer als im Drama bzw. Theater eingesetzt werden kann (vgl. Vodička 1937, 136).

Da Bratři aber mit dem Tod der drei Rivalen endet und Břetislav als der fähigste Fürst den Thron besteigt, kann diese Apotheose in Übereinstimmung mit dem Willen Gottes gesehen werden; der Schluss wäre insofern hegelianisch-dialektisch, als

167 „Es lebe Břetislav, der böhmische Fürst!“

168 „So herrscht die Nemesis, indem sie die für die Herrschaft ungeeigneten sich untereinander vernichten lässt, führt sie den zum Herrschen geeignetsten an die Herrschaft."

169 Dem Kommentar zum Fragment Bratř̀ ist zu entnehmen, dass Mácha während der Arbeit an diesem Shakespeare las und bestimmte Szenen aus Shakespeare-Dramen (vorwiegend den Historien) mit Szenen aus Bratř̀i verknüpfte (vgl. Janský 1948, 457).

170 „Všem se záměr zmaří, jejich oučel se nepodaří, tak že záměr proti záměru stojí a jen Bohu jedině patř́ čest a sláva." (Mácha 1959, 456) 
mit Břetislav eine bessere Herrschaft nach dem notwendigen Untergang „,besonderer" Herrscher eintritt (vgl. Hegel, XV/524). Dass Břetislav von Oldřich mit einer Frau aus einfachem Volk gezeugt wurde, wird zwar kurz erwähnt, aber nicht weiter ausgeführt, sodass man dahinter nicht etwa eine bewusste Favorisierung des Volks für Regierungsaufgaben erkennen kann. Břetislav ist nicht mehr als das Resultat der brüderlichen Konflikte zwischen den Přemysliden Oldřich, Boleslav und Jaromír, die von der Familie der Vršovci entsprechend angefacht wurden. Martin Procházka (vgl. 2011, 90-93) sieht in Máchas Bratřri mit dem Sieg der „Nemesis“ eine Distanznahme von der Ideologie des obrozeni, derzufolge in der Vergangenheit ein Ideal gesehen werden musste: Die Selbstbezüglichkeit der rivalisierenden Brüder und Familien bringe letztlich mit Břetislav einen Herrscher auf den Thron, der eben nicht durch Bezugnahme auf die Tradition legitimiert ist, für den Mácha unter den Zensurbedingungen seiner Zeit aber auch keine andere Legitimation als die abstrakte Nemesis bzw. Gott finden konnte.

Die unvollständige erste Szene von Bratrovrah aneb Václav a Boleslav, die den Kampf von Gut und Böse darstellt, wie es in der Anmerkung heißt, zeigt Boleslav, wie er in Gegenwart seiner Mutter Drahomíra im heidnischen Hain schwört, seinen Bruder Václav zu töten: Er weiß schon beim Schwur, dass ihm diese Tat keine Ruhe geben wird, will aber nicht von ihr ablassen. Der zweite Akt ist mit „Boj vždy tužší - zlé vítězi“" (,Immer härterer Kampf - das Böse triumphiert') überschrieben, auf Václavs Erzählung vom Kainsmal reagiert Boleslav mit der Entgegnung, dass der Tod zum Leben gehört, wenn der Tod schlecht sein soll, dann eben auch das Leben. Zum dritten Akt liegen nur wenige Zeilen vor, in denen die Mörder Václavs diesen mit dem Mond und Boleslav mit einer dunklen Wolke vergleichen. Aus den Ausführungen zum vierten Akt ist ersichtlich, dass dieser Vergleich zwischen den Phänomenen Finsternis - Blitz - Donner einerseits und dem Verhalten des nach dem Mord von Unruhe geplagten Boleslav andererseits hätte weitergeführt werden sollen. Drahomíra wählt nach schweren Alpträumen aus Gewissensbissen den Freitod und Boleslav vermeint, dass ihn alle als Brudermörder betrachten und seine Gesellschaft meiden, was für ihn eine sehr qualvolle Vorstellung ist. Er muss erfahren, dass auch das Gesinde nicht seinem Befehl folgt. Im nicht ausgeführten fünften Akt wird nur die Verzweiflung Boleslavs skizziert, der das Vergessen sucht, aber immer wieder nur an die eigene Schuld erinnert wird. So möchte er sich taufen lassen, erschrickt aber beim Gedanken, damit die Unsterblichkeit der Seele zu erlangen, also immer von den Gewissensbissen geplagt zu werden.

Die Vorrede des Sängers zum auf fünf Akte angelegten Trauerspiel Král Fridrich evoziert die Schlacht am Weißen Berge (Bílá hora) als blutiges Gemetzel zwischen Tschechen, das auch noch nach zweihundert Jahren - der epische Sänger markiert den Abstand - allen Wanderern Schauer über den Rücken jagt, wenn sie Bílá hora besuchen. Dort wurde inzwischen eine Kapelle gebaut, in der ein Priester Gott dafür 
dankt, dass das Christentum gesiegt hat. ${ }^{171}$ Die als einzige ausgeführte erste Szene zeigt den eiligen Aufbruch Budovas von Hradiště nach Prag, da er zum Wächter des Königs Fridrich (= der protestantische „Winterkönig“ Friedrich von der Pfalz) bestellt wurde. Er lässt in Hradiště seine besorgte Tochter unter der Obhut ihres Bräutigams zurück. Wie die wenigen Notizen Máchas zu dem Fragment zeigen, sollte wohl auch hier das im Prolog angesprochene Motiv des „Bruderkriegs“ - Tschechen gegen Tschechen - entwickelt werden. Auch wenn vom Stück nur das kleine Fragment und die Notizen erhalten sind, erscheint es darin originell, dass Mácha bereits noch vor den kulturellen Erfolgen des obrození die „Bürgerkriegsthematik“ von Bílá hora anspricht, dominierten doch bis in die 1840er Jahre aus Zensurgründen Stoffe aus der Zeit vor den Hussiten. Zum einen waren die Hussitenthematik und Bílá hora von der Metternichschen Zensur untersagt (vgl. Černý 1969/DčD II, 209f; Píša 2015, 258), ${ }^{172}$ zum anderen galt der Aspekt des Kampfes innerhalb der Tschechen selbst, den man in der Hussitenzeit erkennen kann, als heikle Angelegenheit, solange die Nationalbewegung noch nicht gefestigt war (vgl. Klosová 1977a/DčD III, 105, Höhne 2000, 49f).

In Bratři und Bratovrah, den beiden umfangreicheren Fragmenten Máchas, stehen, wie die Titel schon andeuten, blutige Konflikte unter Brüdern im Vordergrund. Die Protagonisten werden von ihren Leidenschaften - Machtgier, Herrschsucht, Neid - mitgerissen und zu zerstörerischem Handeln verführt. Man könnte diese Protagonisten - Stich (vgl. 1993, 66) legt dies nahe - als typische Vertreter eines romantischen Subjektivismus bestimmen wollen, wie ihn Mácha in seinem Poem Máj (1836), mit welchem die Dramenentwürfe stellenweise korrespondieren, einige Jahre später ausgeführt hat. Dieser Subjektivismus manifestiert sich u.a. im Rachemotiv (die Vršovci Kochán und Herouš etwa möchten sich für die Bestrafung ihrer Verwandten rächen, Oldřich lässt Jaromír blenden, da dieser schon zuvor Boleslav hatte blenden lassen), das aus der polnischen Romantik stammt, bei den Tschechen aber nur auf geteilte Aufnahme stieß. Stich weist auf die nationalpolitischen Implikationen des Rachemotivs in der polnischen Romantik (vor allem in Mickiewicz' Dziady und Konrad Wallenrod) hin, die bei den Tschechen wenig Widerhall gefunden hätten; Máchas Máj sei die einzige markante Dichtung, in der diese Konzeption von Rache vertreten worden sei. Laut Stich ist das Rachemotiv in der polnischen Romantik keineswegs nur als individueller Racheakt zu lesen, vielmehr müsse

171 Ein etwas rätselhafter Vers, da ja das von den protestantischen Ständen ausgerüstete Heer unter dem zum böhmischen König gewählten Friedrich von der Pfalz gegen die katholischen Truppen des Habsburger Kaisers Ferdinand II. kämpfte und unterlag.

172 Dieses Verbot erstreckte sich auch auf Textsorten, denen kein solches Depräsentations- bzw. Aktualisierungspotenzial wie dem historischen Drama zu eigen ist: historiographische Darstellungen der Hussitenzeit wurden gleichfalls untersagt; aus einem Lehrbuch zur tschechischen Sprache wurde das Deklinationsparadigma des Lexems husita entfernt (vgl. Píša 2015, 258). 
in ihm die allegorische Bedeutung erkannt werden. Die Rache meint dann nicht bloß die Revanche eines Opfers für erlittenes Unrecht, die Heimzahlung der Untat, sondern sei vielmehr symbolischer Ausdruck der Freiheitsliebe, die gegen den erfahrenen Druck von seiten der „Anderen“ - des Nicht-Ichs, der Unterdrücker des eigenen Volks - gewendet wird (vgl. Stich 1993, 73).

Zumal es Mácha bei den dramatischen Entwürfen belassen hat und zu Lyrik gewechselt ist, die seinen poetologischen Präferenzen - Beschreibungen, lyrische Aussprache - eher entspricht als das Drama, wie Vodička (vgl. 1937, 138-141) meint - wäre aber zu fragen, ob die dramatischen Entwürfe nicht gerade eine Bestätigung dafür sind, dass Mácha sehr wohl auch an die „Lage der tschechischen Nation" gedacht hat und keineswegs nur romantischen Individualismus ins Werk setzen wollte: Gerade der Handlungsverlauf von Bratři und Bratrourah - aber auch die in den kürzeren Fragmenten erkennbaren Anlagen (z.B. das rekurrente Thema des Bruderkriegs bzw. -mords) zeigen ja die schmerzvollen oder gar tödlichen Konsequenzen von egoistischem Machtstreben und individueller Rache (wie übrigens auch Máj). ${ }^{173}$ Die Dramenentwürfe führen romantische Individuen mit starken Leidenschaften vor, die versuchen, sich gegen ebenso leidenschaftliche Rivalen durchzusetzen, aber letztendlich für ihr je besonderes Streben mit dem Tod bezahlen. Diese hegelianische Lesart, die von Stich nicht berücksichtigt wird, wenn er Mácha als markantesten Vertreter der tschechischen Romantik seinem Zeitgenossen Tyl gegenüberstellt, dessen nationales Pathos ihn dazu bewegte, Máchas individualistische Ideologie abzulehnen, würde die Differenzen zwischen Tyl und Mácha verringern. Máchas Figuren wären zwar „,romantischer" in dem Sinn, dass ihr Individualismus einen stärkeren Gegensatz zur Umwelt aufbaut und er bevorzugt diese „extremen“ Figuren in lyrischen Monologen zu Wort kommen lässt. Zugleich aber lässt er als Resultat von Konflikten starker Individuen diese sterben und z.B. mit Břetislav eine neue historische Herrscherfigur hervorgehen, die von Mácha in ihren Eigenschaften zwar kaum ausgestaltet ist, als Nachfolgerfigur am Ende des repräsentierten Konflikts aber ihre Vorgänger „aufhebend“ ablöst und übertrifft.

173 Das Rachemotiv wurde vor allem in der polnischen Literatur forciert, Máchas Máj ist eine bewusste Anbindung an die polnische Racheliteratur. Josef Kajetán Tyl aber war ein Gegner dieses romantischen Rachemotivs. Čestmir von Tyl gilt Stich als großes Rachedrama mit romantischem Mácha-Held. Das Rachemotiv wird von Tyl darin aber verworfen, was vor allem anhand der Figur von Neklan zu erkennen sei (Mácha hätte diesen spielen sollen). Auch in seiner Übersetzung von King Lear habe Tyl versucht, das Rachemotiv zu schwächen, da er dieses als zu destruktiv aufgefasst habe (vgl. Stich 1993, 69-73). 


\section{IV.4.6. Josef Kajetán Tyl: Čestmir. Dramatická báseñ ve dvou odděleních (1835)}

[Čestmír. Dramatisches Gedicht in zwei Abteilungen; UA 3.5.1835, publ. 1838]

Josef Kajetán Tyls zweites großes Theaterstück nach der Farce Fidlovacka, die im März 1835 entstandene Tragödie Čestmir, wird in der Literaturgeschichtsschreibung zu den Theaterstücken des obrození gerechnet, die einen Qualitätssprung in der Ausbildung einer dramatischen Nationalliteratur darstellen, weil sie einen für die Entstehungszeit relevanten Konflikt dramatisch - jedoch in historischem Gewand - darstellen (vgl. Štěpánek 1957, 475). Tyl kannte als Mann des Theaters die bislang vorliegende Literatur sowie auch die von den Intellektuellen geäußerten Zweifel an der Qualität des tschechischsprachigen Dramas und Theaters; er hatte daher den Ehrgeiz, ein "großes Drama“"zu verfassen, dass die aktuellen Fragen seiner Gegenwart im historischen Gewand erfasst (vgl. Otruba/Kačer 1961, 117f).

Der Stoff, der aus der legendären vorchristlichen Zeit stammt und dem in der Königinhofer Handschrift ein einzelnes Poem (»O vicestvie nad Vláslavem «) gewidmet ist (dieses folgt dort auf die Dichtung »Jaroslav «) ${ }^{174}$, hat als politischen Hintergrund den Konflikt zwischen den Teilfürstentümern Praha, wo Neklan Fürst ist, und Žatec, wo Vlastislav über die Lučanen herrscht. Der Titelheld Čestmír - bei der Premiere von Tyl selbst gespielt, was allerdings dem Bühnenerfolg abträglich gewesen sein soll (vgl. Ježková 2013c, 77) - ist zuerst ein Schafhirte, der aufgrund seines Ehrgeizes zum berühmtesten böhmischen Kämpfer aufsteigt und schließlich sogar den Prager Fürsten Neklan in einer entscheidenden Schlacht erfolgreich vertritt: Čestmírs Einsatz bewirkt den Sieg für Prag, er freilich findet in dieser Schlacht den Heldentod. Er wechselt dabei zweimal die Seiten: der Prager Hirte verlässt sein Milieu, in welchem er sich nicht entfalten kann, und tritt in die Waffendienste von Vlastislav, zu dessen militärischen Erfolgen er wesentlich beiträgt und dem er in der Schlacht gegen die Sachsen sogar das Leben rettet. Mit seinen Heldentaten möchte er die Pragerin Častava und ihren Vater Vojmír beeindrucken, die Čestmír als nicht standesgemäßen Bräutigam zurückgewiesen haben.

Mit dem Tod des Fürsten von Kouřim entbrennt ein Streit um dessen Territorium. Es sollte Vlastislav als dem ältesten Přemysliden zufallen, doch auch Neklan von Prag erhebt Anspruch darauf und würde es auch mit deutscher Unterstützung einfordern wollen. Čestmír geht als Bote Vlastislavs nach Prag, wechselt aber den Dienst, nachdem der Vladike Kruvoj aus Kouřim in Prager Gebiet eingefallen ist und die Burg von Vojmír in Brand gesteckt hat. Aufgrund seines Kriegsruhms hat Čestmír schon die Liebe von Častava und die Gunst ihres Vaters Vojmír gewonnen, die er beide nun

174 Der deutsch schreibende Prager Autor Karl Egon Ebert (1802-1881), der ebenfalls gerne Stoffe aus der böhmischen Geschichte aufgriff, hatte noch vor Tyl ein Stück um Čestmír verfasst, welches 1835 ebenfalls am Ständetheater aufgeführt wurde, jedoch nie in Druck erschienen ist (vgl. Marinelli-König 2011, 121). Tyl schrieb Čestmír innerhalb von elf Tagen, er legte Wert darauf, dass seine Version keine Umdichtung von Ebert, sondern ein eigenständiges Werk ist. 
aus der Gewalt von Kruvoj befreien kann. Bei der Befreiungsaktion erblickt Čestmír jedoch Kruvojs Tochter Liběna und empfindet Liebe auf den ersten Blick.

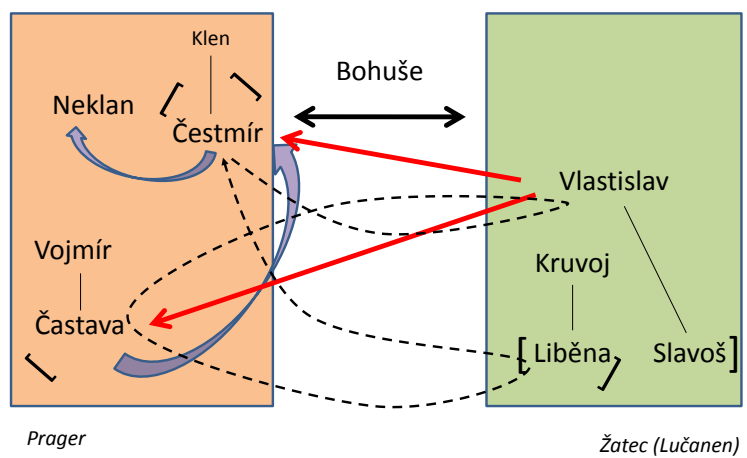

Graphik 9 - Josef Kajetán Tyl: Čestmír (1835)

Wie im Figurenschema mit der strichlierten Linie angezeigt wird, wechselt Čestmír somit aufgrund erotischer Faszination dreimal die Seiten. Als Prager Hirte tritt er zuerst in die Dienste des Lučanen Vlastislav, um mit dem erworbenen Ruhm die zuerst so stolze Prager Vladikentochter Častava für sich gewinnen zu können. Nachdem er, um Častava und ihren Vater zu verteidigen, rasch in Prager Dienste getreten ist, fällt sein Begehren plötzlich auf Liběna, die Tochter des Angreifers Kruvoj, der für Vlastislav kämpft. Čestmírs erotisch motivierter dreifacher Wechsel zwischen den beiden Parteien (von Prag zu den Lučanern, dann wieder für Prag, dann anscheinend wieder für die Lučanern) deuten diese jeweils als Verrat an ihrer Sache. Čestmírs Gesinnungswandel verschafft ihm allenthalben Feinde: Die Lučanen Vlastislav und Kruvoj werden seine erbitterten Gegner, die eifersüchtige Častava kann die Prager glauben machen, dass er in verräterischer Absicht zu den Lučanen ging, als er heimlich Liběna für sich gewinnen will. Zumal sich Liběna jedoch als an Slavoš versprochen erweist, erscheint Čestmír sein Leben und Streben als sinnlos „[...] mé touhy hvězda jitřní / zanikla [...]"175 (III/5, S. 205). Seiner Enttäuschung in Liebesdingen folgt die öffentliche Ablehnung in Prag, die von Častava betrieben wird. Er wird dort als Verräter bezeichnet, da seiner Beteuerung, allein wegen einer Liebesangelegenheit heimlich zu den Lučanen gegangen zu sein, nicht geglaubt wird. Die Konfrontation zwischen dem auf seinem Recht auf private Gefühle beharrenden Čestmír und dem „öffentlichen“ Interesse der Prager gipfelt darin, dass Častava sogar schwört, sie wisse, dass Čestmír nicht allein in privater Angelegenheit zu den Lučanen gefahren sei. In der Regieanweisung wird auf den Widerstreit der Gefühle von Častava bei

175 [Čestmír:] „Der Morgenstern meiner Sehnsucht / ging unter.“ 
diesem Schwur aufmerksam gemacht; wenn sich nun auch noch das Prager Volk und Čestmírs Stiefvater Klen empört von diesem abwenden, scheint Čestmírs subjektive Perspektive in maximalem Widerstreit zur Meinung der anderen, der Titelheld ist ein Zerissener, ein romantischer rozervanec (vgl. Černý 1969, 234), wie er kurze Zeit später paradigmatisch von Karel Hynek Mácha in Máj (1836) entworfen wurde. ${ }^{176}$

Dieser Konflikt zwischen vereinzeltem Individuum und scheinbar unverständiger Umwelt wird in Tyls Tragödie zuerst auf die Spitze getrieben: Čestmírs Appell an den Prager Fürsten Neklan, sein Hinweis darauf, dass die Götter ihm in die Seele blicken können und wissen, er sei bloß in einer Herzensangelegenheit zu den Lučanern gegangen und kein Hochverräter, findet bei diesem kein Gehör: Neklan hält die Stimme des Volkes für maßgeblich in dieser Angelegenheit („Hlasy lidu bud'te vládci svatými [...] a moudré kníže dle nich vy̌̌knutí své pořádej. ${ }^{“ 177}$ III/8, S. 214), und da das Volk Častavas Meineid Glauben schenkt, verzichtet Neklan auf Čestmír als Feldherrn und verbietet ihm sogar, als einfacher Kämpfer in den Reihen der Prager seine Loyalität unter Beweis zu stellen.

Die Meinung des Volkes steht folglich dem Helden entgegen, doch das Publikum hat - aus der Position des Dritten - eine Metaperspektive: es weiß zum einen um die Aufrichtigkeit des Helden, der tatsächlich seinem in Liebesangelegenheiten leicht entflammbaren Herzen folgt, es versteht gleichfalls, dass Častava ihn aus enttäuschter Liebe verleumdet, damit aber gleichzeitig Prag schadet, denn mit der Expellation Čestmírs verlieren die Prager ihren fähigsten Kämpfer.

Die Auflösung bzw. Wendung dieses tragischen Konflikts zwischen dem gefühlsgeleiteten Čestmír und seiner Umgebung erfolgt im fünften Aufzug auf eine ungewöhnliche Weise: Die heidnische Priesterin Bohuše überzeugt Čestmír von seiner Schuld: „Tys při své / slávě nepomyslil na oslavu / národní, a pro lásku bys vlasti / blaženost byl hodil do hry ${ }^{178}$ (V/3, S. 222). Nur der Tod wird seine gebrochene Seele („duše rozpadlá) ganz machen. Die von Čestmír enttäuschte Častava kommt als Mann verkleidet und erklärt, ihr Leben sei verwirkt ohne seine Liebe: Während sie bekennt, einen Meineid geleistet zu haben, als sie ihn des Hochverrats bezichtigte, erklärt Čestmír, nicht ohne Schuld zu sein. Zum einen besteht diese Schuld in seinem raschen Wechsel zwischen den beiden Frauen Častava und Liběna, zum anderen aber liege eine höhere Schuld auch in der Dialektik seines Handelns: Zwar ging er nur „privat" zu Liběna, doch hat er die Auswirkungen seines Handelns auf seine Mitmenschen nicht mitbedacht (dass ihm etwa misstraut wird, dass die Kampfesmoral ins Wanken

176 Mácha übrigens war als Schauspieler unter Tyls Regie für die Rolle des Neklan im Kajetánské divadlo vorgesehen (Stich 1993, 67), aufgrund des Zerwürfnisses mit Tyl kam es jedoch zu keiner Aufführung.

177 [Neklan:] „Die Stimmen des Volkes mögen die heiligen Herrscher sein [...] und der weise Fürst soll seinen Spruch nach ihnen richten."

178 [Bohuše:] „Du hast bei deinem / Ruhm nicht an den Ruhm / des Volkes gedacht, und der Liebe wegen / hättest Du das Wohlergehen der Heimat aufs Spiel gesetzt." 
gerät, wenn die Leute einen „Verräter“ in ihren Reihen vermuten - all dies wurde ihm ja von den Pragern vorgehalten). Die Sühne besteht nun darin, dass Čestmír buchstäblich zur Gänze zur „öffentlichen“ Person wird und in der großen Schlacht zwischen Prag und Žatec sein Leben lassen wird. Äußerlich manifestiert sich dieser Wandel von der privaten zur öffentlichen Person im Anlegen der Rüstung des verletzten Neklan, womit er die Prager Truppen nun sowohl physisch wie auch moralisch (die Prager wie auch ihre Gegner halten Čestmír für Neklan) stärkt (V/7) und den Heldentod stirbt, den Bohuše in der Apotheose zum höchsten Ziel erklärt: „Tot lidí / nejkrásnějsí cíl, z těch země pout se / vyvinouti ku spasení národův." (V/11, S. 239) ${ }^{179}$

Bohuše, die heidnische Priesterin, ist somit die Verkünderin einer höheren Wahrheit, die dem Helden erst allmählich deutlich wird. Ihre Rolle als Prophetin wird auch keineswegs relativiert - so treffen auch all ihre Vorhersagen zu, Bohuše bestimmt also die Perspektive für das Publikum als dritte Person.

Betrachtet man die Rolle von Častava, erweist sich deren Analogie zu Čestmír: Auch sie ist verkleidet und opfert sich, nämlich wirft sie sich schützend vor Čestmír und empfängt dabei eine tödliche Verwundung von Vlastislav. Sterbend erklärt sie Čestmír für unschuldig und schafft damit die Voraussetzung für dessen Rehabilitierung. Ihre aus privaten Gründen (enttäuschte Liebe) motivierte Rache an Čestmír - seine Verleumdung vor den Pragern mittels Meineid - sühnt sie, indem sie die Rolle der Frau verlässt und als Mann verkleidet in die Schlacht geht, als Neklan sich aus dieser verletzt zurückzieht. ${ }^{180}$ Somit ist deutlich, dass Častava faktisch dieselbe Funktion hat wie Čestmír, der in Neklans Rüstung diesen vertritt. Beide opfern ihr Leben für die Allgemeinheit, nachdem sie diese zuvor mit ihren individuellen Bestrebungen, die sie zu Gegnern gemacht haben, in Unruhe versetzt haben. Im Tod sind sie vereint und mit der Allgemeinheit versöhnt.

Čestmírs erotisches Begehren für Častava bzw. Liběna, welches in der Sujetentwicklung als Krise erscheint, hat aber noch eine andere Funktion, nämlich soll es soziale Schranken überwinden (das Begehren für Častava) bzw. die Zusammengehörigkeit der verschiedenen tschechischen Fürstentümer andeuten. Čestmír betont immer explizit die Einheit des tschechischen Gebiets. Zwar erfährt aufgrund des dramatischen Endes - der Kampf zwischen Prag und Žatec - auf manifester Ebene die Position Prags ihre Apotheose, als Nebenthema wird mit Čestmírs persönli-

179 „Der Leute / allerschönstes Ziel, ist es, sich aus diesen Fesseln der Erde / herauszulösen zur Rettung der Völker“ - Schon zuvor hieß es beim Ertönen der Kriegshörner. „Bozi volají - i volá vlast!“ („Die Götter rufen - auch die Heimat ruft!“ - V/4, 229)

180 Stich (vgl. 1993, 67) sieht Čestmír als bedeutendes obrozeni-Drama, das zwar groß das Rachemotiv thematisiere, dabei aber verwerfe. Dies scheint etwas überzogen zu sein: Von Rache ist bei Neklan - ohnehin keine sonderlich imposante Figur der Handlung - wenig zu bemerken, wenn schon, dann eher bei der sich zurückgesetzt fühlenden Častava. Doch ist in Čestmir das Rachemotiv keineswegs sonderlich präsent, es geht vielmehr um das Verhältnis von individuellen, privaten Neigungen und öffentlichem Interesse. 
chem Wechsel zwischen den Parteien wie auch mit seinem Schwanken zwischen zwei Frauen aus verschiedenen Lagern die tschechische Einheit über die Stammesgrenzen hinweg angedeutet. Über die leitmotivisch verwendete Losung „boj a láska“ (,Kampf und Liebe') kann in Entsprechung zur vorgeschlagenen Lesart behauptet werden, dass Liebe für Tyl keine rein persönliche Angelegenheit bleiben darf, sondern erst im Rahmen einer größeren Gemeinschaft sanktioniert wird. Der Kampf für diese größere Gemeinschaft ist der individuellen Liebe übergeordnet, die beiden Hauptfiguren Čestmír und Častava scheitern in ihrem privatem Streben nach Liebe - Čestmír entbrennt in Liebe zu Liběna, die einen anderen heiraten wird; aus Kränkung über ihre verschmähte Liebe gefährdet Častava ihre Heimat, indem sie Čestmír verleumdet, erst im Tod kommt es zur Vereinigung der beiden. Čestmír rettet mit seinem Tod Prag, Častava wirft sich vor Čestmír, weil sie als unglücklich Liebende keinen anderen Sinn mehr im Leben sieht, als Čestmír in den Tod zu folgen. Insofern dieser den Tod im Kampf findet und damit Prag rettet, steht der Tod für die Allgemeinheit wesentlich höher als die private Liebe.

In dieser Tragödie wird Tyls nationalpatriotische Position deutlich, die auf signifikante Weise das romantische Heldenbild (der Held als isolierter Antipode der Menge) in nationales Engagement auflöst - womit Tyl noch knapp vor Erscheinen von Karel Hynek Máchas Máj einen Gegenentwurf zu dessen individualistischer Konzeption vorlegt, der später in Tyls Novelle „Rozervanec“ (1840) gipfelt (vgl. Stich 1993, 71). Interessant in diesem Zusammenhang ist Tyls signifikante Abweichung von der Vorlage in der „Königinhofer Handschrift“; denn in „O vicestvie nad Vláslavem" ist Čestmír keineswegs bloß ein Schafhirte, sondern ein ehrgeiziger junger Ritter. Štěpánek (vgl. 1957, 470) meint, dass Tyl mit seiner Konjektur einen für das obrozeni typischen Helden geschaffen habe, der aus den drückenden Verhältnissen seiner Umgebung fliehen möchte und nach Höherem strebt, aber damit in scharfen Widerspruch zur Umwelt gerät. Dass Čestmír sein Streben nach höherem Ruhm dann im 5. Akt ganz der Allgemeinheit unterordnet und für diese den Heldentod stirbt, hält Štěpánek interessanterweise für eine ideologische Schwäche von Tyls Tragödie (Ganz ähnlich argumentieren auch Otruba/Kačer 1961, 98-100 u. 116f, die das Stück vor allem dafür kritisieren, dass der Konflikt Individuum - Gesellschaft nicht weiter geführt wird, sondern im fünften Akt durch die plötzliche Hinwendung Čestmírs und Častavas zur gemeinsamen Sache an Brisanz verliert).

Jako celek je Čestmir vyznáním revolučních tužeb i jejich odsouzením a výzvou k skromné práci pro národ v daných, starých podmínkách. Čestmír jako celek je takto také odrazem historického rozporu, který ve svém vztahu k společnosti a národu Tyl a jeho generace prožívali. ${ }^{181}$ (Štěpánek 1957, 473)

181 „Als Ganzes ist Čestmír ein Bekenntnis zu revolutionären Hoffnungen und deren Verurteilung, es ist auch eine Aufforderung zur bescheidenen Arbeit für das Volk in den bestehenden 
Demnach wäre für Štěpánek revolutionäres Streben im ehrgeizigen Schafhirten Čestmír auszumachen, dass hingegen Tyl dieses Streben ideologisch ablehnt, sei aus Čestmírs Schuldeinsicht und seinem Opfer im 5. Akt abzuleiten. Štěpáneks ambivalente Interpretion von Tyls Drama als einerseits revolutionär und andererseits konservativ-nationalpatriotisch verdankt sich dabei wohl der zugrunde liegenden Folie marxistischer Literaturgeschichtsschreibung, denn dieser zufolge gelten die Heldenfiguren der Romantik darin als progressive Erscheinungen, dass sie in ihrem Scheitern auf die Widersprüche der zusammenbrechenden feudalen Ordnung hinweisen und somit als Vorboten der bürgerlichen Revolution anzusehen sind. Der romantische Held ist für die marxistische Literaturwissenschaft damit gerade auch in seinem Scheitern Ausdruck geschichtsmächtiger Dialektik. Eine Kritik am romantischen Individuum, wie Tyl sie literarisch in mehreren Werken vorgenommen hat, erscheint ihr problematisch, weil Tyls Kritik die nationalen Aspekte stärker betont als die sozialen: So meinen etwa Otruba/Kačer: „V Tylově vztahu ke skutečnosti objevuje se tedy rozpor mezi pravdivostí jeho osobního a uměleckého poznání skutečnosti a deformací tohoto poznání, kterou působí tlak přijaté a propagované ideologie národního hnuti.“"182 (Otruba/Kačer 1961, 100)

Ändert man die historische Perspektive dieser marxistischen Interpretation von Tyls Drama nur ein wenig, ergibt sich ein bündigeres Bild, das im 5. Akt keinen ideologischen Bruch erkennen lässt. Tyls Anliegen mit Čestmir besteht demnach tatsächlich in einer Favorisierung der nationalen Angelegenheit, der gegenüber private Gefühle nachrangig werden, weil das heroische Individuum sich dem nationalen Kampf unterordnet und opfert. Für diese nationale Angelegenheit werden sogar wichtige Oppositionen aufgelöst: als Kämpfer oder Liebender wechselt der Held die beiden Lager Prag und Lucko/Žatec (und weist so auf die nationale Einheit der verfeindeten Stämme hin), im Kampf werden die Geschlechtsrollen aufgegeben (was sich im fünften Akt darin zeigt, dass Častava als Mann verkleidet an der Schlacht teilnimmt), schließlich werden auch die sozialen Unterschiede unbedeutend: Ein Hirte ist in der Lage, die Funktion des Fürsten zu übernehmen (äußerlich wird diese Substitution damit gekennzeichnet, dass Čestmír die Rüstung des verwundeten Fürsten anlegt und von Freund wie Feind zuerst für Neklan gehalten wird) und das Land zu retten. So wie Ernest Gellner (vgl. 1996, 20-22) im Nationalismus die List der Vernunft erkannt hat, die in der Etablierung moderner Prinzipien unter nationalistischer Verbrämung besteht, lösen sich bei Tyl historische Unterschiede zwischen Stämmen, Geschlechtern und gesellschaftlichen Schichten

Verhältnissen. Čestmír ist als Ganzes auch ein Effekt des historischen Widerspruchs, den Tyl und seine Generation in ihrem Verhältnis zur Gesellschaft und zum Volk erfuhren.“

182 „In Tyls Beziehung zur Wirklichkeit erweist sich ein Widerspruch zwischen der Wahrhaftigkeit seiner persönlichen und künstlerischen Erkenntnis der Wirklichkeit und der Deformation dieser Erkenntnis, die der Druck der affirmierten und propagierten Ideologie der Nationalbewegung ausübt.“ 
in der Unterordnung unter die gemeinsame Anstrengung um die Nation auf, die als höchstes Gut dargestellt wird.

Die grundlegende Opposition, auf welcher der ideologische Konflikt des Dramas beruht, ist diejenige von privatem Glück und Allgemeinheit (vgl. Haman 2007, 112). Der Hauptheld verharrt bei aller martialischen Aktivität und bei allem sozialen Ehrgeiz zuerst im Bereich des Privaten; wegen seines privaten Ehrgeizes und seines erotischen Begehrens wechselt er zwischen den politischen Lagern der Tschechen hin und her. Der Wechsel des Helden zwischen den tschechischen Streitparteien legt die Schlussfolgerung nahe, dass sich diese eigentlich ähnlich sind und somit eine Einheit bilden. Für die dramatische Entwicklung ist freilich die Einsicht des Helden relevant, dass er das öffentliche Interesse über das private Interesse stellen muss. Diese Einsicht wird ihm auf doppelte Weise mitgeteilt. Das Prager Volk erklärt Čestmír zum Verräter, da es seinen Beteuerungen vom rein privaten Interesse keinen Glauben schenkt. In dieser Szene (IV/8) scheint es noch so, dass Čestmír vom Volk zu Unrecht verurteilt wird. Interessanterweise hat das Volk im Stück hier das höhere Recht, obwohl es in der Sache selbst Unrecht hat. Denn im fünften Akt wird Čestmír auch von der Priesterin Bohuše vorgehalten, dass er für sein privates Glück die Sache des Volkes aufgegeben habe, aber mit seinem Heldentod noch alles retten könne (vgl. M. Procházka 2011, 87). Sowohl Čestmír als auch Častava opfern ihr eigenes Leben für die Allgemeinheit, wobei beider Verkleidung die Signifikanz des Wechsels zwischen dem Feld des Privaten zum Öffentlichen (damit quasi die Aufösung der Unterscheidung) unterstreicht: Častava verkleidet sich als Mann und geht in den Kampf, im Einsatz für Prag zieht Čestmír die Rüstung des Fürsten an und findet in ihr den Tod; der Einsatz seines Lebens bringt Prag freilich den Sieg. Das Schlussbild verheißt die Vereinigung der beiden verirrten Liebenden im nationalen Götterhimmel. Dieser ist in diesem frühen Stück von Tyl der allumfassende Bezugsrahmen, der von den beiden Hauptfiguren dadurch verletzt wird, dass sie einen privaten Raum darin für sich reklamiert hatten. Damit gefährden sie die nationale Gemeinschaft, sie retten sie erst wieder dadurch, dass sie ihr privates Glücksstreben aufgeben und sich für die Allgemeinheit opfern (dabei wird die Frau zum Mann und der einfache Hirte Čestmír zum Fürsten bzw. zum Repräsentanten des Volkes). Tyls Drama ist die Apotheose des bedingungslosen Engagements des Einzelnen für sein Volk, es entspricht Tyls Auffassung, dass jedermanns Handeln von der Liebe zum Volk und dessen Wohlergehen bestimmt sein müsse: „Všecky naše kroky musí vésti / láska k národu a jeho štěstí ${ }^{\prime 183}$ (vgl. Strejček 1932, 65).

183 „All unsere Schritte muss leiten / die Liebe zum Volk und seinem Glück.“ 
Bereits das Personenverzeichnis deutet den Grundkonflikt an, wird doch zu vier Hauptfiguren deren religiöse Zugehörigkeit - Christentum oder Heidentum - spezifiziert. Das im frühen zehnten Jahrhundert spielende Drama thematisiert den Konflikt von heidnischen und christlichen Fürsten in Böhmen. Insofern Václav Vojáček (1821-1898) das Drama einem auf Tetíner Gebiet wirkenden Geistlichen (Antonín Burka) widmete, ist seine Parteinahme für die christliche Konfliktpartei wenig überraschend. Im Drama kämpft die auf dem Rückzug befindliche heidnische Partei der Fürstin Drahomíra gegen das vordringende Christentum, das heidnische Kultstätten wie z.B. Götterhaine zerstört und überall im Lande Kreuze als Symbole des neuen Glaubens errichtet. Die Fürstin Ludmila, die Mutter von Drahomíras verstorbenem Mann Vratislav, ist gänzlich vom Christentum durchdrungen. Dieses verleiht ihr eine gleichsam charismatische Stärke, die sich gleich zu Beginn darin zeigt, dass der Heide Kuman sich wehrlos dem Befehl Ludmilas fügt, unverzüglich einen von ihm gefangenen Christen freizulassen und Ludmilas Gebiet Tetín zu verlassen (I/1-3). Ludmila möchte das Land einen und hofft auf Drahomíras Verständnis für dieses Vorhaben. Diese möchte eigentlich nicht kämpfen, dem Christentum aber dennoch Einhalt gebieten. Daher ist sie geneigt, mit Ludmila zu sprechen, wie ihr Ludmilas Bote Čestmír vorschlägt. Drahomíras Ratgeber - Vojmír, Bohdan und Kuman versuchen mit allen Mitteln, eine Einigung zu verhindern, sie wollen das Christentum stürzen und den heidnischen Glauben wieder erstarkt sehen. Zum einen stellen sie den jungen Recken Toman vor die Alternative, entweder für sie zu kämpfen und damit die von ihm verehrte Božena zurückzuerobern, die Christin geworden ist, oder unglücklich und alleine zu bleiben. Zum anderen setzen sie Drahomíra damit unter Druck, dass sie einen Sněm einberufen wollen, der ihr zeigen soll, dass nur der aktive blutige Kampf gegen das Christentum, nicht aber Versöhnungspolitik vom Volk gewünscht werde. Drahomíra würde anderenfalls das Vertrauen im Volk verlieren (vgl. II/7). Sie, obgleich das Blutvergießen scheuend, gibt nach und greift Tetín an. Ludmila wird von Kuman und dem verzweifelten Toman, den Kuman in den Liebes-Double-bind gebracht hat (vgl. III/1), ermordet. Dennoch siegen letztendlich die Christen, die vom jungen Fürsten Václav angeführt werden. Drahomíra führt die Niederlage der heidnischen Götter darauf zurück, dass unnötigerweise das Blut Unschuldiger, v.a. Ludmilas, vergossen wurde. Dies habe die Götter gegen die Heiden selbst aufgebracht. Im Schlussbild stirbt der tödlich verwundete Vojmír, der von der in Gefangenschaft geratenen Christin Božena gepflegt wird, mit der Einsicht, dass die Wahrheit gesiegt habe. Der siegreiche Václav, den laut Bühnenanweisungen am Schluss ein immer stärker werdendes Licht umgeben soll, erklärt, dass die nun fest begründete Wahrheit für immer blühen werde. 


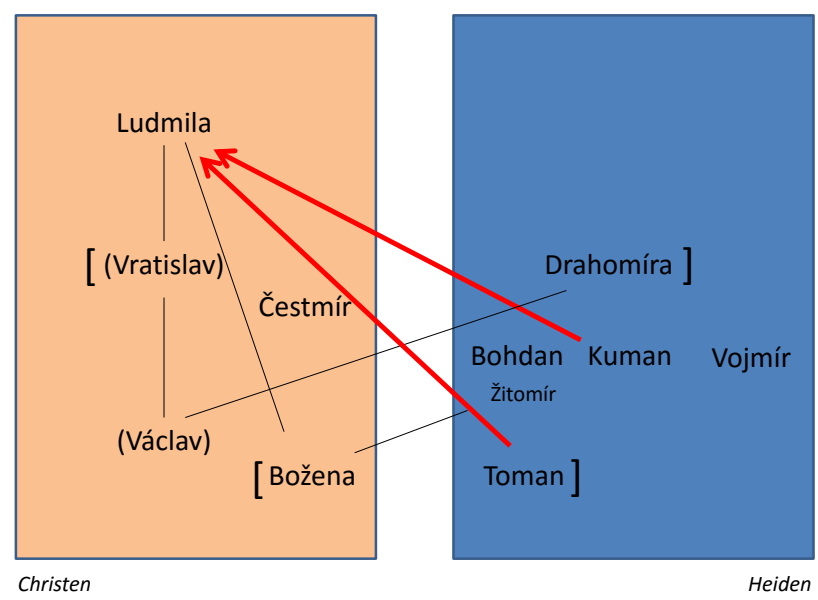

Graphik 10 - Václav Vojáček: Ludmila (1843)

Vojáčeks dramatische Apotheose der siegreichen christlichen Wahrheit, die in der Interpretation der Heiden selbst deren Pantheon zum Einsturz bringt (die Götterstatuen fallen auf diejenigen, die ihnen Opfer bringen, weil eben - wie Drahomíra feststellt - das Blut Unschuldiger vergossen wurde), erscheint auf der Ebene der politischen Handlung praktisch problemlos: Das Christentum siegt durch das Charisma seiner Proponenten (allerdings fällt Ludmila schließlich doch durch Mord), es siegt im bewaffneten Kampf (Vojmír berichtet, dass Václav zwei geflügelte Wesen im Kampf beigestanden haben) und es besiegt die heidnischen Götter. Die militärische Auseinandersetzung unter Brüdern, die Ludmila und Drahomíra beide vermeiden wollten, ist allein aufgrund der Intrigen der Heiden entstanden, mit einigem Blutzoll entscheidet das Christentum den Kampf für sich. Auch auf privater Ebene ist der Kampf zwischen den Glaubensauffassungen rasch entschieden. Er wird veranschaulicht an der Figur Boženas, die zum Christentum übertritt und sich damit sowohl von ihrem Vater Žitomír wie auch von ihrem Freund Toman löst. Dass ihr Vater ohne sie sterben musste, betrübt sie zwar, ihre geistliche Mutter Ludmila spricht ihr aber damit Trost zu, dass anstelle ihres leiblichen Vaters Gott sie als Tochter aufnimmt (I/3 u. II/3-4). Toman, der sich von Božena getrennt sieht, meint zwar zuerst, dass nur sein Übertritt zum Christentum eine Wiederannäherung an sie möglich machen wird. Von Kuman in den Double-bind (Kampf für die Heiden und damit Gewinn von Božena oder diese muss als Christin sterben) getrieben, versucht er noch, Božena zu gemeinsamer Flucht zu überreden. Da diese sich nach kurzem Zögern für Gott entscheidet, sucht er im Kampf das Vergessen und ermordet Ludmila. Damit freilich verliert er Božena, die über seine Tat entsetzt ist, 
gänzlich. Wenngleich Ludmila als Christin sterben muss, siegt in der Folge die von ihr vertretene Wahrheit auf allen Linien.

Interessant ist in diesem Zusammenhang die Erörterung der Frage, ob nicht mit dem Christentum der deutsche Einfluss im Land größer werde. Diesen Vorwurf erhebt die Partei der Heiden gegenüber Ludmila. Deren Bote Čestmír jedoch meint, dass nicht missionarische Interessen die deutsche Expansion bedingen, sondern dass die Deutschen böse Nachbarn seien, der christliche Glaube allein könne sie in die Schranken weisen. Das Drama, das überdeutlich das Christentum als wahre Religion favorisiert, verbindet mit diesem als neuer Nationalidee auch einen nationalistischen Blick auf die Deutschen.

\section{IV.4.8. Simeon Karel Macháček: Záviš Vitkovic, pán z Rưže anebo Pokuta za zradu. Smutnohra v pateru jednáni (1846)}

[Záviš Vítkovic [der Witigone], Herr von der Rose [von Rosenberg] oder Die Strafe für den Verrat. Trauerspiel in fünf Akten; UA 8.11. 1846, publ. 1846]

Als Gymnasiast war Simeon Karel Macháček (1799-1846) in den Jahren 18151818 Schüler von Josef Jungmann am Akademischen Gymnasium Prag, womit sein Engagement für die Entwicklung der tschechischen Literatur und Kultur begann. Als Übersetzer von Goethes Iphigenie auf Tauris, Schillers Jungfrau von Orleáns und Horaz' Schrift De arte poetica sowie als Kompilator von Anthologien mit Musterbeispielen der Versdichtung entsprach Macháček dem in Jungmanns Slovesnost formulierten Programm zur Förderung hochstehender Literatur in tschechischer Sprache, das ja am Vergleich mit den besten Beispielen europäischer Literatur ausgerichtet war. Neben seiner Tätigkeit als Gymnasiallehrer in Jičín war Macháček auch Übersetzer von Opernlibretti ins Tschechische, als Dramatiker hatte er großen Erfolg mit dem Lustspiel Ženichové [Die Bräutigame, 1824]; den hohen Ansprüchen an eine Verstragödie sollte das von einem Artikel Palackýs über Záviš von Falkenštejn angeregte Drama Záviš Vitkovic, pán z Růže anebo Pokuta za zradu genügen, das in Macháčeks Todesjahr 1846 uraufgeführt wurde. Als für die sprachkulturellen Verhältnisse der damaligen Zeit bezeichnend kann wohl der Umstand angesehen werden, dass Macháček dieses Drama zuerst in Deutsch schrieb, es dann aber ins Tschechische umarbeitete (vgl. LčL 3/1, S. 44).

Macháčeks Tragödie um Záviš von Falkenštejn zeigt anhand des Kampfes um die Fürstenmacht in Böhmen die konfligierenden Legitimationen von politischer Macht. Nach dem Tod von Otakar [= Ottokar Přemysl II.] heiratet Záviš von Falkenštejn Kunhuta, Otakars Witwe, die aus Ungarn stammt. Die Hochzeitsfeier findet noch während der Aufbahrung von Otakars Leichnam in Znojmo [Znaim] statt. Insofern Záviš von Otakar verstoßen worden war und ein Verhältnis zu Kunhuta schon zu dessen Lebzeiten begonnen hatte, kann die Hochzeit als Verrat an 
Otakars Erbe gedeutet werden. Jindřich z Kunrinků [Heinrich von Kuenringen], der wegen seines Eintretens für Otakar vom Hofe Rudolf von Habsburgs vertrieben worden war, erhebt im ersten Akt schwere Vorwürfe gegenüber dem Kreis um Záviš, der als der höchste Kammerherr in Böhmen den noch jungen legitimen Thronfolger Václav beraten soll. Záviš erklärt sein Verhalten gegenüber Otakar freilich damit, dass ihm vor allem am Wohl des Landes gelegen sei und sein bisheriges Handeln breite Zustimmung gefunden habe. Otakar hätte, wenngleich er einst so erfolgreich war, später sein Land in die falsche Richtung geführt, für das Wohl des Landes wäre der Verrat nötig gewesen: „Lépe, trpět na čas, ano utít oud [Otakara], / aby dř́k se uhojil a zachoval, / nežli nechat tělo zmrtvět dokona." ${ }^{184}$ (I/5, S. 17) Der als persona dramatis nicht präsente Václav, der legitime Nachfolger Otakars, geht eine Allianz mit Rudolf von Österreich ein, um seine Thronfolge gegenüber Záviš durchzusetzen; da Rudolf als Gegner Otakars aufgetreten war, wird diese Allianz als Gefahr für die Selbstständigkeit Böhmens gesehen.

Záviš wird in Znojmo von den anwesenden böhmischen Adeligen zum König ausgerufen, er hat also nicht allein die Unterstützung seines Geschlechts, der Vítkovci [Witigonen], sondern auch anderer Adeliger sowie des ungarischen Königs, der durch die Hochzeit mit Kunhuta sein Schwager wurde. Ein Angriff auf Mähren durch Jindřichs z Kunrinků Sohn Jindřich wird von Záviš erfolgreich abgewehrt, der junge Jindřich gerät in Gefangenschaft und trifft auf seinen ebenfalls in Gewahrsam befindlichen Vater. Dieser trägt seinem Sohn auf, das Angebot Kunhutas anzunehmen und als Mundschenk in ihre Dienste zu treten. Er gibt Jindřich ein Gift, mit welchem dieser Kunhuta vergiften soll. Nur widerwillig führt Jindřich diesen Auftrag aus, Kunhuta stirbt durch das Gift (III/12) und Záviš stellt sich die Frage, ob dies ein Wink Gottes ist oder ob er nur von Neidern und Feinden daran gehindert wird, König zu werden. Da sein Herz rein ist, weil bloß das Wohl der Heimat sein Anliegen sei, wird er sich nicht irritieren lassen (auch nicht von der Aufkündigung der Unterstützung durch Ungarn nach dem Tode Kunhutas) und weiterhin nach der Königswürde streben. Záviš möchte nach dem Schuldigen am Mord suchen, sein Onkel Milota warnt Záviš vor Erhard, dessen Treue vielleicht nur eine scheinbare ist. Záviš begnadigt Jindřich, der seine Schuld an der Vergiftung einbekennt, sich jedoch bald darauf selbstmörderisch von einem Felsen stürzt. Záviš erkennt, dass seine Milde auch dadurch bedingt war, dass ihm Jindřich als Schuld vorgeworfen hatte, den Thronfolger Václav verraten zu haben. Záviš entschließt sich, anstelle seines Herzens seinem Willen zu gehorchen, nur dieser vollbringe $\mathrm{Au}-$ ßergewöhnliches (IV/6). Seinen Entschluss, Václav zu stürzen und selbst König zu werden, begründet er mit der besseren Politik. Erhard widerspricht ihm mit dem

184 [Záviš:] „Es ist besser, eine Zeit leiden zu müssen und einen Körperteil abzuhacken / damit der Rumpf bestehen bleiben kann / als den Körper ganz sterben zu lassen.“ 
Argument, dass Záviš selbst bei absoluter Zustimmung des Volkes widerrechtlich die Krone an sich reiße.

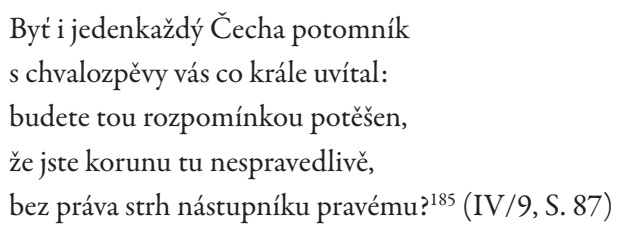

Da der königstreue Erhard dem rachsüchtigen Jindřich z Kunrinků entsprochen und Otakars Nebensohn Mikuláš in die Burg Znojmo eingelassen hatte, wird Záviš im letzten Akt gefangen genommen und zum Tode verurteilt. Erhard bereut seine Unterstützung für Mikuláš, er wollte nicht Záviš Tod, sondern bloß verhindern, dass Záviš Václavs Thronfolge vereitelt. Mikuláš meint, dass Záviš in die Hände der Nachkommen Otakars geraten ist, sei ein Gottesurteil. Záviš klagt darüber, seine besten Absichten nicht verwirklicht haben zu können, diese seien nur im ideellen Zustand wirklich die seinigen, beim Versuch, sie zu verwirklichen, wurden sie zunichte. Záviš sieht sich von Gott als höchstem Richter zum Tode verurteilt und möchte von eigener Hand sterben. Da dies verhindert wird, wird er am Ende des Dramas geköpft. Mikuláš kommentiert die Hinrichtung:

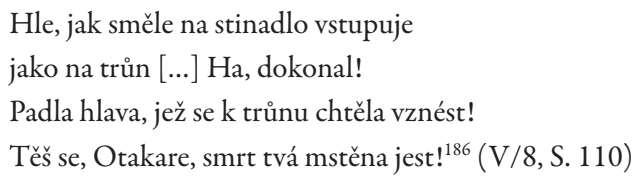

Der dramatische Konflikt besteht zwischen der Position des traditionellen Rechts, derzufolge eindeutig die direkten Nachkommen des verstorbenen Königs Otakar die Thronfolge antreten dürfen und einer Legitimation von politischer Macht, die auf politischer Fähigkeit, Leistung und Anerkennung beruht. Záviš bringt durch sein Handeln die rechtliche Regelung der Thronfolge durcheinander, für diese Verletzung des Rechts bzw. des durch dieses Recht beschriebenen sozialen Raums wird er mit dem Tode bestraft. Dieser Handlungsverlauf kann insofern als tragisch bezeichnet werden, als die Titelfigur Záviš zwar als Person untergeht, die von ihr vertretenen politischen Prinzipien - politische Führung aufgrund von Leistung und

185 [Erhard:] „Wenn auch jeder Nachkomme Čechs / mit Dankesgesang Sie als König begrüßt: / Würden Sie von der Erinnerung erfreut sein, / dass Sie diese Krone widerrechtlich / dem rechtmäßigen Thronfolger entrissen haben?!“

186 [Mikuláš:] „Seht, er besteigt den Richtbock so mutig / wie einen Thron [...] / Er ist gestorben. / Der Kopf ist gefallen, der sich zum Thron erheben wollte. Otakar, freue dich, dein Tod ist gerächt!" 


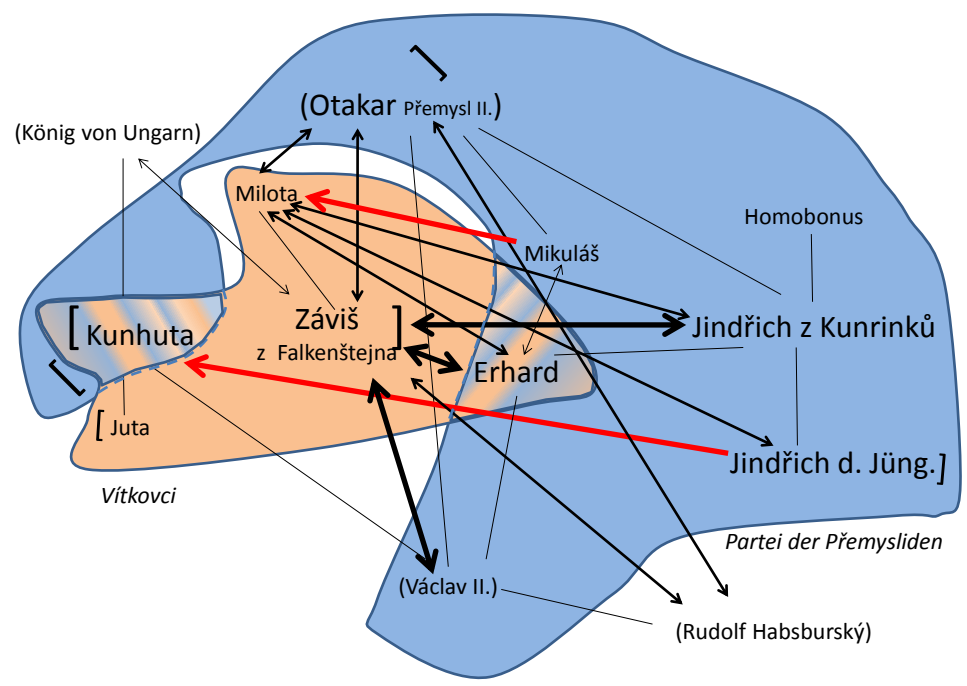

Graphik 11 - Simeon Karel Macháček: Záviš Vitkovic, pán z Růže (1846)

Legitimation durch Wahlen - aber realhistorisch erfolgreich waren. Im Drama erscheint die Partei seiner Gegner politisch wenig zuwegezubringen. Der allzu junge Thronfolger Václav muss sich, um sich gegenüber dem gewieften Záviš überhaupt durchsetzen zu können, an Rudolf von Habsburg anlehnen, wobei er Gefahr läuft, Böhmen und Mähren fremdem Einfluss zu öffnen. Jindřich z Kunrinků als der eigentliche Verursacher der Handlungskette, die zur Dekapitation von Záviš führt, kann als blindwütiger Rächer von Závišs Verrat an Otakar gelten, der die politischen Leistungen von Záviš nicht anerkennen möchte. Die Linie, welche die Seite des traditionellen Rechts von den von Záviš vertretenen neuen Prinzipien trennt, verläuft durch die Personen Kunhuta und Erhard, die beiden Lagern zuzurechnen sind (siehe die schraffierten Flächen im Figurenschema). Als Witwe Otakars und neu verheiratete Gattin von Záviš ist Kunhuta ganz auf der Seite ihres Mannes, als Mutter von Václav ist sie sogar auch damit einverstanden, dass Záviš Anspruch auf die Königswürde erhebt, sie möchte freilich ihrem Sohn nicht schaden. Durch die Heirat zumindest schafft sie die formalen Voraussetzungen, dass Záviš überhaupt den Anspruch auf die Königswürde erheben kann. Erhard, die andere „Grenzfigur“, hingegen ist widersprüchlicher. Er erkennt die politische Leistung von Záviš an, möchte aber keinesfalls, dass dieser die traditionelle Thronfolgeregelung aufhebt und anstelle von Václav König wird. Als Bewahrer der Ordnung führt sein Handeln zur Gefangennahme von Záviš und zu dessen Hinrichtung (die Erhard allerdings nicht gewollt hat). Der Dialog von Erhard und Záviš im vierten Akt unterstreicht die Differenzen 
zwischen der Position des traditionellen Rechtempfindens und der „willkürlich“ anmutenden Aufhebung der Tradition.

Záviš: Co by právo bylo a co neprávo, v každý čas a ve všelikém jednání, žádný zákon napřed neustanoví. Doba jedna ještě nikdá nebylá velí citu našemu a svědomí pravdu činit z práva, právo ze křivdy; a hle, doba taková ted' nastala, Kde se jednomu jest práva odřeknout, aby tisícům se křivda neděla.

Erhard: Nedejte se ctižádosti oklamat, považte to zlé, co svět by potkalo, kdyby každý city své a mínění ustavit chtěl řediteli činů svých!

Záviš: Množstvo leží zamotáno v předsudkách, má, co jest a bylo, za spravedlivé.

Věky uplynou, než někdo smělejší z tenat obyčejnosti se vytrhnuv, krajanům svým nový zákon zvěstuje, jejž ti s podivením zachovávají. ${ }^{187}$ (IV/9, S. 87f)

Diese zentrale Opposition des Dramas könnte auch als Widerspruch von traditionellem bzw. positivem Recht und Naturrecht gesehen werden, doch ist im Drama noch eine weitere Problematisierung zu erkennen: Das naturrechtliche Rechtsempfinden wird nämlich weniger als Korrektiv des traditionellen Rechts gesehen, sondern als von diesem beeinflusst. In der letzten Replik des oben wiedergegebenen Dialogs bezeichnet Záviš die Meinung der Menschen als Vorurteil, welches die be-

187 Záviš: „Was Recht und was Unrecht sei / zu jedem Zeitpunkt und für jedwedes Handeln, / das kann kein Gesetz im Voraus festlegen. / Die [jeweils besondere] Zeit war vorher nie / sie befiehlt unserem Gefühl und Gewissen, / Wahrheit aus Recht, Recht aus Unrecht zu schaffen; / und man sehe: eine solche Zeit ist jetzt gekommen / Wo es darum geht, einem sein Recht abzusprechen, / damit nicht Tausende Unrecht erfahren."

Erhard: „Lassen Sie sich nicht vom Ehrgeiz blenden, / man denke nur an das Böse, das über die Welt kommen würde, / wenn jeder seine Gefühle und sein Meinen / zum Richtmaß seiner Taten erklären möchte!“

Záviš: „Die Mehrheit ist in Vorurteilen befangen, / und hält, was ist und war, schon für gerecht. / Es wird noch Jahrhunderte dauern, bis irgendjemand Mutigerer, / der sich aus der Falle der Alltäglichkeit befreit, / seinen Landsleuten ein neues Gesetz verkündet, / dem diese mit Bewunderung folgen werden." 
stehende Ordnung für die gerechte Ordnung hält. Demnach kann er auch nicht unproblematisch der Stimme seines Gewissens folgen, wie er in IV/4 zuerst erklärt, als er als Strafe für den Mörder seiner Frau diesem die Freiheit schenkt. Bald darauf erklärt Záviš nämlich seine Urteilsfähigkeit als dadurch getrübt, dass Jindřich ihn des Verrats an Václav geziehen habe. Dieser Vorwurf, der objektiv natürlich richtig ist, da Záviš sich ja nicht mit dem Status als höchster Berater des Thronfolgers zufrieden gibt, sondern dessen Rivale um die Königswürde wird, habe sein Herz und sein Gewissen angerührt. Záviš erscheint hier als ein von Gewissensbissen geplagter, weicher Charakter, der seine Handlungen bezweifelt (vgl. Knap 1926, 158). Nach dieser Einsicht beschließt Záviš, nicht mehr seinem Herzen bzw. Gewissen zu gehorchen, sondern allein seinem Willen, da nur dieser imstande sei, mit der bestehenden Ordnung radikal zu brechen (IV/6). Der Wille zur Macht, den Záviš in dieser Szene proklamiert, ist allerdings nicht erfolgreich. Záviš unterliegt seinen konservativen Gegnern, was er selbst als widerstrebendes Schicksal deutet: Als der triumphierende Mikuláš die Niederlage von Záviš zum Gottesurteil erklären möchte, hält Záviš dies zwar für anmaßende Gotteslästerung, sein Hadern mit dem Schicksal erscheint allerdings ebenfalls als pessimistische Umkehrung seines entschlossenen Willens zur Macht. Der Handlungsverlauf führt zu einer Restauration des Přemysliden-Erbes, da die Titelfigur für ihre Verletzung der traditionellen Thronfolgeregelung mit dem Tode bezahlen muss; unter Berücksichtigung des Umstandes aber, dass Záviš als wirklich fähiger Regent gezeichnet wird, dem keine ebenbürtigen Gegner gegenüberstehen, könnte man das Schlussbild aber auch in einer revolutionären Wende sehen: „Hle, jak směle na stinadlo vstupuje / jako na trůn!“188 (V/8). Zwar wird nicht der König geköpft, sondern der nicht legitimierte Prätendent Záviš, das Drama Macháčeks votiert allerdings in seinen wesentlichen Momenten für die Instituierung von politischer Effizienz und demokratischer Legitimation, sodass faktisch der Erbmonarchie der Kopf abgeschlagen wird. Im äußeren Kommunikationssystem wird der Bruch mit der Tradition - versteckt freilich - letztlich radikal affirmiert.

\section{IV.4.9. Josef Jiří Kolár: Monika. Tragédie ve třech jednánich (1846)}

[Monika. Tragödie in drei Akten; UA 20.12.1846, publ. 1847]

Josef Jiří Kolár (1812-1896) war ein vielseitiges Talent, nach seinen Anfängen als Schauspieler und unter der Anleitung von Štěpánek und Tyl war er lange Zeit am Ständetheater und anderen Bühnen - zuerst als Laie, dann als professioneller Schauspieler und Dramaturg - tätig. Seine ursprüngliche Namensform war Kolár, aus Begeisterung für Ján Kollárs Slávy dcera slowakisierte der Schauspieler und Dichter seinen tschechischen Namen. Interessant auch die utraquistische Differenzierung

188 Mikuláš: „Seht, er besteigt den Richtbock so mutig / wie einen Thron!“ 
seiner Rollen als Schauspieler: im deutschsprachigen Theater spielte er Liebhaber, Gesellschaftstypen und Soldaten, im tschechischen Theater "große"Charaktere wie Helden oder tyrannische Herrscher (vgl. Ježková 2013b, 91). Als Übersetzer von Schiller (Die Räuber, 1840; Wilhelm Tell [teilweise 1844]; Kabale und Liebe, 1851; Wallensteins Lager, 1862) und Goethe (Clavigo, 1853; Faust [erster Teil, 1855]; Götz von Berlichingen, 1856; Egmont, 1858) sowie als einer der Übersetzer für die erste tschechische Werkausgabe von William Shakespeare war er darum bemüht, ein anspruchsvolles Repertoire auf die Prager Bühnen zu bringen, wobei auch er den Spagat zwischen intellektuellem Wunsch und theaterpraktischer Wirklichkeit machen musste (vgl. ebd.).

Josef Jiř́i Kolár widmete sein erstes eigenes Drama Monika Baron Karl Maria Drahotín Villani (1818-1883); von dessen militärischem Dienstrang und von der Aufzeichnung der Verdienste und Mitgliedschaften (Kaiserlich-königlicher Leutnant, Mitglied der Böhmischen Stände, Mitbegründer der Matice česká etc.) auf dem Widmungsblatt der gedruckten Ausgabe des Dramas setzte Kolár die einzeilige Charakterisierung „Vlastenci horlivému“ (,dem leidenschaftlichen Patrioten') ab.

Die im Drama repräsentierte Zeit ist diejenige des Dreißigjährigen Krieges, womit sich Kolárs Monika auffällig von den Dramen des obrození abhebt, die allesamt in der Zeit vom 9. bis zum 14. Jahrhundert angesiedelt sind und somit auch keine Repräsentation der Hussitenzeit leisteten. Ein weiterer signifikanter Unterschied zu den bis dato entstandenen tschechischen historischen Dramen besteht bei Monika darin, dass die handelnden Personen allesamt fiktiv, jedoch fest in die Zeit des DreiBigjährigen Krieges „eingelassen“ sind. Ohne konkrete Textzeugnisse des Autors ist es natürlich immer spekulativ, Gründe für die Wahl „unhistorischer" Personen interpretativ festzustellen; im Fall von Monika könnte man mit Lindenberger (vgl. 1975, 1-3) mutmaßen, dass die Wahl unhistorischer Personen aufgrund der größeren Freiheit in der Handlungsentwicklung eine deutlichere dramatische - durch die Handlung vermittelte - „Aussage“ erlaubt. Im vorliegenden Fall strebte Kolár wohl - soviel sei vorausgeschickt - nach der dramatischen Illustration hegelscher Geschichtstheoreme.

Die Tragödie - man hat Kolár gleich nach der Uraufführung vorgeworfen, er habe Passagen aus Byrons Werner kopiert (vgl. Strejček 1932, 60) ${ }^{189}$ - zeigt im ersten Akt Benedikt Kolon Felsecký in einem Unterschlupf, in dem er sich unter dem Namen Lambert vor Feinden versteckt. Nach der Unterwerfung des Prager Ständeaufstands 1620 musste Benedikt/Lambert Böhmen verlassen; nach zwölfjähri-

189 Kolár hat auf den Vorwurf reagiert und eingeräumt, dass er sich von Byrons Drama hat inspirieren lassen (vgl. Strejček 1932, 61). Tatsächlich lassen sich sowohl im Sujet wie in einzelnen Repliken Ähnlichkeiten erkennen, insgesamt ist Kolárs Drama aber als durchaus eigenständig einzuschätzen. 
gem Exil nützt er die Gelegenheit, mit den sächsischen Truppen, die in Böhmen vordringen, nach Prag zurückzukehren. Was Benedikt/Lambert in seiner ehemaligen Heimat vorfindet, stimmt ihn nur traurig, die alten Freunde sind alle gestorben, die Familie ist nicht mehr aufzufinden, nach ihm selbst, über den die Todesstrafe verhängt wurde, wird noch immer gefahndet. Er, der Abkömmling eines alten Adelsgeschlechts, hat allenfalls noch den Wunsch nach Rache, von dem ihn sein frommer Diener Ondřej allerdings abbringen möchte. Monika tritt in schwarzen Männerkleidern auf, sie hat soeben gemeinsam mit ihrem Bruder Hypolit einen Mann, der bei der Überfahrt über den Fluss kenterte, vor dem Ertrinken gerettet. Sie gibt sich in ihren Reden entschieden tschechisch-patriotisch. (Čech, s tělem i duš́, jenž krále a vlast svou miluje.“ - I/5, S. 22, „[Ich bin] ein Tscheche mit Leib und Seele, der den König und seine Heimat liebt"). Sie interessiert sich für Benedikt/Lambert, der nicht viel von sich preisgibt, und erfährt, dass er ein vertriebener Lutheraner ist. Beide fühlen eine Nähe zueinander, was sie jedoch auf ein ähnliches Schicksal und ähnliche Ansichten zurückführen. So erklärt etwa Monika, dass sie die Schulter eines Giganten sei, die aus der Erde herausrage und nach Rache rufe (vgl. I/6, S. 25). Der vor dem Ertrinken Gerettete wird gebracht, es ist Věrnosta, der höchste Richter in Böhmen, der zugleich Benedikt/Lamberts Bruder wie auch dessen größter Feind ist. Die Brüder erkennen einander sofort; in Benedikt/Lambert erwacht wieder der Wunsch nach Rache für das vom Bruder ausgegangene Unrecht. Er unterdrückt die Rache am Bruder damit, dass sich nicht einmal Tiere gegen seinesgleichen erheben würden. Věrnosta, der eigentlich Lazar Kolon Felsecký heißt, ist gegenwärtig ohne seine höchste Richtermacht, weil ja die sächsischen Truppen in Prag Einzug gehalten haben. Der erste Akt der Tragödie endet damit, dass Monika von Benedikt/Lambert ebenfalls die wahre Identität Věrnostas erfährt.

Im zweiten Aufzug wird die Vorgeschichte aufgerollt: Einst hatten die Brüder Benedikt/Lambert und Lazar um das väterliche Erbe zu konkurrieren. Der Vater sprach Benedikt/Lambert, dem Jüngeren, das Erbe zu, weil dieser zehn Männer, Tschechen und Deutsche, aus türkischer Gefangenschaft befreien konnte. Benedikt/Lambert war einigermaßen großzügig gegenüber Lazar, dem der Vater das Erbe nicht zugeteilt hatte. Beide begehrten jedoch auch dieselbe Frau, Klára. Diese entschied sich für Benedikt/Lambert. Lazar riet seinem Bruder, sich dem Winterkönig und den aufständischen protestantischen Ständen anzuschließen. Als dieser dem Rat folgte und der Ständeaufstand schließlich niedergeschlagen wurde, schlug sich Lazar auf die Seite der neuen Machthaber und verriet seinen dem Protestantismus nicht abschwörenden Bruder. Nachdem Benedikt/Lambert fliehen musste und seinen Besitz verloren hatte, misshandelte und vergewaltigte Lazar seine Schwägerin Klára. Als Klára verbittert im Sterben lag, rang sie ihrem Sohn Hypolit den Racheschwur für das erlittene Unrecht ab. Nun, zu Beginn des zweiten Akts wird er von Monika zur Rache am Onkel aufgefordert. Hypolit hingegen wird wahnsinnig, 
er möchte Frauenkleider tragen, an seiner Statt wird Monika die Rache vollziehen müssen. Věrnosta bzw. Lazar möchte hingegen der Rache dadurch entkommen, dass Benedikt/Lambert gefangen genommen werden soll. Er lässt nach Truppen schicken. Sein Vorgehen rechtfertigt er mit dem geltenden Recht: Schon in der Vergangenheit habe das Recht der Gemeinschaft bzw. der neuen Machthaber in Böhmen über dem Familienrecht gestanden, an Klára habe er sich deswegen vergangen, weil er seinen natürlichen Instinkten gefolgt sei und sie sich ihm verweigerte (vgl. II/5). Monika, die sich als Tochter Kláras zu erkennen gibt, vollzieht die der Mutter gelobte Rache an ihrem Onkel und erschießt ihn. Lazars (Věrnostas) Sohn Odolan ist über diese Tat entsetzt, er möchte nach dem Mörder fahnden. Er weiß nicht, dass dies Monika ist, die Odolan bald - in Gegenwart seines Vaters Věrnosta, von dessen Vergangenheit Odolan nichts weiß - heiraten wollte.

Der letzte Akt der Tragödie führt die Reaktionen auf die vollzogene Rache an Věrnosta vor: Während Monika die von der Mutter aufgetragene Rache im Namen der göttlichen Gerechtigkeit ausgeführt meint, ist ihr Verlobter Odolan anderer Auffassung. Als nämlich Benedikt/Lambert und Ondřej als Tatverdächtige vorgeführt werden, meint Odolan, dass die Vergeltung nicht dem natürlichen Recht entspreche, das weder Mord noch ein Blutgericht kenne („Přírody zákony o vraždě nevědí, Aniž o soudu krvavém.“ - III/3, S. 86) Mit Monika will Odolan beraten, was zu geschehen habe. Diese habe einst, als sie an der Belagerung von Odolans Burg beteiligt war, ihn geschont, somit seien sie ein Paar geworden. Wenngleich er über den Tod Věrnostas froh ist, streitet Benedikt/Lambert ab, Věrnosta getötet zu haben (dessen wahre Identität er nicht verrät), dem eigenen Tod nahe, verrät er, dass sein eigentlicher Name Benedikt Kolon Felsecký ist. Die hinzugekommene Monika erkennt somit, dass dieser ihr eigener Vater ist. Auch stellt sich heraus, dass Věrnosta der Vater Odolans war, da er im Zuge des Ständeaufstands und des Verbrechens am Bruder und dessen Familie seine Identität gewechselt und dabei seine eigentliche frühere Identität verschwiegen hatte. Monikas Rache am Onkel war damit zugleich auch die Ermordung ihres Schwiegervaters in spe. Odolan wie auch Benedikt/ Lambert missbilligen Monikas Rache. Diese sieht jedoch dadurch das Recht der Familie wiederhergestellt, Odolan hingegen meint, dass das allgemeine Recht dem Familienrecht übergeordnet sei. Wer sich dem allgemeinen Recht widersetze, müsse bestraft werden. Monikas Vater Benedikt/Lambert ist ebenfalls der Auffassung, dass die Rache falsch gewesen sei; schon Klara hätte nicht den Kindern den Racheschwur abverlangen dürfen, Monika sei damit zu ihrem Werkzeug geworden. Nun müsse aber das Recht wiederhergestellt werden: den Rachemord müsse Monika mit dem Tod büßen (was sie auch annimmt), Odolan soll die Todesstrafe ausführen. Da sich dieser dazu außerstande sieht, tötet Benedikt/Lambert die eigene Tochter, um ihr die Hinrichtung zu ersparen. Monika dankt ihm dafür, weil sie ihren Fehler erkennt. Hypolit springt daraufhin in die Elbe und ertrinkt, während Lambert, der weiß, dass er ohnehin bald sterben muss, zum Schluss erklärt, dass das Schicksal auf 
der sündigen Erde Schuldige wie auch Unschuldige sterben lässt. Nach seiner Tötung Monikas verlangt nun auch er, getötet zu werden.

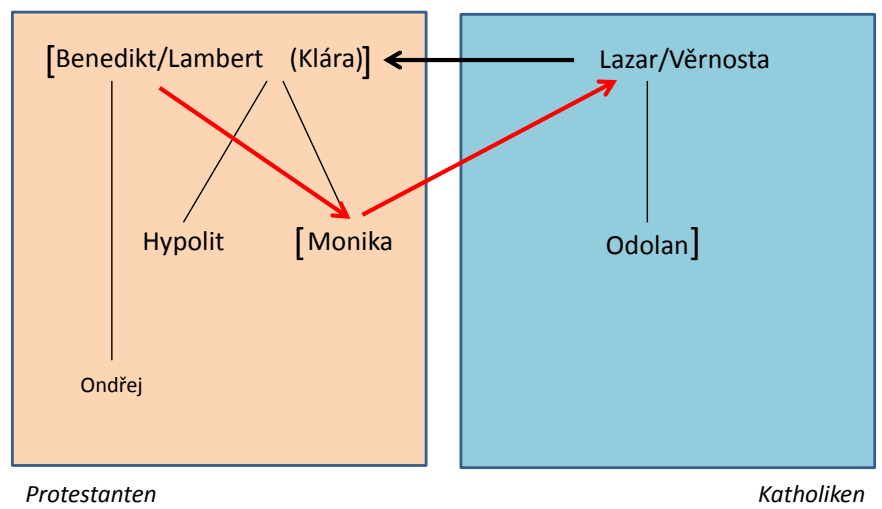

Graphik 12 - Josef Jiří Kolár: Monika (1846)

Kolárs Tragödie enthüllt als analytisches Drama die Identitäten der drei Hauptfiguren Monika, Lambert und Věrnosta sowie deren Verhältnis zueinander. Dass diese engste Blutsverwandte der Familie Kolona-Felsecký sind, nämlich Tochter, Vater und Onkel, kann der Leser bzw. Zuschauer wahrscheinlich bald erraten, die falschen Identitäten entsprechen jedoch nicht nur einem dramaturgischen Einfall, sie stehen wohl auch mit der politischen Grundaussage im Zusammenhang. Monika führt damit auch eine falsche Welt vor, die die Menschen dazu drängt, eine falsche Identität und Rolle anzunehmen. Illustriert wird dies an Monikas Bruder, der ihr dramaturgisch-strukturelles Gegenstück ist: Hypolit kann das Rachegelöbnis nicht ausführen, er wird darüber wahnsinnig und möchte Frauenkleider tragen. Monika hingegen, die offenbar von robusterer Natur ist als ihr Bruder, verkleidet sich als Jüngling und führt die Rache aus. Diese ist, wie am Ende erörtert wird, gleichfalls Folge der falschen Welt, in der es zu solchen Bizarrerien gekommen ist, dass jemand wie Lazar, der schwere Verbrechen an der eigenen Familie begangen hat (Verrat, Vertreibung, Vergewaltigung) zum höchsten Richter im neuen politischen System aufsteigt.

Die Tragödie behandelt, wie man insbesondere im dritten Akt erkennen kann, das Problem des Verhältnisses von Rache und Strafe. Benedikt/Lambert erklärt zu Beginn des Dramas ja bereits, dass er sich gerne an den Verursachern seines Leids rächen will, sein Diener Ondřej hingegen weist ihn auf Gott hin, dem allein es obliege, zu strafen. Der Mensch solle sich nur an Gott halten. Die ein Jahr vor den repräsentierten Ereignissen verstorbene Mutter Klára hingegen möchte, dass das Leid der 
Familie gerächt wird, Monika ist diejenige, die imstande ist, die Rache auszuführen, wobei sie sich als Schulter eines Giganten bezeichnet, der aus der Erde ragt und nach Rache ruft (vgl. I/6). Nachdem sie ihren Onkel erschossen hat, erklärt sie, nur im Namen der göttlichen Gerechtigkeit aufgetreten zu sein. Das Racheprinzip wird aber gerade von Odolan, Věrnosta/Lazars Sohn, verworfen, Rache käme selbst in der Natur nicht vor (vgl. III/3, S. 86). Höher als das Recht der Familie, das Monika durch die Rache wiederhergestellt sieht, stellt Odolan das Recht der Gemeinschaft. Wer sich diesem allgemeinen Recht dadurch entgegenstellt, dass er die private bzw. familiäre Rache ausübt, zieht die Rache der Allgemeinheit auf sich (Odolan: „Pomstu

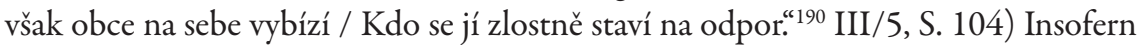
auch Benedikt/Lambert die Rache Monikas verurteilt, stimmt er Odolan zu, dass Monikas Handlung von der Allgemeinheit bestraft/gerächt werden soll. Sogar Monika erklärt sich mit der Bestrafung einverstanden. Da Odolan, immerhin Monikas Verlobter, diese nicht vollstrecken will, ist es Benedikt/Lambert, der seine Tochter ersticht, auch um ihr eine öffentliche Hinrichtung als schuldig Gesprochene zu ersparen. Monika bedankt sich dafür, weil sie ihren Fehler erkannt hat. Der Schlusssatz von Benedikt/Lambert, der nach der Tötung Monikas auch verlangt, dass man ihm den Tod bereite, lautet: „Na rány člověčenstva patří mezi líky / By zhynul nevinný mezi všemi viníky!" ${ }^{191}$ (III/5, S. 111) - Nun ist nicht ganz klar, auf welche Figuren dieser Satz referieren soll: Dass der Schuldige wohl Vèrnosta/Lazar ist, ist klar, dessen Untaten haben ja zu dem großen Leid der Familie geführt. Ob nun aber die Rächerin Monika wie auch der strafende Benedikt/Lambert, die beide - wenngleich nach unterschiedlichen Prinzipien: aufgrund von Rache oder von Strafe - töten, in dem Satz zu den Unschuldigen gerechnet werden, die ebenso wie die Schuldigen sterben müssen, bleibt offen. Anzunehmen ist, dass sich zumindest Benedikt/Lambert unschuldig wähnt. Wenn er seinen Tod als „Arznei“ bezeichnet, so wohl nur deshalb, weil er den Tod als Erlösung aus dem Jammertal ansieht.

Der im Drama thematisierte Unterschied zwischen Rache und Strafe erscheint insofern verwunderlich, als die Strafe, die nach dem - von Odolan höher gewerteten - allgemeinen Recht vollzogen wird, auch als "Rache der Gemeinschaft“ („pomsta obce“, vgl. 104) gilt. Der Unterschied zwischen der vollzogenen Rache und der vollzogenen Strafe - beide enden mit dem Tod des bzw. der Schuldigen (Verrnostas/Lazars bzw. Monikas bzw. letztlich auch Lamberts/Benedikts) - ist im Drama nur der, dass die Rache gegen den Widersacher bzw. Feind der Familie gerichtet ist, während die im Namen der Allgemeinheit vollstreckte Strafe von Odolan und Benedikt/Lambert gegenüber Monika gefordert bzw. vollzogen wird, die

190 [Odolan:] „Die Rache der Gemeinschaft zieht derjenige auf sich, der ihr bösartig Widerstand leistet."

191 [Benedikt/Lambert:] „Auf die Wunden der Menschheit gehört auch als Heilmittel, dass der Unschuldige zusammen mit dem Schuldigen vergehe!“ 
beiden als Verlobte bzw. Tochter nahe steht und zu der niemals eine feindschaftliche Beziehung bestanden hat. In diesem Rigorismus ist wohl die entschiedenste Distanzierung vom Rachemotiv der Romantik zu erkennen, die Kolár mit Monika vornimmt. ${ }^{192}$

Bemerkenswert ist überdies die Position Věrnostas, der das Recht der Gemeinschaft als Rechtfertigung für sein Vorgehen gegenüber seinem Bruder Benedikt/ Lambert vorschiebt. Zugleich aber gesteht er ein, dass sein eigener Wille das Recht setzt bzw. dass dieses von seinen Trieben bestimmt wird:

„Co mne káráš, svědomí, ty blekotavé děcko? Jsemt́ muž, a vůle má jest moje právo a jediný můj Bůh! - Nic jsem na něm nezavinil. An jsem jej zkazil, hájil jsem práva obce proti jeho právu rodinnému, - na straně všeobecnosti jsem stál, kdežto on v jednotlivém nerozumu se jitřil a duchu času opíral. - A Klára - Klára? - Ona mnou povrhla, a já s ní nakládal podle práva přirozených chtíčů svých.“193 (II/5, S. 63)

Wenngleich auch Věrnosta/Lazar das Recht der Gemeinschaft als Legitimation für sein Vorgehen reklamiert, unterscheidet sich seine Position von derjenigen Odolans bzw. Lamberts/Benedikts dadurch, dass er sein Gewissen, welches ja meist als Korrektiv gegenüber ungerechten oder falschen Normen des gesetzten Rechts gesehen wird, ignorierend übergeht. Odolan und Benedikt/Lambert hingegen, die ja gleichfalls im Namen der Allgemeinheit Monika verurteilen, handeln in Übereinstimmung mit dem eigenen Gewissen.

Die unterschiedlichen Schritte in der Abfolge von Verbrechen, Rache und Strafe innerhalb der Familie Kolona-Felsecký lassen sich wie folgt schematisch darstellen:

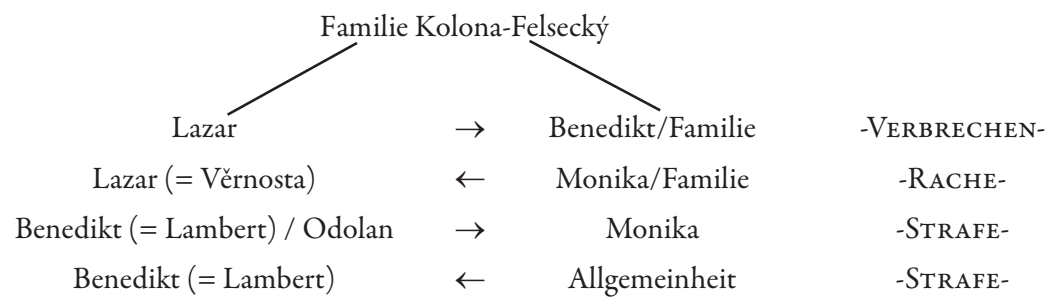

192 Aufgrund dieser strengen Thematisierung des Unterschieds von Rache und Strafe muss wohl Monika - und nicht Tyls Čestmír, wie Stich (vgl. 1993, 67) insinuiert - als dasjenige Drama gelten, das am vehementesten das in der Romantik so verbreitete Rachemotiv aufgreift und verwirft.

193 „Was strafst du mich, Gewissen, du stammelndes Kind? Ich bin doch ein Mann, und mein Wille ist mein Recht und mein einziger Gott. - Ich habe mich gegenüber ihm nicht schuldig gemacht. Auch als ich ihm geschadet habe, habe ich das Recht der Gemeinschaft gegen sein Familienrecht verteidigt, ich stand auf der Seite der Allgemeinheit, während er in vereinzeltem Unverstand aufbegehrte und sich dem Geist der Zeit widersetzte. Und Klára - Klára? Sie hat mich verschmäht, ich bin mit ihr nach dem Recht meiner natürlichen Triebe verfahren." 
Das Schema lässt sich auch diachron lesen: Zuerst gab es die Familie Kolona-Felsecký mit den beiden Brüdern Lazar und Benedikt. Zwischen diesen entstand ein Streit ums väterliche Erbe und um die von beiden begehrte Klára. Lazar beging dabei an Benedikt ein Verbrechen, das er allerdings unter dem Schutz der neuen Machthaber zu legitimieren vermeinte. Monika rächt in der Tragödie das Verbrechen. In der Folge bestrafen Odolan und Benedikt/Lambert Monikas Rache im Namen der Allgemeinheit. Und letztendlich verlangt auch Benedikt/ Lambert nach dem Tod durch die Allgemeinheit, weil er ja Monika getötet hat, um der Tochter einen schmachvollen Tod durch Hinrichtung zu ersparen. Liest man die Abfolge der Agens (bzw. Täter)-Patiens-Beziehung (der Pfeil $[\rightarrow]$ symbolisiert dabei die Transitivität der Tat), ergibt sich dem Anschein nach eine zyklische Bewegung:

Allgemeinheit $\rightarrow$ Benedikt (=Lambert) / Odolan $\rightarrow$ Monika/Familie $\rightarrow$ Lazar $\rightarrow$ Benedikt/Familie

Das Irritierende an Kolárs Stück sind die strukturellen Homologien, die von den Figuren als Differenzen ausgegeben werden. So etwa fügt Lazar seinem Bruder und dessen Familie (Klára, Monika und Hypolit) schweres Leid zu, die Rache Monikas besteht jedoch in der Tötung Lazars. Benedikt tötet seinerseits strafend/mitleidig seine Tochter. Während Verbrechen und Rache im Kreise der Familie bleiben, erklären Odolan und Benedikt/Lambert, dass ihr Vorgehen von der Allgemeinheit gefordert sei, faktisch allerdings sind die Involvierten in diesen „Strafvollzug" wieder die Familienmitglieder. Ein solcher Strafvollzug scheint dabei insofern als tragisch, weil seine Notwendigkeit, die von den Agenten des Vollzugs wie auch von Monika qua Patiens proklamiert wird, wissentlich vom Vater an der eigenen Tochter vollzogen wird. Die so demonstrierte „alttestamentarliche“ Strenge des Gesetzes kann dabei - möglicherweise gegen die Intentionen des Autors - ambivalent erscheinen. Folgende Lesarten sind möglich: a) das allgemeine Gesetz erscheint - gerade weil es innerhalb der Familie exekutiert wird - als tragisch "erhaben“ und damit der bloßen Rache überlegen; b) weil zwar behauptet wird, dass das Gesetz mehr als bloße Rache sei, die Exekution aber sowohl bei der Rache wie auch bei der Strafe mit dem Exitus des Patiens endet, soll das Publikum eine kritische Distanz gegenüber einer solchen Auffassung des Gesetzes entwickeln, die obendrein auch noch nicht davor zurückschreckt, nahestehende Familienmitglieder in den Tod zu befördern; c) wenn sich sowohl der Verbrecher Věrnosta/Lazar als auch die Exekutoren des strafenden Gesetzes Odolan und Benedikt/Lambert auf die Allgemeinheit berufen, soll das Publikum die spezifische Differenz zwischen den Auffassungen erkennen: bei Věrnosta/Lazar handelt es sich mit dem Bezug auf die Allgemeinheit um eine Ausflucht, um persönliche Interessen zu kaschieren; bei den Exekutoren der Strafe im Namen der Allgemeinheit aber um wirklich tragisch erhabene Figuren, deren "Größe" sich gerade in der Tatsache erweist, dass sie dem Gesetz opfern, was ihnen 
persönlich nahe steht. Die Strafe wäre damit die Synthese; die Rache die Antithese zum Verbrechen Věrnostas/Lazars, der These, die dialektisch überwunden wird.

Das Drama lässt zumindest diese drei Lesarten zu: die hegelianische dritte Lesart, die mit der ersten Lesart verwandt ist, wird von Klosová in den DčD III angedeutet. Allerdings sind die Verweise Klosovás darauf, dass Kolár mit dem Drama Monika seine Hegel-Rezeption dramatisch verarbeitet hätte, sehr kursorisch und überdies - was die historische Wahrheit bzw. die Textverweise betrifft - schlichtweg falsch. ${ }^{194} \mathrm{Hegel}$ ist nun tatsächlich als Rechtsphilosoph der Auffassung, dass die Gerechtigkeit das "Gleichgewicht“ herstellen muss, das durch das Tun eines Einzelnen zwangsläufig gestört wird. Die Gerechtigkeit realisiert sich im menschlichen Recht, das das „Allgemeine“ wieder herstellt, aber auch in der Rache des Einzelnen (vgl. Hegel III/340f). Bei Hegel selbst entspricht die Strafe durch das Gesetz der Rache, nur dass letztere eine weniger vollkommene Form der Gerechtigkeit ist als das allgemeine Gesetz. Bei der Rache sieht der Einzelne sein Wesen bzw. Fürsichsein als vom anderen verletzt oder zerstört an, er "repariert" die Verletzung, indem er "pariert“ und als Handelnder das Wesen des anderen aufhebt. Die Strafe beruht demgegenüber auf der Allgemeinheit der Gesetze, die als überindividuelle Institution die einzelne Verletzung eines Wesens durch einen anderen ebenfalls repariert: die strafende Allgemeinheit allerdings "pariert" nicht (sie steht auch nicht auf einer Ebene mit dem Täter), sie „belehrt“ den Täter über den Verstoß, der er begangen hat, indem sie ihm denselben Verstoß angedeihen lässt:

Die Strafe, die vollstreckt werden muss, ist keine Rache, d.h. keine besondere Handlung, die der besonderen Handlung des Unrechts entgegengestellt wird. Die Strafe ist auf die Wiederherstellung des allgemeinen Rechts gerichtet, d.h., ihr Ziel ist es, den besonderen Willen des Täters, der im Unrecht dem allgemeinen Recht widerspricht, wieder zur Allgemeinheit des Rechts zu führen. (Cobben 2006, 379)

Sterbend erklärt Monika, den für Hegel wichtigen Unterschied von Rache und Strafe erkannt zu haben, der in der Allgemeinheit des Rechts besteht, das die Partikularität der Rache übersteigt (vgl. Hegel VII/\$\$103 bzw. 197).

194 So behauptet Klosová (vgl. 1977b, 27) leichterhand, dass Hegel in der Phänomenologie des Geistes drei Stufen des Selbstbewusstseins anhand von Goethes Faust, Schillers Räubern und Brachvogels Narziß analysiert hätte. Abgesehen davon, dass es in der Phänomenologie natürlich keine solchen Analysen gibt - das einzige Zitat aus Faust steht in anderem Zusammenhang, die Räuber kommen gar nicht vor -, passt der Bezug auf Albert Emil Brachvogels Narziß schon zeitlich überhaupt nicht. Narziß erlebte seine Uraufführung 1856, Brachvogel war Jahrgang 1824, die Phänomenologie des Geistes erschien aber schon 1807! Sachlich näher liegend wäre ein Verweis auf die Vorlesungen über die Ästhetik (in den 1820er Jahren entstanden) gewesen, wo immerhin die Räuber und Faust im Zusammenhang mit der Herausbildung moderner Subjektivität angeführt werden (vgl. Hegel XV/557). 
In Lazar/Věrnosta hat Kolár überhaupt das Unrecht dadurch pointiert personifiziert, als dieser ja nach seinen Verbrechen zum höchsten Repräsentanten der Rechtsordnung aufsteigt, unter deren Titel er die Verbrechen verübt hat. Insofern Věrnosta/Lazar als rein negative Figur gilt, kann die Negativität metonymisch auch auf die von ihm vertretene Rechtsordnung - also diejenige der Habsburger, die mit der Verneuerten Landesordnung von 1627 Böhmen rekatholisiert und an den Wiener Hof gebunden haben - bezogen werden.

Kolárs Monika irritiert dadurch, dass die Ausführenden der Rache und des Gesetzes jeweils nur in Einzelpersonen repräsentiert sind, die „Allgemeinheit“ des Gesetzes, die in den Figurenreden behauptet wird, aber nie demonstriert wird. Dadurch kann der Anschein entstehen, dass Lazars/Věrnostas Berufung auf die Allgemeinheit dieselbe ist wie diejenige Benedikt/Lamberts, wenngleich diese Parallele keine Gleichsetzung ist: Vielmehr scheint Kolár mit einer solchen Parallelisierung von Berufungen auf die Allgemeinheit eher den Unterschied hervorheben zu wollen, der nur bei oberflächlicher Betrachtung übersehen wird. Auch wenn die vorgeführte Fabel aus Opfern Täter werden lässt und diese wieder Opfer werden (das Opfer Monika wird Rächerin, letztlich aber von ihrem Vater getötet), so soll damit keine Identität von Tätern und Opfern vorgeführt werden. Die Schlussworte von Benedikt/Lambert heben ja gerade hervor, dass zwar beide sterben müssen die Schuldigen wie die Unschuldigen - dass aber dies nicht als Nivellierung der Unterschiede aufgefasst werden dürfe, vielmehr sei der Tod eine „Arznei“ für die Wunden den Menschheit. Die „Heilkraft“ dieser Arznei zu erkennen, erfordert freilich einige interpretative Langmut, da ja die Tragik des Todes „Unschuldiger“ dominant erscheint. Das in der Handlungsentwicklung stark analytisch konzipierte Stück - dessen Dramatik ja großteils darauf beruht, dass die Identitäten der Figuren und deren in der Vergangenheit liegende Taten offenbar werden - bedarf einer distanzierten Analyse, um nicht als Stück zu gelten, das wichtige begriffliche Unterschiede wie Opfer und Täter, Verbrechen, Rache und Strafe im Milieu einer Familie aufhebt.

Und doch ist dieses familiäre Milieu wahrscheinlich ideologisch signifikant. Anhand der blutigen Handlungen innerhalb ein und derselben Familie soll wohl auch metonymisch auf die konfessionelle Spaltung der Tschechen aufmerksam gemacht werden, die mit der Niederschlagung des Ständeaufstandes 1620 virulent wurde. Kolár zeichnet zwar Věrnosta/Lazar als Quelle des Unrechts, der Umstand aber, dass Monika und Věrnostas Sohn Odolan ein „überkonfessionelles“ Paar bilden und die private Rache Monikas von Odolan selbst wie auch von Benedikt/ Lambert missbilligt wird, kann aber derart interpretiert werden, dass Verbrechen nur im Namen einer höheren Allgemeinheit als im Namen der Familie oder Glaubensgemeinschaft geahndet werden soll. 
IV.4.10. Ferdinand Břetislav Mikovec: Zábuba rodu Přemyslovského. Tragédie ve ćtyrech jednánich (1848)

[Der Untergang des Přemyslidengeschlechts. Tragödie in vier Akten; UA. 9. Jänner 1848, publ. 1851]

Ferdinand Břetislav Mikovec' (1826-1862) Tragödie Zábuba rodu Premyslovského möchte eine Tragödie nach dem Muster Shakespeares sein. Bei seiner Premiere galt das Stück als Sensation; wegen einer deutlich erkennbaren Tendenz gegen den Adel und gegen Deutsche wurde es 1853 verboten (vgl. Klosová 1977b/DčD III, 13). Sein Autor wählte den Vornamen Břetislav (vgl. Štěpáneks Stück) wohl deshalb, um seine Identifikation mit der tschechischen Bevölkerung auszudrücken - er war zweisprachig und verkehrte in beiden Milieus, die sich in den 1840er Jahren immer stärker voneinander zu unterscheiden begannen (vgl. Petrbok 2010, 7f).

Das Stück zeigt den Untergang des letzten Přemysliden, Václav III., der einer Intrige zum Opfer fällt. Václav war unglücklich mit der polnischen Prinzessin Viola verheiratet worden, vom Papst erhält er die Erlaubnis zur Scheidung, somit möchte er nun Jarmila heiraten. Bislang hat er sich nur inkognito mit Jarmila getroffen; als seine königliche Identität preisgegeben wird, verflucht ihn Jarmilas Vater Přech, der als letzter Nachfahre der Vršovci gelobt hat, sich an dem Přemysliden Václav für das während der jahrhundertealten Feindschaft zwischen den Geschlechtern entstandene Leid zu rächen. In Anbetracht der an blutigen Konflikten der beiden Familien reichen Vorgeschichte möchte Václav mit der Heirat die Versöhnung einleiten. Dies gelingt ihm jedoch nicht, weil Přech bei allem Respekt für Václav als Herrscher Rache für seine Vorfahren geschworen hat und obendrein Kunrád von Pottenštejn, ein enger Vertrauter Václavs, der ebenfalls Interesse für Jarmila hat, intrigant die unversöhnliche Rache Přechs provoziert. Diese alte Feindschaft zwischen den Přemysliden und den Vršovci wird von den Adeligen für ihre Intrige ausgenutzt. Kunrád von Pottenštejn und Bavor Strakonický - ersterer kommt aus Thüringen, der zweite wird zwar als Tscheche bezeichnet (IV/2), der Name Bavor lässt aber „Bayern“ assoziieren - zeichnen sich durch besonders abgefeimte Machenschaften aus. Nachdem Kunrád von Pottenštejn maskiert Jarmila rauben wollte und daran von Václav gehindert worden war, erzählt er Přech, Václav habe Jarmila rauben wollen und er habe dies verhindert. Als Václav erkennt, dass Kunrád der Räuber Jarmilas war, verstößt er ihn. Kunrád sucht unter den von Václav in die Schranken gewiesenen Adeligen Verbündete und führt diese mit Přech zusammen. Jarmila erfährt von dem Mordplan an Václav, den ihr Vater Přech, Bavor Strakonický und Pottenštejn fassen. Václav ignoriert jedoch alle Warnungen vor einem Verrat in den eigenen Reihen. In Olmütz schließlich wollen die Adeligen Václav erledigen. Da sich Jarmila die Gewänder Václavs angezogen hat, tötet Přech seine eigene Tochter; nachdem er dies erkannt hat, verübt er Selbstmord. Kunrád z Pottenštejn ersticht den schlafenden 
Václav, Bavor Strakonický gibt am Schluss gegenüber den Gefolgsleuten Kunrád als Königsmörder an, sodass dieser in flagranti erstochen wird.

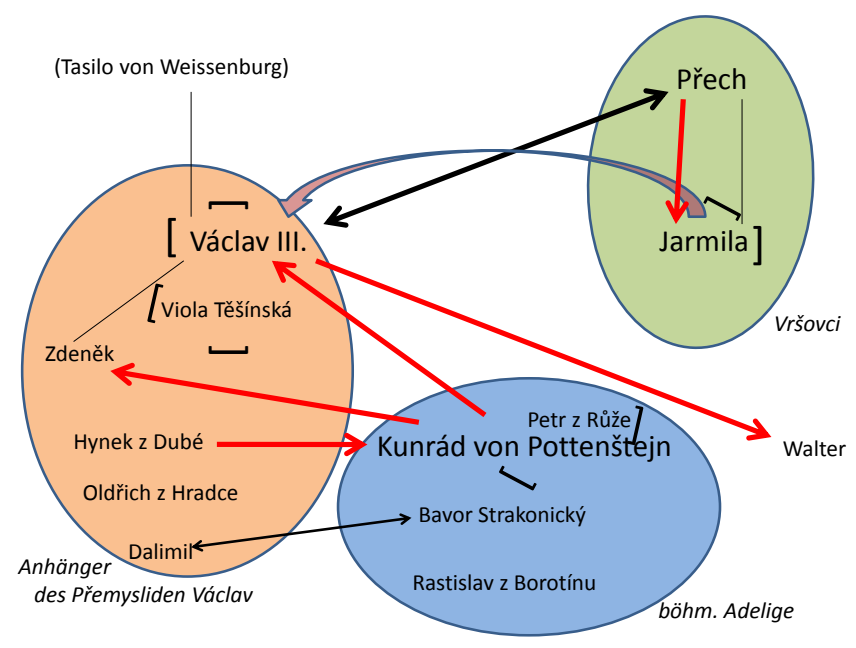

Graphik 13 - Ferdinand Břetislav Mikovec: Zábuba rodu Přemyslovského (1848)

Das blutige Ende der Tragödie erinnert an Lukács' Feststellung, dass der tragische Untergang der Heldenfigur in der Tragödie eher nicht als pessimistische Konsequenz aus der Handlung aufgefasst werden soll, sondern mit ihm eine Erhöhung des Helden verbunden ist (Lukács 1965, 118f). Václav scheitert bei seinem großen Versuch, Böhmen neu aufzubauen und stark zu machen. Statt des Adels baut er auf das gemeine Volk, welches er - wie übrigens auch die Juden - vor adeliger Willkür und Selbstsucht schützen möchte. Gleichfalls möchte Václav die alte Feindschaft mit den Vršovci begraben, indem er Jarmila zu heiraten beabsichtigt und ihrem Vater Přech das zweithöchste Amt in Böhmen anbietet. Eigentlich hält Přech Václav für einen klugen und umsichtigen König und würde ihn auch als Schwiegersohn akzeptieren, allein das Rachegelöbnis verbietet ihm eine versöhnliche Haltung.

Beide Vorhaben Václavs werden vom Egoismus seiner adeligen Gegner bekämpft, die allein ihr Standesinteresse und ihre Willkür behaupten wollen. Dies zeigt sich etwa in der Szene III/2, in welcher Václav seinen Vertrauten Kunrád mit einem Lehen beschenkt, das er einem anderen Adeligen, Rastislav z Borotinu, wegen dessen Grobheiten gegenüber einem Untergebenen entzogen hat. Die Adeligen protestieren zuerst gegen diese Schenkung mit dem Argument, Kunrád sei Deutscher und kein böhmischer Ritter. Als Václav dann kurzerhand Kunrád zum Ritter schlägt, beim dritten Ritterschlag aber erkennt, dass dieser der Räuber Jarmilas war, 
verjagt er ihn. Nun protestieren die Ritter deswegen, weil Václav einen der ihren aufgrund der drei Schläge erkennen sie Kunrád schon als Ritter an - beleidigt hat und planen einen Anschlag auf Václav. Als die als Knappe verkleidete Jarmila diesen vereiteln will, zwingen sie die Ritter zum Gelöbnis, Václav nicht zu warnen. Diese weigert sich zuerst, gelobt dann jedoch überraschend, Václav mit keinem Wort zu warnen.

Im Drama werden Gelöbnisse und Schwüre (allgemeiner formuliert: vertragliche Bindungen) in Frage gestellt: Diese Bindungen verpflichten zu einem Handeln, dessen Motivation in der Vergangenheit liegt, das unter den gegenwärtigen Umständen aber unangemessen wirkt. So erklärt auch Přech, dass er eigentlich nicht gegen Václav vorgehen möchte, sein Gelöbnis sei freilich heilig: „Odpust, předrahá! Jak bych tomu chtěl, jinak mi nelze konat./ Pomsta svatá, přísaha je nejsvětějusis “ ${ }^{195}$ (IV/5). Das Handlungsgefüge lässt auch in weiteren Aspekten die Fragwürdigkeit von rein symbolischen Ordnungen deutlich werden, die sich u.a. in Familienzugehörigkeiten und Schwüren, in der sozialen Hierarchie allgemein äußern. Die Liebe Václavs zu Jarmila ging über ein Jahr dahin, ohne dass sie von der königlichen Position ihres Verehrers wusste, sodass Václav mit Recht annehmen darf, dass sie ihn selbst und nicht die Krone liebt (vgl. I/5). Die Person des künftigen Schwiegersohns gefällt auch Přech, solange er nichts von dessen Herkunft weiß. Ähnlich widersinnig erscheint Václavs Ehe mit Viola; die päpstliche Erlaubnis, dieses Bündnis zu lösen, wird von Václav freudig begrüßt, der sich über Traditionen hinwegsetzt, sobald diese unangemessen erscheinen (Václavs Gegner hingegen beharren auf alten Rechten oder Verpflichtungen).

Der Schwur, Václav vor dem Anschlag nicht zu warnen, den Jarmila nach einer "göttlichen Eingebung" leistet, erscheint dramaturgisch zwiespältig: einerseits hat ihr entschlossenes Handeln und ihre Verkleidung den endgültigen Untergang der Vršovci zur Folge, da mit ihr und ihrem Vater dieses Geschlecht erlischt, andererseits könnte man einwenden, dass sie Václav auch noch einmal hätte warnen können: damit hätte sie den Schwur gebrochen (und auf ein Weiteres die im Stück feststellbare Kritik an alten Bindungen fortgesetzt), das Leben Václavs und ihr eigenes wären vielleicht aber erhalten geblieben. Jarmilas Handeln entspricht also völlig dem hegelschen Ideal des Tragischen: der Untergang der einzelnen Person unterstreicht die überindividuelle geschichtliche Wirkmächtigkeit der Idee, die in diesem Zusammenhang im Zusammenhalt der Tschechen besteht.

Jarmila vollzieht mit ihrem Verhalten spiegelbildlich die gleiche Bewegung wie Václav: auch sie möchte die alte Feindschaft zwischen den Geschlechtern überwinden, sie wechselt auf die Seite Václavs, was bildlich dadurch zum Ausdruck kommt, dass sie - verkleidet - zu Václav wird. Der Dolchstoß, der ihm hätte gelten sollen,

195 „Vergib mir, meine Teure! Wenn ich es auch anders wollte, anders darf ich nicht handeln. / Die Rache ist heilig, das Gelöbnis ist am heiligsten!“ 
aber die eigene Tochter traf, impliziert mit der angedeuteten „Identität“ von Václav und Jarmila die Idee der Einheit der beiden Geschlechter: Die Auslöschung des Geschlechts der Přemysliden ist faktisch die Auslöschung des eigenen Geschlechts (der Vršovci) bzw. überhaupt - in allegorischer Interpretation - die Auslöschung der Tschechen.

Im äußeren Kommunikationssystem soll die nationale Einheit der Tschechen als Wert vermittelt werden. Dass Přech gegen die Versöhnung der Geschlechter kämpft, ist nur ein vordergründiges dramaturgisches Moment, denn er erklärt ja wiederholt, mit der Verbindung von Václav und Jarmila und überhaupt mit der Politik Václavs einverstanden zu sein; als die eigentlichen Widersacher der böhmischen Einheit erscheinen in Zábuba rodu Premyslovského vor allem die deutschen Adeligen, wobei alle Adeligen des Landes als arrogant gezeichnet sind: Die deutschen Adeligen spinnen nicht nur die verhängnisvolle Intrige, von ihnen geht auch sonst verderblicher Einfluss aus (so wird im ersten Akt der soeben verstorbene Tasilo von Weissenburg als Vertrauter und Freund des Königs charakterisiert, der Václav mit vergänglichen Zerstreuungen davon abhielt, das Herz des Volks zu gewinnen. Nach dem Tod Tasilos hingegen entspricht Václav den Idealvorstellungen vom Fürsten.)

Das Publikum bei der Uraufführung im Jänner 1848 soll die depräsentierenden bzw. zeitbezogenen Elemente des Dramas - die nationale Schwäche durch Uneinigkeit sowie Unmut gegenüber den arroganten Deutschen - deutlich verstanden haben. Im Jahre 1853 wurde die Spielerlaubnis vom Polizeidirektor Leopold von Sacher-Masoch (dem Vater des nachmaligen Autors von Venus im Pelz) entzogen, weil darin ein Anschlag auf den Herrscher gezeigt werde, der Adel schlecht wegkomme und Deutsche in ungünstigem Licht erscheinen - diese Maßnahme wurde nach dem Attentatsversuch auf Franz Joseph I. getroffen und erst 1861 im Zusammenhang mit der Verfassung aufgehoben (vgl. Petrbok 2010, 18f u. 31f; Pokorná 2015, 409).

Als persona dramatis tritt in der Tragödie auch der Chronist Dalimil auf, dessen Arbeit Václav schätzt. Einige Zitate aus der alttschechischen sogenannten Dalimil-Reimchronik vom Beginn des 14. Jahrhunderts, deren Autorschaft ungeklärt ist (die Zuschreibung der Autorschaft an Dalimil wurde beibehalten, aber durch „sogenannt“" gekennzeichnet), werden dieser Figur in den Mund gelegt, die im Drama nach Meinung von Václav den wahren Kern aller Handlungen ausspricht und der Nachwelt überliefert. Mit dieser Repräsentation von Dalimil - die 1848 bereits als historischer Fehler gelten musste, widerlegte doch Josef Dobrovský die vermeintliche Autorschaft eines Dalimil Meziřičský (vgl. Kutnar/Marek 1997, 33) - unternimmt Mikovec eine Quasi-Authentifizierung der von ihm repräsentierten dramatischen Ereignisse. Eigentlich aber handelt es sich dabei um eine Zirkelbewegung: Zumal anzunehmen ist, dass die alttschechische Reimchronik Mikovec den historischen Stoff geliefert hat, soll die Repräsentation ihres vermeintlichen Autors im Drama und ihre Charakterisierung als „objektive“ Chronistenfigur gleichzeitig 
wohl auch dem historischen Drama Mikovec' Authentizität bzw. Objektivität verschaffen. Nun gilt gerade diese Reimchronik heutzutage als besonders tendenziös, was das Zusammenleben der Deutschen und Tschechen betrifft. Der Chronist des 14. Jahrhunderts erklärte alles Fremde, insbesondere alles Deutsche, das damals unter Förderung der letzten Přemysliden in die böhmischen Städte strömte, für gefährlich und dem Wohle der Tschechen abträglich. ${ }^{196}$ Mit der Repräsentation des Chronisten und seiner Apotheose als objektiver und das Wesen der Handlung erfassender Zeitzeuge positionierte sich Mikovec wohl dezidiert in der nationalpatriotischen Tradition, wie sie prominent von der sogenannten Dalimil-Reimchronik vertreten wurde. „Dalimil ist unverkennbar antideutsch eingestellt und weist größtenteils Züge eines extremen Nationalismus auf." (Pynsent 1999, 226) ${ }^{197}$ Zábuba rodu Přemyslovského liefert eine historisierende Darstellung des verderblichen Einflusses von Deutschen auf das Zusammenleben der Tschechen und den Versuch ihrer nationalen Einigung, wie auch Haman (vgl. 2007, 239f) feststellt.

\section{IV.4.11. Josef Kajetán Tyl: Krvavý soud aneb Kutnohorštti haviríi. Činohra v pèti jednánich (1847)}

[Blutgericht oder Die Knappen von Kutná Hora; Schauspiel in fünf Akten; UA 24.4. 1848, publ. 1848]

Das im Jahre 1493 während der Herrschaft des Polenkönigs Vladislav II. angesiedelte Drama spielt im Milieu der Bergknappen von Tyls Heimatstadt Kutná Hora, die unter der Ausbeutung durch ihre Herrschaft, die Bergherren, zu leiden haben. Die Zensurbehörde sah im Drama die Darstellung der „Unterdrückung des Volks, gewaltsame Aufstände und den überstürzten Einsatz von Waffengewalt" (vgl. Otruba/Kačer 1961, 293) und verbot das Stück; wegen der Veränderungen im Revolutionsjahr 1848 konnte es aber aufgeführt und gedruckt werden, die Ereignisse

196 Aufgrund ihrer antideutschen Tendenz galt diese Reimchronik in Zeiten ethnischer bzw. nationaler Differenzen als brisant, so wurde die Auflage der kurz vor der Schlacht am Weißen Berge gedruckten Ausgabe von Pavel Ješín von den Habsburgern verbrannt, die Wiener Regierung untersagte in den 1830er Jahren Václav Hanka (dem mutmaßlichen Fälscher der beiden Handschriften, die in Zelená Hora und Dvůr Králové „gefunden“ wurden) eine weitere Übersetzung ins Neutschechische (1786 erfolgte eine erste Übersetzung) (vgl. Kutnar/ Marek 1997, 37). Die Hanka untersagte Neuausgabe konnte erst 1849 - nach der Uraufführung von Mikovec' Drama, das also mit Dalimil eine subversive Person affirmiert - erscheinen (vgl. Pynsent 1999, 201).

197 Die Dalimil-Chronik wurde bezeichnenderweise immer nach nationalen Umbruchsituationen erneut herausgegeben, etwa 1920 oder unmittelbar nach dem kommunistischen Putsch 1948. Pynsent weist darauf hin, dass der tschechische Literaturhistoriker Albert Pražák die Vertreibung der Sudetendeutschen 1945 unter dem Titel „Národ se bránil“ als Erfüllung von Dalimils politischem Programm affirmierte. 
im Revolutionsjahr waren aber einem Theatererfolg abträglich, im Ständetheater wurde das Stück nur einmal gespielt. ${ }^{198}$ Der 1848 noch vor der Uraufführung erfolgte Erstdruck des Stücks gilt als erster Druck in Österreich, der ohne Einflussnahme der Zensurinstanzen durchgeführt wurde (vgl. Ježková/Ludvová 2013, 81).

Die offiziöse marxistische Literatur- und Theaterwissenschaft der Tschechoslowakei nach 1948 hat Tyl zum volksnahen Kämpfer für das arbeitende tschechische Volk stilisiert, der mittels Kunst zu dessen Befreiung beitragen wollte. Demnach sollten für Tyl Literatur und Theater patriotische und demokratische Ideale vermitteln und vom Leiden und den Hoffnungen des tschechischen Volks Zeugnis ablegen. Insbesondere Kutnohorští haviri gilt aufgrund des Bergknappenmilieus als eine auch im europäischen Vergleich einmalig frühe Thematisierung sozialer Probleme (vgl. Novák/Novák 1936-1939, 426; Hájek 1951, 204f; Otruba/Kačer 1961, 294f). Dass die Vereinnahmung von Tyls Drama nicht zuletzt auch der sozialistischen - und zugleich patriotischen - Historiographie (vgl. die im Band Živý odkaz J.K. Tyla 1952 versammelten Beiträge) zuzuschreiben ist, wird auch daraus ersichtlich, dass die ursprüngliche Widmung Tyls aus der Erstausgabe von 1848 in der Ausgabe von 1951 ins Kleingedruckte des kritischen Apparats gerückt wurde. Die Widmung an den Prager Bürger Václav Veith, der wohl dem Adelsstand angehört - Tyl nennt ihn den „Herren“ von Kolín, Klenov, Mlázov und Žikov - ist zeittypisch pathetisch gehalten: „Spanilomyslnému příznivci všeho národního snažení na důkaz hluboké úcty. ${ }^{199}$ Der soziale Stand des Widmungsträgers und seine von Tyl hervorgehobenen Verdienste um den Böhmischen Industrie-Verein vertragen sich schlecht mit der propagierten Lesart als klassenkämpferisches Arbeiterdrama.

Neben der sozialkritischen Lesart, die allzu offensichtlich naheliegt, wurde aber auch auf andere originelle Aspekte dieses Dramas hingewiesen: So fiel schon Jan Máchal $(1903,770)$ auf, dass anstelle einer zentralen Heldenfigur eine soziale Gruppe im Mittelpunkt einer historischen Tragödie steht, aufgrund des Handlungsaufbaus im Rahmen der klassischen fünfaktigen Konstruktion gilt Kutnohorští havirí für Otruba/Kačer (vgl. 1961, 304) und Dušan Jeřábek als eines der wenigen gelungenen historischen Dramen des 19. Jahrhunderts (vgl. Tureček 2007, 53).

Der junge Knappe Šimon erklärt gleich zu Beginn, als die Kumpel über den niedrigen Lohn klagen, dass man sich die Behandlung durch die Bergherren nicht gefallen lassen dürfe. Zugleich aber ist man sich des Umstandes bewusst, dass es einen Widerspruch zwischen Wort und Tat gibt; es wird mehr geklagt und gejammert, als tatsächlich gegen die Missstände unternommen. So erklärt etwa Šimon:

198 In der Theaterkritik von Ferdinand Břetislav Mikovec wird berichtet, dass vor der Aufführung des Stücks aus Anlass des Geburtstags von Kaiser Franz Joseph I. gemeinsam die Kaiserhymne gesungen wurde. Mikovec zeigt sich weder vom Stück noch von der Aufführung angetan (vgl. Mikovec 2010, 126).

199 „Dem vornehm denkenden Förderer völkischer Anstrengungen im Ausdruck tiefer Ehrerbietung." 
"Jen abychom mluvením nezabili, co chce být živo jednáním. ${ }^{200}$ Opat, der Älteste der Kumpel, müsse nur eine Rebellion gutheißen, dieser aber zögert. Ein Zwist in der Heimat („domácí různice“ - I/2, S. 123) wird von ihm gefürchtet. Seine Tochter Anežka wird von Bergmeister Hynek, dem Sohn des Beneš z Vaitmile (auch Vaitminar genannt) verehrt. Hynek hat Anežka vor der Vergewaltigung durch einen polnischen Adeligen bewahrt. Vít, der ebenfalls Anežka begehrt, wirft Opat vor, aus opportunistischen privaten Gründen - um seine Tochter Anežka mit der Herrschaft zu verheiraten - eine Rebellion gegen Vaitminar zu unterbinden. Dieser zweigt - so die allgemeine Auffassung unter den Bergleuten - das Silber in die eigene Tasche ab, anstatt es an den König abzuliefern. Opat verbietet Anežka, Hynek weiter zu treffen („[...] posilni se myšlénkou, že nesmíme přáteliti s krví našeho úhlavního odpovědníka - že se tomu vzpírá naše občanská povinnost. ${ }^{“ 201}-\mathrm{I} / 3$, S. 124). Anežka hält Hynek für untadelig, er hat in ihren Augen nichts mit dem Unrecht zu tun, der Standesunterschied wäre kein unüberwindbarer, weil ihr Herz und ihre Gunst jedem Mann als erstrebenswertes Ziel erscheinen müssten. Anežka fügt sich widerstrebend in das Verbot, Hynek zu sehen. Als Opat Hynek dieses Verbot mitteilt, begründet er es nicht allein mit dem Standesunterschied und dem Verhalten von Hyneks Vater Beneš gegenüber den Bergleuten, er erzählt auch, dass er einst gegen Beneš z Vaitmile/Vaitminar aufgetreten ist und dessen Berufung zum Münzmeister verhindern wollte. Wenn Hynek bei seinem Vater eine Veränderung im Verhalten erreichen könnte und die Bergleute endlich wieder fröhlich sein könnten, dann werde er in Opats Haus willkommen sein. Hynek verspricht, mit seinem Vater zu sprechen, das Bild von Anežka werde immer sein Leitstern sein. Opat ist aber pessimistisch über den Ausgang des Gesprächs, aufgrund von Beneš Charakter und der Stimmung unter den Knappen werde es zu einer Eskalation kommen müssen.

Der zweite Akt zeigt zuerst das Milieu der Bergherren. Der Schreiber Rekordat berichtet von der Zufriedenheit der Bergherren mit dem Ertrag, der ihnen aufgrund von Beneš Vaitminars Praktiken zufällt. Von Rekordat erfährt Beneš zugleich auch von der Unzufriedenheit der Kumpel. Beneš möchte diese jedoch weiter darben lassen; sie werden sich schon nicht erheben. Rekordat erzählt nun, dass die Knappen in Hynek Vajtminar ihren Fürsprecher haben, der sich in Opats Tochter Anežka verliebt hat, nachdem er sie vor der Vergewaltigung rettete. Als Hynek seinem Vater die Liebe zu Anežka bestätigt, fordert Beneš, dass er Anežka schände und erniedrige. Hynek erschrickt ob dieser Forderung und weist sie mit dem Hinweis auf die Gerüchte über Beneš Veruntreuung zurück. Die Erwartungen und Forderungen seines Vaters lehnt er ab, er steht auf Seiten der Knappen (II/2). Nachdem Rekor-

200 [Šimon:] „Dass wir nur nicht durch Reden töten, was durch Handeln lebendig werden soll!"

201 [Opat:] „[...] stärke dich am Gedanken, dass wir nicht mit dem Blut unseres Hauptfeindes Freund sein dürfen - dass sich unsere bürgerliche Pflicht dagegen stellt.“ 
dat Beneš gemeldet hat, dass die Knappen in die Stadt ziehen, lässt dieser alle Tore schließen und die Wache bewaffnen. Die Situation spitzt sich zu. Beneš möchte das niedrige Volk wie eine Giftschlange zertreten (II/3). Unter den Knappen gibt es Meinungsverschiedenheiten zwischen dem radikaleren Flügel um Vít und Šimon und dem gemäßigteren um die Familienväter Holý und Lana, die meinen, man solle eher auf Verhandlungen statt auf Gewalt setzen. Als der ängstliche Kroupa im Namen des Richters vor den Knappen spricht und sie zur Ruhe auffordert, wird er ausgelacht. Hingegen respektieren sie Opat eher, der sich besorgt zeigt und ebenfalls einem Aufstand wenig abgewinnen kann, fürchtet er doch eine Eskalation und große Unruhe, den Krieg im eigenen Haus (Opat: „Pamatuj, že je veliký rozdíl mezi tím, jak spravedlivý člověk práva svého hájí, a mezi tím, jak se běsný pes ze řetězu utrhne!" 202 (II/6, S. 141) Opat meint, wenn Verhandlungen nichts fruchten, solle man zu König Vladislav schicken, der ihnen hoffentlich gewogen sein werde (II/6). Hynek kommt hinzu, wird von einigen freundlich begrüßt; er möchte die Kluft zu den Bergherren überbrücken, indem er vorschlägt, zu diesen eine Gesandtschaft zu schicken. Vít ist skeptisch und weigert sich, daran teilzunehmen. Opat überlegt, ob er mitgehen soll, da er seit dem Konflikt mit der Einsetzung von Beneš diesen nicht gesehen hat. Schließlich geht er hoffnungsfroh mit Lana und Šimon zu den Bergherren, was Vít heftig missbilligt.

Die Gesandten werden von Beneš im Vlašský dvůr in Geiselhaft genommen, obwohl ihnen Hynek freies Geleit versprochen hat. Vít, der ja ebenfalls ein Auge auf Anežka geworfen hat, legt dies als List aus, Anežka hingegen möchte Beneš bitten, die Gesandten freizulassen, sie meint, dass Beneš der Bitte nachgeben werde, wenn sie als Tochter Opats diese vorträgt. Vít fürchtet um sie, lässt sie aber gehen. In ihren Augen fällt mit jedem ihrer Schritte ein Dorn aus der Dornenkrone, die dem unschuldigen Opat auf die Stirn gedrückt wurde. ${ }^{203}$ Beneš braucht die Unterstützung von Bewaffneten, um die Ordnung aufrechtzuerhalten, er ist zu keinerlei Verhandlungen mit den Gesandten der Knappen bereit. Hynek allerdings hat inzwischen die Gesandten wieder freigelassen, weil er nicht wortbrüchig erscheinen wollte. Damit widersetzt er sich seinem Vater Beneš endgültig. Dieser beabsichtigt, seinen Sohn, Anežka und Opat dadurch zu erniedrigen, dass er Anežka zu einem Schandmarsch durch Kutná Hora zwingt. Hynek möchte sie zwar davor mit dem Schwert bewahren, Anežka unterzieht sich dem Schandmarsch aber freiwillig, um Hynek zu beschützen.

202 [Opat:] „Denk daran, dass es einen großen Unterschied ausmacht, wenn ein gerechter Mensch seine Rechte verteidigt, und wenn ein wütender Hund sich von seiner Kette losreißt!"

203 [Anežka:] „[...] a každým kročejem opadne trn z bodavého věnce, kterýž mému otci na nevinné čelo vtlačili.“ („[...] und mit jedem Schritt fällt ein Dorn aus der Dornenkrone, die sie meinem Vater auf die unschuldige Stirn gedrückt haben.“ - III/2, S. 149) 
Als Opat und Vít die Schandprozession mit Anežka sehen, erkennen sie den Starrsinn und die Härte von Beneš. Sogar die Soldaten, die die Prozession begleiten, leisten wenig Widerstand, als Vít und Opat sich Anežka nähern. Rekordat, der den Befehl von Beneš ausführt, rät vom Appell an den König ab. Opat ist nun entschlossen: „Potrhaný bud'tež úvazky tiché pokory a ochotného poslušenství, jakož je porušeno právo královské a utlačeno vše milosrdenství; uvidíme, která strana toho bude litovati. ${ }^{\text {“204 }}$ (III/11, S. 163) Er will Kutná Hora, wo nur Ungerechtigkeit herrscht, nun auch verlassen, die Knappen sind bereit, ihm zu folgen.

Im vierten Akt wird die Situation nach dem Auszug der Knappen gezeigt. Beneš möchte diese wieder zurückhaben, der opportunistische Schreiber Rekordat meint, dass die 6.000 Leute, unter ihnen auch Frauen und Kinder, nicht lange durchhalten werden und aus Hunger wieder zurückkehren werden. Beneš beauftragt Rekordat, mit dem geldgierigen Oněk, dem Hauptmann aus Poděbrady, die Leute zurückzuholen. Rekordat stichelt Oněk geschickt an, er möchte zehn Tote haben als Warnung für die Zukunft. Im Lager der Knappen gibt es Uneinigkeit über den eingeschlagenen Weg. Der Knappe Holý möchte ebenso wie einige der Frauen aufgeben und zurückgehen. Die Knappen und ihre Familien haben Hunger; Dorota, die Mutter Šimons, meint, schlimmer sei aber der Verlust der Heimat. Vít, der unbedingt weiter durchhalten möchte und den Defätisten sogar mit dem Hammer droht, hält sie vor:

„Ty nevíš, s jakou bolestí se člověk s domovem loučí, protože jsi jeho sladkých zvyků nepoznal, neštastný člověče, protože jsi se od prvních let mezi cizím lidem potloukal - bez otce a bez matky! Ale kdybys byl slýchal hlasy jejich, držel by ses pevněji té půdy, kde tě matka pod srdcem a na srdci nosila."205 (IV/4, S. 172)

Opat ruft dazu auf, zurückzugehen, was von fast allen bis auf Vít freudig aufgenommen wird. Er hofft auf eine Verbesserung in Kutná Hora, eine andere Chance gebe es auch nicht. Der König ist zu weit weg, eine neue Stadt können sie nicht einnehmen. Opat hat verhandelt, ihm sind Verbesserungen verheißen worden, die Knappen müssen zehn Männer als Geiseln stellen, die dafür garantieren sollen, dass die Knappen in Zukunft Ruhe bewahren. Opat, Šimon und Lana stellen sich freiwillig zur Verfügung; Vít, der nicht daran glaubt, wieder aus der Geiselhaft bei Oněk in

204 [Opat:] „Das Bündnis stiller Demut und eifrigen Dienstes sei hiermit gelöst, zumal das königliche Recht gestört ist und alle Barmherzigkeit unterdrückt; wir werden sehen, welche Seite dies mehr bereuen wird.“

205 [Dorota:] „Du weißt nicht, mit welchem Schmerz sich der Mensch von der Heimat trennt, weil Du nicht die Annehmlichkeiten kennen gelernt hast, Du Unglücklicher! Weil Du dich seit frühesten Jahren selbst unter Fremden behaupten musstest - ohne Vater und Mutter! Hättest du aber jemals ihre Stimmen gehört, würdest Du fester an dem Boden festhalten, auf dem Deine Mutter dich unter und in ihrem Herzen getragen hat." 
Poděbrady freizukommen, willigt dennoch ein, weil alles besser sei als die Sklaverei in Kutná Hora. Anežka, die nach ihrer Erniedrigung kein Vertrauen in die Herrschaft mehr hat, ist bestürzt über den Entschluss ihres Vaters, sich als Geisel zu melden. Dieser weist den Zweifel von sich, er hat sich aus Bürgerpflicht („z občanské povinnosti“ - IV/6, S. 176) gestellt. Die Knappen stimmen das Lied an, das von der Hoffnung spricht: „Těšme se blahou nadějí, / že se vrátí zlaté časy!“206

$\mathrm{Zu}$ den erhofften Verbesserungen kommt es freilich nicht. Im fünften Akt wird sogar Beneš bewusst, dass er sich in Rekordat einen gefährlichen Helfer geholt hat. Gegenüber Hynek erklärt er, dass jetzt die Stunde der Rache gekommen sei. Beneš rächt sich dafür, dass ihn die Knappen bzw. Opat als deren Ältester nicht als Münzmeister dulden wollten, er musste zuerst ihre Sprache lernen und widerwillig den Schüler spielen. Hynek sagt sich vom Vater los, er schämt sich für seinen $\mathrm{Na}-$ men, Beneš bleibt allein und verlassen zurück. Beneš hat eine Vision von Opat, der schon vor der Hinrichtung steht, dieser warnt vor der göttlichen Gerechtigkeit, die ihn einholen wird. Beneš bricht nervlich zusammen und stirbt, während Rekordat über dessen Schwäche frohlockt. Im Namen von König Vladislav tritt unverhofft Jaroš auf, der Rekordat gefangen nimmt. Auch die Knappen kommen; sie wollen sich rächen und Genugtuung verschaffen (V/6). Rekordat verübt Selbstmord, Vít bedauert, nicht mehr selbst grausame Rache an Rekordat nehmen zu können. Jaroš verheißt im Namen des Königs, der mehr als sechs Jahre nicht in Böhmen war, Gerechtigkeit und Ordnung, was von den Knappen und Vít begrüßt wird. Hynek und Anežka können nach dem Vorgefallenen nicht mehr zusammenkommen. Anežka erklärt, dass sie ins Kloster geht, Hynek will fern der Heimat das Vergessen suchen und verabschiedet sich bedauernd von seiner Liebe. Vít kommt und berichtet von seiner Flucht; der Auftrag Opats, Anežka ein letztes Mal grüßen zu lassen, hat ihn hergeführt. Er fragt Anežka, ob er sie auf immer beschützen dürfe, sie weist dies zurück; in der letzten Szene wird sie von zwei Nonnen abgeholt. Eine Totenglocke für die Knappen ertönt, auch Vít bittet Gott, dass er ihn bald zu den hingerichteten Kameraden gehen lassen möge.

In seiner prüfenden Relektüre von Kutnohorští haviři sieht Dalibor Tureček (2007) im Drama eine zeittypische Entwicklung vom nationalromantischen Drama des obrození hin zum Charakterdrama. Diese Tendenz sei nicht nur an den schon von Otruba/Kačer (vgl.1961, 298) festgestellten romantisch-shakespearschen Momenten (Verstorbener erscheint als Gespenst, Liebespaar scheitert an Familien- bzw. Standesfeindschaft) zu erkennen, sondern vor allem an der Komposition: der tragische Handlungsbogen des großen Konflikts endet mit der Hinrichtung der Knappen schon zu Beginn des letzten Akts, es folgen aber noch acht Szenen, die das innere Drama des Knappen Vít zu Ende führen, das sich nur interpretativ erschließt:

206 [Lied der Knappen:] „Freuen wir uns in der Hoffnung, dass die goldenen Zeiten wieder kommen werden!“ 
Víts bedingungslose Haltung und sein Drängen zum Aufbegehren haben letztlich dazu geführt, dass die Knappen die Stadt verlassen; der sich letztlich ebenfalls Víts Standpunkt angeschlossen habende Opat wird zusammen mit acht anderen Geiseln hingerichtet, Vít kann als einziger fliehen, um Anežka die Todesnachricht zu überbringen, die seinem nun zurückhaltenderem Werben noch immer nicht nachgibt, sodass er sich in der letzten Replik den Tod wünscht. Er muss erkennen, dass seine ursprüngliche Geringschätzung der Werte von Familie und Heim, die einen Zwist zwischen ihm und den Knappen mit stärkerer familiärer Bindung verursacht, zu dieser tragischen Entwicklung beigetragen hat. Für Tureček ist Kutnohorští havirí das am stärksten psychologisierende Drama des obrozeni:

Zdá se, že poslední replika Tylovy hry je jednou z nejpsychologičtějších replik obrozenské dramatiky vůbec. Dění významu, které se za ní otevírá, je ryze existenciální povahy a nevyčerpává se otázkami národního bytí. [...] Kutnohorští haviri přispívali k uvědomování si a pojmenovávání spletité problematiky moderní lidské existence v rozporuplném, nejednoznačném a v mnohém ohledu paradoxním světě. ${ }^{207}$ (Tureček 2007, 56)

Ohne diese Beobachtungen in Abrede stellen zu wollen, möchte ich gemäß dem in dieser Arbeit diskutierten Zusammenhang aber doch auf auf diejenigen Elemente in Kutnohorstí haviri hinweisen, die weder bei der traditionellen sozialrevolutionären Lektüre noch bei Turečeks produktionsästhetischer Analyse nähere Berücksichtigung finden: nämlich auf die ins Drama eingefalteten nationalpolitischen Momente, die im Zusammenhang mit der Figurenkonstellation besser sichtbar werden:

Der dramatische Konflikt zwischen Bergknappen und Bergherren entwickelt sich vor der schwachen bzw. abwesenden Königsmacht. König Vladislav von Polen wird von den Figuren des Dramas mehrfach als Instanz genannt, an die appelliert werden sollte, um die Ungerechtigkeit anzuzeigen. Im fünften und letzten Akt tritt zwar Jaroš auf, der als königlicher Stadthauptmann von Prag den König repräsentiert, sein Eingreifen erfolgt aber zu spät, das titelgebende „Blutgericht“ - die Hinrichtung unschuldiger Geiseln - hat schon stattgefunden. Dieses wurde bezeichnenderweise exekutiert von einem anderen „königlichen Hauptmann“, dem geldgierigen Oněk, der sich von Beneš und vor allem von Rekordat für die gewaltsame Unterdrückung der Knappen einspannen lässt. Vít erzählt in der vorletzten Szene, dass der König nach sechs Jahren Abwesenheit wieder feierlich in

207 „Es scheint, dass die letzte Replik in Tyls Stück eine der psychologisierendsten Repliken des Dramas des obrození überhaupt ist. Der Bedeutungshorizont, der sich hinter ihr auftut, hat rein existenziellen Charakter, er erschöpft sich nicht in Fragen des nationalen Lebens. [...] Kutnohorstí haviri trug zur Bewusstwerdung und zur Benennung der komplexen Problematik der modernen menschlichen Existenz in einer widersprüchlichen, uneindeutigen und in vielerlei Hinsicht paradoxen Welt bei.“ 
Prag eingezogen sei und immerhin sofort gegen den Missbrauch der Amtsgewalt durch Oněk einschreiten wollte, es sei aber auch schon in diesem Fall zu spät gewesen (vgl. V/9).

(König)

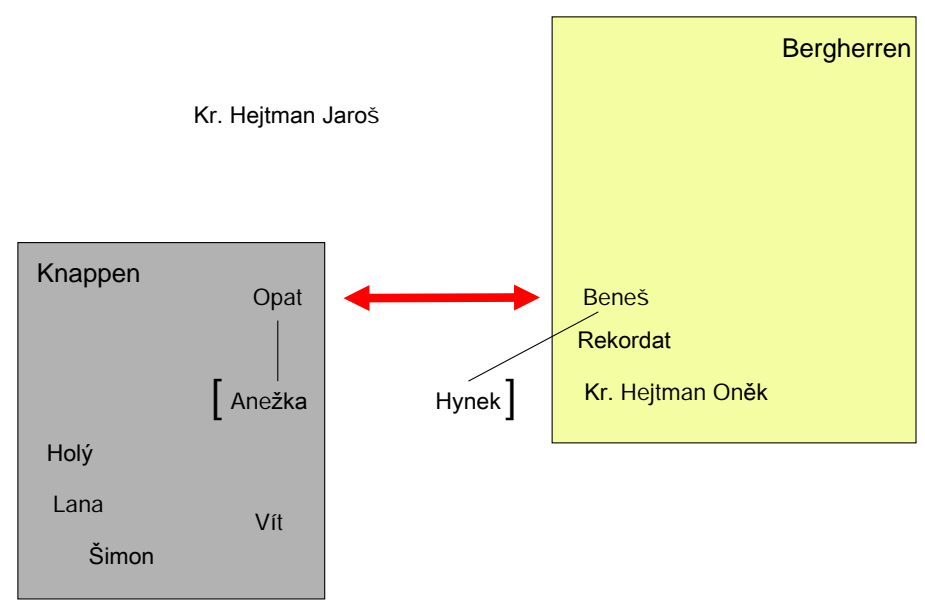

Graphik 14 - Josef Kajetán Tyl: Krvavý soud aneb Kutnohoršsti haviři (1847)

Die Abwesenheit des Königs und seiner Autorität wird in den Figurenreden zwar angesprochen, aber nicht explizit als Grund dafür thematisiert, dass die Bergherren von Kutná Hora ihre Macht missbrauchen, die Knappen darben lassen und vom gewonnenen Silber in die eigene Tasche abzweigen, anstatt es ordnungsgemäß an den König weiterzuleiten. Für die Analyse der Handlungsentwicklung ist dieser Umstand aber insofern relevant, als er den Machtmissbrauch durch die Bergherren, besonders durch Beneš z Vaitmile, ermöglicht. Ein weiteres Indiz für die im Drama ausgedrückte Kritik an der abwesenden Königsmacht besteht darin, dass Anežka in der Vorgeschichte beinahe von einem polnischen Adeligen vergewaltigt worden wäre, der sich in Sicherheit wähnte, weil er wie der König Pole ist, wie Rekordat berichtet („Pán si myslí: Král Polák, já Polák, proč bych si trochu nezadováděl?“208). Hynek hat sie gerettet und sich in sie verliebt.

Zumindest der Umstand der Beinahe-Vergewaltigung durch einen Nicht-Tschechen, der es deshalb wagt, seine niederträchtige Absichten auszuführen, weil er sich unter dem Schutz eines nicht-tschechischen Königs wähnt, trägt dazu bei, dass nach

208 [Rekordat:] „Der König ist Pole, ich bin ein Pole, warum sollte ich nicht [mit ihr, Anežka] ein paar Scherze treiben?" 
meiner Auffassung die Rolle des abwesenden Königs in Tyls Drama keineswegs eine rein positive ist, wie dies Otruba/Kačer (vgl. 1961, 300f) behaupten. ${ }^{209}$

Die Liebe zwischen Hynek und Anežka, welche die Schranken zwischen den Konfliktparteien und auch die sozialen Standesunterschiede überwinden soll, findet im Drama keine Erfüllung deshalb, weil Hyneks Vater Beneš gänzlich unbarmherzig seine Macht demonstrieren möchte. Dieses Liebespaar wird tatsächlich sehr idealisiert gezeichnet, wie bereits von der Kritik bemerkt wurde. Es entspricht wohl Tyls Idealvorstellung von allgemeiner - auch sozialer Harmonie (vgl. Otruba/ Kačer 1961, 299f). Als heterogenes Sinnelement jedoch erscheint es nur dann, wenn man wie Otruba/Kačer das Drama auf progressive sozialrevolutionäre Elemente und auf traditionelle literarische Klischees hin absucht und das Verhältnis beider Ideologeme als Widerspruch deutet, der letztlich in den Zeitumständen des Autors begründet liegt. Aus der hier vertretenen anderen Perspektive, welche die Handlungszusammenhänge der dramatischen Fabel analysiert und möglichst viele Aspekte der repräsentierten Welt in diese Zusammenhänge zu bringen versucht, ist das Liebespaar Hynek - Anežka genauso ein Element der repräsentierten Welt wie es die anderen Figuren und ihre Sprach- und Redehandlungen sind. Die Geschichte

209 Die der Doktrin der marxistischen Analyse verpflichteten Autoren begründen ihre Einschätzung, die den Zusammenhang von drohender Vergewaltigung und Königsmacht schlechthin übergeht, damit, dass der König im „Off“, also im nicht auf der Bühne darzustellenden Hintergrund der Fabel, ja doch in den Handlungszusammenhang eingreift und dem Machtmissbrauch ein Ende setzen möchte. Dies entspreche zum einen sowohl den von Palacký im Časopis českého museum 1827 (Bd I, sv.4) veröffentlichten „Výpisky z pamětí Mikuláše Dačického z Heslova“, dem einen Quellentext, der Tyl als Vorlage gedient hat, zum anderen habe Tyl, so Otruba/Kačer sehr wohl zu dieser Zeit Hoffnungen in die Königsmacht gesetzt. - Dieser Argumentation, die selbst in guter marxistischer Dialektik damit argumentiert, dass die historische „Objektivität" des Werks oft die subjektiven Absichten seines Autors übersteige, wäre entgegenzuhalten, dass in Kutnohorští haviřri Evidenzen des Textes - wie das Zuspätkommen des königlichen Eingreifens, die Abwesenheit des Königs und die hergestellte Verbindung von Königsmacht und Vergewaltigung der positiven Frauenfigur - „objektiv“ genug sind, um eine subjektive Interpretation nach dem Schema marxistischer Geschichtstheorie - die Autoren heben hervor, dass ja in den antifeudalen Aufständen des Spätmittelalters immer Hoffnungen auf die Königsmacht gesetzt wurden, wie Engels festgestellt habe (vgl. Otruba/Kačer 1961, 301) - fragwürdig erscheinen zu lassen. Otruba/Kačer behaupten, dass Tyl subjektiv ein „falsches“ - monarchenfreundliches - Bewusstsein gehabt habe, dass er aber durch seine Treue zur Quelle schon historisch-realistisch verfahren sei und eben die Hoffnungen in die Königsmacht im Drama dargestellt habe, die auch historisch belegt - und von Engels gleichsam sanktioniert - seien. Hingegen ist die hier vertretene Auffassung die, dass Tyl trotz seiner affirmativen Haltung zur Figur des Monarchen im Drama eine Situation dargestellt hat, in der die Herrschaft eines fremden - und notorisch abwesenden - Monarchen die Bedingungen für die so ungünstige Entwicklung der Ereignisse abgibt. Tyl mag als Person monarchiefreundlich gewesen sein, im Text aber erscheint die Königsmacht problematisch. 
dieses Paares (von seiner literaturhistorischen Genealogie und seiner Bestimmung als Rudiment romantischen Sentiments kann abgesehen werden) ist demnach im Fabelzusammenhang zu sehen und macht dort kein heterogenes Element aus: Da Hynek für die Bergknappen eintritt und gegen den Willen seines Vaters handelt, der die Gesandtschaft, die mit ihm verhandeln wollte, einfach gefangen genommen hat, erniedrigt Beneš Anežka, um damit auch Hynek und Opat zu treffen.

Beneš Motiv für den unversöhnlichen Hass gegen Opat besteht darin, dass Opat einst gegen ihn aufgetreten ist, als dieser zum Münzmeister des Königtums Böhmen mit dem Sitz in Kutná Hora eingesetzt wurde. Beneš Hass gegen Opat hat bezeichnenderweise eine sprachnationale Implikation: Opats Auftreten gegen Beneš lag darin begründet, dass dieser kein Tscheche war und die traditionelle Regel von Kutná Hora es erforderte, dass nur ein Tscheche Münzmeister werden konnte (vgl. II/1, S. 131f):

Beneš: Nenáviděl jsem horní čeledě - ona se mi vzpírala - když mě královská milost učinila mincmistrem - vzpírala se, že jsem nemohl k ní hned promluviti jejím jazykem jak si nestydatě smyslila - a já se musel pokořiti - žáka dělati - kletba jim! $!^{10}(\mathrm{~V} / 2, \mathrm{~S} .180)$

Betrachtet man diese Motivierung von Beneš Handeln, so werden im ständischen Kampf die nationalen Momente deutlicher: der Kampf zwischen Bergherren und Bergknappen kann somit allegorisch auch als Kampf zwischen Deutschen und Tschechen gesehen werden, Tyl hat jedoch diese nationale Implikation ziemlich "tief" in der Fabel versteckt, immerhin konnotiert der Name Beneš nicht sofort ,deutsch', nur die Orts- bzw. Familiensitzbezeichnung „Vaitmile“ [= Weidmühle] deutet dies an. Aus einer Analyse, die diese nationalen Momente berücksichtigt, erscheint das Scheitern der Liebe zwischen Hynek und Anežka - dem Deutschen und der Tschechin - historisch gleichsam prophetisch, nimmt sie doch die Verschärfung des nationalen Antagonismus am Ende des 19. Jahrhunderts und den endgültigen Bruch zwischen Tschechen und Deutschen im Zweiten Weltkrieg und der dadurch bedingten Vertreibung der Sudetendeutschen vorweg.

Otruba/Kačer bemerken zwar die nationalen Implikationen von Kutnohoršstí havirí, die in den sozialen Konflikt hineinspielen, sie äußern sich dazu aber widersprüchlich-undeutlich und verzichten auf eine genauere Erläuterung, wie sie in der vorliegenden Analyse gegeben wird (abwesende fremde Königsmacht als Rahmenbedingung, sprachnationale Motivation für den unüberwindlichen Hass des bösen deutschen Adeligen etc.). ${ }^{211}$

210 [Beneš:] „Ich hasste das Berggesindel - es hat sich mir entgegengestellt, als mich die königliche Gnade zum Münzmeister ernannte - es stellte sich entgegen, weil ich zu ihnen nicht sofort in ihrer Sprache sprechen konnte, wie sie schändlicherweise meinten - und ich musste mich fügen und den Schüler abgeben - es sei verflucht!"

211 Erwähnenswert ist in diesem Zusammenhang die allgemeine Bemerkung des „Doyens“ der tschechischen Theatergeschichtsschreibung, František Černý: „Ale jde mu [=Tylovi] 
Die Furcht vor Unfrieden in der Heimat, die Opat wiederholt äußert, lässt ihn zögern, wenn es darum geht, gegen die von den Bergherren verursachte Not anzukämpfen. In der Peripetie des vierten Akts verhandelt Opat die Rückkehr und die Aufstellung von zehn Männern als Garanten für die Rückkehr und die Vertragssicherung, die allerdings von der anderen Seite gebrochen wird. Als die heimatverbundenen Knappen ein Lied anstimmen, deutet Opat dies als Zukunftshoffnung („Slyšišs ty hlasy nadějné - to radování tovaryšstva, že se $\mathrm{k}$ starému pořádku navrací. O nech to být i naším heslem a neklesejme v bohabojné důvěře!" ${ }^{12}$ (IV/6, S. 176f). Diese Hoffnung auf die Rückkehr zur alten Ordnung wird ja im falschen Sinn realisiert, nämlich als Rückkehr zur alten Ungerechtigkeit, für die Opat sogar mit seinem Leben büßen muss. In der Tat erfährt durch die Handlungsentwicklung die pessimistische Einschätzung der Situation durch Vít eine Bestätigung, nur dass seine radikalere Haltung dabei auch als Ergebnis seiner Heimatlosigkeit und romantischen Zerissenheit erscheint (vgl. Otruba/Kačer 1961, 303 u. 467, Fn 11).

Alle positiven Figuren müssen für ihre Haltung und Werte mit dem Leben oder mit ihrem existenziellen Unglück leiden; zur Verdeutlichung der Axiologie ertönt im Zusammenhang mit der Hinrichtung der unschuldigen Knappen „Theaterdonner" (vgl. V 2 u. 3, S. 180-182). Neben so vereindeutigenden Hinweisen für die äußere Kommunikationssituation des Dramas weist der Text aber auch noch subtilere Passagen auf, bei denen eine metaphorische Lesart möglich ist: so können Elemente der Arbeitssituation der (Stollen, Finsternis, Mine, Licht) auch in übertragener Bedeutung gelesen werden, man vergleiche Wendungen wie den Vers „sešli světlo do temnosti“ (I/1, S. 120 - ,schick Licht in die Finsternis“) im Gesang der Knappen oder Víts Erklärung: „Já chtěl vědět, na jakou rudu tady uhodím. V jalové skále nemůžeme déle pracovati, sice budeme naposled perlíky ohryzovati “213 (I/2, S.121). Die metaphorische Potenz dieser Verse kann sowohl auf die im Stück

o rozvoj českého etnika, českého obyvatelstva, a to za všech okolností. Tedy i proti těm poněmčelým Čechům. Ve chvíli, kdy se rozbíhalo národní hnutí, si uvědomil, že je důležité, aby Praha, centrum české národnosti, hlavní město tohoto procesu, který se rozvíjel, bylo české. A tak se obrátil na diváky divadla a řekl jim: nestyd'te se mluvit česky, važte si české řeči, mluvte česky“. (Černý 2007, 116 - „Es geht ihm [=Tyl] um die Entwicklung der tschechischen Ethnie, der tschechischen Bevölkerung, dies unter allen Umständen. [Er war also] auch gegen die deutsch gewordenen Tschechen. In der Zeit, als die Nationalbewegung an Fahrt gewann, wurde ihm bewusst, dass es wichtig sei, wenn Prag, das Zentrum der ganzen Nation, die Hauptstadt dieses Prozesses, der sich entwickelte, tschechisch ist. Und so wandte er sich an die Theaterzuschauer und teilte diesen mit: Schämt euch nicht, Tschechisch zu sprechen, haltet die tschechische Sprache hoch, sprecht Tschechisch.“)

212 [Opat:] „Hörst du diese hoffnungsvollen Stimmen? - das ist die Freude der Genossen, dass man zur alten Ordnung zurückkehren wird. O möge dies auch unsere Losung sein und lassen wir in unserem gottesfürchtigen Vertrauen nicht nach!“

213 „Ich wollte wissen, auf welches Erz wir hier stoßen. In einem tauben Felsen können wir nicht länger arbeiten, sonst müssen wir letztendlich an unseren Hämmern nagen." 
vorgeführte Lage der Knappen wie auch auf die nationale Situation der Tschechen bezogen werden.

\section{IV.4.12. Josef Kajetán Tyl: Jan Hus. Dramatická báseň v 5 oddèleních (1848)}

[Jan Hus. Dramatisches Gedicht in 5 Abteilungen; UA 26.12. 1848, publ. 1849]

Der verfassungsgebende Reichstag des Jahres 1848 musste aufgrund der Unruhen in Ungarn, die erneut auch nach Wien überzugreifen drohten, im Oktober in das ruhigere mährische Kremsier (Kroměřiž) verlegt werden. Josef Kajetán Tyl war als Vertreter der böhmischen Länder am Reichstag in Wien und in Kremsier zugegen und schrieb dortselbst - er nahm bestätigtermaßen kaum an den Debatten um die Reichsverfassung teil - neben dem Zauberspiel Turdohlavá žena zwei Dramen mit historischen Stoffen, Jan Hus sowie Krvavé kŕtiny. Diese gelten neben Strakonický dudák [Der Dudelsackpfeifer von Strakonice] als Höhepunkt von Tyls dramatischem Schaffen.

Das am 26. Dezember 1848 im Prager Ständetheater uraufgeführte Drama Tyls erlebte sechs Aufführungen, um im Februar 1850 - ebenso wie die 1849 erfolgte Druckfassung - verboten zu werden. Zumal es 1848 nicht mehr untersagt war, Jan Hus oder den hussitischen Feldherren Jan Žižka vorzuführen, ${ }^{214}$ thematisiert Tyl erstmals die hussitischen Auseinandersetzungen, wobei er den Kirchenreformer Hus zu einer nationalpatriotischen Identifikationsfigur stilisierte, was gerade im Revolutionsjahr 1848 von besonderer Bedeutung war (vgl. Fischer 1919, 7f). Wie bereits ausgeführt (vgl. oben S. 141f), brachten die Tschechen in den Jahren 1848/49 historischen Dramen ein verstärktes Interesse entgegen.

Původní dramata, uvedená v sezóně 1848-1849 měla [...] jeden společný rys. Byly to romantické hry o současnosti, ale ne ze současnosti. [...] V rozhodujícím revolučním okamžiku, na vrcholu českého národního obrození, neprosadila se tedy hra ze současnosti [...] Čeští dramatikové obrazili naopak revoluční dobu v romantických historických hrách, tedy v žánru, který sice v minulosti významně působil na ideologii utvářejícího se českého národa, avšak měl leckdy exkluzívní ráz a především těžce zápasil o uměleckou úroveň. Můžeme tu proto

214 Tyl schreibt 1848 in seiner Zeitschrift Pražský posel: „Když jste chtěl mluvit o našem Husovi nebo Žižkovi, to jste to musel pořád kroutit a kroutit, až to nebylo $\mathrm{k}$ sobě ani podobné. Ano, není tomu ještě tak dlouho, co jsme nejen tyto muže, ale i mnohé jiné v knihách ani jmenovati nesměli, leda bychme byli hned připojili, že byli daremní a velicí škůdcové.“ (Tyl zitiert nach Strejček 1932, 73). („Wenn man über unseren Hus oder Žižka sprechen wollte, musste man es so lange drehen und wenden, bis es schon gar keine Ähnlichkeit mehr hatte. Ja, es ist gar nicht einmal so lange her, dass man nicht allein diese Männer, sondern auch viele andere in Büchern nicht einmal erwähnen durfte, außer man hat schnell hinzugefügt, dass sie Halunken und große Übeltäter waren.“) 
právem mluvit o triumfu českého historického dramatu. Tuto skutečnost nevysvětlí snaha po úniku cenzuře, nebot právě v této sezóně [1848-49] se mohlo hrát bez cenzury. Ani záliba Čechů v národní historii vysvětlení nepodává. ${ }^{215}$ (Černý 1969/DčD II, 334)

Die insinuierte Erklärung Černýs für diesen „Boom“ historischer Dramen ist die lukácsche Auffassung vom Zusammenhang von Drama bzw. Tragödie mit „großen welthistorischen Umwälzungen“ (vgl. Lukács 1965, 116). Die revolutionäre Atmosphäre legt demnach die Erinnerung an eine Epoche nahe, in der die Tschechen unter dem Wirken von Jan Hus eine religiöse Reformbewegung schufen, die von der katholischen Kirche als Revolution und ernste Gefahr angesehen wurde. Mit der Auswahl des Hussitenstoffes und seiner dramatischen Gestaltung entsprach Tyl seinem eigenen Streben nach Aktualität in der Form historischer Analogie, das er 1847 als dramaturgisches Programm formuliert hatte (vgl. Otruba/Kačer 1961, 363). Friedrich Engels sollte ca. sieben Jahre später bemerken, dass bei den Tschechen jede revolutionäre Bewegung von Reminiszenzen an die Hussitenkriege begleitet sei (vgl. Engels 1856, 122).

Wie die Berichte von der Premiere zeugen, waren dem Theaterpublikum die Zeitbezüge damals durchaus bewusst; eine Replik im Drama, in der es hieß, dass die Prager Kleinseite immer zur Herrschaft hält (auf der Kleinseite waren die Verwaltungsgebäude des Königreichs Böhmen sowie die Wohnsitze der höheren Beamten), wurde mit „schier endlosem Applaus“ bedacht, was in der Folge wohl ebenfalls zu einer Verschärfung der Theaterordnung Anlass gab (vgl. Strejček 1932, 75).

Im ersten der fünf Akte zeigt Tyl das Wirken von Hus in Prag. Viele Menschen besuchen die Bethlehems-Kapelle, um Hus dort auf Tschechisch predigen zu hören. Doch nicht alle Tschechen sind von Hus eingenommen; in der ersten Szene tadelt ein Mann seine Frau, dass diese die ketzerische Kapelle besucht. Die Frau entgegnet ihm:

215 „Die Originalwerke, die in der Saison 1848-49 aufgeführt wurden [...] hatten eine Gemeinsamkeit. Es waren romantische Stücke über die Gegenwart, die aber nicht in der Gegenwart spielten. [...] Im entscheidenden revolutionären Augenblick, am Höhepunkt der tschechischen nationalen Wiedergeburt, dominierten also keineswegs Stücke, die in der Gegenwart angesiedelt waren. [...] Im Gegenteil: die tschechischen Dramatiker stellten die revolutionäre Zeit in romantischen historischen Stücken dar, in einem Genre also, das in der Vergangenheit signifikant auf die Ideologie der sich herausbildenden tschechischen $\mathrm{Na}$ tion einwirkte, das jedoch mitunter einen exklusiven Zug hatte und das vor allem schwer um ein künstlerisches Niveau bemüht war. Wir können also zurecht von einem Triumph des tschechischen historischen Dramas sprechen. Diese Tatsache kann nicht durch den Versuch erklärt werden, die Zensur zu umgehen, denn just in dieser Saison [1848-49] konnte ohne Zensur gespielt werden. Auch die Vorliebe der Tschechen für die nationale Geschichte reicht als Erklärung nicht aus." 
Pojd' do chrámu - jako ty, nedovařený Čechu -, kde mi němčinou duši mordují, abych tam stála jako sloup a nepocítila teplý paprslek slova Božího. Jdi si ty sám do takového papežského doupěte; ale mou duši nech se napájeti rosou nebeskou, kteráž kape od ust kazatele betlémského! ${ }^{216}$ (I/1, S. 12)

Marketa, die Mutter von Hus, hört sich dieses Gespräch an, sie ist nach Prag gekommen, um sich selbst zu überzeugen, ob ihr Sohn ein Ketzer ist oder nicht. Lupáč, ein begeisterter Theologiestudent und Anhänger von Hus, preist die Bethlehems-Kapelle als heiligen Ort für die Tschechen, aus ihm gehe ein tschechischer Messias hervor (I/2, S. 13). Dementsprechend begrüßt Lupáč Marketa als „gebenedeite unter den Müttern “ [matko požehnaná mezi matkami, I/2, S. 15] Im ersten Akt sucht auch Štěpán Páleč seinen ehemaligen Freund und Studienkollegen Jan Hus auf. Páleč hat jedoch mit Hus gebrochen und ist auf die Seite des konservativen Klerus übergegangen. Er überwacht die Bewegung um Hus. Er ist der Auffassung, dass nicht alle Christen erleuchtet werden wollen, so manchen wäre die Dunkelheit lieber (vgl. I/3). Páleč möchte Hus dazu bringen, zu widerrufen, aber dieser ist keineswegs dazu bereit, wenngleich ihm die Prophezeiung, dass die Macht des Klerus allzu groß sei, Sorgen bereitet. Auf Drängen von Páleč gibt Hus die Schriften von John Wyclif heraus, in der Meinung, dass diese einer Prüfung durch den Bischof standhalten werden, weil in ihnen die Wahrheit stehe. Jeronym Pražský [Hieronymus von Prag], ein enger Freund von Hus, berichtet, dass er nach einigen Nachstellungen durch die Kirche auch zu den Russinen gereist sei, die er als slawisches Kernvolk betrachtet, das auch die alte Tradition einer Liturgie in der Volkssprache noch bewahrt habe. Von diesen überbringt er Hus einen Gruß und die Hoffnung, dass man sich künftig in einer gereinigten großen Kirche vereinen werde. ${ }^{217}$ Hus ist es allerdings schon untersagt worden, Messen abzuhalten und zu predigen, dies dürfe nur noch in deutscher Sprache geschehen. Er müsse die Bethlehems-Kapelle schließen „wo der Tscheche fühle, dass er ein Tscheche ist" (kde Čech cítí, že je Čechem - I/6, S. 26). Die Mutter von Hus, Marketa, meint hingegen, dass er lieber nicht mehr

216 „Wenn ich in die Kirche gehe - so wie Du, unausgegorener Tscheche -, dorthin, wo sie mit der deutschen Sprache die Seele abtöten, damit ich dort wie eine Säule stehe und nicht den warmen Strahl des göttlichen Wortes spüre. Geh doch selbst in eine solche päpstliche Höhle; lass aber meine Seele sich am himmlichen Tau laben, der von den Lippen des Predigers der Bethlehems-Kapelle tropft."

217 Dass Jeronym mit seinem Botenbericht von den Russinen dem Programm des Austroslawismus entspricht, das prominent von Palacký in seinem berühmten Antwortbrief an die Frankfurter Reichversammlung vertreten wurde (vielleicht halbherzig, wie Uffelmann 2008 meint), behaupten Otruba/Kačer (vgl. 1961, 366). Allerdings wäre fragend anzumerken, wo in Tyls Text das Indiz dafür liegt, im sensus allegoricus die Schirmherrschaft der Habsburger als Option für die Tschechen zu sehen? Jeronyms Hoffnung auf eine gemeinsame Kirche aller Slawen könnte ja auch ohne Habsburger angestrebt werden. 
weiter seinen Weg gehen soll, sie habe einen Traum gehabt, in welchem das Feuer des Morgenrots, in welchem er gestanden sei, sich letztlich in einen blutroten Himmel verwandelt hatte. Hus meint, er könne nicht untätig zusehen, wenn das Wort Gottes missbräuchlich verwendet werde. Als ihm berichtet wird, dass der Bischof die Bücher von Wyclif verbrennen hat lassen, entschließt er sich für den Kampf: Entweder wird die Wahrheit siegen, oder er als ihr treuer Verteidiger untergehen. Die Mutter soll für ihn beten (I/8).

Der zweite Aufzug spielt auf Vyšehrad: Václav IV. möchte Einigkeit und Frieden im Land haben. Páleč soll dies Albík, dem Bischof von Prag, ausrichten, auf dass die Kirche ihre internen Angelegenheiten selbst regele und sich nicht in weltliche Belange einmische. Nachdem Vok, ein Anhänger von Hus, eine päpstliche Bulle, in welcher Ablass für Kriegsdienst und Kriegsfinanzierung versprochen wird, verbrannt hatte, hat Václav, um den inneren Frieden zu sichern, es bei Strafe verboten, mit päpstlichen Botschaften so umzugehen. Páleč beschuldigt Hus, dieser schädige die Kirche, indem er jahrhundertealte Fundamente erschüttere. Václavs Gemahlin, die Königin Žofie, ist dagegen eine begeisterte Anhängerin ihres Beichtvaters Hus; das bischöfliche Verbot hat inzwischen noch mehr Menschen zur Bethlehems-Kapelle geführt. Žofie möchte von Václav mehr Unterstützung für Hus, Václav ist auf die Schlichtung des Streits bedacht, da ansonsten sein Ansehen vermindert würde. Aufgrund des Drängens von Páleč und anderen Klerikern erlässt der Papst den Befehl, dass sich Hus nach Rom begebe. Dieser erklärt Václav, dass er bereit wäre zu gehen, nur fürchtet er um seine Anhänger und seine Lehre. Václav ist verärgert über die Einmischung des Papstes in innere Angelegenheiten, der bischöfliche Prokurator Míchal z Českého Brodu, der Václav schon um ein Goldbergwerk in Jíloví gebracht hat, ist das Verbindungsglied zum Papst. Da seine Anhänger um Hus Angst haben, untersagt auch Václav diesem die Fahrt nach Rom, er bittet ihn allerdings um Mäßigung.

Der in Polen erfolgreiche Jan Žižka bietet Václav seine Feldherrendienste an. Jeronym Pražský gewinnt ihn für die Angelegenheit von Hus, den Žižka für seine Leistungen für die Tschechen und für die Zurückweisung der Deutschen sehr bewundert. In der Prager Altstadt kommt es zu Tumulten, als Anhänger von Hus gegen den Ablasshandel eines Minoriten auftreten und auf der Grundlage des Verbots von Václav verhaftet werden.

Im dritten Akt beschwert sich Hus bei Václav, dass die Verhafteten schon mit dem Tod bestraft wurden. Der königliche Erlass, der eine solche Behandlung von Kritikern des Ablasshandels möglich mache, sei nicht gerecht. Der Bischof Albík soll Argumente für diesen vorbringen. Da die Kleriker dies mit dem Hinweis auf die kirchliche Tradition und Kontinuität verweigern, protestiert Hus im Namen der menschlichen Vernunft: Allein deren Urteilsvermögen müsse respektiert werden. Als der päpstliche Gesandte zu Václav kommt und diesen im Namen der Kirche auffordert, gegen die Ketzerei in Böhmen vorzugehen, ist dieser über die Einmi- 
schung empört. Als Hus aber offen die Fehler der Kirche aufzählt und daraufhin vom Gesandten exkommuniziert wird, der auch gleich Böhmen mit verflucht, ersucht Václav ihn, Prag zu verlassen, um die Ruhe im Volk zu wahren. Václav bittet ihn um Verständnis für diese politische Maßnahme, er müsse den König Václav vom Freund Václav unterscheiden. Hus entscheidet sich, mit seiner Mutter zurück in sein Heimatdorf zu gehen, sein Name soll in Prag hochgehalten werden.

In der Heimat allerdings ist Hus betrübt, obwohl viele seiner Anhänger zu ihm kommen. Er bedauert, nicht mehr an seiner Prager Wirkungsstätte sein zu können. $\mathrm{Zu}$ früh habe er klein beigegeben und ignoriert, dass ,aus dem Blut die Befreiung geboren wird“ (že se z krve rodí osvobození - IV/2, S. 77). Allein seine Mutter hält ihn noch davon ab, nach Prag zu geben und seinen Standpunkt weiter zu verteidigen. Als Marketa allerdings stirbt, gelobt sie, bei Gott zu bitten, dass Hus nicht verbrenne. In der Todesagonie hat sie eine Vision vom Aufstieg ihres Sohnes als weiße Taube. In Prag ist inzwischen eine Krise spürbar geworden. Žižka rät dem enttäuschten König Václav, Hus wieder predigen zu lassen. Václav lehnt dies ab, weil damit nur von neuem der religiöse Streit entfacht werde (IV/4). Zikmund [= Sigismund], Václavs Bruder, wünsche als Kaiser Václavs Tod, obwohl dieser ihm die Kaiserkrone überlassen hat. Václav beschuldigt Hus, mit seiner Agitation das Land verdorben zu haben. Als der nach Prag geeilte Hus verkündet, sich dem Konzil stellen zu wollen, löst er bei Václav Begeisterung aus, bei seinen Anhängern hingegen Bestürzung, da diese um ihn fürchten. Žižka schwört der ganzen Welt Rache, falls Hus etwas zustoßen werde (vgl. IV/5, S. 89).

Der fünfte und letzte Akt zeigt das Konzil in Konstanz. Bereits vor der letzten Anhörung steht das Urteil schon fest. Páleč müsste über dieses Ende zwar froh sein, er bedauert jedoch seinen Jugendfreund Hus, dessen Aufrichtigkeit und Mut er bewundert. Páleč selbst sieht seinen Abfall von Hus als Verrat an der Wahrheit, den er aufgrund seines Karrierestrebens begangen hat. Der von Kaiser Zikmund ehrfürchtig behandelte Papst erklärt, mit Gottes Hilfe den Streit beenden zu wollen. Chlum, der Hus auf der Reise beschützen soll, beklagt sich bei Zikmund, dass die Zusage auf freies Geleit gebrochen wurde und Hus bereits in Haft ist. Jener weicht aus und meint, die Kirche werde schon wissen, warum sie Hus gefangen genommen habe. Auch Chlum droht, dass die Welt in Blut getaucht werde, wenn Hus ein Haar gekrümmt werde. Der Papst Jan XXIII. [= Johannes XXIII.] wirft dem Inquisitionskardinal Petr vor, das Versprechen von freiem Geleit für Hus gebrochen zu haben. Bei der Befragung von Hus wird dieser angeklagt, die Bücher Wyclifs verbreitet zu haben sowie die Hierarchie der Kirche - den Papst als Oberhaupt und die Bischöfe als die Körperteile der Kirche - nicht anerkannt zu haben. Hus führt demgegenüber die Rolle der anderen Gläubigen ins Treffen, die auch ein Recht auf den Laienkelch hätten. Der Papst sei nicht unfehlbar, kein unverrückbarer Fels. Die Kardinäle erklären Hus, der nicht widerruft, zum Ketzer. Dessen Appell auf freies Geleit wird von Zikmund relativiert: der Freibrief gäbe nicht alle Freiheit; für das 
Unrecht, über das die Kirche befunden habe, kann es keine Freiheit geben. Nach der Urteilsverkündung erklärt Hus' Mitstreiter Chlum:

Vzpírám se mu [ortelu] jménem všeho lidstva,/ ježto touží po osvícení, / vzpírám se mu jménem národa, kde / první jiskra pravdy zasvitla, a / kteráž jednou v taký plamen, vzejde, / že ní celá vaše říše sejde! $!^{218}$ (V/4, S. 101 )

Vor Hus' Hinrichtung besucht ihn noch Páleč in der Zelle. Er möchte von Hus Verzeihung erlangen und erklärt, aus Neid und falschem Stolz gehandelt zu haben. Er versucht noch einmal, Hus zum Abrücken von seinen Standpunkten zu bewegen, der Augenblick sei günstig, weil der Papst geflohen sei und der Kaiser jetzt mehr Macht über die Kardinäle habe. Hus lehnt ab; man müsse ihn schon mit Argumenten widerlegen (V/6). Auch Hus' Beschützer Chlum bittet ihn, zu widerrufen, da er fürchten muss, für die schlechte Erfüllung seiner Schutzmission bestraft zu werden; es gelte nur, Zeit zu gewinnen, denn Jeronym halte sich schon heimlich in Konstanz auf. Hus lehnt auch diesen Vorschlag ab, er bittet Chlum, dass seine Anhänger sich an die Bibel halten und nicht rächend Blut vergießen sollen (V/7). Die Konstanzer Bürger sind nur neugierig auf Hus, sie empfinden kein Mitleid und fürchten die Ketzer. Jeronym klagt das Konzil an, während der Hinrichtung von Hus wird er von Páleč festgenommen. Chlum bittet Gott um Beistand, dass er in Böhmen von den Vorgängen berichten kann: „[...] a naplň české oči tokem / přehořkým, by mohly zmáčet drahý / poklad, co jim přinesu, - ten Husův popel!“ ${ }^{219}$ (V/10, S. 114)

Gewissermaßen ist das Schlusswort von Chlum eine mise-en-abyme-Figur von Tyls Repräsentationsleistung: denn es ist doch er selbst, dessen erfolgreiches Stück im Jahr 1848 die „tschechischen Augen“ mit jenem „bitterem [Tränen-]Fluss erfüllt", der Hus' Asche wieder fruchtbar machen soll. Laut Strejček, der anlässlich des 75-jährigen Gedenkens an den Tod von Tyl eine sehr panegyrisch angelegte Studie verfasst hat, in der er dem rundum positiv gezeichneten Nationalpatrioten Tyl einen intriganten kosmopolitischen Egomanen in der Person von Josef Jiří Kolár gegenüberstellt, seien in der persona dramatis Jan Hus nicht nur einige von Tyls Charakterzügen (Mutterliebe, Beharrlichkeit und Standfestigkeit) zu erkennen, sondern vor allem dessen Tschechentum (českost - vgl. Strejček 1932, 74f). Sachlicher und textbezogener ist demgegenüber die Feststellung, dass Hus vor allem als Ideenträger im Zentrum des Stücks steht; anstelle entscheidender Handlungen sind es die Re-

218 [Chlum:] „Im Namen der gesamten Menschheit / die sich nach Aufklärung sehnt, / lehne ich mich gegen es [= das Urteil] auf, / ich lehne mich auf im Namen des Volkes, in welchem / ein erster Funken Wahrheit geleuchtet hat, und dieser / wird einmal zu einer solchen Flamme aufschießen, / dass durch sie euer ganzes Reich vergehen wird.“

219 [Chlum:] „[...] und erfülle alle tschechischen Augen mit bitteren / Tränen, damit sie den teuren Schatz / befeuchten, den ich ihnen bringe - die Asche von Hus!“ 
aktionen auf die von Hus vertretenen Standpunkte, die den Konflikt bedingen (vgl. Otruba/Kačer 1961, 370).

Dass in den religionspolitischen Konflikt um die Reformvorschläge von Jan Hus auch nationale Fragen - des Verhältnisses der Tschechen zu den in Böhmen, vor allem zu den in Prag lebenden Deutschen - hineingespielt haben, ist ja an der Auseinandersetzung um das Kuttenberger Dekret erkennbar, durch welches Václav IV. die Mitbestimmungsrechte der Bayern, Sachsen und Polen an der Prager Universität geschmälert hat (vgl. Hoensch 1992, 141f). In Tyls Drama wird nun aber gleich in der ersten Szene die sprachnationale Frage besonders akzentuiert, wobei eine klare Bewertung der Alternativen erfolgt: die deutsche Sprache tötet die Seele der Tschechen, das göttliche Wort wird nur in Form der tschechischen Volkssprache als wärmend empfunden; die in der Bethlehems-Kapelle gepredigten Worte empfindet seine Anhängerin als himmlischen Tau aus Hussens Mund. Diese eingangs geschaffene Opposition von göttlichem Wort und göttlicher Wahrheit einerseits und klerikaler, päpstlicher Kälte andererseits, zu dessen positivem Pol eben explizit die lebendige tschechische Sprache gerechnet wird, während die deutsche Sprache dem negativen Paradigma zugeordnet wird, erfährt im Verlauf des Dramas keine wesentliche Veränderung. Allerdings heißt die Opposition genau genommen nicht ,tsche-

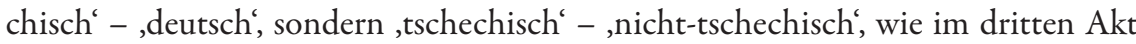
ersichtlich wird, als der vom Papst nach Prag gesandte Kardinal Petr Angeli über Jan Hus, dessen Anhängerschaft und über Böhmen generell den Bannfluch ausspricht. Chlum stellt sich empört der Rede des „Ausländers“ (cizinec) entgegen und erklärt: „Svobodný jsem Čech, a vedu tady / slovo jménem svobodného národu! [...] Jsme národ silný, / pro svobodu krev svou vylévati / zvyklý - a dost dlouho dopouštěli / jsme, že v práva domácí nám cizí / ruce sahaly."220 (III/4, S. 67) Wenngleich Hus das Temperament seines Parteigängers, der gegen den Kardinal sogar das Schwert zieht, zügelt, spricht er selbst auch im vierten Akt von der Befreiung, die aus dem Blut geboren wird (vgl. IV/2, S. 77). Diese Replik, die Hus selbst später weder verbal noch durch sein Handeln relativiert, stellt tatsächlich eine für die äußere Kommunikation des historischen Dramas ungewöhnlich direkt revolutionäre Aussage dar. Otruba/Kačer, die dies ebenfalls konstatieren, sehen in dieser Aussage von Hus zu Recht die Distanznahme von einer konservativ-patriarchalischen Position, die ängstlich vor jeder Veränderung zurückschreckt, selbst wenn sie wie bei Hussens Mutter Marketa die Gründe für die Veränderungen versteht und neue Ideen gutheißt. Hus äußert den Revolutionsgedanken bezeichnenderweise, nachdem seine Mutter verstorben ist, die ihn zu einem abwartenden Rückzug aus Prag gedrängt hat (vgl. Otruba/Kačer 1961, 367f).

220 „Ich bin ein freier Tscheche, ich führe hier / das Wort im Namen eines freien Volkes! [...] Wir sind ein starkes Volk / gewöhnt, für die Freiheit das eigene Blut / zu vergießen - allzu lange haben wir es zugelassen, / dass in die häuslichen Rechte uns / fremde Hände greifen." 
Vom prominenten historischen Konflikt zwischen Hus und dem nach Rom ausgerichteten Klerus, dem die nationale Opposition ,tschechisch' - ,nicht-tschechisch' zugeordnet ist, heben sich die „lokalen“ Konflikte von Tyls Drama ab, die auf dem Schematismus des Hauptkonflikts aufbauen, diesen aber differenzierter erscheinen lassen. Beispiele für diese lokalen Konflikte wären etwa die Eingangsszene, wo das tschechische Ehepaar über die hussitischen Reformen ins Streiten gerät; der Konflikt zwischen Václav IV. und seiner Frau, der Königin Žofie; der Konflikt zwischen Hus und seinem Jugendfreund Štěpán Páleč; der Konflikt zwischen Hus und seiner besorgten Mutter Marketa; der nur angedeutete Konflikt zwischen Papst und Kaiser, Papst und Václav IV. oder derjenige zwischen Václav IV. und seinem Bruder, dem Kaiser Zikmund.

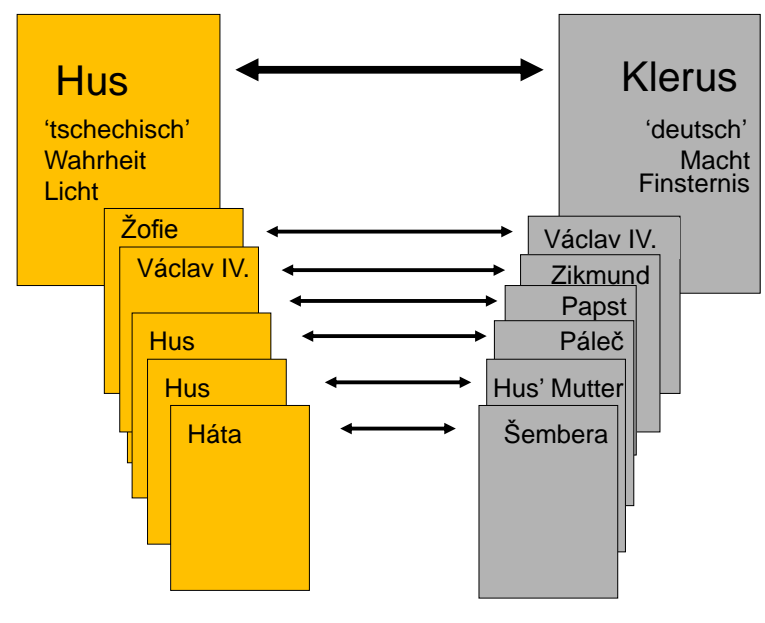

Graphik 15 - Josef Kajetán Tyl: Jan Hus (1848)

Diese schematische Darstellung ist so zu verstehen, dass die im Drama vorgeführten „lokalen“ Konflikte natürlich nicht linear auf den Hintergrundkonflikt und dessen axiologische Bewertung reduziert werden dürfen, sie sind vielmehr als dessen „Spezifikation“ bzw. „dramaturgische Funktion“ (um eine Metapher der Mathematik zu gebrauchen) anzusehen, sie machen das Drama abwechslungsreicher und lassen es differenzierter erscheinen. Den jeweiligen Konfliktpaaren ist ein gemeinsames Merkmal inne: so sind es etwa Ehepaare (Václav IV. und Žofie, Šembera und Háta), nahe Verwandte (Hus' Mutter Marketa und ihr Sohn, die Brüder Zikmund und Václav IV.) oder ehemalige Jugendfreunde (Štěpán Páleč und Jan Hus), die sich zur Reformfrage jeweils anders - jedoch konfligierend - verhalten. Aufgrund des den Konfliktpaaren gemeinsamen Merkmals erscheinen die ideologischen Grundoppositionen von ,tschechisch ${ }^{-}$, deutsch' und ,Wahrheit ${ }^{`}-$,Macht ${ }^{`}$ differenzierter bzw. 
wird der Kontrast dieser Opposition durch sie abgeschwächt: Nicht alle Tschechen sind Hussiten, nicht alle Opponenten der hussitischen Bewegung sind Deutsche, die Zuordnung zu den Lagern erfolgt vielmehr in Relation auf den Grundkonflikt in dessen jeweils spezifischer Ausformung.

Zudem lassen sich auch innerhalb der beiden ideologischen Lager Paare bestimmen, die über das Vorgehen gegenüber dem Gegner jeweils anderer Auffassung sind. So will sich Hus zu seiner Verteidigung dem Konzil stellen, seine Mitstreiter wie Jan Žižka, Vok oder Jeronym Pražský sehen darin aber eine tödliche Gefahr; im Lager des Klerus lassen sich gleichfalls unterschiedliche Auffassungen erkennen.

Im obigen Schema ist der böhmische König Václav IV. (wie sein Vater Karl IV. aus der Dynastie der Luxemburger stammend) die einzige Figur im Drama, die in verschiedenen Konstellationen auf beiden Seiten anzutreffen ist. Dies hat seinen Grund darin, dass er als König darauf Wert legt, sein Land nicht von Konflikten gespalten zu sehen. Den Reformen steht er also insofern reserviert gegenüber, als sie den religiösen Konflikt verschärfen. Václav ermahnt beide Seiten zur Mäßigung, wobei er allerdings einmal Beschlüsse zugunsten der einen Partei, dann wieder zugunsten der anderen fällt. Anders als Žofie, seine für Hus entbrannte Frau, hat er keine religiösen Prinzipien, ihm geht es allein darum, politisch die Oberhand über Böhmen zu behalten. Dementsprechend zwiespältig ist auch sein Verhalten gegenüber Hus. Um nach dem Kirchenbann über Hus und seine Anhänger den religiösen Frieden in Prag wahren zu können, fordert er diesen auf, die Stadt zu verlassen; er ist auch darüber erfreut, dass sich Hus freiwillig dem Konzil stellen möchte, weil er sich von diesem eine innerkirchliche Lösung des Konflikts erwartet. Václav wird somit als Herrscher gezeigt, der nicht wirklich auf der Seite des Volks steht, wie ihm seine Frau Žofie und Jan Žižka vorwerfen, die bei Václav eine Aufhebung seiner antihussitischen Verbote erreichen wollen. Otruba/Kačer (vgl. 1961, 366) sehen in Jan Hus eine merklich veränderte Haltung Tyls zur Herrscherfigur, die sie in direkte Beziehung zum Revolutionsjahr 1848 bringen, in dem Ferdinand I. (bzw. V.) dem jungen Franz Joseph den Thron abtreten musste. ${ }^{221}$

Noch deutlicher wird die Kritik an der Figur des Monarchen, wenn nicht allein Václav als König von Böhmen, sondern auch dessen Bruder Zikmund bei der Analyse berücksichtigt wird. Václav sieht sich im Verlauf des Stück zusehends nicht mehr als souveräner Herrscher, sondern als Spielball des Volkes sowie als Opfer politischer Intrigen, die sein Bruder, der römisch-deutsche Kaiser und der Papst gegen ihn richten (vgl. IV/3). Zikmund, der Václav als König von Böhmen nachfolgen sollte, erscheint als noch feiger, wie sich beim Konzil von Konstanz zeigt. Im Namen des tschechischen Volks appelliert Chlum an Zikmund, das zugesicherte, aber

221 Noch im Frühjahr 1848 hat Tyl in der Nachdichtung Jan Nepomucký, kanovnik pražský [Johannes Nepomuk, Domherr zu Prag] Václav IV. als Anwalt des Volks gezeichnet (vgl. Otruba/Kačer 1961, 356). 
gebrochene freie Geleit wiederherzustellen: „V tvé ruce / kladu naši věc, věc lidu českého! / Ceň ji vysoko! To prosím jménem / téhož lidu, jehož trůn ty jednou / nastoupís.'222 (V/3, S. 93) Zikmund aber erweist sich dieses Gesellschaftsvertrages als unwürdig, er protestiert nicht einmal gegen die Inhaftierung von Hus, sondern überlässt die ganze Angelegenheit der Kirche.

Bei all der aufgezeigten Differenzierung durch die lokalen Konfliktparteien und deren Verhältnis zu den Reformen von Hus muss aber darauf hingewiesen werden, dass Hus selbst als eine absolut positive Figur erscheint, deren Glanz durch keinerlei Fehl getrübt wird. Der Konflikt mit seiner Mutter Marketa rührt daher, dass diese betrübt vorausahnt, welche Folgen Hus' Beharren auf den eigenen Standpunkten haben wird. Die Hussitenkriege als die historische Folge von Hus' Reformen bzw. seiner Hinrichtung in Konstanz bleiben im Drama ja ausgespart, sie werden in den Vorahnungen der Mutter aber angedeutet. Dass Hus hingerichtet wird, ist als sinistre Machtdemonstration des Klerus anzusehen, der eine Kritik an den etablierten Dogmen aus prinzipiellem Machtkalkül nicht zulässt. In Opposition zur Machtkirche erscheint Hus im Drama als Sprecher der Wahrheit, als Priester für die Tschechen, die über ihn Gottes Heil teilhaftig werden. ${ }^{223}$ Dies zeigt sich etwa am „lokalen“ Konflikt zwischen Hus und seinem ehemaligen Mitstreiter Štěpán Páleč, der letztlich zugibt, sich der Kirche rein aus Opportunismus wieder zugewandt zu haben und damit vom Weg der Wahrheit abgefallen zu sein.

Eine entscheidende theologische Frage wird im dritten Akt erörtert, als Hus den Prager Erzbischof auffordert, nach eigenem Gewissen über den Ablasshandel $\mathrm{zu}$ sprechen. Da dieser ausweichend antwortet, verweist Hus noch einmal auf das Sprechen des Herzens und Verstandes, anstelle des Erzbischofs erklärt Štěpán Páleč, dass ein einzelner schwacher Mensch nicht die Unfehlbarkeit des Papstes bezweifeln dürfe, die ihre Macht von Jesus Christus selbst ableitet. Hus entgegnet darauf mit einer pathetischen Apologie von gesundem Menschenverstand und menschlicher Sinneserfahrung, auf die sich zu berufen ihm niemand verwehren dürfe (vgl. III/2, S. 61f).

Im Zusammenhang des Revolutionsjahres 1848, in dem die Theaterzensur kurzfristig aufgehoben war, konnte ein solcher Rekurs auf das Gewissen als Verweis auf die Meinungsfreiheit aufgefasst werden. Demnach bestimmt das Gewissen einen Standpunkt, von dem der Sprecher (= Hus) nicht abgeht und den er gegen alle

222 [Chlum:] „In deine Hände / lege ich unsere Angelegenheit, die Angelegenheit des tschechischen Volkes! / Schätze diese hoch! Das bitte ich im Namen / des Volkes, dessen Thron du einmal / besteigen wirst!“

223 Dass Hus als „tschechischer Messias“ (vgl. I/2, S.13) verehrt wird, steht in bezeichnendem Widerspruch zur eigentlich egalitären Lehre von Hus, die ja die Unterschiede zwischen Klerus und Laien aufheben möchte. Die vom Drama generierte „Erlöserrolle“ hat wohl auch gattungsimmanente Gründe: Die tragische Titelfigur muss sich irgendwie von ihrer Umgebung unterscheiden, und sei es um den Preis eines theologischen Widerspruchs. 
Autoritäten zu verteidigen bereit ist. Tyls Drama um Jan Hus eröffnete eine Reihe von Dramen, die in der Epoche der Herrschaft Václavs IV. und der Hussitenepoche angesetzt waren, Černý (vgl. 1969/DčD II, 334) nennt etwa Václav IV, král český von Josef Václav Frič [Václav IV., der böhmische König, 1849], Eduard Svěráks Klášter sv. Tomáše [Das Kloster des hl. Thomas, 1849], Josef Kajetán Tyls Jan Nepomucký, kanovnik pražský [Johannes Nepomuk, der Prager Chorherr, 1849] und sein Žižka z Trocnova a bitva u Sudoméric [Žižka aus Trocnov und die Schlacht bei Sudoměřice, 1849]. ${ }^{224}$ Ein Kleriker beschwerte sich Mitte des 19. Jahrhunderts entsprechend darüber, dass Hus und Žižka in seinen Augen zu Leimruten wurden, auf welche sich das gutgläubige Volk setze und für die Agitation gegen den Katholizismus gewonnen werde. Auch die Behörden hielten namentlich Žižka z Trocnova für ein sehr gefährliches Stück, da sein Protagonist erklärt, der Dienst am Volk gelte mehr als Gefolgsamkeit gegenüber dem König. Das Stück wurde wegen seiner Parteinahme für die Tschechen und der antideutschen und antikatholischen Tendenz scharf verurteilt. Während des Ausnahmezustands über Prag (Mai 1849 bis September 1853) wurden alle Aufführungen von Žižkaz Trocnova und Jan Hus untersagt (vgl. Pokorná 2015, 409).

\section{IV.5. Synopsis: Themen und Tendenzen des historischen Dramas von 1812 bis 1848}

Die Geschichte des neuzeitlichen tschechischen Theaters nimmt im Zusammenhang mit der Nationsbildung der Tschechen eine Sonderstellung ein: Die gescheiterte Revolution von 1848 brachte zwar eine kurze Periode eines wirklich politisch offenen und entschlossenen Theaterlebens mit sich, das kurz darauf wieder durch die Administration unterdrückt wurde, doch schließen die 1850er Jahre die erste Entwicklungsphase im tschechischen Theaterleben ab. Diese begann mit dem Umstand, dass überhaupt auch tschechischsprachiges Theater auf einiger größeren Bühne angeboten wurde: dafür musste erst ein Publikum gewonnen werden, was in hohem Maß den Charakter der aufgeführten Stücke prägte. Während es in seiner Anfangszeit im späten 18. Jahrhundert sowohl aufgrund der sprachlich-kulturellen Situation wie auch wegen der sozialen Stratifizierung der Bevölkerung darum ging, erst einmal ein tschechisches Publikum zu gewinnen, das in der Lage war, textzentrierten Drameninszenierungen interessiert zu verfolgen und adäquat zu rezipieren, standen die Theatermacher im obrozeni vor dem Problem, die unterschiedlichen

224 Dass die zeitgenössischen Implikationen der Stücke nationalpolitisch und nicht konfessionell waren, zeigt etwa der Umstand, dass Tyl sowohl Jan Nepomuk, den in der Barockzeit kanonisierten katholischen Heiligen, wie auch Jan Hus und Jan Žižka zu Heldengestalten eigener Dramen gewählt hat. Zumindest in den Dramen des obrození gab es noch nicht die synekdochische Verbindung von Hussitismus und tschechischer Nation, wie sie später etwa von Alois Jirásek vorgenommen wurde. 
Erwartungen und Möglichkeiten des Theaters im Hinblick auf ein keineswegs homogenes Publikum umzusetzen. Unter der Voraussetzung der ökonomischen Umstände, die jeden Theaterbetrieb prägen, waren zwei verschiedene Aspekte für die Dramatiker von Relevanz: einerseits die Akzeptanz des Publikums, andererseits die Möglichkeiten des Mediums Theater, welches in der damaligen Zeit dasjenige Medium war, mit dem eine relativ große Zahl von Menschen erreicht werden konnte. Es schien daher dafür geeignet, auch als Medium für die Verbreitung diverser Anliegen zu dienen: Im aufgeklärten Absolutismus setzte eine Theateroffensive der Regierung auf die Bildungsmöglichkeiten des Theaters und während der Napoleonischen Kriege warb das Kaiserreich in der Bevölkerung um Loyalität und Unterstützung.

Das historische Drama in der tschechischen Literatur des 19. und 20. Jahrhunderts hat seine Wurzeln in der zweiten Hälfte des 18. Jahrhunderts, als im Zuge des aufgeklärten Absolutismus von Joseph II. das Theater als Bildungsdispositiv begriffen wurde, mittels welchem man aufklärerische Inhalte unter das Volk bringen konnte.

Das einzige historische Drama in tschechischer Sprache, das vollständig aus dem 18. Jahrhundert erhalten geblieben ist, weil es - anders als die meisten anderen Dramen - auch gedruckt wurde, ist Antonín Josef Zímas „patriotische“ Tragödie Oldrich a Božena, die am 27. Dezember des Revolutionsjahres 1789 im Theater U Hybernů Premiere hatte. Das Stück, das seinen Stoff aus der Chronik von Hájek z Libočan (Mitte des 16. Jahrhunderts) bezieht, führt die Liebe des Fürsten Oldřich zum Bauernmädchen Božena vor, die der böhmische Adel wegen seiner ständischen Interessen hintertreiben möchte. Der Adel betont zwar seine Verbundenheit mit dem Vaterland, ist aber in Person des Vršovec Kochan dazu bereit, sich sogar mit dem deutschen Kaiser zu verbünden, um Oldřichs nicht standesgemäße Verbindung mit Božena zu verhindern. Fürst Oldřich begründet seine Überzeugung von der Gleichheit aller Stände mit den Worten: „jako by sedlák nebyl dílo rukou božských jako kníže, vladyka a zeman“, ${ }^{225}$ er vertritt dabei die Position des aufgeklärten Absolutismus: gegenüber dem Fürsten sind alle Untertanen gleichberechtigt, das Beharren des Adelsstandes auf Privilegien ist egoistisch.

Bei der ideologischen Analyse von Oldřich a Božena müssen die im Stück dargestellten Oppositionen Fürst - Adel - Volk bzw. Tschechen - Ausländer auf unterschiedliche Weise interpretiert werden. Wenn die Gegnerschaft des Adels gegenüber Auflösung der gesellschaftlichen Opposition Adel - Volk negativ konnotiert ist, so soll sie als solche auch dem Publikum qua „Drittem“ erscheinen. Heikler erscheint die implizit intendierte Interpretation durch das Publikum (den „Dritten“) beim Verhältnis der tschechischen Figuren zum „Ausland“. Ein Bündnis mit diesem soll dem Publikum zwar als Landesverrat erscheinen, dabei jedoch nicht zu direkt auf die zeitgenössische politische Situation des späten 18. Jahrhunderts bezogen werden:

225 „Als ob der Bauer nicht Werk von Gottes Händen wäre wie der Fürst, Vladike und Edelmann." 
Das Stück darf als Interpretation also nicht etwa eine Ablehnung des "deutschen“ bzw. österreichischen Monarchen nahelegen, wenngleich das nationale Thema in Oldřich a Božena schon vorhanden ist. Die Antagonisten der positiven Fürstenfigur Oldřich sind nämlich entweder übertrieben patriotisch (wenn sie etwa meinen, der Fürst dürfe keine Ausländerin heiraten) oder paktieren auf verwerfliche Weise mit dem Ausland. Daraus wird deutlich, dass die negativ gezeichneten Figuren zu zwei Extremen neigen; implizit erscheint damit der positiv gezeichnete Fürst als der bessere Patriot: er lehnt die Extreme ab (er verurteilt den Pakt mit dem deutschen Kaiser und er stimmt zumindest gedanklich der nationalen Durchmischung zu).

Die sich nach dem Ende der Kriege gegen Napoleon herausbildende Theaterbewegung um Jan Nepomuk Štěpánek artikulierte bereits deutlich nationale Tendenzen im Theater, wobei allerdings einige Kompromisse in Anbetracht der politischen Situation des tschechischsprachigen Theaters zu erkennen sind (vgl. V. Procházka 1969/DčD II, 112f). Auch wenn Štěpáneks Dramatik, die er für eine weitgehend aus Laien- bzw. halbprofessionellen Schauspielern bestehende Truppe verfasst hat, wenig anspruchsvoll oder elaboriert erscheinen mag, so enthält sie doch charakteristische Tendenzen. Das in dieser Arbeit analysierte historische Drama Břetislav První (1813), dessen Handlung im 11. Jahrhundert angesetzt ist, wird meist im Kontext der Erhebungen gegen Napoleon gesehen: Štěpáneks historische Dramen betonen die Tapferkeit, den Kampfesmut sowie die Loyalität der Tschechen gegenüber dem österreichischen Kaiser (vgl. Císař 2004a, 39f). Doch gibt es in den zeitspezifischen Anachronismen Momente, die bereits eine subversive Kritik an der politischen Dominanz durch Wien erkennen lassen: Břetislav adressiert seine Landsleute etwas unhistorisch mit „Tschechen, Patrioten, Landsmänner!“ und äußert sich gegenüber Tributforderungen des deutschen Kaisers auf eine Weise, dass ein zeitgenössischer Bezug auf die Situation der Tschechen gegenüber dem Hof in Wien möglich ist: So erklärt der Protagonist gegenüber einem Gesandten des Kaisers „Ein Volk ist nur solange selbstständig, solange es nicht das Knie vor einem anderen beugen muss."226 Noch in derselben Replik aber akzeptiert - wohl um sie zu entschärfen - Břetislav bereits die Autorität des deutschen Kaisers. Auf diese widersprüchlichen Momente in Štěpáneks „patriotischen Spielen“ machte auch bereits Procházka aufmerksam; für seine Behauptung, dass der böhmische Landespatriotismus mit dem Vertrauen in Monarchie und Adel gleichgesetzt werden kann (vgl. V. Procházka 1969/DčD II, 113), bringt er allerdings wenig Argumente vor: Es scheint eher, dass die „antikolonialen" Wendungen in Břetislav První nur mit Mühe durch andere ideologische Aussagen abgefedert werden konnten.

Alle drei historischen Dramen Štěpáneks thematisieren also die Situation politischer Dependenz, in Obleženi Prahy od Švejdů aneb Vèrnost a udatnost česká (1812)

226 „Jen tak dlouho jest národ samostatný, jak dlouho mu třeba není, kolena před jiným národem ohybovati." (Štěpánek: Břetislav Pruní, II/11, S. 42). 
und Osvobozeni vlasti aneb Korytanév Čechách (1814) erscheint die Belagerungssituation bereits im Titel. Die drei historischen Dramen haben auch einen entsprechenden Handlungsverlauf: die Belagerer oder Aggressoren erfahren angesichts der tschechischen Kampfstärke eine Niederlage. In seiner letzter Replik erklärt der siegreiche Břetislav: „Der Ruhm unserer Heldentaten wird sich ringsum weit verbreiten, somit werden wir auf jedes Volk abschreckend wirken, das mit uns kämpfen

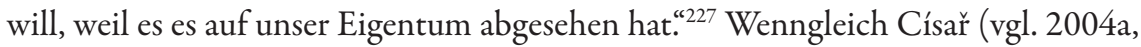
40) den allegorischen Charakter einzelner Repliken und deren herausfordernden Ton bemerkt, sieht er darin noch keinen sprachgebundenen Nationalismus, weil er einen zeittypischen Landespatriotismus ansetzt, der während der Napoleonischen Kriege auch von der österreichischen Regierung angefacht wurde, um die Verteidigungsbereitschaft in den Ländern zu heben. Diese historisch mutmaßlich tatsächlich zutreffende Relativierung reduziert allerdings die semantischen Möglichkeiten allegorischer Lesarten auf eine spezifische Rezeptionssituation.

In den „patriotischen“ Theaterstücken (vlastenské činohry), die also am Ende des 18. Jahrhunderts nur ca. 10 Prozent des Repertoires ausmachten, lag ein brisantes politisches Potenzial. Die Vermittlung einer politischen Botschaft an das Publikum wurde mit einer Loyalitätsbekundung „nach oben“ zusammengespannt, was bei allegorischer Lesart potenziell Irritationsmomente mit sich brachte.

Die Brisanz der „patriotischen“ Theaterstücke der 1810er und 20er Jahre bestand in den Differenzen zwischen der repräsentierten Vergangenheit in den Stücken und der politischen Gegenwart der Tschechen im multinationalen Habsburgerreich, das vom Habsburger Katholizismus und der ständischen Organisation zusammengehalten wurde. In den patriotischen Dramen, die Ereignisse aus der tschechischen Geschichte repräsentierten, mussten sich die Tschechen meist gegen die Ansprüche von „Fremden“ bzw. von anderen Völkern behaupten. Der Patriotismus dieser Stücke sollte im Sinn des aufgeklärten Paternalismus ein Staatspatriotismus sein, der die Herrschaft der Habsburger nicht in Frage stellte; aufgrund der Beschaffenheit des historischen Stoffes war aber die Möglichkeit nicht ausgeschlossen, die patriotischen Dramen im Sinne eines potenziell subversiven tschechischen Patriotismus zu rezipieren.

Diese Spannung zwischen transnationaler imperialer Loyalität und nationalem Pathos entspricht weitgehend dem von Ernest Gellner beschriebenen Übergangsphänomen in der Etablierung des Nationalismus als Ideologie einer modernen industriellen Gesellschaft. Für eine solche musste in seinen Augen eine kulturelle Homogenität ausgebildet werden, was im Wesentlichen mit der Verbreitung nationalistischer Ideen einherging. Die Anfänge dieser Homogenisierung wurden

227 „[...] pověst našich hrdinských činů roznese se daleko široko, a tím budeme strašlivi každému národu, kterýby našeho nábytku žádostiv, s námi zápasiti chtěl. (Štěpánek: Břetislav Pruní, V/13, S. 133). 
allerdings bereits vom aufgeklärten Absolutismus unternommen, der somit dem Nationalismus unwillkürlich Vorschub leistete. Die „Schlange des Nationalismus ist bereits im Garten“, denn „[...] es wirkt bereits der bürokratische Gedanke der Zentralisierung" (Gellner 1996, 27). Die Zentralisierung durch die Staatsbürokratie benötigt eine polyfunktionale Literatursprache und eine Bevölkerung, die sich diesem Standardisierungsprozess unterzieht, was bedeutet, dass sie kulturell einheitlicher wird. Übertragen auf die Situation der tschechischen patriotischen Schauspiele könnte man somit formulieren: in den Stücken sind bereits nationalistische Ideen zu erkennen, obwohl die „aufgeklärte“ österreichische Regierung in ihrer Kultur- und Theaterpolitik loyale Gefühle zum Imperium promulgieren wollte. Laut Císař (vgl. 2004a, 39f) kann man diese Spannung zwischen politischer Loyalität und „erwachendem“ Nationalismus sogar auch auf der Ebene einzelner Repliken dramatischer Figuren ausmachen, insofern diese sich nämlich allegorisch oder unumwunden zur Freiheit eines Volkes äußern.

Die alternative Möglichkeit, nämlich die fraglichen Repliken nicht landespatriotisch, sondern im Zusammenhang mit der Nationalbewegung zu lesen, wird ja nur kurze Zeit später aktuell, wie man anhand von Josef Lindas pseudohistorischem Okkupationsdrama Jaroslav Šternberg v boji proti Tatarüm erkennen kann. In dessen Entstehungsjahr 1823 ist die Bedrohung durch Napoleon bereits längst passé, die Nationalbewegung beginnt ja nach 1815 mit einer offensiven Phase. Lindas Drama konzentriert sich auf die belagerte Stadt Olmütz - metonymisch für die Tschechen - und auf die Darstellung von deren Befreiungsbemühungen, während die tatarischen Okkupanten im Hintergrund bleiben. Indem dieses pseudohistorische Drama seinen Stoff aus einem Fragment der Königinhofer Handschrift nimmt, kann es auch als strategischer Kommentar zum Kampf um nationale Selbstbehauptung gelesen werden, führt es doch vor, wie die „Polis“ Olmütz aus einer aussichtslosen Lage heraus dennoch über einen übermächtigen Gegner siegen kann. Die im erfolgreichen Drama vorgeführten strategischen Mittel bestehen in der Täuschung, der Lüge und der Maske, was auch durch das Gleichnis vom Löwen in der Schlangengrube unterstrichen wird: Der Löwe kann nur deshalb darin überleben, weil er ebenso falsch ist wie die Schlange, was diese nicht erwartet. Dieses strategische Kalkül findet seine dramaturgische Verstärkung darin, dass der Gegner die Tschechen zuerst als durch und durch ehrliche Menschen einschätzt, die die Lüge nicht kennen; die unterlegenen Tschechen gewinnen aber schließlich, weil sie eben zu den Mitteln von List, Lüge und Täuschung greifen, die ihnen der Gegner nicht zutraut.

Die Unterschiede zwischen Landes- und Nationalpatriotismus, die unter Berücksichtigung der Napoleonischen Kriege festgestellt werden können, lassen sich im historischen Drama nur schwer festmachen: in allen vier Okkupationsdramen vermögen sich die Tschechen zu befreien; dass ihre in den Dramen repräsentierten Gegner allerdings variieren - es sind Deutsche, Schweden, Kärntner oder Tataren - 
tut bei der allegorischen Lesart, die dem zeitgenössischen Publikum nahegelegt wurde, wenig zur Sache.

Im frühen obrození betrachteten die patriotischen Intellektuellen um Jungmann das Theater noch nicht als Medium für nationalpolitische Agitation, sondern es diente ihnen als Index für den kulturellen Zustand des tschechischen Volkes. Die Theaterpraktiker ihrerseits mussten die Interessen und die Rezeptionshaltungen des Publikums berücksichtigen; sie übernahmen daher Genres des deutschsprachigen Theaters, die sich in diesem als erfolgreich erwiesen hatten und adaptierten sie für die tschechische Situation. Entsprechend dominierte auf den Spielplänen lange Zeit unterhaltendes Repertoire bzw. wurde dem Musiktheater und der Oper ein großer Stellenwert zugebilligt. „Ernste“ Dramen bzw. Tragödien, denen Gebildete traditionsbedingt größere Werte zugeschrieben haben, waren auf den Spielplänen zwar ebenfalls vertreten, konnten aber begreiflicherweise keinen so starken Zuspruch finden wie Farcen, Sing- oder Zauberspiele. Innerhalb des „ernsten Fachs“ wiederum lässt sich eine klare Präferenz für historische Stoffe erkennen; Dramen aus der Geschichte bzw. der mythologisierten Geschichte des tschechischen Volkes waren auch beim Publikum einigermaßen beliebt, Klicpera und Tyl, den beiden wichtigsten tschechischen Dramatikern und Dramaturgen der ersten Hälfte des 19. Jahrhunderts konnten sie wohl als Lösung der unterschiedlichen Publikumserwartungen erscheinen. Aufgrund ihres ernsten Charakters kam historischen Dramen im Wertsystem der Bildungselite ein ästhetischer Mehrwert zu, sie galten zugleich als volksbildend; darüber hinaus war die Repräsentation geschichtlicher Ereignisse beim tschechischen Publikum auch noch einigermaßen populär, womit dem ökonomischen Aspekt des Theaterbetriebs Genüge getan werden konnte, zugleich aber politische Ideen in die Dramen Eingang finden konnten.

Im 1826 erschienenen Soběslav, selský kniže ist die Schwäche der handelnden männlichen Hauptfiguren auffällig, die eigentliche Initiative geht von Beratern oder von der Frau des Titelhelden aus. Bei dieser impliziten Kritik an einer dynastisch-genealogischen Legitimation politischer Herrschaft wird aber eine Herrschaft des Volkes (der Bauern) in dunklen Farben gezeichnet. Anders als Štěpánek und Linda behandelt Klicpera in seinem Drama also nicht die nationale Frage; er thematisiert einigermaßen offen eine politische Krise, die einem Thronfolgeproblem geschuldet ist. Die Prätendenten bzw. Rivalen um die politische Führung scheinen dabei aber nicht aus eigenen Stücken handeln zu können oder zu wollen, vielmehr gehen die wichtigen und richtigen Entscheidungen von deren Umfeld aus. Soběslavs polnische Frau Eližběta oder der Berater Bedřich sind die kompetenteren Agenten des politischen Lebens, das einfache Volk - repräsentiert durch die Bauernkrieger um Soběslav - hingegen erscheint als kulturelle Bedrohung für das Land (was von der Forschung in der sozialistischen Tschechoslowakei aber offenbar nicht festgestellt werden durfte, da sie aus ideologischen Gründen eine ganz andere Interpre- 
tation von Klicperas Drama - nämlich eine Apologie der Volksverbundenheit und der Bauernkrieger - gesehen hat).

Josef Kajetán Tyls Drama Čestmír behandelt die Frage, wie sich der Einzelne zum Gemeinwesen verhalten soll, die vorgeführte Lösung kann als typisch für die quasi-totalitäre Ideologie der Nationalromantik angesehen werden. Tyls Stück propagiert mittels des Handlungsverlaufs den Einsatz für die Heimat und die Unterordnung privaten Glücks unter den patriotischen Kampf. Um seine fraglich gewordene Loyalität zu Prag unter Beweis zu stellen, verkleidet sich der Hirtensohn Čestmír als der Prager Fürst; Častava, die zuvor aus Eifersucht Čestmír verleumdet hat, verkleidet sich als Ritter und gibt im Kampf ihr Leben für Čestmír, der sich für Prag opfert. An Stelle des eigentlichen Fürsten tritt eine noch erfolgreicher kämpfende Figur aus dem Volk auf, die ihr privates Glück dem eigenen Lager unterordnet und ihr Leben für die Gemeinschaft lässt. Bei Klicpera war eine ähnliche Tendenz zu erkennen, in Soběslav, selský kniže sympathisiert er mit ergeben-treuen Vertrauten bzw. mit adeligen Kennern des politischen Lebens, die weniger umsichtigen Fürstenfiguren zur Seite stehen. Tyl hingegen liefert ein einigermaßen pathetisches Bild vom aufopfernden Einsatz für die politische Gemeinschaft, wobei der nationale Antagonismus zwischen Tschechen und Deutschen keine Rolle spielt. Vergleichbar mit Lindas Jaroslav Sternberg v boji proti Tatarim, das als Allegorie einer nationalen Strategie angesichts der Bedrohung der politischen Gemeinschaft gelesen werden will, ist Tyls Čestmir eine Allegorie auf das individuelle Verhalten vor dem Hintergrund der bedrohten Gemeinschaft.

Das Thema der Legitimierung politischer Macht, für welches es bereits bei Klicpera und Tyl über den Einfluss von Nebenfiguren auf die Fürstenfiguren Anzeichen gibt, wird vollends brisant bei Simon Karel Macháčeks ZávišVitkovic, pán z Růže anebo Pokuta za zradu (1846), wo der Usurpator der Fürstenwürde am Schluss zwar enthauptet wird, aber als der fähigste Politiker weit und breit erscheint. Sein vom Thronfolgerecht sanktionierter Untergang - das Stück stammt aus dem Jahre 1846 - verheißt implizit, dass das geltende Recht später einmal aufgehoben werden wird. Dass der Verrat von Záviš am Thronfolger, sein Verstoß gegen die herrschende Ordnung, für den Záviš mit seinem Leben bezahlen muss, einmal nicht mehr bestraft werden wird, könnte man als Mitteilung im äußeren Kommunikationssystem verstehen; Záviš stirbt demnach einen tragischen Tod, weil er als Einzelperson untergeht, die Gründe seines Untergangs (das Thronfolgerecht, das nicht nach Befähigung, sondern nur genealogisch regelt) selbst aber dem historischen Untergang anheimfallen werden.

Josef Jiř́ Kolárs ebenfalls 1846 entstandene Tragödie Monika thematisiert geschichtliche Entwicklung durch die Verkettung der Handlung, nämlich durch die Abfolge von Aktion und Reaktion, die im Namen der Allgemeinheit Verstöße gegen die allgemeine Rechtsordnung ahndet und dabei sogar nicht einmal die allernächsten Familienmitglieder von der Bestrafung ausnimmt. Die Verkettung von 
Aktion und Reaktion ist kein simpler Kreislauf, sondern eine Entwicklung innerhalb des Familienkreises, der letztlich auf die Allgemeinheit hin überschritten wird: Der eine Bruder begeht das Verbrechen, die Schwägerin verlangt Rache, ihre Tochter führt sie aus, der Vater bestraft die Tochter für den Rachemord mit dem Tod. Das Tragische des Todes von Monika besteht darin, dass sie die der Mutter gelobte Rache ausgeführt hat, dann aber von ihrem Vater, der seine eigenen Rachegelüste überwunden hat, für diese Rache bestraft wird. Da nach dieser Tat auch der Vater aus Altersgründen allerdings - den Tod erwartet, bleibt in der Tragödie praktisch keine Hauptfigur mehr am Leben. Diese Aufhebung des Besonderen im Allgemeinen, von der Hegel auch im Zusammenhang mit der Tragödie spricht (vgl. Hegel $\mathrm{XV}$ /524), hat in Kolárs Familiendrama eine sehr direkte Umsetzung erfahren. Die Rache wird durch die Strafe aufgehoben, der Tod der Hauptfiguren ist als Aufhebung der falschen Einseitigkeit der streitenden Individualität zu sehen, die das „ewig Substantielle“ zum Vorschein bringt und die Sittlichkeit der Familie ablöst.

Der in Kutnohorstí haviri dargestellte Kampf der ausgebeuteten Bergknappen hat neben den sozialen auch einige politische und nationale Aspekte: Die ausbeutenden Bergherren - insbesondere die am stärksten negativ gezeichnete Figur Beneš z Vaitmile - werden als Antagonisten des einfachen tschechischen Volks gezeichnet. So liegt etwa der Grund für Beneš unversöhnlichen Hass gegenüber Opat, dem bedächtigen Ältesten der Knappen, darin, dass diese keinen Münzmeister anerkennen wollten, der nicht Tschechisch spricht; Beneš war somit zum Erlernen dieser Sprache genötigt. Er empfand dies als Demütigung, und sein heimtückisches und rücksichtsloses Vorgehen gegenüber den Knappen wie auch gegenüber Opat und dessen Tochter Anežka, die von seinem Sohn Hynek geliebt wird, ist also letztlich durch die sprachnationale Barriere motiviert. Diese kann auch nicht vom Liebespaar Hynek - Anežka überwunden werden, das somit nur potenziell als Chance für die Lösung des sozialen und nationalen Antagonismus gelten kann. Wenn die nationalen Differenzen Motiv für Beneš’ Hass sind, so ist die langjährige Abwesenheit des Jagiellonen-Königs in Böhmen die Rahmenbedingung für den Konflikt in Kutná Hora. Die Königsmacht erscheint zwar als Korrektiv, sie kommt jedoch zu spät und kann also die tragische Entwicklung der Ereignisse nicht mehr verhindern.

In Ferdinand Mikovec' Drama Zábuba rodu Premyslovskébo (1848) wird ähnlich wie bei Štěpáneks Břetislav První (1813) - der ruinöse Streit zweier tschechischer Geschlechter beschrieben. Während beim ersten hier behandelten Stück des obrozeni aus der Feindschaft der Familien keine politische Aussage gewonnen wird, ist im Handlungszusammenhang von Mikovec' Stück aus dem Revolutionsjahr 1848 sehr wohl eine allegorische Aussage zu erkennen: die Uneinigkeit der Tschechen untereinander befördert die nationale Tragödie; als Nutznießer derselben erscheinen die Deutschen, die auch die verderbliche Intrige anzetteln. Neben dem indirekten Appell an die nationale Einigkeit und der negativen Darstellung der Deutschen fallen noch zwei weitere Momente auf: die negative Darstellung des 
Adels als egoistischer Stand und die Kritik an traditionellen Bindungen und Verträgen. An deren Stelle soll vielmehr die Möglichkeit neuer Allianzen, neuer Zusammenschlüsse propagiert werden.

Die bisher analysierten Dramen sind vor dem Hintergrund der Ansprüche der patriotischen Intellektuellen der zweiten obrozeni-Generation zu betrachten. Diese waren mit dem real existierenden Theaterleben notorisch unzufrieden, obwohl allmählich ein Publikum gewonnen werden konnte, das auch für die politischen Anliegen, die in den aufgeführten historischen Dramen der 1830er und 1840er Jahre immer deutlicher werden, empfänglich war, sodass mit Fortschreiten des obrozeni die Dramen verstärkt für nationalpatriotische Zwecke verwendet wurden.

Divadlo mělo především substituovat neexistující politickou platformu. [...] Nadto divadlo mohlo působit i na pologramotné a negramotné diváky, kterých bylo stále dost. Všech těchto skutečností čeští buditelé využívali. P̌riřkli divadlu v národním životě větší význam, než tomu bylo v řadě jiných zemí. ${ }^{228}$ (Černý 1969/DčD II, 356f)

Die tschechische Theatergeschichtsschreibung, welche merklich auch von $\mathrm{Mu}-$ kařovskýs funktionalistischer Ästhetik geprägt wurde, spricht in diesem Zusammenhang von „mimodivadelní funkce“ [außertheatraler Funktion], ein Ausdruck, der nur insofern relativiert werden muss, als er impliziert, dass "normalerweise “ im Theater die ästhetische Funktion dominiere und alle anderen Funktionen, die ihm in seiner langen Geschichte zukamen - kultische, religiöse, repräsentative, didaktische, unterhaltende etc. - dem Theater „uneigentlich“ wären. Für das obrození waren im anspruchsvollen Theater eben tatsächlich andere Funktionen als die ästhetische dominant.

Das historische Drama hat in der tschechischen Theater- bzw. Literaturgeschichte mit dieser politischen Funktion also einen besonderen Stellenwert, der dem deutschsprachigen Theater, das ja vielfach emuliert wurde, weitgehend fehlt. „Naši dramatikové věnovali zvýšené úsilí historickému dramatu, o které autoři národů nacionálně neutlačovaných tolik neusilovali “229 (Černý 1969/DčD II, 357). Der zeitpolitische Aspekt - ob eine Nation politisch selbstständig ist oder von an-

228 „Das Theater musste vor allem die fehlende politische Plattform ersetzen. [...] Darüber hinaus konnte das Theater auch auf halbgebildete und ungebildete [des Lesens und Schreibens unkundige] Zuschauer wirken, deren es immer noch genug gab. Die tschechischen Erwecker haben all diese Umstände genützt. Sie sprachen dem Theater im nationalen Leben eine gröBere Bedeutung zu, als dies in einer Reihe anderer Länder der Fall war."

229 „Unsere Dramatiker widmeten dem historischen Drama verstärkte Anstrengungen; Autoren national nicht unterdrückter Völker bemühten sich um dieses [Genre] nicht in diesem Ausmaß." 
deren dominiert wird - gilt mithin als entscheidender Faktor für die Produktivität des Genres Historisches Drama.

Mezi divadlem českým a německým byl však především jeden podstatný rozdíl. V tomto období chybějí německému divadlu historické hry s nacionální útočnou tendencí. Němci jako národ plnoprávný a v rakouské monarchii nacionálně nadřazený takovéto hry, s výjimkou krátkého údobí za válek napoleonských, nepotřebovali. Naproti tomu v českém divadle neztratily vlastenecké hry politický význam ani ve druhé polovině 19. století, aktivně působily až do roku 1918, za okupace apod. ${ }^{230}$ (V. Procházka 1969/DčD II, 103)

Das theatergeschichtlich größte Ereignis des Revolutionsjahres 1848, Josef Kajetán Tyls Jan Hus, zeigt eine klare Frontstellung. Gegen die Reformen und Überzeugungen des Titelhelden stellt sich die von Rom aus regierte Kirche, deren Repräsentanten in Prag entweder Ausländer oder opportunistische Tschechen sind, die eigentlich innerlich für die Hus'schen Ideen Verständnis haben. Diese Ideen sind deutlich als „Wahrheit“ ausgewiesen, gegenüber welcher sich die Kirche aus schierem Machterhalt verwehrt. Von den Monarchen geht im Konflikt der Tschechen gegen die Kirche keine entscheidende Kontrolle mehr aus; Václav IV. möchte keine Unruhen in Böhmen, als sich diese aber nicht vermeiden lassen, zieht er sich beleidigt aus dem Konflikt zurück und hofft auf eine Einigung am Konzil. Zikmund (Sigmund), der Kaiser des Hl. Römischen Reichs und Václavs Bruder, ist aber zu feige, um gegen die Willkür des Klerus gegenüber Hus aufzutreten.

Das populäre Potenzial des historischen Dramas, das in den voraufgegangenen Jahrzehnten aufgrund der Dominanz anderer Genres im Repertoire nicht so deutlich erkannt werden kann, erweist sich in der Zeit um 1848, als im Spielplan verstärkt Stücke mit historischem Inhalt erscheinen (vgl. die Jahre 1848/49 in Laiske 1974, II/37-54) und auf außerordentliches Publikumsinteresse trafen. So fanden bei der Uraufführung von Tyls Jan Hus am 26. Dezember 1848 gar nicht alle Interessierten im Ständetheater Platz; der vor dem Theater versammelten Menge wurde in den Pausen von den Akten erzählt. Ähnlich war dies bei der Uraufführung von Josef Václav Fričs Václav IV., král český am 4. März 1849, als sogar der Orchestergraben des Ständetheaters für das Publikum geöffnet werden musste. Dass das tsche-

230 „Zwischen dem tschechischen Theater und dem deutschen gab es jedoch vor allem einen wesentlichen Unterschied. In dieser Zeit [dem Vormärz bzw. der ersten Hälfte des 19. Jahrhunderts] fehlen dem deutschsprachigen Theater historische Stücke mit offensiver nationaler Tendenz. Die Deutschen als vollrechtsfähiges und innerhalb der österreichischen Monarchie national privilegiertes Volk benötigten solche Stücke nicht, nur die kurze Zeit der Napoleonischen Kriege stellt hier eine Ausnahme dar. Im Gegensatz dazu haben im tschechischen Theater die patriotischen Stücke auch nicht in der zweiten Hälfte des 19. Jahrhunderts ihre politische Bedeutung verloren, sie wirkten aktiv bis ins Jahr 1918, während der Okkupation etc." 
chische Publikum mit den Aufführungen dieser historischen Dramen politische Momente verband, war offensichtlich, denn im November 1850, als das Scheitern der Revolution und die Wiederherstellung zentralistischer Machtstrukturen besiegelt waren, geriet die Premiere von Josef Jiří Kolárs Žižkova smrt - bereits der Titel konnte allegorisch als Untergang der Revolution gelesen werden - zu einer Manifestation politischen Unmuts über die neue Regierung und die Fortsetzung des Belagerungszustandes: Laut Zeitungsbericht (Pražský večerní list, 20.11.1850) reagierte das Publikum auf viele Repliken mit Gejohle oder Applaus (vgl. Černý 1969/DčD II, 335; Haman 2007, 239). ${ }^{231}$

\section{IV.6. Das historische Drama in der zweiten Hälfte des 19. Jahrhunderts}

\section{IV.6.1. Exkurs zur Geschichte des Nationaltheaters}

Wie oben (vgl. S. 119f) gezeigt wurde, nimmt die Bewegung für das 1881 bzw. 1883 eröffnete tschechische Nationaltheater bereits vor 1848 ihren Beginn, wobei zuerst von einer ausgeglichenen „utraquistischen“ Nutzung des Ständetheaters (tschechische Aufführungen fanden immer nur an Sonn- und Feiertagen, meistens nachmittags, statt) ausgegangen wurde, auch mit Unterstützung von deutschsprachiger Seite. ${ }^{232}$ Nach den Erfahrungen im Ständetheater ging man aber dennoch bald dazu über, die Errichtung eines eigenen Theatergebäudes zu planen; erste Pläne dazu scheiterten aus finanziellen Gründen. 1850 wurde schließlich unter František Palacký ein Verein gegründet, der »Sbor pro zř́zení českého národního divadla v Praze«, welcher die finanziellen Mittel für die Errichtung eines solchen Theaters aufbringen sollte (vgl. Štěpán 2006, 11). Allerdings blieben größere Fortschritte in der Finanzierung in unmittelbarer Folge aus, da sich in den 1850er Jahren das politische Klima hier wieder zu einem rigorosen zentralistischen Absolutismus hin entwickelte.

Nach der blutigen Niederschlagung des Prager Aufstandes von 1848 und der Etablierung einer neoabsolutistischen Ordnung unter dem Innenminister Alexan-

231 Wenn nur wenige Tage später die neue Theaterordnung proklamiert wurde, so war deren repressiver Charakter wohl auch von dieser Premiere beeinflusst (vgl. Strejček 1932, 94). Kolárs Žižkova smrt wurde in der Folge auch für den Nachdruck verboten, weil die Behörden erst bei der Premiere erkannten, wieviel Aktualisierungspotenzial im Stück steckt (bzw., nach der hier vorgeschlagenen Terminologie wieviel „Depräsentation“ - vgl. Pokorná 2015, 427-434).

232 Karel Havlíček Borovský freilich proklamierte, dass man von den böhmischen Ständen fordern müsse, dass in ihrem Theater (= dem Ständetheater) viermal die Woche tschechisch und dreimal deutsch gespielt werden solle, was selbst Tyl aus organisatorischen Gründen unrealistisch vorkam (vgl. Otruba/Kačer 1961, 349). 
der von Bach war auch das tschechische Theaterleben in Prag, das im Zuge der Revolution 1848 große politische Relevanz bekommen hatte, wieder stark eingeschränkt. Für das Theater hatte die Wiedereinführung der präventiven Zensur durch die Bach'sche „Theaterordnung und Instruktion“ vom 25. November 1850 schwerwiegende Folgen. Zumal Bach alle Versammlungen unterbinden wollte, bei denen "gefährliche" Patrioten zusammenkommen, wurden von Polizeibediensteten - in der Prager Zensurbehörde war Leopold von Sacher-Masochs Vater in leitender Funktion tätig - die Generalproben und Aufführungen überwacht und gegebenenfalls auch untersagt.

Divadlo, působící bezprostředně svou názorností, uvědomující a burcující zástupy, bylo rakouské vládě ze všech uměleckých druhů nejnebezpečnější, a proto mu věnovala zvláštní pozornost. [...] V nótách a hlášeních pražskému místodržitelství upozorňovali cenzoři několikrát, že pro plebejské a nevzdělané české obecenstvo jsou i zdánlivě bezvýznamné pasáže důvodem $\mathrm{k}$ demonstracím, že záměrně vyhledává $\mathrm{v}$ historických kusech vztahy $\mathrm{k}$ současným poměrům atd. ${ }^{233}$ (Klosová 1977b/DčD III, 16)

Im Jahr 1854 konnte der »Sbor pro zřízení českého národního divadla v Praze« zwar einen ersten Architektenwettbewerb für das Nationaltheater ausschreiben, aufgrund fehlender Mittel aber keine Ausführung des Bauvorhabens einleiten (vgl. McCord 1993, 97f). Empfindliche Kürzungen der finanziellen Mittel für tschechische Aufführungen kamen hinzu, um in den 1850er Jahren das tschechische Theaterleben administrativ zu kontrollieren. Den in den Jahren 1848/49 gespielten Stücken wurde somit die Chance auf Aufführungsmöglichkeit genommen. In den 1850er Jahren konnten im professionellen Ständetheater auf Tschechisch wiederum praktisch nur Nachmittagsvorstellungen an Sonn- und Feiertagen gegeben werden; das Repertoire zielte auf den Geschmack eines breiten Publikums ab und genügte nicht den Ansprüchen der tschechischen Intelligenz. Drama und Theater verloren künstlerisch und gesellschaftlich an Bedeutung; die Anstrengungen für die Errichtung eines Nationaltheaters, die 1850 einsetzten, gerieten in dieser repressiven Atmosphäre ins Stocken - so wurden Spendenwerber angezeigt, der Trägerverein wurde inaktiv etc.

Gegen Ende des Jahrzehnts kam wieder etwas mehr Bewegung in das Theaterleben, einerseits weil aus der Haft entlassene Aktivisten der 1848er-Revolution wie-

233 „Ein Theater, das unmittelbar durch seine Anschaulichkeit wirkt, dass die Menge zum Bewusstsein bringt, war für die österreichische Regierung die gefährlichste aller Kunstformen, daher widmete sie ihr besondere Aufmerksamkeit. [...] In Noten und Anzeigen für den Prager Statthalter wiesen die Zensoren einige Male darauf hin, dass für das plebejische und ungebildete Prager Publikum auch die scheinbar bedeutungslosen Passagen Anlass für Demonstrationen sind, dass dieses vorsätzlich in historischen Stücken Beziehungen zu gegenwärtigen Verhältnissen sucht." 
der tätig wurden (Karel Sabina, Josef Václav Frič, Vincenc Vávra Haštalský) und in Zeitungen und Zeitschriften (Národní listy, Lumír, Máj) eine neue Generation von Dramatikern und Theaterkritikern (allen voran Jan Neruda) Publikationsmöglichkeiten bekam.

Obschon die politischen Regelungen das Theater - nicht allein das tschechische - einschränkten, werden die 1850er Jahre mit einer neuen Form von Schauspielarbeit in Verbindung gebracht, nämlich der des individualistischen Schauspielers romantischer Prägung, der seine Persönlichkeit den Rollen aufprägte, also nicht mehr nur "Typen“ mittels konventionalisierter Zeichen darstellte. Die Unmöglichkeit, politische Anliegen in den 1850er Jahren explizit zu äußern, bewirkte, dass die Dramentexte selbst politisch weitgehend unverfänglich gestaltet wurden, zugleich aber Extemporationen während der Aufführung an gesellschaftlicher Brisanz erlangen konnten. So entsprach der „,romantische“ Schauspielstil des "genialischen“ Darstellers den Dramenkonzeptionen: markante Schauspielerpersönlichkeiten - allen voran der vielseitige Theateraktivist Josef Jiř́ Kolár (Schauspieler, Dramatiker und Übersetzer in einer Person) - verkörpern außergewöhnliche Heldenfiguren, die Ensembleleistung bzw. der fiktionale Kontext der Heldenfigur sind zweitrangig. Dieser ausgeprägte Individualismus wird als künstlerische Reaktion auf die repressive Politik verstanden; er ermöglichte zugleich auch die aktualisierende Referenz auf zeitgenössische Angelegenheiten, die in Ergänzung zu den dramatischen Textvorlagen erfolgten konnte. Noch immer galt es in den 1850er Jahren, das tschechische dramatische Schaffen in seiner Qualität dem Drama anderer europäischer Nationen anzupassen, wobei vor allem die deutsche und englische Literatur (man organisierte ab 1854 die Ausgabe von Shakespeare-Übersetzungen; im Jahr 1857 gab es elf Shakespeare-Inszenierungen, die auf der gedruckten Übersetzung beruhten und damit wohl etwas steif ausgefallen sind - Drábek 2012, 124f) als maßgeblich angesehen wurden (vgl. Císař 2004a, 80-88; H. Schmid 2006, 294). Mit einiger Verspätung wurde so der romantische Stil im Theater etabliert, ${ }^{234}$ das Publikum akzeptierte vermehrt auch ein ernstes Repertoire, in dessen Inszenierungen oft allegorisch auf die Gegenwart angespielt wurde (vgl. Haman 2007, 238f).

1857 bildete sich im Ständetheater, der nach wie vor wichtigsten Bühne für das tschechische wie deutsche Theaterleben, ein eigenes tschechisches Ensemble heraus, dessen Mitglieder nicht „utraquistisch“ engagiert wurden; immer noch aber musste das Ensemble von Laienschauspielern unterstützt werden, wenn die Zahl der dramatispersonae - wie etwa bei den Shakespeare-Dramen - zu groß war.

234 Allerdings verzeichnet die tschechische Theaterhistoriographie im Schaffen Tyls der Jahre 1847-49 realistische Tendenzen: Dies geschah nicht unberechtigt, zugleich aber entspricht es natürlich dem Schematismus marxistischen Geschichtsdenkens, wenn in einer Zeit revolutionärer Atmosphäre auch im Bereich von Kunst und Literatur Sozialkritik und Klassenkampf hervorgehoben werden. 
Der tschechische Landtag forderte 1861 die Landesvertretung (zemský výbor) auf, die Theaterfrage zur Zufriedenheit beider Nationen zu lösen bzw. für die Tschechen ein neues Gebäude zu errichten. An der Spitze der Theaterbewegung befand sich als Vorsitzender des 1850 gegründeten Vereins für ein tschechisches Nationaltheater zuerst František Palacký, dem 1863 František Ladislav Rieger, der Führer der tschechischen Nationalpartei, folgte.

Rieger, der dem konservativeren Flügel der Nationalpartei, den sogenannten Alttschechen angehörte, konnte sich im Theaterverein gegen die Jungtschechen mit der Auffassung durchsetzen, ein kleineres Theater zur Überbrückung der Wartezeit auf ein repräsentatives Theatergebäude zu errichten. Der umgangssprachliche Name »Prozatímní divadlo « (,einstweiliges Theater', ,Interimstheater ${ }^{c}$ - der offizielle Name lautete »Královské zemské české divadlo v Praze « - Císař 2004b, 10) war Programm, denn entgegen der Auffassung, dass die seit 1850 vom Theaterverein gesammelten Gelder gleich in ein repräsentatives Gebäude investiert werden sollten, war Rieger den Ansicht, dass ein provisorisch adaptiertes Theatergebäude notwendig sei, um Schauspieler auf das Nationaltheater vorzubereiten, entsprechende Dramenliteratur anzuregen und um ein Publikum heranzubilden, das das Nationaltheater frequentieren sollte. Das Prozatímní divadlo - es musste auch als Bühne für Musiktheater dienen - wies architektonisch und bühnentechnisch gravierende Mängel auf, sodass es gleichsam als Memento für die Fertigstellung eines voll funktionalen Theatergebäudes wahrgenommen wurde. Für Aufführungen mit größerem Ensemble wich man auf großzügigere Freiluftbühnen aus, die schon im Vormärz für Theaterzwecke gedient hatten und auf denen sich das Volkstheater weiterentwickelte.

Als 1862 mit der Gründung eines wirklich dauerhaften tschechischen Theaters, dem Prozatímní divadlo, das Theater weiter professionalisiert und ausdifferenziert wurde, bildete die scheinbar unpolitische Theaterpraxis der 1850er Jahre die Grundlage für den Ausbau des tschechischen Theaters, der allerdings nicht ganz wunschgemäß vonstatten ging: Abgesehen von den Mängeln des Theatergebäudes fehlte es an guter und populärer Dramenliteratur in tschechischer Sprache, mit der ein Publikum gebunden werden konnte. Einen wahren Boom hingegen erlebte das aus Wien übernommene Operettengenre, das ein großes Publikum erreichen konnte.

Zudem gab es Schwierigkeiten bei der Besetzung der Leitung: Zwei Direktoren scheiterten daran, das Theater auch ökonomisch zufriedenstellend zu führen. 1866, nach Ausbruch des Österreichisch-Preußischen Krieges, suchte das Ensemble um die Erlaubnis an, selbst den Betrieb weiterführen zu können; es war damit erfolgreich. Als es 1866 zu einer Neuausschreibung des Direktorenpostens kam, schrieb Jan Neruda in den Národní listy:

Přejde-li řízení divadla do rukou nových, musí to být ruce české. Postavte v čelo našeho divadla muže Čecha, který jest národovcem uvědomělým, který úkol svůj plně zná a nadšen jest 
pro rozkvět umění českého! [...] Sám myšlenky jsa schopen, přinutí muž takový vše kolem sebe k celému duševnímu životu; nadšený, pevný směr, důstojné sobě počínání pokryje jeviště $\mathrm{v}$ době co možná blízké milým květem i zdravým ovocem, nadšení z jeviště vanoucí vzbudí i udrží také nadšení v obecenstvu, a málo let vzorné vzájemné práce zabezpečí budoucnost ústavu pro dlouho, snad i pro vždy!235 (Neruda zit. nach McCord 1993, 143)

Da es aber keine ausreichend vermögende und einschlägig qualifizierte Person aus dem Kreis tschechischer Patrioten gab, wurde ein Theaterverein (»Divadelní družstvo «) gegründet, dem die Leitung des Prozatímní divadlo anvertraut wurde. Bedřich Smetana und Josef Jiř́i Kolár konnten als verantwortliche künstlerische Leiter für die Bereiche Musik- bzw. Sprechtheater gewonnen werden.

Für das Prozatímní divadlo entstand eine Reihe von Opernkompositionen, die auf historischen oder pseudohistorischen Stoffen beruhten, etwa Bedřich Smetanas Branibori v Čechách [Die Brandenburger in Böhmen; 1865; Libretto: Karel Sabina], Karel Šebors Templári na Moravě [1865; Die Templer in Mähren] und Smetanas Dalibor, eine wagnerianische Oper, die anlässlich der Grundsteinlegung für das Národní divadlo am 16. Mai 1868 Premiere hatte. Dass „historisches“ Material die Vorlage für diese Kompositionen abgibt, liegt im bereits oben diskutierten Prestige von geschichtlichem Material begründet. Die große Oper als ursprünglich höfische Kunstform, die dem bürgerlichen 19. Jahrhundert gleichfalls als repräsentativstes Genre galt, erhob mit dem Rückgriff auf die Vergangenheit die Nation zum vornehmen Thema von Kunstwerken. Bezeichnenderweise war Sabinas Libretto für Braniboŕi v Čechách allegorisch konzipiert: Der ohne große historische Faktentreue dargebotene Stoff sollte die Lage eines unter Fremdherrschaft stehenden Volks repräsentieren, auch die Elemente aus der tschechischen Volksmusik, die Smetana in diese Oper und kurz darauf noch erfolgreicher in die komische Oper Prodaná nevěsta [Die verkaufte Braut] integrierte, entsprachen der nationalen Orientierung, die allerdings sogar unter den Tschechen selbst nicht unumstritten, aber immerhin für unterschiedliche Rezeptionsinteressen attraktiv war (vgl. SIUD, 452; Císař 2004b, 16-18).

František Rieger, dem von seiten der Jungtschechen vorgehalten wurde, den Bau eines ständigen Nationaltheaters zu wenig energisch zu betreiben, trat 1865 als Ob-

235 „Wenn die Theaterleitung in neue Hände gelegt wird, müssen dies tschechische Hände sein. Stellt an die Spitze unseres Theaters einen tschechischen Mann, der ein bewusster Nationalpatriot ist, der seine Aufgabe bestens versteht und der sich für die Blüte der tschechischen Kunst begeistert. [...] Wenn er zu Gedanken fähig ist, vermag es ein solcher Mann, alle um sich zu einem ganzen Seelenleben zu führen; ein enthusiastischer, fester Kurs, ein würdiges Treiben soll möglichst bald auf der Bühne sein und auf dieser liebliche Blüten und gesunde Früchte bringen, eine Begeisterung, die von der Bühne kommt, weckt und hält die Begeisterung in der Bevölkerung aufrecht, nur wenige Jahre mustergültiger gemeinsamer Arbeit schaffen eine Zukunft der Einrichtung für lange Zeit, wahrscheinlich für immer.“ 
mann des »Sbor pro zřízení českého národního divadla v Praze « zurück; an seine Position kamen mit Ferdinand Urbánek und Karel Sladkovský zwei Vertreter des „jungtschechischen“ liberalen Flügels der Nationalpartei, die den Bau zu einer causa prima machten und den jungen Prager Architekten Josef Zitek mit dem Bau beauftragten. Zítek schlug eine Gestaltung im Stil der Neo-Renaissance vor, um symbolisch die Wiedergeburt der Nation zu unterstreichen.

Die festliche Grundsteinlegung für das Národní divadlo erfolgte am 16. Mai 1868; zuvor wurden unter feierlichem Geleit Felsen von den in verschiedenen Sagen und Mythen verklärten Bergen Ríp, Blaník und Radhošt, Gesteinsgaben aus anderen Gebieten der böhmischen Länder und Kieselsteine aus Konstanz, wo 1415 Jan Hus am Scheiterhaufen hingerichtet worden war, an den Bauplatz transportiert. Josef Jiř́ Kolár, der künstlerische Direktor des Prozatímní divadlo, rezitierte »Libušes Prophezeiung « am Neustädter Theater; als am Ende der Lesung eine große Darstellung des Nationaltheaters projiziert wurde, war das Publikum völlig begeistert. ${ }^{236}$ Die pompöse Zeremonie zur Grundsteinlegung zeugt noch deutlicher als die Eröffnungsfeierlichkeiten von der „mythische[n] Signifikanz [des Nationaltheaters] vor allem für kleinere Ethnien" (Tökei 2006, 5) in der Donaumonarchie. František Palacký, die prominenteste Persönlichkeit bei der Eröffnung, sprach beim Spatenstich die Worte:

Ve jménu národa, v Čechách a na Moravě jednotného! Požehnej Pán Bůh dílu svatyně této, ve které národu českému zjevovati a před oči stavěti se má všeliká mravní pravda i krása. ${ }^{237}$ (zit. nach Ksandr 2009, 48)

Kaiser Franz Joseph bleibt den Feierlichkeiten fern, weil er in ihnen eine nationalistische Veranstaltung - die sie ja auch war - sah. Stattdessen kam er einen Monat später, am 21. Juni 1868, zur Eröffnung einer neuen, nach ihm benannten Brücke über die Moldau. Da an diesem Datum 1621 am Altstädter Ring die Anführer der protestantischen Stände hingerichtet worden waren, organisierten tschechische Studenten Demonstrationen gegen Österreich (vgl. zu den Feierlichkeiten McCord 1993, 198-209, Ther 2006, 267-271).

Die Jahre der Planungs- und der Bauphase blieben von heftigen Streitereien zwischen dem alttschechischen und dem jungtschechischen Flügel geprägt. Diese Auseinandersetzungen hatten bereits deutlich nationalistische Implikationen, so warfen etwa die Alttschechen den Jungtschechen vor, eine große Kreditsumme

236 Eine detaillierte Beschreibung der Feierlichkeiten durch einen anonymen patriotischen Berichterstatter sowie der Abdruck von Kolárs Zeremonienspiel Věstba Libušina [Libušes Prophezeiung] findet sich im Band 68 der »Divadelní bibliotéka « (Anonymus 1868).

237 „Im Namen des Volkes, das eines ist in Böhmen und Mähren. Gott der Herr segne das Werk dieses Heiligtums, in dem sich dem tschechischen Volk die sittliche Wahrheit und Schönheit offenbaren und vor Augen treten soll." 
bei der Česká sporititelna zu leihen, die als deutsche Bank galt, auch wurden nun für die künstlerische Dekoration bewusst tschechische Künstler gewählt und deutschböhmische implizit ausgeschlossen (vgl. ebd., 217 u. 228).

Das Národní divadlo wurde anlässlich der Hochzeit von Kronprinz Rudolf eröffnet. Beim Pragbesuch des frisch vermählten Paares wurde zum Auftakt am 15. Juni 1881 Bedřich Smetanas Oper Libuše als erste Aufführung gegeben. Die Eröffnung fand statt, obwohl noch nicht alle Arbeiten abgeschlossen waren. Smetanas Auftragswerk war hervorragend geeignet, allen Anforderungen und Interessen zu genügen: der Stoff aus der Nationalmythologie war wohlbekannt, Tschechisch als Opernsprache überzeugte, die Musik kombinierte die klassischen Opernelemente mit Folkloreelementen, der Stoff aus der tschechischen Nationalgeschichte sollte auch die Annahme der Wenzelskrone durch Rudolf als Desiderat anzeigen (vgl. Ther 2006, 281).

Eine weitere pompöse Eröffnung des vollends fertig gestellten Theaters war für den September 1881 geplant; zu dieser sollte es aber nicht kommen, da am 12. August 1881 durch Unachtsamkeit bei Dacharbeiten ein Feuer ausbrach, das große Teile des Theaters wieder zerstörte. Die Brandkatastrophe rief einen energischen Wiederaufbaugeist hervor, sodass bereits am 18 . November 1883 das wiederaufgebaute Theater, das nun nach Plänen von Josef Schulz um das Gebäude des angrenzenden Prozatímní divadlo erweitert worden war, eröffnet werden konnte. ${ }^{238}$

Dass die berühmte Widmungsinschrift am Bühnenportal „Národ sobě“ („Das Volk widmet sich dieses Gebäude selbst") kein bloßer Mythos ist, der nicht den tatsächlichen (Finanz-)Leistungen bei Planung und Bau bzw. Wiederaufbau entspricht, geht aus dem Kontoauszug des »Sbor pro zř́zení českého národního divadla v Praze « hervor, der in den Národní listy am 20. November 1883 abgedruckt wurde (vgl. McCord 1993, 283f): Demnach beliefen sich die Einnahmen aus diversen - meist über Zeitungen und Zeitschriften organisierten - Spendenaktionen auf eine Höhe von 784.474 Gulden, die Stadt Prag leistete 50.000 Gulden, der Kaiser spendete 20.000 und Erzherzog Rudolf 5.000 Gulden. Die Gesamtkosten für den Wiederaufbau betrugen in dieser Bilanz 815.224 Gulden.

Nach der Eröffnung wurden fast zwei Jahre lang Sonderzugfahrten aus dem ganzen Land organisiert, um die tschechische Bevölkerung mit ihrem neuen kulturellen Zentrum bekannt zu machen und um aus den Erlösen dieser Theaterfahrten die Budgetnöte auszugleichen, die den Betrieb schon früh belasteten. Als markantestes kulturelles Zeichen der erstarkten tschechischen Nation hatte das Národní divadlo nämlich bald mit dem Problem zu kämpfen, einerseits repräsentativ für die

238 Josef Schulz war zeitweise ein junger Mitarbeiter von Josef Zítek. Später bauten sie zusammen den Konzert- und Ausstellungsbau Rudolfinum; Schulz war auch der Architekt des großen Nationalmuseums am Wenzelsplatz (1891 eröffnet). Auch wenn dies wichtige Bauten der Hauptstadt Böhmens waren, hatten sie bei weitem nicht denselben Symbolwert für die tschechische Nation wie das Národní divadlo. 
Nation zu sein und diese künstlerisch von ihrer besten Seite zu zeigen, andererseits wurden vom Theaterverein, in dem die bürgerliche Elite Prags, die sich politisch an den „Alttschechen“ orientierte, bestimmend war, auch kaufmännische Interessen artikuliert, die sich nicht immer mit den künstlerischen Ansprüchen trafen. Darüber hinaus war es angesichts der fortgeschrittenen sozialen Differenzierung der tschechischsprachigen Bevölkerung schwierig, dem Anspruch einer dem ganzen Volk verpflichteten Institution zu genügen, sodass in der Programmgestaltung die verschiedensten Kompromisse und Kombinationen getroffen werden mussten (vgl. Císař 2011, 13-16).

Das Verhältnis des Provisoriums Prozatímní divadlo zum Národní divadlo wird von Císař (vgl. 2004, 30-35) als kontinuierlicher Übergang gedeutet. Die Theaterpraxis und ihre Auswirkungen auf die Dramenproduktion blieben nach der Eröffnung des Národní divadlo weitgehend unverändert, das Národní divadlo aber hat einen großen symbolischen Wert für die tschechische Kultur, markiert doch seine Eröffnung die endgültige Emanzipation bzw. Konstituierung der tschechischen Kultur und Nation. ${ }^{239}$

\section{IV.6.2. Josef Václav Frič: Svatopluk a Rastislav. Truchlohra v pateru dějstvích z dějin moravských (1857)}

[Svatopluk und Rastislav. Trauerspiel in fünf Akten aus der mährischen Geschichte; UA 29.11. 1857, publ. 1879]

In den 1850er Jahren sind kaum historische Dramen entstanden, eine rare Ausnahme ist dieses Trauerspiel von Josef Václav Frič, das zwar erst 1879 erstmals gedruckt erschienen ist (als Band 1 der im Eigenverlag publizierten Sebranéspisy Josefa Václava Friče), aber nur eine einzige Aufführung erfahren hat. ${ }^{240}$ Das Stück ist dem Andenken an L'udovít Štúr, den slowakischen Politiker und Philologen, gewidmet, der 1856 verstarb. ${ }^{241}$

239 Vgl. die knappe, aber präzise Darstellung in Schmitz/Udolph (2001, 88f).

240 Diese erfolgte um 1858, denn im Nachwort der gedruckten Ausgabe berichtet Frič von den schwierigen Umständen dieser Inszenierung „,vor 21 Jahren“ unter der Regie von Josef Chauer (1805-1859), der zugleich auch den Fürsten Rastislav spielte. Die geschilderte Schwierigkeit bestand vor allem darin, dass Szenen weggelassen werden mussten, um rechtzeitig die Bühne für die Vorbereitung einer deutschsprachigen Aufführung freizumachen (vgl. Frič 1879, 145).

241 Die Widmung lautet: „Vzácným stínům šlechetného Ljudevíta Štúra, pěvce »Nitry« co upomínka srdce, jím osiřelého, v smutku posvěceno.“ („Dem kostbaren Schatten des vornehmen Ljudevít Štúr, dem Sänger von »Nitra «, als Andenken des Herzens, das ohne ihn verwaist ist, in Trauer gewidmet.") 
Das im Großmährischen Reich des 9. Jahrhunderts angesiedelte Trauerspiel stellt den Mährern die Franken gegenüber, die in Gestalt von ihrem König Ludvík und dessen Sohn Karloman die Oberherrschaft über das Großmährische Reich behalten wollen. Dagegen wehren sich - unterschiedlich beständig - der mährische König Rastislav und sein Neffe Svatopluk.

Der gesamte erste Akt zeigt die Spannungen innerhalb des Lagers der Franken. Gondaker wird vorgeworfen, bewusst Lügen gestreut zu haben, um Karloman gegen seinen Vater Ludvík aufzuwiegeln. Gondaker allerdings behauptet, er habe die Vorwürfe gegen Karloman nicht erfunden, dieser sei tatsächlich ein Gegner seines Vaters und wolle im Verein mit den Mährern Ludvík angreifen. Drago, der betagte Vertraute Ludvíks, bezweifelt allerdings die Anschuldigungen Gondakers gegen Karloman. Zwar liege es in der Familie, dass es zu heftigen Kämpfen der Familienmitglieder gegeneinander komme, Karloman aber sei seinem Vater nicht feindlich gesinnt. Als angeblicher Beweis für die Richtigkeit der Vorwürfe gegen Karloman wird dessen Sohn Arnulf von Gondaker und dem intriganten Priester Vichink zu Ludvík gebracht. Arnulf hat die Verleumdungsabsichten Gondakers und Vichinks durchschaut, er erbittet den Schutz seiner Tante Judita, der Schwester Karlomans. Arnulf erklärt, sein Vater Karloman habe immer nur hasserfüllt von den Mährern gesprochen; dass er sich mit ihnen verbünde, sei ausgeschlossen. Tatsächlich hat Karloman mährisches Gebiet unterworfen, um es seinem Vater zu schenken. Damit werden die Verleumdungen Vichinks und Gondakers widerlegt.

Der gefangen genommene Fürst von Nitra, Svatopluk, sieht sich gedemütigt; anstatt wie vereinbart dem fränkischen König Ludvík Gefolgsam und Loyalität zu geloben, ruft er den Kampf gegen die Franken aus (I/6, S. 28). Judita reißt ihm aber dabei die mährische Fahne aus der Hand und wirft sie zu Boden. Svatopluk, der von Karlomans neidischem Bruder Luděk Unterstützung erhält, geht stolz ab. Luděk folgt ihm. Ludvík sieht diese Entwicklung als vorteilhaft, es gäbe nun einen Grund, in Mähren einzufallen und es zu unterwerfen. Judita kündigt an, als Frau über die Männer herrschen zu wollen.

Der zweite Akt führt die Unterschiede zwischen Rastislav, dem Fürsten des Großmährischen Reichs, und dessen Neffen Svatopluk vor, der Fürst von Nitra ist. Svatopluk ist ein jugendlicher und ungestümer Fürst, der im Zorn über eine vorwurfsvolle Botschaft von Rastislav auch gerne gleich einmal mit dem Speer auf den Boten zielt. Rastislav bittet Svatopluk, dass er ihm Waffenhilfe im Kampf gegen die Franken leiste, die er schon teilweise besiegt hat; nur für den endgültigen Sieg über Karloman benötige er in Nitra Svatopluks Unterstützung. Dessen jugendlicher Ehrgeiz will Rastislav den Ruhm eines Sieges über die Franken nicht gönnen. Als der heimtückische Vichink nach Nitra kommt und im Namen Rastislavs die Festnahme Svatopluks fordert, beginnen dessen Gefolgsleute gegeneinander zu kämpfen. Karloman, der Svatopluk eine Allianz mit den Franken vorschlägt, um Rastislav besiegen zu können, kommentiert dies belustigt: „Rozkošné divadlo! Výborně, Slované! / 
patrně vás ten Vichink dobře zná. / Jen se nám takto ničte navzájem: / konečná z toho nám je kyne žeň! “242 (II/6, S. 49).

Die Versuche von Strachota, zwischen Rastislav und Svatopluk zu vermitteln, misslingen, weil sich Svatopluk tatsächlich im Ärger über Rastislavs Machtansprüche mit den Franken verbündet. Die fränkischen Kämpfer werden allerdings von Vichink und Karloman so instruiert, dass sowohl Rastislav wie auch Svatopluk in ihre Gefangenschaft geraten.

Im dritten Akt stoßen die bei der Jagd umherirrenden Judita und Arnulf auf den von den Franken geblendeten Rastislav, der als Einsiedler in einer Klosterruine mit dem Schicksal Mährens hadert. Svatopluk, der aus fränkischer Gefangenschaft geflohen ist, kommt in Rastislavs Einsiedelei. Der seine Allianz mit Karloman bedauernde Svatopluk wird vom sterbenden Rastislav beauftragt, Mähren von der fränkischen Herrschaft zu befreien. Judita, die heimlich diese Szene beobachtet und Svatopluk eigentlich gefangen nehmen sollte, empfindet plötzlich Respekt für die mährischen Fürsten, sie schlägt ihm also vor, dass sie die mährische Angelegenheit in Regensburg bei Gericht vorbringen will.

Beim im vierten Akt gezeigten fränkischen Gottesgericht, bei dem Judita sehr zum Missfallen ihres Vaters Ludvík die Anklage Mährens vertritt, wird durch Zweikampf entschieden. Svatopluk überwältigt Luděk, der anstelle von Ludvík in den Kampf tritt. Trotz der „höheren“ gerichtlichen Bestätigung von Svatopluks Klage wird diese von Ludvík und Karloman willkürlich aufgehoben und jener wegen Landesverrats verurteilt. Der alte Drago und Judita sind über dieses Unrecht empört. Judita bezeichnet sich entgültig als Frau Svatopluks, sie möchte ihm helfen.

Im fünften und letzten Akt, der ein Jahr nach der ungerechten Verurteilung Svatopluks spielt, schenken Ludvík und Karloman aus Kummer darüber, dass Judita verschwunden ist, Svatopluk die Freiheit und setzen ihn als freien König von Mähren ein. Nur muss er sie aus der vermeintlichen mährischen Gefangenschaft befreien. Die Mährer haben sich wieder einmal gegen die Franken erhoben. Da sich Svatopluk Judita zu seiner Frau auserkoren hat, kämpft er mit vollem Einsatz und mit fränkischer Unterstützung gegen die Mährer. Er verwundet deren erfolgreichen Anführer Slavoměr mit einem Pfeil. Dieser ist aber niemand anderes als die als Mann gewandete Judita, die sich in dieser Verkleidung an die Spitze des mährischen Heeres gestellt hat, um Svatopluk zu befreien. Die wechselseitigen Befreiungsversuche des mährisch-fränkischen Paares enden also damit, dass Svatopluk unwissentlich Judita tödlich verwundet. Als Reaktion auf ihren Tod übt Svatopluk blutige Rache an den Franken. Das Stück endet mit einer Warnung, dass der Siegesjubel der Mährer in sein Gegenteil werde umschlagen können. Jedenfalls sind die Gegensätze

242 „Ein tolles Schauspiel. Großartig, ihr Slawen! / Dieser Vichink kennt euch wohl recht gut / Vernichtet euch nur gegenseitig auf diese Weise / letztendlich fahren wir dann die Ernte ein!“ 
zwischen den Franken und den Mährern, die überdies auch noch Unterstützung von Prag erhalten, am Ende größer als je zuvor.

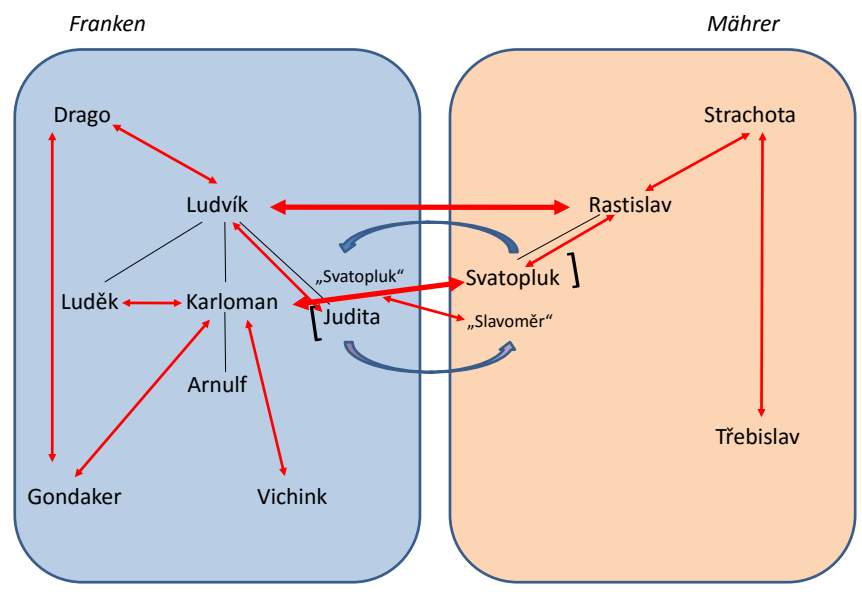

Graphik 16 - Josef Václav Frič: Svatopluk a Rastislav (1857)

Der Grundkonflikt besteht darin, dass die Franken Ansprüche auf das Großmährische Reich erheben. Diese werden aber nicht allein von Rastislav und Svatopluk in Frage gestellt, sondern auch innerhalb des fränkischen Lagers. Insbesondere Judita und Drago halten diese Ansprüche und das aus diesen abgeleitete Vorgehen gegen die fürstlichen Repräsentanten des Großmährischen Reichs für nicht gerechtfertigt.

Aus der obenstehenden Handlungs- und Figurenkonstellation ist gleich ersichtlich, dass die Franken einen größeren Anteil an den dramatis personae haben als die Mährer. Zudem sind auch die Konflikte innerhalb des fränkischen Lagers zahlreich, wobei sie allerdings nicht immer dramaturgisch klar ausgeführt sind. ${ }^{243}$ Zum Grundkonflikt zwischen den beiden „nationalen“ Lagern gesellt sich ein Generationenkonflikt, der im Lager der Franken gleich in mehrfacher Hinsicht auftritt: im Verhältnis des Königs Ludvík zu seinen drei Kindern Luděk, Karloman und Judita sowie auch im Verhältnis von Arnulf zu seinem Vater Karloman bzw. seiner Tante Judita, der sich Arnulf ganz zuwendet. So groß die Zwistigkeiten unter den Deutschen auch sein mögen - Ludvík spricht ja von einem Fluch, der über seiner Familie hängt -, sie werden ausgeräumt, sobald es um die Interessen gegenüber Mähren

243 So ist etwa nicht klar, weshalb Gondaker und Vichink im ersten Aufzug hartnäckig gegen Karloman intrigieren oder was die Ursache des Vater-Sohn-Konflikts zwischen Ludvík und Karloman ist. Diese Konflikte sind einer Vorgeschichte zuzurechnen, sie haben relativ wenig Bedeutung für den Verlauf der repräsentierten Handlung. 
geht. Das Großmährische Reich ist gleichsam ein Mittel, um die Konflikte innerhalb der fränkischen Königsfamilie zu beseitigen. Entsprechend freut sich Karloman über die hinterhältige List Vichinks (dieser hatte Rastislav so lange eingeredet, dass Svatopluk sich gegen ihn wenden würde, bis er misstrauisch wurde und diesen verflucht), mit deren Hilfe sowohl Rastislav als auch Svatopluk von den Franken gefangen genommen werden: „Mistrný kate podlých Slovanů,/ smíril jsi nás, ty statný Vichinku. / Nad zkázou těchto dvou, ti ruku podávám!“²44 (II/12, S. 65).

Während die Franken ihre internen Konflikte vermittels der Unterwerfung eines vermeintlichen Gegners beseitigen, lassen sich die Mährer blindwütig in Konflikte treiben, die ihre Einheit schwächen. Anders als Ludvík und Karloman, die sich versöhnen und gemeinsame Interessen in Großmähren verfolgen, vermögen es Rastislav und sein Neffe Svatopluk nicht, die zwischen ihnen bestehenden Spannungen auszugleichen, welche durch die beschriebene Hinterlist Vichinks noch vergrößert werden. Dieser charakterisiert die Slawen durch ihre unbesonnene Leidenschaft:

Jen cit ho vede, vášeň zavádí

to slávské plémě, snivé, podajné -

myšlénky krotící pak zůstavuje nám! ${ }^{245}$ (II/5, S. 45)

Diese Aussage hat „Sprachrohrcharakter“, denn im Nachwort schreibt Frič, dass er sich bei dezidiert freiem Umgang mit historischem Material einer Tendenzpoesie verpflichtet fühlt, um die grundlegenden Charakterzüge der Völker nachzuzeichnen, die sich schon bei ihrem ersten Aufeinandertreffen in der Geschichte offenbaren: Während die „Gegner" die Gelüste und Launen des Einzelnen dem Wohl für das Gesamte unterordnen, würden die Slawen entgegen allem Eifer für den Erfolg und den nationalen Kampf, allzuoft leider augenblicklichen Launen, entweder persönlicher Eifersucht oder gar einem immer noch nicht ausgemerzten kindlichen Fatalismus nachhängen. ${ }^{246}$

244 [Karloman:] „Meisterlicher Henker der gemeinen Slawen, / du hast uns versöhnt, Du tapferer Vichink. / Über dem Verderbnis dieser beiden hier reiche ich Dir die Hand!“

245 [Vichink:] „Nur das Gefühl leitet ihn, die Leidenschaft verleitet ihn / den slawischen Stamm, träumerisch, nachgiebig / die Gedanken zu zähmen überlässt er uns [den Germanen]!“

246 Vgl. die oben frei wiedergegebene Passage im ursprünglichen Wortlaut: „[...] mi šlo o to, abych vylícil hlavní rysy a rozdíly, jaké se ukazují v národní povaze Němců a Slovanů již v prvních známých, srážkách [...] chybám to [...] vystříhati se musíme, zvláště vůči patrně větší ochotě našich soupeřů, snažících se podřizovat choutky jednotlivce prospěchu celku, kdežto my [Slované], vzdor svému nadšení pro zdar i zápas národní, řídíváme se želbohu spíše okamžitým rozmarem, bud' osobní řevnivostí, aneb dokonce i nevykořeněným v nás dosud, k nemalé naší škodě, právě dětinským fatalismem!“ (Frič 1879, 144) 
Die Franken erscheinen in Svatopluk a Rastislav als die Verursacher aller Widrigkeiten, die über das Großmährische Reich kommen. Zwar gibt es unter den Slawen die Disposition zum Zwist - ähnlich wie in der Familie des fränkischen Königs -, nur sind es die Machenschaften der Franken Ludvík, Karloman und Vichink, die diese Disposition ausnützen und verstärken. Im Stück werden diese Interessen aus der Sicht der Franken zwar mit Rechtsansprüchen begründet, die Handlungsentwicklung widerlegt aber deutlich deren Rechtmäßigkeit. Überdies wird ja sogar innerhalb des fränkischen Lagers Distanz genommen, wie sich am Gesinnungswandel Juditas und an ihrem Wechsel ins mährische Lager zeigt: Im ersten Akt noch „schändet" sie die mährische Fahne, indem sie diese in den Schmutz ziehen möchte, als Svatopluk stolz den Widerstand der Mährer und den Befreiungskampf unter der mährischen Fahne gelobt. Im dritten Akt, als Judita und Arnulf den von den Franken geblendeten und misshandelten Rastislav in der Waldeinsiedelei beobachten, äußert sie bereits großes Verständnis für die Lage Mährens, wie sich in ihren erzieherischen Unterweisungen für Arnulf zeigt: „A kdyby tobě bylo souzeno, že dědictvím bys vládl zemí tou: nebránil bys až do té poslední krůpěje národ svůj a ř́ši svou?" "247 (III/1, S.69). Arnulf antwortet auf diese Frage sogar damit, dass er es nicht bei der Verteidigung beließe, sondern die Franken niederringen würde. In der Hoffnung auf Gerechtigkeit für Svatopluk und Mähren schlägt Judita ja auch vor, dass sie die Angelegenheit vor das fränkische Gericht bringen werde. Bei dieser gerichtlichen Entscheidung wird auf verschiedene Weise eine eindeutige Bewertung der konfligierenden Positionen vorgenommen: So wird zum einen darauf hingewiesen, dass eine hochfeierliche Gerichtsverhandlung seit der Herrschaft Ludvíks eine seltene Angelegenheit geworden sei, da er ein so idealer Herrscher sei. Diese stark parteiische Ansicht Karlomans wird jedoch umgehend widerlegt, denn es gibt nun tatsächlich eine wichtige Klage, Beklagter ist noch dazu der fränkische König selbst. Insofern das Urteil über Recht und Unrecht durch einen Zweikampf entschieden wird, in dem Svatopluk mit dem von Rastislav feierlich vererbten Schwert Luděk besiegt, ihn aber edelmütig am Leben lässt, kann man von einer gleichsam transzendenten Bestätigung der mährischen Position sprechen. Dass diese mutwillig aufgehoben wird, bekümmert und empört den weisen Drago, dem das Wohlergehen der Franken immer ein Anliegen war, sowie Judita, die daraufhin ja das Lager wechselt und auf mährischer Seite kämpft. Ihr Wechsel ins andere Lager wird auch noch durch den Kleider- und den Geschlechterrollentausch unterstrichen. Als Slavoměr bekämpft Judita erfolgreich das von den Franken ausgehende Unrecht.

Im fünften Akt wird die tragische Konstellation mittels sehr gattungspezifischer theatralischer Mittel entwickelt: Das im Handlungsverlauf ,ideal“ gewordene Lie-

247 [Judita:] „Und wenn es dir bestimmt wäre, aufgrund von Erbe dieses Land [Mähren] zu regieren: würdest du nicht bis zum letzten Blutstropfen dein Volk und dein Reich verteidigen?" 
bespaar ist räumlich wie auch topologisch voneinander getrennt, es versucht aber, die Trennung zu überwinden, um den Partner zu erreichen. Als Slavoměr verkleidet, will Judita gegen die Franken (also gegen ihr eigenes Lager) kämpfen, um Svatopluk zu befreien. Im Glauben, dass diese im Großmährischen Reich gefangen ist, kämpft Svatopluk gegen das eigene Lager. Der zweifache Wechsel ins jeweils andere Lager wird zu einer tragischen Reflexion, als Svatopluks Pfeil Judita alias Slavoměr tödlich verwundet.

Während die ersten vier Akte von Svatopluk a Rastislav eine deutliche Zuweisung von Recht und Unrecht, Schuld und Unschuld an die beiden Konfliktparteien Franken und Mährer bzw. Deutsche und Slawen vornehmen, ist der "theatralische“ fünfte Akt in seinem Resultat unentschiedener: Zwar macht die Ungerechtigkeit den Kampf erforderlich, dieser führt aber zu einem tragischen Ende. Svatopluks wütende Konsequenz aus dem tragischen Ende - die blutige Rache an den Franken - wird aber nicht gerechtfertigt: der weise, um Vermittlung bemühte Strachota verurteilt die Rache als unchristlich. Wie die beiden letzten Repliken des Dramas zeigen, kann der blutige Triumph der Mährer ins Gegenteil umschlagen: Auf den Ruf der siegreichen Mährer „Bud' sláva Moravě!“ antworten die Franken mit „Aj běda vám!" ${ }^{248}$ Frič lässt das Stück also damit enden, dass eine radikal nationalchauvinistische Position, die den politischen Gegner negiert, als gefährlich dargestellt wird. Freilich könnte man diese beiden Repliken auch als Indiz dafür sehen, dass der Kampf zwischen den Mährern und den Franken weitergehen wird.

\section{IV.6.3. Exkurs zum Dramenwettbewerb für historische Dramen aus der slawischen Geschichte}

Die neoabsolutistische Politik der Wiener Regierung bemühte sich in den 1850er Jahren einigermaßen erfolgreich um einen wirtschaftspolitischen Aufschwung, der vor allem Handwerkern und Gewerbetreibenden Prosperität verschaffte und zur Stärkung bürgerlicher Schichten beitrug. Diesen war direkte politische Partizipation noch versagt, doch konnten sie auf anderem Gebiet aktiv werden, etwa im Kulturleben, das somit größere politische Relevanz bekam, was sowohl den politischen Kräften wie auch den Behörden bekannt war. Illustrativ für die „außertheatralische Funktion" des tschechischen Theaters zur damaligen Zeit ist etwa der Umstand, dass der aktivste tschechische Politiker des liberalen Lagers, František Ladislav Rieger, damals Theaterkritiken schrieb, die er mit den Initialien „L. R.“ oder „R“ versah (vgl. Klosová 1977b/DčD III, 16).

Der von Ferdinand Náprstek 1857 ausgerufene Wettbewerb, der Dramen aus der tschechischen bzw. slawischen Geschichte fördern sollte, um das kulturelle Niveau der Tschechen und Slowaken zu heben, kann im vorliegenden Zusammenhang

248 „Ruhm über Mähren!“ - „Die Not möge über euch kommen!“ 
von Literatur und politischer Geschichte als signifikant für diese nachrevolutionäre Restaurierungsperiode gelten. Ferdinand Náprstek stammt aus einer tschechischen Prager Familie, die im Gastgewerbe zu einigem Vermögen gekommen war. Gleich wie sein berühmterer Bruder Vojtěch ${ }^{249}$ ließ Ferdinand Náprstek den Namen seines Vaters, der beim Militärdienst germanisiert worden war, in einem sich dreißig Jahre hinziehenden Verfahren rebohemisieren; als Theaterliebhaber wollte er ein vergleichbares Zeichen zur Stärkung der tschechischen bzw. tschechoslowakischen Kultur setzen. Zwar hat es bereits $1849 / 50$ von der Landesversammlung ausgeschriebene Dramenwettbewerbe gegeben - einen für ein ernstes historisches Drama aus der Geschichte der Heimat, einen anderen für ein in der Gegenwart angesetztes Lustspiel -, deren Verlauf ist allerdings nicht weiter dokumentiert (vgl. Černý 1969/DčD II, 334); er dürfte wohl in der ersten Reaktionsphase der beginnenden 1850er Jahre wenig ersprießlich gewesen sein.

Ferdinand Náprstek war unter den 237 tschechischen Delegierten des ersten Slawenkongresses 1848 in Prag, wo bekanntlich die Idee einer slawischen Einheit als Pendant zu existierenden Verhältnissen in der Habsburgermonarchie große Zustimmung fand und im verabschiedeten Manifest „An die Völker Europas“ nur diplomatisch vage von der Freiheit, Gleichheit und Brüderlichkeit „aller im Staate Lebenden" geschrieben wird (vgl. Urban 1982, 42-44; Hoensch 1992, 342f). Fingerhut bemühte sich entschieden um eine tschechoslowakische Gemeinsamkeit, denn 1861 gab er die Hlasy Slovákiov heraus, welche revisionistisch - denn die Zeitschrift erschien nach Etablierung einer slowakischen Literatursprache durch L'udovít Štúr in den 1840er Jahren - für eine gemeinsame tschechoslowakische Sprache eintraten (vgl. Pohorský 1961, 54-56).

Dem Text von Náprsteks Ausschreibung zum Wettbewerk von historischen Dramen ist zu entnehmen, dass er die eigene Kultur als eine besonderer Pflege bedürftige Pflanze ansah. Wie die Vertreter der zweisprachigen tschechischen Intelligenz vor ihm, die die tschechische Kultur mit anderen Nationalkulturen - vornehmlich der deutschen - verglichen, war auch Náprstek der Auffassung, die Tschechen hät-

249 Vojtěch Náprstek (Fingerhut), 1826-1894, engagierte sich als Student in Wien politisch; wegen seiner Aktivitäten in der Revolution von 1848 musste er mit einer Verurteilung rechnen und flüchtete in die Vereinigten Staaten, wo er sich in Emigrantenkreisen engagierte und 1856 an einer ethnologischen Expedition zu den Dakota-Indianern teilnahm. Die dabei erhaltenen Geschenke bildeten den Grundstock für das von ihm gegründete ethnographische Museum in Prag, wohin er nach einer Amnestie 1858 zurückgekehrt war. Das von den Eltern geerbte Gasthaus U Halánků am Betlémské náměstí wurde zum Zentrum der tschechischen patriotischen Intelligenz (darin befindet sich heute das Náprstkovo muzeum, das bedeutendste ethnologische Museum der Tschechischen Republik). Als Stadtrat und Amerika-erfahrener Unternehmer beförderte Náprstek technische Entwicklungen und die Emanzipation der Frau; auch sein Privatleben entsprach seiner progressiven Orientierung, so schloss er seine zweite Ehe nur standesamtlich und wünschte als Atheist testamentarisch eine Kremation. http://www.nm.cz/Historie-NM/Osobnosti/ [Stand 30.10.2015]. 
ten dringenden Nachholbedarf: Während andere Äste der Dichtkunst eines kleinen Volks, die zwei oder sogar noch mehr Jahrhunderte "geschlafen“ hat (zu den sieben Millionen Sprechern zählt Náprstek die Bewohner von Böhmen, Mähren, Schlesien und der Slowakei) bereits herrliche Blüten zeigten, sei das Drama als „Höheund Endpunkt jeder Dichtkunst, ja überhaupt aller Schöpferkraft des menschlichen Geistes“ ${ }^{\star 250}$ noch nicht entsprechend entwickelt (vgl. Zprávy soudců [...] 1860, 5). Die Einrichtung seines Preises möchte Náprstek als Teil einer nationalen Anstrengung verstanden wissen; so solle die tschechische Ständevertretung entsprechend zum kostspieligen Theaterbetrieb beitragen; der Kaiser wird gleichfalls aufgefordert, ebenso großzügig wie für das Hoftheater in Wien, das ungarische Theater in Pest und das italienische Theater in Mailand zu einem tschechischen Nationaltheater in Prag beizutragen.

Der von Náprstek ausgelobte Betrag von 400 Gulden in Silber inkl. Zinsen soll gezielt Autoren historischer Dramen unterstützen, da diese Gattung zum einen beim Volk sehr beliebt sei, zum anderen aber aufwändiger Vorarbeiten bedürfe und sich nicht allein einem schöpferischen Moment verdanke. Náprstek hofft mit seiner Initiative letztlich darauf, dass die "tschechoslowakische Literatur" mit einem klassischen dramatischen Werk bereichert werde, dessen Autor nicht allein die Anerkennung des tschechischen Volkes, sondern überhaupt von ganz Europa erhalten würde, zu dessen entwickelten und gebildeten Nationen die Tschechoslowaken mit einer entsprechenden Dramenliteratur und einem Nationaltheater aufschließen würden. ${ }^{251}$

Dass Náprsteks Wettbewerb ambitiös war und nicht bloß als wohlmeinende Initiative eines erfolgreichen Prager Unternehmers gelten kann, die nur inkonsequent durchgeführt wurde, kommt in den Juryberichten zum Ausdruck. Für die Zuerkennung des Hauptpreises waren 7 von 9 Stimmen der Jury (bzw. 5 von 7 Stimmen im zweiten Jahr) erforderlich, deren Mitglieder allesamt Vertreter der tschechischen Intelligenz der damaligen Zeit waren, so etwa Karel Jaromír Erben, Ferdinand Mikovec, František Ladislav Rieger und der jeweilige für tschechische Aufführungen zuständige Dramaturg am Ständetheater Josef Chauer bzw. dessen Nachfolger Josef

250 „Drama, vrch a konec veškerého básnictví, ba všeliké tvorčí síly ducha lidského [...] (vgl. Zprávy soudců [...] 1860, 5).

251 Die entsprechende Passage des Ausschreibungstextes, von Náprstek an seinem Geburtstag, am 24. Mai 1857 formuliert, lautet: „[aby obět' (= ausgelobtes Preisgeld)] přispěla nejen $\mathrm{k}$ oživení básnictví dramatického u nás, ale tím i k oživení a obnovení onoho ušlechtilého účastenství a té vřelé lásky $\mathrm{k}$ umění, ježto $\mathrm{k}$ obětem hotovy jsou, kdež běží o vyšší záležitosti národu. Pak by zajisté krásnou shodou vzájemného spolupůsobení tvorč́ho ducha a čilých i obětovných přátel umění, vysoké šlechty a možnějších spoluobčanů vzrostl na základě u velké naději položeném ústav národu důstojný - samostatné národní divadlo a literatura dramatická, $\mathrm{v}$ nichž básnictví dochází svého vrchole, a bez nichž by národ náš v roveň stavěti se nemohl s ostatními, kteří stojí na výši uměleckého vývinu a novověké vzdělanosti." $(1860,9)$. 
Jiří Kolár. Begutachtet wurde anonym, in den ersten beiden Durchführungsjahren konnte aufgrund fehlenden Konsenses für keines der anonymisiert vorgelegten Stücke der Hauptpreis ausbezahlt werden. In den Begründungen für die Zuerkennung des zweiten (100 Gulden) bzw. dritten Preises (50 Gulden) in der ersten Wettbewerbsrunde 1859 an Leopold Hansmanns Stück Jaroslav bzw. an František Jeřábeks Svatopluk bemängelte die Jury allzu viele Szenenwechsel, starre Syllabotonik und lange monologische Deklamationen (im Fall von Jaroslav) bzw. störende sprachliche (etwa den Gebrauch von vy als Anredeform) oder dramaturgische Anachronismen (Versatzstücke romantischer Theatralik wie heimtückische Dolchstöße) sowie mangelnden psychologischen Tiefgang im Fall von Svatopluk. Beifall hingegen fand die Zeichnung historischer Figuren, eine dramatische Handlung sowie das Streben nach sprachlicher Adäquatheit. ${ }^{252}$

Im zweiten Durchführungsjahr wurde der historische Skopus von der tschechischen auf die slawische Geschichte erweitert und von der Jury ein deutlicher Anstieg des Niveaus konstatiert (vgl. Zprávy soudců [...] 1860, 18-20). Zwar wurde der Hauptpreis wegen fehlender Stimmenzahl erneut nicht vergeben, den zweiten und dritten Preis gewann Vítězslav Hálek mit der Tragödie Záviš z Falkenštejna bzw. mit Král Rudolf (zu Závišz Falkenštejna siehe unten S. 263ff). Für das dritte Durchführungsjahr wurde die Preisgeldsumme noch einmal um den Zinsertrag auf 525 Gulden erhöht, das damit erwartete Drama sollte die bisherige tschechischen Dramenliteratur übertreffen. Inwieweit dies gelungen ist, lässt sich nicht mehr feststellen, da die Juryberichte zum letzten Durchführungsjahr nicht erschienen sind. Im Ausschreibungstext werden bereits weitere Stifter für Preisgelder angeführt - Unternehmer, aber auch der Fürst von Taxis. Am 9. September 1860 erklärt Náprstek noch einmal die Beweggründe, die Stoffauswahl der Dramen auf die slawische Geschichte zu beschränken. Diese lassen sich der traditionellen Ästhetik subsumieren, die schon in der Stoffwahl eine Vorentscheidung für die Gattung ansetzt: allgemeinere Stoffe sind dementsprechend vornehmer und erhabener

252 Die Jury befand auch über die Eignung für Drucklegung und Inszenierung und urteilte beispielsweise vernichtend über Libušin soud [Autorschaft nicht angegeben], das im ersten Durchführungsjahr gänzlich leer ausgegangen ist: „Všude jeví se nevyspělost mladistvé sily a úplný nedostatek studií, ku provedení díla dramatického nezbytně potřebných. Anachronismů hojnost. O staroslovanských poměrech a zvycích rodinných a veřejných ani malého tušení. Nedostatek grammatiky a syntaxí. K tisku ani ku provození drama to na prosto a dokonce se nehodí. („Überall zeigt sich die Unreife der jugendlichen Kraft und das gänzliche Fehlen von Studien, die für ein dramatisches Werk unerlässlich sind. Es gibt eine Menge von Anachronismen. Von den altslawischen Verhältnissen und den Sitten in Familie und im Gemeinschaftsleben hat [der Autor] nicht die geringste Ahnung. Die Grammatik und Syntax ist nicht perfekt. Das Drama eignet sich schlichtweg nicht zur Drucklegung und Aufführung." - Zprávy 1860, 17). 
als jene, die auf den privaten Bereich beschränkt sind. ${ }^{253}$ Mit dem Verweis auf die Themenwahl der griechischen Dramatiker und die Dominanz von Stoffen aus der englischen Geschichte bei der historischen Dramatik Shakespeares wird auch den eigenen dramatischen Dichtern empfohlen, aus der eigenen Geschichte oder der Geschichte der slawischen Völker zu schöpfen, denn die Geschichte des eigenen Volkes sei der ausdrucksvollste Gedanke des Weltgeistes („nejvýmluvnější myšlénka [sic] ducha světového" - Zprávy soudců [...] 1860, 92). Ebenfalls hegelianisch mutet die unumwundene Behauptung an:

Nejvyšší své vyspělosti dosáhlo posud pokolení lidské ve formách státního a národního života, a obmezením tímto zároveň poněkud' vykazány jsou koleje umělé činnosti básníkově. Každému národu, jenž trvání svého se posud neodřekl, jsou národní jeho dějiny pokladem budoucího dospívání v nejčistší lidskosti. Touto cestou, byt i oklikami mnozí ji zvali, vede duch světa lidstvo dále. ${ }^{254}$ (Zprávy soudců [...] 1860, 91)

Nach einer Aufzählung der potenziell für Tragödien geeigneten Geschichte der Tschechen, Polen, Polaben, Serben und Russen schließt Náprstek erneut Zitate aus Jan Kollárs „panslawistischem“ Sonettenwerk Slávy dcera an: „Jméno i prach svojich mužů hlavných / Ctí Vlach, Němec, Francouz, Anglové / I my vlastenci a bratové / Slavme slavně slávu Slávóv slavných“255 (Zprávy 1860, 94), um seiner Hoffnung auf entsprechendes dramatisches Engagement für die eigene Literatur und damit für das eigene Volk und seine weitere Geschichte Ausdruck zu verleihen.

1869, also nur einige Jahre nach Náprsteks Wettbewerbsidee für historische Dramen aus der slawischen Geschichte, diskutierte Otakar Hostinský im Artikel »Umění a národnost « das Verhältnis von „Stoff“ (látka) und Form (er verwendete dafür die Ausdrücke tvar, forma oder roucho). Hostinský, ein Anhänger der

253 Diese traditionelle ästhetische Reihung der Tragödie vor der Komödie findet auch ökonomisch Ausdruck darin, dass der - wahrscheinlich nicht allzu große - Verkaufserlös aus den Juryberichten über den Wettbewerb für das historische Drama, also des vorliegenden Büchleins Zprávy soudcu (1860), von Náprstek als Preisgeld für eine einaktige Komödie ausgelobt wurde.

254 „Die allerhöchste Entwicklung erreichte das Menschengeschlecht bislang in Formen des staatlichen und nationalen Lebens, von dieser Dimension sind damit auch gleichzeitig die Wege der künstlerischen Dichtung vorgezeichnet. Jedem Volk, das seine Existenz noch nicht aufgegeben hat, ist die eigene Geschichte der Grundstock für weiteres Reifen in allerreinster Menschlichkeit. Auf diesem Wege, selbst wenn ihn viele einen Umweg nennen, führt der Geist der Welt die Menschheit weiter."

255 „Den Namen und die Asche ihrer wichtigsten Männer / ehren der Italiener, der Deutsche, der Franzose, die Engländer / und wir, Patrioten und Brüder / lasst uns ruhmvoll den Ruhm ruhmreicher Slawen rühmen!“ - Die sprachgeschichtlich heutzutage nicht mehr als korrekt angesehene figura etymologica des letzten Verses lässt sich nicht ins Deutsche übertragen. 
Ästhetik Kants, setzte die Form über den Stoff, von ihr hänge die Schönheit des Kunstwerks ab. Der Form ordnet Hostinský auch den nationalen Stil zu, was bedeutet, dass ein Kunstwerk national sein könne, ohne dass es dafür notwendig einen Stoff aus der eigenen Geschichte behandeln müsse. Ein patriotisches Werk, das allein auf dem nationalen Stoff beruht, nicht aber dem Nationalstil entspricht (den Hostinský ziemlich unbestimmt lässt, obwohl er für ihn ein entscheidendes Moment darstellt) wird von ihm abgelehnt. Die Synthese von nationalem Stoff und nationalem Stil ist für Hostinský nicht besser als Kunstwerke, die einen fremden Stoff übernehmen, diesen aber im nationalen Stil bearbeiten. Dass er tschechischen Künstlern und Schriftstellern dennoch rät, Stoff aus der Volkstradition zu übernehmen, ist darin begründet, dass in der Folklore der nationale Stil bereits vorgeformt ist (diese Ausführungen zu Hostinský beruhen auf H. Schmid 2006, 289f). Fingerhuts Wettbewerb ist demnach aufgrund seiner Stoffbezogenheit eindeutig patriotisch gedacht, die in den Juryberichten erkennbare Strenge lässt aber ein großes Formbewusstsein erkennen, das jedoch - anders als bei Hostinský - nicht national verbrämt ist, sondern allgemeine literaturästhetische Momente ins Treffen führt.

Dass, wie in der Folge gezeigt werden wird, ab ca. 1860 verstärkt auch Dramen aus der Geschichte anderer slawischer Völker verfasst worden sind, kann wohl mit Fingerhuts Fördermaßnahmen und Hostinskýs ästhetischer Rechtfertigung in $\mathrm{Zu}$ sammenhang gebracht werden.

\section{IV.6.4. Vítězslav Hálek: Závišz Falkenštejna. Tragedie v pěti jednáních (1860)}

[Záviš von Falkenštejn. Tragödie in fünf Akten; UA 8.12. 1860, publ. 1861]

Die Bearbeitung der Geschichte um den Thronprätendenten Záviš von Falkenštejn durch den jungen Vítězslav Hálek, der bereits als Lyriker im Almanach Máj hervorgetreten war, wurde vom Publikum der Uraufführung mit großer Begeisterung aufgenommen. Es unterbrach die Aufführung oft mit Szenenapplaus, wenn entsprechend zweideutige Repliken vorgetragen wurden. Der Herausgeber von Háleks Schriften, Ferdinand Schulz, schreibt über diese Premiere:

Závišz Falkenštejna hlavně pro [...] obsah byl obecenstvem českým přijat s nadšením, provozování jeho zavdávalo podnět ke skvělým manifestacím národního citu a vlasteneckého přesvědčení, tehdy na veřejnosti stále ještě stíhaného, zakazovaného a potlačovaného. Zejména řeč krále Otakára k českým pánům hned v první scéně jednání prvního a pak slova Závišova k týmž šlechticům v první scéně jednání čtvrtého měla na posluchačstvo účinek úchvatný, velikolepý. [...] po celá desítiletí násilně umlčovaný národ český prolomil při té př́ležitosti ledovou kůru, tížící jeho vlastenecký oheň, a plnou silou, se vším důrazem svého práva projevil své politické snahy, nadšeně vyslovil svůj program. Hálek promluvil tehdy celému národu 
českému ze srdce; jeho Záviš z Falkenštejna byl netoliko slavný literární, ale ještě slavnější vlastenecký čin. ${ }^{256}$ (Schulz 188x, 292f)

Das Stück, dessen Stoff bereits von František Turinský und Simon Karel Macháček dramatisch verarbeitet worden war, beginnt mit einer Szene am Marchfeld, vor der großen Schlacht Otakárs II. Přemysl gegen die Habsburger. Ruperto, ein Gefolgsmann von Záviš, erinnert Milota z Dědic, den Hauptmann von Mähren, an die Repressalien, die der böhmische Adel von Seiten Otakárs erfahren musste. Obwohl Milotas Bruder enthauptet wurde und er selbst im Kerker gesessen hatte, ist er in den Dienst Otakárs getreten. Im Auftrag von Záviš gewinnt Ruperto Milota jedoch für eine rächende Verschwörung gegen Otakár. Dieser ist bereits in einem Brief vor den Feinden im eigenen Lager gewarnt worden und erbittet von seinen Mannen einen Treueschwur:

Neprosím já, leč prosí za mne vlast; ne krále osoba, leč celý národ ten, jehož jest hlavou pomazanou král. ${ }^{257}$ (I/1, S. 108)

Zwar weiß Otakár, dass die adeligen Truppenführer Gründe haben, sich an ihm zu rächen; rhetorisch fordert er diese sogar auf, dies jetzt zu tun, niemand aber reagiert darauf. Als Milota schwören muss, dass kein Verräter in den Reihen ist, bemerkt Otakár, dass seine Hand kalt ist. Milota annulliert seinen Schwur und entschließt sich, sein Aufgebot nicht zu stellen.

In der zweiten Szene wird deutlich, dass Otakárs Frau Kunhuta diesen nicht mehr liebt, sondern Záviš zum Geliebten hat. Als gemeldet wird, dass Otakár in der Schlacht gefallen ist, lacht Kunhuta sogar und Záviš muss die Situation damit retten, dass er erklärt, der Schmerz sei so groß, dass er sich auf gegenteilige Weise äußert. Kunhuta möchte ihn bald heiraten, damit er König werden kann. Beiseite erklärt Záviš, dass der Tod Otakárs ihm zwar willkommen sei, Kunhuta ihm aber

256 „Závǐ̌z Falkenštejna wurde vor allem wegen [...] seines Inhalts vom tschechischen Publikum mit Begeisterung aufgenommen. Die Aufführung gab Anlass zu prächtigen Manifestationen des Nationalgefühls und patriotischer Überzeugungen, die damals in der Öffentlichkeit noch verfolgt, verboten und unterdrückt wurden. Besonders die Rede von König Otakár zu den böhmischen Adeligen gleich in der ersten Szene des ersten Aktes und dann Záviš’ Rede zu denselben Adeligen in der ersten Szene des vierten Akts war von großartig mitreißender Wirkung auf das Publikum. [...] nach ganzen Jahrzehnten gewaltsamer Knebelung hat bei dieser Gelegenheit das tschechische Volk die Eiskruste gebrochen, die schwer auf seinem patriotischen Feuer lag. Mit voller Kraft, mit dem ganzen Nachdruck seines Rechts manifestierte es seine politischen Bestrebungen und sprach begeistert sein Programm aus. Hálek sprach damals dem ganzen Volk aus dem Herzen; sein Závišz Falkenštejna war nicht nur eine große literarische, sondern eine noch größere patriotische Tat."

257 [Otakár:] „Nicht ich bitte, die Heimat spricht aus mir, nicht die Person des Königs, sondern das ganze Volk, dessen gesalbtes Haupt der König ist." 
Schauer einjage. Sie durchschaut seine Pläne sofort. Záviš weiß, dass um Otakár wenig Trauer herrscht, dennoch muss er bei seinem Usurpationsversuch umsichtig vorgehen. Bei der Trauerrede verweist er auf den Thronfolger Václav, auf den Böhmen hoffen könne, und noch während der Aufbahrung Otakárs heiratet er heimlich und rasch Kunhuta.

Im zweiten Akt wird zuerst gezeigt, wie Ruperto im Auftrag von Záviš das einfache Volk aushorcht, was es von Záviš als König halten würde. Da die Brandenburger in Böhmen eingefallen sind und den Thronfolger Václav gefangen genommen haben, ergreift Záviš die Gelegenheit, sich als Beschützer Václavs zu inszenieren, als er bei einem Trinkspruch dazu auffordert, diesen zu befreien. Gegenüber Kunhuta hegt Záviš heftige Abneigung, weil er auf den Thronfolger Václav eifersüchtig ist. Er stellt sie vor die Alternative, entweder seine Gemahlin oder Václavs Mutter zu sein. Kunhuta wählt schweren Herzens die Gattinnenrolle.

Im dritten Akt wird der aus der Gefangenschaft befreite Václav feierlich begrüßt. Er dankt Záviš für die Ratschläge und Wünsche zur Thronfolge, indem er ihn zum obersten Heerführer macht. Die anderen böhmischen Adeligen sind skeptisch ob des Aufstiegs von Záviš und möchten ihn aus Václavs Nähe entfernen, was durch einem Feldzug nach Mähren geschehen soll. Auch sind die Mitglieder von Závišs Familie (die Rožmberks/Rosenberger) in ihrem Verhalten zusehends anmaßender geworden. Záviš selbst hat schon ein Auge auf Jitka, die Schwester des ungarischen Königs geworfen. Bevor er nach Mähren aufbricht, mischt er Gift in einen medizinischen Trunk Kunhutas und vergiftet so unerkannt seine Frau.

Als Václav Záviš zum Markgrafen von Mähren ernannt hat, gibt sich dieser zunehmend überheblich, was das Missfallen und die Animosität des böhmischen Adels zur Folge hat. Václav verteidigt Záviš immer wieder, und dieser verzeichnet auch Erfolge gegen die Raubritter in Mähren. Als Záviš von den Kämpfen zurückkehrt, verbeugt er sich nur leicht vor Václav, den Adel verhöhnt er. Als er eine Gesandtschaft empfängt, fühlt er sich bereits wie der König selbst. Záviš Diener Ruperto ist ein Mitwisser von dessen Machenschaften; als Záviš ihn mit Geld zum Schweigen bringen will, entschließt er sich dazu, seinen Herrn zu verraten. Über Beneš lässt Ruperto Gerüchte über Záviš Machenschaften und Absichten im Volk verbreiten (IV/2). Auf der Hochzeitsfeier von Záviš und Jitka soll Václav getötet werden, damit Záviš mit Unterstützung des ungarischen Königs (des Bruders von Jitka) zum König von Böhmen ausgerufen werden kann. Záviš hat schon wirre Visionen von seiner bevorstehenden Königsmacht.

Im fünften Akt kommt es im Zuge der Hochzeitsvorbereitungen und der Hochzeit zum jähen Umschwung. Zuerst schenkt Václav den Warnungen der Adeligen vor Záviš keinen Glauben, erst als Ruperto ihm den Brief zeigt, den er Ladislav von Ungarn hätte bringen sollen, erkennt Václav das Ausmaß von Závišs Intrige. Záviš wähnt sich unmittelbar vor dem Erlangen der Königsmacht, er zerstreut Jitkas Vorahnungen vom Verrat. Ruperto aber hat alles listig eingefädelt. Aufgrund der von 
ihm verzögerten Briefe wird Ladislav verspätet eintreffen, inzwischen kommen die böhmischen Adeligen und zeihen Záviš des Verrats. Dieser erkennt, dass Ruperto sich gegen ihn gewandt hat, und ersticht ihn. Da ihm die Enthauptung droht, trinkt Záviš aus dem Giftbecher, der für Václav bestimmt war. So kann er seinen Tod selbst wählen („A protož Záviše zas přemoh’ Záviš jen!“258 V/3, S. 228). Ladislav kommt zu spät, um Záviš noch beistehen zu können.

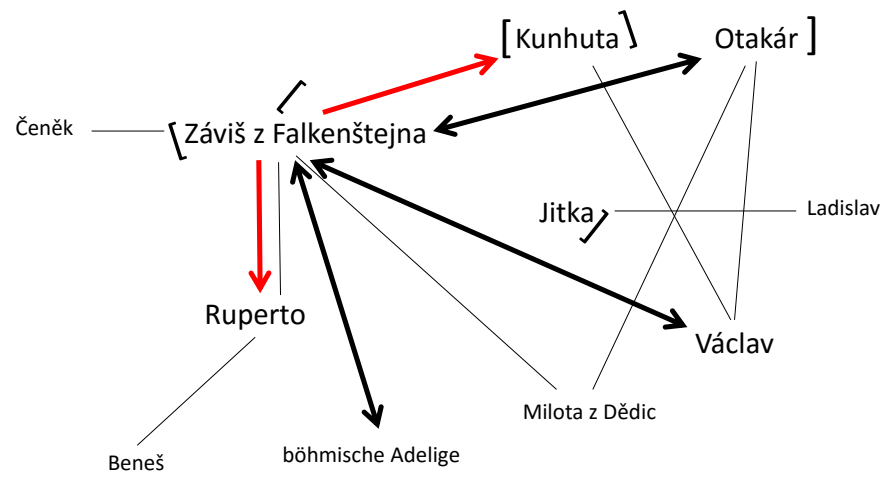

Graphik 17 - Vítězslav Hálek: Závišz Falkenštejna (1860)

Die zeitgenössische Kritik hat festgestellt (vgl. Knap 1926, 158f), dass Háleks in Blankversen gehaltenes Drama deutlich von der Shakespeare-Mode seiner Zeit geprägt ist, wie man an den zahlreichen Orts- und Milieuwechseln, der Motivtechnik sowie der Rolle von Dialogen und Monologen erkennen kann. In den Dialogen sprechen die Figuren oft „uneigentlich“ miteinander, sie lügen und verstellen sich, meist kann nur das Publikum als übergeordneter dritter Beobachter in der Rhetorik der Rede deren Doppelsinn erkennen, die anderen Figuren sind dazu oft nicht in der Lage. Größere Eindeutigkeit über Intentionen und Einstellungen wird durch das Beiseite-Sprechen und die Monologe hergestellt.

Gezielter und heimtückischer Verrat kann als das Thema von Záviš z Falkenštejna gelten. Schon im ersten Akt ist das Thema doppelt vorhanden: Ruperto meint, Milota z Dědic hätte seine Familie verraten, als er trotz der von Otakár ausgegangenen Drangsalierungen in dessen Dienste getreten sei, Otakár selbst befragt die Adeligen, ob sie ihm treu sind oder ihm in den Rücken fallen werden. In der Volksszene des zweiten Akts wird doppelt verraten: Zuerst beteiligt sich Rupertos Gehilfe Beneš an Diebstählen der Brandenburger - gewissermaßen verrät er damit das eigene Volk - dann verrät er auf Rupertos Geheiß die Brandenburger, weil er nicht deren Diebsgut verkauft, sondern die Brandenburger des Diebstahls gezie-

258 [Záviš:] „Und daher kann wieder nur Záviš Záviš überwältigen!“ 
hen werden. Auf persönlicher Ebene ist der Verrat von Záviš an Kunhuta zentral: Záviš nützt die Ehe primär ja dafür, um größeren Einfluss zu erlangen; als er erkennt, dass Václav ihm immer im Weg stehen wird und er selbst bereits ein Auge auf Jitka geworfen hat, vergiftet er Kunhuta. Als Mordwaffe entspricht das Gift insofern dem Verratsmotiv, als das Giftopfer im guten Glauben den vergifteten Trank zu sich nimmt und nicht die Gefahr sieht, die von den Nächststehenden ausgeht. Und schließlich verrät Ruperto, der ja der spitzzüngige Diener von Záviš ist, diesen, indem er Václav vor der Ermordung warnt.

Die für das Verhalten vieler Figuren charakteristische Zweideutigkeit oder Gespaltenheit manifestiert sich in den zahlreichen persönlichen Dreiecksverhältnissen: Kunhuta zwischen Otakár und Záviš, Záviš zwischen Kunhuta und Jitka, Milota zwischen der Gebundenheit an seine Familie und dem Dienst für Otakár, die böhmischen Adeligen zwischen dem Dienst für Otakár und den eigenen Interessen, die von Otakár beschnitten werden.

Die Zweideutigkeit findet auf der politischen Ebene explizit Entsprechung in den ominösen zwei Körpern des Königs, einem Problem, das in der politischen Theologie des Spätmittelalters entstand und dem Ernst Kantorowicz eine eigene Monographie (Kantorowicz 1957) gewidmet hat. Die Zweiheit des königlichen Körpers besteht darin, dass zum einen der König eine sterbliche Person ist, die meist dynastisch legitimiert ist. Wer König wird, wird im „Normalfall“ durch die Erbfolgeregelung festgelegt. Im späten Mittelalter und der frühen Neuzeit entstand jedoch auch die Vorstellung vom Staat als „Körperschaft“ („political body“), derzufolge die Person des Königs die politische Gemeinschaft repräsentiert. ${ }^{259}$ Zumal der Staat ja weiter bestehen soll, kann bzw. darf der König nicht sterben (vgl. ebd. 408f). Stirbt nun aber der König wirklich, so stirbt dessen erster Körper, der repräsentierende Körper lebt weiter. Kantorowicz hat ja selbst darauf hingewiesen, auf das von ihm beschriebene Problem auch durch Gespräche über Shakespeares Richard II. gestoßen zu sein, und ein ganzes Kapitel diesem Historiendrama gewidmet (vgl. ebd. vii u. 24-41).

In Háleks Shakespearismus findet die Frage der zwei Körper des Königs in der ersten Szene des Dramas eine Entsprechung, als Otakár sich misstrauisch an die Adeligen wendet und darum bittet, ihm vor der großen Schlacht nicht die Gefolgschaft aufzukündigen, da dies bedeute, die Heimat im Stich zu lassen. Sofern den Adeligen nach Rache zumute sei, sollten sie diese auf der Stelle nur an ihm selbst ausführen:

259 Die „zwei Körper des Königs“ sind gewissermaßen eine Vorwegnahme systemtheoretischer Grundauffassungen, denen zufolge ein und dieselbe Person in unterschiedlichen Systemen agiert. Im vorliegenden Fall ist der Körper des Königs einmal ein biologisches System, das sterblich ist, und zugleich ist er entscheidender Teil des gesellschaftlichen Systems bzw. des Staates, das eigentlich unabhängig vom biologischen Körper des Königs wäre, gäbe es nicht die Vorstellung der königlichen Repräsentation des Staates. 
Leč pakli napnut již jest pomsty šíp

a nedočkavý tak, by dočkal boje skončení -

rozvažte, že jsem já to zase jediný,

jenž proti sobě váš roznítil hněv,

na němž svou pomstu máte ukojit -

mé vojsko a s ním celý národ můj

že nevinen na hř́chu, který spáchal král. ${ }^{260}$ (I/1, S. 108)

Otakár nützt die zweifache Gestalt des königlichen Körpers rhetorisch geschickt, denn von den Adeligen wagt es niemand, sich auf der Stelle an ihm zu rächen, da damit ja letztlich auch die Heimat bzw. das Volk Schaden erleiden würde. Dasselbe erfolgt bei Milotas Verrat: Um sich für die an der Familie der Rožmberks begangenen Untaten zu rächen, hat er offenbar den Brandenburgern verraten, wann die Zeit für einen Einfall Böhmen günstig sei. Als diese in das Land einfallen, erklärt Milota „Já nejsem zrádce, já jsem pomsty syn “ ${ }^{261}$ (I/3, S. 129). Milota setzt damit die von Otakár einführte Unterscheidung fort, nur dass er sie auf absurde Weise realisiert, denn ein Einfall von Feinden betrifft nun einmal den Staat und nicht nur dessen König.

Závišs Streben nach der Königsmacht ist demnach ein Streben nach dem zweiten Körper, der mit dieser verbunden ist. Solange Záviš nämlich nur politisch handelt, als Oberbefehlshaber des Heeres oder als Markgraf von Mähren, solange ist er noch nicht König. Selbst wenn er die Königswitwe heiratet, ist er dieser nicht, weil es ja den legitimen Thronfolger gibt, der beseitigt werden soll, damit Záviš in den Königskörper schlüpfen kann. Als Záviš vor der Hochzeit mit Jitka, bei der Václav vergiftet werden soll, bereits die Königsinsignien mustert und sich die Krone aufsetzt, spricht er davon, dass er nun mit Erlangen der Königswürde endlich seinen wahren Körper hätte, die Zweiteilung seines Körpers, unter welcher er bislang gelitten habe, würde bald vorbei sein, wenn sich sein souverän gewordener Wille vor niemandem mehr beugen müsse.

Již rozpukni se, těsná skořápko,

v níž Záviš dozrál, tajmo zapředen.

Již pukni - slij se v jedno dávná dvojatost,

Věz celý svět již zřejmě vůli mou -

již pukni, nebot jasný motýl vylétá! ${ }^{62}$ (V/3, S. 218)

260 [Otakár:] „Wenn aber schon der Pfeil der Rache aufgezogen ist / und er ungeduldig nicht auf das Ende des Kampfes warten möchte / so überlegt, dass wiederum ich es ganz allein bin / der euren Zorn auf sich gezogen hat, / an dem ihr eure Rache stillen wollt -/ mein Heer und mit ihm mein ganzes Volk / ist nicht schuld an der Sünde, die der König begangen hat.”

261 [Milota:] „Ich bin kein Verräter, ich bin ein Sohn der Rache““

262 [Záviš:] „So brich endlich auf, enge Schale, / in dem Záviš heranreifte, geheim eingesponnen. / Brich auf, alte Zweiheit löse dich in Einheit auf / die ganze Welt soll deutlich meinen Willen kennen / zerbrich, denn der helle Schmetterling fliegt heraus!“ 
Als die von Ruperto alarmierten Adeligen kommen, um Záviš festzunehmen, begrüßen sie diesen mit den Worten: „Ve jménu krále“, woraufhin er erwidert mit „Iménem krále vítám vás! ${ }^{263}$, der Nebentext weist aus, dass er dies „majestátně“ (,majestätisch') spricht, also sich noch stärker bereits als König wähnt.

Insofern Záviš zwar sorgfältig und skrupellos handelt, letztlich aber doch mit seiner Usurpation scheitert, liegt die Interpretation nahe, dass Hálek die Idee der Usurpation verwirft: Zwar geht aus zahlreichen Szenen die Umsicht und Schläue von Záviš hervor, auch wird er zuerst durchaus von allen als umsichtig Handelnder anerkannt, der anstelle des gefangenen und minderjährigen Václav die Geschicke Böhmens lenkt, doch geht er bei seinen Usurpationsversuchen über Leichen. Letztlich sieht es so aus, als ob die Usurpation durch eine zwar fähige, aber nicht legitimierte Person keine Option ist. Záviš Verrat an Václav scheitert, der legitimierte Herrscher kann dem Usurpationsversuch begegnen.

Allerdings darf dabei nicht übersehen werden, dass Hálek neben dieser historischen Ebene, auf der die Usurpation scheitert bzw. verworfen wird, eine fiktive Parallelhandlung geschaffen hat, auf der die Usurpation rundum gelingt. Dem Verhältnis von Záviš zu Otakár bzw. Václav, das Hálek als permanenten Verrat im Drama darstellt, entspricht das Verhältnis von Ruperto zu Záviš: Ist anfangs Ruperto ein so effektiv arbeitendes Instrument von Záviš, wie dieser es zuerst als Vertreter Václavs war, so verrät Ruperto seinen Herren und kehrt die Dominanzverhältnisse um letztlich zieht er die Fäden, die Záviš zu Fall bringen und Václav retten. Mithin kann der als nichtadelig vorgestellte Ruperto als Entsprechung des adeligen Záviš von Falkenštejn gelten, der letztlich die Kontrolle über die Ereignisse gewinnt und den legitimierten Václav vor dem Untergang bewahrt.

Die funktionale Entsprechung von Záviš und Ruperto wird von letzterem gleich in der ersten Szene angesprochen, wo sich Ruperto als Medium von Záviš präsentiert („[Záviš] [c] htěl alespoň duchem tady býti př́tomen a vyslal mne - neb já jsem jeho dobrý duch. ${ }^{264}$ (I/1, S. 104) und sich mit ihm vergleicht:

\author{
Já nejsem šlechtic, a protož jsem míň - \\ bez statků jsem, a protož míň než Záviš jsem. \\ Však věz: kam Záviš nestačí, tam stačím já! ${ }^{265}$ (ebd.)
}

263 [Ondřej:] „Im Namen des Königs - [Záviš:] „Mit königlichem Namen begrüße ich euch!“ - Der Unterschied zwischen Lokativ („ve jménu“) und Instrumental (,jménem“) im Tschechischen ist hier wohl signifikant: Der Instrumental hat eine deutlichere Referenzbeziehung auf das Subjekt des Sprechers, er indiziert hier, dass sich Záviš den Königstitel gleichsam performativ zueigen macht.

264 [Ruperto:] „Er [Záviš] wollte wenigstens mit dem Geist hier anwesend sein und hat mich geschickt - denn ich bin sein guter Geist.“

265 [Ruperto:] „Ich bin kein Adeliger, und deswegen bin ich weniger - / und habe kein Gut, und bin deshalb weniger als Záviš. / Doch wisse: Wo Záviš nicht hinkommt, dort komme ich hin!“ 
Diese Worte von Ruperto sind prophetisch, zumindest was die Rolle angeht, die ihm dramaturgisch zugeschrieben wird. Er ist der bessere Záviš, er entspricht ihm nicht nur in seinem strategischen Geschick, sondern übertrifft ihn darin sogar, wobei er moralisch weitgehend tadellos ist (wenngleich er doppelsinnig redet und handelt). Wie Záviš begeht er einen Verrat, doch rettet er mit diesem Verrat nicht nur das Leben des Thronfolgers, sondern auch Böhmen vor der Herrschaft von Záviš, dem egomanisch-tyrannische Züge eigen sind. Gewissermaßen kann Ruperto als Personifikation eines bürgerlichen Konstitutionalismus gelten. Als Nichtadeliger stützt er das monarchisch repräsentierte Böhmen und fällt adeliger Willkür zum Opfer.

\section{IV.6.5. Vítězslav Hálek: Král Vukašin. Tragedie v pèti jednánich (1862)}

[König Vukašín. Tragödie in fünf Akten; UA 18.11. 1862, publ. 1881]

Mit Král Vukašin wurde am 18. November 1862 feierlich das Prozatímní divadlo eröffnet. Dass dafür ein historisches Drama ausgewählt wurde, unterstreicht ein weiteres Mal die Bedeutung, die dem Genre der großen Tragödie mit historischem Stoff in der tschechischen Nationalbewegung beigemessen wurde. Klosová (vgl. 1977a, 61) zufolge wurde gerade in den 1860er und 1870er Jahren versucht, mit historischen Stoffen rasch auf die Gegenwart zu reagieren, was mitunter sogar bis zu tagesaktuellen Bezügen ging. Háleks historische Tragödie nimmt ihren Stoff aus dem serbischen Mittelalter vor der heraufziehenden Osmanenherrschaft. Diese Bedrohung durch eine fremde Macht bildet allerdings nur den Hintergrund, im Vordergrund der Tragödie steht mit der Titelfigur ein Usurpator, der durch Falschheit und Lüge an die Macht kommt. Vukašín nützt die Schwäche des jungen Thronfolgers aus, sein Aufstieg führt Serbien an den Rand der Katastrophe.

In dem in den Jahren 1356-1371 angesetzten Stück wird gleich zu Beginn die Frage erörtert, wer der beste serbische Kämpfer sei. Zuallererst wird Marko genannt, der Sohn Vukašíns, der an Kampfeskraft alle übertrifft, auch den Zaren Stefan Dušan, der Serbien zu seiner Größe aufgebaut hat, aber nun schon etwas alt ist. Marko gilt als ihm ebenbürtig. Markos Vater Vukašín, der Župan bei Dušan ist, verspottet den Thronfolger Uroš als verzärteltes Muttersöhnchen, das die Härte des Krieges nicht aushält. Tatsächlich ist dieser wenig entschlossen, gegen die heranrückenden Türken in den Kampf zu ziehen. Der verschlagen agierende Vukašín versucht, die Schwäche des jugendlichen Thronfolgers auszunützen und seinen Sohn Marko dazu anzustacheln, die eigenen Stärken und Fähigkeiten auszuspielen. Dieser tritt hingegen als rechtschaffener Patriot auf, der sich glücklich schätzt, für sein Volk zu kämpfen: „Nás jeden národ, jedna poutá matka vlast / a jedno srdce bratří - “266 (I/1, S. 153). Marko

266 [Marko:] „Uns verbindet ein Volk, die eine Mutter Heimat, das eine Herz macht uns zu Brüdern -“ 
lebt für das Volk („žije národu - der dativus finalis ist eine der Schlüsselkonstruktionen des vom Drama propagierten Nationalismus), während sein Vater Vukašín nur nach der Vergrößerung seiner Macht strebt. Vukašín verstellt sich gegenüber allen permanent, um seine Ziele zu erreichen: Dreimal wiederholt er beschwörend im Monolog, der seine innerste Motivation offenbart: „Viň se, hade, hlásej důvěru! ${ }^{\prime 267}$ (I/1, S. 153f). So ruft er etwa zu Eintracht auf, während er eigentlich bemüht ist, Streit und Unstimmigkeit zu verbreiten. Der zur Verteidigung Serbiens und Europas aufrufende Zar Dušan wird nach seiner Mobilisierungsansprache krank und muss sich aus dem Kampfgeschehen zurückziehen, was jedoch geheim bleiben soll. Vukašín versucht sofort, aus eigensüchtigen Gründen aus Dušans Schwäche Profit zu schlagen. Als dieser stirbt, heuchelt Vukašín Anteilnahme und Trauer und erklärt seine beratende Unterstützung für den Thronfolger Uroš, der jedoch erst nach dem Kampf gegen die mit den Griechen verbündeten Türken als König ausgerufen werden soll.

Dies geschieht nach einem interimistischen Friedensschluss tatsächlich. Die Schwäche des jugendlichen Uroš bemerkt auch Siniša, der sich als Bruder Dušans gleichfalls um die Fürstenmacht bemüht. Jelena, die Witwe Dušans, übernimmt die Osthälfte Serbiens, Uroš soll mit Hilfe Vukašíns über den Westen gebieten. Vukašín erkennt in seiner berechnenden Schlauheit, dass seine Loyalität zum König geprüft werden soll, er verbirgt also geschickt seine Absichten und kann damit beim Fürsten Lazar und Dušans Höfling Rajko Vertrauen gewinnen. Vukašíns Gehilfe Nikola inszeniert eine diffamierende Intrige gegen Rajko, als deren Effekt Vukašíns Ansehen steigen soll. Als er dem allzu naiven Uroš erzählt, dass dessen Onkel Siniša den Zarenthron haben möchte, ist dieser so verwirrt, dass er Vukašín zum serbischen König ernennt. Als Uroš dies durch einen Schwur bestätigt, erscheint der verstorbene Dušan als Geist, der vehement von dem Schwur abrät. Diese Erscheinung erklärt Vukašín als Mummenschanz all derjenigen, die gegen ihn und Uroš seien. Seine Gegner sind über die Machtübertragung bestürzt, der protestierende Rajko wird sofort hingerichtet, womit Vukašíns despotisches Regime einsetzt.

Uroš erkennt erst im dritten Akt, dass er der Macht verlustig gegangen ist und dass er von Vukašín und Nikola bevormundet und gedemütigt wird. Vukašíns Sohn Marko erklärt die Herrschaft seines Vaters für unrechtmäßig; aufgrund der Blutsverwandtschaft stellt er sich zuerst nur schweren Herzens Vukašín entgegen, politisch freilich ist seine Anklage des Vaters massiv („ty vrah jsi národa - “268). Dem Konflikt seines persönlichen Zwiespalts entspricht der aufgrund der Anmaßungen Vukašíns ausgelöste Bürgerkrieg. Auch Siniša behauptet ein Anrecht auf den Zarenthron, womit ein Bürgerkrieg im serbischen Volk ausgelöst wird, der umso gefährlicher ist, als ein Feind von außen droht. In der Schlacht von Zeta siegt Vukašín über die Türken,

267 [Vukašín:] „Winde dich, Schlange, verbreite Vertrauen!“

268 [Marko:] „Du bist der Mörder des Volkes -“. 
er lässt sich daraufhin als Sieger und Einiger Serbiens feiern. Wenngleich ihm viele aus Feigheit und Angst huldigen, so gibt es dennoch auch kritische Stimmen, die jedoch umgehend durch Mord oder Verbannung mundtot gemacht werden. Schließlich erkennt sogar Uroš, dass Vukašín hinter seiner Kerkerhaft steckt und tyrannisch regiert; frühere Getreue Vukašíns fallen ebenfalls von diesem ab und erklären sich als Volk, das den verbannten Zaren Uroš vor den Nachstellungen Vukašíns in Schutz nimmt. Dieser kann sich freilich mit despotischen Mitteln behaupten: Als der zum Betteln gezwungene Uroš zum Aufstand gegen Vukašín ruft, wird er von diesem mit dem Schwert erstochen. Vukašín setzt die innere Opposition mit dem äußeren Feind gleich. Letztendlich aber plagen ihn die Erinnerungen an vergangene Untaten. In einer Schlacht gegen die Türken an der Marica, in der er sich vergeblich um eine Großtat bemüht, ersticht ihn sein Gefolgsmann Nikola, der gleich wie Vukašín einst nach einem Adelsrang strebt, der ihm nicht gebührt. Als Vukašíns Sohn verspricht Marko, der Lazar am Ende die Fürstenkrone überreicht, durch Einsatz seines Lebens die Schuld seines Blutes auszugleichen.

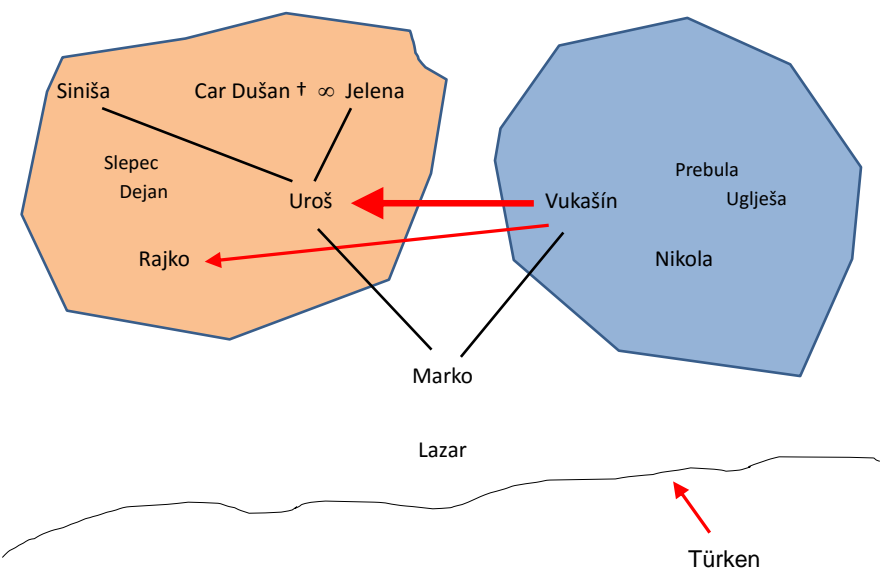

Graphik 18 - Vítězslav Hálek: Král Vukašin (1862)

Das im Zentrum von Háleks Tragödie stehende Usurpationsthema ist auf interessante Art variiert. Der legitime Thronfolger Uroš ist - wegen seiner Jugend bzw. auch später aufgrund von seiner Naivität - tatsächlich wenig geeignet, die Zarenrolle als starker Feldherr auszuführen. Die Eröffnungsszene verschiebt die Diskussion über das Problem von Legitimität und Befähigung zur Herrschaft dabei um eine Generation. In dieser Szene wird der Hauptkonflikt der Fabel (zwischen Vukašín und Uroš) anhand von Dušan und Marko dargestellt. Dušan hat Serbien zwar zu großer Macht und Ansehen geführt, Marko aber könnte in jeder Hinsicht mit Dušan verglichen werden, ja, er übertrifft diesen sogar. 


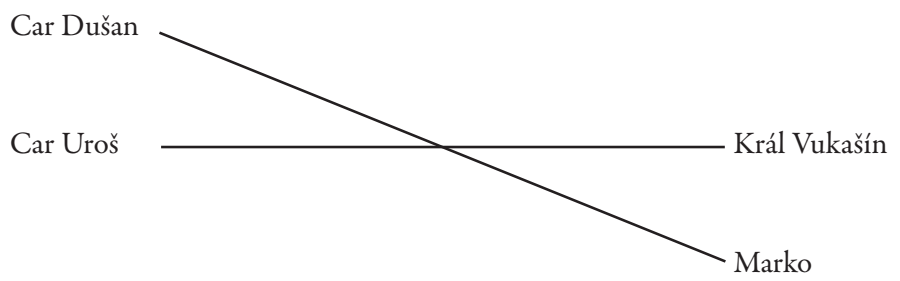

Marko ist auch die entscheidende Instanz nach dem Tod der beiden legitimierten Herrscher Uroš und Vukašín. Er krönt den Fürsten Lazar zum serbischen Zaren, obwohl dieser im Verlauf der Handlung wenig aktiv war. Diese Rolle von Marko - der einzigen Figur ohne negative Züge, es sei denn, dass er während der Tyrannis von Vukašín gleich wie das Volk zu trinken beginnt (vgl. IV/1) - erscheint gerade deshalb bedeutsam, weil die Zeichnung der Hauptfigur Vukašín so eindeutig negativ ist. Er ist der listig und heimtückisch agierende Usurpator, der in Uroš ein gutgläubiges Opfer findet. Die Machtgier des Einzelnen, der um die Macht mit allen Mitteln kämpft, ist ein eindeutig negativer Faktor. Insofern Vukašín als Emporkömmling gilt, der von Dušan gefördert wurde, könnte man meinen, dass der Konflikt um die Macht in Serbien von Hálek so gestaltet wurde, dass er eine konservative, auf rechtlicher bzw. genealogischer Legitimation basierende Herrschaftsauffassung vertritt. Vukašíns Frage am Ende der Eröffnungsszene: „Co stojí v cestě mně, bych tím též byl, čím jsem?" ${ }^{269}$ (I/1, S. 163) markiert meiner Ansicht nach aber nicht allein die Position eines Usurpators, der meint, das Fürstenamt stehe ihm aufgrund seiner Befähigungen (seines vermeintlichen „Seins“, wie es Vukašín im obigen Zitat ausdrückt) zu. Die usurpatorische Position wird im Drama nur allzu offensichtlich verworfen. Im Hintergrund aber - verschoben in der Generationenfolge - zeichnet sich die gegenteilige Position ab, welche die Herrschaftsbegründung durch Genealogie und Recht gerade in Frage stellt. In der Eingangsszene wird Marko als Dušan nicht bloß als ebenbürtig, sondern vielleicht sogar als überlegen genannt; in einer kurzen, als Nebenszene erscheinenden Kampfszene, in der nach Dušan gerufen wird, erklärt Marko selbst „Není-li zde car, jest Marko vůdce váš!“270 (I/2, S. 163). Als Sohn Vukašíns ist Marko strukturell in Äquivalenzrelation zum anderen Sohn, Uroš, zu bringen, und beim Vergleich der beiden Söhne zeichnet sich deutlich ab, welcher Figur der Vorzug einzuräumen ist. Král Vukašin kann somit als durchaus doppeldeutig gelten: Während es auf der Ebene der Haupthandlung, auf der die Figuren zur Entwicklung der Ereignisse ihren Teil beitragen, die Idee von Usurpation verurteilt und durchaus konservativ erscheint, kann in den Repliken einzelner Szenen sowie auch in struktureller Hinsicht eine Infragestellung dieser ideologi-

269 [Vukašín:] „Was steht mir im Wege, damit ich auch dieser werde, der ich bin?“

270 [Marko:] „Wenn der Zar nicht hier ist, ist Marko euer Führer!“ 
schen Position erkannt werden. Demnach wäre derjenige der beste Fürst, der die idealen Fähigkeiten dazu hat. In dieser Tragödie wäre das - wie in einigen Repliken geäußert - Marko, Vukašíns Sohn. Doch dieser wird nicht selbst Zar, immerhin aber tritt er im Moment des „Interregnums“, als beide Herrscherfiguren - Zar und König - tot sind, als Zarenmacher auf und krönt im Schlussbild Lazar, der als Figur allerdings selbst dann noch im Hintergrund bleibt und keine Replik hat.

Dass die Frage nach der Legitimierung des Herrschers eine der Schlüsselfragen in Král Vukašin ist, wird auch etwa dadurch angezeigt, dass mit der Erschleichung der Königswürde durch Vukašín ja ein Problem auftritt: Uroš hat Vukašín tatsächlich zum König erhoben und damit seine eigene Macht leichtfertig vermindert, wie ihm vorgehalten wird (II/2, S. 209). Und bei den Untergebenen entsteht Unsicherheit über die Legitimitätsfrage: „At zcepením, když vím, čí právo jest“ “271 (III/2, S. 223) äußert Dejan, der letztendlich doch gegen Vukašín aufsteht, zuerst aber noch verwirrt ist. Marko, der als der eigentliche ideale Fürst präsentiert wird, äußert im Streit mit seinem Vater Vukašín, worauf er eigentlich die Legitimation zu herrschen gründet:

[Marko:] To právo mé, jež národ přisoudí / tvé právo však, jež vzals ty sám! Neb právo trůnu př́sluší jen Uroši! $!^{272}$ (III/2, S. 224)

Vor dem oben Geäußerten ist somit deutlicher, dass Hálek mit dieser Replik wohl keineswegs einer konservativen Legitimation des Fürsten durch das Geburtsrecht das Wort redet und die Usurpation einfach verwirft, sondern dass er eigentlich die demokratische Legitimation von Herrschaft als Ideal herausstellt, wobei dies aber nur durch längere Analyse und strukturellem Vergleich von Positionen ersichtlich wird, also bei den Zensurinstanzen wohl wenig Anstoß erregt haben wird. Die Tragödie weist auf eine Präferenz für die konstitutionelle Monarchie hin; das Volk erscheint als diejenige Instanz, der der Herrscher verantwortlich ist. Zumal Herrschaftsmacht vom Volk gebilligt sein muss, muss sich der Herrscher für das Volk einsetzen (wie Marko es vorführt), das Volk seinerseits kämpft nicht um des Fürsten willen, sondern für das vom Fürsten repräsentierte Land bzw. für sich selbst als dessen Bevölkerung. ${ }^{273}$

Bei all dieser konstitutionalisierenden Relativierung der Monarchie ist in einigen Szenen auch deutlich, dass Hálek das Volk als Quelle der Fürstenmacht keineswegs unproblematisch sieht: So ist es ziemlich leicht durch Rhetorik manipulierbar

271 [Dejan:] „Möge mich der Schlag treffen, wenn ich nur wüsste, wer Recht hat.“

272 [Marko:] „Mein ist das Recht, welches das Volk mir zuspricht / Deines hingegen hast Du Dir selbst genommen / Denn das Recht auf den Thron gehört allein Uroš!“

273 [Dejan:] „Mé heslo: Srbsko, ne král Vukašín!“ („Meine Losung: Serbien, nicht König Vukašín!“) 
(was in Háleks Sergius Catilina, [s.u.] noch deutlicher wird), es hat Angst und lehnt sich nicht gegen die Unterdrückung auf.

Král Vukašin tangiert mithin unterschiedliche politische Themen: Es mahnt zu nationaler Einigkeit vor dem Hintergrund einer anrückenden Gefahr, das Ideal eines dem Volk dienenden Fürsten wird durch die negative Figur eines tyrannischen Usurpators konterkariert, der die Schwäche des legitimierten Fürsten ausnutzt.

\section{IV.6.6. Vítězslav Hálek: Sergius Catilina. Tragedie v pèti jednáních (1863)}

[Sergius Catilina. Tragödie in fünf Akten; UA 1863, publ. 1881]

Vítězslav Hálek hat über den Catilina-Aufstand in Rom des Jahres 63 v. Chr. eine Tragödie geschrieben, in der die Zusammenhänge von revolutionären Veränderungsversuchen und deren Niederschlagung vor Augen geführt werden. Offensichtliches literarisches Vorbild für Hálek waren die Dramen Shakespeares über die römische Antike; neben der Wahl des geschichtlichen Schauplatzes und der gerade bei Geschichtsdramen besonders beliebten offenen Form sind sogar in der sprachlichen Gestaltung (expressive Metaphorik, Hyperbeln, Stilwechsel in der dramatischen Rede, Wechsel von Vers und Prosa) mehr als nur Anklänge an Shakespeare zu erkennen: Sergius Catilina erscheint wie ein Versuch, ein Shakespeare-Drama auf Tschechisch zu verfassen. Das Stück ist demnach nicht bloß ein historisches Drama, sondern es kann geradezu paradigmatisch zugleich als „historistisches“ Drama gelten, weil es bewusst die Tradition imitiert und damit die tschechische Shakespeare-Einflusslinie fortsetzt (erinnert sei in diesem Zusammenhang an die Shakespeare-Welle der 1850er Jahre, vgl. oben, S. 247).

Das Drama beginnt mit einem Stimmungsbild. Zwar feiert das Volk auf Kosten von Julius Cäsar ausgelassen in den Straßen, hinter der Ausgelassenheit seien aber echte Sorgen verborgen, wie Fulvius meint, den ebenfalls Schwierigkeiten plagen, wurde er doch von seinem Vater aus dem Haus geworfen und erfährt keine Unterstützung mehr von diesem. Ein Bürger artikuliert die Erwartung großer Veränderungen in der Stadt, die er mit einem neuen Hoffnungsträger, der dem Volk vieles verheißen und geben wird, verbindet. Dieser Umstürzler wird aber nicht Cäsar sein, sondern jemand, der noch größere Versprechungen macht. Die gesellschaftliche Elite der Patrizier (panstvo) und Priester erscheint lasterhaft und saturiert. Cicero, der selbst aus einfacher Familie stammt, gilt als junger Parteigänger der Patrizier, der zum Konsul gewählt werden soll. Sein entschiedener politischer Gegner ist der gleichfalls verarmte Sergius Catilina, der das Angebot Ciceros ablehnt, auf die Seite der Herren zu wechseln, um gleichfalls Schulden begleichen zu können. Mit Catilina, der als aufmerksamer Beobachter der römischen Politik konstatiert, dass Pompejus als Feldherr zuviel Macht und Ruhm erlangt habe und damit leichterhand triumphal nach Rom zurück kehren wird können, verbündet sich Cäsar, der nach 
mehr Macht im Staate strebt. Catilinas Freund Cornelius engagiert eine Gruppe von Banditen und Vagabunden, nach deren Ansicht schlechthin ganz Rom nur von einer Diebesbande regiert wird: „Neb koho okradeš, to zloděj jest, / a zloděj okrade zas zloděje. ${ }^{\text {"274 }}$ (I/25) Diese Banditen sollen auf Abruf bereitstehen und weitere Kräfte mobilisieren. Um Catilina formiert sich eine Gruppe, die auf Veränderungen hinarbeitet und dabei etwa die Philosophie wegen ihres bloß theoretisch-kontemplativen Charakters verachtet. Catilina schreitet zur Tat, indem er nach einer längeren Phase der Zurückgezogenheit und Passivität, welche ihm seine Freunde vorwerfen, beginnt, die Schuldscheine des Volks zu zerreißen und den Unfreien die Freiheit zu versprechen. Catilina erhebt Anspruch auf das Amt des Konsuls, für das die Herren Cicero vorschlagen, dessen Wahl sie mit Festen für das Volk unterstützen.

Im zweiten Akt werden zuerst die Verschwörer und ihre Pläne gezeigt. Catilina und Curius sind auch zum politischen Mord entschlossen, falls Cicero gewählt würde. Die von Cornelius mobilisierten Banditen sollen für den Fall der Wahl Ciceros bereit zum Aufstand sein. Curius weist die ihn liebende Fulvia auf sehr unschöne Weise zurück; diese will sich dafür rächen und die umstürzlerischen Pläne zunichte machen. In Faesula (Fiesole) hat Catilina gleichfalls Truppen gesammelt, die für einen Aufstand zur Verfügung stehen sollen. Bei der Agitation vor dem Volk im Forum verspricht er dem Volk Gerechtigkeit und Wohlstand und erfährt lautstarke Unterstützung für das Konsulsamt, während Cicero gar nicht zu Wort kommt. Fulvia ist empört über Catilina und seine Versprechungen; sie ergreift als Frau das Wort und verrät die Attentatspläne auf Cicero und Cato, die sie im Catilina-Lager gehört hat. Cicero tritt dann mit einer geschickten Rede auf, in der er sein Schickal dem Volk überantwortet. Er gewinnt damit Sympathien, sodass von zwei römischen Bürgern gar überlegt wird, ob sie nicht beiden Kandidaten ihre Stimmen geben sollen. Der Senat wählt Cicero, Catilina wendet sich wütend an das Volk und ersucht es, Cicero zu beobachten, ob er auch wirklich dem Volk helfen werde. Wütend kündigt er an, in Rom schneller die Macht zu ergreifen als Cicero.

In Etrurien werden die Sklaven von einem Banditen mobilisiert. Dabei kommt es freilich zu einigen Missverständnissen, weil die rhetorischen Figuren in der Ansprache des Banditen von den Sklaven nicht verstanden werden. In Rom misslingt der Putschversuch, weil sich die Vagabunden mit Versprechungen der Gegenseite kaufen lassen, Stellungen verraten und falsche Signale geben. Der Senat lässt gegen Catilina wegen Verhetzung vorgehen, Cäsar bietet Catilina ein Versteck bei sich an, dieser aber lehnt brüsk ab; er versteht den Kleinmut unter seinen Mitverschwörern nicht und möchte allein in den Senat gehen, obwohl überall nach ihm gefahndet wird. Catilina hält den Senat für schwach und meint, mit dem Rückhalt des Volkes und der Provinzen könne er sehr wohl gegen den Senat bestehen.

274 „Wen immer man bestiehlt, der ist selbst ein Dieb / und der Dieb bestiehlt wiederum einen Dieb.“ 
Im Senat wettert Cicero gegen Catilina. Er möchte Vollmachten erhalten, um gegen Catilina vorzugehen. Allein Cäsar meint, dass die Gefahr im Inneren Roms nicht so groß sei wie jene, die von außen, nämlich von Pompejus, drohe. Bei der Abstimmung wird zugunsten von Cicero entschieden, der daraufhin den tatsächlich erscheinenden Catilina wegen Verrats mit dem Tode bestrafen möchte. Cäsar hingegen optiert für eine mildere Bestrafung, nämlich für den Verweis aus der Stadt. Catilina nennt Rom und seine Eliten verkommen und wird dafür von den empörten Senatoren verjagt.

Im vierten Akt wird zuerst ein Stimmungsbild vom Lager Catilinas gemalt. Dort ist die Stimmung gedrückt, Catilina nimmt die Unterstützungserklärungen einiger Provinzen an, denen er dafür Zusagen macht. Das Angebot, sich reuig dem Senat zu ergeben, lehnt Catilina stolz ab („Já senát jsem - to vyřid’ senátu!“275 - IV/1, S. 104). Nachdem Catilina nach Faesula zu seinem Heer gefahren ist, werden jedoch seine Getreuen von den Römern unter der Führung von Metellus gefangen genommen und vor den Senat gebracht, wo man sie zum Tod verurteilt. Zuvor noch wird der aufständische Fulvius von seinem eigenen Vater, der Senatsmitglied ist, erstochen. In Faesula muss Catilina einige Hiobsbotschaften entgegennehmen. So haben sich Sklaven, die unter ihm dienen wollten, aber zurückgewiesen wurden, weil sie nur als Freie kämpfen dürften, in römische Dienste begeben. Truppen werden von Rom gegen Catilina entsandt und die Freunde Cethegus, Crassus, Capito werden hingerichtet. Catilina beginnt, allerdings gezeichnet von diesen Nachrichten, mit seinem Angriff.

Im fünften und letzten Akt ändern sich die Aussichten für die Aufständischen um Catilina. Zuerst steht es um sie schlecht, dann aber können sie die Römer zurückdrängen. Catilina wähnt sich schon als Alexander der Große. Von Metellus wird das römische Angebot überbracht, dass Catilina nach Rom zurückkehren könne. Er beginnt sogar Forderungen zu stellen und es stellt sich heraus, dass er sogar die Krone Roms fordern könnte. Nur kann Metellus ihm zwar vieles, aber nicht alles einräumen. Catilina entscheidet sich ohnehin für die Fortführung des Kampfes, der entscheidend sein müsse. Auch Metellus beschwört die Römer, dass es um die Stadt und das Recht geht. Erneut sind die Truppen Catilinas stärker, dieser frohlockt schon über den bevorstehenden Sieg, doch dann kommt die Kundschaft, dass Cäsar mit seinen Truppen doch nicht verstärkend hinzustoßen wird, sondern gegen Pompejus zieht, weil er die Sache Catilinas für verloren hält. Catilina startet einen letzten gewaltigen Angriff. Metellus möchte Catilina lebend haben, doch dieser kehrt tödlich verwundet zurück und erklärt, dass Rom zwar gesiegt habe, jedoch „však v smíchu tvém již rána smrtelná“276 (141).

275 „Ich bin der Senat - richte das dem Senat aus!“

$276,[\ldots]$ in Deinem [adressiert ist der römische Senat] Lachen ist jedoch schon eine tödliche Wunde [zu erkennen].“ 
Für die Dramen Vítězslav Háleks wurde deren sensible Bezugnahme auf die Zeitumstände von der Forschung bereits festgestellt. Über Sergius Catilina, das für Klosová als beispielhaft für Háleks historische Dramatik gilt, heißt es:

Prostřednictvím historické paralely reagoval Hálek na soudobé volby do českého zemského sněmu a do vídeňské říšské rady. Autor tu zastával tehdy obecně platný názor, že prosazením požadavků buržoazní demokracie (v dramatě revolty Catilinovy) bude pomoženo i lidovým vrstvám, realizovány jejich sociální nároky a zažehnána jejich bída. Na druhé straně měl však odvahu vyřknout prostřednictvím analogie s ř́mským senátem kritiku zkorumpovaných orgánů demokratické zemské správy. V komické scéně III. jednání, v níž bandita přichází bouřit Etrusky, aby se připojili k povstání Catilinovu, se Hálek dokonce odvážil zparodovat i demagogii, frazérství a pozérství některých českých buržoazních řečníků. ${ }^{277}$ (Klosová 1977a, 61)

Zwar ist in diesem Zitat deutlich die Phraseologie offiziöser marxistisch-leninistischer Ideologiekritik zu erkennen (etwa an den Begriffen „buržoazní demokracie“, „buržoazní řečník“ oder an der Gegenüberstellung von ,falschen` Hoffnungen in die bürgerliche Demokratie und ,richtiger 'Kritik an den „korrumpierten Organen demokratischer Landesverwaltung"), doch kann der allegorischen Deutung eine gewisse Plausibilität nicht abgesprochen werden. Die Stringenz und Bestimmtheit der Analogiesetzung in der Interpretation erscheint freilich etwas fragwürdig: Warum etwa ist die komische Szene im dritten Akt, in der die rhetorischen Figuren des Agitators missverstanden werden, allein eine Parodie von bourgeoiser Propaganda? Könnte in dieser nicht etwa auch die Beschränktheit der Adressaten dieser Rede vorgeführt werden?

Betrachtet man den Handlungszusammenhang und dessen Hintergrund, so ergibt sich ein stärker differenziertes Bild, das auch die Raffinesse von Háleks politischer Kritik stärker hervortreten lässt. Die Verhältnisse in Rom, welche die Verschwörer um Catilina radikal ändern wollen, die der Senat aber als die rechtmäßigen zu konservieren trachtet, sind tatsächlich deutlich korrumpiert: dies zeigt vor allem der zynische Dialog der beiden heidnischen Priester, die sich ihre Privilegien mittels

277 „Mithilfe einer historischen Parallele reagierte Hálek auf die zu dieser Zeit stattfindenden Wahlen zum tschechischen Landtag und zum Wiener Reichsrat. Der Autor vertrat die damals allgemein akzeptierte Auffassung, dass mit der Durchsetzung der Forderungen der bürgerlichen Demokratie (im Drama ist es die Revolte Catilinas) auch dem einfachen Volk geholfen werde, dass es seine sozialen Ansprüche umsetzen könne und dass seine Not zurückgedrängt werde. Andererseits hatte er auch den Mut, über die Analogie mit dem römischen Senat eine Kritik an den korrumpierten Organen der demokratischen Landesverwaltung auszusprechen. In der komischen Szene des III. Akts, in der ein Bandit zu den Etruskern kommt, um sie für den Catilina-Aufstand zu gewinnen, wagte es Hálek sogar, die Demagogie, Phrasendrescherei und das Poseurtum einiger tschechischer bürgerlicher Demagogen zu parodieren.“ 
gezielten Priestertrugs sichern. Die gleich in der ersten Szene vom römischen Bürger Petrejus ausgesprochene apokalyptische Erlösungshoffnung (,Bald wird irgendjemand kommen und dann zerbricht das alles') ist ein deutlicher Hinweis auf die Missstände in Rom. Gerade die schärfste Kritik an den Verhältnissen wird aber von Banditen ausgesprochen, was man als eine doppelte Brechung bezeichnen könnte, nämlich gerade im Hinblick auf den Gegenwartsbezug: Die von Klosová festgestellte Kritik an bourgeoisen Politikern äußern nämlich Personen wie der Bandit, was die Kritik selbst fragwürdig macht. Wenn etwa ein Vagabund meint, dass er nicht wirklich Konsul sein könne, weil er dazu nicht geeignet sei, so belehrt ihn ein anderer Bandit, wie man sich als Konsul am besten verhält. Diese Ratschläge, die im Wesentlichen in der Simulation von Kompetenz und Kenntnissen bestehen, zielen zum einen natürlich kritisch auf die tatsächlichen Konsuln bzw. Politiker, zum anderen aber relativiert die Person des Banditen als Ratgeber die Kritik.

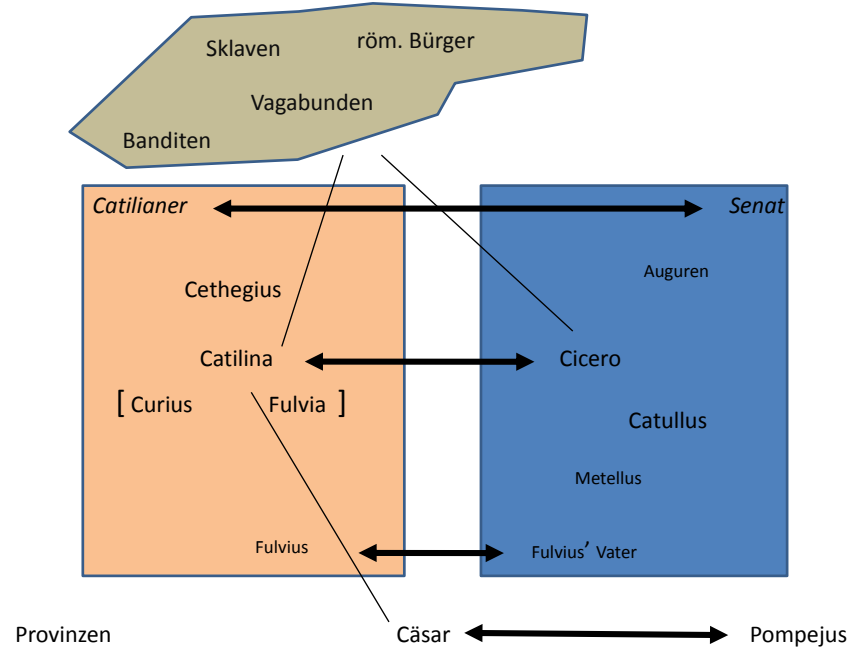

Graphik 19 - Vítězslav Hálek: Sergius Catilina (1863)

Dass die Stoffwahl Háleks mit der Einführung eines beschränkten Parlamentarismus in der Monarchie aufgrund der Verfassung von 1861 in Zusammenhang steht, ist durchaus wahrscheinlich. Möglicherweise hat auch eine Zahlensymbolik eine gewisse Rolle gespielt, denn die Verschwörung Catilinas erfolgte im Jahr 63 v. Chr. und Hálek veröffentlichte sein Drama 1863. Die römische Republik erscheint in Háleks Drama als ziemlich fragwürdiges System politischer Partizipation. Die im Senat vertretenen Herren schlagen zwar ihren Kandidaten Cicero zum Konsul vor, die Wahl wird aber von den Bürgern im Forum Romanum vorgenommen. Nun zeigt das Stück die Machinationen um politische Einflussnahme (das Veranstalten 
von Festen durch Kandidaten, die Unterdrückung und Manipulation öffentlicher Rede sowie die Wirksamkeit von politischer Rhetorik, die auf das Volk manipulierend wirkt). Der Kreis der Verschwörer um Catilina möchte, nachdem das Volk für Cicero gestimmt hat, dieses am liebsten mit der Hacke hauen (vgl. II/2, S. 61); im Ringen um die Gunst des Volkes verwenden die politischen Rivalen unterschiedliche Techniken: die Senatoren richten Feste aus, Catilina inszeniert sich als Klassenkämpfer, der gegen die Herren auftritt und dem Volk deren Position und Privilegien verspricht. Während er mit seinen großen Versprechungen auf das Volk einwirkt, mobilisieren die Banditen mit noch phantastischeren Erfüllungsszenarien die Sklaven. Das Volk als vermeintlicher "Souverän“ der Republik wird bei Hálek als manipulierbare Größe dargestellt, die sich allzu leicht beeindrucken lässt. Nach den Auftritten von Catilina und Cicero im Forum äußern zwei Bürger die Ansicht, dass es für sie wohl am besten wäre, wenn sie beide Kandidaten wählten, dann profitierten sie von den Versprechungen beider. Bei den Vagabunden, welche die Banditen für den Aufstand gewinnen wollen, überwiegen ohnehin allein die materiellen Interessen. Dies wird etwa bei Scheitern des Aufstands im 3. Akt deutlich, wo sich ein Vagabund von den Römern kaufen lässt, die Stellungen der Aufständischen verrät und ein falsches Signal gibt. Als dann in der Folge Catilina den Vagabunden bestrafen möchte und ihn durch einen anderen abführen lässt, teilen sich beide das römische Bestechungsgeld und machen sich davon (III/2). Und die Sklaven machen einen wenig klassenbewussten Eindruck: Abgesehen davon, dass sie - wie erwähnt - die politische Agitation und ihre Rhetorik nicht adäquat verstehen, wollen sie auch nicht wirklich ihre Freiheit. Catilina, dem Ventidius Sklaven als Kämpfer anbietet, weist diesen darauf hin, dass er nicht mit Sklaven, sondern nur mit Freien kämpfen wolle. Später wird Catilina dann jedoch gemeldet, dass die Sklaven aus Kränkung über die Zurückweisung zu den Römern übergelaufen sind (vgl. IV/3, S. 121).

Insofern sich also die republikanische Partizipation im Drama als sehr fragwürdig erweist, muss gefragt werden, ob überhaupt eine positive Kraft vorgeführt wird. Der Titelheld Catilina ist keineswegs mehr eine fraglos positive Figur: er erscheint vielmehr als entschlossen revolutionärer Führer, der auch vor politischer Gewalt nicht zurückscheut, um den Umsturz einer ungerechten Gesellschaftsordnung herbeizuführen. Seine Emphase ist dabei sehr groß und mitreißend; dass er - dem Sieg nahe - letztlich aber dennoch scheitert, liegt auch an den Allianzen, die er eingegangen ist und die er zuwenig gut kontrolliert hat. So hat Julius Cäsar etwa aus starkem Eigeninteresse heraus auf Catilina zu setzen begonnen, letztlich aber lässt er diesen im Stich, weil er die Chancen des Aufstands für gering hält und sich lieber mit seinem Heer Pompejus entgegenstellt als Catilina Waffenhilfe zu leisten. Die Umsetzung von Catilinas Vision von historischer Größe - er vergleicht sich bereits mit Alexander dem Großen - scheitert spektakulär; der letzte Vers jedoch verheißt auch der siegreichen konservativen Ordnung in Rom den bevorstehenden Untergang. 


\section{IV.6.7. Josef Václav Frič: Ivan Mazepa. Tragedie v 5 dèjstvích (1865)}

[Ivan Mazepa. Tragödie in 5 Akten; publ. 1865, UA 1874]

Die in den Jahren 1708 und 1709 spielende Tragödie führt die Schwierigkeiten des Kosakenhetmans Ivan Mazepa vor, die Ukraine zu einem selbstbestimmten Land zu machen.

Der wegen seines Engagements bei den revolutionären Aufständen 1848 in Prag meist im ausländischen Exil lebende Autor Josef Václav Frič greift mit der Tragödie einen Stoff auf, der im 19. Jahrhundert europaweit stark verbreitet war. Dies hängt stark mit der Rezeption von Lord Byrons Verserzählung Mazeppa (1819) zusammen, die ihrerseits die seit Voltaires Histoire de Charles XII legendär gewordene Geschichte des Hetmans der Kosaken im Geiste der Romantik zu einem prototypischen Narrativ der Romantik machte. ${ }^{278}$ In den slawischen Literaturen ist der Mazepa-Stoff natürlich einigermaßen prominent in den Poemen Poltava (1828/29) von Aleksandr S. Puškin, Vojnarovskij vom Dekabristen Kondratij Ryleev (1825) und in Juliusz Słowackis Drama Mazepa (1839) vertreten. Josef Václav Fričs Drama ist weitgehend unbekannt; es hat auch noch keine szenische Aufführung erfahren.

Das Stück setzt mit einer Szene auf dem Schloss von Kočubej ein, der der oberste Richter der Kosaken ist. Jiskra, sein Sekretär und Verwalter, geht sehr rüde mit den Bauern um, die ihrem Herrn für ein Fest Abgaben liefern müssen. Das Fest soll für eine polnische Gesandtschaft (die Gräfin Dulská, den Grafen Poniatovský und den Jesuiten Zalenský) gegeben werden, vor welcher sich Kočubej sehr unterwürfig zeigt. So spricht er etwa von seinen eigenen Leuten als „orthodoxen Barbaren“" (vgl. S. 7). Seine Tochter Marje ist gegenüber den Bauern mitfühlend und verständig, ihre außergewöhnliche Schönheit fällt dem polnischen Grafen Poniatovský auf. Inzwischen wird Ivan Mazepa, der Hetman der linksufrigen Ukraine, die zu russischem Territorium gehört, erwartet. Er ist Marjes Taufpate, nur hat er sie seit der Tauffeier nicht mehr gesehen, während sie von seinem großen Ruhm überaus beeindruckt ist und seine Ankunft gespannt erwartet. Über ein mittels Spähern und Signalsprache funktionierendes Kommunikationssystem der Kosaken wird auch das Kommen des Kosakenobersten Semën Palej gemeldet, der mit Gewalt gegen die polnischen Herren und gierige Gutsverwalter vorgeht. Sowohl der Verwalter Jiskra wie auch Kočubejs polnische Gäste fürchten Palej, der bei den Bauern sehr beliebt ist. Die Gräfin Dulská, die von Mazepas Neigung zu den Frauen weiß, versucht ihn mit Marje zu umgarnen, um ihn für einen weitgehend vage bleibenden polnischen Plan zu gewinnen. Mazepa ist von der Schönheit

278 Für eine sehr breite - und dabei profunde - kulturwissenschaftliche Darstellung des Mazepa-Stoffes in der europäischen und amerikanischen Literatur- und Kunstgeschichte siehe Grob (2005), die hier besprochene Tragödie bleibt in dieser jedoch unerwähnt. 
seines Patenkindes sehr angetan. Er spricht von der Hoffnung auf eine blühende Zukunft seines Landes. Seine 150 Mann starke Leibgarde erscheint den polnischen Gästen und Kočubejs Verwalter als ausreichender Schutz vor Palejs Leuten. Mit der Ankunft zweier Boten werden erste Spannungen offenbar, denn die Boten, die stolz auf ihre kosakische Rohheit gegenüber den Polen und Juden sind, werden von Mazepas Getreuen abweisend behandelt. Die Boten, die den Zaren als ihren höchsten Befehlshaber ansehen, halten Mazepa für einen verrückt gewordenen Verräter. Vojnarovský, ein gegenüber Mazepa loyal gesinnter Sänger, streicht den Unterschied zwischen Mazepa und Palej hervor. Letzterer handle schnell und entschlossen, was ihm viel Sympathie beim Volk einbringe, Mazepa setze demgegenüber auf Intrigen und List, deren Sinn und Zweck den meisten verborgen seien. Peter der Große hat bereits Verdacht gegenüber Mazepa geschöpft. Protasjev, ein orthodoxer Priester, ist als Spion im Einsatz, der prüfen soll, ob es bei Mazepa Zeichen einer moskaufeindlichen Stimmung gibt. So möchte er Lieder finden, die dieser gegen Moskau geschrieben haben soll.

Die Gräfin Dulská will Mazepa mit Marje für ihre Interessen gewinnen, sie verspricht ihm die Herrschaft über die Ukraine. Er bleibt jedoch von Marjes Liebreiz weitgehend unbeeindruckt; der Kampf für die Heimat ist ihm wichtiger als die weibliche Schönheit. Mazepa erklärt, dass der Zar bereits vor einem schwedischen Angriff gewarnt sei und dass russische Truppen in Stellung gebracht werden. In Palej hat Mazepa einen gewichtigen Gegner, der schwerlich für einen Pakt mit den Polen und Schweden zu gewinnen sein wird, zerstört er doch mit Billigung des Zaren Städte auf polnischem Territorium. Bílá Církev, seine eigene Geburtsstadt, wurde von Palej mit ausdrücklicher Billigung bzw. auf Geheiß Peters erobert, aber der Zar erließ daraufhin auch den Befehl, dass Palej für die Einnahme der Stadt bestraft werden sollte. Palej sieht darin eine Intrige Mazepas. Dieser hingegen möchte Palej die Falschheit und Unzuverlässigkeit Peters vor Augen führen; er erklärt ihm, dass der Zar Palej einfach austricksen wollte. Indem er Palej davon zu überzeugen versucht, dass der Zar widersprüchlich und nicht zum Wohl der Ukraine handle, will er diesen für einen gemeinsamen Kampf an der Seite der Polen gewinnen. Palej weigert sich jedoch, den Befehl Mazepas zu befolgen, keine polnischen Besitzungen mehr anzugreifen. Bei einem mit den Polen gemeinsam gefeierten Fest kommt es zum Bruch, da Palej nicht gemeinsam mit den Polen auf das Wohl der Ukraine trinken will.

Im zweiten Akt lässt Mazepa die von Palej eingenommene Stadt Bílá Církev belagern, um Palej festzunehmen. Er möchte bei Peter dem Großen den Eindruck von großer Loyalität erzeugen, daher soll auch Palej von Mazepas Getreuem Orlík nach Moskau gebracht und dort mittels einer fingierten Geschichte als Verräter denunziert werden. Mazepas Täuschungsspiel ist riskant: Er möchte keine Kosaken stellen müssen, die Peter im Kampf gegen den anrückenden Karl XII. dienen sollen, und dabei zugleich loyal erscheinen. Die Bestrafung bzw. Auslieferung von Palej als 
angeblichem Verräter soll als Loyalitätsbeweis dienen. Hauptsächlich jedoch geht es Mazepa mit der Festnahme Palejs darum, seinen stärksten Widersacher innerhalb der Kosaken auszuschalten. Palej ist ja ein erklärter Gegner der Polen und Schweden, auf die Mazepa setzt. Palej wird durch eine List gefangen genommen; das Versprechen einer Unterredung mit Mazepa lockt ihn aus seiner Verteidigung, er wird entwaffnet und von Orlík nach Moskau gebracht.

Die Liebesgeschichte zwischen Marje und Mazepa wird im Drama eher als Nebenhandlung betrachtet. Das Liebeswerben geht vor allem von Marje aus, während Mazepa ihre Liebe nur erwidert, weil er sie nicht verstoßen möchte. Er bedauert sie eher, gibt ihrem Werben aber letztlich doch nach. Für ihn zählt vor allem der Kampf für das Vaterland. In dieser Hinsicht unterscheidet sich die Tragödie sehr stark von Puškins Bearbeitung des Mazepa-Stoffs in Poltava (1828/29), wo Mazepa vor allem von seiner erotischen Leidenschaft für Kočubejs Tochter getrieben wird; sein durch ukrainische Unabhängigkeitsbestrebungen motivierter Verrat an Russland bildet in Puškins Poem nur einen zweiten Handlungsstrang. Kočubejs Wut über Mazepas vermeintliche Verführung von Marje nimmt sich bei Frič entsprechend auch eher als komische Episode aus. Marje, die Mazepa über alles liebt, erzählt ihren Traum von der Vertreibung Mazepas aus Polen, die in vielen Darstellungen des Mazepa-Stoffs in der Literatur und anderen Künsten ins Zentrum gerückt wurde. Mazepa, dessen Vorliebe für schöne Frauen im Drama immer wieder angesprochen wird, hatte in seiner Jugend ein Liebesverhältnis zu einer verheirateten Polin; er wurde von deren Ehemann auf erniedrigende Weise - nackt auf ein Pferd gefesselt - verjagt. In Fričs Drama hat diese Traumerzählung aber wohl keine weitere Funktion, als dass Marje im Traum das ihr bevorstehende Unglück angedeutet wird: Die Kosaken, die das Pferd mit dem nackten Mazepa in den Wald verjagen, sagen zu Marje, die im Traum Mazepa retten will: „Zlý duch tvou naději' ${ }^{\text {“279 }}$ (III/5).

Zumal Mazepa sich als Hetman auch über alte Kosakentraditionen hinwegsetzt, kommen unter den Kosakenobersten Zweifel auf; die Pläne Mazepas sind ihnen ja nicht wirklich bekannt. Orlík, der für Mazepa als Denunziant von Palej in Moskau fungieren soll, sieht seine Aufgabe als Sünde an; auch fürchtet er, die ganze Denunziationsintrige könne misslingen (II/5). Als ein Getreuer Palejs dessen Herausgabe fordert und Mazepa töten will, erschießt ihn Mazepa und erklärt, dass er vom Zaren die Vollmacht habe, gegen Aufständische vorzugehen. Mazepa muss, um seine Täuschungsstrategie umsetzen zu können, sich auch gegenüber den Kosakenobersten in der Staršina als russlandtreu präsentieren; unter den Kosakenführern gibt es unterschiedliche Meinungen darüber, wie das Verhältnis Russlands zu den Kosaken bewertet werden soll.

Als Mazepa von seinem Sänger Vojnarovský erfährt, dass die Schweden nur langsam vorrücken und dass Karl von Mazepa verlangt, er solle mit den Kosaken einen

279 Ungefähr: „Ein böser Geist hofft auf dich.“ 
Aufstand gegen die Russen beginnen, um Peter zu schwächen, überlegt er, ob er nicht etwa den ganzen Plan an Peter verraten und in der Folge an dessen Seite gegen die Polen und Schweden kämpfen soll, um als Belohnung die Sicherung alter Kosakenrechte von ihm zu fordern.

Der Zar schickt Mazepa sogar zwei Gefangene, Kočubej und seinen Sekretär Jiskra, die Mazepas Plan dem Zaren verraten haben. Mit dieser Auslieferung setzt er Mazepa unter Loyalitätszwang. Tatsächlich hatte Mazepa selbst in einem Brief dem Zaren seine polnischen Pläne verraten, um damit seine Loyalität zu bekunden. Mazepa lässt Kočubej hinrichten, er nimmt bewusst in Kauf, dass er Marje damit ins Unglück stürzt. Diese verübt Selbstmord, als sie die Hinrichtung ihres Vaters durch ein Fenster beobachtet.

Mazepa gerät zusehends unter Druck, weil Karl XII. noch nicht weit genug vorgerückt ist und weil er Peter seine zusehends fraglicher werdende Loyalität beweisen muss. Seine Botschaften an Karl werden abgefangen und dem Zaren bekanntgegeben.

Als bei Poltava die große Schlacht der Schweden mit den Russen bevorsteht, rechtfertigt Mazepa seinen Loyalitätsbruch mit den Russen und seine Unterstützung für Karl XII. damit, dass die Kosaken ein unfreies Volk seien und von Russland keine Freiheit zu erwarten hätten. Wohl aber von den Schweden; es sei gleichgültig, dass diese Protestanten seien. Für diese Erklärung erhält Mazepa großen Beifall und Unterstützung von den Kosaken.

Karl XII. ist gegenüber den Kosaken und ihrer Trinkfreudigkeit skeptisch; mit Mazepa entsteht ein strategischer Streit, ob die zahlenmäßig viel stärkeren Russen angegriffen werden sollen, was der ungestüme Karl möchte, oder ob sich die Schweden und Kosaken nicht besser nach Polen zurückziehen und auf Unterstützung warten sollen, wie Mazepa vorschlägt. Karl, der am Bein schwer verwundet ist, lässt die Truppen in Bereitschaft bringen; Mazepa erkennt, dass die Schlacht - und mit ihr sein Vorhaben, die Ukraine zu befreien - schlecht enden wird. Auch kommt die Meldung, dass die Russen die von den Kosaken verteidigten Städte bereits eingenommen haben. Palej ist aus Sibirien zurückgekehrt, er wurde vom Zaren rehabilitiert und viele Kosaken laufen zu ihm über.

Im fünften Akt wird die Schlacht um Poltava aus der Mauerschau dargestellt. Karl XII. ist blindwütig angriffslustig, die Polen und Schweden haben keine Chance. Der schwer verletzte Karl, Mazepa und Poniatovský müssen fliehen; sie geraten an den Dnjepr und setzen über. Mazepa verabschiedet sich von seinem Freund Hordějenko, dem Führer der Zaporoger Kosaken.

Ivan Mazepa endet mit dem fünften Akt in der Stadt Bender, die sich auf türkischem Territorium befindet. Karl und Mazepa haben am Hof von Pascha Izmaël Zuflucht gefunden. Doch möchte Peter der Große über den Popen Protasjev die Herausgabe Mazepas erreichen. Der türkische Rat („Diwan“) zeigt sich zunächst abweisend, Mazepa aber weiß, dass die Angebote Peters so hoch sein werden, dass 
er ausgeliefert werden wird. Er löst tödliches Gift aus einem Ring auf, den er einst von Marje erhalten hat. Seine Getreuen Orlík und Vojnarovský kommen aus der Ukraine und vermelden, dass seine schlimmsten Befürchtungen eingetroffen sind. Peter geht tatsächlich rücksichtslos gegen die Kosaken vor. Mazepa lehnt es ab, erneut Führer der Kosaken zu sein, und beauftragt seine Getreuen, sein Lebenswerk fortzusetzen. Mit seinem Freitod möchte er erreichen, dass die schwedischen Gefangenen von Peter freigelassen werden. Alle sind ob Mazepas Tod bestürzt. Er wird in der letzten Replik als Vater bezeichnet; mit ihm werde die Mutter Ukraine begraben werden.

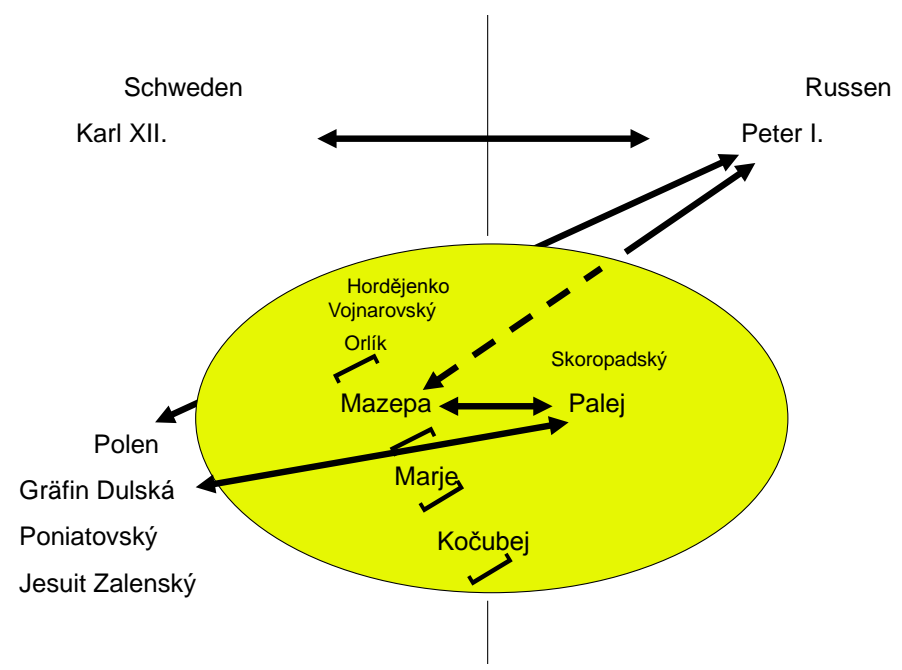

Graphik 20 - Josef Václav Frič: Ivan Mazepa (1865)

Die Tragödie Ivan Mazepa zeigt die Schwierigkeiten, die Idee nationaler Unabhängigkeit in der Wirklichkeit umzusetzen, wenn der Unterdrücker der Nation sehr stark ist und dafür Allianzen mit Partnern und anderen Handelnden einzugehen sind. Damit unterscheidet sie sich deutlich von den zahlreichen Bearbeitungen des Stoffs in der Literatur - sie gehört zur Reihe der Texte, die unter Beibehaltung vieler überlieferter historischer Umstände das nationale Befreiungsmoment hervorheben. Beliebte Motive des Stoffes werden dabei zurückgenommen, um stärker die Schwierigkeiten und kontingenten Unwägbarkeiten einer politischen Strategie hervorzuheben. Frič war offensichtlich einer traditionellen Vorstellung von Tragödie verpflichtet, gemäß derer widrige Umstände die Bemühungen des Protagonisten vereiteln oder zunichte machen. Nicht alle anderen politischen Akteure verhalten sich so, wie es das Kalkül eines Einzelnen erfordert; damit ist der politische Kampf immer wieder unvorhersehbaren Wendungen ausgesetzt, die sei- 
nen Ausgang ungewiss machen. Das Freiheitspathos, welches den Mazepa-Stoff für die slawische Romantik so attraktiv machte (vgl. Grob 2005, 58-66), motiviert freilich das Handeln des Titelhelden; der Akzent von Frič liegt aber weniger auf dem Wert der Freiheit, sondern auf den Mühen und Schwierigkeiten, diese zu erlangen oder zu erkämpfen.

Als Titelheld sieht sich der Hetman Mazepa diesen Schwierigkeiten ausgesetzt, die zu seinem tragischen Scheitern führen. Nicht umsonst hat ein von ihm geschriebenes Lied den beschwörenden Refrain: „Podejte si všickní ruce, tak vám vypomohu!" ${ }^{280}$ (vgl. I/10). Mit dem Fehlen von nationalem Konsens über die politische Orientierung - die Ukraine wird im Stück vorwiegend durch die Kosaken dargestellt, deren militärische bzw. territorial abgegrenzte Einheiten durch ihre Führer bzw. Obersten repräsentiert sind - beklagt Mazepa gleichfalls auch die Kontingenz des Handelns der Beteiligten, die für seine Pläne einen ungewisseren Ausgang erwarten lässt und die etwa beim Schachspiel nicht berücksichtigt werden muss (vgl. II/1). Unter den Kosaken ist Mazepas Position nicht fraglos autokratisch: Die Kosaken sind in Truppen und Einheiten organisiert, die jeweils ihre eigenen Führer haben und für diese gleichsam eine Hausmacht bilden. Der größte militärische Gegner Mazepas innerhalb des Kosakenlagers ist eindeutig Semën Palej, der im Gegensatz zu Mazepa auf Moskautreue setzt. Mazepa hat in der Staršina der Kosaken auch eine Institution neben sich, deren Beschlüssen er sich als Hetman beugen müsste; er aber setzt sich über sie hinweg im Glauben, dass seine Befreiungsstrategie keiner institutionellen Erörterung oder gar Einschränkung bedürfe. Ein dritter Gegner im eigenen Lager erwächst ihm in der Person von Kočubej, der aufgrund des Umstands, dass seine Tochter Mazepas Geliebte wurde, in Rage gerät und dessen Pläne an den Zaren verrät. Seine größten „außenpolitischen“ Gegner sind die Russen unter Peter I., darunter auch russische Adelige, die aus persönlichen Gründen Mazepas Feinde sind.

Mazepa verspricht sich durch einen heimlichen Pakt mit den Polen und Schweden mehr Freiheiten und Chancen für die Kosaken bzw. die Ukraine. Da er jedoch um die massiven Vorbehalte der orthodoxen Kosaken gegenüber den Polen weiß, muss er seinen Plan heimlich umsetzen, was ihm nur teilweise gelingt. Mazepa hält die Unterredungen mit den Polen geheim, die ihrerseits auf Mazepa setzen und dabei keineswegs uneigennützige Gründe haben. Ihre Herrschaft ist nämlich durch die Angriffe von Palejs Kosakentruppen gefährdet; von Mazepa erwarten sie eine Befriedung ihrer Herrschaft über die Westukraine, die besonders den Bauern und dem einfachen Volk gegenüber grausam und ausbeuterisch ist. Da es Palej grundsätzlich ablehnt, gemeinsam mit den Polen zu feiern (damit endet der erste Akt) und sich nicht Mazepa bzw. dem Verbot, gegen die Polen vorzugehen, unterordnen

280 „Gebt euch alle die Hände, sodass ich euch aushelfen kann!“ 
möchte, heckt Mazepa einige Listen aus: So versucht er etwa Palej zu erklären, dass Peter I. diesen in eine Falle gelockt habe und dass auf Peter kein Verlass sei. Palej hingegen ist der Auffassung, dass Mazepa selbst dahintersteckt, wenn der Zar Palej vor Gericht stellen möchte. Als Palej sich Mazepa widersetzt, verwendet dieser alle möglichen Täuschungsmittel, um seinen politischen Rivalen auszuschalten. So lässt er Palej etwa entgegen der Zusicherung freien Geleits überwältigen und nach Moskau bringen, wo ihm fingierte Vorwürfe gemacht werden. Mit Kočubej verfährt Mazepa ebenso entschlossen. Da er fürchten muss, dass dieser den Plan nicht nur Peter dem Großen verraten möchte (der ihm nicht glaubte), sondern auch den Kosaken, was sein Gelingen gefährden würde, lässt er Kočubej hinrichten. Er wird sich dabei bewusst, dass die Liebe bzw. das Privatleben sehr wohl auch mit der Politik zusammenhängt (vgl. III/6).

Die Allianz mit Karl XII. verläuft gleichfalls nicht nach Plan, da zum einen die Schweden anders und langsamer vorrücken, als es geplant war, und zum anderen Karl eigensinnig und allzu risikofreudig ist. Karl erwartet von Mazepa einen Aufstand, was Peter I. den Loyalitätsbruch offenbaren würde. Ob ein solcher Aufstand aber überhaupt erfolgreich sein würde, bezweifelt Mazepa stark. Die andere Alternative, die Mazepa ja gleichfalls beginnt, nämlich den ursprünglichen Plan vom Angriff der Polen und Schweden an Peter zu verraten, um gerade dadurch als Gegenleistung von Peter Zusicherungen für die Ukraine zu bekommen, schlägt insofern fehl, als ja der skeptische Kosakenoberst Skoropadský Mazepas Boten Vojnarovský abgefangen und nach Kiev entführt hat, sodass Mazepas Appell an Peter diesen gar nicht mehr erreicht.

Mazepa hat sich mit wenigen Getreuen, die ihrerseits nicht vollständig in sein Vorhaben eingeweiht sind, gegen starke Gegner innerhalb der eigenen Reihen durchzusetzen, weswegen er alle möglichen Listen ergreift. Er muss gegenüber den zarentreuen Kosakenobersten und gegenüber Peter Loyalität simulieren und gleichzeitig seine faktische Illoyalität - die Pläne mit den Polen und Schweden - dissimulieren. Dieses schwierige Spiel muss er zumindest so lange aufrechterhalten, solange er keine militärische Unterstützung von den Schweden hat. Als die Schweden aber vor Poltava liegen, erweist sich Karl XII. als allzu unbedachter Feldherr, der Mazepas überlegtere Taktik mutwillig ablehnt und somit die Niederlage heraufbeschwört.

Im Doppelspiel von Simulation und Dissimulation, das Mazepas Handeln kennzeichnet, liegen nun auch die dramaturgischen Probleme des Stücks. Weil die Partner und Gegner Mazepas getäuscht werden müssen, geben die Dialoge dem Lese-/Publikum qua Adressat zuwenig Aufschluss über die eigentliche Strategie, es hat zuwenig Informationsvorsprung gegenüber den Figuren, um die Doppelbödigkeit von Mazepas Rede und um darüber hinaus das tragische Scheitern der Strategie erkennen zu können. Ein weiteres Problem ist auch der Umstand, dass viele entscheidende Wendungen nur durch Botenberichte erzählt werden, während den 
Szenen selbst mitunter Dramatik abgeht bzw. diese aufgrund der angesprochenen Doppelstrategie nur schwer erkennbar ist. ${ }^{281}$

Mazepas Anlehnung an die Polen und Schweden, die sich strategischen Gründen verdankt, erscheint aufgrund der polnischen Interessen und der Ausbeutung der Bauern durch die Gutsbesitzer zweifelhaft, was eben Mazepas größten innenpolitischen Gegner Palej auf den Plan ruft, der sich seinerseits loyal gegenüber Peter und Russland verhält. In der Tragödie wird im letzten Akt - da aber ist die militärische Entscheidung bei Poltava schon gefallen - Mazepas Einschätzung der Russen bestätigt, denn nach dem Sieg über die Schweden und Polen sowie die abtrünnigen Kosaken beginnt Peter noch intensivere Repressionen gegenüber den Kosaken, sogar gegenüber den loyalen, die er zum Bau von Petersburg einsetzt. Das mit Palej verknüpfte soziale Moment gerät ob dieses Endes in den Hintergrund; Mazepas Idee von ukrainischer Souveränität, die von den Ereignissen gebrochen wird, ist gegenüber dieser dominanter.

Mazepa stirbt einen im Rahmen des Tragödienschemas wenig überzeugenden Heldentod (mit seinem Selbstmord glaubt er, dass die schwedischen Gefangenen Peters freikommen werden) und wird als tragischer Kämpfer für die ukrainische Freiheit verabschiedet. Diese Apotheose, deren positiver Tenor in einigem dem Mazepa-Bild gleicht, das seit den 1930er Jahren in der Ukraine und speziell wieder nach 1991 populär wurde (vgl. Grob 2008, 90-95), „überdeckt“ gleichsam einige strittige Aspekte von Mazepas Handeln, die in den vorangehenden vier Akten zwar kurz thematisiert werden, aber im abschließenden und zusammenfassenden fünften Akt verloren gehen. Orlík und Vojnarovský, Mazepas treueste Agenten, die im fünften Akt von den betrüblichen Folgen des Sieges von Peter berichten und Mazepa noch einmal die Führung anvertrauen wollen, äußern sich ja zuvor kurz kritisch über sein Verhalten: Vojnarovský ist der Auffassung, dass man dem Unrecht wie Palej offen entgegen treten solle und nicht so verstohlen und listig wie Mazepa (I/5). Orlík seinerseits plagen schwere Gewissensbisse, als er Palej in eine Falle lockt und bei Peter mit fingierten Verleumdungen denunzieren muss (II/5). Das Misslingen von Mazepas Plan sowie die geäußerten Zweifel an der Ethik seines politischen Handelns, die im letzten Akt freilich nicht weiter thematisiert werden, sind aber immer noch gewichtig genug, um den etwa in Josef Lindas nationalem Befreiungsdrama Jaroslav Šternberg v boji proti Tatarum (1823) legitimierten Gebrauch von Mitteln wie Lüge, Trug, Täuschung durch den finalen Zweck (nationales Überleben bzw. Befreiung) als zumindest problematisch erscheinen zu lassen.

281 Ein Beispiel für die dramaturgischen Reize und Schwierigkeiten, Simulation und Dissimulation szenisch darzustellen, ist der Dialog zwischen den „Agenten“ Vojnarovský und Protasjev, die für die politischen Kontrahenten Mazepa und Peter handeln (I/5): Vojnarovský weiß, dass Protasjev für Peter spioniert, Protasjev weiß aber nicht, dass sein Gegenüber Vojnarovský ist und dass dieser ihn verwirren möchte, indem er dissimuliert, also eigentlich die Wahrheit - („Mazepa ist ein Gegner Peters“) - sagt. 
Josef Václav Frič hat der im Selbstverlag erschienenen Buchausgabe ein Nachwort beigefügt, in dem er die Schlacht bei Poltava in eine Reihe von für slawische Völker schicksalhafter Schlachten stellt: Kosovo polje, Bílá hora und die Schlacht von Maciejowice (1794), welche das Ende polnischer Souveränität markiert. An diese Kategorisierung schließt er ein längeres wörtliches Zitat aus einem historiographischen Beitrag an, welchen er selbst als Quelle für seine Tragödie ausweist. ${ }^{282} \mathrm{Das} \mathrm{Zi}$ tat ist ein Ausschnitt aus einer Protestrede des Kosaken Polubotek an Peter I. nach der Schlacht von Poltava. Polubotek, der gegenüber Peter loyal geblieben ist und sich nicht mit Mazepa den Schweden angeschlossen hat, wirft Peter vor, in Verkennung seiner fürstlichen Souveränität den Kosaken ihre traditionellen Sonderrechte zu nehmen und ein ganzes Volk zu Zwangsarbeiten zu verpflichten. Mit Gewalt und Druck sei aber nicht viel zu gewinnen. Wenn hingegen der Herrscher ein wahrer Führer und Vater des Volkes sei, dann würde sich dieses, beeindruckt von seiner Liebe und Güte, gerne für des Herrschers Erfolg und Ruhm opfern. Das Zitat endet mit einer an Peter gerichteten Ermahnung, dass er sich noch für alles Unrecht, das er am Volk verübe, vor Gott werde verantworten müssen. Frič ergänzt zum Zitat, dass Polubotek für die geäußerte Kritik an Peter I. gemeinsam mit anderen Kosaken in den zaristischen Gefängnissen hat sterben müssen und dass Katharina II. sich empört über die Dreistigkeit der Kosaken der Zaporoger Sič geäußert habe, die darin besteht, dass diese ihr Land als ihnen auf ewig gehörend betrachteten. Das Nachwort endet mit der Klage darüber, dass sich keine europäische Macht um die Wiederherstellung ukrainischer Selbstständigkeit und kosakischer Freiheit gekümmert habe.

Selbst wenn man die Allegoriesignale - den Vergleich von Poltava mit Bílá hora und der Schlacht am Amselfeld und die im Nachwort zitierend erfolgende Adressierung und Ermahnung des Souveräns - als insgesamt zu schwach erachtet, um einen direkten Bezug der Tragödie zur tschechischen Situation in der Mitte des 19. Jahrhunderts herstellen zu wollen, wird man doch nicht umhin können, Ivan Mazepa als resignatives politisches Drama zu lesen: Es führt die Risiken des Befreiungskampfes vor Augen, der eben auch misslingen kann, wenn die Umstände ungünstig und die nationale Einigkeit nicht gegeben ist.

\section{IV.6.8. Emanuel Bozděch: Baron Goertz. Truchlohra v pèti dějstvích (1867)}

[Baron Goertz. Trauerspiel in fünf Akten; entst. 1867, UA 1868, publ. 1871]

Die Anfang des 18. Jahrhunderts in Schweden situierte Tragödie zeigt die Rivalität im Kampf um die Regierungsmacht. Baron Goertz, die Titelfigur, ist der Kanzler des schwedischen Königs Karl: Er gilt als Zugereister, der als Günstling des Königs

282 Frič verweist auf F. Vinkler: „Assimilace maloruského národa“ in Pravda 1863, diese Quelle konnte aber nicht verifiziert werden. 
allergrößten Einfluss auf die höchsten Entscheidungen nimmt. Goertz wird von praktisch allen als Verantwortlicher für die schlechte Lage im Land angesehen.

Ulrika, die Schwester Karls, ist gegenüber Goertz besonders hasserfüllt. Goertz will eine Heirat der Tochter Peters I. von Russland mit Karl erreichen, um Schweden mittels der so entstehenden Allianz mit dem einstigen Gegner im Nordischen Krieg eine neue Machtstellung zu verschaffen. Im Heiratsvertrag soll vereinbart werden, dass auch bei Kinderlosigkeit Anna Petrovna Thronfolgerin sein soll. Um ihre Chance auf die Thronfolge zu wahren, setzt Ulrika den Franzosen Siquier auf Karl an, der noch vor einer Heirat mit Russland zu Tode kommen soll. Siquier nimmt diesen - sehr zweideutig ausgesprochenen - Auftrag an, weil Karl seine Hoffnung auf Erhebung in den Adelsstand frustriert, Ulrika ihn aber für den Anschlag belohnen will (I/3).

Der intrigante Goertz kennt in der Politik keine moralischen Grundsätze, in seinen machiavellistischen Überlegungen geht es nur um den Machterhalt („Nemravností jest u knížat jen co je trůnu může zbaviti ${ }^{\text {“283 }}$ - I/6, S. 17). Die von ihm vorgeschlagene Allianz mit Russland könne Schweden nicht allein die Herrschaft über die Dänen und Holsteiner bringen, letztendlich müsste auf kriegerischem Wege dasjenige von Russland zurückgefordert werden, was durch Heiratsdiplomatie zugesprochen worden war. Goertz möchte Karl vor allem im Krieg wissen, um seine eigene Macht während der Abwesenheit des Königs besser ausspielen zu können („Kde král vojákem, ministr králem jest.“284, I/6, S. 17). Goertz warnt ihn vor Ulrika und den Interessen der im Sněm (Landtag) vertretenen Stände. Als Sněm-Abgeordnete unterbreiten Rhenstjern und Ribbing Karl die Bitte des Landes, von weiteren Kriegen abzusehen und Goertz zu entmachten. Er sieht dies als Affront an und lässt die beiden festnehmen. Sein Herrscherwille stehe über allen Gesetzen (die etwa diese Festnahme verbieten); den Willen des Volks respektiert Karl nicht.

Vor dem Stimmungsbild der unzufriedenen Bevölkerung, die die Last von 18 Kriegsjahren tragen musste, wird im zweiten Akt die private Parallelhandlung entwickelt. Wie auf der höchsten Ebene des Staates geht es auch den einfachen Menschen um ein Mehr an Ansehen und um Aufstieg. So möchte Ebba endlich den Theologiestudenten Olaf heiraten, um als Pastorsfrau Respekt von ihrer Umgebung zu erfahren. Olaf, der als eigenbrötlerischer ewiger Student gilt, trachtet nach großem Ruhm: Herostrat gibt ihm mit seiner Brandlegung, die diesem in die Weltgeschichte Eingang verschafft hat, ein Vorbild ab. Ein Gespräch über eine von Ebba gekaufte Uhr bringt Olaf auf den Gedanken, das zentrale Zahnrad, dessentwegen sich alles dreht, zu entfernen: Mit dem Königsmord werde er zu großer Berühmtheit gelangen: „Vzácnost oběti i obětníka povznáší!“285

283 [Goertz:] „Unsittlich ist für Fürsten nur dasjenige, was sie den Thron kosten kann.“

284 [Goertz (beiseite)]: „Wenn der König zum Soldaten wird, ist der Minister König““

285 [Olaf:] „Die Besonderheit des Opfers erhöht auch denjenigen, der opfert.“ 
Olaf geht zum Heer, um seinen Anschlag ausführen zu können. Bei der Belagerung der dänischen Festung Frederiksteen nutzt er schließlich die Gelegenheit, Karl zu erschießen. Der nach dem Mord hinzukommende Siquier sieht seine Chance, vor Ulrika als erfolgreicher Auftraggeber des Anschlags gelten zu können; Olaf müsse nur vor Ulrika bestätigen, dass er von Siquier mit dem Mord betraut worden wäre.

Im vierten Akt werden die Komplikationen deutlich, die aus der Dissimulation des Anschlags entstehen. Siquier überbringt Ulrika die Nachricht vom Tod Karls, diese zeigt sich darüber erfreut. Er erwartet die erhoffte Belohnung für die Ausführung des Auftrags. Die offizielle Version vom Tode Karls soll freilich sein, dass er einer dänischen Kugel zum Opfer gefallen ist. Ulrika setzt eine Untersuchungskommission ein, die letztlich offiziell diese Version bestätigen soll. Sie sieht nun die Gelegenheit, sich an Goertz zu rächen. Dieser wird ein Weile lang im Zweifel gelassen über die Ereignisse, doch dann festgenommen. Die aus dem Gefängnis befreiten Abgeordneten zum Landtag, Ribbing und Rhenstjern, mischen sich im Streit um die Thronfolge ein. Goertz möchte seinen Neffen als Thronfolger eingesetzt sehen, Ulrika freilich sich selbst, Ribbing und Rhenstjern vertreten aber die Auffassung, dass bei abgerissener Genealogie der Landtag den König zu wählen hat. Ulrika willigt hierin ein, weil sie meint, dass sie vom Landtag genug Unterstützung bekommen wird, wenn sie sich ihm gegenüber freundlich zeigt.

Ribbing erzwingt von Ulrika Zugeständnisse an den Landtag. Er erklärt, dass der Landtag sie nur dann zu Königin wählen wird, wenn sie schriftlich einige königliche Rechte an ihn delegiert: sie dürfe auch nicht Siquier zum Militäroberbefehlshaber von Göteborg ernennen. Mit dem Wissen, dass dieser als Handlanger des von Ulrika beauftragten Mordes gelten kann, haben Ribbing und General Rhenskjoeld ein entsprechendes Druckmittel in der Hand. Wenn Ulrika die Rechte nicht abtreten will, könne der Landtag ja auch den Neffen von Goertz zum König wählen. Ulrika unterzeichnet widerwillig und resigniert diese Bedingungen, die das Ende absoluter Königsmacht sind: „Sem ten ortel moci královské!“286 (V/5, S. 68) Der Landtag ruft die neue Königin aus. Ihr erstes Gesetz proklamiert die Todesstrafe dafür, dass jemand an der offiziellen Todesversion zweifelt. Ulrika ist wegen der ihr aufgezwungenen Beschränkungen der Königsmacht enttäuscht, sie beschuldigt Siquier, nicht sorgfältig genug den Auftrag ausgeführt zu haben und rät ihm, Schweden zu verlassen, weil die schwedischen Stände keine Ausländer in offiziellen Diensten mehr sehen möchten.

Die beiden Schlussszenen führen den hochpolitischen und den privaten Handlungsstrang zusammen: Gegen Baron Goertz und andere Ausländer soll wegen Landesverrats das Todesurteil vollstreckt werden; Olafs Geliebte Ebba sieht sich als mitschuldig an deren Tod, weil sie seinen Entschluss, den König zu ermorden, nicht

286 [Ulrika:] „Her mit dem [Todes-]Urteil über die Königsmacht!“ 
rechtzeitig gemeldet hat und damit auch alle auf den Mord folgenden Ereignisse als von sich mitverursacht sieht. Sie ertränkt sich in einem See. Als Olaf ihre Leiche sieht, entschließt er sich, die Wahrheit preiszugeben. Nach der Proklamation der offiziellen Todesursache und des Gesetzes der Todesstrafe bei Zweifel an der offiziellen Version möchte Olaf seine Tat verkünden, um die ersehnte Fama zu erlangen. Er wird jedoch als Verrückter abgeführt und nicht ernst genommen. Ribbing verkündet das Todesurteil über Goertz wegen Landesverrat.

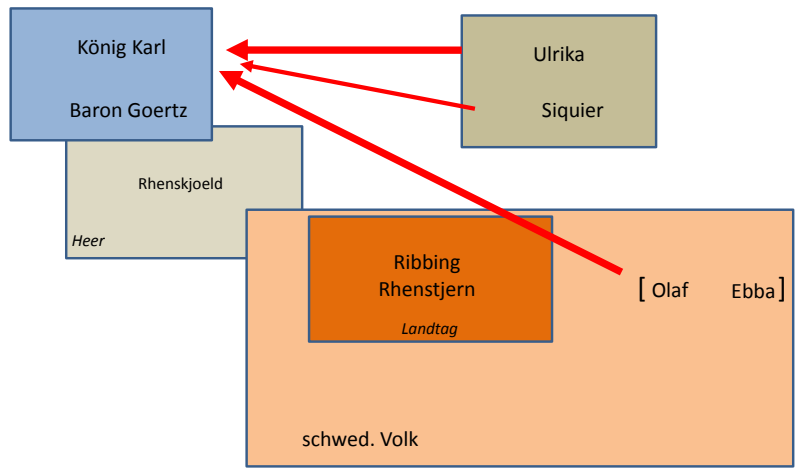

Graphik 21 - Emanuel Bozděch: Baron Goertz (1867)

Baron Goertz war laut Klosová (vgl. 1977a, 62) vor allem deswegen beim tschechischen Publikum erfolgreich, weil in der Titelfigur eine satirische Darstellung des österreichischen Ministers Friedrich Graf Beust gesehen wurde, der bei den Tschechen dafür verachtet war, dass er als Reichskanzler den Österreichisch-Ungarischen Ausgleich von 1867 ausgehandelt hatte, den Tschechen aber keine solche staatsrechtliche Aufwertung zugestand. Tatsächlich gilt ja auch für Beust das Merkmal, welches von Goertz' Gegnern immer wieder betont wird: dass er nämlich als Politiker zuerst im Dienst eines anderen Landes gestanden hat - Goertz u.a. in Schleswig-Holstein, Beust war Minister in Sachsen - und dann zu großem Einfluss im eigenen Land gekommen ist.

Die Tragödie geht in ihren politischen Bezügen weit über eine tagesaktuelle satirische Bezugnahme hinaus, zeigt sie doch in dramatischer Form den Übergang von absoluter zu (konstitutionell) begrenzter Souveränität. Karl wird als absoluter Monarch gezeichnet, der keinerlei Verständnis dafür hat, sich dem Willen des Volks in irgendeiner Weise zu beugen. Als etwa die Abgeordneten zum Landtag ihm die Bitte überbringen, die Kriegshandlungen zu beenden und Goertz aus seiner Funktion zu entfernen, lässt er die Abgeordneten umgehend festnehmen. Auf ihren protestierenden Verweis, dass nach dem Gesetz allein der Landtag befugt sei, seine Mitglieder festzunehmen, entgegnet Karl bestimmt: 
Král: Rozpouštím jej, neb zapomíná na první zákon říše: vůli mou.

Rhenstjern: Odvolávám se k národu.

Král: K této smečce vášní zaslepené, kterou proti mně štvete?287 (I/8, S. 22)

So wie Karl danach strebt, sein Ansehen als schwedischer König zu vergrößern er vergleicht sich mit Alexander dem Großen und seinem Vorfahren Gustav Adolf (vgl. III/7) - und in Baron Goertz den dafür passenden Ratgeber sieht, so sind schlechthin alle anderen Hauptfiguren von Ehrgeiz und Ruhmsucht getrieben. ${ }^{288}$ Baron Goertz, wiewohl ohnehin schon Minister, beansprucht insgeheim den Platz des Königs, wenn schon nicht für sich, so für seinen holsteinschen Neffen; Ulrika möchte Thronfolgerin sein und hasst Goertz dafür, dass dieser es verhindern möchte. Siquier, der Erfüllungsgehilfe Ulrikas, möchte nichts anderes, als in den schwedischen Adel erhoben zu werden.

Die scheinbar private Welt ist gleichfalls durch Eitelkeit und Ehrgeiz gezeichnet: Ebba träumt von einem besseren Leben als respektierte Pastorenfrau, das wäre für sie so etwas, wie Königin zu sein. Sie unterscheidet sich damit nur graduell von Olafs Ruhmsucht, die diesen zum Königsmörder werden lässt. Für Klosová (vgl. 1977a, 62f) und Haman (vgl. 2007, 242f) gilt er als Parodie auf die romantische Figur des rozervanec, des nihilistisch-leidenschaftlichen Außenseiters, weil sein starker Wunsch nach einer großen, weltgeschichtlich bedeutsamen Tat völlig ins Leere läuft: er tötet zwar den König, statt aber als gefürchtet und verrucht zu gelten, wird er für wahnsinnig gehalten und nicht ernst genommen. Wenn er aus Ruhmsucht seine Verantwortung für die Tat erklärt, misslingt diese Sprechhandlung, weil er für nicht zurechnungsfähig angesehen wird. Die geschichtliche Veränderung erscheint damit nicht mehr als Leistung einzelner Figuren, wie es etwa Otokar Fischer (vgl. 1919, 27f) gemeint hat, der Baron Goertz noch ganz in die romantische Tradition einordnet.

Mit der Distanznahme vom absolutistischen Herrschermodell, die freilich für das romantische Drama nach Schiller charakteristisch ist, ist in Baron Goertz ein Moment verknüpft, das durchaus originell erscheint. So ist nämlich die im Landtag (snèm) repräsentierte Stimme des Volks keine ungebrochen positive politische Kraft, sondern gleichfalls vom Ehrgeiz und dem Streben nach mehr Macht ergriffen. Dies ist an Ribbing zu erkennen, dessen Aktivitäten eben die Konstitutionalisierung politischer Macht nach sich ziehen. Als er von Ulrika indirekt aufgefordert wird, Goertz zu töten, reagiert Ribbing zuerst mit einem Monolog, der auf die weltgeschichtlichen Implikationen des Handelns aufmerksam macht.

287 [König:] „Ich löse ihn [den Landtag] auf, weil er auf das erste Gesetz vergisst: meinen Willen.“ - [Rhenstjern:] „Ich berufe mich aufs Volk.“ - [König:] „Auf diese Meute verblendeter Leidenschaft, die ihr gegen mich aufhetzt?"

288 Klosová (vgl. 1977a, 65) spricht nur in einer Nebenbemerkung von einer „mnohonásobná tragedie slavomamu“ (einer „mehrfachen Tragödie der Ruhmsucht“), geht aber nicht weiter auf dieses Moment ein. 
Dravec dravce požírá a pýchou se nadýmá, že kus dějin utvořil; nad ním věčná moudrost se usmívá - chytrák byl jí nástrojem. Ne ženo [Ulriko]! Ni ty, ni já ho [Goertze] nesoudíme; velký dějin duch ho soudí - a odsoudí. Říše vládkyní chceš býti? Než svěříme vlády otěž rukoum těmto, nutno jest, bychom je spoutali silnou opratí zákonův. Jen velkému duchu radno svěřiti osudy národův; velký duch jen srdce čistého synem jest a čisto toto srdce [Ulričino] není. ${ }^{289}$ (IV/11, S. 59)

Neben dieser „welthistorischen“ Einsicht in die Beschränkungsnotwendigkeit absoluter Macht, die sein Handeln begleitet, akzeptiert Ribbing aber zugleich auch Ulrika als Königin. Er widerspricht auch nicht, wenn der Machtwechsel auf einer Lüge gründet, denn er weiß genau, dass das per Androhung der Todesstrafe proklamierte Verbot, an der offiziellen Version vom Tod Karls zu zweifeln, vom Dissimulationserfordernis begründet ist. Ribbing ist bewusst, dass Ulrika keineswegs unschuldig ist; im Namen der Weltgeschichte, als deren Ausführungsinstrument er sich begreift (aus obigen Zitat geht ja hervor, dass nur ein vermeintlicher "Schlaumeier" meint, Geschichte zu machen, während über ihn die ewige Weisheit lacht), nimmt er am Beginn der neuen ,weltgeschichtlichen“ Epoche eine von der Staatsmacht forcierte Lüge in Kauf. Vor dem Hintergrund der Lüge erscheint die große demokratische Geste Ribbings, in der er erklärt, einem größeren Herrn, nämlich dem Volk, zu dienen, ${ }^{290}$ nicht mehr unproblematisch: Auch die sogenannten Volksvertreter handeln nicht allein im Namen des Volks, sie nehmen dabei auch die Lüge hin, wenn dies für ihr Handeln opportun ist. Ribbing kann auch als neue Art von Heldentypus im historischen Drama gelten, wie Klosová meint, die in ihm als der noch am ehesten positiv gezeichneten Figur eine Art Diplomat sieht, einen Menschen mit prinzipiell positiver Einstellung zur gesellschaftlichen Wirklichkeit der konstitutionellen Monarchie, der aber nicht mehr aufrührerisch und widerständisch agieren möchte (vgl. Klosová 1977a, 64).

So wie Ribbings Verhalten angesichts der Gründungslüge des Konstitutionalismus im äußeren Kommunikationssytem zwiespältig erscheint, so distanziert wird auch das Verhalten gegenüber Ausländern vorgeführt. Ribbing und andere Vertreter des schwedischen Landtags bzw. Heeres sind offen chauvinistisch: Sie haben nicht allein gegenüber Goertz Aversionen, sondern auch gegenüber den vielen

289 Ein Raubtier frisst das andere Raubtier und bläht sich vor Stolz, dass es ein Stück Geschichte geschrieben hat; über es lacht die ewige Weisheit - der Schlaumeier war ihr Werkzeug. Nein, Frau. Weder du noch ich richten über ihn [Goertz] und verurteilen ihn. Du möchtest Herrscherin des Reiches sein? Bevor wir die Last der Regierung diesen Händen anvertrauen, ist es nötig, dass wir sie mit dem starken Zügel der Gesetze binden. Es ist geraten, nur einem großen Geist die Schicksale der Völker anzuvertrauen; ein großer Geist ist Sohn eines reinen Herzens, rein aber ist dieses Herz [dasjenige Ulrikas] nicht.

290 [Ribbing:] „Sloužím většímu pánovi - svému národu““ („Ich diene einem größeren Herrn meinem Volk." - V/4, S. 68) 
Franzosen, die in Schweden in Heer und Verwaltung Karriere machen. Als Ribbing Goertz mit den negativen Folgen konfrontiert, die seine Politik im schwedischen Volk verursacht hat, und dieser daraufhin die französische Politik als Allheilmittel allen Staaten empfiehlt, entgegnet Ribbing mit einer Apologie nationalen Partikularismus: „Své zvláštnosti právo v sobě každá bytost chová, necht́ osobou se zove, církví, národem. Že právě tací jsme, jací jsme, to naše právo jest “291 (IV/9, S. 57). Zumal aber die „fremdenfeindliche“ Tendenz der schwedischen Figuren an keiner Stelle ,gebrochen“, sondern nur dargestellt wird, kann keineswegs von einer explizit kritischen Haltung gesprochen werden. Weil ja auch Goertz als Ausländer am Hof diesen großen Einfluss hat, und weil die schwedische Position gegenüber den Fremden bei Hof oder in den Truppen niemals gebrochen wird, scheint Bozděch für die „nationale" Position der Schweden Verständnis gehabt haben.

Baron Goertz entspricht zum einen seiner Entstehungszeit darin, dass im Stück die Beschränkung absoluter Fürstenmacht vorgeführt wird, zum anderen wird aber in der dramatischen Ausgestaltung dieses Beschränkungsverhältnisses politisches Handeln insofern kritisch reflektiert, als allenthalben durchaus persönliche Motive (wie Geltungssucht, Ehrgeiz, Machteifer) das Handeln der zentralen Figuren leiten. Der ,welthistorisch' bedeutsame Wechsel wird also nicht rundweg idealisiert, indem etwa die Bindung von Herrschaft an das Volk bzw. den Landtag als problemloses Positivum vorgeführt wird; stattdessen kann man im Drama aufgrund der in ihm angelegten Machtanalyse realistische Tendenzen erkennen.

\section{IV.6.9. František Zákrejs: Králsvého lidu. Truchlohra v péti dějstvích (1879)}

[Ein König seines Volkes. Trauerspiel in fünf Akten; UA 1879, publ. 1879]

Das Trauerspiel in fünf Aufzügen spielt vor der Wende zum 10. Jahrhundert; es zeigt, wie sich die Franken den Einfluss und die Dominanz über das Großmährische Reich sichern wollen und wie sich die Mährer, Slowaken und Tschechen dieser Einflussnahme widersetzen. Sein Autor František Zákrejs (1839-1907) war im öffentlichen Leben seiner Zeit sehr aktiv, er wirkte u.a. auch als Leiter einer Laientheatergruppe in seinem nordböhmischen Heimatort Polička, später in Prag gehörte er dem historischen Verein (Spolek historický) und dem Verein der tschechischen Dramenautoren und Komponisten (Jednota dramatických spisovateli a skladateli českých) an. Zusammen mit Václav Vlček redigierte er seit 1873 die Zeitschrift Osvèta, die eine konservative Haltung gegenüber den symbolistischen und naturalistischen Innovationen der europäischen und der tschechichen Literatur vertrat; als ein überzeugter Vertreter der Echtheit der Handschriften trat er in den 1880er und

291 „Jedes Wesen hat das Recht auf seine Besonderheiten in sich, ob es nun Person, Kirche, Volk heißt. Dass wir so sind, wie wir sind, das ist unser Recht." 
1890er Jahren gegen deren Kritiker Tomáš Masaryk, Jan Gebauer und Josef Pekař auf (vgl. LčL 4/II, 1675-1677).

Das Stück beginnt mit einer Versammlung, die von Rostislav, dem König des Großmährischen Reiches, geleitet wird und zu der neben Bořivoj, dem böhmischen Herzog, und Rostislavs Vetter Svatopluk, dem Fürsten des Teilfürstentums Nitra, auch eine Abordnung des deutschen Königs Ludvík [= Ludwig] gekommen ist. Als Englšalk sich bei der Audienz vordrängt, erklärt der erboste Rostislav sogleich: „Pán a vládce nejvyšší jsme na Moravě my! Na Moravě patří první slovo Slávům. ${ }^{“ 292}$ (I/1, S. 4). Von seinen gräflichen Boten Englšalk und Vilém, auch vom Abt des Klosters von Medlice [Mödlitz in Südmähren] wird Ludvík als Stellvertreter Gottes auf Erden angesehen, was Rostislav jedoch wenig beeindruckt. Für ihn sind die Völker nach Gottes Willen gleich, Unterwerfung widerspräche dieser göttlichen Ordnung. Nach der Christianisierung durch die Slawenapostel Kyrill und Method lässt Rostislav bewusst zu Ehren des slawischen Gottes Svatovít ein Fest veranstalten, was Slavomír, ein mährischer Adeliger, wie folgt erklärt: „Svatovít je vzkřísen, žije v dobrém božstvu; jehož blahověsti lásky bratrské našim vlastem hlásali a pevnili Konstantin a Method, bratř́ solunští.' 293 (I/1, S. 6) Dieses Element einer slawischen Religion wird dem von den Franken propagierten lateinischen Christentum entgegengesetzt (vgl. I/4). Während Ludvík auf einem Untertanenverhältnis besteht, erklärt Rostislav, dass für ihn, den König des Mährischen Reiches, allein die Unabhängigkeit der Heimat wichtig ist, nur ein Vertrag unter gleichberechtigten Partnern käme für ihn in Frage, niemals aber sklavische Unterwerfung. Ludvík setzt für seine politischen Zwecke seine Tochter Hermina ein, die er Svatopluk, der von Rostislav zum Nachfolger bestimmt wurde, zur Frau geben möchte. Hermina spielt dieses politische Spiel mit, sie rät Svatopluk, dass er sein Fürstentum Nitra für unabhängig vom Großmährischen Reich erkläre und er dieses erobern solle. Dann würde sie seine Frau werden (vgl. I/5). Rostislav und Slavomír erkennen die Möglichkeit einer solchen Verbindung und warnen vor ihr, das würde ein fremdes Element ins Land bringen. Svatopluk soll besser eine Slawin heiraten. Diesem widerstrebt diese Einflussnahme auf seine Wahlfreiheit; er könne sein Herz nicht verleugnen. Ludvík erklärt das Fürstentum Nitra unter Svatopluk für souverän und unter seinem Schutz stehend. Dies führt zum Bruch zwischen Rostislav und Svatopluk, der mit Unterstützung der Deutschen Nitra und die Slowakei unabhängig machen möchte. Der von Rostislav befragte Sněm sieht dies als Hochverrat an, was eigentlich mit dem Tod bestraft werden müsse. Nur soll Svatopluk davor bewahrt werden.

292 [Rostislav:] „Herr und höchster Herrscher bin ich in Mähren. In Mähren haben zuerst die Slawen das Wort."

293 [Slavomír:] „Svatovít ist auferstanden, er lebt in guter Gottheit; seine Frohbotschaft brüderlicher Liebe haben die Brüder Konstantin und Method aus Solun/Saloniki unseren Ländern verkündet und gefestigt." 
Der in der Slowakei angesetzte zweite Aufzug zeigt die Slowaken und Deutschen beim gemeinsamen Feiern. Svatopluk sieht der bewaffneten Auseinandersetzung mit Rostislav besorgt entgegen. Sein Lech (Lehensmann) Zemižízeň warnt ihn vor allzu viel Gemeinschaft mit den Deutschen. Entgegen erster freudig aufgenommener Meldungen von einer Niederlage Rostislavs kommt es zu einem Angriff von dessen Truppen. Vor diesem wird Svatopluk von Rostislavs Ziehtochter Svatožízna, die in der Kindheit mit ihm gut befreundet war, gewarnt. Als Rostislav in Nitra eintrifft, haben sich die slowakischen und deutschen Einheiten aus der Stadt zurückgezogen, sodass er erkennen muss, dass sein Plan verraten wurde. Svatožízna gesteht ihren aus Liebe zu Svatopluk begangenen Verrat und wird von ihrem Ziehvater Rostislav verstoßen, der darüber bestürzt ist, dass nahestehende Menschen von ihm abfallen. Svatopluk wendet eine strategische List an, um Rostislav zu besiegen. Er gibt vor, von den Slowaken verlassen zu sein und reumütig zu Rostislavs Politik zurückzukehren. Als es zum Kampf zwischen den verbündeten Deutschen und Slowaken gegen die Mährer unter Rostislav kommt, unterliegt letzterer. Rostislav gerät in fränkische Gefangenschaft, wo er nach einer Verurteilung wegen Widerstand gegen die Herrschaft Ludvíks geblendet wird. Svatopluk aber wird von Ludvík nicht mit der Herrschaft über das Großmährische Reich belohnt, sondern fortwährend vertröstet. Auch werden von dessen Statthaltern im Großmährischen Reich Aufbegehren und Unruhen vermeldet. Svatopluk bereut sein Vertrauen in Ludvík, sein eigenes Handeln erkennt er nun als Verrat an seinem Land; weil er immer noch nicht der König des Großmährischen Reiches ist, habe dieser Verrat nicht einmal seinen Zweck erfüllt. Svatopluk, der sich auch schon wie Rostislav im Kerker sieht, fordert Ludvík zum Kampf heraus (IV/4). Als im fünften und letzten Akt die aufständischen Mährer unter Slavomír die fränkischen Stellungen an der Thaya angreifen, erbittet sich Ludvíks Sohn Karloman von seinem Vater die Erlaubnis, nach eigenem Gutdünken handeln zu dürfen. So befreit er Svatopluk von den Fesseln und ernennt ihn - wie einst von Ludvík versprochen - zum König des Großmährischen Reiches. Svatopluk sträubt sich zuerst und zeigt sich skeptisch, da aber auch Hermina aus politischem Kalkül ihn in die Königsrolle drängt, gibt er schließlich nach und akzeptiert das Amt. Ludvík freilich fordert von ihm, dass er als König immer freundschaftlich die Bemühungen der Franken um die Freiheit Großmährens anerkennen wird. Rostislav und Svatopluk setzen über die Thaya, um von den siegreichen Mährern empfangen zu werden. Da Rostislav nun Svatopluk vertraut, setzt er ihn als Herrscher ein, nachdem er dazu auch die Zustimmung des Volks erhalten hat. Svatopluk nimmt aber nicht Hermina zur Frau, wie zu erwarten gewesen wäre, sondern entscheidet sich für Svatožízna. Rostislav kann glücklich aus dem Leben scheiden: „Touhy mého života docíleny. Sdruženou zřím

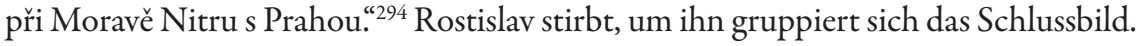

294 [Rostislav:] „Die Wünsche meines Lebens sind erreicht. Ich sehe mit Mähren Nitra und Prag in freundschaftlichem Bund.“ 


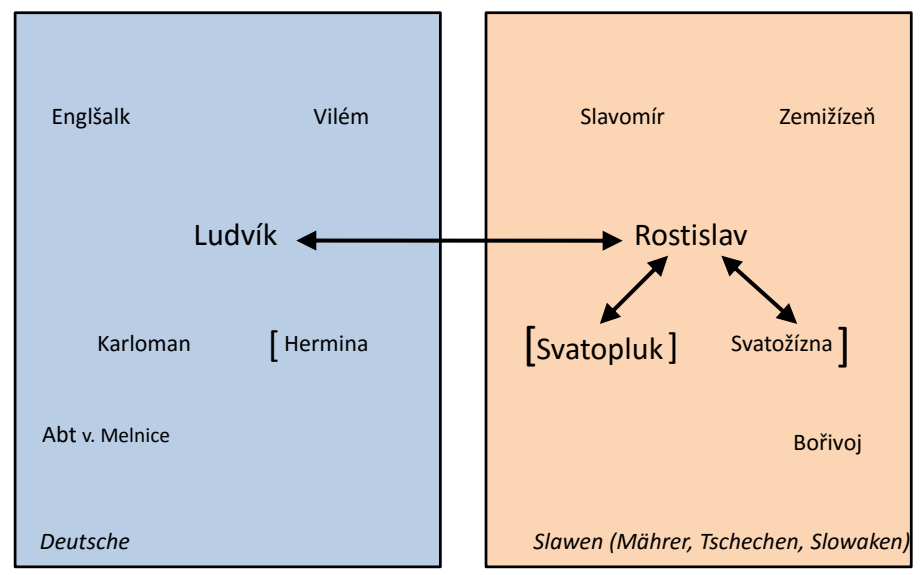

Graphik 22 - František Zákrejs: Král svého lidu (1879)

Die Hauptfigur von Zákrejs' Trauerspiel ist ohne Zweifel Rostislav, den der Titel des Stücks als „král svého lidu“ (,König seines Volkes') charakterisiert. Dieser beharrt auf der Unabhängigkeit Großmährens von den Deutschen, deren König Ludvík offensiv seine Vormachtstellung über Großmähren behaupten möchte. Gegenüber den deutschen Ansprüchen erklärt Rostislav wiederholt, dass er keine Subordination hinnehme, sondern allein zu einer Allianz von gleichberechtigten Partnern bereit sei. Ludvík betreibt seine Expansionspolitik in Richtung des Großmährischen Reichs auch mithilfe seiner Tochter Hermina: Mittels einer Verbindung zwischen ihr und Svatopluk, der als Rostislavs Nachfolger eingesetzt ist, könnte der fränkische Einfluss auf das Großmährische Reich gesichert werden; Rostislav ist gegen eine solche Verbindung seines Vetters Svatopluk, da er den deutschen Einfluss eingedämmt sehen möchte. Svatopluk allerdings setzt auf eine mit deutscher Unterstützung souveräne Slowakei, weswegen er sich seinen Ziehvater Rostislav zum Gegner macht. Svatopluk erscheint als opportunistische Figur, die gut die Chancen auf ihren eigenen Vorteil abschätzen kann. Er gibt etwa gegenüber Rostislav vor, dass er von seinen Slowaken verlassen und von den Deutschen gefesselt worden ist, um wieder das bereits verspielte Vertrauen Rostislavs zu gewinnen. Gleichzeitig strebt er nach dem großmährischen Königsthron. Er sieht sich jedoch um diesen betrogen, als die Deutschen Rostislav besiegen, aber ihn nicht zum König einsetzen, weil Ludvík mit Vilém und Englšalk als Statthalter den deutschen Einfluss auf Großmähren sichern möchte. Erst als Svatopluk erkennt, dass Ludvík sein Versprechen niemals einlösen wird, begehrt er auf und setzt auf die Unterstützung Rostislavs. Dass die Deutschen ihn letztlich doch als König einsetzen, wobei sie immer noch ein Patronanzverhältnis beanspruchen, liegt allein darin begründet, dass sich im Großmährischen Reich erfolgreich Widerstand gegen die Deutschen regt und sich 
diese bedroht fühlen. Unter diesem Druck erst sind die Deutschen bereit, Großmähren in die Souveränität zu entlassen, dies allerding auch nur auf unbestimmte Zeit, wie Ludvík andeutet, der diese Lösung als eine vorläufige, unter dem Druck der Umstände entstandene, betrachtet. Wenn Svatopluk in der Schlussszene doch zum König des Großmährischen Reiches geworden ist und sich Svatožízna zur Frau nimmt, erfüllt er damit letztendlich alle politischen Hoffnungen, die Rostislav als König seines Volkes gehegt hat.

Svatopluk hat die - politische - Grenze ins feindliche Lager überschritten, um dort aber zu erfahren, dass dies ein Irrtum war, der weder für ihn noch für sein Volk von Vorteil war. Das gleiche kann für seine Frau Svatožízna gelten, die aus Liebe zu Svatopluk ebenfalls ihren Ziehvater Rostislav verraten hat, aber letztendlich erkennen muss, dass Rostislav in seiner Einschätzung der Deutschen recht hatte.

Die Politik Rostislavs - Unabhängigkeit und Zusammenhalt der slawischen Länder Böhmen, Mähren und Slowakei gegenüber dem deutschen Nachbarn - wird auf allen Linien bestätigt: Die dramatische Handlung besteht darin, dass vorgeführt wird, welche Gefahren diesen slawischen Ländern drohen, wenn von dieser Politik abgewichen wird. So etwa lässt Ludvík Mähren und die Dörfer der Tatra zerstören, um seine Herrschaft zu demonstrieren.

In Rostislav wird das Ideal eines slawischen Fürsten vorgeführt, der neben dem unermüdlichen Beharren auf der Souveränität seines Volks mit vollem Recht als dessen Repräsentant angesehen werden kann: Beim heidnisch-slawischen Erntefest im ersten Akt spricht der böhmische Herzog Bořivoj bei der Lobpreisung Rostislavs aus: „Štastný Slovan! Od Ondavy k šumné Sále / tvojí Rostislave, zásluhou

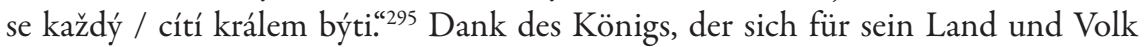
bemüht, kann sich jeder als König fühlen. Dieses ideale Repräsentationsverhältnis von König und Volk ist gleichfalls in Rostislavs Umgang mit dem Sněm oder anderen Repräsentanten zu erkennen: Bei allen wichtigen Entscheidungen - wie soll Svatopluks Absicht, sein slowakische Fürstentum Nitra unabhängig von Großmähren zu machen, gewertet werden (I/7-8)?, ist das Volk einverstanden mit Svatopluk als König? (V/6) - wird das Volk befragt und seine Meinung berücksichtigt. In einer Replik, in der das Einverständnis mit Svatopluk als König ausgedrückt wird, heißt es sogar, wenn der König nach dem Willen des Volkes auf den Thron steigt, werde es ihm treu Gefolgschaft leisten. ${ }^{296}$ Der König ist also auch insofern König seines Volkes, als er seine Legitimation aus diesem bezieht und diesem gegenüber verantwortlich ist. ${ }^{297}$

295 [Bořivoj:] „Glücklicher Slawe! Von der Ondava bis zur rauschenden Saale / kann sich jeder dank deines Verdienstes, Rostislav / als König fühlen.“

296 [Zemižízeň:] „když nám po vůli vystoupí naň [přestol]“ (V/6, S. 107).

297 [Rostislav:] „Soudci králů slovanských jsou pouze lid a lidu tlumočník: um dobrých pěvců.” (IV/2, S. 74) („Richter über die slawischen Könige sind nur das Volk und das Sprachrohr des Volkes: der Verstand guter Sänger“). 
Rostislav kontrastiert damit deutlich mit dem deutschen König Ludvík, der seine Königswürde durch den transzendenten Bezug auf Gott legitimiert. Letzterer sieht sich als Statthalter Gottes auf Erden („Träger des Weltenschwerts, Allherrscher

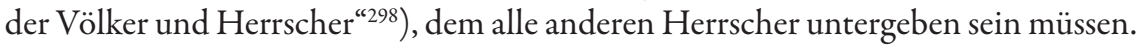
Als er über Rostislav Gericht halten lässt und dieser dagegen protestiert, dass er von Ludvík nicht als gleichrangiger König, sondern als aufbegehrender Lehensmann betrachtet wird, entspinnt sich folgender Disput

Ludvík: Rouhovče, mluv, neníli dle boží vůle / moje veleříše matkou říší všech / a zda nemá dítě poslušno být matky!

Opat (soucitně k Rostislavovi): Jeden toliko jest bůh, i nemůže / vlásti zemí veškerou než jediný / jeho náměstník: náš nejjasněǰš́ král.

Rostislav: Ó že člověk zapomíná k vưli bohu stále na člověka, na svobodu matku! ${ }^{299}$ (IV/2, S. 75)

Das Herrschaftsverständnis, das Ludvík in Zákrejs' Drama an den Tag legt, ist offensichtlich ein Anachronismus mit stark zeitaktuellen Bezügen bzw. ein deutliches Beispiel für eine „Depräsentation“. Zákrejs, der als Vorlage offenbar auf Palackýs Geschichte von Böhmen zurück gegriffen hat, komprimierte Ereignisabfolgen, um mit seinem Drama eine klarere politische Aussage zu erreichen. ${ }^{300}$ Ludvíks sakrales Herrschaftsverständnis steht historisch zwar wohl im Zusammenhang mit dem fränkischen Kaisertum, gleichzeitig ist aber auch der allegorische Zeitbezug auf die Habsburger Monarchie nicht zu übersehen, begann doch der Titel von Kaiser Franz Joseph I. mit „von Gottes Gnaden Kaiser von Österreich, König von Ungarn und Böhmen, von Dalmatien, Croatien, Slawonien, Galizien, Lodomerien und Illyrien [...]", eine Formel, die zum einen den Gottesbezug, zum anderen die Superiorität über die verschiedenen Herrschaftsgebiete zum Ausdruck bringt.

Král svého lidu ist ein Drama, das das schwierige Verhältnis zu den Deutschen wie auch die Frage des Verhältnisses benachbarter slawischer Völker zueinander the-

298 [Ludvík:] „[...] mně držiteli světového meče, vševládcovi národův a vladařư “ (I/4, S. 11).

299 [Ludvík:] „Lästerer, sprich, ist nicht etwa nach Gottes Wille / mein Großreich die Mutter aller Reiche / und muss nicht das Kind gegenüber der Mutter folgsam sein!“ - [Der Abt (mitleidig zu Rostislav):] „Es gibt nur einen Gott, und es kann nur sein einziger Statthalter die gesamte Erde regieren: unser durchlauchtester König.“ - [Rostislav:] „O, dass der Mensch wegen Gott ständig auf den Menschen vergisst, auf die Mutter Freiheit!“

300 Die deutlichste Veränderung gegenüber Palacký besteht darin, dass Rostislav im Drama Svatopluk verzeiht und nach Befragung des Volks inthronisiert. Damit bleibt das auch in Palackýs Darstellung vorhandene zwiespältige Verhältnis zwischen Rostislav und Svatopluk bestehen, die Opposition zwischen dem beharrlichen Kämpfer für Selbstständigkeit und seinem opportunistischeren Nachfolger wird aber verstärkt und durch die Inthronisierung schließlich aufgehoben. 
matisiert. So ist einerseits auffällig, dass im Lager der Slawen die Hauptfiguren miteinander verwandschaftlich verbunden sind: Svatopluk, der Teilfürst von Nitra und der Slowakei, ist Rostislavs Neffe, Svatožízna stammt zwar aus Böhmen, sie ist aber die Ziehtochter von Rostislav. Zumal sowohl Svatopluk als auch Svatožízna einen Verrat an Rostislavs Plänen begehen (Svatopluk, indem er mit seinen Slowaken mit Unterstützung der Deutschen einen eigenen Weg gehen will; Svatožízna, indem sie ihn vor dem Angriff Rostislavs warnt und damit der deutschen Dominanz Vorschub leistet), erscheint der familiäre Zusammenhalt gefährdet. Rostislav ist ja gerade darüber betrübt, dass die Personen, die er als seine Nächststehenden betrachtet hat, von ihm abfallen. Umso größer ist daher seine Erleichterung, dass Svatopluk am Ende Svatožízna zur Frau nimmt und nicht die Deutsche Hermina. Zwar wird auch das Verhältnis zu den Deutschen in der Verwandtschaftsmetaphorik beschrieben, das Verhalten der Deutschen straft aber diese Metaphorik Lügen. Sie stammt aus dem Mund von Svatopluk, der im Streit zwischen Ludvík und Rostislav wie folgt eingreift: „Teut a Sláv jsou dvojeňátka, Frank a Vend / rodní bratřri. ‘301

Rostislavs politisches Konzept, das sich im Drama als das richtige erweist und von der Handlung bestätigt wird, besteht auf einer nachbarschaftlichen Separierung der Völker auf der Grundlage sprachlicher, kultureller und verwandtschaftlicher Besonderheiten. Eine Mischung - etwa durch die Ehe - lehnt Rostislav vehement ab. Weil Svatopluks Wahl zuerst auf Hermina gefallen ist, warnt Rostislav vor der Gefahr, die mit einer solchen Verbindung eingegangen werde. Der verheirateten Prinzessin werden immer mehr Deutsche nachfolgen, wodurch deren Hochmut im Lande überhandnehmen werde (I/6). Diese Einschätzung wird ja vom Handlungsverlauf bestätigt, vom sehr negativen Bild der Deutschen weicht allein Ludvíks Sohn Karloman ab, der immer wieder Einspruch gegen die Maßnahmen und Handlungen seines Vaters einlegt und sich letztendlich von seinem Vater die Erlaubnis holt, eigenmächtig handeln zu dürfen, was zur Freilassung und Inthronisierung Svatopluks als König des Großmährischen Reiches führt. Insofern am Ende die Slawen unter Slavomír die deutschen Besatzer des Großmährischen Reiches vertreiben können, kann als ideologisches Fazit von Král svého lidu gelten, dass sich die kulturell und sprachlich verwandten Völker zusammenschließen sollen, um mit militärischer Stärke ihre politische Unabhängigkeit gegenüber andersstämmigen deutschen - Aggressoren zu behaupten. Zákrejs vertritt mit seinem Drama eine nationalromantische Vision von slawischem Zusammenhalt (zumindest der benachbarten slawischen Völker in Böhmen, Mähren, der Slowakei), die aber die kulturelle Fundierung von slawischer vzájemnost - Kollárs Schlüsselbegriff wird von Rostislav gleich im ersten Akt ins Spiel gebracht (vgl. I/2, S. 10) - um die Apologie von poli-

301 [Svatopluk:] „Der Teutone und der Slawe sind Zwillinge, der Franke und der Wende - Brüder einer Familie.“ 
tischer Selbstständigkeit und Gleichberechtigung der Slawen erweitert, was für den Austroslawismus Palackýs charakteristisch ist (vgl. Vlček 2006, 16f).

Diese ideologische Botschaft wird auch auf nonverbaler Ebene durch Dingsymbolik unterstrichen: Im ersten Akt werden die Konflikte, die aufgrund des hegemonialen Anspruchs von Ludvík entstehen, von Slavomír vorausgeahnt; er möchte sie mit Lindenzweigen bannen. Wiewohl er weiß, dass gemäß den Volksvorstellungen eigentlich Weidenruten oder Zweige der Pimpernuss verwendet werden müssen, versucht er es mit der Linde, dem Symbolbaum der Slawen. Da aber Slavomír von Karloman aufgefordert wird, in die Kirche zu gehen, muss er den unvollendeten Lindenkranz am Thron Rostislavs liegen lassen (I/4, S. 14f). Hermina bricht von diesem einen Zweig ab und reicht ihn Svatopluk als Zeichen seiner Königswürde (I/5, S. 19), Slavomír deutet das Abreißen des Lindenzweiges als verräterischen Bruch Svatopluks mit seiner Heimat (I/6, S. 20). ${ }^{302}$ Dennoch wäre der Lindenkranz stärker:

\author{
Avšak vezmi tento svazek větvic \\ a silou veškerou svých mladých rukou se \\ snaž jej rozpůliti: odolá, spíš utká \\ tebe. Láska jen - tot́ síla národu! \\ Ne snad Slavomír, to Slovan tebe prosí. ${ }^{303}$ (I/6, S. 21)
}

Slavomír, der eigentlich Priester werden will und der nach der Verwüstung Großmährens durch die Deutschen zuerst nicht als militärischer Führer das Heft in die Hand nehmen möchte, wird von Svatožízna dadurch zu patriotischer Aktivität gebracht, dass sie symbolisch die Heimat begräbt und den Kranz zerreißt. Slavomír hält diese betrübliche Perspektive nicht aus, er entreißt ihr den Kranz und entschließt sich zum patriotischen Kampf (vgl. III/9, S. 72).

Im Schlussbild, bei seiner Inthronisierung, erhebt Svatopluk ein Bündel aus Lindenzweigen und erklärt: „Chci je chovat jako nejsvětějšś desku pravodatnou“ ${ }^{304}$ (V/6, S. 107). Der symbolisch veranschaulichte Verbund slawischer Völker garantiert ihnen Unabhängigkeit und politische Selbstständigkeit.

302 Im zweiten Akt, in dem Svatopluk ja mit den Deutschen gemeinsame Sache macht, aber bereits an dieser Allianz zu zweifeln beginnt, erfolgt eine analoge Veranschaulichung eines zwiespältigen Verhältnisses mittels eines Eichenzweigs (vgl. II/1) - die Eiche als Nationalsymbol des deutschen Volkes wird also der Linde als dem „slawischen“ Baum gegenübergestellt.

303 [Slavomír:] „Nimm aber diesen Bund Zweige / und versuche, mit der ganzen Kraft deiner jungen Hände / ihn zu halbieren: er wird es nicht zulassen, eher noch dich einweben / Die Liebe allein ist die Kraft des Volkes! / Gar nicht einmal Slavomír, sondern ein Slawe bittet dich.“

304 [Svatopluk:] „Ich werde es [den Bund Zweige] hüten wie die allerheiligste Rechtstafel.“ 
IV.6.10. Václav Vlček: Lipany. Truchlohra v pèti jednánich (1881)

[Lipany. Trauerspiel in fünf Akten; UA 12.6. 1881, publ. 1881]

Václav Vlček (1839-1908) hat neben einer Reihe von Gesellschaftsromanen und autobiographischer Prosa eine große Zahl von Werken mit historischen Stoffen (Romane, Dramen, Erzählungen) verfasst. Vlček, der seinen Vornamen selbst digraphisch mit "Vácslav" schrieb, war auch der Gründer, Herausgeber und Autor der seit 1871 erscheinenden Monatszeitschrift Osvěta [Aufklärung], die bis über seinen Tod hinaus Bestand hatte. Sein schriftstellerisches und publizistisches Werk ist mithin sehr umfangreich, heutzutage allerdings weitgehend vergessen. Dass Vlček zu Lebzeiten ein weithin respektierter Autor war, ist schon daran zu erkennen, dass die lang erwartete Eröffnung des Národní divadlo im Juni 1881 durch Smetanas Oper Libuše und Vlčeks historisches Drama Lipany erfolgte. Dieses führt die innertschechischen Konflikte während der Zeit der Hussitenkriege vor Augen, die 1434 mit der Schlacht von Lipany ihr Ende gefunden haben (vgl. Hoensch 1992, 148).

Der dramatische Konflikt entspinnt sich zwischen der von Prokop Holý angeführten hussitischen Gruppierung der Taboriten und dem tschechischen Adel, dessen Angehörige vielfach ebenfalls Hussiten sind, sich teilweise jedoch nur widerwillig zum Laienkelch, dem wichtigsten Symbol hussitischen Glaubens, bekennen. Prokop ist als Priester wider Willen militärischer Anführer der Hussiten, die er gegenüber den Angriffen der katholischen Allianz immer wieder erfolgreich verteidigen hat können.

Das in der sehr bewegten Zeit der Hussitenkriege spielende Drama beginnt mit der Klage Blaženas, der Frau Prokops, über die nicht endenwollenden kriegerischen Auseinandersetzungen in Böhmen („>Mír v zemi naší dej nám, hospodine< tak tvrdí muži zbožně zpívají, ale vždy zas jen nové boje strojí! “" ${ }^{05}$ ). Der junge Jiř́ z Poděbrad ist zwar Hussit, er kämpft aber im Namen des Landesverwalters Aleš $z$ Risenburka gegen räuberische Taboriten, die das Land unsicher machen. Von außen bedroht immer noch die katholische Allianz das hussitische Böhmen. Jiř́ ist Jitka sehr verbunden, die über die zahlreichen Parteien und Fraktionen unten den Tschechen klagt.

Jitka ist die Tochter Menharts z Hradce, der für den tschechischen Adel politische Intrigen spinnt, weil er die Stärke der Taboriten unbedingt mindern möchte, von der er die Macht des - konfessionell uneinheitlichen - böhmischen Adels bedroht sieht. Um den Landesverwalter Aleš z Risenburka in seinem Sinn beeinflussen zu können, verspricht er ihm Jitka zur Frau, wovor Jitka wegen des großen Altersunterschieds panisch flüchtet. Menhart versteckt auch den fanatischen Hus-

305 [Blažena:] „>Herr, schenk Frieden in unserem Land<, so singen die harten Männer fromm, dabei bereiten sie ständig neue Kämpfe vor!“ 
sitenhasser Oldřich z Rosenberka in seinem Haus in Prag. Um hussitische Adelige für seine Pläne zu gewinnen, erzählt er ihnen, dass Rosenberk den Kelch nicht mehr radikal ablehnt und sich Aleš unterstellen würde. In Prokop sieht Menhart seinen stärksten Gegner, weil dieser von großem Einfluss auf fast alle Hussiten ist, was ihm auch Adelige wie Jiří z Poděbrad oder Vilém Kostka versichern. Allerdings ist auch Prokop mit Zwietracht im hussitischen Lager konfrontiert, etwa bei der - im Stück nur erzählten Belagerung der katholischen Stadt Plzeň durch die Taboriten und Waisen (Sirotci) - der Name soll den Zustand des Verwaistseins anzeigen, den die Anhänger des wichtigsten Heerführers Jan Žižka nach dessen Pesttod 1424 empfanden). Prokop wollte die Unterhändler von Aleš in die Stadt lassen, er wurde aber von den radikaleren Kräften, die die Stadt zerstören und nicht verhandeln wollten, dafür attackiert. Prokops Ziel ist die Hussitisierung Böhmens, deshalb möchte er Plzeň erobern und Oldřich z Rosenberka wegen seiner Intrigen und Kollaboration mit den Katholiken durch Landesverweis bestraft sehen.

Prokop greift in der Prager Neustadt vermittelnd ein, weil sich diese unter dem hussitischen Priester Jakub Vlk den Anordnungen des Landesverwalters Aleš widersetzt. Wenngleich Aleš bestrebt ist, mit allen politischen Kräften zu sprechen und als Autorität respektiert zu werden, erkennen ihn de facto nur die Adeligen an. Menhart kann Aleš weitgehend beeinflussen. Diviš Bořek führt ein Adelsaufgebot gegen Prag, das mit militärischen Mitteln gegen die Neustadt vorgehen soll. Mit Oldřich z Rosenberka plant Menhart einen politischen Mord an Prokop. Oldřichs Ziehsohn Radoslav soll diesen ausführen.

Auch der zweite Akt beginnt mit Blaženas Hoffnung, dass bald Friede im Land herrschen wird. Prokop meint, der Widerstand gegen den Hussitismus werde bald gebrochen werden, dann könne auch er sich zur Ruhe setzen. In einem abgefangenen Brief des vertriebenen Königs und römisch-deutschen Kaisers Zikmund [Siegmund] an Oldřich liest Prokop, dass Aleš nur vorgeschoben sei, um das eigentliche Interesse des Adels zu verbergen, das darin besteht, die Taboriten auszuschalten. Auch Jakub Vlk bestätigt Prokop diese Taktik. Von der Gegenseite möchten Diviš Bořek und Vilém Kostka ihm vor Augen zu führen, dass die radikalen Kräfte die Einheit gefährden, wenn sie sich Aleš widersetzen. Prokop dreht diese Version um, er meint, die Radikalität im Volk sei nur die Folge davon, dass der Adel nicht entschlossen genug die hussitische Position beziehe und damit den Kelch verrate. Der abgefangene Brief bestätige nur diese Einschätzung. Gegenüber den radikaleren Hussiten gerät Prokop immer stärker unter Druck, er versucht sie zu disziplinieren: „[...] ne v hejnech, v šiku vaše moc a čest! K řádu a kázni hned se navrátíte."306 (II, S. 32) Angesichts des mit dem Brief bewiesenen Verrats der Adeligen am Hussitismus sei auch das unbotmäßige Verhalten Jakub Vlks gerechtfertigt. Das von Diviš Bořek

306 [Prokop:] „Nicht als Haufen, in Formation liegen eure Kraft und Ehre! Kehrt sofort zu Ordnung und Disziplin zurück.“ 
kommandierte Adelsaufgebot soll nicht gegen die Prager Neustadt, sondern gegen Plzeň ziehen, dann würden die Vereinbarungen eingehalten werden. Als Radoslav den von Rosenberk und Menhart beauftragten Anschlag auf Prokop in Form eines Duells ausführen möchte, um nicht als Meuchelmörder zu gelten, kann ihn Prokop davon einfach damit abbringen, indem er Radoslav auffordert, nur unverstellt zu morden. Mit dem Auftritt des Taboritenhauptmanns Jarek, der verheißt, dass Plzeň wahrscheinlich der hussitischen Belagerung nicht standgehalten haben wird, stellt sich heraus, dass Radoslav dessen Sohn ist. Rosenberk habe einst im Kampf gegen die Taboriten einen weinenden, vermeintlich verwaisten Knaben bei sich aufgenommen und im leidenschaftlichen Hass auf die Taboriten erzogen. Dessen Vater Jarek ist zum leidenschaftlichen Bekämpfer des Adels geworden, während Radoslav aufgrund seiner Erziehung in Prokop und allen Taboriten generell seine Todfeinde sah. Jarek ist über diese Entfremdung des Sohnes, die Rosenberk verursacht hat, entsetzt. Er möchte seinen eigenen Sohn töten, was von Prokop allerdings verhindert wird. Radoslav selbst möchte sein Gelöbnis einhalten, den größten Feind seiner Familie zu töten (da er von seinem Vater Jarek die Wahrheit über kindliches Schicksal kennt, ist dieser größte Feind nun Rosenberk), dann werde er zu Prokop zurückkehren. Zumal er sich nur eine Stunde für die Ausführung der Rache an Rosenberk erbittet, kann Prokop schließen, dass Rosenberk in Prag versteckt ist. Prokop lässt Radoslav beschatten. (Die von Jarek verheißene Einnahme von Plzeň durch die Taboriten ist allerdings gescheitert, weil sich unter den ihnen Verräter befanden, die im Auftrag von Rosenberk die belagerte Stadt mit Lebensmitteln versorgten.)

Als Prokop im dritten Akt der Einladung Aleš folgt, bei ihm wegen eines gemeinsamen Kampfes zu verhandeln, kommt es zum Eklat. Prokop klagt Menhart an, einen Mordanschlag gegen ihn beauftragt zu haben. Da Rosenberk von Menhart im Gebäude des Landesverwalters Aleš versteckt wurde, bricht ein Tumult aus, sobald dies entdeckt wird. Bei diesem kann Menhart fliehen. Radoslav wird von Rosenberk getötet, sterbend verrät er allerdings noch die Pläne des geflüchteten Rosenberk, die Taboriten und den Laienkelch zu vernichten. Aleš und Jiří werden von Prokop in Gewahrsam genommen, Aleš wegen des von ihm gutgläubig gedeckten Verrats, Jiř́ deshalb, weil er im Auftrag Menharts Adelige alarmieren wollte. Als radikale Taboriten unter den Anführern Sova und Suk in das Haus Prokops eindringen, dem sie allzu zögerliches Vorgehen und die Ehe mit Blažena vorwerfen, die als Aleš’ Schwester auf der Seite des Adels stünde, ermöglicht Blažena Aleš und Jiř́, denen von Sova und Suk der Tod droht, die Flucht. Diese können damit die Altstadt vor den Angriffen der Taboriten warnen. Prokop verstößt deswegen beinahe seine Frau, er verdächtigt sie der Kollaboration mit der gegnerischen Partei. Da die Adelspartei im Kampf siegt, kann Rosenberk auch Prokops Haus in Brand setzen. In diesem hat sich allerdings Jitka auf der Flucht vor ihrem Vater versteckt. Menhart erkennt somit endlich die ungeheure Radikalität Rosenberks, mit dem er immer gemeinsame Pläne ausgeheckt hat. 
Im fünften und letzten Akt kommt es zum finalen Aufeinandertreffen der Truppen Prokop Holýs und des Adelsaufgebots. Es heißt zuerst, dass aufgrund der radikalen Standpunkte Kolmans einige hussitische Adelige auf die Gegenseite gewechselt haben. Vor der Schlacht kommt es noch zu Gesprächen, bei denen die tschechische „Finsternis“ damit beschrieben wird, dass auf beiden Seiten Utraquisten stehen, die sich gegenseitig bekämpfen. Vermittlungsangebote werden abgelehnt. Als Kolman Prokop offen des Verrats bezichtigt, lässt ihn dieser verhaften, begnadigt ihn aber gleich wieder, um ihn im Kampf verfügbar zu haben. Nachdem zuerst die Taboriten in der Schlacht erfolgreich sind, wendet sich das Blatt damit, dass sich Kolman zum alleinigen Anführer der Taboriten erklärt. Inzwischen konnten die Gegner unter Menhart zum Angriff übergehen. Prokop sieht sein Ende nahen, er möchte ein Pulverfass zünden, das mit ihm auch die Angreifer in den Tod reißt. Als er den Kelch, das Symbol seines Kampfes erhebt, wird er von Pfeilen Rosenberks tödlich verwundet. Oldřich möchte auch noch den Kelch schänden, was von Jiř́ jedoch verhindert wird. Der sterbende Prokop überträgt Jiří die Sorge um den Laienkelch; Blažena, Prokops Frau, klagt die Adelspartei des Mordes an. Jiří ruft zuletzt aus: „Ó místo bezmezného zármutku, přehořké slzy v proudech po věky tě budou omývat!“307

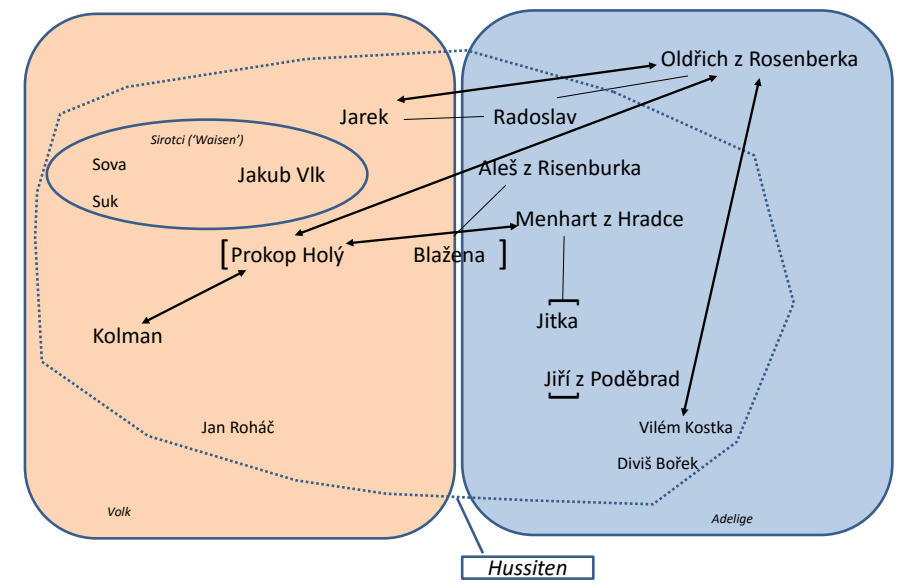

Graphik 23 - Václav Vlček: Lipany (1881)

Die Gegenüberstellung zweier konfligierender Gruppen - Adel und Volk - setzt sich im Schema durch Konflikte innerhalb jeder Gruppe fort. Beide Gruppen haben einen gemäßigten wie einen extremen Flügel, wodurch sie als Gruppe instabil und verwundbar werden. Dies zeigt sich am deutlichsten im letzten Akt, wo Kolman

307 [Jiř́::] „O Ort grenzenloser Trauer, allerbitterste Tränen werden dich noch Jahrhunderte lang umspülen!“ 
offen den Gehorsam gegenüber Prokop verweigert und sich zum alleinigen Führer der Taboriten erklärt. Damit leistet er der Niederlage der Taboriten Vorschub. Auf der Seite des Adels ist es vor allem Oldřich von Rosenberk, dessen extreme Position zum Unheil führt. Er ist eine durchwegs negativ gezeichnete Figur, die für die Durchsetzung ihrer Interessen auch vor Mord nicht zurückschreckt. Rosenberk ist brutal gegen die Taboriten vorgegangen; er erzieht seinen Ziehsohn Radoslav zum politischen Mörder, und als dieser die wahren Zusammenhänge seines Lebens erkennt und sich gegen Rosenberk selbst wendet, tötet er ihn. Weiters zündet er Prokops Prager Haus an, was zum Tod von Jitka, Menharts Tochter führt. Im letzten Akt befiehlt er, unverzüglich auf Prokop zu schießen. Menhart erklärt letztendlich, dass sein Mitspieler Rosenberk jeden Sieg zur Schande macht.

Dass die Spaltungen in den beiden Lagern eine eigene Entwicklungsdynamik nach sich ziehen, wird in den Repliken zweimal explizit thematisiert: So bedauert der um seine Adelsprivilegien fürchtende Menhart, dass der Laienkelch den Adel spalte:

Menhart (ohnivě): „Nač mysliti nutno, tot jednota všeho panstva českého! At́ on pije z kalicha či nic, jsou stejně vrahy jemu Táboři, těm všichni na jistou jsme zkázu vydáni, když kalich má i dále šlechtu klínem rozrážet. Vš́ šlechty sílu v jedno spojte, sic jak pod obojí tak i pod jednou vás jeden konec čeká hanebný! “308 (I, S. 8f - kursiv im Orig.)

Ähnliches wirft auch Bořek Rosenberk vor. Als Strategie, um die Gegner zu schwächen, schlägt Menhart vor, sie auseinanderzubringen: „Vštěpovati mezi nimi rozdvojení, boj kalicha proti kalichu, tot nejostřejší na ně zbrañ، “309

Dass dieser Sieg der Adelstruppen über Prokop Holý ein tragischer ist, der dem im Untertitel („Truchlohra v pěti jednáních“) benannten Moment des Trauerspiels entspricht, unterstreichen nicht allein die Schlussworte Jiř́s,s, sondern die wiederholten Klagen mehrerer Figuren über die langwierigen blutigen Auseinandersetzungen in Böhmen. Letztendlich sind diese eine Spaltung des Volkes, die einen Bruderkrieg sowie den Verfall der Gesellschaft nach sich zieht. Ähnlich dunkle Vorahnungen hat Jitka bereits in einer Eingangsszene:

Jitka: „Němci se počínají mezi sebou nejednotit? Nu, než to přivedou na tolik stran jako my v Čechách, budou pražské ulice dávno zarostlé hložím a trním! Nač bychom měli své Rímany

308 [Menhart (sich ereifernd):] „Woran wir denken müssen, das ist die Einheit des gesamten böhmischen Adels! Ob er jetzt aus dem Kelch trinkt oder nicht, die Taboriten sind in jedem Fall seine Mörder. Wir sind dem Untergang durch sie ausgeliefert, wenn der Kelch den Adel weiter wie ein Keil spaltet. Vereinigt die ganze Kraft des Adels, andernfalls wartet sowohl auf die Utraquisten wie auf die Katholiken ein schändliches Ende!“

309 [Menhart:] „Eine Spaltung bei ihnen erreichen, den Kampf des Kelches mit dem Kelch, das ist die schärfste Waffe gegen sie." 
a kališníky, husity a wiklefity, tábory a Sirotky, Pražany, obec a pány, panoše a rytí̌e, vladyky a zemany? Ti se o to postarají! "310 (I, S. 3)

Auch wenn Prokop Holý im Vergleich zu radikaleren Hussiten wie Kolman oder Suk eine positive Figur ist - er wird nicht allein von seiner Frau, sondern auch vom Adeligen Vilém Kostka als größter Tscheche bezeichnet -, trägt sein Wunsch, Böhmen rein hussitisch zu machen, insofern zu einer Verhärtung der Frontstellung bei, als von Hussiten im Adel (Aleš, Bořek) dieser Anspruch als letztendlich verheerend angesehen wird. Prokop strebt zwar nach einer maximalen Einheit, er kann diese aber nicht zuwege bringen, weil es angesichts der Entwicklungen unmöglich ist, die unterschiedlichen Interessen und Positionen unter der Gemeinsamkeit des Kelches zusammenzubringen. Das Scheitern der Vereinigung aller "guten“ Tschechen, die Vilém Kostka als die große Leistung Prokops hervorhebt („At není Prokopa, hned bude národ jen rozpolcovaným mraveniskem stran!"'311, III, S. 51) erfolgt aufgrund des wechselseitigen Misstrauens und der Verhärtung der Fronten. Prokops Vermittlungsbemühungen werden auch szenisch deutlich, etwa wenn sich der den Befehlen Aleš nicht fügende hussitische Priester der Neustadt Jakub Vlk und Diviš Bořek, der Kommandant des Adelsaufgebots, das Aleš unterstellt ist, in die Haare geraten. Im Nebentext heißt es dann: „Prokop geht dazwischen“ (vgl. II, S. 31). Noch dramatischer erfolgt dies in der Erkennungsszene, bei der sich heraussstellt, dass Radoslav, der von Rosenberk im Hass gegen die Taboriten erzogen wurde, im Taboritenhauptmann Jarek seinen leiblichen Vater hat. Dieser ist über den geplanten Mordanschlag Radoslavs so empört, dass er seinen eigenen Sohn erstechen möchte. Wieder stellt sich Prokop dazwischen und verhindert so die blindwütige Tötung. Prokop hat subjektiv die Absicht, ganz Böhmen unter dem Laienkelch zu vereinen; trotz aller Bemühungen gelingt es ihm aber nicht einmal unter den Hussiten, diese Einheit herzustellen: Die radikaleren Taboriten und Sirotci werfen dem hussitischen Adelsaufgebot zu wenig militärisches Engagement beim Erreichen des Ziels eines homogen hussitischen Böhmens vor, die Adeligen ihrerseits meinen, dass die Taboriten in ihrem Selbstbewusstsein, „Kämpfer Gottes“ (boží bojovníci) zu sein, marodierend das Land verheeren (vgl. den Streit zwischen Prokop und Menhart, I, S. 15f).

Das große Thema von Lipany - das Fehlen einer nationalen oder religiösen Einheit, das zum fatalen Bruderkrieg führt, wird nicht allein in den angesprochenen Repliken deutlich, sondern auch noch in der Figurenkonstellation unterstrichen.

310 [Jitka:] „Die Deutschen fangen an, uneins zu werden? Nun, bis sie es zu so vielen Parteien wie wir in Böhmen gebracht haben werden, sind dann die Prager Straßen lange schon von Unkraut und Dornen überwuchert. Wozu hätten wir denn sonst unsere Römischen und Utraquisten, Hussiten und Wiklefiten, Taboriten und Waisen, Prager, Gemeine und Adelige, Knappen und Ritter, Vladiken und Gutsherren? Diese sollen sich darum kümmern!“

311 [Kostka:] „Wenn es Prokop nicht gibt, wird das Volk sofort ein loser Ameisenhaufen von Parteien sein!“ 
Dies betrifft zum einen das „Familientrio“Jarek - Radoslav - Rosenberk, bei welchem Radoslav keineswegs die Position der Mitte vertreten kann. Er muss entweder einen der beiden Väter - der leibliche Vater wird metonymisch durch Prokop ersetzt - töten oder die Väter töten ihn, weil es unmöglich ist, beiden Lagern gleichzeitig anzugehören (zuerst verhindert Prokop zwar noch den Tod Radoslavs durch den eigenen Vater, letztendlich aber wird dieser von seinem Ziehvater erstochen). Der Umstand, dass die Position der Mitte nicht möglich ist, wird in einer Replik Jareks deutlich, mit der dieser seine Absicht, den eigenen, vermeintlich ans gegnerische Lager verlorenen Sohn zu töten, folgendermaßen erklärt:

[Jarek:] „Tys nejvzteklejší papeženců štír? A moje krev. (Bez sebe) Kdy bysi ve středu se ukryl mého serdce, tisíckrát je probodnu, bych niveč obrátil své krve jedovatý výpuček!“312 (II, S. 39)

Wenn im tiefsten Innern das eigene Familienmitglied als gefährlichster Feind angesehen wird, ist die Spaltung des Landes existenziell bedrohlich. Sie muss in letzter Konsequenz ans Leben gehen, könnte man aus dieser Replik folgern. Auf ähnliche und noch deutlichere Weise kann die Spaltung anhand des „Familientrios“ Prokop - Blažena - Aleš verfolgt werden. Blažena ist als Schwester des böhmischen Landesverwalters Aleš z Risenburku und Ehefrau Prokops eine Figur, die ebenso von den beiden gegnerischen Lagern „zerrissen“ wird. Sie ersehnt deshalb mehrmals ein Ende der Kämpfe, sieht aber ein solches nie kommen. Sie ist zwar ihrem Mann treu ergeben, doch kann sie dem Versöhnungsvorhaben ihres Bruders Aleš einiges abgewinnen und unterstützt dieses weitgehend. Als Prokop sie über den von Menhart ausgeheckten Verrat in Kenntnis setzt, meint sie, dass dieser ein Verbrechen gegen die Vereinigungsbemühungen der beiden ihr selbst nächststehenden Männer Prokop und Aleš ist. Dass Prokop mit ihr, einer Adeligen verheiratet ist, nährt ja auch gleichzeitig beständig den Verdacht im Lager Prokops, sie selbst - und mit ihr Prokop - stünde auf Seiten des Adels. Als sich dieser Verdacht durch den Arrest Alešs und Jiř́s in Prokops Haus verdichtet und die radikaleren Sirotci (Waisen) unter Sova und Suk die Herausgabe der beiden fordern, ermöglicht ihnen Blažena ja tatsächlich die Flucht, was dazu führt, dass ihr Mann Prokop sie beinahe verstößt (vgl. IV, S. 77). Als sie sich zu guter Letzt zu Prokop auf dem Schlachtfeld von Lipany bringen lässt, ist sie wieder parteiisch genug, um der Adelsfraktion die Schuld am Tod Prokops zu geben. Damit ist auch sie eine Figur, die letztlich bei den vorgeführten Bedingungen keine politische Mitte repräsentieren kann.

Laut Klosová (vgl. 1977a, 62) forderte Lipany zur Versöhnung zweier verfeindeter politischer Parteien - gemeint sind wohl die Alttschechen und die Jung-

312 [Jarek:] „Du bist der wütendste Skorpion der Päpstlichen? Und von meinem Blut? (Außer sich). Wenn du dich in der Mitte meines Herzens versteckt hieltest, würde ich dieses tausendmal durchstoßen, damit das Nichts den giftigen Sproß meines Blutes erfasse!“ 
tschechen - und zur Zusammenarbeit mit dem patriotisch gesinnten Adel auf. Die Darstellung der Niederlage der Taboriten sei als Warnung vor allzu großem politischen Radikalismus zu verstehen, die Vlček als „offizieller Autor der tschechischen Bourgeoisie" mitteilen hätte wollen. Diese Kurzcharakterisierung der Mitteilung im äußeren Kommunikationssystem des Dramas ist im Allgemeinen durchaus richtig, gegenüber ihrer allzu großen Bestimmtheit - dass das Drama etwa die Versöhnung zweier verfeindeter Parteien anrege oder den Adel als Handlungspartner empfiehlt - kann aber auch vorsichtig darauf hingewiesen werden, dass Lipany die negativen Folgen eines Konflikts vor Augen führt, der aufgrund der Unflexibilität in der Haltung der Antagonisten entsteht. Die Antagonisten sind Adelige und Taboriten; gemeinsam ist ihnen - mit Ausnahme von Oldřich z Rosenberka - freilich der Laienkelch, der mithin als Symbol nationaler Gemeinsamkeit gelten konnte. Dass der Hussitismus als tschechisches nationales „Alleinstellungsmerkmal“ fungieren konnte, ist für die Entstehungszeit des Dramas durchaus kennzeichnend. Mit der Thematisierung einer (fiktiven) religiösen Gemeinsamkeit aller "guten“"Tschechen konnten direkte nationalpolitische Aussagen auf eine allegorische Ebene verschoben werden, deren Sinn es wohl war, die gemeinsame Sache der Nation vor das Trennende zu stellen. Im Národní divadlo, dem neuen Zentrum der tschechischen Nationalkultur, sollte die Negativität des Trauerspiels dem Publikum wohl als Warnung vor allzu viel nationaler Differenzierung gelten.

\section{IV.6.11. Ladislav Stroupežnický: Paní mincmistrová. Aktovka (1885)}

[Frau Münzmeisterin. Einakter; UA 27.4.1885, publ. 1886]

In den 1880er Jahren war das Genre des historischen Dramas schon so weit im tschechischen Theater etabliert, dass sich unter dem Einfluss von Eugène Scribe und von Shakespeares Merry Wives of Windsor Ladislav Stroupežnický und Jaroslav Vrchlický um Komödien mit historischen Personen bemühten. Anstelle großer historischer Taten wurden bekannte Personen aus der Geschichte in ihrem Privatleben gezeigt: Vrchlickýs Noc na Karlštejnè (1884) zeigt, wie Karl IV. seine unbegründet eifersüchtige Frau diskret ins Leere laufen lässt, Stroupežnickýs Einakter spielt in der für ihren Silberbergbau berühmten Stadt Kutná Hora im Jahre 1611. Beide historischen Komödien haben trotz ihrer zum Teil burlesken Momente klare politische Implikationen.

In Paní mincmistrová dreht sich die komische Handlung um einen schlauen Adeligen vom Typus eines Cyrano de Bergerac, nämlich den protestantischen Lebemann Mikuláš Dačický z Heslova, der eine historische Person ist. ${ }^{313}$ Ladislav Strou-

313 Mikuláš Dačický z Heslova (1555-1626) war Chronist seiner adeligen Familie, er verbrachte viele Jahre in seiner Heimatstadt Kutná Hora und schrieb neben seinen eigenen 
pežnický, der erste Dramaturg am neueröffneten Národní divadlo, setzte Mikuláš Dačický schon erfolgreich im Einakter Zvikovský rarášek [Der Bengel von Zvíkov, 1883] ein; in Pani mincmistrová überführt dieser den königlichen Alchimisten David Wolfram des Betruges und korrigiert damit seinen Ruf als Zechbruder und Schwerenöter. Die beiden Einakter stellen in der Geschichte des tschechischen historischen Dramas insofern eine Innovation dar, als sie erstmals komödiantische Elemente in eine fiktive Handlung einbauen, die Materialien aus der tschechischen Geschichte vermittels einer historisierenden Sprache verwendet.

Mikuláš wird vom königlichen Münzpräger Tobiáš Tríska angeklagt, aus Übermut seine junge Frau Žofka auf offener Straße geküsst zu haben. Diese Anklage will Vilém z Vřesovic, der allerhöchste Münzmeister im Königreich Böhmen, auch nützen, um Mikuláš eins auszuwischen, für den seine Frau Ludmila immer wieder Fürsprache gehalten hat. David Wolfram erbittet vom Münzmeister weitere 5.000 Taler für seine alchimistischen Versuche; er plant mit Žofka, die aus der unglücklichen Ehe mit ihrem alten Ehemann ausbrechen möchte, die Flucht nach Sachsen. Mikuláš hat ein Spottgedicht auf Wolfram geschrieben, in dem er diesen des Betrugs bezichtigt. Als Wolfram deswegen Mikuláš zum Degenkampf herausfordert, verliert er einen Zettel, den ihm Žofka wegen der bevorstehenden Flucht geschrieben hat. Dieser Zettel wird vom Diener des Münzmeisters Zdeněk gefunden, der mit Mikuláš eng befreundet ist. Das Gericht unter der Leitung des Münzmeisters verurteilt Mikuláš wegen des erzwungenen Kusses zu einer Arbeitsstrafe nach dem Vorbild eines Urteils aus dem Jahre 1445: Mikuláš soll eine Straße so weit pflastern, wie sein Haus an Umfang hat. Wegen der Ehrenbeleidigung Wolframs, die sogar als Beleidigung des Königs ausgelegt wird, wird er auch zu einer Kerkerstrafe verurteilt. Aufgrund seines Adelstitels könne Mikuláš jedoch gegen eine Kaution von 2.000 Talern in Freiheit bleiben. Der Münzmeister vermeint, dass der verarmte Lebemann diese Summe nicht aufbringen werde können, doch Mikuláš bekommt das Geld von der Frau des Münzmeisters, die er wegen seines Einsatzes für die Rettung eines verschütteten Bergmannes für sich eingenommen hat. Die für die Rettung benötigten 100 Taler hat er mit der Wette aufgebracht, auf offener Straße Žofka zu küssen. Mikuláš, der aufgrund des ihm zugesteckten Zettels von der betrügerischen Flucht des Alchimisten Wolfram weiß, kann dank der durch die Kaution erlangten Freiheit diese verhindern. In einer wirkungsvollen Inszenierung lässt er die sichergestellten Geldsäcke sowie das noch rechtzeitig vor der Flucht gestellte Paar Wolfram und Žofka vor dem Münzmeister auftreten. Dieser ist sehr erleichtert, dass der königlichen Kasse kein Schaden entsteht. Er verzeiht Mikuláš und seiner eigenen Frau,

Memoiren auch Gedichte. Seine handschriftlich redigierte Prostopravda (1619 u. 1620) gilt als erster Gedichtband der tschechischen Literatur. Die unter dem Titel Paméti verfassten Erinnerungen verknüpfen die Familienchronik mit den Memoiren und liefern somit eine gut hundert Jahre umfassende zusammenhängende Chronik einer böhmischen Adelfamilie der frühen Neuzeit (vgl. LčL I, 509f). 
dass sie diesen bei der Hinterlegung der Kaution geholfen hat. Der schlaue Mikuláš triumphiert und lässt die Frau Münzmeisterin hochleben.

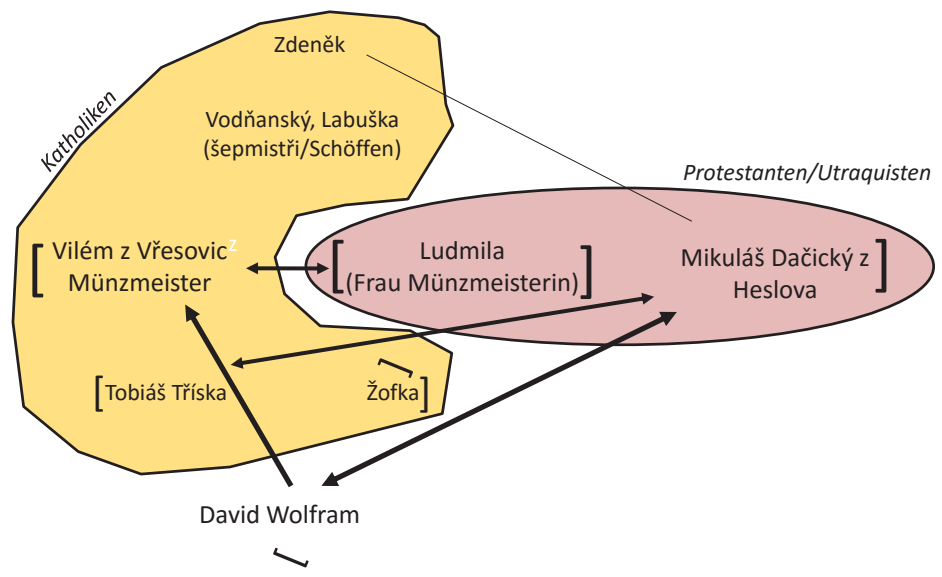

Graphik 24 - Ladislav Stroupežnický: Pani mincmistrová (1885)

Die Komödie, die von Stroupežnickýs Lektüre von Dačickýs zu Anfang der 1880er Jahre herausgegebenen Pamèti inspiriert ist, einzelne Ereignisse und Personen aber frei kombiniert (vgl. Hampl 1942, 168-172), berührt mit ihrem historischen Hintergrund einige politische Themen, wodurch eine Diskussion des Stücks im Zusammenhang mit den Fragestellungen der vorliegenden Arbeit gerechtfertigt ist. Es handelt sich vor allem um die Frage des Verhältnisses von Böhmen zur Königsmacht und um den religionspolitischen Konflikt zwischen Katholiken und Protestanten bzw. Hussiten. Die Relationen zwischen den drei zentralen Figuren - Mikuláš Dačický, Herr und Frau Münzmeister - werden von diesen politischen Fragen beeinflusst.

Der Münzmeister Vilém z Vrresovic ist gleichsam der höchste Finanzbeamte des Königreichs Böhmen, er legt großen Wert auf Respekt für die Königsmacht und ihre Repräsentanten. Als ihm etwa das Spottlied vorgelegt wird, das Mikuláš auf den vom König bestellten Alchimisten verfasst hat, möchte er diese Angelegenheit, die er als Ehrenbeleidigung eines königlichen Offiziers ansieht, bevorzugt vom Schöffengericht verurteilt wissen. Die Schöffen (šepmistrí $)$, wiewohl eher komische Figuren, verweisen aber auf die Gerichtsordnung der Stadt Kutná Hora, derzufolge die Fälle durch das Gericht in der Reihenfolge der Eingabe zu behandeln sind, der König habe dabei keinen Vorrang. Etwas widerwillig akzeptiert der Münzmeister diese Abfolge der Behandlung, die einen Bürger vor den König reiht (Szene 8). Dass Mikulás dann tatsächlich den Betrug Wolframs aufdeckt und dessen Flucht nach Sachsen vereitelt, bedeutet für den Münzmeister, dass ihm eine große Blamage er- 
spart bleibt, hat er doch diesem immer vertraut und aus der Staatskasse Geld zukommen lassen. Daher dankt der Münzmeister Mikuláš für die Dienste, die er ihm und „Seiner gnädigen Majestät dem König“ („Jeho Milosti králi“) erwiesen hat (Szene 21, S. 144).

Auf komische Weise überzeichnet werden die Repräsentationsverhältnisse eine Form von Metonymie in der Sphäre des Politischen - in der Klage von Tobiáš Tríska gegen Mikuláš: Jener führt nämlich an, dass Mikuláš durch das Küssen seiner Frau Žofka sowohl eine Gotteslästerung - Tř́ska ist langjähriger Posaunenspieler in der katholischen Klosterkirche - als auch eine Majestätsbeleidigung vorgenommen habe. Als dem König ergebener Münzpräger habe er viele Münzen in die Staatskasse fließen lassen:

A když pan z Heslova těžce potupil mou ženu, potupil mne - a když potupil mne, urazil následovně také Jeho Milost císaře a krále našeho Rudolfa Druhého. ${ }^{314}$ (Szene 8, S. 88)

Dass in das Verhältnis zum König auch nationalpolitische und religiöse Momente hineinspielen, wird erst deutlich, wenn das private Verhältnis des Münzmeister-Ehepaars betrachtet wird. Gleich in der ersten Szene nämlich zeichnet sich ein Konflikt zwischen den Eheleuten ab. Der katholische Münzmeister Vilém nämlich erklärt missbilligend, dass seine Frau immer wieder Mikuláš rechtfertige, weil sie wie dieser dem evangelischen Bekenntnis anhänge, während er der wahren katholischen Religion angehöre und ein treuer Diener seiner gnädigen Majestät des Kaisers und Königs Rudolfs sei (Szene 1, S. 67). Als er Verdacht schöpft, dass seine Frau Mikuláš zu den 2.000 Talern für die Kaution verholfen habe, kommt es zum Streit. Die Frau Münzmeisterin erklärt trotzig, dass es ihren Mann wohl nichts angehe, wenn sie die Kaution aufgebracht hat. Darauf antwortet Vilém gereizt mit dem Hinweis auf sein Amt als höchster Münzmeister des Königreichs und seine katholische Religion. Seine Frau nimmt dies zu Anlass, sich darüber zu beschweren, dass das unterschiedliche Bekenntnis der Eheleute doch immer wieder von ihrem Mann ins Spiel gebracht würde, obwohl im Ehevertrag festgehalten worden sei, dass das utraquistische Bekenntnis ihr nicht zum Vorwurf gemacht werden dürfe (vgl. Szene 18, S. 126). Sie droht ihrem Mann sogar damit, das gemeinsame Haus zu verlassen und wieder auf ihr Erbgut zu ziehen, durch welches sie ohnehin ausreichend versorgt sei. Ihre Vorwürfe an den Mann können durchaus metaphorisch als politische Vorwürfe der Tschechen - metonymisch hier durch den Utraquismus repräsentiert, durch welchen sie sich vom katholischen Österreich unterscheiden - an die Regierung in Wien gelesen werden:

314 [Tř́ska:] „Und wenn der Herr von Heslov meine Frau schwer beleidigt hat, hat er mich beleidigt - und wenn er mich beleidigt hat, hat er folglich auch Seine gnädige Exzellenz den Kaiser und unseren König Rudolf den Zweiten beleidigt." 
[Paní mincmistrová:] [...] nikdo, ani sám král této země, nemůž zkracovati mne ve svobodách a právích, jež zaručuje mi zřízení zemské!“ [...] „Ty, pane Viléme, často činíš mi z vyznání mého podobojí, jako ze zločinu nějakého, těžké výčitky, a svobod mých i práv a spravedlností nešetř́ís a v nic je obracíš! Tím bez práva mne urážíš a nešlechetně ke mně se chováš! [...] A protož žádám, abys zkoušeným odprošením spravil se z křivd, jichž jsi na mých svobodách se dopustil! ${ }^{15}$ (Szene 18, S. 127f)

Die allegorische Doppelsinnigkeit dieser Replik ist hier insofern gegeben, als für den Beginn des 17. Jahrhunderts die konfessionelle Frage eine große Rolle in der habsburgischen Politik gegenüber Böhmen gespielt hat, während am Ende des 19. Jahrhunderts der österreichischen Regierung die Missachtung des böhmischen Staatsrechts vorgeworfen wurde.

Diese historisierende Komödie führt ihren de-präsentierenden Vergangenheitsbezug auch als mise-en-abyme vor: Durch eine ungewöhnliche Kombination von expliziter Thematisierung des „Historismus“, Dingsymbolik und Polysemie werden Konnotationen nahegelegt, welche auf die Bedeutsamkeit von Tradition und Geschichte hinweisen. Zum einen erklärt Mikuláš der Frau Münzmeisterin, die von seinem selbstlosen Einsatz für den verschütteten Bergmann eingenommen ist, dass er seine Familienchronik fortschreibt und dabei Aufstieg und Verfolgung des evangelischen (bzw. hussitischen) Bekenntnisses festhält und der Nachwelt tradiert; zum anderen ist als Dingsymbol das schöne alte Spinnrad (preslice) der Frau Münzmeisterin auf der Bühne (bzw. im Nebentext) präsent. In Szene 6 wird dieses Spinnrad Gegenstand der Aufmerksamkeit der Figuren, wobei mehrfach die Bewunderung für dessen kunstvolle Ausführung explizit geäußert wird („mistrně řezané“ „mistrné dílo“ - Szene 6, S. 79). Im ersten Nebentext der ersten Szene wird es als altertümlich und kunstvoll geschnitzt beschrieben. ${ }^{316}$ Über die Benennung dieses Dinges Spinn$\operatorname{rad}$ (preslice) wird eben jene Konnotation von Wertschätzung für die Überlieferung erzeugt. Das Wort preslice ist im Tschechischen polysem, neben dem Spinnrad existiert auch noch die konventionalierte metaphorische Phrase po presslici (,mütterli-

315 [Frau Münzmeisterin:] „[...] niemand, auch nicht der König dieses Landes, kann mich in den Freiheiten und Rechten beschneiden, die mir die Landesordnung garantiert!“ [...] „Du, Herr Vilém, machst mir oft wegen meines utraquistischen Bekenntnisses, wie wegen eines Verbrechens, schwere Vorwürfe, und achtest nicht meine Freiheiten und Rechte, sondern machst sie zunichte! Damit beleidigst du mich ungerechtfertigt und verhältst Dich unhöflich zu mir! [...] Daher bitte ich, dass du wohlüberlegt um Verzeihung für die Verstöße bittest, die du dir gegen meine Freiheiten erlaubt hast."

316 Nebentext: „Paní mincmistrová u malého stolku a přede př̌i starobylé, uměle řezané přeslici“” („Frau Münzmeisterin sitzt an einem kleinen Tisch und spinnt auf einem altehrwürdigen, schön geschnitzten Spinnrad." - Szene 1, S. 65). 
cherseits, in weiblicher Linie`), die Mikuláš verwendet, wenn er von seiner Familienchronik zu erzählen beginnt. ${ }^{317}$

Die Münzmeisterin erklärt herausfordernd:

[Paní mincmistrová:] Jsem, pane Viléme, hrdá žena a nedám sobě ve svobodách svého svědomí, aniž ve svých právích světských nikým, ani tebou, aniž samým této země králem závad a překážek činiti! ${ }^{318}$ (Szene 18, S. 129)

Aus diesen Repliken wird deutlich, warum Stroupežnický seinen Einakter nach der weiblichen Hauptfigur benannt hat, wiewohl die wichtigste handelnde Figur nicht die Frau Münzmeisterin, sondern Mikuláš Dačický ist. Dieser hat die dramaturgische Funktion des schalkhaft-komödiantischen Helden; für sein Handeln erfährt er freilich entscheidende Unterstützung von der Frau Münzmeisterin. Der Einakter endet entsprechend auch damit, dass Mikuláš folgende Huldigung seiner Vertrauten proklamiert:

[Mikuláš:] Šlechetná této země české dcera a religionu evangelického i památky Husovy věrná ctitelka paní mincmistrová! ${ }^{319}$ (Szene 21, S. 145)

Im Stück triumphiert also die protestantische Tradition über die katholische, und diese protestantische Tradition ist mit der „weiblichen Linie“ der Frau Münzmeisterin bzw. des von ihr protegierten, traditionsbewussten Chronisten Mikuláš verbunden.

Interpretiert man den Handlungsverlauf unter Berücksichtigung seiner politischen Implikationen, so ergibt sich, dass ein schwerer Schaden für den König und seinen Repräsentanten bzw. für das ganze Königreich dadurch verhindert worden ist, dass die diskriminierten Protestanten aufmerksam und selbstbewusst genug waren und sich gegenüber den Zumutungen der Macht durchsetzen konnten. Diese Interpretation wird auch vom Nebentext unterstützt, der darauf hinweist, dass die Schnur, mit welcher Wolfram, der betrügerische Alchimist des Königs von Mikuláš gefesselt wurde, jene Schnur ist, die zur Strafe von Mikuláš selbst vorgesehen war, sie trägt noch die Siegeln des Schöffengerichts, dessen Urteil Mikuláš entgehen musste (vgl. Szene 21, S. 139).

317 [Mikuláš]: Můj děd po přeslici, dobré paměti pan Bartoš z Práchňan, pilně zapisoval této země české osudy všeliké [...] („Mein Großvater mütterlicherseits, der selige Herr Bartoš von Práchňany, hat eifrig allerlei Fährnisse dieses böhmischen Landes aufgezeichnet [...]").

318 [Frau Münzmeisterin:] „Ich bin, Herr Vilém, eine stolze Frau und lasse mich weder in den Freiheiten meines Gewissens, noch in meinen weltlichen Rechten behindern und beschneiden, weder von Dir, noch vom König dieses Landes selbst.“

319 [Mikuláš:] „Die vornehme Tochter des böhmischen Landes und die Anhängerin der evangelischen Religion und treue Anhängern von Hus - Frau Münzmeisterin!“ 
In allegorischer Verallgemeinerung könnte als politisches Fazit von Stroupežnickýs Panímincmistrová gelten: Die Tschechen tragen entscheidend zum Wohl des Habsburgerreiches bei, obwohl sie in ihren Rechten von den Repräsentanten der Zentralmacht beschnitten werden.

\section{IV.6.12. Julius Zeyer: Neklan. Tragedie o pèti jednáních (1893)}

[Neklan. Tragödie in fünf Akten; publ. 1893, UA 30.3. 1896]

Der aus einer deutsch-jüdischen Unternehmerfamilie stammende Julius Zeyer (1841-1901) hat nach ersten literarischen Versuchen in deutscher Sprache sich später dazu entschlossen, in Tschechisch, das er von seiner Amme gelernt und im Gymnasium als Zweitsprache gewählt hatte, zu schreiben. Er wurde neben Jaroslav Vrchlický zum wichtigsten Vertreter der Lumír-Generation; vor allem für sein erzählerisches Werk und für seine Versepik ist Zeyer in die Literaturgeschichte eingegangen. Doch auch sein dramatisches Oeuvre ist ziemlich umfangreich; Zeyer hatte mit diesem jedoch anfangs wenig Erfolg, weil seine Versdramen in eine Zeit fielen, in der unter der dramaturgischen Leitung von Ladislav Stroupežnický am Národní divadlo die realistische Dramatik gefördert wurde. Erst in den 1890er Jahren wurden seine Dramen wieder auf der ersten Bühne des Landes gespielt und von der nachfolgenden symbolistischen Generation positiv aufgenommen. Seinen Versepopöen aus der mythischen Frühgeschichte der Tschechen hat Zeyer drei Dramen mit ähnlicher Thematik an die Seite gestellt: Libušin hnèv (1886), Šárka (1887) und Neklan (1893). Diese Beschäftigung mit der vorgeschichtlichen Epoche ist laut Macura im 19. Jahrhundert immer auch schon Ausdruck einer Sehnsucht nach vergangener Größe gewesen.

Obraz dávnověku nebyl v té míre výpravou do hájemství mýtů (tuto stránku starých českých pověstí pro sebe objevil po stopách německých literárních výbojů na tomto poli až mnohem později snad jedině Julius Zeyer), jako spíše teskným připomenutím někdejši české slávy. Pověst o Libuši byla u nás především tradována a vnímána jako vyprávění o počátcích české samostatnosti národní, o české původnosti, ba dokonce prímo o základech českého státu. ${ }^{321}$ (Macura 1998, 88)

320 Śárka war inspiriert von Bedřich Smetanas musikalischem Zugang zur nationalen Thematik, das Stück knüpfte an Smetanas Libuše an. Antonín Dvořák dachte kurzzeitig an eine Vertonung, ließ diesen Plan aber fallen, dafür schrieb sein Schüler Leoš Janáček die Musik zu Šárka. Zeyer gestattete aber keine Aufführung, erst 1925 erfolgte die Premiere von Janáčeks Opernversion in Brünn (vgl. Vlašínová 2003, 64f).

321 „Das Bild der vorgeschichtlichen Zeit war nicht so sehr ein Ausflug in die Gefilde der Mythen (diese Seite der alten tschechischen Legenden hat viel später wohl als einziger Julius Zeyer in der Nachfolge deutscher literarischer Errungenschaften für sich entdeckt), sie war 
Obwohl Macura hier eine wesentliche Aussage über den tschechischen Historismus des 19. Jahrhunderts macht, bedarf diese hinsichtlich des Werks von Julius Zeyer einer kleinen Korrektur. Denn wie in der Folge gezeigt werden wird, ist $\mathrm{Ne}$ klan keineswegs ein eskapistischer Ausflug in die ferne Vergangenheit, sondern in der Darstellung der Vergangenheit sind sehr wohl allegorische Bezüge auf die Gegenwart zu erkennen.

Im Vorwort zur Druckfassung von Neklan in den Sebranéspisy [Gesammelten Schriften] schreibt Zeyer, dass er ein Drama von der Art der shakespeareschen Historien habe schreiben wollen. Der Stoff für die Tragödie aus der prähistorischen, mythenumwobenen Zeit, den er der Chronik des Václav Hájek z Libočan entnommen hatte, erschien insofern passend, als nur wenig gesichertes historisches Wissen über diese Zeit vorhanden sei, was die Dichtung auf den Plan rufe, nur sie allein könne in einem solchen Fall als Führerin auftreten. ${ }^{322}$ Ihn habe die vermeintliche Atmosphäre der vorchristlichen Epoche berührt, in der vage Vorzeichen das Wirken der Slawenapostel und den späteren Glanz der byzantinisch-christlichen Kultur angekündigt hätten. Zeyer widmete das Stück dem Andenken an Ferdinand Náprstek, der 1894, also bald nach Abschluss der Tragödie, verstorben ist. Für Neklan erhielt Zeyer den Náprstek-Preis, der auch noch in den 1890er Jahren vergeben wurde.

Der erste Akt der Tragödie spielt auf der Burg des Fürsten der Lučanen. Fürst Vlastislav ist soeben aus einer Schlacht zurückgekehrt, in der er erfolgreich die Sachsen aus Böhmen vertrieben hat. Er rivalisiert mit Neklan, dem Prager Fürsten, um die Vorherrschaft in Böhmen. Er möchte das mächtige Reich Samos wieder errichten und ein großer König werden. Straba, die Großmutter Vlastislavs und Neklans, weist darauf hin, dass ihr Vorfahr Samo, von dem sie die Krone geerbt hat, die sie nun versteckt hält, die Feinde aus Böhmen vertrieben und das Land zu einer Einheit gebracht hat; das Schwert wurde aber niemals in Böhmen eingesetzt, um Recht zu erzwingen; gegen die eigene Verwandtschaft dürfe es niemals gerichtet werden. Sie weist auf die Vorzüge eines gerecht handelnden Fürsten nach dem Beispiel des Pfügers Přemysl hin, der friedlich das Land bestellt habe. Vlastislav erhebt Anspruch auf die Krone Samos, doch Straba wirft Vlastislav vor, dass seine Frau Svatava und sein Sohn Zbislav nicht mehr bei ihm leben.

Durink, der kürzlich in die Dienste Vlastislavs getreten ist, berichtet diesem von den Entwicklungen in der Folge von Vlastislavs Überfall auf die Burg Pačov, die auf Prager Gebiet liegt. Eine Kriegserklärung der Prager sei zu erwarten. Bei Vlastislav erscheint seine Frau Svatava und bringt den gemeinsamen Sohn Zbislav, damit

eher ein sehnsüchtiges Erinnern einstigen Ruhms der Tschechen. Die Legende von Libuše wurde bei uns [den Tschechen] vor allem als Erzählung von den Anfängen tschechischer nationaler Selbstständigkeit, tschechischer Ursprünglichkeit, ja sogar von den Grundlagen des tschechischen Staates überliefert und rezipiert."

322 „Tu může vůdcem býti pouze poesie.“ („Hier kann nur die Dichtung Führerin sein.“ - Zeyer $1896,6)$. 
er diesen bei sich aufnimmt. Eine erste Befremdung Vlastislavs wird überwunden. Gerührt schließt er Zbislav in seine Arme und erkennt, dass er Svatava Leid zugefügt hat. Die der Astrologie und Magie zugetane Svatava warnt ihn vor kriegerischen Unternehmungen, in den Sternen stehe sein Unglück geschrieben. Vlastislav schenkt diesen Warnungen keinerlei Glauben. Straba und Svatava sehen einander erfreut nach zehn Jahren wieder.

Vlastislav spricht den Kampfgenossen für die erfolgreiche Schlacht gegen die Sachsen seinen Dank aus, vor allem Tyr z Chýnova, der sich bei aller Tapferkeit und Kampfesstärke aber doch eher nach einem friedlichen Leben nach dem Beispiel des Pflügers Přemysl sehnt und Vlastislav den Dienst aufkündigt. Vlastislav spricht von einem neuen großen Reich, das ganz Böhmen umfassen werde; als Erbe von Samos Krone soll Zbislav über es herrschen. Die Gesandten von Neklan sind über die Herrschaftsansprüche Vlastislavs erbost. Er nimmt diese jedoch nicht zurück und lehnt sogar die Gastgeschenke ab, die Neklan ihm anstelle der erwarteten Kriegserklärung sendet. Vlastislav kündigt an, sich nicht Geschenke, sondern Beute in Prag zu holen. Auch „schenkt“ er die schüchterne Klimba seinem tapfersten Mitstreiter Tyr. Svatava sieht den Stern Vlastislavs untergehen, er selbst hingegen interpretiert den Stern als einen funkelnden Edelstein in Samos Krone, die ihm nun die Götter aufsetzen.

Der zweite Akt zeigt die Reaktionen in der Prager Burg Vyšehrad auf die Vorkommnisse in Lucko. Die Vladiken Prags sind bestürzt; Neklans Ratgeber Kruvoj und sein Heerführer, der mit Vlastislav ja in Lucko unterhandelt hat, wollen entschlossener handeln als Neklan selbst, der als ausgesprochen feige gilt und den sie verachten. Da sie aber Neklan selbst zum Fürsten gewählt haben, sind sie mitverantwortlich. Er selbst verachtet sie wohl dafür, dass sie sich ihm gegenüber loyal zeigen: „Zná svoje nic, však vaše nic zná téžc“" 323 (II/1, S. 43) Kruvoj erklärt, dass Neklan sehr wohl wisse, dass die Gemeinschaft der Prager durch ihn zusammengehalten und allein damit gestärkt werde (II, S. 43). Er selbst diene - arbeitsam wie eine Biene weniger Neklan als Prag, damit irgendwann einmal ein würdiger Erbe das Land, dem Libuše ein großes Schicksal verheißen hat, führen werde können.

Neklans Neffe Krasník, der Fürst von Kouřim, ist verärgert, als er hört, dass Vlastislav Klimba, die immerhin seine Schwester ist, Tyr zur Frau gegeben hat. Der weibisch gezeichnete Krasník beansprucht ebenfalls die Vorherrschaft über Böhmen, er prahlt mit Beziehungen zum großmährischen König und zu den Franken. Von einem gemeinsamen Rachezug mit Neklan gegen Vlastislav erwartet er sich zumindest Beute; insofern Neklan aber ankündigt, er wolle Vlastislav nichts wegnehmen, sondern ihn nur in die Schranken des Rechts weisen, überlegt Krasník, ob er nicht besser heimlich diesen unterstützen soll. Dass auf Krasník kein Verlass ist, erkennen Neklan und Kruvoj, der befürchtet, dass möglicherweise sogar auch Tyr gegen Prag

323 „Er kennt ja das Nichts [das er ist], kennt aber ebenfalls Euer Nichts““ 
ziehen könnte, weil er ja Vlastislavs Freund ist. Neklan jedenfalls fürchtet den Krieg und benötigt deswegen immer Unterstützung und Zuspruch, seine Vladiken möchten jedoch gegen Vlastislav ziehen.

Die Ehe zwischen Klimba und Tyr wird nicht vollzogen, da diese darüber zutiefst betrübt ist, von Vlastislav, der sie bereits entjungfert hatte und dem sie noch immer zugetan ist, wie ein Gegenstand dem nichtsahnenden Tyr geschenkt worden zu sein. Tyr hat aus großer Liebe zu Klimba dieses Geschenk angenommen; da er aber auch schon Christ geworden ist, stellt er ihr frei, sich ihm hinzugeben oder nicht.

Die sehr gedrückte Stimmung der Eheleute auf Tyrs Burg Chýnov bemerken Klen und Kruvoj, als sie im dritten Akt Tyr besuchen, um ihn für Neklan zu gewinnen, dem Chýnov untersteht. Dass Tyr mit Vlastislav gegen die Sachsen gekämpft hat, erklärt er mit seinem Pflichtverständnis:

\author{
[...]. Vrahové \\ jsou vezdy Němci nám, potírat je \\ at s luckým knížetem či s Neklanem \\ jest každému z nás právo, mnohem víc \\ to povinností nejsvětější jest. ${ }^{324}$ (III, S. 72)
}

Trotz seiner Freundschaft mit Vlastislav will Tyr zu Neklan stehen, der seiner Ansicht nach im Recht ist. Vlastislav kommt ebenfalls zu Tyr, um ihn zu gewinnen; er verspricht ihm sogar ein eigenes Fürstentum, woraufhin dieser erklärt, ganz Böhmen, das einstige Reich Samos, sei seine Heimat. Vlastislav sei zu selbstbezogen, er solle sich besser dem Recht fügen, ihm selbst, Tyr, ginge es um ein großes Böhmen, das unterdrückten Verwandten Hilfe leistet. Auch wenn er nicht mit Vlastislav einer Meinung ist, wolle er selbst nicht mit Neklan gegen ihn kämpfen, sondern diesem nur Waffenhilfe leisten. Eine Wendung in der Beziehung der Freunde bringt das Verhalten Klimbas, die in der Gegenwart Vlastislavs, den sie immer noch liebt, sichtlich befangen ist. Als die Nachricht vom Tod Svatavas eintrifft, kommt das Verhältnis zwischen ihr und Vlastislav ans Licht: Klimba meint nun, Vlastislav könne ja nun sie zur Frau nehmen, aber dieser lehnt brüsk ab. Tyr ist empört über Vlastislavs Verhalten; er zerreißt symbolisch den Mantel, unter dem er und Vlastislav einst im Feld geschlafen haben. Klimba erkennt den Unterschied zwischen den beiden, sie sucht nun nach der Möglichkeit einer Reinigung von ihrer Sünde.

Der vierte Akt zeigt zuerst den Kampf zwischen Vlastislav und Neklan. Vlastislav hat schon Siege errungen, die eigentliche Schlacht steht aber noch bevor. Krasník, der Neklan schwächen wollte, um hierauf mit Unterstützung des mährischen

324 [Tyr:] „Mörder / sind die Deutschen für uns überall. Sie zu bekämpfen / - ob nun mit dem Fürsten von Lucko oder mit Neklan -/ ist das Recht eines jeden von uns, mehr noch:/ das ist die heiligste Pflicht." 
und auch des fränkischen Königs auch noch Vlastislav zu besiegen, wurde von Klen gestellt. Der jeden Kampf scheuende Neklan zaudert; er ist pessimistisch, sodass er von Kruvoj zu Taten angestachelt werden muss. Er hat die Idee, dass sich Tyr als Neklan verkleiden und in die Schlacht ziehen soll, somit können die Prophezeiungen erfüllt werden. Weil Tyr nur vage von anderen, nämlich christlichen Zielen spricht, die er anstrebt, wird er von Kruvoj missverstanden, der meint, Tyr ziele ebenfalls auf die Macht in Böhmen ab. Kruvoj, der anstelle von Neklan die wichtigen Entscheidungen trifft, möchte Kouřim zerstören lassen. Dort verflucht Straba Krasníks Allianz mit dem mährischen und dem fränkischen König; nicht die sühnende Klimba, sondern Krasník sei eine Hure. ${ }^{325}$ Krasník wird bei der Zerstörung Kouřims von Klen erstochen, die über ihn und Vlastislav entsetzte Straba sucht in den Flammen den Tod, ohne zu verraten, wo die Krone Samos versteckt ist.

Im abschließenden fünften Akt berichten die Söhne Neklans und Vlastislavs, Hostivít und Zbislav, vom Verlauf der großen Schlacht, in der Tyr als Neklan verkleidet Vlastislav in die Flucht nach Lucko schlägt, während Neklan selbst es nicht einmal ertragen kann, die Schlacht aus der Ferne zu beobachten. Sein Diener Durink rät Vlastislav zu einer Allianz mit den Deutschen; Vlastislav lehnt dies freilich als Hochverrat ab. Klimba kommt mit der Krone Samos, die Straba für Tyr bestimmt hat. Sie rächt sich mit einem vergifteten Dolch an Vlastislav, dieser muss langsam sterben, er setzt sich im Sterben die Krone Samos auf. Doch er hat im Handgemenge auch Klimba tödlich verwundet, die dem herbeieilenden Tyr noch mitteilt, dass sie ihn gerächt habe. Der christlich denkende Tyr tadelt sie dafür, sodass Klimba einen bitteren Tod stirbt. Kruvoj ersticht Tyr, weil er in ihm einen Prätendenten auf den böhmischen Thron sieht. Und Durink, der nach dem Tod Vlastislavs sofort das Lager wechselt, ersticht und enthauptet Zbislav, weil auch dieser ja den Anspruch auf die Krone haben könnte. Auf dem abgetrennten Kopf Zbislavs sitzt Samos Krone. Durink wird für seinen grausamen Mord am Knaben bestraft, und Hostivít, Neklans Sohn, bekommt nun als neuer König über ein großes Böhmen Samos Krone aufgesetzt. Mit der Hoffnung auf einen Neubeginn durch den unschuldigen Knaben Hostivít, der die aufgehende Sonne wie im Gebet umarmt, endet die Tragödie.

Aus dem Schema kann man ersehen, dass Samos Reich einen historischen Bezugspunkt abgibt, vor welchem sich der Konflikt im Böhmen zur Zeit Neklans entwickelt. Im Wesentlichen handelt es sich um den Kampf zwischen Vettern um die oberste Fürstenmacht in Böhmen (die andere Handlungslinie, das Dreiecksdrama zwischen Tyr und Vlastislav um Klimba, braucht in unserem Zusammenhang nicht weiter berücksichtigt zu werden). Dem extrem feigen und militärisch völlig unfähigen Neklan wird Vlastislav gegenübergestellt, der zwar ein erfolgreicher und

325 Vgl. Strabas Vergleich: „Ty [=Krasník], který na trh nese volnost svou / jak tělo svoje prodá nevěstka“ - (IV, S. 111 - „Du [=Krasník], der du deine Freiheit auf den Markt trägst / wie eine Hure ihren Körper verkauft"). 


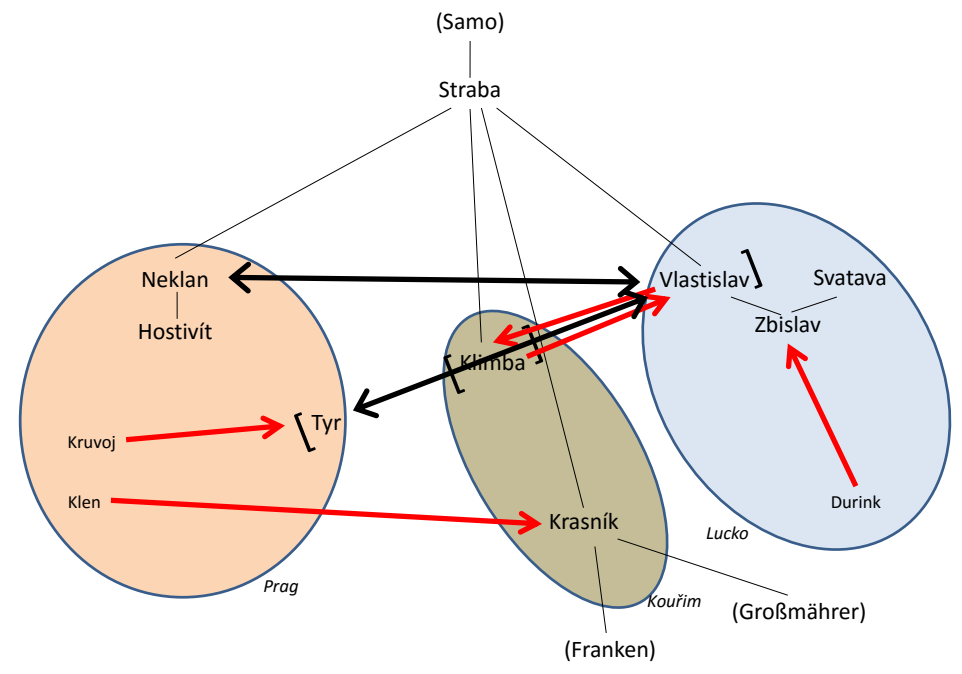

Graphik 25 - Julius Zeyer: Neklan (1893)

kämpferischer Fürst ist, der aber nicht vom Recht dazu ermächtigt ist, der Fürst von ganz Böhmen zu werden und als solcher Samos Krone zu tragen. Krasník, der Fürst von Kouřim, hat wie Vlastislav ebenfalls den Ehrgeiz, seine Macht zu vergrößern; da er aber dafür bereit ist, die Oberherrschaft der Franken anzuerkennen, wird er von seiner Urgroßmutter Straba, die um das Schicksal Böhmens besorgt ist, als Verräter verstoßen. Von Straba, die ihre Nachkommen genau beobachtet, wird Tyr von Chýnov als ein würdiger Träger der Krone Samos ausgewählt: Er ist zwar nur Vladike und dem Prager Fürsten Neklan unterstellt, er ist aber der bei weitem fähigste Kämpfer im Land. Zum militärischen Einsatz ist Tyr jedoch nur dann wirklich bereit, wenn es um die Bestrafung von Unrecht oder um die Bekämpfung der Deutschen geht; sein eigentliches Vorbild ist der Pflüger Přemysl: überdies lebt Tyr bereits nach christlichen Vorstellungen, worin einerseits seine „sittliche“ Überlegenheit, andererseits fatales Unverständnis gründen. Da Tyr ja vage von einem neuen Reich spricht, für das er eintreten möchte, wird er von Kruvoj fälschlich als Prätendent auf den Fürstenthron angesehen und erstochen. Ähnlich wie Kruvoj, nur noch grausamer, handelt auch Durink, der Vlastislavs Sohn Zbislav sadistisch tötet, um einen weiteren Rivalen Neklans auszuschalten. Neklan lässt Durink dafür mit dem Tod bestrafen. Einzig verbleibender Erbe und rechtmäßiger Anwärter auf den böhmischen Thron ist Neklans Sohn Hostivít, der schon zuvor gezeigt hat, dass es ihm um ein brüderliches, gemeinschaftliches Verhältnis geht. Während nämlich ihre Väter Neklan und Vlastislav gegeneinander Kriege führten, kommentierten Hostivít und Zbislav aus der Ferne gemeinsam das Geschehen. 
Drahomíra Vlašínová (vgl. 2003, 76) stellt in Hinblick auf die personae dramatis fest, dass keine der Hauptpersonen, die nach einem bestimmten Prinzip gezeichnet seien (der herrschsüchtige Vlastislav, der fromme Tyr, der allzu friedliebende Neklan, die um Samos Erbe besorgten Frauen Straba und Klimba), sich durchsetzt; allein Hostivít bleibt als Versprechen der Jugend übrig.

Tyr z Chýnova ist also ein mustergültiger Fürst; er ist bereit, sein Vaterland zu verteidigen und bedrängten verwandten Völkern militärisch beizustehen; eigentlich ist er aber friedliebend und möchte nur das Land veredeln. Tyrs oben zitierte Aussage, dass es die heiligste Pflicht eines jeden Tschechen sei, gegen die deutschen Mörder vorzugehen, wird im Drama niemals relativiert, sondern indirekt noch einmal bestätigt: Als nämlich Krasník seiner Urgroßmutter von dem Vorhaben erzählt, im Verein mit den Franken Vlastislav niederzukämpfen und dafür die Oberherrschaft der Franken anzuerkennen, verflucht Straba Krasník (IV, S. 105f). Die massiv antideutsche Tendenz in Neklan wird auch mit der Homophonie des Namens der mit Abstand negativsten Figur indiziert: Durink, Vlastislavs Diener, der bei seinem Erscheinen Straba sofort schaudern macht und der am Schluss Zbislav brutal ersticht, erinnert mit seinem Namen an Durynsko, das tschechische Toponym für Thüringen; die Stammesbezeichnung Durynk (,Thüringer ${ }^{c}$ ) unterscheidet sich nur grafisch, nicht phonetisch vom Namen der abstoßendsten Figur der Tragödie. Man kann gewissermaßen von einem Spiel mit der differánce der Schrift sprechen, das nationalistisch antideutsch gewendet ist. Zeyer hat die Figur des Durink freilich der Kronika česká des Václav Hájek z Libočan entnommen, wo sie Durýňk heißt und annähernd dieselben Untaten ausführt. Wie aber auch diese Chronik zahlreiche Invektiven gegen die Deutschen aufweist, so hat auch Zeyers Gestaltung der Figur eine synchronische, zeitgenössische Funktion. Diese ist wohl durch den parteiischen Eifer des sprachlich-nationalen Konvertiten Zeyer verstärkt worden.

In seinem Mörder Kruvoj findet Tyr z Chýnova ein Gegenstück in der Figurenkonzeption: Auch Kruvoj ist nicht an der Spitze der Machtrelation, er widmet sich ganz seinem Dienst und tritt an die Stelle des praktisch handlungsunfähigen Neklan, um wichtige Entscheidungen zu fällen. Auf vergleichbare Weise tritt Tyr an Neklans Stelle als Kämpfer, er kämpft ja auch in dessen Rüstung. Neklan wird also mehrfach „gedoublet“, weil er zu seiner Funktion, erster Fürst von ganz Böhmen zu sein und Samos Krone zu tragen, nur durch das Recht, nicht aber durch seine Fähigkeiten legitimiert ist. An Stelle des vom Recht legitimierten Fürsten handeln andere Personen wesentlich effizienter: Klen und Kruvoj vernichten Krasník, der mit deutscher Unterstützung Neklan gefährlich werden könnte, Tyr schlägt Vlastislav in die Flucht, Klimba konstatiert entsprechend: „Stín Neklan je, a Tyr jest knížetem!"326 (V, S. 136)

326 [Klimba:] „Neklan ist ein Schatten, und Tyr ist ein Fürst!“ 
Zeyer stellt in Neklan also die Legitimation durch (Geburts-)Recht und Qualifikation einander gegenüber: Auch Vlastislav wäre der bessere Fürst als Neklan, er ist aber durch die Geburt benachteiligt. Nun sprechen sich ja Straba und Tyr mehrfach für das geltende Recht aus, demzufolge Neklan der erste Fürst Böhmens ist; beide aber vollführen Handlungen, die ihr verbales Bekenntnis zur Legitimation durch Recht konterkariert. Tyr kämpft anstelle von Neklan erfolgreich; Straba ordnet an, dass weder Neklan noch Vlastislav, und natürlich auch keineswegs der mit den Deutschen paktierende Krasník, sondern der vorbildliche Tyr Samos Krone tragen sollen. Die konservative Rechtsposition, die Tyr und Straba ostentativ vertreten, wird durch ihr eigenes Handeln unterlaufen. Einerseits möchten sie am geltenden Recht festhalten, andererseits freilich relativieren sie die Tradition, aus der sich das Recht ja ableitet. So fragt Tyr:

\author{
Nač rozjímat o krvi otců svých, \\ a zdroj svých skutků hledat pouze v ní? \\ Být otcem velkých činů lépe jest, \\ než pouze synem velkých otců být. ${ }^{327}$ (III, S. 80)
}

Die Abwendung von der Vergangenheit und dem Streit der Väter wird auch dadurch unterstrichen, dass am blutigen Ende Samos Krone als Symbol einer großen Tradition nicht Neklan aufgesetzt wird, sondern dessen Sohn Hostivít. Schlussendlich wird die Jugend gekrönt, die alte Feindschaften nicht mehr kennt und sich in die Zukunft orientiert. Die Krone, in Neklan das begehrte Symbol eines starken böhmischen Reiches, kann dementsprechend auch mit dem Kampf um das böhmische Staatsrecht assoziiert werden, dem zentralen Thema der tschechischen Forderungen in der zweiten Hälfte des 19. Jahrhunderts. Dementsprechend erweist sich die historische Tragödie Neklan als durchsichtig in Bezug auf politische Positionen ihres Autors, bei dessen vielthematisierter poetischer Weltflucht zeitaktuelle Fragen trotzdem nicht ausgeblendet werden. ${ }^{328}$

327 [Tyr:] „Warum über das Blut der eigenen Väter nachdenken / und die Grundlage seiner Handlungen nur in diesen suchen? / Großer Taten Vater zu sein ist besser / als nur der Sohn großer Väter zu sein."

328 In einem tschechischen Aufsatz (Deutschmann 2011) habe ich diese Behauptung auch anhand einer Analyse von Zeyers pseudohistorischem Drama Doña Šanca (UA 1887, ersch. 1889) begründet. Ähnlich wie in Neklan sind dort die Zwistigkeiten zwischen Verwandten ein Grund für die Unruhen im Land - der zeitgenössische Hintergrund, der Konflikt zwischen Alttschechen und Jungtschechen in den 1870er und 1880er Jahren mag für Zeyers Ausgestaltung der Vorlage den Anlass gegeben haben. In der vieraktigen Tragödie erscheint im Vergleich zur willkürlich handelnden Königsfigur die Funktion des Statthalters aufgewertet, der mäßigend und korrigierend auf zentrale Willkür einwirkt. Dies ist wohl ebenfalls eine allegorische Bezugnahme auf einen Topos des tschechischen politischen Lebens nach der $\mathrm{Zu}$ rückweisung der sog. Fundamentalartikel 1871 durch den österreichischen Kaiser. 


\section{7. Das historische Drama im ersten Drittel des 20. Jahrhunderts}

\section{IV.7.1. Alois Jirásek: Jan Žižka. Historická hra o pèti jednánich (1903)}

[Jan Žižka. Historisches Spiel in fünf Akten; UA 4.7. 1903, publ. 1903]

Alois Jirásek hat sich in seinem umfangreichen Prosa- und Dramenwerk vor allem um eine Darstellung von wichtigen Epochen der tschechischen Geschichte - Hussitenzeit, Gegenreformation, obrozeni - bemüht, wobei ein intensives Studium historiographischer Quellen sowie die Autopsie der Schauplätze oft die Grundlage dafür lieferte. Seine populären Werke haben das historische Bewusstsein der Tschechen im 20. Jahrhundert in unvergleichlich hohem Maß geprägt (vgl. Borová 1995, 13).

Nach dem Erfolg mit historischer Erzählprosa wandte sich Jirásek auch dramatischem Schaffen zu, wobei er den historischen Stoff ähnlich wie vor ihm Stroupežnický und Vrchlický mit komödienhaften Elementen (Kolébka [1891], M. D. Rettigová [1901]) verband. Das Drama Jan Žižka stellt das Mittelstück einer historischen Dramentrilogie zur Hussitenzeit dar, deren erster - Jan Hus (1911) und dritter - Jan Roháć (1914) - Teil allerdings später entstanden sind. Mit der Trilogie hat Jirásek drei Kollektivdramen geschaffen, ein Genre, dessen wichtigster tschechischer Präzedent in Josef Kajetán Tyls Kutnohorští havíri gesehen werden kann. Jiráseks um historische Detailtreue bemühte Dramatik macht sich auch darin bemerkbar, dass die gedruckte Ausgabe von Jan Žižka für jeden Akt gesondert ein Personenverzeichnis führt. Die personae dramatis lassen sich meist bestimmten Bevölkerungsgruppen zuordnen; für bessere Übersichtlichkeit führt die untenstehende Figurenkonstellation nur ausgewählte einzelne Vertreter dieser Gruppen an.

Jirásek folgt in der Repräsentation der Ereignisse der Jahre 1421-1424 ziemlich genau der Darstellung von Palackýs tschechischer Ausgabe Déjiny národu českého (1850 - Palacký 1939/III), in deren drittem Band die Darstellung der Hussitenzeit, die Palacký als seine wichtigste Aufgabe erachtete (vgl. Kutnar/Marek 1997, 219 u. 228), sehr minutiös ausgestaltet ist. ${ }^{329}$ Die Umsetzung der sich über ca. 60 Seiten erstreckenden historiographischen Erzählung (vgl. Palacký 1939/III, 418-487) in einem Drama mit den konventionellen fünf Akten konnte nur mit mehrfachem Wechsel der Schauplätze - auch innerhalb der Akte -, längeren Erzählungen in Repliken und Botenberichten bewältigt werden.

Jan Žižka repräsentiert die religiösen Differenzen der Hussitenzeit; die Handlung ist 1521 angesiedelt, der Konflikt dreht sich um die Uneinigkeit innerhalb der tschechischen Bevölkerung, die in Hussiten und Katholiken gespalten ist und völlig

329 Palacký hatte für die Druckgenehmigung des dritten Bandes seiner Geschichte Böhmens ungleich mehr Einwänden von Seiten der Zensurbehörde zu begegnen (vgl. Píša 2015, 260f). 
unterschiedliche Vorstellungen von der politischen Führung Böhmens hat. König Sigmund wird aufgrund seines politischen und militärischen Vorgehens gegen die Hussiten von den Utraquisten vehement abgelehnt. Die Hussiten haben schon Gesandte zum litauischen Großfürsten geschickt, um diesen für das Amt des böhmischen Königs zu gewinnen. Diese Gesandten aber wurden von Sigmund gefangen genommen, der im Allgemeinen seine Gegner sehr brutal bekämpft. Der hussitische Feldherr Jan Žižka kämpft sehr erfolgreich gegen Sigmund und verhindert dessen Eroberung Prags; er wird in seinem Kampf für die Hussiten jedoch von den Auffassungsunterschieden im hussitischen Lager selbst irritiert.

Der erste Akt spielt auf der Brünner Burg, wo der von den Utraquisten abgelehnte König Sigmund auf Kosten von Pfandleihen ein lustiges Leben führt, während Böhmen von den konfessionellen Unruhen geplagt wird. Viele böhmische Adelige sind schon auf die Seite von König Sigmund gewechselt, weil sie sich davon Besitzvorteile erwarten. Sigmund möchte, dass sich die adeligen mährischen Utraquisten, die auf den snèm nach Brünn gekommen sind, von den vier Prager Artikeln distanzieren und den Laienkelch aufgeben. Um dies durchzusetzen, bedient sich Sigmund einer brutalen Einheit von Kumanen, die drohend die Säbel ziehen. So wie sich die Utraquisten über Sigmunds Verhalten beklagen, beschweren sich katholische Adelige über die Drangsalierungen, die sie in Prag von Seiten des radikalen Hussitenpriesters Želivský erfahren haben; dessen Anhänger waren wortbrüchig und hieben einem Adeligen den Kopf ab, statt ihm wie versprochen freies Geleit zu gewähren. Die mährischen Utraquisten weisen darauf hin, dass Sigmund seine Gegner hart strafe, nichts aber für seine Anhänger unternehme. Als die gefangene utraquistische Gesandtschaft sich nicht vor Sigmund verbeugt und diesen einen Feind Böhmens und der tschechischen Sprache heißt, lässt der König den utraquistischen Priester Martin aufhängen, was bei den mährischen utraquistischen Adeligen, die soeben wie gefordert unter Zwang den Prager Artikeln abschwören mussten, betroffene Reue auslöst. Ein Bote berichtet, dass Žižka, der schon umzingelt war, die Belagerung durchbrechen konnte und weiter gegen die königlichen Truppen kämpfen wird.

Der zweite Akt spielt in Prag, das von katholischen Truppen aus Ungarn und deutschen Ländern angegriffen wird, die Sigmund gerufen hat. Die Unruhe in der Stadt ist groß, die radikalen Utraquisten um Želivský haben durch ihre Forderungen bewirkt, dass sich die Adeligen zu distanzieren beginnen. So möchte der ehemalige Richter Aleš keine gemeinsame Sache mit den aufständischen Utraquisten machen. Auch die Magister der Prager Universität um Kř̀ištan treten für ein behutsames Vorgehen ein; dieser etwa bittet Želivský, nicht auch die Taboriten zu holen, weil diese seltene Bücher und Bilder zerstört haben. Křištan, immerhin ein enger Freund von Hus und mit diesem einst in Haft, wird Parteilichkeit vorgeworfen, wenn er die Zerstörungen von Seiten König Sigmunds ignoriere und sich allzu kompromissbereit zeige. Žižka wird von den Leuten um Želivský freudig empfangen, weil sich die 
Hussiten von ihm eine tatkräftige Unterstützung erwarten. Žižka mahnt zur Einigkeit gegen den Feind; alle Gegner des Laienkelchs und der tschechischen Sprache, vor allem Sigmund und der Adel, der Sigmund unterstützt, sollen entschlossen hart bekämpft werden. Als Žižka dazu aufruft, gegen den König zu ziehen, geloben dies auch die zurückhaltenderen Magister.

Der dritte Akt zeigt das Lager Sigmunds nach einer Schlacht im Jänner 1422, in der Žižka erfolgreich war. Geschlagene ungarische Soldaten nehmen den frierenden Alten und Kindern die Decken weg. Der gichtkranke Sigmund muss im Schlitten flüchten. Während der Adelige Lhotský sich für ihn opfern möchte, bereut Strážnický seinen Eid, weil er nun gegen seine Überzeugung kämpfen muss und sein Sohn sich für die Hussiten einsetzt. Als Hussiten Lhotský und Strážnický gefangen nehmen, fällt Lhotský; Václav Strážnický hingegen meint, Žižka soll über seinen Vater befinden, der am liebsten auf Seiten der Hussiten kämpfen möchte.

Unter den Utraquisten kommt es zu Unstimmigkeiten darüber, für welches politische Ziel gekämpft werden soll. Während Žižka anstelle des flüchtenden Sigmund einen polnischen König haben möchte, weil der immerhin eine slawische Sprache spreche, wollen die Taboriten überhaupt keinen König. Sigmund lässt über einen polnischen Vermittler ausrichten, dass er Žižka als Statthalter über Böhmen einsetzen würde. Dieser ist jedoch über das Angebot empört; er würde keinesfalls Verrat begehen (vgl. III/2-7). Wie ihm von Prager Bürgern berichtet wird, gehen in Prag die Leute Želivskýs gegen die Magister vor; Žižka soll für Ordnung und Disziplin sorgen und einen König einsetzen. Žižka mahnt Prag zur Eintracht und lässt - nachdem er Alte, Frauen und Kinder aus der Stadt hat führen lassen - Německý Brod niederbrennen, das sich hinter Sigmund gestellt hat.

Der vierte Akt spielt ein Jahr später (1423): In der belagerten und von Aufruhr geprüften Stadt Prag werden vom Magister Křištan drei katholische Adelige ins Rathaus geschleust, unter ihnen ist auch der gefürchtete Hussitenhasser Městecký. Es soll eine geheime Unterredung geben, zu der Křrištan die drei katholischen Adeligen beigezogen hat. Die Unruhen wurden auch genährt von der Hinrichtung von Želivský, eines Embargos gegen die Stadt und der fehlenden Königsmacht. Vaněk Pivo ist gegen die Teilnahme der Katholiken, da er meint, dass die Adeligen dann wohl bald den nach wie vor gegen Sigmund kämpfenden Žižka und das Hussitenlager Tábor angreifen werden. Závada hingegen fürchtet das Andauern der Unruhen und die Vernichtung durch die versammelten Gegner; sogar die Polen und die Litauer haben sich schon mit Sigmund verbündet, obwohl ein Litauer von den Utraquisten zum böhmischen König gewählt worden war. Městecký schickt tatsächlich einen Attentäter ins mährische Heerlager Žižkas. Dieser hat aufgrund seiner Erblindung ein umso schärferes Gehör entwickelt und kann anhand des Zitterns in der Stimme des Attentäters, der ihm aus der Bibel vorliest, Verdacht schöpfen. Der Attentäter wird gefangen genommen. Als Žižka erfährt, dass der Anschlag von Městecký geplant wurde und inzwischen in Prag tatsächlich jeweils sechs Hussiten und sechs 
Katholiken mit Vollmachten ausgestattet wurden, ist er empört und zieht gegen Prag, um es zu bestrafen. Wie an der dramatischen Ausgestaltung (Einschleichen des Attentäters in die Hütte, Vorlesen aus der Bibel - bezeichnenderweise die Erzählung von den Mordabsichten Sauls an David aus 1. Samuel 19,1-7 -, Zittern der Stimme des Mörders) unschwer zu erkennen ist, ist die Episode mit dem von Městecký ausgehenden Attentatsversuch auf Žižka Jiráseks Fiktion, die Leerstellen von Palackýs Erzählung ergänzt.

Im 1424 angesetzten fünften Aufzug leidet Prag unter der schweren Belagerung durch Žižka. Kritik an der Führung wird laut, weil mit den Katholiken paktiert wurde. Křišťan wird von der aufgebrachten Menge bedroht, der Priester Rokycana und Vaněk Pivo müssen das Volk beruhigen. Tatsächlich möchte Žižka Prag vernichten, wenn es sich nicht ergibt. Eine Prager Abordnung kann dies jedoch verhindern, indem sie Žižka überredet. Dieser ruft schließlich unter großem Jubel zum einigen Kampf gegen Sigmund auf. „Ale pro boží boj! Bojovati jej v jednotě a dokončiti jej!“330

Die nachfolgende Figurenkonstellation muss bei Jiráseks Jan Žižka noch stärker abstrahieren als in den anderen Fällen, weil ja wie gesagt Jirásek eine große Menge an personae dramatis auftreten lässt, die synekdochische Funktion für die Gruppierung haben, die sie repräsentieren. Daher wurden den Gruppierungen nur einige wichtigere Figuren zugeordnet, damit die Lektüre des Textes leichter mit der Figurenkonstellation verglichen werden kann.

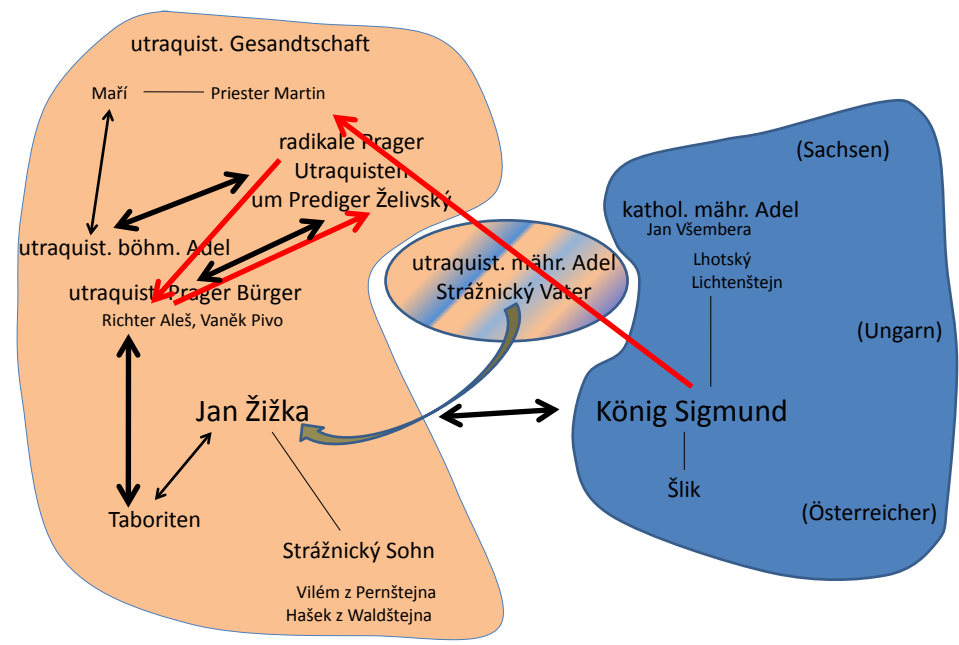

Graphik 26 - Alois Jirásek: Jan Žižka (1903)

330 [Žižka:] „Aber für einen göttlichen Kampf. Diesen in Einheit bis zum Ende kämpfen!“ 
Der Grundkonflikt ist ganz deutlich ein Konflikt zwischen Hussiten und Katholiken, wobei die Bewertungen der Konfliktparteien sehr eindeutig ausfallen. Jiráseks Sympathien sind eindeutig mit dem hussitischen Lager verbunden; die Vertreter des katholischen Lagers werden in der Regel negativ gezeichnet. König Sigmund erscheint als äußerst brutal und mitleidlos, sein Sekretär Šlik hat immerhin noch eingewisses Verständnis für die Positionen der Gegenseite, weil er die Brutalität Sigmunds beobachtet hat. Die ausländischen Verbündeten von Sigmund - Polen, Sachsen, Ungarn, Österreicher - werden in den unterschiedlichen Botenberichten ebenfalls als rücksichtslos und gewalttätig charakterisiert. Differenzierter zeichnet Jirásek das Lager der Hussiten, das in sich - die vielen Konfliktpfeile in der Figurenkonstellation zeigen dies an - stark gespalten ist. ${ }^{331}$ Nämlich sind es in erster Linie soziale Differenzen, nach denen sich die Lager bilden. Die Prager Bürger und der Adel Böhmens und Mährens zeigen sich von den Forderungen und dem Gehabe der radikalen Hussiten um den Prediger Želivský und von den Taboriten abgestoßen. Diese radikalen Gruppen verdächtigen jedoch die Adeligen und die Prager Magister einer allzu großen Kompromissbereitschaft, wodurch König Sigmund gestärkt würde. Jan Žižka, im Drama der über alle moralischen Zweifel erhabene Feldherr der Hussiten, mahnt wiederholt zur Eintracht aller Hussiten, damit der Feind effektiv bekämpft werden kann. Da er meist mit seinen Truppen unterwegs ist und seinen Hauptfeind Sigmund verfolgt, kann er in Prag keine Einheit zwischen dem einfachen Volk einerseits und den Adeligen, Magistern und Bürgern andererseits herstellen. Die chaotischen Zustände in Prag veranlassen Křištan schließlich dazu, dem bekämpften katholischen Feind paritätisch ein Mitspracherecht in Prag einzuräumen. Der Hussitenhasser Městecký verhält sich aber nun tatsächlich so, wie es die radikalen Hussiten befürchtet haben. Er plant einen Anschlag auf Žižka, der als unbesiegbarer Feldherr gilt. Žižka, der immer wieder zu Einigkeit unter den Hussiten aufgerufen hat (was zumindest momentan Wirkung zeigte), ist über die Entwicklung in Prag äußerst erbost und möchte Prag militärisch bestrafen. Letztlich muss aber selbst er einsehen, dass die Zerstörung der Stadt keinen positiven Effekt haben würde und dass die Forderung der Einigkeit der Hussiten weiterhin den Kampf gegen die Katholiken bestimmen muss.

An Jiráseks Jan Žižka fällt die Gleichsetzung von konfessioneller Distinktion und nationaler Zugehörigkeit auf. Die Katholiken werden allesamt als Sympathisanten von König Sigmund gezeichnet, der mehrfach als Hauptfeind der tschechischen Sprache benannt wird (vgl. I/14, S. 108; II/10, S. 135; III/7, S. 164). Deshalb wird ja auch nach einem anderen König gesucht, bevorzugt in Polen, denn damit wäre es immerhin ein König mit slawischer Sprache, wie Žižka meint (II/3, S. 156). Nun haben in der Hussitenzeit gewiss auch schon nationale Fragen eine Rolle ge-

331 Auch Jiráseks Darstellung der unterschiedlichen ideologischen Lager in Böhmen findet bei Palacký ihre Entsprechung (vgl. Palacký 1939/III, 249-253). 
spielt, wie der berühmte Fall des Auszugs der deutschen Magister aus der Karlsuniversität in der Folge des von Hus angestrengten Dekrets von Kutná Hora 1409 (vgl. Hoensch 1992, 139f) zeigt; Jiráseks Darstellung der Hussitenkriege übernimmt auch ideologisch sehr viel von Palackýs Déjiny národu českého, deren Grundidee ja im geschichtsbildenden Konflikt von Deutschen und Tschechen besteht (vgl. Kutnar/Marek 1997, 220 u. 225f). Wenn Palacký in seine Grundkonzeption die sprachnationalen Aspekte zwar massiv einfließen lässt, aber in der Erzählung der Ereignisse selbst keine explizit negativen Attribuierungen der handelnden Personen vornimmt, so legt Jirásek diese Urteile den personae dramatis in den Mund und schafft damit eine viel deutlichere nationale Antinomie. ${ }^{332}$ Die Hussitenbewegung erscheint im Drama Jiráseks letztlich als zentraler Bezugspunkt nationaler Spezifik: zwar gab und gibt es auch katholische Tschechen in sehr großer Zahl, in der Welt des Dramas jedoch werden alle Gegner des Hussitentums als Feinde der tschechischen Sprache oder Nation repräsentiert. Bezieht man diese Beobachtungen auf die Entstehungszeit von Jan Žižka, so erscheint die Hussitenzeit als Resonanzraum zeitgenössischer nationaler Antagonismen (vgl. Obst 1977/DčD III, 314). ${ }^{333}$

\section{IV.7.2. Jaroslav Hilbert: Falkenštejn. Hra o pèti dèjstvích (1903)}

[Falkenštejn. Spiel in fünf Akten; entst. 1901, UA 24.5. 1903, publ. 1903]

Lenka Řezníková weist in ihrer Studie über die Polemik um den „Historismus“ nach, dass die vermeintliche Geschichtsfeindlichkeit der tschechischen Moderne ein Diskursphänomen war, das aufgrund von wechselseitigem Missverstehen der Generationen und ihren Abgrenzungsversuchen entstanden ist. Tatsächlich gibt es auch in der Epoche der tschechischen Moderne, deren Beginn gemeinhin mit Josef Svatopluk Machars Polemik gegen Vítězslav Hálek (1895) angesetzt wird, genügend großes Interesse an historischen Themen und Stoffen. Nur der Umgang mit diesen habe sich verändert: Während im 19. Jahrhundert der Historismus darin bestand,

332 So bezeichnet etwa der festgenommene Hussitenpriester Martin König Sigmund als „ukrutný neprrítel království i jazyka českého“ (,grausamer Feind des böhmischen Königtums und der tschechischen Sprache'); zumal Sigmund Martin dann umgehend köpfen lässt, ist die Unterscheidung von positiven und negativen Figuren nur allzu deutlich ersichtlich.

333 Das von Jirásek im Anschluss an Jan Žižka verfasste historische Drama Gero (1904) repräsentiert den verheerenden Zug der Germanen gegen den elbslawischen Stamm der Stodoranen im 9. Jahrhundert. Nachdem die Stodoranen unter hohem Blutzoll geschlagen wurden und die Germanen ihre Herrschaft mit christlicher Missionierung etabliert haben, erklärt der heidnische slawische Priester in einer der letzten Repliken resigniert: „Zda z našich ran a naší bídy někdy prohlédnou a poznají, čím nepryítel je silný a čím jsme slabí my.“ (Dohra/7, S. 322) („Ob man vielleicht einmal aus unseren Wunden und unserer Not erkennen wird können, wodurch der Feind stark und wir schwach sind.") 
auf die vermeintliche Größe der tschechischen Kultur hinzuweisen oder das historische böhmische Staatsrecht politisch zu instrumentalisieren, hätte die Moderne ein reflexiveres Verhältnis zur Vergangenheit. Dieses bestehe u.a. in metahistorischem Denken, das in alle Genres Eingang gefunden habe, in der Öffnung der Vergangenheit für die Gegenwart, in der Tendenz zu bruchstückhaften Repräsentation und im Abgehen von nationalen Klischees (vgl. Řezníková 2004, 271-274).

Jaroslav Hilbert gilt als derjenige Dramatiker, der eine neue Auffassung von Geschichte im historischen Drama zum Ausdruck gebracht hat (vgl. LčL II/1, 177f; Řezníková 2004, 65). Ob sich die mit der Moderne einhergehenden Veränderungen des Geschichtsbewusstseins auch merklich auf die ideologische Ebene des historischen Dramas ausgewirkt haben, sollen die nachstehenden Analysen der Dramen Hilberts, Dyks und Dvořáks klären.

Nach einigen Dramen, deren Handlung in der Gegenwart angesetzt ist und die als wichtige Stücke moderner Dramatik gelten, weil sie wie Vina (1896) eine klassische Einheit von Zeit, Ort und Handlung mit psychologischen Auslotungen des Innenlebens einzelner Figuren verbinden oder wie Psanci (1900) eine Darstellung von Bohème-Dekadenz bieten, wählte Jaroslav Hilbert mit Falkenštejn einen historischen Stoff, in den er aber, wie schon die Zeitgenossen erkannten, zeitaktuelle Fragen und Stimmungen projizierte. Dies wird bereits im ,an einen ungenannten Meister" (Knap [vgl. 1926, 138] erkennt darin Jaroslav Vrchlický) gerichteten Widmungssonett der Druckausgabe von 1903 angezeigt, in dem es u.a. heißt, dass sich zwar die Zeiten geändert haben, immer aber noch das Leben im Menschen spreche und eine blutige herzzerreißende Sehnsucht immer dieselbe Sehnsucht sei. ${ }^{334}$

Wie schon vor ihm Simeon Karel Macháček in ZávišVitkovic, pán z Růže anebo Pokuta za zradu (1846) und Vítězslav Hálek in Záviš z Falkenštejna (1860) behandelt Hilbert die Zeit nach dem Tod von Přemysl Otakar II., als es zum Kampf um dessen politische Nachfolge kam. Der Konflikt zwischen der nationalen Eigenstaatlichkeit Böhmens und der Subordination unter den deutschen Einflussbereich bildet den allgemeinen Hintergrund für den dargestellten politischen Konflikt.

Das Drama Hilberts beginnt mit einer Szene auf einer Burg im Gebiet von Troppau (Opava). Man spricht von einem Schicksalsstern, der beobachtet wurde. Der sternengläubige Pförtner verbindet den Stern mit Záviš z Falkenštejna, der auf dieser Burg bei Kunhuta, der Witwe Otakars, weilt und als Prätendent auf die Königswürde gilt. Záviš wird als geheimnisvolle dunkle Gestalt dargestellt, bereits seine Erscheinung lässt den Pförtner vor Respekt zu Boden gehen. Záviš spinnt offenbar - die nächt-

334 Vgl. die Verse „Víte, jak život mluví ve člověku / a že, co jeho, nelze zalhávat. [...] však celkem vládne stará dálava - / co jedné touhy sten nám přec rve duši, / ach, stejné touhy touha krvavá!“(„Ihr wisst, wie das Leben im Menschen spricht / und dass man nicht verleugnen darf, was diesem zugehört. [...] Die Ferne jedoch beherrscht das Ganze - / wenn das Stöhnen der einen Sehnsucht uns zwar die Seele quält / ach, [so ist dies] die blutige Sehnsucht derselben Sehnsucht!“ 
liche Verabschiedung eines Boten lässt darauf schließen - von diesem Rückzugsort aus politische Ränke, wie Hroznata und Hynek z Dubé meinen, die gegenüber Kunhuta erklären, dass sie am Gedeih der böhmischen Sache interessiert sind. Kunhuta ist zutiefst betrübt: Drei Jahre zuvor ist sie auf diese Burg geflohen; wiewohl sie immer Hoffnung hatte, muss sie jetzt feststellen, dass sich trotz vieler Bittschreiben inzwischen keine einzige Hoffnung erfüllte. Ihr Sohn, der Thronfolger Václav ist immer noch in Meißen gefangen, während Rudolf von Habsburg und Oton [Otto von Brandenburg] Václavs Erbe unter sich aufzuteilen beginnen. Kunhuta beginnt auch an Záviš zu zweifeln, der ihrer Zofe als verkörperte Treue gilt. Sie war bzw. ist mit beiden Männern - Přemysl Otakar II. und Záviš - engstens verbunden und spürt, dass der verstorbene Otakar in ihr sich gegen Záviš wendet. Dieser verweist darauf, dass er seinerzeit als einziger in der Schlacht auf dem Marchfeld Otakar die Unterstützung seines Geschlechts, der Vítkovci [Witigonen] angeboten habe, die dieser zum Schaden Böhmens aber ablehnte. Záviš erklärt in der von Kunhuta geforderten Aussprache, dass er nach Prag fahren werde, wo er auf Václav warte, der mit dem Geld der Vítkovci freigekauft worden sei. Kunhutas Feinde in Prag hätten niemals das Lösegeld zahlen wollen. Kunhuta ist über diese Wendung sehr erfreut.

In Prag (1. Akt, 2. Bild) werden beim Empfang für den freigekommenen Václav die Differenzen zwischen den Parteien deutlich. Die Vítkovci (der Bruder von Záviš, Vítek z Krumlova, sowie der mit ihm verwandte Adelige Ojiŕ z Lomnice) meinen, sich durch ihre Lösegeldzahlung einen Vorteil verschafft zu haben und entsprechend nun auf den erst 13-jährigen Václav Einfluss nehmen zu können. Einst hatten sie Otakar die Unterstützung versagt und damit eine lange Krise im Land ausgelöst. Das Přemyslidenerbe sehen die beiden Nonnen Anežka und Kunhuta (die Tochter der Königin Kunhuta) durch Záviš gefährdet, den sie zurecht verdächtigen, auf die Königsmacht abzuzielen. Anežka hat einst Otakar gelobt, das Přemyslidenerbe zu bewachen. Die Gegner von Závišs, der Bischof Dobeš und Purkart, möchten diesen genau beobachten, um seinen Plänen zuvorkommen zu können. Záviš höhnt, dass nun einem Dreizehnjährigen gehuldigt werde, wobei noch vor kurzer Zeit sich niemand um den König gekümmert habe. Záviš ist sich ziemlich sicher, dass er bald die Königsmacht erringen wird, weil er wie kein anderer dafür geeignet sei. Tatsächlich ernennt Kunhuta unter Protest der Partei Purkart Záviš zum höchsten Landesverwalter, der anstelle des noch minderjährigen Václav entscheiden dürfe. Záviš hat also gleichsam königliche Vollmacht; er verkündet, dass die Besitzungen und Pflichten der Adeligen von nun an vom böhmischen König und nicht mehr von Otto von Brandenburg vergeben werden.

Im zweiten Akt wird zuerst gezeigt, dass Záviš mit Widerständen des deutschen Adels in Mähren gegen seine Herrschaft konfrontiert ist, wenngleich die Bauerschaft hinter ihm steht. Záviš möchte mit einem militärischen Aufgebot den Widerstand des Adels brechen. Václav hat inzwischen bemerkt, dass einige Entscheidungen von Záviš eigenmächtig getroffen werden, ohne dass er selbst über diese Bescheid weiß. 
Er fordert daher, umgehend gekrönt zu werden. Václav möchte zeigen, dass er auch schon tatkräftig zu handeln wisse, doch er fällt in Ohnmacht, als Záviš ihm drohend entgegentritt, weil Václav von ihm als Geste der Unterwerfung einen Handkuss verlangt hat. Záviš lässt Václav an der Strafexpedition gegen die mährischen Adeligen teilnehmen, womit er dessen Krönung hinauszögert oder sogar auf dessen Tod spekuliert. Václav selbst ist zu einfältig, um diese Absicht zu erkennen; als ihn Purkart warnt, wird er sogar zornig und möchte diesen in Haft nehmen. Nach Záviš Einschätzung stimmt Bischof Dobeš nur deswegen der Teilnahme von Václav am Feldzug zu, weil er mit Rudolf von Habsburg im Bunde stehe und dieser auch nichts dagegen hätte, wenn der einzig legitimierte Thronfolger ums Leben käme.

Im dritten Akt bestätigt sich, dass der Bischof Dobeš tatsächlich für die Vereinigung Böhmens mit den Deutschen („ve splynutí její ovčí krve se lví krví Němcư “335 - III, S. 73) eintritt und deswegen die Ermordung von Záviš für nötig erachtet. Von Purkart verlangt Dobeš die Durchführung der Ermordung; dieser zögert jedoch, als er erkennt, dass er damit nicht den eigenen Interessen bzw. der Heimat, sondern einer fremden Macht (Rudolf von Habsburg) in die Hände arbeiten würde. Als Kunhuta von einem Boten erfährt, dass Václav mit den Vítkovci gegen die deutschen Mährer erfolgreich war, entschließt sie sich, Záviš offiziell zu ehelichen, womit der fähigste Kopf des Landes die Krone haben würde. Als Anežka von den Heiratsplänen erfährt, läutet sie Alarm, wobei sie den Tod findet. Aus dem Dramentext geht nicht klar hervor, warum sie beim Läuten stirbt. Knap (vgl. 1926, 148) ist der Auffassung, das die wohl schon alte Anežka vor Aufregung stirbt; dramaturgisch plausibler ist aber, dass sie - wohl auf Geheiß von Záviš - ermordet wird. Kunhuta trifft auf einen Boten mit einem Brief von Záviš an dessen Bruder Vítek, aus dem klar hervorgeht, dass es Záviš um die Königsmacht geht. Dies erkennend, ersticht Kunhuta kaltblütig den Boten. Sie beginnt nun, gegen Záviš zu handeln, so lässt sie etwa durch List die Vítkovci in Mähren die Stellung halten, damit diese ihm nicht zu Hilfe eilen können. Gegenüber Záviš deutet sie an, dass sie ein Kind von ihm erwarte und nun heiraten möchte. Dieser ist etwas skeptisch; er erinnert sich daran, dass ihm Kunhuta vom Traum erzählt hat, in dem sich Otakar gegen ihn ausspricht, er lässt sich aber von dem lockenden Angebot umgarnen. Auch meint er, dass Kunhuta sich für ihn entscheiden werde, weil er die Geschehnisse kontrolliere.

[Záviš:] Zrovna hmotně přesunuje se království do mne, a vše, co jest na majestátu podstaty krásy, vidím zase zastupováno tebou. Beze mne byla jsi jen vdovou, kterou smýkal osud, proti mně budeš ničím, jež ke všemu zdrtím, ale se mnou jsi králová [sic!]. ${ }^{336}$ (III, S. 94)

335 [Bischof Dobeš:] „Für die Vereinigung ihres [der Tschechen] Schafsblutes mit dem Löwenblut der Deutschen.“

336 [Záviš:] „Gleichsam spürbar überträgt sich das Königtum auf mich, und alles, was die Herrlichkeit der Majestät ausmacht, sehe ich durch dich verkörpert. Ohne mich warst du nur 
Kunhuta wartet aber nur solange mit der Rache, bis sie Václav in Sicherheit weiß.

Im vierten Akt erfolgt die Gefangennahme von Záviš im Zuge der vermeintlichen Hochzeitsvorbereitungen. Als Záviš bei der Trauungszeremonie vor Kunhuta kniet, lässt sie ihn gefangen nehmen. Dobeš nutzt die Chance, da Záviš nun handlungsunfähig ist, um seinerseits die Direktiven zu geben. So möchte er Václav mit der Tochter Rudolfs verheiraten; Václav erkennt, dass über ihn bestimmt wird und dass er eigentlich kein König ist: „Moc královská nejsem, jenom její poslední

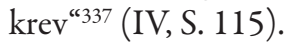

Im fünften Akt, der zwei Jahre nach den zuvor geschilderten Ereignissen angesetzt ist, wird Záviš in Gefangenenschaft gezeigt. Er meint in einem langen Monolog, der Knap (vgl. 1926, 149f) an romantische byroneske Kerkerszenen erinnert, er sei nicht wie ein König gebrochen worden, der noch sterbend Respekt einflößt, von ihm bleibe nichts übrig. Seiner Einschätzung nach werden aufgrund der Aktivitäten von Dobeš die Nachbarn Böhmens das Land kontrollieren. Er sieht ein, dass sein Versuch, sich Václavs mittels der mährischen Expedition zu entledigen, ein schwerer Fehler war, weil er damit Kunhuta gegen sich aufgebracht hat. Kunhuta besucht Záviš im Gefängnis, sie ist gebrochen, weil mittlerweile Dobeš Böhmen kontrolliert und Václav gegen diesen machtlos ist. Dieser wurde inzwischen mit der Tochter Rudolfs verlobt; die Heirat komme aber nur unter der Bedingung zustande, dass in Böhmen Einigkeit hergestellt wird. Kunhuta erzählt, sie habe von Záviš einen Sohn geboren, der ihr aber genommen und nach Polen gebracht wurde. Weil sich die Vítkovci trotzig auf die Burgen zurückgezogen haben und die Freilassung von Záviš verlangen, ist die Lage in Böhmen angespannt und Rudolfs Bedingungen für die Hochzeit von Václav können nicht erfüllt werden. Kunhuta möchte, dass Záviš seine Verwandten dazu bewegt, die Königsmacht Václavs anzuerkennen. Er lehnt dies brüsk ab, weil Kunhuta ihn ja schon einmal wegen Václav verraten hat.

[Záviš:] Mne jsi obětovala za něho a nyní padneme všichni. Tvá jest práce skácení Čech a zadání jich moci cizí. Otakarova velikost počala, tvá slepota dokonala. Já byl záchranou, ale já byl sklán. ${ }^{338}$ (V, S. 124)

Die schweren Vorwürfe bringen der zutiefst betrübten Kunhuta, die erkennt, dass alles verspielt ist, weil ohne Záviš, den sie für Václav geopfert hat, dieser keine

eine Witwe, der das Schicksal mitgespielt hat, gegen mich bist du ein Nichts, das ich sogar zermalme, mit mir aber bist du königlich.“

337 [Václav:] „Ich bin nicht die Königsmacht, sondern nur von deren letztem Blut.“

338 [Záviš:] „Mich hast du für ihn [Václav] geopfert und nun fallen wir alle. Dein Verdienst ist es, Böhmen zu Fall gebracht und einer fremden Macht ausgefolgt zu haben. Otakars Größenwahn hat es begonnen, deine Blindheit hat es zu Ende geführt. Ich war eine Rettung, doch ich wurde beseitigt." 
Chance gegenüber Dobeš hat, den Tod. Záviš verabschiedet sich von ihr mit der Erklärung, er habe sie geliebt, wie Männer lieben.

Der gefesselte Záviš wird von Dobeš dazu verwendet, um die Vítkovci zur Aufgabe des Widerstands zu bewegen. Dobeš möchte Böhmen in die Hände Rudolfs von Habsburg legen.

[Dobeš:] Ó, přijměte jej, beřte, Habsburci!

Vy všichni prríští rodu potomci,

nepustite, držte, co vám osud dal,

leč množte! Jaká velemocná ř́šs!

Jak já ji zřím, jest středem Evropy!

Jest moc, jest síla, velkost, osudnost

a rod, jenž nad ní, jeden z největších!

Vy štastní pak, ó muži při vládě,

jimž bude jednou v dálkách století

ŕíditi tu slavnou, mocnou lod' -

oh, moji lod' -

vzpomeňte mne pak vděčně v myšlence,

že, nebýt mne, tu svět váš vrcholil

by v kalužině české ... ${ }^{339}$ (V, S. 129f)

Záviš ruft seinem Bruder Vítek z Krumlova, dem Herren der letzten „trutzenden“ Burg der Vítkovci zu, weiter Widerstand zu leisten, da sein Leben ohnehin verwirkt sei; nur über seine Leiche könne Böhmen seine Selbstständigkeit aufgeben. Nach diesem Entschluss, trotzig den Tod anzunehmen und keinerlei Handlung zu unternehmen, die dem politischen Gegner in die Hände spielt, wird Záviš auf Befehl von Dobeš hingerichtet. Janovič, ein eifriger Anhänger von Záviš, erdolcht aber unmittelbar darauf Dobeš mit der Erklärung, dass man mit ihm nicht anders als meuchlerisch verfahren könne. Záviš findet also insofern ein tragisches Ende im klassischen Sinn, als das von ihm vertretene Prinzip - das Einstehen für die Unabhängigkeit Böhmens - durch seinen Tod nicht negiert, sondern bestätigt wird (vgl. Knap 1926, 153; Lukács 1965, 118f u. 146).

339 [Dobeš:] „So nehmt es [Böhmen], nehmt es, Habsburger! / Ihr künftigen Nachkommen / lasst nicht aus, was das Schicksal Euch gegeben hat / sondern vermehrt es! Welch großmächtiges Reich! / So wie ich es sehe, ist es die Mitte Europas! Es ist eine Macht, eine Kraft, Größe, Schicksal / und das Geschlecht, das über es herrscht, ist eines der größten! / Ihr glücklichen Männer der Regierung, die ihr in fernen Jahrhunderten / einmal das große, ruhmvolle Schiff lenken werdet / oh, mein Schiff - / erinnert euch meiner mit dem dankbaren Gedanken, / dass ohne mich diese eure Welt / im tschechischen Dreck geendet hätte ...!“ 
Was daher in dem tragischen Ausgange aufgehoben wird, ist nur die einseitige Besonderheit, welche sich dieser Harmonie nicht zu fügen vermocht hatte und sich nun in der Tragik ihres Handelns, kann sie von sich selbst und ihrem Vorhaben nicht ablassen, ihrer ganzen Totalität nach dem Untergange preisgegeben oder sich wenigstens genötigt sieht, auf die Durchführung ihres Zwecks, wenn sie es vermag, zu resignieren. (Hegel XV/524)

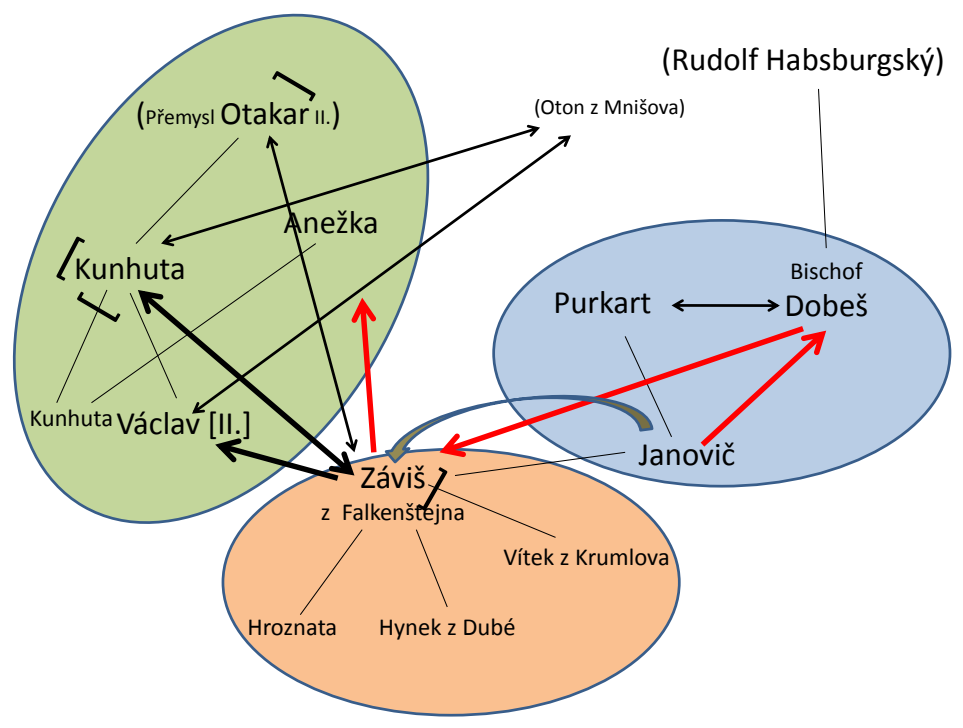

Graphik 27 - Jaroslav Hilbert: Falkenštejn (1903)

Die Figurenkonstellation zeigt die drei Hauptparteien, denen ein bestimmtes politisches Programm zugeschrieben werden kann. Das Přemyslidenerbe ist aufgrund der Jugend des Thronfolgers Václav gefährdet, was Anežka als deren strengste Hüterin weiß. Záviš als Gemahl Kunhutas und interimistischer Vertreter Václavs vertritt am entschiedendsten die Auffassung, dass Böhmen stark und unabhängig sein müsse („[...] jen já dnes znamenám svébytí Čech.“340 - III, S. 71), während der Bischof Dobeš die Eingliederung Böhmens in das Habsburger Reich vertritt.

Wie schon Macháček und Hálek zeichnet auch Hilbert mit dem Protagonisten Záviš eine Figur, deren Problem darin besteht, zwar alle Fähigkeiten zu besitzen, um Böhmen aus der schwierigen Situation nach dem Tod von Přemysl Otakar II. herauszuführen, die dazu aber rechtlich nicht legitimiert ist. Um den politisch überlegenen Záviš als König zu verhindern, lassen ihn seine Gegner hinrichten. Dass Hilberts Falkenštejn als erstes modernes historisches Drama der tschechischen Tra-

340 [Záviš:] „Nur ich stehe heute für die Eigenständigkeit Böhmens.“ 
dition gilt, wie es im Programmheft zu einer Aufführung des Národní divadlo heißt (vgl. Král 1992b, 10), kann einerseits der im Anschluss auf die Analyse von Hilberts Version folgende Vergleich mit den Dramen Macháčeks und Háleks zeigen, andererseits aber auch die Analyse der im Drama dargestellten Widersprüche der Hauptfiguren Záviš und Kunhuta. Dramentechnisch auffällig sind in Falkenštejn die großen Monologe, in denen die Hauptfiguren ihre Visionen und Wünsche zum Ausdruck bringen und die eine Tendenz zum Lyrismus erkennen lassen. Wie die zeitgenössische Kritik bereits feststellte (vgl. Fischer 1919, 117; Knap 1926, 150f), kommt mit dieser Forcierung des Monologs der Widerspruch zwischen individuellen Bestrebungen und den „objektiven“ Bedingungen bzw. den diesen Bestrebungen entgegenstehenden Umständen deutlicher zur Geltung. Andererseits ist der für die Fragestellung dieser Arbeit relevante Handlungszusammenhang nicht immer ganz deutlich; er stützt sich auf Verknüpfungen, die durch nicht motivierte Zufälle wie dem Abfangen eines Boten hergestellt werden.

Die Ambitionen von Záviš, der sich auf sein Geschlecht, die Vítkovci stützt, sind eine wichtige Hilfe bei der Stärkung des Landes. Er jedoch will die Liebe Kunhutas dafür nützen, selbst König zu werden und die Přemyslidendynastie abzulösen. Der dynastisch nicht legitimierte Záviš gilt im Stück als die einzige politische Kraft, die Böhmen dauerhaft souverän halten will, während Bischof Dobeš mit abgefeimten Mitteln die Habsburgerherrschaft über Böhmen anstrebt. Wenngleich Hilbert alle Parteigänger für fremden Einfluss auf Böhmen gänzlich unsympathisch zeichnet und damit ein konstrastreiches Bild der nationalen Antagonismen zwischen Tschechen und Deutschen/Österreichern schafft, besteht die Originalität seines Werkes darin, dass er in Záviš und Kunhuta ein Paar zeigt, dessen Bindung aneinander tragisch ist: Kunhuta weiß um die einzigartigen politischen Qualitäten von Záviš, der es auch vermag, ihr Václav zurückzubringen; als sie jedoch erkennen muss, dass Záviš über die Verbindung mit ihr die böhmische Königsmacht anstrebt und den schwachen und naiven Thronfolger ausschalten würde (wie er auch vor blutiger Gewalt nicht zurückschreckt, wenn er auf Widerstand trifft), verstößt sie den Geliebten erbittert und verbündet sich mit dessen Gegnern, die aber ihrerseits über Václav bestimmen und ihn klein halten. Zumal diese Gegner nur eigene, noch dazu tschechenfeindliche politische Ziele verfolgen, sieht Kunhuta keinen anderen Ausweg als den Tod. Indem sie Záviš verstößt, will sie ihren Sohn retten, doch ist nur Záviš in der Lage, den Sohn und mit ihm Böhmen vor der Aufgabe der Selbstständigkeit zu bewahren. Auch Záviš nimmt den Tod auf sich, weil er keinerlei Zugeständnisse an die habsburgerfreundliche Politik seiner Gegner machen möchte.

In Falkenstejn impliziert erfolgreiches politisches Handeln auch die Anwendung moralisch fragwürdiger Mittel. Der Titelheld, der allein in der Lage wäre, sich für ein souveränes Böhmen einzusetzen, ist zu Mord an Rivalen und Gegnern fähig, so beseitigt er kaltblütig die Äbtin Anežka, als diese angesichts des Machtstrebens 
von Záviš die Alarmglocke läutet. Kunhuta ihrerseits ersticht den Boten, von dem sie den Brief zu lesen bekommt, aus dem hervorgeht, dass Záviš tatsächlich nach der Königsmacht strebt und nicht nur gänzlich lautere und uneigennützige politische Absichten hegt, sondern offenbar auch beabsichtigt, ihren Sohn Václav zu Tode kommen zu lassen. Záviš von Falkenštejns Fall erfolgt zwar aufgrund der Absicht, den legitimen Thronfolger zu beseitigen, aber weil er nicht böhmischer König wird, gerät Böhmen unter den Einfluss der Habsburger.

Die Eingliederung Böhmens in ein großes Habsburgerreich ist ja erklärtes Ziel des Bischofs Dobeš, wie Purkart erkennen muss, den Dobeš auffordert, Záviš zu beseitigen. Purkarts Replik lautet:

„Habsburg - Nikdo jiný - Habsburg. Čechy císařovi, starý český stolec cizinci ... Po samostatnosti, po vlastní vládě ... po nás.“ ${ }^{341}$ (III/1, S. 76f)

Wie aus einer Bemerkung Otokar Fischers (vgl. 1919, 9) hervorgeht, griff die Zensur an dieser Stelle ein und strich diese Replik, die als beispielhaft für den benjaminschen „Tigersprung in die Vergangenheit“ gelten kann, der sich genau dasjenige aus der Vergangenheit holt, was für den aktuellen Zweck - der in diesem Fall als „antikolonial“ bezeichnet werden kann - nützlich erscheint. Die repräsentierten Ereignisse geschahen ja Ende des 13. Jahrhunderts, also gute 200 Jahre vor dem Beginn der Habsburgerherrschaft über Böhmen (1526). Zwar erhoben nach dem Tod von Přemysl Otakar II. (1278) Rudolf von Habsburg wie auch Otto V. von Brandenburg Ansprüche auf Mähren und Böhmen, eine Etablierung der Habsburger in Böhmen erfolgte damals aber noch nicht (vgl. Hoensch 1992, 104-107). Die zitierte Replik Purkarts war von Hilbert vorwiegend auf die zeitgenössischen böhmischen Verhältnisse gemünzt, wie vom Zensor erkannt wurde. Otokar Fischer $(1919,97)$ bemerkt den depräsentierenden Zug des Dramas: „Učiniv Falkenštejna hlasatelem své básnické ctižádosti, Hilbert přihlížel v historickém ději k soudobým strázním své vlasti, jejíž jednotlivé politické programy symbolicky a náznakově vložil do minulosti. “342 Hilbert hat selbst in einer programmatischen Schrift „O dramatu“ [Über das Drama, 1914] seine Einstellung zum historischen Drama wie folgt charakterisiert:

Byt to znělo i paradoxně, tož přece jest nám postaviti axiom, že to co v historickém dramatu nás nejsilněji jímá, jest prvek př́tomnosti, který se jeví již ve volbě látky a jenž živým svým

341 [Purkart:] „Habsburg - niemand anders. Habsburg. Böhmen an den Kaiser. Der alte böhmische Thron an einen Fremden. Aus ist es dann mit der Selbstständigkeit, der eigenen Regierung ... aus ist es mit uns."

342 „Indem er Falkenštejn zum Sprachrohr seines dichterischen Ehrgeizes machte, legte Hilbert sein Augenmerk auf die gegenwärtigen Leiden seiner Heimat, deren politische Programme er symbolisch und anspielend in die Vergangenheit verlegte." 
dechem, at chceme či nechceme, prostupuje a bude vždy prostupovati každou naši snahu po žití v dobách, jichž nejsme dětmi. ${ }^{343}$ (Hilbert 1941, 30)

Diese Einstellung, so eine der Prämissen der vorliegenden Arbeit, ist aber keine idiosynkratische Präferenz des Dramatikers Hilbert, sondern gattungsimmanenter Zug des historischen Dramas. Wie sich die Zeitbezüge des Stoffes um Záviš von Falkenštejns Usurpationsvorhaben verändert haben, soll im Folgenden in einem kurzen Vergleich der Dramen Macháčeks, Háleks und Hilberts gezeigt werden, die alle drei sich - auf jeweils unterschiedliche Weise - ziemlich weit von der historiographischen Version der Ereignisse entfernen (vgl. Knap 1926, 163-166).

\section{IV.7.3. Ein Vergleich der Usurpationsdramen um Záviš von Falkenštejn und Otokar Fischers Přremyslovci. Hra o pèti dèjstvích (1918)}

[Die Přemysliden. Spiel in fünf Akten; UA 26.4. 1918, publ. 1918]

Záviš von Falkenštejn ist als Figur eines historischen Dramas zuallererst nicht in der tschechischen, sondern in der österreichischen Literatur gestaltet worden. In Franz Grillparzers fünfaktigem Trauerspiel König Ottokars Glück und Ende (1825), das als eine depräsentierende Panegyrik der Habsburgerherrschaft gelesen werden kann (vgl. Höhne 2008, 40-45), ist der Rosenberger Zawisch derjenige, der Ottokar wiederholt täuscht und ihn so zu Fall bringt.

Bei Macháček (1846) und Hilbert (1903) ist Záviš von der Figur des Intriganten zum tragischen Helden geworden, der zwar den Tod findet, jedoch leben die von ihm vertretenen Prinzipien als Ideen weiter. In beiden Dramen erscheint Záviš als ehrgeiziger und fähiger Politiker, dessen Manko vor allem darin besteht, keine Legitimation für die Königsmacht zu haben. Er sucht daher, über die Heirat mit Otakárs Witwe diese zu erlangen. Bei Macháček ist Záviš, sieht man von der frühen Eheschließung (während Otakár noch aufgebahrt ist) ab, weitgehend positiv gezeichnet; sein Interesse gilt Böhmen, für das er sich einsetzt. Hingegen ist Hilberts Záviš in seinem Willen zur Macht weitaus „dunkler“. Als hervorragender Stratege weiß er um die Mittel, die Macht zu erlangen, dabei allerdings plant er den Tod von Václav ein. Das bei Macháček und Hálek deutliche Motiv des Verrats, das in beiden Stücken Záviš mit einigen anderen Figuren verbindet, fehlt augenscheinlich bei Hilbert, dessen Konfliktgestaltung sich auf das zentrale Paar Kunhuta-Záviš konzentriert, wodurch die psychologische Komplexität der beiden Personen grö-

343 „Auch wenn es paradox anmutet, können wir dennoch als Axiom postulieren, dass dasjenige, was uns für das historische Drama am stärksten einnimmt, sein Anteil an der Gegenwart ist, der sich bereits in der Stoffwahl äußert und der mit seinem erfrischenden Zug, ob wir dies wollen oder nicht, jeden unserer Versuche durchdringt und durchdringen wird, in Zeiten zu leben, deren Kinder wir nicht sind.“ 
ßer wird als in den Dramen von Macháček und Hálek. Im Verhältnis zu Kunhuta erweist sich letztlich das Machtstreben als zerstörerisch für ihn selbst. Weil sie seine Absichten erfährt, lässt sie ihn gefangen nehmen.

Deutlich anders hingegen ist Háleks Záviš: Hier tötet Záviš Kunhuta, weil sie sich auch Václav zugehörig fühlt und er ihrer überdrüssig geworden ist. Sein Handeln gilt weniger dem Land als der Befriedigung des eigenen Ehrgeizes. Sein Machtstreben scheitert letztlich aber an seinem Diener Ruperto, den Hálek als fiktive Figur neben die historischen Figuren gestellt hat. In der ideologischen Analyse kommt dieser Figur eine zentrale Bedeutung zu: Ruperto nämlich entspricht weitgehend Záviš in seinen Eigenschaften und seiner Funktion als Diener, der bloß die Befehle seines Herren ausführt. Er kehrt sich aber gegen Záviš und löst sich somit aus seiner instrumentellen Funktion, um seinerseits die Rolle des handlungstragenden „Herrn“ zu übernehmen. Während Záviš in der Verwirklichung seiner Usurpationsgedanken scheitert, dominiert letztlich Ruperto über seinen Herrn. Er kann demnach als erfolgreicher Usurpator gelten; wenn er auch durch das Schwert von Záviš stirbt, so entspricht er damit nur dem tragischen Helden, dessen Leben zwar endet, dessen Idee aber weiterlebt.

Um die politische Aussage von Háleks Drama zu erkennen, genügt es also nicht, allein die Titelfigur zu betrachten und mit Macháčeks Gestaltung von Záviš zu vergleichen. Damit gelangt man nur, wie etwa Klosová, zur Feststellung, dass sich Macháček mit seinem Titelhelden identifiziert, während Hálek eine kritisch-reservierte Haltung einnimmt (vgl. Klosová 1977b/DčD III, 28). Auch Knap (1926, 158-161) sieht vor allem in Záviš einen Klon von Shakespeares Richard III., Ruperto wird von ihm gar nicht beachtet.

Im späten obrození ist Macháčeks Záviš also eine weitgehend positive Figur, bei Hálek eine sehr negative, die allerdings in Ruperto ein Double hat, das die Usurpation insofern durchführt, als sie über Záviš dominiert und zur entscheidenden handlungstragenden Figur sich wandelt; bei Hilbert ist Záviš psychologisch gezeichnet, er unterscheidet sich in seinen charakterlichen sowie politischen Fähigkeiten deutlich von seiner Umwelt. In Knaps Vergleich der drei wichtigsten Dramen um Záviš von Falkenštejn - es gibt auch noch zwei kleine, in den 1820er Jahren entstandene Fragmente von Dramen um Záviš von František Turinský sowie František Zavřels Drama Král Přemysl Otakar Druhý (1921), in dem Otakar der für Zavřel typische energische Held ist und Záviš sein intriganter, aber durchschnittlicher Gegenspieler - wird die Person des Záviš recht zutreffend bei Macháček als Idealist, bei Hálek als skrupelloser Spekulant und bei Hilbert als moderner Diplomat charakterisiert (vgl. Knap 1926, 160). Macháček gestaltete einen fast noch unschuldigen Záviš, Hálek einen über Leichen gehenden Machtmenschen, Hilbert einen zur Machtergreifung entschlossenen Politiker.

Nun kann zwar der Protagonist sehr oft - insbesonders in diesen drei Dramen als integrale Bezugsfigur für die Analyse gelten; wie anhand von Háleks Drama aber 
deutlich wurde, ist dies aber nicht immer ausreichend, wenn man die politische Tendenz bzw. den Zeitbezug bestimmen möchte. Hier gilt es, auch noch andere Aspekte zu berücksichtigen. Unter Bezugnahme auf die oben vorgenommene Analyse kann Macháčeks Version als Tragödie der Usurpation gelten, bei der die Frage der Herrschaftslegitimierung anhand der Hauptfigur zentral wird. An ihr wird der Konflikt von Legitimierung durch Recht und jener durch Befähigung vorgeführt, zwar noch nach dem ersten Prinzip entschieden, das alternative Prinzip erscheint aber durchaus attraktiv. Bei Hálek ist Záviš zwar die machtgierige Titelfigur, Ruperto jedoch vermag Záviš auf der Grundlage des geltenden Rechts Einhalt zu gebieten; Ruperto kann somit als Personifikation einer konstitutionellen Monarchie gelten, in der der Monarch zwar "formal“ noch auf seinem Thron sitzt, nichtadelige Personen aber die Geschicke des Landes bestimmen. Und Hilbert veranschaulicht an Záviš die Entschlossenheit zur Herrschaft in Böhmen; aufgrund des Festhaltens an der traditionellen dynastischen Erbfolgeregelung, aufgrund der berechtigten Sorge von Kunhuta um ihren Sohn und nicht zuletzt auch aufgrund der für die Habsburger intrigierenden Partei scheitert Záviš tragisch.

Otokar Fischer, der sehr genaue Beobachtungen zu Hilberts Falkenštejn in seiner Schrift K Dramatu (1919) festgehalten hat, veröffentlichte noch während des Ersten Weltkriegs, im März 1918, im Verlag Politika sein Drama Přemyslovci, das am 26. April 1918 im Národní divadlo uraufgeführt wurde. Für die Handlung wurde der Konflikt um den Thron um eine Generation verschoben: Nicht mehr der gewiefte Záviš und der jugendliche Václav II. rivalisieren, bei Fischer ist der erwachsene Václav II. ein machtbewusster böhmischer König, der weiß, dass ihm die Ermordung Záviš von Falkenštejn zum Verhängnis werden kann. Die Königskrone erscheint als umkämpftes Machtsymbol, dessen Wert von den Figuren ganz unterschiedlich bemessen wird: als Zeichen des Gottesgnadentums von Václav II., als Narrenkappe von seinem Sohn Václav III., der an der Schwierigkeit zu regieren scheitert und der auch nicht die Intrigen um sich erkennt. Václav III. ist keineswegs sonderlich befähigt zu regieren, das Gottesgnadentum wird von ihm selbst angezweifelt; als er nach dem Tod seines Vaters reumütig dessen Erbe antreten möchte, entschließen sich seine Gegner zum Mord.

Das für den Závišs-Stoff zentrale Usurpationsthema wird in einem parallelen Vater-Sohn-Konflikt zwischen Petr z Lomu und seinem Sohn Štěpán entwickelt, mit dem Fischer die geschichtliche Überlieferung geschickt um Fiktion erweitert. Štěpán soll, wie Petr z Lomu behauptet, der vor der Ermordung gerettete Sohn Záviš von Falkenštejn sein; ihm gebühre damit die Krone Ungarns. Štěpán jedoch ist der Freund und Ratgeber von Václav III., er möchte gänzlich loyal bleiben und sieht Václav als rechtmäßigen Herrscher an. Bei Petr z Lomu ist ein Übergang des Denkens von Rechtsanspruch, der in der Vergangenheit begründet liegt, zu einem naturrechtlichen Denken zu bemerken. Zuerst ist er der Auffassung, Štěpán habe aufgrund seiner Abstammung von Záviš Anspruch auf die ungarische Krone, spä- 
ter allerdings meint er, das Recht der Könige stehe dem Recht gegenüber, Könige zu töten. „Králi jsou a proto v právu. Nám však právo dí, že vyhladit je nutno“344 (III, S. 78). Könige hätten sich die Macht durch Gewalt genommen und sie dem Volk geraubt: „Smí lhát / a loupit, kdo se králem zve? Když v tvář / tě udeří, rci dík! Když korunu, / jež vládu dává, uloupí, necht́ lid / mu okradený jásá vstř̌ic “345 (III, S. 79f).

Gegenüber dieser Position hält Štěpán an der formalen Begründung von Herrschaft fest. Er erwidert auf seines Vaters naturrechtliche revolutionäre Forderung mit dem Verweis auf das Gottesgnadentum, das für Ordnung sorge; die Tötung des Königs würde nur zu Chaos führen. Štěpáns Position gibt seiner Umgebung Anlass zu spöttischen Bemerkungen über das Erbkönigtum. Das Drama Fischers endet mit der Ermordung von Václav III. durch Petr z Lomu, der sich zum Vollstrecker des göttlichen Willens erklärt, seinerseits damit also wieder einen transzendenten Bezug in das politische Handeln einführt, obwohl er mit dem Gottesgnadentum brechen möchte. Diese Ironie gegenüber der Legitimation von Politik scheint aber eher unintendiert zu sein, da sie im Drama nicht weiter ausgeführt wird. Vielleicht verdankt sie sich auch den spezifischen Umständen der Entstehungszeit des Dramas. Es wurde wohl schon im Jahr 1917 geschrieben und 1918 ein halbes Jahr vor der Kapitulation der Mittelmächte zur Uraufführung gebracht: Die Bezüge auf die zeitgenössische Situation sind offenbar so weit verdreht, dass - wie bei den meisten historischen Dramen - keine eindeutigen Entsprechungen zu erkennen sind: Zum einen ist mit dem Bezug auf das Ende der Přemysliden wohl der Untergang des Habsburger Dynastie mitgemeint (vgl. Burget 2014, 59), zum anderen werden gerade die beiden letzten Vertreter der Přemysliden in ihrem Einsatz für Böhmen gezeigt; in ihrem Umfeld und unter ihren Widersachern finden sich einige, die auf einen Ausgleich mit dem Habsburger König Albrecht hoffen. Jedenfalls aber markiert Fischers Drama das Ende einer Epoche: Das einer mittelalterlichen Chronik entnommene Motto des Dramas „Kdo krále zabil, nevím. Bůh to ví ${ }^{\prime \prime 346}$ sowie die oben erwähnte Berufung des Königsmörders auf Gott zeigen aber an, dass das Ende einer transzendent legitimierten Politik damit noch nicht gekommen ist.

344 [Petr z Lomu:] „Sie sind Könige und deswegen im Recht. Uns hingegen sagt das Recht, dass es nötig ist, sie auszumerzen."

345 [Petr z Lomu:] „Darf denn der, / der sich König nennt, lügen und rauben? Wenn er dir / ins Gesicht schlägt, sag Danke! Wenn er die Krone, / die Macht verleiht, raubt, dann soll das beraubte Volk ihm entgegen jubeln.“

346 „Wer den König getötet hat, weiß ich nicht. Gott weiß es.“ 


\section{IV.7.4. Jaroslav Hilbert: Česká komedie. Válečná episoda z roku 1866 o jednom dèjstvi (1908)}

[Tschechische (bzw. böhmische) Komödie; entst. 1907, ersch. 1908, UA 28.01. 1909]

Der Einakter Česká komedie verbindet mit einer Handlung in der jüngeren Vergangenheit - sie ist im Österreichisch-Preußischen Krieg des Jahres 1866 angesetzt, genauer gesagt nach der Schlacht bei Česká Skalice am 28. Juni 1866 und vor der Schlacht bei Sviništany - eine Kritik an der Situation der Tschechen innerhalb des politischen Gefüges der Habsburgermonarchie. Während Falkenštejn jedoch geschichtliche Ereignisse in einer sehr freien Form auf der Höhe der herrschenden und entscheidenden Figuren darstellt, fokussiert die Česká komedie die Ebene der kleinen Soldaten. Im Figurenverzeichnis sind von dreizehn angeführten Figuren acht "prostý “ - einfache Soldaten, die teilweise ihr Leben für die Entscheidungen der Herrschenden zu lassen haben.

Der Einakter zeigt einerseits gleichsam naturalistisch die Schrecken des Krieges - Schlachtgeschehen bildet ständig den Hintergrund -, andererseits aber ist seine Anlage symbolisch. Die ganze Handlung spielt auf einem Dorffriedhof, der gegen Ende zum Ausgangspunkt einer „,nationalen“ Erhebung wird. Die tschechischen Soldaten, die sich auf dem Dorffriedhof einfinden, sind auf dem Rückzug, der in den Führungsfehlern in der österreichischen Armee - es werden falsche Befehle gegeben und die Offiziere lassen die einfachen Soldaten kämpfen, während sie selbst Wein trinken - seine Ursachen hat. Ein totaler Rückzug würde bedeuten, dass die Heimat den Preußen in die Hände fällt, was das patriotische Gefühl der auf dem Friedhof versammelten jungen Soldaten aber nicht zulassen möchte. Gegen die verständlichen Fluchtgedanken lehnt sich ein harter Kern von fünf Soldaten auf: sie missachten die Befehle des österreichischen Vorgesetzten Ebner, der zu Rückzug und Disziplin auffordert, und fesseln diesen sogar. Gegen alle Aussicht und ohne jede Verbindung zu ihren Einheiten nehmen die fünf Tschechen todesmutig den Kampf gegen eine auf dem Vormarsch befindliche preußische Einheit auf und können sich tatsächlich - zumindest in diesem Scharmützel - behaupten. Die politische Botschaft des Stücks scheint zu sein, dass ein starkes Heimatgefühl einen unbedingten Einsatz verlangt; die Mutter Heimat wird mit der biologischen Mutter gleichgesetzt (vgl. S. 41). Die österreichischen Offiziere haben dieses Heimatgefühl nicht (auch nicht der jüdische Soldat Levinský); sie begegnen der Entschlossenheit der Freischärler mit Skepsis oder Flucht. Levinský wird von einem Kollegen erschossen, nachdem er sich allein zum Rückzug entschließt. Der Tscheche Havlín hingegen, der ebenfalls Fluchtgedanken hegt, erschießt den Offizier einer vorbeiziehenden preußischen Einheit, was wie ein Selbstmordattentat anmutet, denn er wird unmittelbar darauf erschossen. Wie aus den Repliken hervorgeht, ist der todesmutige Kampf kein Kampf mehr für Österreich, sondern für die Heimat, 
die als Heimat und Territorium der Tschechen verstanden wird. Gegenüber Ebner erklären die Tschechen:

[...] nejde již o poroučenou a prohrávanou válku, nýbrž že to, na čem stojíme, je vlast! [...] tady slyšte ještě, že jsme, kde chceme být, a že nijak nás nezmatete, abychom z místa, kam nás osud hodil, nebránili svou rodnou zemi, vámi opouštěnou. ${ }^{347}$ (S. 37)

Dass die Tschechen ein nationales Exklusivrecht auf das Territorium beanspruchen, erkennt man auch an den Worten, mit denen ein gefallener ungarischer Soldat begraben wird: „Spi Mad'are. Nebyla to tvá vlast.“348 (S. 20)

Die fünf kämpferischen Nationalpatrioten meinen vor ihrem Ausfall aus dem Friedhof, dass früher nur mit Worten gekämpft wurde, jetzt aber die Zeit für Taten gekommen sei („Slovy bylo včera bojováno, dnes již jen činem!“349 - S. 45). Fürs Erste zumindest ist der Ausfall erfolgreich, denn der gefesselt am Friedhof zurückgelassene Ebner kommentiert das Geschehen mit den Worten: „Kdo je to s nimi? - Kdo je to s nimi?! - Vítězi! Śílenci!! - - A já bezmocný ... Bezmocný ... Smrt!“350

Die martialische Handlung von Česká komedie konstrastiert zur Genrebezeichnung im Titel: Der Einakter hat in seiner militärischen Drastik keinerlei komische Elemente; auch eine symbolische Lektüre - die Rettung der zum Friedhof gewordenen Heimat ist nur durch letzten Einsatz möglich - erscheint wenig komisch. Das Pathos der Freischärler, die das Unmögliche wagen, hat allenfalls tragikomische Züge, weil die letzte Hoffnung der fünf Soldaten gegen die bedrückende Realität steht, gegenüber welcher sie kaum Chancen zu haben scheinen. Neben dieser tragikomischen Lesart des Titel wäre auch eine zynische möglich: Aus der Sicht eines Zynikers erscheint es komisch, dass sich die einfachen tschechischen Soldaten mit größter Opferbereitschaft im Krieg gegen Preußen einsetzen, während die militärische Führung Österreichs schon feige zurückweicht. Diese Soldaten haben insofern Todesmut, als sie ihren Kampf zu Ende fechten wollen; wie Záviš von Falkenštejn in Hilberts Drama gehen sie keinen Kompromiss ein, sie fliehen nicht, sondern setzen für ihr Böhmen das Leben ein; wenn es vom Feind bedroht wird. Česká komedie könnte einen Epilog zu einem mehrteiligen Zyklus abgeben, der die tschechische Geschichte als Abfolge von Abwehrkämpfen und Zusammenstößen erfasst, meint

347 „Es geht schon nicht mehr um einen befohlenen und verlorenen Krieg, sondern das, worauf wir stehen, ist die Heimat. Wenn das soeben Gesagte ihnen nicht reicht, so hören sie noch, dass wir dort sind, wo wir sein wollen, und keineswegs werden sie uns dazu bringen, von dem Platz aus, wohin uns das Schicksal geworfen hat, nicht die Heimat zu verteidigen, die von euch verlassen wurde."

348 „Schlafe, Ungar. Das war nicht deine Heimat.“

349 „Mit Worten wurde gestern gekämpft, heute bereits nur mit der Tat!“

350 [Ebner:] „Wer ist da mit ihnen? - Wer ist da mit ihnen?! - Sieger! Diese Wahnsinnigen!! Und ich bin machtlos ... Machtlos ... der Tod!“ 
Knap (vgl. 1926, 178), der Hilbert als idealen Autor für eine solche Themenstellung sieht. Der Einakter zeige gleichsam in essenzieller Form die Themenstellung Hilberts: sich aufzulehnen, zu unterliegen, aber einen hohen Preis vom Gegner für diese Niederlage zu verlangen.

\section{IV.7.5. Viktor Dyk: Posel. Drama o třech déjstvích (1907) und Revolučni trilogie (1908-1917)}

[Der Bote. Drama in drei Akten; UA 1. 10. 1907, publ. 1907; Revolutionstrilogie; UAn 19081917, publ. 1921]

Viktor Dyk (1877-1931) gehört zu den politisch prononciertesten Autoren der Prager Moderne. Seine Kindheit verbrachte Dyk in Mittelböhmen, ab 1888 lebte er in Prag, wo er Alois Jirásek als Geschichtslehrer im Gymnasium hatte. In seiner nationalpolitischen Ausrichtung übertraf Dyk Jirásek an politischem Engagement als Autor. Während des Ersten Weltkriegs befand sich Dyk im Zuge der Hochverratsaffäre gegen Prof. Štěpánek in einem Wiener Gefängnis in Haft (er schrieb dort sein berühmtes patriotisches Gedicht „Země mluvi“ [Das Land spricht]), nach dem Krieg war der studierte Jurist Abgeordneter der Nationaldemokratischen Partei und Gegner von Masaryk als Staatspräsident. Dyk war als Autor überaus vielseitig, er schrieb in allen Gattungen und war auch publizistisch sehr aktiv. ${ }^{351}$

Die repräsentierte Welt des Jahres 1620 ist deutlich in zwei Lager gespalten, nämlich ins kaiserliche Lager einerseits und ins Lager der protestantischen Stände um den Winterkönig Friedrich von der Pfalz andererseits. Am Ort der Handlung, dem Haus des frommen Anhängers der Brüdergemeinde Tomáš Roh, treffen die Lager in Gestalt einzelner nichthistorischer Figuren aufeinander, wobei die titelgebende Figur des Boten der einzige Vertreter des kaiserlichen Lagers ist; die anderen Figuren stehen für unterschiedliche ideologische Positionen innerhalb des protestantischen Lagers. Eine ausgesprochen christliche Position vertritt Tomáš Roh, der entschieden jeden Kampf für die Interessen der Protestanten ablehnt, weil er der Auffassung ist, dass Kämpfen bereits sündhaft ist. Den zu erwartenden Angriff der Kaiserlichen sieht er als Strafe Gottes für sündhaftes Verhalten an; eine Niederlage würde ihm nichts ausmachen, solange er sich von Verstrickungen in sündhafte weltliche Angelegenheiten freihalten kann. Sein Sohn Jan allerdings hat sich gegen den Willen des Vaters den Truppen des Königs angeschlossen. Tomáš Rohs Bruder, der Priester Matyáš, vertritt ebenfalls die Auffassung, dass man den Angriff der kaiserlichen Truppen nicht kampflos hinnehmen dürfe. Der Konflikt innerhalb der Familie

351 Eine Diskussion der Möglichkeit, das vielfältige Schaffen Dyks als eine Einheit zu betrachten, liefert Brabec (2004). 
kommt vollends zum Ausbruch, als zu nächtlicher Stunde ein unbekannter Reiter um ein Nachtlager im Haus von Tomáš Roh bittet und gleich beim Eintreten in die Wohnung der Familie ein begehrliches Auge auf Anna, die achtzehnjährige Tochter, wirft, die sich von diesem erotischen Begehren faszinieren lässt. Zumal der fremde Gast eine nicht sonderlich plausible Erklärung für sein Kommen erzählt, erweckt er bald Verdacht beim Priester Matyáš und bei Petr Skalník, dem Bräutigam Annas, der auch auf den Fremden eifersüchtig wird. Matyáš will die königlichen Truppen herbeiholen, um den Fremden zu ergreifen, der eifersüchtige Petr Skalník will den Boten überhaupt ermorden; er bezeichnet ihn als eine giftige Schlange, die getötet werden müsse, bevor sie Unheil bringt. In seiner radikalen Ablehnung von Gewalt hingegen möchte Tomáš Roh seinen Gast vor den Angriffen schützen.

$\mathrm{Zu}$ Beginn des zweiten Akts schleicht sich Anna zum fremden Boten, um ihn vor der drohenden Gefahr zu warnen. Der Bote gibt sich angesichts dieser gleichgültig, da er meint, er wisse sich gut mit dem Schwert zu wehren. Ihm scheint viel mehr an Anna zu liegen, die er zu verführen versucht. Sie gesteht ihm ein, dass sie ihren Bräutigam Petr Skalník gar nicht liebe, sondern ihn nur heiraten werde, weil die Eltern dies für sie so bestimmt hätten. Der Bote, der sich Anna gegenüber freimütig als Kaiserlicher ausgibt, vertritt einen epikureischen Lebenswandel. Er legt Anna dar, wie lebensfeindlich die Mentalität ihrer Eltern bzw. von Böhmens Menschen überhaupt sei. „Neviděl jsem tak smutné země“352 (II, S. 46). Während Anna zum Aufbruch mahnt, verzögert der Bote diesen bewusst. Von Anna erhält er die Erlaubnis, sich gegenüber Angriffen mit der Waffe zur Wehr zu setzen. Petr Skalník schleicht sich in der Nacht ins Zimmer des Boten, der sich schlafend stellt und ruhig abwartet, ob Petr Skalník ihn töten will oder nicht. Dieser zieht zwar den Dolch, sticht aber nicht zu und verlässt das Zimmer wieder. Als der Bote Anna dies erzählt, bezeichnet Anna ihren Bräutigam als Feigling. Sie erkennt den Unterschied zwischen den um sie werbenden Männern: Der Bote setzt für Anna leichterhand sein Leben aufs Spiel; Petr Skalník hingegen wagt weder einen offenen Zweikampf, noch nützt er die Gelegenheit zum Mord an seinem Gegner, mit dem er seine Absicht, dem gegnerischen Lager zu schaden und den Nebenbuhler zu beseitigen, verwirklichen hätte können. Anna, die schon zuvor gegenüber der religiösen Rigorosität ihrer Eltern auf Distanz gegangen ist, wechselt nun das Lager und will mit dem Boten davongehen.

Im dritten Akt kommt es zur Gegenüberstellung der Lebensauffassungen des Boten und Tomáš Rohs. Letzterer warnt den Boten sogar vor den Königlichen; der Bote kann die Paradoxie nicht begreifen, dass Tomáš damit seinem Gegner hilft, er antwortet mit einer anderen paradoxen Handlung: anstatt zu fliehen, möchte er bleiben, bis der Hahn dreimal gekräht hat. Der Bote, der freimütig äußert, gar nicht wegen religiöser Überzeugungen auf der Seite des Kaisers zu kämpfen, sondern weil er sich auf dessen Seite größere Chancen auf das Anwachsen seines eigenen Ranges

352 [Bote:] „Ich habe nirgends ein so trauriges Land [wie Böhmen] gesehen““ 
erhofft, kritisiert Tomáš Rohs Haltung, die mit ihrer ausschließlich transzendenten Orientierung den Bezug zum Diesseits aufgebe. Als Epikuräer will der Bote ganz die irdischen Genüsse für sich haben. Dass Anna mit dem Boten fortgehen will, betrübt die Mutter zutiefst; sie macht ihr Vorhaltungen. Tomáš Roh erklärt, seine Frau und er hätten nun keine Tochter mehr; er verstößt diese als Fremde, über welche gewiss die göttliche Strafe kommen werde. Da der Hahn inzwischen schon zum dritten Mal gekräht hat, ohne dass die königlichen Truppen gekommen wären, deutet dies der Bote als Fügung des Schicksals zu seinen Gunsten und geht mit Anna davon. Tomáš Roh und seine Frau lesen daraufhin bewegt die Geschichte von Isaaks Opferung aus der Bibel. Der mit einigen königlichen Soldaten zurückgekehrte Petr Skalník macht Tomáš Roh Vorwürfe, dass er den Boten hat ziehen lassen. Als er erfährt, dass Anna mit diesem gegangen ist, bezichtigt er Tomáš Roh der Kuppelei und möchte ihn erstechen. Als sich die Frau schützend vor ihren Mann stellt, lässt Petr ab und sagt, dass er zweimal nicht zugestoßen habe, bei dritten Mal aber zustoßen werde. Zuletzt kommen die von Matyáš geführten königlichen Truppen, sie treffen natürlich zu spät ein, da der Bote bereits fort ist.

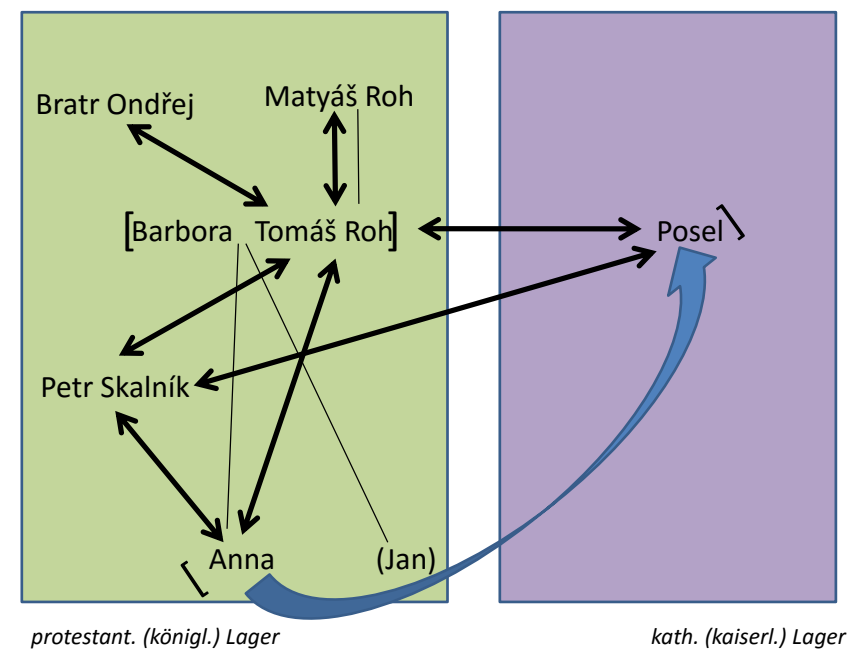

Graphik 28 - Viktor Dyk: Posel (1907)

Viktor Dyk hat die Zeit der Handlung ziemlich genau angegeben: Das Drama repräsentiert eine fiktive Begegnung Anfang November 1620, also kurz vor der Schlacht von Bílá Hora ${ }^{353}$, in der die Truppen der protestantischen Stände von

353 Im vorangestellten Gedicht schreibt Dyk „Bílá Hora“ das Wort „hora“ mit Großbuchstaben, weswegen in diesem Abschnitt diese Schreibung beibehalten wird. 
Friedrich von der Pfalz (damit sind unterschiedliche Konfessionen gemeint, die sich seit der Hussitenzeit gegen die katholische Kirche gestellt haben: Hussiten, Lutheraner, Böhmische Brüder) eine vernichtende und geschichtlich folgenschwere Niederlage erleiden sollten. Dyk stellt zwar keinen direkten Zusammenhang zwischen den im Stück dargestellten Ereignissen und der historischen Schlacht her, mit der Datierung und dem chronologischen Ablauf aber weist er unmissverständlich auf einen Zusammenhang zwischen der Handlung des Dramas und der Schlacht von Bílá Hora hin. Der Bote gibt ja an, dass er einen sehr wichtigen Auftrag für die kaiserlichen Truppen ausführen müsse. Nachdem die dargestellten Personen aus unterschiedlichen Gründen - aus religiöser Überzeugung wie Tomáš Roh oder aus Scheu vor der Ausführung eines Mordes - den Boten der Gegner nicht an der Erfüllung seiner Mission gehindert haben, kann ihnen in dieser impliziten Lesart wohl eine Mitschuld am Ausgang der Schlacht von Bílá Hora zugeschrieben werden.

Wie die Figurenkonstellation zeigt, ist das in der Schlacht so rasch unterlegene protestantische Lager in sich gespalten. Die Gründe dafür liegen in den Auffassungsunterschieden darüber, welches Verhalten gegenüber dem konfessionellen bzw. politischen Gegner zulässig sei. Bis auf Tomáš Roh und dessen Frau Barbora, die am konsequentesten die Morallehre der Böhmischen Brüder leben, derzufolge Gewaltanwendung verboten ist, vertreten alle die Auffassung, dass eine militärische Verteidigung der Glaubensüberzeugung notwendig sei. Ondřej - auch er wohl ein Mitglied der Brüdergemeinde - etwa erzählt im ersten Akt von den bitteren Erfahrungen des Exils, die er schon hatte hinnehmen müssen; er nimmt dabei proleptisch vorweg, was den Protestanten und Utraquisten nach dem Sieg des kaiserlichen Katholizismus tatsächlich widerfahren ist. Die in seiner Erzählung enthaltene Mahnung wird allerdings nur von Anna verstanden. Sie selbst kann nicht als Verräterin der protestantischen Position gelten, wenn sie mit dem Boten mitgeht. Sie äußert ja wiederholt den Willen, wie die alttestamentarliche Judith die Heimat mit Gewalt verteidigen zu wollen. Dass sie nun mit dem Boten mitgeht, hat mit der in ihr heranwachsenden Erkenntnis von der welt- und lebensfremden Position ihres Vaters Tomáš Roh zu tun. Zu dieser Erkenntnis kommt sie durch die Begegnung mit dem Boten, dessen Verhalten ideologisch als das genaue Gegenteil des Verhaltens ihres Vaters bestimmt werden kann. Während letzterer in religiöser Jenseitsgewissheit von jeglichem Handeln, das seine eigene Position stärken und dabei einem anderen Menschen schaden könnte, absieht und eine weltabgewandte Frömmigkeit vertritt, steht der Bote für einen nietzscheanischen Willen zur Macht, der allein diesseitig ausgerichtet ist („,...] nechtěl bych hledat Boha, ale chtěl bych být králem““354 _ III, S. 71). Zugleich hängt er nicht verzweifelt an seinem Leben, um es zu retten. Vielmehr ist er bereit, es einzusetzen, wenn er dadurch etwas gewinnen kann. Im vorgeführten Fall ist es die Bewunderung und Liebe von Anna, der er sogar dann

354 [Der Bote:] „[...] ich würde ja gar nicht Gott suchen, ich würde lieber König sein wollen““ 
noch den Hof macht, als ihm die Festnahme durch die Gegner droht. Den Boten verbindet mit Tomáš Roh eine Gemeinsamkeit, insofern er bereit ist, vieles zu riskieren. Im Unterschied aber zu Roh sieht er im Risiko die Chance auf einen großen Gewinn im Diesseits, Roh hingegen gibt das Diesseits in der christlichen Zuversicht auf ein Jenseits kampflos auf. Die nächtliche Szene, in der Annas Bräutigam Petr Skalník den Boten zu erdolchen gedenkt, kann überhaupt als eine Art Konfrontation gesehen werden, in der unterschiedliche Prinzipien aufeinandertreffen. Petr Skalník führt den Anschlag auf den augenscheinlich Schlafenden nicht aus, wohl weil ihn Gewissensbisse plagen (die Beweggründe werden jedoch nicht angeführt); der Bote hingegen setzt sein Leben ein, nur um mit dem Verzicht auf Selbstverteidigung Anna zu beeindrucken. Dies gelingt ihm umso besser, als er sie zunächst bewusst in eine Zwickmühle gebracht hat, in der sie hätte entscheiden müssen, welcher der Rivalen durch den jeweils anderen getötet werden soll. Als der Bote ihr die Szene erzählt, dass Skalník den Dolch zwar gezückt, die Hand aber wieder gesenkt hat, während der Bote keine Anstalten zu seiner Verteidigung unternommen hat, ist Anna tatsächlich beeindruckt vom Mut des Boten, ihren Bräutigam Skalník nennt sie aber feige. Ein zweites Mal verzichtet der Bote auf aktives Handeln, denn er wartet mit dem Aufbruch, bis der Hahn dreimal gekräht haben wird. Bei dieser Bezugnahme auf das Evangelium riskiert er, von den gegnerischen Truppen gestellt zu werden; er lässt also das Schicksal walten, ohne alles daran zu setzen, um sein Ziel zu erzwingen. Des Boten Schicksalsergebenheit unterscheidet sich insofern von Tomáš Rohs Gottesergebenheit, als er sein Handeln nicht auf ein Jenseits hin ausrichtet, sondern im Augenblick lebt und nach intensiven existenziellen irdischen Erfahrungen strebt. Mit dieser Einstellung ist er eigentlich gar kein Repräsentant des katholischen Lagers des 17. Jahrhunderts, sondern eine anachronistisch moderne Figur, die mit dem christlichen Rigorismus von Tomáš Roh kontrastiert, der allein auf eine höhere metaphysische Wahrheit ausgerichtet ist.

Mit dem Drama Posel führt Dyk die Konsequenzen zweier gegensätzlicher ethisch-ideologischer Positionen vor, die epikuräisch-fatalistische des Boten und die streng einer christlichen Moral verpflichtete von Tomáš Roh. Im Dialog der Positionen zu Beginn des dritten Akts scheint es kurzfristig sogar so, dass der Bote von Rohs Prinzipientreue und Starrsinn beeindruckt ist. Letztendlich aber kann das Publikum unschwer erkennen, dass aus den Prinzipien von Tomáš Roh für den Boten immense Handlungsvorteile erwachsen. Er kann deswegen die wichtige Botschaft an die kaiserlichen Truppen überbringen. Diese Botschaft - so die Fiktion des Dramas - wird entscheidend für den Ausgang der Schlacht bei Bílá Hora gewesen sein: Die tschechische Geschichte nach 1620, die von den Habsburgern aufgezwungene Gegenreformation sind - dies ist die wohl nahe liegende Folgerung aus der Analyse - letztlich eine Konsequenz aus einer frommen Passivität, die in ihrer weltabgewandten Orientierung auf eine metaphysische Wahrheit davon absieht, sich um die nächstliegenden Interessen der eigenen Partei zu bemühen. 
Die für die Analyse verwendete zweite Auflage des Dramentextes stammt aus dem Jahr 1922. Dyk hat in dieser Ausgabe für Dramaturgen hilfreiche Auslassungsvorschläge vorgenommen und ihr einen lyrischen Prolog vorangestellt - „Na den 8. listopadu 1920“, mithin auch in diesem Rahmentext des Dramas auf die am 8. November 1620 stattgefundene Schlacht bei Bílá Hora als Bezugspunkt verwiesen. Das lyrische Ich des Gedichts apostrophiert die Schlacht selbst direkt als seine persönliche Last, als Problem und Mahnmal der Geschichte, von dem es mit einem Mal (gemeint ist die Selbstständigkeit der Tschechoslowakei 1918) befreit schien, sodass es nun wieder lachen kann, ohne vor den Gespenstern Angst haben zu müssen.

Proráží mraky slunce vítězíc,

hodina pomsty udeřila katům.

A Bílá Hora nebude už víc

než - smutné ovšem historické datum. ${ }^{355}$

Allerdings ruht das Gespenst von Bílá Hora nicht, wie es in der Folge heißt. Es sucht den Dichter heim und erklärt, dass ein nationaler Zusammenhalt erforderlich sei, ansonsten sei der Staat gefährdet. Im 17. Jahrhundert hatten die Stände nur an sich gedacht, deswegen hätten sie auch alles verloren. Als Gespenst warnen zu müssen, sei Teil der Bestrafung für dieses ständebezogene Verhalten. Nachdem diese Warnung ausgesprochen wurde, verschwindet das Gespenst, und der Dichter hofft, dass es nicht noch einmal geistern werde müssen, wenn seine Warnung nur gehört werde.

Die Rahmung durch das Gedicht unterstreicht zwar den Bezug des Dramas auf das Nationaltrauma Bílá Hora, seine politische Aussage hat aber mehr mit seiner eigenen Entstehungszeit als mit jener des Dramas im Jahr 1907 zu tun. Das Gedicht warnt die Leser des jungen Staates vor der Aufgabe des nationalen Zusammenhalts, das Drama hingegen führt vor, welche Haltungen und Überzeugungen zur Niederlage am 8. November 1620 geführt haben. Es sind jedoch weniger ständischer Eigendünkel und Eigensinn als vielmehr die religiösen Überzeugungen der Protagonisten, die ihnen eine entschlossene Verteidigung unmöglich machen. Es scheint so, als ob Dyk hier gegen das ideologische Programm Masaryks polemisiert, das dieser in den Schriften der 1890er Jahre „Česká otázka“ [Die tschechische Frage], „Naše nynější krize“ [Die gegenwärtige Krise] (beide 1895) und „Jan Hus“ (1896) entworfen hat. In diesen Schriften gilt die Hussitenzeit und inbesondere die aus den Hussiten hervorgegangene Brüdergemeinde als ethisch-politisches Ideal, an das die Tschechen auch in der Gegenwart anknüpfen sollen. Dyks Drama liefert zum ei-

355 „Siegreich dringt die Sonne durch die Wolken, / die Stunde der Rache hat den Henkern geschlagen. / Und Bílá Hora wird nicht mehr / als ein - freilich trauriges - historisches Datum sein." 
nen eine fiktionale Rekonstruktion der ideologischen Gründe für die Niederlage der Tschechen, zum andern zeichnet diese in der Figur des Boten eine Lebensauffassung, die dem moralischen Rigorismus Masaryks diametral gegenübersteht, indem sie auf Aspekte des Lebens und der Existenz hinweist, die von der moralischen Selbstdisziplinierung schlechthin ignoriert werden.

Nach der Entstehung von Posel hat Dyk in den Jahren 1907-1909 drei Einakter geschrieben, die er unter dem Namen Revolučni trilogie zusammengefasst hat. Ähnlich wie Hilberts Česká komedie repräsentieren diese Einakter fiktive Begebenheiten aus der Zeit der Französischen Revolution, wobei sie eben nicht Szenen mit den für den Verlauf der Revolution entscheidenden Begebenheiten wählen, sondern deren Auswirkungen auf das Alltagsleben zeigen.

Der erste der Einakter, Ranni ropucha [Die morgendliche Kröte, UA 1908] spielt mit dem Titel auf ein Bonmot von Nicolas Chamfort an, einem französischen Schriftsteller des 18. Jahrhunderts, der sowohl vor als auch während der Französischen Revolution reüssieren konnte. Dieses als Motto dem Stück vorangestellte Bonmot besagt, dass man jeden Morgen eine Kröte schlucken müsse, wenn man in der Gesellschaft lebt. Dieses findet insofern im Stück eine Realisierung, als eine fiktive Begebenheit aus der ersten Hälfte des 18. Jahrhunderts gezeigt wird: Zwei Adelige, De Chauvelin und De Breteuil, unterhalten sich beim Wein. De Chauvelin beklagt sich darüber, dass er im Krieg für seinen König einen Arm verloren habe, was De Breteuil damit kommentiert, der Verlust des Armes entspreche eben der morgendlichen Kröte. De Breteuil wird dann selbst auf eine harte Probe gestellt: Der auf der Fahrt zu einer Mätresse reisende König hat sich wegen eines Unwetters verirrt und muss im Schloss von De Breteuil Station machen. Als er ein Bild von dessen verstorbener Frau sieht und zu hören bekommt, dass die 16-jährige Tochter die Mutter noch an Schönheit übertreffe, äußert er den Wunsch, die Nacht mit der Tochter zu verbringen. De Breteuil wagt es nicht, den Wunsch des Souveräns abzuschlagen. Die mitgereisten Höflinge gratulieren ihm, weil sie erwarten, dass dieser bald am Hofe entsprechend aufsteigen werde. Nachdem der König aber die Tochter zu Gesicht bekommen hat, verspürt er nicht mehr das Verlangen und verabschiedet sich mit einer beiläufigen Einladung nach Versailles. De Breteuil hat nun selbst eine „morgendliche Kröte“ geschluckt.

Die 1917 am Národní divadlo uraufgeführte Szene Figaro spielt zu Beginn der Französischen Revolution. Während im ersten Teil der Trilogie die erschreckenden Möglichkeiten absoluter Herrschaft und Servilität dargestellt sind, handelt der zweite Teil von den revolutionären Vorgängen auf lokaler Ebene. Die Unruhen in der Hauptstadt Paris beginnen verzögert in der Provinz; der Umsturz erfolgt hier erst, als Figaro, ein am Schloss erzogener Findling, der unstandesgemäß die Komtessa begehrt, die Einwilligung zum Aufstand gibt und das rebellierende Volk ins Schloss führt. Er sieht im Aufstand die einzige Chance, die Komtessa zu erobern, 
die herablassend mit ihm ihre Scherze getrieben hat und von adeligen Verehrern umworben wird. Figaro hat sich von den Aufständischen die Schutzherrschaft über die Frauen am Schloss erbeten, das aufgebrachte Volk jedoch möchte sich auch an diesen für die jahrzehntelange Demütigung rächen. Er gerät somit zur tragischen Figur; die einzige Möglichkeit, die Komtessa zu gewinnen, impliziert den Verrat an allem, was ihm, dem Findling mit vermutlich adeliger Abstammung, beim Leben im Schloss zuteil wurde. Gerade deswegen und wegen seiner Liebe zur Aristokratin wird er jedoch am Ende zusammen mit den Frauen vom aufständischen Volk im Fluss ertränkt.

Poražení [Die Besiegten], auch Přemoženi [Die Überwältigten] genannt, 1911 am Národní divadlo uraufgeführt, der letzte Teil der Trilogie, spielt im Jahre 1793: Vier Adelige, zwei Männer und zwei Frauen, warten im Gefängnis auf ihren Prozess, auf den mit großer Wahrscheinlichkeit die Guillotinierung folgen wird. Der drohende Tod bringt sie dazu, ihr Leben zu reflektieren. Dies erfolgt allerdings nicht in längeren Monologen, sondern nur in kurzen Repliken, aus denen hervorgeht, dass zwischen dem Vicomte und dem Chevalier eine lebenslange Rivalität bestanden hat und die Comtessa unglücklich darüber ist, dass ihre Klugheit für die Männer immer eher abschreckend war. Der Vicomte erfährt in dieser Nacht, dass er sich sein Leben lang nur zerstreut hat, der Chevalier, sein Rivale um die Gunst der Marquise, kann diese dazu überreden, einen Brief des Vicomte ungelesen zu zerreißen. Als der Kerkermeister kommt und die Marquise und den Chevalier abholt, umarmt die Marquise den Vicomte aber dennoch heftig, sodass der Chevalier erkennen muss, es nicht vermocht zu haben, den Rivalen auszustechen. Sein resignierendes Fazit, die letzte Replik des Einakters lautet: „Nebyl jsem k ničemu, zdá se ... Nebyl jsem opravdu k ničemu. Revoluce přišla včas (ukloni se) Madame! Vicomte!“356 (S. 175)

Dieser Einakter zeigt die Adeligen in einer existenziellen Extremsituation, doch lassen diese selbst kurz vor dem zu erwartenden Tod kaum von ihren Gewohnheiten (Intrigen, Spöttereien, Koketterie etc.) ab. Nur ansatzweise gibt es Momente der Selbsterkenntnis. So wird dem Vicomte angesichts der Stille im Kerker bewusst, dass er sich zeitlebens immer nur um Unwichtiges gekümmert hat. Allerdings ist es nun zu spät, denn die Marquise, die er eigentlich geliebt hat, ohne sich dies einzugestehen, wird vors Gericht gebracht. Der Chevalier andererseits erkennt die Sinnlosigkeit seines Lebens und erklärt sich darob mit der Revolution einverstanden.

In den Einaktern der Revolučni trilogie werden die geschichtlichen Ereignisse auf einer mikropolitischen bzw. privaten Ebene vorgeführt; in das Handeln der Figuren spielen verschiedene Beweggründe hinein, zentral sind dabei intime Aspekte der Persönlichkeit: Sexualität, soziales Ansehen, klassenbezogene Differenzen und

356 [Chevalier De Gresset:] „Ich war zu nichts gut, scheint es ... Ich war wirklich zu nichts gut. Die Revolution ist rechtzeitig gekommen. (verbeugt sich) Madame! Vicomte!“ 
Antagonismen ergeben eine Verkettung, die vom Einzelnen nicht willkürlich gelöst werden kann.

Die Einteilung der Trilogie in Bezug auf die Französische Revolution zeigt die zeitbedingten Veränderungen: Vor der Revolution ist die Ordnung derart, dass sie selbst den Adeligen die Erfahrung und die perverse Komplizenschaft mit der königlichen Herrschaft zumutet und sie zwingt, die sprichwörtliche Kröte zu schlucken. Während der Revolution sind die entbundenen Energien so stark, dass sie individuelle Pläne und Neigungen annullieren. So vermeint der sozial zwischen den Fronten stehende Figaro, die begehrte adelige Frau gewinnen und retten zu können, wenn er den revolutionären Aufstand im Dorf anführt. Die Eigendynamik der revolutionären Situation ist jedoch wesentlich stärker und reißt ihn mit den Adeligen in den Tod. Mit Etablierung der revolutionären Gerichtsbarkeit erst gelangt der Adel zu späten Einsichten, die ihm aber nichts mehr helfen. Stellvertretend für seine Klasse äußert der Chevalier sein Einverständnis mit deren Vernichtung durch die Revolution. Die Trilogie porträtiert vorwiegend die untergehende Adelsklasse bzw. die Gesellschaftsordnung, die mit ihr fällt. Dass sie untergeht, erscheint angesichts der Auswüchse des feudalistischen Absolutismus wenig bedauerlich; wie sie untergeht, wird ohne verklärende romantische Beschönigung gezeigt. Nur im abschließenden letzten Teil der Tragödie wird dem Adeligen zugestanden, Einsicht in das eigene Ungenügen zu gewinnen.

\section{IV.7.6. Arnošt Dvořák: Král Václav IV. Drama o pěti dèjstvích (1910)}

[König Václav IV. Drama in fünf Akten; publ. 1910; UA 2. 2. 1911]

Mit seinem ersten historischen Drama hat der zu dessen Entstehungszeit knapp 30-jährige Arnošt Dvořák gleich einen Achtungserfolg bei der Kritik und beim Publikum erzielt. Es handelt sich um ein Massendrama mit einer Reihe von Figuren, die oft nur in einer einzigen Szene erscheinen. Die repräsentierte Zeit ersteckt sich über 25 Jahre; die Handlung setzt 1394 ein und endet mit Václavs Tod im Jahre 1419. Das Drama hat sehr detaillierte Ausstattungsanweisungen, die von einer Erzählerstimme in der Wir-Form gegeben werden und damit an auktoriale Erzähler in narrativen Genres erinnern. ${ }^{357}$

Das Drama zeigt die Schwierigkeiten des sich volkstümlich gebenden Königs Václav IV. aus der Dynastie der Luxemburger, sich in turbulenten Zeiten auf dem Königsthron zu halten und seine Autorität im Land zu sichern. Es zeichnet damit ein Bild des volksnahen Königs, welches mit den populären Václav-Darstellungen

357 „A k nám, do prostranné jizby s vysokým trámovým stropem, nahlédá jaro aspoň otevřenými dveřmi a okny.“ (S.1 - „Und zu uns, in eine große Stube mit hoher Tramdecke, blickt der Frühling durch die offenen Türen und Fenster herein.") 
in der Erzählliteratur v.a. des obrození entspricht, in der Václav gleichsam als deus ex machina firmierte und den von deutschen Adeligen bedrängten Frauenfiguren aus dem Volk rettend zu Hilfe kam (vgl. Borová 1995, 33f). Václav bewegt sich in Dvořáks Drama in einem Feld, das von verschiedenen Interessenskonflikten und Einflussfaktoren geprägt ist. Er hat ein schweres Erbe angetreten, weil sein Vater Karl IV. ein innen- und außenpolitisch äußerst erfolgreicher Regent war. Václav hat im Unterschied zu seinem Vater keine so großen außenpolitischen Ambitionen, ihm liegt viel mehr daran, dass es dem einfachen Volk in Böhmen wohl ergeht. $\mathrm{Zu}$ dessen Gunsten beschneidet er die Privilegien des Adels, des Klerus sowie der ausländischen Kaufleute, deren Gegnerschaft und Intrigen er damit jedoch auf sich zieht. Das Volk ist sehr gläubig, dies macht die wesentliche Differenz zu Václav aus, der im Nebentext als „pohan“ (Heide) bezeichnet wird und im Drama als lebensfroher Lebemann und Hedonist dargestellt ist, der Leidenschaft in Glaubensfragen wenig Verständnis entgegenbringt. Kirchliche Missstände wie Ablass- und Ämterhandel werden kurz angedeutet, Václav reagiert auf diese nicht als gläubiger Christ, sondern als Politiker, der darauf bedacht ist, in der Kirche keine zweite Autorität neben sich zu haben. Er denkt sehr kritisch über die katholische Kirche, so hat er Jan Nepomuk ertränken lassen, weil dieser sich gegen seine politische Autorität gestellt hat. Ebenso bestraft er einen Ablass versprechenden Bettelmönch, der meint, er unterstehe nicht Václavs weltlichem, sondern nur einem geistlichen Gericht. Václav möchte sich mithin gegen eine zweite Autorität stellen, welche obzwar geistlich - durchaus realpolitische Implikationen hat: „Já ti ukáži, kdo je pánem! V mém království! Já či arcibiskup! Pryč!!"358 (I/1, S. 13.) Seine Unterstützung für die Kirchenkritik von Hus ist nicht religiös-theologisch, sondern rein politisch motiviert: Er möchte eine konkurrenzlose politische Herrschaft durchsetzen; seine Rivalen dabei sind der Klerus und der Adel, im Verlauf der Handlung aber immer stärker auch das religöse Denken, das moralische Grundsätze über die politische Vernunft stellt.

Im zweiten Akt ist Václav in Wien im Kerker gefangen, weil die in ihren Rechten beschnittenen Adeligen und der Erzbischof ihn beseitigen wollten. Sein Bruder Zikmund sowie Ruprecht von der Pfalz streiten sich um den böhmischen Thron. Die reichen Kaufleute stehen hinter Zikmund, die deutschen Magister der Prager Universität treten für Ruprecht von der Pfalz ein. Beide Rivalen drangsalieren aber die Bevölkerung, sodass selbst einst loyale Gruppen sich von ihnen abgekehrt haben. Die Hussitenbewegung wird immer stärker und populärer, was Václav aus der Distanz zwar nicht versteht, aber insofern begrüßt, als sie ja vom einfachen Volk ausgeht, das aus den kirchlichen Missständen diese Konsequenz zieht. Ein Hussitenanhänger befreit Václav aus der Haft, indem er bei einem Besuch im Kerker mit

358 [Václav:] „Ich zeige dir noch, wer Herr ist! In meinem Königreich! Ich oder der Erzbischof! Verschwinde!!“ 
ihm die Kleidung tauscht. Als die Flucht entdeckt wird, muss der an Václavs Stelle im Kerker gebliebene Hussite sein Leben lassen.

Der dritte Akt ist zu Weihnachten des Jahres 1403 angesetzt. Der aus der Haft zurückgekehrte Václav hält Gericht in Prag. Er ist gegenüber seinen Feinden versöhnlich, wenn diese bereuen, straft er nur milde. Er versucht, politische Gerechtigkeit durchzusetzen, was sich darin manifestiert, dass er selbst einen ehemaligen Weggefährten wegen Fälschung zum Tode verurteilt. Die Hussitenbewegung ist mittlerweile zu einer breiten und starken Volksbewegung geworden. Nachdem Václav aus einem abgefangenen Botenbrief erfahren hat, dass der Papst Ruprecht darin unterstützt, böhmischer König zu werden, sagt er sich von der Autorität des Papstes los, was den warnenden Stimmen zufolge fortschreitenden Ungehorsam bzw. die Untergrabung der königlichen Autorität nach sich ziehen würde. Jan Hus hingegen, dem Václav dafür gedankt hat, das einfache Volk wieder stolz und mutig gemacht zu haben, erklärt optimistisch, dass das Volk sich an der Wahrheit orientiere.

Im vierten Akt steht Václav vor der Entscheidung, welche Seite er mit seiner königlichen Autorität stützen soll, die päpstliche Kirche oder die beim Volk so beliebten Hussiten. Er bleibt weiterhin ein Herrscher für das einfache Volk und versucht, möglichst alle Privilegien von Ausländern - in Ämtern, in der Gerichtsbarkeit und an der Universität - aufzuheben, um damit die Möglichkeiten der Inländer zu heben. Den deutschen Magistern entzieht Václav das Privileg dreier Stimmen an der Universität, die Lehre an der Karlsuniversität wird somit eine böhmische Angelegenheit. Hus erklärt daraufhin erfreut Václav zum ersten böhmischen König.

Als Václav vernimmt, dass die Kirche Hus als Ketzer betrachtet, ist er erschrocken, da er erkennt, dass er der Lage nicht mehr Herr werden wird. Er muss für das Volk Partei ergreifen und weiter gegen die deutschen Magister auftreten, gleichzeitig aber weiß er, dass bei einer Fortsetzung der religiösen Antagonismen die Situation nicht beruhigt werden kann. Die Hoffnung, dass ein neuer Papst (beide Päpste, derjenige in Rom und der Gegenpapst in Avignon, wurden von ihren Kardinälen abgesetzt) ein Urteil sprechen wird, das zugunsten der Hussitenbewegung ausfallen wird, erscheint trügerisch, da sich der Erzbischof von Böhmen sowie Jan Železný durch einen Treueschwur dem römischen Papst verpflichtet fühlen. Václav hofft zwar, dass sich eine politische Lösung für den theologischen Konflikt finden wird sowie auf die Akzeptanz eines Kirchenkonzils durch Hus. Dieser erklärt jedoch, dass er ein solches nicht anerkennen würde, da es vom Antichristen sei. Nur wenn man ihn davon überzeugen könne, dass er ein Ketzer ist, würde er der anderen Partei Recht geben.

Václav strebt eine außenpolitische und kirchliche Beruhigung an, die ihm gestatten würde, seine volksnahe Regierung auszubauen und ständische Privilegien sowie Vorrechte von Ausländern einzuschränken. Er hätte gerne, dass Žižka eine Strafexpedition gegen Vladislav von Polen führt, weil dieser die versprochene Gefolgschaft nicht leistet. Žižka verweigert aber einen Kriegszug gegen die Polen, weil auch unter 
ihnen bereits Utraquisten seien. Die Weigerung entspricht einer Befehlsverweigerung, die Václav so erzürnt, dass er Žižka am liebsten erdolchen möchte.

Das Königreich in familiärer Eintracht, das patriarchalische Ideal von Václav, in welchem er als politischer und geliebter Vertreter des Volkes anerkannt wird, lässt sich nicht realisieren, da das Volk und seine Streitkräfte unter Jan Žižkas Führung die abstrakte religiöse Realität über die politische stellen. Dementsprechend äußert Hus die Ansicht, dass sich das Ideal einer populären böhmischen Herrschaft Václavs erst dann verwirklichen lasse, wenn dieser zum Utraquisten wird. Dies würde aber bedeuten, dass Václav sein politisches Ziel, das im Ausgleich zwischen den kirchlichen Lagern besteht, nicht erreichen kann, zudem versucht ja auch der katholische Klerus seine Interessen zu wahren, indem er Hus zum Ketzer erklärt.

Der fünfte Akt spielt 1419, vier Jahre nach der Hinrichtung von Hus in Konstanz. Der alte König ist erschrocken über die Entwicklung der Situation in Böhmen. Seine politische Lebensbilanz fällt schlecht aus, weil sein Bestreben, eine internationale Anerkennung für die Hussitenbewegung zu finden, zu Hussens Hinrichtung und den Hussitenunruhen geführt hat. Statt einer Beruhigung der Situation ist das Gegenteil erreicht worden. Diese Verkehrung der Intention einer Handlung in ihr Gegenteil bei der Realisation wiederholt sich, denn Václav hat die Rückkehr der katholischen Geistlichkeit angeordnet, um den Untergang zu verhindern. Damit aber empört er das Volk; selbst seine einstigen Mitstreiter und Günstlinge verlassen ihn, sie sind ebenfalls leidenschaftliche Anhänger der Hussiten, die sich bei Tábor versammelt haben, um kämpfend den Kelch zurückzuerobern. Die persönliche Tragik Václavs besteht darin, dass er, der er dem Volk ganz nahe sein wollte, von diesem nun maximal entfernt ist. Dies entlädt sich in seiner Wut, in der er alle vernichten und verjagen möchte. In tiefem Gram über die Aussichtslosigkeit der Entwicklung stirbt er. Jan Žižka wird von Bischof Železný vorgeworfen, dass er am Tod von Václav mit Schuld trage (was soweit stimmt, als Žižka ja die Hussitenmacht verkörpert, die sich als nicht mehr kontrollierbar und eigenwillig erwiesen hatte und an der Václavs politische Vision letztendlich gescheitert ist). Żižka meint hingegen, dass Václav nicht der erste König der Böhmen hat werden können, weil er Ausländer war und den göttlichen Kampf nicht verstehen wollte. Die Hussiten seien entschlossen, gegen die ganze Welt zu kämpfen, wenn es denn sein müsse. Mit dem berühmten hussitischen Kampllied „Kdož jú Boží bojovníci“ endet das Drama.

Wenngleich Dvořáks Drama nach dem Namen des Herrschers betitelt ist und dessen politisches Handeln über einen langen Zeitraum hinweg vorführt, zeigt der Untertitel an, dass es sich auch um eine "Tragödie des Volkes“ handelt. Das Streben Václavs nach Popularität, seine Liebe zum Volk, die auch durch das Verhältnis zur „Badefrau“ Zuzana metonymisch unterstrichen wird, scheitert letztendlich; das vom Hussitengedanken mobilisierte Volk wie auch Václavs engste Vertraute wenden sich von ihm ab. Dieses Scheitern hat auffällige national-ethnische Implikatio- 
nen, die in der dramatischen Handlung wie auch im Nebentext erkennbar sind. So heißt es etwa im Nebentext beim ersten Auftritt Václavs:

Král Václav (vejde rychle. Hned ho poznáme, táž milá, téměr dětsky dobrá a laskavá tvár̆, jaká na nás hledíze starých kronik. „Tento král byl nazýván českým Neronem??" tážeme se v údivu - a nevěrime pravdomluvnosti dějepisců. Jeho jasné, veselé oči se usmivaji ... Předevšim však jeho milý poněkud nepravidelný, dètský nos slovanského typu... Jak mlád jest tento král, ač je mu více než tricet let. $)^{359}(\mathrm{I} / 1$, S. 11)

Im Nebentext wird mit dem ethnischen Körpermerkmal der Nase „slawischen Typs“ der persönliche Widerspruch Václavs, an dem er letztlich zerbricht, ja schon angedeutet. ${ }^{360}$ Denn als sympathisch präsentierter Träger dieser Nase stammt er ja aus dem Geschlecht der Luxemburger und ist eben kein Slawe, als König in Böhmen handelt er aber sehr tschechenfreundlich. Seine Hinwendung zum Volk misslingt letztlich aufgrund des religiösen Konflikts, der mit der Hussitenbewegung entsteht. Im Verlauf der Handlungsentwicklung wird Václavs Annäherung an das Volk durch dessen „Hussitisierung“ verunmöglicht. Das Drama zeigt die Kritik an den Missständen der Kirche in ihrer Verbindung mit nationalen Elementen. So klagt Hus etwa über die Bevorzugung anderer nationes an der Prager Universität.

[Křivě nám se děje n]árodem bavorským, saským a polským Vysokého učení pražského. Tři národové proti jednomu! A kdo jest tento národ jeden, jemuž křivě se děje? Zdaliž národ bavorský, či kterýkoli jiný z národů cizích? Nikoliv: národ český, tohoto království dědic! Byl kdysi maličký ve vědění a učiti se musel, jako dítě nemluvně od starších choditi se učí. Ale dnes vyrostl tělem i duchem nad své učitele, i slušno jest, aby v dědictví své se uvázal, co hlava jeho. Jsme hlavou ve svém dědictví? Ne, ocasem! A cizozemci námi vládnou, v radách, v učení, v soudech nás hlasy nespravedlivými přehlasují, ba i - svědomí našemu poroučeti chtějí! ${ }^{361}$ (IV/S. 69)

359 [Václav:] „,König Václav (kommt schnell herein. Wir erkennen ihn sofort. Dasselbe liebliche, beinahe kindlich gute und liebevolle Gesicht, wie es uns von alten Chroniken anblickt. »Dieser König wurde, der böhmische Nero' genannt??«, fragt man sich überrascht und glaubt nicht der Wabrhaftigkeit der Geschichtsschreiber. Seine klaren, lustigen Augen lachen ... Vor allem aber seine liebliche leicht unregelmäßige, kindliche Nase vom slawischen Typ ... Wie jung wirkt dieser König, obwohl er schon über dreißig ist.)"

360 Eric Hobsbawm (vgl. 1991, 80-82) weist im Übrigen darauf hin, dass körperliche Merkmale für die Konstituierung von Nationen vorwiegend insofern eine Rolle spielen, dass sie eine der Ethnie nicht zugehörige Gruppe anhand eines Merkmals (die „Schwarzhaarigen“) negativ ausschließen. Seltener hingegen dienen körperliche Merkmale als positives Kriterium der Zugehörigkeit zu einer Nation. Im oben zitierten Nebentext erfolgt aber eben dies, bezeichnend ist dabei jedoch die „falsche“ Identifizierung von Václav als Slawe, die im Handlungsverlauf dann korrigiert wird.

361 [Jan Hus:] „[Unrecht geschieht uns durch die] bayerische natio, die sächsische und die polnische natio der Prager Universität. Drei nationes gegen eine! Und wer ist diese eine natio, 
Dieses Zitat kann als Musterbeispiel für die allegorische Doppelsinnigkeit des historischen Dramas insofern gelten, als - ob intendiert bzw. bewusst oder in Unkenntnis der begrifflichen Differenz ${ }^{362}$ - die Polysemie des natio-Begriffs hier ins Spiel gebracht und durch die tschechische „Entsprechung" národ noch gesteigert wird. Im inneren Kommunikationssystem beklagt sich ja Hus hier über die Dominanz der anderen nationes qua Korporationen an der Universität, im äußeren Kommunikationssystem kann dies aber auch auf die zeitgenössische Situation des Nationalitätenkonflikts bezogen werden.

Da Václav ja dann im Sinn von Hus das Stimmenverhältnis ändert, wird er von diesem begeistert als erster böhmischer König („první český král“ - IV, S. 76) bezeichnet, womit er seine Volksnähe anerkannt wähnen kann. Die weitere Entwicklung kann als Peripetie dieser Annäherung gelten: Mit der konfessionellen Begründung weigert sich Jan Žižka, Václavs Aufforderung, einen Feldzug gegen die Polen zu führen, nachzukommen, was diesen ungeheuer aufregt. Wo er zuvor in der katholischen Kirche einen Rivalen um die Macht sah, erfährt er nun von Seiten der Hussiten ebenfalls Beschränkungen. Jan Hus, der ihn eben noch zum ersten böhmischen König ausgerufen hat, fordert nun (und dies ist in Großbuchstaben gesetzt), dass er auch Utraquist werde, erst dann könne er der erste böhmische König sein. Das religiös-konfessionelle Moment wird im Stück mit dem nationalen Moment verknüpft und kehrt sich damit gegen den Monarchen, dem als hedonistischem „Heiden" theologische und religiöse Eiferei fremd ist.

Im letzten Akt wird deutlich, dass Václav als Herrscher mit seinen Entscheidungen nichts mehr bewirken kann. Nicht nur das breite Volk, auch seine Entourage ergreift für den Utraquismus Partei und treibt damit Václav in den Tod. Dass das Ende des Monarchen zugleich auch für das tschechische Volk tragisch ist, darf das Publikum per historischer Inferenz ex post erkennen: Václav scheitert ja beim Versuch, die vertriebenen katholischen Priester wieder ins Land zu holen, am Protest

der Unrecht getan wird? Etwa die bayerische natio oder eine andere fremde? Keineswegs: die böhmische natio, die Erbin dieses Königreichs. Sie war einst noch klein im Wissen und musste lernen, so wie ein noch nicht sprechendes Kind von den Eltern das Gehen lernt. Heute aber ist sie an Geist und Körper über ihre Lehrer hinausgewachsen, und es würde sich gehören, dass sie als Haupterbe eingeführt wird. Sind wir das Haupt in unserem Erbland? Nein, wir sind der Schwanz! Und die Fremdländischen regieren über uns, in den Ämtern, in der Lehre, bei Gericht überstimmen sie uns mit ungerechten Stimmen, ja sie wollen sogar über unser Gewissen gebieten.”

362 In Anbetracht des Umstandes, dass die Hussitenzeit und insbesondere das Dekret von Kutná Hora, das die Stimmverhältnisse an der Universität zugunsten der böhmischen natio änderte, in der tschechischen Historiographie - etwa auch von Palacký (vgl. 1939/III, 82-87) - als historische Belege für den Nationalitätenkonflikt dienten, und dass viel später erst auf die Differenzen zwischen diesem spätmittelalterlichen universitären natio-Begriff und dem der modernen „Nation“ hingewiesen wurde, darf man annehmen, dass Dvořák die allegorische Doppeldeutigkeit „naiv“ und nicht „raffiniert“ herstellte. 
seiner utraquistischen Umgebung. Er aber sah die blutigen Auseinandersetzungen der Hussitenkriege voraus und wollte diese durch sein Handeln verhindern, während Jan Žižka entschlossen ist, im Namen der Wahrheit gegen die ganze Welt zu ziehen. Der säkular gestimmte, in politischen und nicht in moralischen Kategorien denkende König scheitert am religiös fanatisierten Volk, das nationale Zugehörigkeit mit dem Utraquismus verknüpft und die Deutschen damit ausschließt.

Dvořáks erstes Drama aus der Hussitenzeit steht somit gewissermaßen im Gegensatz zu Jiráseks Jan Žižka, weil Jirásek die Verbindung von utraquistischer Konfession und tschechischer Nation im äußeren Kommunikationssystem affirmiert, während Dvořák diese Verbindung zwar im inneren Kommunikationssystem gestaltet, im äußeren aber fragwürdig erscheinen lässt.

\section{IV.7.7. Arnošt Dvořák: Husité. Tragedie národa o pèti dějstvich (1919)}

[Die Hussiten. Tragödie eines Volkes in fünf Akten; UA 26.11. 1919, publ. 1919]

Während des Ersten Weltkriegs schrieb Arnošt Dvořák ein fünfaktiges Drama über die Hussitenkriege in den zwanziger Jahren des 15. Jahrhunderts. Die „Tragödie eines Volkes" besteht darin, dass die Tschechen von den konfessionellen Konflikten der Zeit gespalten werden und gegeneinander kämpfen. Mit Husité schuf Dvořák ein Kollektiv- bzw. Massendrama, das von Karel Hugo Hilar im Městské Divadlo na Královských Vinohradech im expressionistischen Stil sehr erfolgreich inszeniert wurde (vgl. Obst 1983, 24; Brabec 2010a, 338).

Das Stück beginnt mit einer Szene im südböhmischen Dorf Chelčice, wo Truppen des katholischen Adeligen Rožmberk von den Bauern unbarmherzig hohe Abgaben verlangen. Gleich wird offenbar, dass konfessionelle Divergenzen auch innerhalb einer Familie vorkommen. So ist etwa Ondřej gegen jede Heiligenverehrung und gegen Heiligenbilder, während sein Sohn Jakub vor diesen noch kniet. Jakubs Schwester Jana ist zu den Adamiten gegangen, was ihre Eltern zutiefst betrübt. Jana kommt mit ihrem sterbenden Kleinkind, dem bayrische Soldaten eine Hand abgehauen haben. Mit äußerst blutrünstigen Rachevorstellungen kündigt Jana an, künftig alle Anhänger des „Antichristen“ verfolgen zu wollen (vgl. I/1, S. 17). Petr Chelčický ist der einzige, der gegen die Gewalt im Namen der konfessionellen Überzeugung Einspruch erhebt, so etwa gegen Prokop, der unter einer Linde zum Kampf

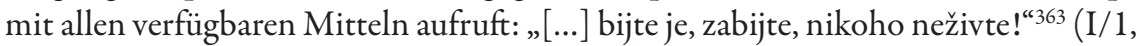
S. 18) Prokop berichtet, dass Jan Žižka mit großem Zuspruch Leute um sich schart und nach Prag zieht, um es gegen die katholischen Truppen zu verteidigen, die mit starker ausländischer Beteiligung Prag angreifen werden.

363 [Prokop:] „Schlagt sie, tötet sie, lasst niemanden am Leben.“ 
Auch in Böhmens Hauptstadt gehen die Differenzen quer durch die Familien, wie das zweite Szenenbild des ersten Aktes zeigt. So ist der Purkmistr der Prager Altstadt ein gemäßigter Utraquist, der dafür eintritt, dass die Taboriten Zikmund als König akzeptieren, der nach dem Tod von Václav IV. als dessen Bruder für die Thronfolge vorgesehen ist. Auch sein Sohn Hanuš nimmt Anstoß an den extremen Ansichten der Taboriten, die Prag zum Sündenpfuhl Babylon erklären; seine Tochter Magdalena hingegen meint, dass dies nur Vorzeichen einer neuen Ordnung sei, die bald eintreffen werde und auf die sie selbst sich bereits vorbereitet.

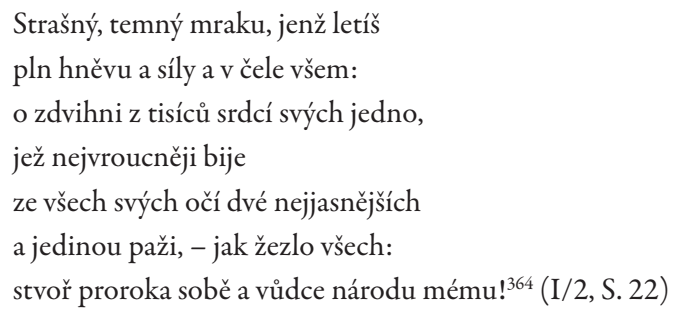

Dem Feldherr Jan Žižka missfällt das Ansinnen, mit Zikmund zu paktieren. Er kritisiert andererseits auch die Taboriten für ihre radikalen Anschauungen, denen zufolge sogar Hus selbst einst an der Buhlerei der Kirche beteiligt gewesen sei, weil er Ornat getragen hat. Žižka fordert eine Einigung aller Utraquisten unter den vier Artikeln (diese sind als Prager Artikel in die Geschichtsbücher eingegangen). Ihm schwebt als neuer König ein litauischer Fürst vor, der für den Utraquismus gewonnen werden soll. Unter seiner Herrschaft könne ein großes utraquistisches Königreich entstehen. Jedes Paktieren mit Zikmund, auch dasjenige Prags, will Žižka äußerst hart bestrafen. Nachdem Magdalena empfiehlt, ihm zu folgen, bricht der Purkmistr mit Zikmund und fordert alle Prager zur Unterstützung von Žižka bei der Verteidigung der Stadt auf.

Der zweite Akt zeigt das Lager Zikmunds, der bereits von Jan Žižka verfolgt wird und keinerlei Erfolge im Kampf gegen die Hussiten hat. Zikmund wird als ehebrecherisch, verlogen und depressiv gezeichnet, er möchte seine Tochter mit dem österreichischen Herzog Albrecht verheiraten und seine Schwägerin Žofie, die Witwe Václavs IV., mit dem polnischen König. Der böhmische Adelige Menhart z Hradce bringt die Nachricht, dass Žižka aus Wut über das Verhalten Prags und den neuen König Korybutovič, den er selbst hat holen lassen, die Hauptstadt vernichten wollte, dabei aber Widerstand aus den eigenen Reihen zu spüren bekam.

364 [Magdalena:] „Schreckliche, finstere Wolke, die Du voller Zorn und Kraft voranfliegst: Erhebe aus den tausenden Herzen eines, das am eifrigsten schlägt, aus all deinen Augen nimm die zwei klarsten / und mit einem Arm - wie das Zepter von allen: / Schaff dir einen Propheten und einen Führer für mein Volk!" 
Zikmund hofft auf einen neuen Kreuzzug, den der päpstliche Legat mobilisieren soll. Menhart z Hradce soll die Prager mit falschen Versprechungen von den anderen utraquistischen Gruppierungen abspalten und für Zikmund gewinnen. Wenn möglich, soll Menhart auch wichtige Personen des gegnerischen Lagers ans Messer von Zikmunds Auftragsmörder Jánoš liefern.

Die anhaltenden Kämpfe in Böhmen zermürben die Bevölkerung; die eifrigsten Kämpfer der Taboriten jedoch kennen weder Pardon noch Innehalten. Jan Žižka liegt im Sterben, der erfolgreiche Feldherr erweist sich als hartherzig und unnachgiebig. So bereut er, Prag nicht vernichtet zu haben, auch seien die Taboriten in ihrem Radikalismus noch schlimmer als die Adamiten und verdienen in seinen Augen den Tod. Er möchte die rachewütige Jana am Scheiterhaufen hinrichten lassen. Doch Prokop, der Führer der Taboriten, verhindert dies: er möchte wieder eine schlagkräftige Einheit herstellen im Namen einer Glaubensfreiheit und eines gemeinsamen Kampfes gegen den „Antichristen“.

Nachdem Prokop, der Führer der Taboriten, beschlossen hat, vom Verteidigungs- zu einem Angriffskrieg überzugehen und den Feind bereits in dessen Heimat anzugreifen, kommt es zu Notlagen in Böhmen selbst. Die Prager Bevölkerung etwa beklagt die schlechten Zustände im Land, Frieden wird ersehnt. Der für das Königsamt vorgesehene Korybutovič will den Frieden um den Preis einer demütigen Unterordnung unter den Papst erreichen, was von den Pragern jedoch nicht akzeptiert wird. Hanuš und Rokycana protestieren heftig; Magdalena, die eine eifernde Taboritin geworden ist, entdeckt mit einer erotischen List diesen Plan. Im zweiten Bild des dritten Aktes wird der politisch wie militärisch erfolglose Zikmund gezeigt, der in Bratislava von seiner Frau spöttische Bemerkungen zu hören bekommt. Bei Verhandlungen mit Prokop, seinem selbstbewussten Gegner, wird der sich jovial gegebende Zikmund von diesem düpiert. Er lässt daraufhin einen großen Kreuzzug organisieren. Prokop stellt sich als Kämpfer für ein Paradies auf Erden dar, wie es noch keines gegeben habe.

Der vierte Akt zeigt die Gewalttaten, die beim Kampf für dieses Paradies verübt werden. So erdolcht etwa die rasende Jana im sächsischen Naumburg drei wehrlose Frauen. Als Kinder aus Naumburg Prokop ersuchen, Gnade walten zu lassen, lässt sich dieser kurzfristig davon rühren, weil er gerade von Magdalena ein Heiratsversprechen bekommen hat und auch von den nach dem Tod Žižkas „,verwaisten“ Kämpfern für den Utraquismus als Oberbefehlshaber anerkannt worden ist. Radikalere Kräfte unter den Taboriten aber bezichtigen ihn wegen seiner Milde gegenüber dem „Antichristen“ des Verrats.

Menhart z Hradce verfolgt den Auftrag, in das gegnerische utraquistische Lager einen Spaltkeil zu treiben und dabei die Prager für das Lager Zikmunds zu gewinnen. Wie sich bei der Belagerung der katholischen Stadt Plzeň erweist, verhalten sich die Taboriten sehr undiszipliniert, sie ruinieren und plündern sogar die Besitzungen utraquistischer Adeliger und Bauern. Prokop ist als Führer der Taboriten 
abgesetzt worden; nach ihm wird aber wieder gerufen, um die fehlende Disziplin wieder herzustellen. Menhart besticht die Gegner oder belügt sie über seine eigentlichen Ziele. Als klar wird, dass er darauf sinnt, die Utraquisten zu spalten, um die Taboriten militärisch vernichten zu können, kommt es nicht mehr zu einer Versöhnung, sondern der Krieg zwischen den Konfessionen wird proklamiert. Die gemäBigteren Prager Utraquisten Hanuš und Rokycana sehen in der Haltung Prokops, der starr an der Vision einer herrschaftsfreien Zukunft festhält, eine Gefahr für Böhmen, und um diese abzuwenden, wechseln sie die Seiten und gehen mit Zikmunds Truppen eine Allianz ein.

Im abschließenden fünften Akt zeigen sich die Folgen der andauernden Religionskriege. Die Frauen von Ondřej und Jakub sind tot, die Taboriten haben nun auch Dörfer mit utraquistisch gesinnter Bevölkerung geplündert und zerstört. Trotz dieser Verluste, die Petr Chelčický anklagend erzählt, hält Ondřej an der Auffassung fest, mit den anderen Taboriten ein Rachewerkzeug Gottes zu sein. Prokop, der die ehemaligen Truppen Žižkas (die sirotci bzw. „Waisen“) und die Taboriten vereinigen konnte, um den massiven Angriff eines weiteren Kreuzzugheeres abwehren zu können, hält Chelčický vor, dass seine Visionen einer friedliebenden christlichen Gemeinde nur möglich seien, weil andere mit dem Schwert für diese Vision eintreten. Vor dem Kampf gegen die mit Prager Unterstützung kämpfenden Kreuzritterheere kommt noch einmal eine Prager Abordnung ins hussitische Lager; Hanuš und der vierzehnjährige Jiř̌́ z Poděbrad verlangen die Entwaffnung der Taboriten, unter dieser Bedingung würde vom Kampf abgesehen werden. Es kommt zur schmerzhaften Abschiedszene zwischen den Geschwistern Hanuš und Magdalena, die inzwischen Mutter geworden ist und weiterhin zu ihrem Mann Prokop steht, der zu einem gnadenlosen Kampf aufruft. Allerdings hat die auf Magdalena eifersüchtige Rächerin Jana bei den Taboriten das Gerücht verbreitet, dass die Hauptmänner aus Feigheit den Befehl erlassen hätten, die Stellungen hinter den Wagenburgen nicht zu verlassen und die Gegner nicht zu verfolgen. Dies war jedoch Prokops Befehl, um zu vermeiden, dass die kämpfenden Einheiten eingeschlossen werden. Somit erfolgt der blutige Untergang der Taboriten und der Waisen. Prokop fällt, laut Jana durch das Schwert von Hanuš. Jana ersticht Magdalena und deren Kind. Hanuš kommt dazu und ist bestürzt über das schreckliche Ende. Bevor er sich selbst mit dem Schwert durchbohrt, ermahnt er die Nachkommen, das Beste von Žižka und Prokops Vermächtnis zu übernehmen, aber sich vor deren Verirrungen zu hüten; vielleicht werde es in Zukunft einmal Zustände geben, wie Prokop sie sich erträumt hat. Die Schlussapotheose erfolgt während einer Ansprache Jiř́s z Poděbrad:

Pochovejme slavně mrtvé tohoto dne. Jejich velikost, kterou dosud jen tušíme, ještě větší úkoly ukládá nám, živým. Ale mladí jsme! A naše mládí žízní po úkolech nejtěžších! Rozezvoňme všecký zvony země poselstvím, že skončilo se krveprolévání, a budujme dílo pokoje! Vítězný svatý kalich Husův bud' prvním jeho kamenem! (Zvony blizkých kostelikui se rozeznèly, 
slunce vyšlo z pod mraku) Hle, zvony veských kostelíků! O drahé, truchlé zvuky, jež vyzváníte pád největšího lidu světa, probud'te sílu ve všech mladých hrudích této země - a pravnukové naši za tisíc let vám žehnati budou! ${ }^{365}$ (V, S. 101)

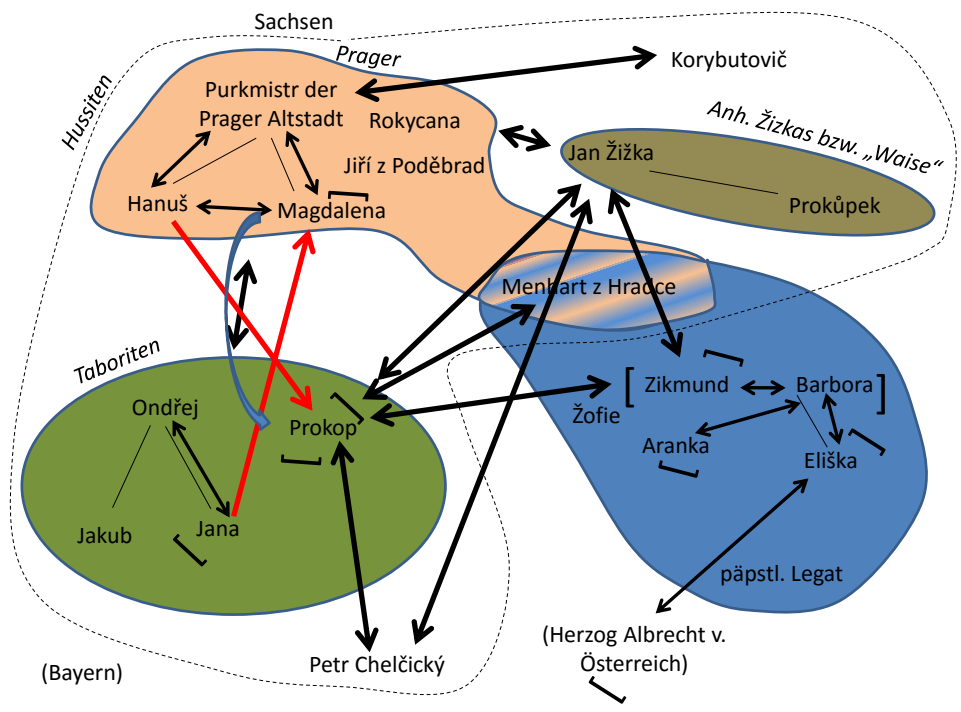

Graphik 29 - Arnošt Dvořák: Husité (1919)

Die erhöhte Komplexität des Dramas lässt sich auch in der Figurenkonstellation erkennen. Zu den beiden Hauptkonfliktparteien, den Hussiten einerseits und den katholischen Truppen andererseits, die gegen jene mobilisiert wurden, kommt die Uneinigkeit innerhalb des hussitischen Lagers, welche das Drama als die „Tragödie eines Volkes" vorführt. Abgesehen von dieser auch in den historiographischen Darstellungen der Hussitenperiode immer thematisierten Uneinigkeit besteht bei Dvořák deren dramatische Veranschaulichung darin, dass innerhalb eines jeden Lagers noch einmal einzelne Vertreter miteinander konfligieren. Diese Konflikte sind zum Teil um historische, zum Teil um fiktive Figuren gestaltet.

365 [Jiř́ z Poděbrad:] „Begraben wir die Toten des heutigen Tages feierlich. Ihre Größe, die wir jetzt nur noch erahnen können, stellt uns Lebende vor noch größere Aufgaben. Aber wir sind jung! Und unsere Jugend trachtet nach den schwersten Aufgaben! Läuten wir alle Glocken des Landes mit der Botschaft, dass das Blutvergießen ein Ende hat und errichten wir ein Werk des Friedens! Der siegreiche heilige Kelch von Hus wird dessen Fundament sein! (Es ertönen die Glocken der Kirchen in der Umgebung, die Sonne kommt hinter den Wolken hervor). Hört, die Glocken der Dorfkirchen! Oh ihr lieben traurigen Klänge, die ihr den Untergang des größten Volks der Erde verkündet, stärkt die Kraft in der Brust der Jugend dieses Landes - und unsere Urenkel werden euch in tausend Jahren segnen!“ 
Die Anzahl der personae dramatis, die in der Figurenkonstellation aus Darstellungsgründen vereinfacht wurde, ist auch durch die Episodenhaftigkeit bedingt, denn nicht alle Figuren sind in den größeren dramatischen Handlungszusammenhang eingelassen. Manche Episoden geben nur ein Stimmungsbild innerhalb des jeweiligen Lagers wieder, ohne dass die dargestellten Figuren mit ihren (Sprech-) handlungen großen Einfluss auf den Verlauf der Ereignisse nehmen. Darin kann freilich eine dramaturgische Schwäche erkannt werden, jedoch nur, wenn man davon ausgeht, dass im Drama ein umfassender Handlungszusammenhang dargestellt wird und dass jede Figur in diesem Zusammenhang stehen soll. Dvořák löst sich allerdings von einer solchen Auffassung, bei ihm gibt es zum Teil Figuren, die rekurrierend den Handlungsbogen tragen, aber es gibt eben auch Figuren, die deutlicher gezeichnet sind, ohne in diesen Zusammenhang eingebunden zu sein: so etwa - im Lager Zikmunds - dessen Tochter Eliška, die mit ihrer Mutter Barbora streitet und davon spricht, ihren Mann Herzog Albrecht von Österreich zu töten, nur dass dieses Vorhaben nicht weiter ausgeführt wird. Prokůpek, der vom sterbenden Žižka mit pathetischen Worten als Nachfolger eingesetzt wird, spielt in der Folge keine große Rolle, er stimmt nur der Allianz mit den Taboriten zu, ohne selbst weiter initiativ zu werden.

Die Handlungsentwicklung wird zum einen von der Interaktion der Vertreter der vier Gruppierungen bestimmt (Jan Žižka, der Purkmistr der Prager Altstadt bzw. von Rokycana, der in Prag an Einfluss gewinnt, Prokop auf Seiten der Hussiten und Zikmund auf Seiten der Katholiken), zum anderen gibt es ein fiktives Handlungsmoment, das von Dvořák den geschichtlichen Akteuren hinzugefügt wurde: Dieses besteht in der blindwütigen Rache Janas, die als Adamitin schweres Leid von den Bayern, aber auch von Jan Žižka erfahren musste. Ihre Rache sowie ihre Eifersucht auf Magdalena, die Prokop zur Frau wählt, motiviert einen beträchtlichen Anteil der dargestellten Ereignisse. Sogar der Ausgang der Schlacht von Lipany, bei der die Taboriten eben von den Kreuzzugsheeren im Verein mit den Pragern aufgerieben wurden, ist durch Janas Rache bedingt. Sie lässt ein Gerücht verbreiten, das dazu führt, dass die bislang unbesiegbaren Taboriten die Schlacht verlieren.

Die Wahl dieser fiktiven Handlungslinie durch Dvořák ist wohl davon motiviert, dass er auf den Fanatismus einiger Gruppierungen - insbesondere der Taboriten und Adamiten, aber auch Žižkas - hinweisen wollte. Dieser Fanatismus bedingt, dass die Positionen zwischen den Gruppierungen unvereinbar werden und dass die Prager letztendlich auf die Seite der Katholiken wechseln und gegen ihre einstigen Verbündeten kämpfen. An Jana, an ihrem Vater Ondřej, aber auch an Žižka und Prokop wird die Blindwütigkeit dargestellt, die einerseits die Kampfkraft der Taboriten und von Žižkas Heer ausmacht, andererseits aber dazu führt, dass gemäßigtere Utraquisten in ihnen eine große Gefahr für das Land sehen. Aus utraquistisch-theologischer Sicht verurteilt die Militanz und Gewalt vor allem Petr Chelčický, der als kritischer Kommentator im ersten und fünften Akt eingeführt wird, selbst aber 
keine Handlungen setzt, die für den Verlauf des Dramas folgenschwer werden. Er, die Prager Hanuš und Rokycana sowie der Jiř́ z Poděbrad kommen mit ihrer gemäßigten Position vielleicht am ehesten einer Sprachrohrfunktion nahe, die - wie auch schon in Dvořáks Král Václav IV. - zu Kompromissbereitschaft mahnt. Nach der vorgeschlagenen Lesart weist das Drama im äußeren Kommunikationssystem eine deutliche Bevorzugung der Position Chelčickýs auf und eine Verurteilung des fanatischen Hussitentums. ${ }^{366}$

Auch wenn das Drama den Fanatismus der Taboriten und Žižkas Hartherzigkeit als wesentliche Momente des tragischen Scheiterns der Hussitenbewegung zeigt, ist nicht zu übersehen, dass mit dieser dennoch ein positives utopisches Ideal verknüpft wird, von welchem nur die negativen Seiten abgezogen werden müssen. Die Hussitenbewegung gilt als Sinn der tschechischen Geschichte, meint etwa Hanuš im Zuge einer pathetischen Liebeserklärung an die Mutter Heimat („„...] svatý kalich Husův je smyslem této země! A vše, co jej kazí, jest této zemi jedem, velkým neštěstím, strašnou zkázou!“"367 - I/2, S. 21). Als er am Ende nach dem Sieg über die Taboriten verkündet, dass die Gefahr vom Land nun abgewandt sei, fügt er hinzu, dass man von Žižkas und Prokops Tugenden lernen müsse, sich zugleich aber auch vor deren Irrwegen hüten solle.

Das ungefähr ein Jahr nach der Proklamation der Tschechoslowakei am Národní divadlo uraufgeführte Drama weist an mehreren Stellen die depräsentierenden Resonanzerscheinungen auf: Äußerungen, die auf die Gegenwart der Rezeption gemünzt sind, werden in die Vergangenheit gelegt. So verkündet im ersten Aufzug Hanuš Schwester Magdalena beim Nähen einer Fahne mit dem utraquistischen Kelch in lyrischen Tönen:

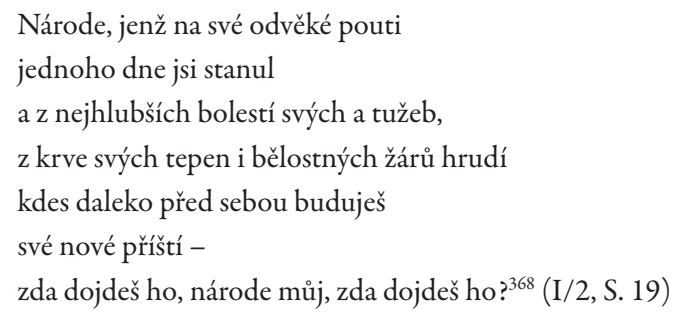

366 Papoušek (vgl. 2010, 327) sieht in einer kurzen Darstellung dagegen ein balancierteres Verhältnis zwischen den ideologischen Positionen.

367 [Hanuš: ] „[...] Hussens heiliger Kelch ist der Sinn dieses Landes! Und alles, das diesem schadet, ist Gift für das Land, ein großes Unglück, eine schreckliche Verderbnis!“

368 [Magdalena:] „Du Volk, das eines Tages auf seiner ewigen Wallfahrt / inne gehalten hat / und jetzt aus den tiefsten Schmerzen und Hoffnungen / aus dem Blut seiner Adern und dem Weißglut der Brust / irgendwo in weiter Ferne vor Dir / Deine neue Zukunft baust - / wirst Du sie erreichen, mein Volk, wirst Du sie erreichen?“ 
In der Rezeption des Jahres 1919 hat die Frage eine mehrfache Referenz: im buchstäblichen Sinn referiert sie auf die Zukunft der Hussitenbewegung, also auf eine historische Vergangenheit. Zugleich aber ist die Gegenwart des Jahres $1919 \mathrm{Zu}$ kunft für die Vergangenheit, ein unabhängiger tschechisch-slowakischer Staat ist ja - etwa in Masaryks geschichtsideologischen Schriften - durchaus als eines der Ziele der Hussitenbewegung proklamiert worden, und schließlich referiert die Frage auf eine Zukunft aus der Sicht des Jahres 1919, als die Tschechoslowakei noch jung und im Begriff war, sich selbst eine Zukunft zu erbauen. Entsprechend zukunftsoffen und -hoffend sind die pathetischen Schlussworte Jiřís z Poděbrad, der an die Jugend appelliert und an die großen Aufgaben mahnt, denen sich diese stellen möchte. Das Schlachten, dessen Ende er verkündet, ist nicht allein das Blutvergießen von Lipany, mit dem die Hussitenkriege ein Ende gefunden haben, es ist auch das des Ersten Weltkriegs, aus dem ein junger Staat hervorgegangen ist, der sich bei seiner Identitätsbildung auf die hussitische Tradition beruft.

\section{IV.8. Diachroner Überblick über Dramen um den hl. Václav/Wenzel}

Der schon bald nach seiner Ermordung als außergewöhnliche Fürstengestalt wahrgenommene Václav I. Přemysl hat die Mythenbildung in zweierlei Hinsicht inspiriert. Václav ist zum einen der erste bedeutende Fürst des tschechischen Mittelalters, zum anderen wurde er wegen seines gelebten Christentums (das sich in Mildtätigkeit, Nächstenliebe, Friedenspolitik etc. äußerte) und wegen seines gewaltsamen Todes bereits im 10. Jahrhundert als Märtyrer und Schutzpatron Böhmens verehrt. Václav wurde zu einer legendären Gestalt der böhmischen Geschichte; bei den unterschiedlichen Ausformungen der Legendenbildung spielte immer auch das nationale Verhältnis von Tschechen und Deutschen hinein, gilt doch Václav als derjenige Fürst, der aufgrund seiner christlichen Haltung den Deutschen eher freundlich gesinnt war.

Václav, der auch als der „himmlische Herrscher Böhmens“ betrachtet wurde, dessen leuchtendem Vorbild seine Nachfolger verpflichtet sind, wurde in der Folklore zum Anführer der im Berg Blaník eingeschlossenen Ritter, die im Fall von allergrößter Not für Land und Leute aus dem Berg heraustreten werden, um die Tschechen zu retten.

Die im Folgenden untersuchten Dramen, die den Václav-Stoff zu ihrer thematischen Vorlage haben, sind jeweils spezifische Beiträge zur Tradierung der Legende, gestalten sie doch die in den Stoff verwobenen Konflikte und Figuren auf unterschiedliche Weise. Die tschechische Verehrung für den Landespatron - wie für andere Heilige, die von der katholischen Kirche als Nationalheilige propagiert wurden (sv. Prokop, sv. Nepomuk, sv. Vojtěch, sv. Marie) - war im obrození im Schwinden begriffen, weil nicht mehr himmlische Fürsprecher, sondern das „Volk“ selbst, seine Natur und seine Vergangenheit gleichsam kultisch verehrt wurden und die katholische Kirche bzw. die Gegenreformation für die Unterdrückung dieses Volkes ver- 
antwortlich gemacht wurde (vgl. Rak 1994, 39f). Weil die während des gesamten Untersuchungszeitraums entstandenen Dramen um den hl. Václav durchaus zahlreich sind, eignen sie sich sehr gut für eine Überblicksdarstellung der Veränderungen in der historischen Dramatik. Im Unterschied zu Pulicarová, die im Rahmen einer Diplomarbeit (Pulicarová 2006) die Veränderungen der Dramatik anhand der Darstellungen von Václav als Figur mit merklicher katholischer Emphase untersucht hat, ist die nachfolgende Analyse auf die politischen Aspekte der Dramen fokussiert, womit es auch leichter wird, die von Pulicarová zwar wiederholt angedeuteten (vgl. ebd., 91), aber kaum ausgeführten zeitgenössischen Bezüge der Václav-Dramen zu erkennen.

\section{IV.8.1. Josef Kajetán Tyl: Krvavé kř̀tiny, čili, Drabomira a její synové: Romantický obraz z dávných dèjin českých ve čtyřech oddèleních (1849)}

[Blutige Taufe oder Drahomíra und ihre Söhne. Romantisches Bild aus der frühen böhmischen Geschichte in vier Abteilungen; UA 11.2. 1849, publ. 1868]

Neben Jan Hus als theatralischem Großereignis, das am Stefanitag 1848 uraufgeführt wurde und somit das Revolutionsjahr 1848 beschloss, war Krvavé krttiny das zweite von drei Theaterstücken, die Tyl während des Reichstags in Kremsier (Kroměřǐz) niedergeschrieben hat. Aus dem schon von Václav Vojáček in Ludmila (siehe oben S. 193ff) behandelten Konflikt zwischen Christentum und Heidentum im frühen 10. Jahrhundert gestaltete Tyl ein veritables Drama zwischen zwei profiliert gezeichneten Antagonisten, das bis in die Gegenwart noch auf tschechischen Bühnen gespielt wird. Der dramatische Konflikt entwickelt sich einerseits - ähnlich wie bei Vojáček - zwischen Drahomíra und ihrer Schwiegermutter Ludmila, zugleich auch andererseits zwischen Drahomíras Söhnen Václav und Boleslav. Wie Jan Hus ist Krvavé kŕtiny von Tyl bewusst mit allegorischer Bezugnahme auf die Entstehungszeit des Stücks verfasst worden (vgl. Otruba/Kačer 1961, 372).

Das Stück setzt mit der Ankündigung der Throneinsetzung Václavs ein, der seinem verstorbenen Vater Vratislav nachfolgen soll. Drahomíra, die Witwe Vratislavs, war mit der Politik ihres Mannes nicht einverstanden, da sie zu einer Abhängigkeit von Fremden, insbesondere vom bayrischen Bischof geführt hat. Sie möchte wieder ein starkes slawisches Reich - ähnlich dem Reich Samos oder dem Großmährischen Reich - aufbauen, trifft dabei jedoch auf Widerstand bei Ludmila und Václav, die anstelle des Schwerts das christliche Wort favorisieren und Krieg und Blutvergießen ablehnen. Drahomíra erklärt Ludmila: „Já nechci slouti matkou knižete, kterýž by panoval nad otroky německého krále. ${ }^{\text {“369 }}(\mathrm{I} / 3,224)$ Das Bündnis mit den christ-

369 [Drahomíra:] „Ich möchte nicht Mutter eines Fürsten heißen, der über die Sklaven des deutschen Königs herrschen würde." 
lichen Deutschen, das Ludmila befürwortet, hält Drahomíra für unnatürlich, es führe zum Untergang des tschechischen Volkes. Václav steht zwischen den beiden Frauen, seiner Großmutter Ludmila, die ihn im christlichen Geist erzogen hat, und seiner Mutter Drahomíra, die ihrerseits meint, zwischen Václav und seinem jüngeren Bruder Boleslav zu stehen (was sich darin zeigt, dass sie - obwohl noch Heidin - zum Kirchenbau beitragen möchte, zugleich aber Boleslavs militante Ablehnung des deutschen Einflusses unterstützt). Der intrigante Hněvsa gibt Drahomíra zu verstehen, dass ihre Antagonistin Ludmila durch Mord beseitigt werden könnte und empfiehlt ihr die Dienste des blutrünstigen Ungarn Tyra, der ein willfähriges Mordinstrument ist. Drahomíra schickt ein tschechisches Aufgebot in den Krieg, um in der Waffenhilfe für brüderliche Stämme die Macht der Tschechen zu demonstrieren und um durch Stärke das Land abzusichern. Als das Volk Klagen über den Kriegsdienst vorbringt, erklärt sie, dass man für das Gemeinwohl Opfer bringen müsse (II/2). Ludmila möchte Václav auf dem Thron sehen; von ihm erwartet sie, dass er Drahomíras unchristliche Politik unterbindet. Diese beauftragt daraufhin Tyra, Ludmila zu ermorden. Von seinen Feldzügen bringt Boleslav seine Frau Světimíra mit, die als Christin von Václav sehr freundlich begrüßt wird und die selbst für ihn mehr Sympathie als für ihren Gatten hat. Václav möchte der offensiven Kriegspolitik Hněvsas Einhalt gebieten, wird von diesem aber weibisch und feige geheißen. Als deutsche Gesandte gegen das Wüten der Tschechen protestieren, kann Václav nicht die Provokation der Gesandten durch Hněvsa unterbinden, die die Kriegserklärung der Deutschen nach sich zieht. Den Mord an Ludmila will Václav nicht rächen, stattdessen meint er, dass der Mörder von Gewissensbissen gequält werden soll. Diese hat freilich Drahomíra als Anstifterin zum Mord. Nach der Kriegserklärung der Deutschen ist sie erst recht in Sorge um ihr Volk. Sie und Boleslav wollen gegen das starke deutsche Aufgebot auch bei Gefahr einer Niederlage kämpfen, da sie dies für ehrenvoller ansehen als in Schmach zu leben. Václav hingegen ist der Auffassung, dass unnötiges Blutvergießen vermieden werden soll, jeder Krieg sei ein Bruderkrieg (III/3, S. 259). Um das Leben der einfachen Soldaten zu schonen, schlägt Václav Heinrich dem Vogler zuerst einen Zweikampf vor; bei der Unterredung erscheint er ihm wie der Erzengel Gabriel. Um den Frieden überhaupt dauerhaft zu sichern, bietet Václav Heinrich die Freundschaft an; dieser fordert dafür jedoch eine Tributleistung von Vieh und Silber, der Václav sogleich zustimmt, aber als Gegenleistung müsse Heinrich die Schirmherrschaft über Böhmen übernehmen und die Verbreitung des christlichen Glaubens fördern (III/7). Drahomíra hält diesen Vertrag für bedrohlich, denn diese Ruhe zwischen den Völkern würde das Leben, das sich im Kampf bewähre und stärke, abtöten. Boleslav ist außer sich über Václavs Abkommen, nur ein Teil des Volkes ist vom so erreichten Frieden ganz begeistert. Kritik am Friedensvertrag wird auch von Popel vorgebracht, das Volk habe nicht dafür Václav die politische Macht übertragen, dass er dann eigenmächtig in Tributzahlungen einwillige und so die Arbeitsleistung des Volkes vergeude. Václav 
rechtfertigt das Abkommen mit dem dauerhaften Frieden, der dem Land zugute komme, er wolle nur das Licht der Wahrheit verbreiten (III/12).

Im vierten Akt kommt es schließlich zu weiteren Gewalttaten aufgrund der unterschiedlichen politischen Auffassungen. Zuerst tötet der heidnische Priester Česta die von Václavs Charisma begeisterte Heidin Velena, seine Enkelin, die sich schützend vor Václav wirft. Bei der Tauffeier für Boleslavs Sohn ist auch Drahomíra geladen, die noch immer von Gewissensbissen wegen des Mordes an Ludmila gequält wird und Václav ihren Mordbefehl gesteht. Gespalten zwischen ihren beiden Söhnen, fleht sie Václav an, nicht an der Feier teilzunehmen, weil Boleslav ihr bereits eine jähe Veränderung in Böhmen angekündigt hat (IV/7, S. 288) Drahomíra teilt Václav aber auch zugleich ihr Missfallen an den Tributzahlungen mit und empfiehlt ihm die Kündigung des Paktes mit den Deutschen. Václav möchte bei der Tauffeier bleiben, weil er als Christ die Gastfreundschaft hochschätzt. Nachdem Boleslav Václav in den Hinterhalt gelockt hat, wird dieser von Hněvsa und dem wahnsinnigen Mörder Tyra erstochen. Das Schlussbild zeigt eine trauernde Drahomíra, der Priester Chrastej spricht die Apotheose Václavs aus: er steht zur Rechten Gottes, sein Name lebt tief im Herzen des christlichen Volks.

Trotz dieser Verklärung Václavs am Ende unterscheidet sich Tyls Drama zum einen von der legendenhaften Darstellung Václavs, Boleslavs und Drahomíras, die seit der Barockzeit eindeutige Bewertungen der Figuren angestrebt hat (vgl. Rak 1994, 41-44), zum anderen auch von Vojáčeks Lobpreisung einer christlichen Herrschaft. Während Ludmila, die Titelheldin Vojáčeks, als Opfer des Mordanschlags zum ungeschmälerten Triumph des Christentums beiträgt, balanciert Tyl den Konflikt besser aus (die Waage ist übrigens rekurrentes Motiv in den Figurenreden, vgl. ,das Wort auf die Waagschale legen' [223], die göttliche Waage' [238], ,die Waage, die den Kampf entscheidet' [266]), indem er den Konflikt zwischen politischer christlicher Nächstenliebe und nationaler Selbstständigkeit doppelt um die Titelfigur Drahomíra aufspannt. Für ein selbstbewusstes und unabhängiges Böhmen eintretend steht sie zwischen ihren Söhnen, wobei sie politisch mit Boleslav sympathisiert, aber dennoch am Thronfolgerecht für Václav festhält. Letzterer steht zwischen den beiden weiblichen Antagonistinnen, seiner Großmutter Ludmila und seiner Mutter Drahomíra. Insofern Drahomíra und Václav nicht allein Mutter und Sohn sind, sondern beide jeweils Verbindungen zu beiden Lagern haben, lassen sich zwischen diesen beiden Hauptfiguren und um diese herum symmetrische Beziehungen feststellen. 


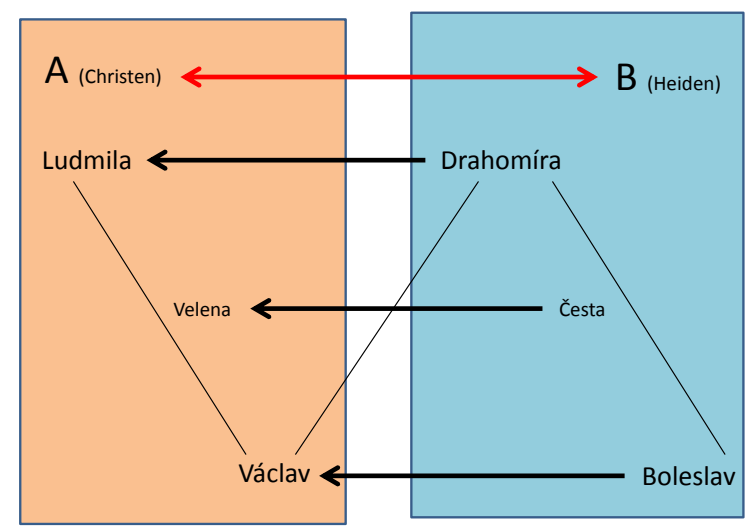

Graphik 30 - Josef Kajetán Tyl: Krvavékřtiny, čili, Drahomira a její synové (1849)

Es wiederholt sich auch der Mord: die leibliche Mutter Václavs ermordet Ludmila, die als seine geistliche Mutter gelten kann (eigentlich ist sie ja die Großmutter), Boleslav wiederholt den Mord am politischen Opponenten, der zugleich sein Bruder ist. In einer „romantischen“ Nebenhandlung gibt es einen dritten Mord, der dieser Struktur entspricht. Der heidnische Priester Česta tötet seine Enkeltochter Velena, die mit Václav sympathisiert.

Wie das Schema zeigt, geht der Konflikt zwischen Christentum und Heidentum bzw. zwischen christlich inspirierter Nachbarschaftspflege und nationaler Stärke durch die Familien (vgl. Otruba/Kačer 1961, 373). Tyl lässt die Figuren entsprechend über die Zusammenhänge zwischen Verwandtschaft und politischer Allianz räsonieren. Vom heidnischen Priester Česta wird Václav gleich zu Beginn als „fürstlicher Sproß, der in den Händen fremdgläubiger Gärtner erblühte “370 charakterisiert, Drahomíra begründet ihre Militärhilfe für slawische Nachbarstämme mit dem nötigen Mitleid für die Brüder eines Reises. ${ }^{371}$ Česta verflucht alle, die der , heiligen Linde“ - dem Symbolbaum der Slawen - „die Wurzeln abgraben“ ${ }^{372}$ Ludmila adressiert er als die „Gebärerin der verdorbenen Frucht“. Sie habe mit ihrem verstorbenen Mann Bořivoj eine Giftpflanze gezüchtet, wegen deren Samen vierzehn verblendete Fürsten zu jenen tauben [němým] Ausländern gelaufen seien. ${ }^{373}$ Václav ist demnach für Česta die „Knospe des verdorbenen Baums“, dem die neue Lehre

370 [Česta:] „[...] letorost knížecí, ježto vzkvětla v rukou cizověrných zahradníkư“ (I/1, S. 216).

371 [Drahomíra:] „[...] lásku k rodu vlastnímu i slitování nad bratry štěpu jednoho“ (I/3, S. 220).

372 [Česta:] „[...] podkopali kořen lípy posvátné [...]“ (ebd.).

373 [Česta:] „[...] roditelko zkaženého ovoce [...] Ty jsi pěstoval s Bořivojem jedovatou bylinu, pro jejižto símě čtrnácte zaslepených lechů k těm němým cizozemcům zaběhlo." (I/3, S. 221) 
befehle, das "slawische Leben bis auf die Wurzel auszumerzen“. ${ }^{374}$ Das Bündnis mit den Deutschen erscheint entsprechend als „unnatürliche Freundschaft" [nepřirozené prátelství - I/3, 224] oder als „böser Frost, der auf die Blüte des nationalen Gottesdienstes niederkommt, das slawische Wort, den slawischen Gesang erstickt und hungrige Fremdlinge ins Land holt. ${ }^{\text {“375 }}$ Dies sagt Hněvsa, der wie Drahomíra nur nach außen hin Christ ist, für die moralischen Konsequenzen der neuen Lehre und die politischen Implikationen aber überhaupt kein Verständnis aufbringt.

Es sind vor allem die heidnischen Gegner Václavs, die eine biologische Metaphorik in politischen Überlegungen verwenden und die christliche Politik Václavs dementsprechend als schädlich für das „Leben“ des tschechischen Volkes bzw. der Slawen überhaupt ansehen. Der das Drama prägende Konflikt der beiden Lager ist dadurch „ausbalanciert", 376 dass die moralische Überlegenheit Václavs mit seiner außenpolitischen Schwäche und Nachgiebigkeit einhergeht, die seinen innenpolitischen Gegnern Anlass für ein moralisch verwerfliches, nationalpolitisch aber durchaus verständliches Handeln geben. Auf konnotativer Ebene wird der Konflikt um die Pole „Kultur“ vs. „Natur“ erweitert. Auch wenn die Taten der „Heiden“ - drei Morde an frommen Menschen - abstoßend erscheinen, tut dies der biologischen Metapher insofern wenig Abbruch, als diese nicht wirklich diskutiert oder in Frage gestellt wird. Die Applikation des Bildspenders „Natur“ auf die Politik erscheint genauso unwidersprochen wie die in dieser Metaphorik geäußerten Urteile. Weil also diese Metaphorik (Drahomíra verbindet die Einheit der Slawen mit der „Natur") nicht konterkariert wird, kann in der ausbalancierten ideologischen Architektur des Dramas eine Neigung zur nationalen Position Drahomíras und Boleslavs ausgemacht werden (vgl. Otruba/Kačer 1961, 374f). Bei der Premiere am 11. Februar 1849 haben laut Zeitungsbericht die Zuschauer minutenlang geklatscht, als Drahomíra den untätig bleibenden Václav auf Knien anfleht, das Schwert zu ergreifen und gegen die Erniedrigung durch die Deutschen vorzugehen (vgl. Ježková/ Ludvová 2013, 81).

Die Idee einer nationalen Selbstständigkeit und die Bindung an slawische Stämme kann wohlbegründet auf die romantischen Vorstellungen von einer slawischen Gemeinsamkeit zurückgeführt werden (vgl. Otruba/Kačer 1961, 373). Dass aber die repräsentierten Probleme einer christlichen Politik per analogiam auf die Demokratiebestrebungen zu beziehen wären, erscheint doch ein wenig schema-

- Die Replik spielt auf die urkundlich bezeugte Taufe von vierzehn tschechischen Stammesführern in Regensburg an.

374 [Česta:] „[...] ty poupě stromu zkaženého, - [...] Do kořene vyhubit život slovanský velí tobě nové učení " (ebd.).

375 [Hněvsa:] „Ale ty jsou právě zlá jinovatka, co padá na květ bohoslužby národní - a co nám slovanské slovo, slovanské zpěvy udusí a hladových cizáků do země nasadí.“ (II/7, S. 248)

376 Auch Pulicarová schätzt die Balance der Positionen in Tyls Stück, das sie für das künstlerisch gelungenste der Dramen um den hl. Václav hält (vgl. Pulicarová 2005, 9). 
tisch. Der von Otruba/Kačer vorgeschlagene Analogieschluss lautet, dass die in Tyls Drama dargestellten Widersprüche zwischen heidnischer nationalbewusster Kampfbereitschaft und entschlossenem, dabei aber außenpolitisch naivem christlichen Ethos im intendierten Bezugszeitrahmen 1849 den Konflikt zwischen Nationalbewusstsein und Demokratie reflektieren. Allerdings gibt es für den postulierten Zusammenhang zwischen Nächstenliebe und Demokratie in Krvavé kŕtiny überhaupt keine plausible Grundlage im Text. Otruba/Kačer sind der Auffassung, dass Drahomíras Schwanken in der Liebe zu beiden Söhnen Tyls Schwanken beim Reichstag in Kremsier entspreche: So, wie Drahomíra den Konflikt zwischen den Söhnen sieht und vorausahnt, dass der von ihr in seinem nationalpolitischen Eifer bestärkte Boleslav seinen Bruder Václav töten wird, hätte Tyl 1849 die Position der Tschechen im Reichstag wahrgenommen. Er musste letztlich mit Vorbehalten zustimmen, dass sich die tschechischen Abgesandten gegen den ersten Artikel der Verfassung aussprechen, in dem erklärt werden sollte - was der Wiener Regierung missfiel -, dass alle Macht vom Volk ausgeht. ${ }^{377}$ Das Abstimmungsverhalten der Tschechen sei dadurch motiviert gewesen, dass man sich durch ein konformes Verhalten eine bessere Situation für die eigene Nation erwartete.

Eine so stark zeitbezogene Interpretation des Konflikts erscheint auch deswegen überzogen, weil die historische Verortung allzu spezifisch und allenfalls Spezialisten der tschechischen Geschichte bekannt ist. ${ }^{378}$ Viel näher liegt doch die Bezugnahme auf das tschechisch-deutsche Spannungsverhältnis im 19. Jahrhundert: Die Partei von Drahomíra und Boleslav favorisiert die separatistische Abgrenzung von allen Deutschen, Václav und Ludmila hingegen machen gemäß den christlichen Geboten keine Unterschiede zwischen Tschechen und Deutschen, wobei letztere durch das Entgegenkommen Václavs begünstigt werden. Das Verhältnis der Tschechen zu den Deutschen war ja 1848 gleich in dreierlei Hinsicht aktuell: erstens war das Verhältnis zur deutschsprachigen Bevölkerung in Böhmen im 19. Jahrhundert stets prekär, zweitens musste die tschechische Nationalpolitik mit der Wiener Regierung rechnen (was etwa im geschilderten Abstimmungsverhalten in Kremsier zum Ausdruck kommt), drittens wurde ja zur Entstehungszeit von Krvavé křtiny mit der Frankfurter Nationalversammlung die Bestrebung erneut aktuell, alle Deutschen - und mit den Deutschen vielleicht auch gleich die Tschechen - in einem Nationalstaat zusammenzufassen. Dass der allegorische bzw. ,analogische“ Bezug von Tyls Drama eher in diesem permanenten Spannungsfeld als im konkreten Abstimmungsverhal-

377 Urban (vgl. 1982, 74) weist gleichfalls auf die Unterschiede zwischen den ursprünglichen Forderungen und dem Abstimmungsverhalten hin; er erklärt es damit, dass die Delegierten einen offenen Konflikt mit der Regierung vermeiden wollten.

378 Hoensch (1992) etwa erwähnt die Diskrepanz zwischen den Diskussionen und dem Abstimmungsverhalten gar nicht. 
ten der böhmischen Fraktion in der Reichsversammlung zu Kremsier am 10. Jänner 1849 liegt, muss aus heutiger Sicht wohl als plausibler gelten.

Tatsächlich macht Tyls letztes historisches Drama den Eindruck, für keinen der vorgeführten Standpunkte - weder für eine christliche und damit deutschfreundliche noch für eine militant nationalistische - klar zu votieren; die Motive und Momente der beiden repräsentierten Konfliktparteien erscheinen nachvollziehbar und politisch gerechtfertigt. Hiermit unterscheidet sich Krvavékŕtiny klar von Kutnohorstí havíri und von Jan Hus, den beiden vorausgegangenen historischen Dramen Tyls, in welchen sich die Antagonisten viel eindeutiger bewerten lassen, weil die Voraussetzungen, Motivationen und Implikationen von Handlungsketten der Interpretation wenig Spielraum einräumen.

Man vergleiche die schematischen Reduktionen der Konfliktparteien und ihre ideologischen bzw. positionellen Entsprechungen:

\begin{tabular}{|c|ccc|}
\hline & A & $\leftrightarrow$ & B \\
\hline Kutnohoršti havirí & Knappen & $\leftrightarrow$ & Bergherren \\
\hline Jan Hus & Tschechen & $\leftrightarrow$ & Klerus \\
\hline Krvavé křtiny & Boleslav & $\leftrightarrow$ & Václav \\
\hline mögl. Analogie? & Tschechen & $\leftrightarrow$ & (Deutsche?) \\
\hline
\end{tabular}

Der entscheidende Unterschied zwischen den drei prominentesten historischen Dramen Tyls ist schlechthin der, dass in Kutnohoršti haviri wie auch Jan Hus ein klarer Antagonismus vorgeführt wird, der durch den entschlosssenen Kampf gegen die Widersacher der jeweiligen Vertreter des „tschechischen Volks“ (vgl. die unter "A“ angeführten Positionen) überwunden werden könnte. Die „Widersacher“ sind negativ dargestellt: Während sie in der Tragödie von Kutná Hora die Unterdrückung aufrechterhalten können, verheißt Jan Hus ein Aufbegehren. Krvavé krttiny jedoch ist insofern verschieden, als die Antagonisten nicht die Nicht-Tschechen sind, sondern der Konflikt zwischen den Brüdern Boleslav und Václav (bzw. ihren „Müttern“ Drahomíra und Ludmila) verläuft. Vorgeführt wird nun vor allem der Streit zwischen politischen Positionen: nationaler Kampf einerseits (Drahomíra, Boleslav) und ,appeasement“/smireneni-Politik andererseits (Ludmila, Václav). Strukturell ist die Differenzierung des tschechischen Lagers auch schon in Kutnohorstí haviríi angelegt, gibt es doch darin die konfligierenden Strategien des bedächtigen Opat einerseits und des radikaleren Vít andererseits. Der tragische Ausgang von Kutnohorstí haviři gibt Vít im Nachhinein eigentlich Recht (wie dieser es prophezeit hatte, waren die Bergherren auf der Gegenseite abgefeimt, heimtückisch und unnachgiebig), doch fühlt er sich mit seinem entschlosseneren Handeln auch nicht ganz unbeteiligt an der fatalen Entwicklung. In Jan Hus stellt sich die Frage nach der Strategie des Kampfes gar nicht, dieser wird vielmehr als gerechtfertigt darge- 
stellt. Krvavé křtiny hingegen exponiert noch einmal die alternativen Positionen: die friedliche Position der Christen gefährdet die Nation, weil sie im Antagonisten nicht den Feind erkennt und sich diesem unterordnet. Ist das dargestellte Problem mit der christlichen Politik dasjenige der Subordination (entsprechend der radikalen evangelischen Forderung, auch die linke Backe hinzuhalten, wenn jemand auf die rechte schlägt), so besteht das Problem bei der Politik des nationalen Kampfes eben darin, dass so viel Blut fließt. Zeitgleich mit dem Scheitern der Revolution von 1848 hat Tyl in großer Deutlichkeit die große politische Alternative von nationalem Kampf und internationalen Verbindungen bzw. Verpflichtungen dargestellt, ohne klar für eine Position zu votieren.

\section{IV.8.2. Jan Dvorský: Drahomíra. Dramatický obraz z českých dèjin v třech jednánich (1859)}

[Drahomíra. Dramatisches Bild aus der böhmischen Geschichte in drei Akten; entst. 1859, publ. 1863, unaufgef.]

Das mit der Apostrophe „muži národa“ („dem Mann des Volkes“) dem lange Zeit wichtigsten Politiker der tschechischen Nationalbewegung in der zweiten Jahrhunderthälfte, nämlich František Ladislav Rieger, gewidmete Drama weicht sehr stark von Tyls Fassung ab, wodurch sich eine viel entschiedenere Parteinahme in der äußeren Kommunikationssituation und ein ideologisch klares Fazit ergibt. Der Autor Jan Dvorský ist weitgehend unbekannt, was sich etwa daran zeigt, dass es über ihn keinen Eintrag im Lexikon české literatury gibt. ${ }^{379}$

Die Titelheldin Drahomíra ist in dieser Tragödie eine noch entschiedenere Vertreterin des Heidentums. Sie schreckt nicht vor einem Mordversuch an Boleslav zurück, als dieser nach dem Mord an seinem Bruder Vácslav von Gewissensbissen geplagt wird und reumütig zum Christentum übertreten möchte. Aufgrund einer dramaturgisch etwas simplen Vertauschung der Trinkbecher wird jedoch Drahomíra zum Opfer ihres eigenen Mordversuchs und Boleslav zum Fürsten in Böhmen.

Der Kampf zwischen der alten heidnischen Welt und dem neuen christlichen Glauben, dem die Proponenten des Christentums, Ludmila und Vácslav, zum Opfer fallen, wird mit dem Tod Drahomíras eindeutig zu Gunsten eines christlichen Herrschertums entschieden, das Vácslav auf eine ganz andere Weise energisch vertritt, als er das in Tyls Version tut. Er ist nämlich sofort zum militärischen Verteidigungskampf entschlossen, als er erfährt, dass die Deutschen zum Angriff rüsten

379 Aus den Nachbemerkungen des anonymen Herausgebers geht nur hervor, dass es sich mit Dvorský um einen im literarischen Leben unbekannten Mann handelt, der im Jahr 1863 bereits im 58. Lebensjahre steht. 
(I/2), allein in der Strategie unterscheidet er sich von seinem Bruder Boleslav, der den Deutschen entgegenziehen möchte und die von Vácslav beabsichtigte Konzentration der tschechischen Truppen um Prag ablehnt. Der Konflikt zwischen den beiden Brüdern steigert sich aber durch das großzügige Friedensangebot des siegreichen Vácslav an die Deutschen, welches Boleslav und Drahomíra als Preisgabe der Landesfreiheit auffassen (I/5), das Vácslav aber deshalb unterbreitet, um das Christentum in Böhmen ohne äußere Bedrohung stärken zu können. Nach der Abwehr der Deutschen im ersten Akt ist der zweite Akt von der Auseinandersetzung zwischen Vácslav und den Gegnern des Friedensvertrags mit den Deutschen geprägt, was faktisch ein Bürgerkrieg unter den Tschechen ist. Vácslav ist schweren Herzens auch hier zur militärischen Auseinandersetzung entschlossen; es gelingt ihm, seine Anhänger unter der Losung „Pro slávu Boží, pro vlast a vévodu!“380 (II/3) zu versammeln und seinen Gegner Radslav Zlický im Zweikampf zu besiegen. Vácslav vertritt seine Politik, die wie bei Tyl mit Opfern verbunden ist, aber gut begründet erscheint, durchaus entschlossen; er greift auch zu den Waffen, wenn die Gegnerschaft zu seiner Position zu vehement wird.

Im dritten Akt sieht Boleslav seine Chance, die Herrschaft zu erlangen, wenn er Vácslav ermorden lässt. Als dies unter himmlischen Vorzeichen geschieht, befällt Boleslav die reuige Erkenntnis, dass er einen Brudermord verübt hat. Er ist zwar zur Herrschaft entschlossen, doch erscheint diese gefährdet, weil das Volk seine und Drahomíras Taten verurteilen würde. Von christlicher Reue erfasst, fordert er auch Drahomíra zur Annahme des Christentums auf, was diese allerdings entschieden ablehnt. Stattdessen sinnt sie sogar auf Mord an Boleslav und mischt Gift in seinen Becher. Sie verwechselt die Becher jedoch, was dieser als Triumph des Himmels deutet; er sieht den unfreiwilligen Tod Drahomíras als Beweis dafür, dass er mit der Annahme des Christentums den richtigen Weg gewählt hat. „Hle, zjasněné oko nebeské tou zde usmířeno obětí radostně pohlíží na naše vítězstvi'. ${ }^{381}$ (III/4) Boleslav setzt nun im Wesentlichen Vácslavs christliche Politik fort, seine Führungsvision drückt er mit der Schifffahrtsmetaphorik aus:

Já pevně vesla vlády se uchopím a koráb, jenž na rozbouřeném moři bez veslaře od zkázy zachráním, zlobivé vlny v stěny lodě peroucí ukrotím a břehu - spásného cíle dospěju! Však orel jsem já, jenž roztočenýma křídloma mocně pere vzduch a skrz oblaky deštivé, křižujícími se blesky provázen k zř́dllu světla, k slunci uletá. ${ }^{822}$ (III/3, S. 45)

380 „Zum Ruhm Gottes, für die Heimat und den Herzog!“

381 [Boleslav:] „Siehe, das aufgehellte himmlische Auge, das von diesem Opfer hier besänftigt wurde, blickt freudig auf unseren Sieg."

382 [Boleslav:] „Ich nehme das Ruder des Herrschers fest in die Hand und rette den Kahn auf dem aufgepeitschten Meer ohne Ruderer vor dem Untergang, ich besänftige die bösen Wellen, die gegen die Wände des Boots schlagen und werde das rettende Ziel erreichen. Doch bin ich ein Adler, der mit weit ausgespannten Flügelns mächtig die Luft peitscht und durch 
Als christlicher Fürst wendet Boleslav sich an die Lechen als Vertreter des tschechischen Volkes und fordert sie zum Schwur auf, in der linken Hand das Kreuz zu halten, um das Licht des Glaubens zu verbreiten, in der Rechten aber das Schwert, um die Nation zu verteidigen. (,[...] a př́sahejte, že po celý život váš chcete nosit v levé ruce kříž, šírít světlo víry, v pravé meč, hájit’ národnost! ${ }^{\text {“383 }} \mathrm{III} / 4, \mathrm{~S}$. 50)

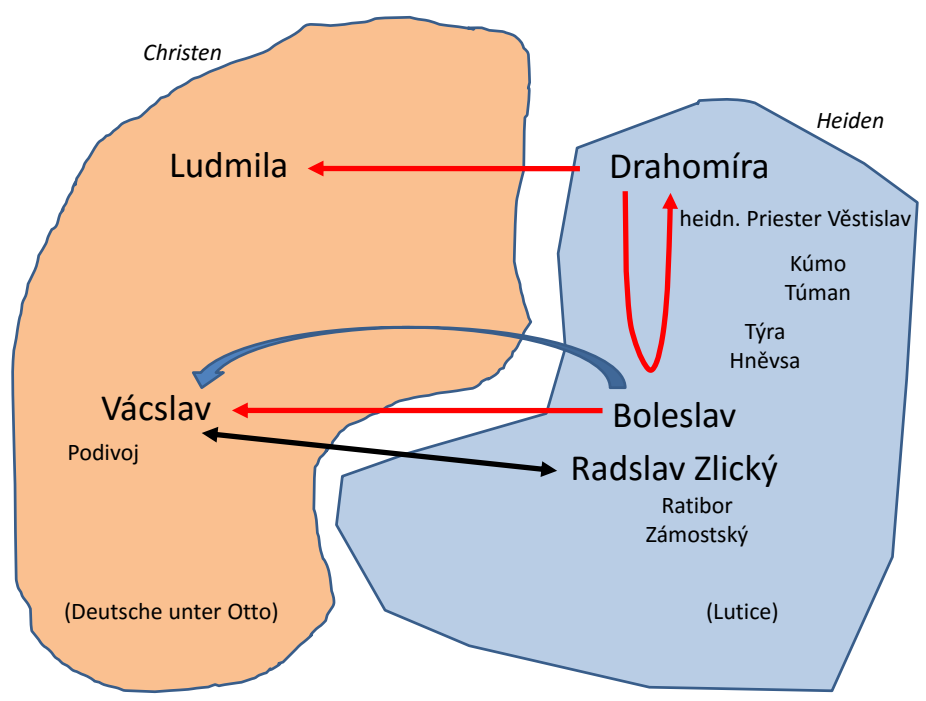

Graphik 31 - Jan Dvorský: Drahomira (1859)

Zumal der Schluss ein zum Kampf gegen die Deutschen entschlossenes tschechisches Volk zeigt, erscheint Vácslav als Vermittler, dessen Untergang wesentlich zur Etablierung des Christentums beiträgt. Demnach könnten in dialektischer Interpretation Drahomíra und Vácslav als These und Antithese gesehen werden, die die Synthese Boleslavs aufhebt. Da dieser das Christentum mit der militärischen Verteidigung des Volkes verbindet, ist Dvorskýs Drahomíra das Gegenteil - um nicht zu sagen die Antithese - von Tyls Drama, in dem die Gegensätze Christentum und nationale Selbstbehauptung gleichsam als unvermittelbar erscheinen.

die Regenwolken, von sich überkreuzenden Blitzen begleitet zur Quelle des Lichts, zur Sonne fliegt."

383 [Boleslav:] „Und gelobt, dass ihr euer ganzes Leben in der linken Hand das Kreuz tragen werdet, um das Licht des Glaubens zu verbreiten, und in der Rechten das Schwert, um die Nation zu verteidigen!“ 


\section{IV.8.3. Jaroslav Vrchlický: Česká trilogie (1882-1903)}

IV.8.3.1. Drahomira. Tragedie v pèti jednáních (1882)

[Drahomíra. Tragödie in fünf Akten; UA 1882, publ. 1883]

Das umfangreiche schriftstellerische Werk von Jaroslav Vrchlický enthält auch einige Stücke, die man als pseudohistorische Dramen bezeichnen könnte. Herta Schmid (2006) hat in einer stark formorientierten Studie deren Gattungsbezeichnung „,historisches Drama" unter Anführungszeichen gesetzt, weil sie zur Auffassung kommt, dass Vrchlický mit der Wahl von Stoffen aus der Geschichte anderer Völker zum einen die künstlerische Freiheit unterstreichen wollte, weil er sich von der Erwartung distanzierte, sich mit der böhmischen Geschichte zu befassen, und zum anderen in diesen „historischen Dramen“ die Möglichkeiten des strukturellen Aufbaus von Komödie und Tragödie erkundete. Er hat aber auch Stoffe aus der böhmischen Geschichte für konventionellere historische Dramen bearbeitet. ${ }^{384} \mathrm{Im}$ Zusammenhang mit dem Wandel des Václav-Stoffs werden hier die ersten beiden Dramen der »Böhmischen Trilogie « besprochen; Knižata, der dritte Teil der Trilogie, führt die historischen Folgen des Brudermords vor, die in innertschechischer Uneinigkeit bestehen (vgl. Berwanger 2003, 71-75; Deutschmann 2008, 31-33). ${ }^{385}$ Drahomíra, der erste Teil, schildert die Machtkrise, die mit dem Tod von Vratislav eintritt und die mit der Inthronisierung von Václav ein vorläufiges Ende findet (bezogen auf die historischen Ereignisse umfasst dieses Drama also einen Zeitraum, der von Tyl in den ersten beiden Akten von Krvavé kŕtiny dargestellt wird).

Die entscheidende politische Instanz in Vrchlickýs Drama ist immer der Sněm (der Landtag der Adeligen), welcher Interessenskonflikte zu lösen versucht. Diese bestehen zuerst in der Vertretung für den erstgeborenen Thronfolger Vácslav/ Václav, der noch ein Kind ist und noch nicht allein regieren kann. Ludmila, die Mutter des verstorbenen Fürsten Vratislav, versucht, die noch unsichere Sache der Christen in Böhmen zu befestigen, indem sie meint, Drahomíra könne nur dann Vácslav vertreten, wenn sie in christlichem Geist herrsche und zudem ihr die Erziehung ihrer beiden Söhne Vácslav und Boleslav überlasse. Drahomíra ruft deswegen den Sněm bzw. Landtag an („Však této země starý obyčej,/ jejž nezrušišs ni ty, ba ni tvůj bůh, / u věcech vlády vyhrazuje vždy / jen sněmu rozhodnutí poslední. ${ }^{\text {“386 }}$ - I/4, S. 27). Dessen Sprecher Radslav Zlický ist ihr immer nahege-

384 Die meiner Kenntnis nach bislang umfassendste Analyse von Vrchlický historischen Dramen aus der böhmischen Geschichte erschien einigermaßen obskur in zwei Jahresberichten der k.u.k Realschule Tábor.

385 Knižata hat bereits 6 Akte, Zeitgenossen Vrchlickýs haben erwartet, dass aus der Böhmischen Trilogie eine Tetralogie erwachse (vgl. Strúbrný 1908, 12).

386 [Drahomíra:] „Es ist jedoch alte Sitte in diesem Land, / und diese hebst nicht du auf, und nicht dein Gott,/ in Angelegenheiten der Macht bestimmt / allein die letzte Entscheidung des Sněms." 
standen. Nun hat Drahomíra eine Vorahnung davon, dass der Sněm nicht mit ihr konform geht, obwohl auch dieser noch dem Heidentum anhängt und Ludmilas Christentum ablehnt. Über das im adeligen Sněm repräsentierte Volk meint Drahomíra abfällig, dass man auf dieses nicht bauen dürfe: „Však stavět na lid - to jest na pokraj / si lehnout podemleté skaliny “387 (II/1, S. 28). Der Sněm überträgt Drahomíra zwar die Vertretung für Vácslav; die Erziehung von Vácslav und Boleslav soll aber Ludmila übernehmen. Die Beratung des Sněm ist auch strukturell ins Zentrum des Dramas gestellt, sie findet im dritten Akt der fünfaktigen Tragödie statt (vgl. Berwanger 2003, 64). Drahomíra akzeptiert diese Lösung nicht, da sie in einem Kompromiss besteht („Když děti ztratím - tratím korunu, když získám ji, co ona bez dětí? “"388 - II/1, S. 29), sie aber alles haben möchte. Ihr Ratgeber, der heidnische Priester Větruš, hat vorsorglich ihre Kinder auf die Burg Kazín entführen lassen. Damit aber verletzt Drahomíra den rechtsetzenden Spruch des Sněm, der diesen mit Waffengewalt erzwingt - übrigens nach Aufforderung durch die christlich gestimmte Ludmila und den Bischof Pavel, die damit um ihre Einflusssphäre kämpfen. Die Burg wird erobert und die Kinder werden Drahomíra genommen. Radslav unterstreicht Drahomíra gegenüber schon früh die Autorität des Sněm:

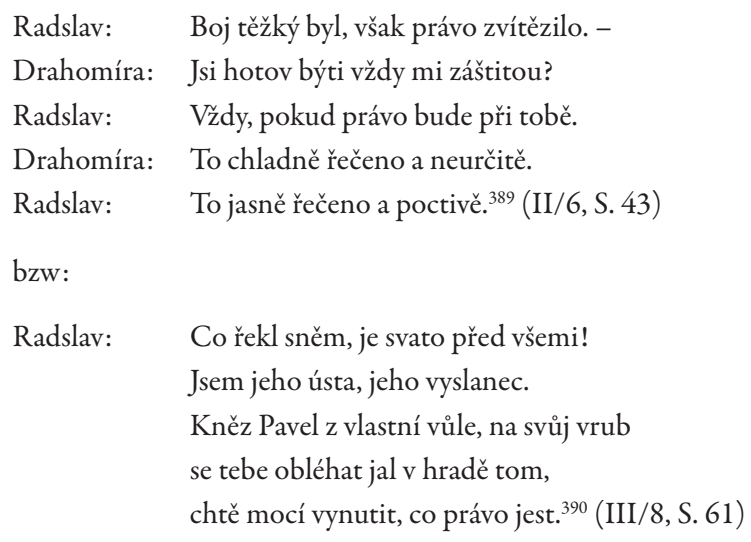

387 [Drahomíra:] „Aufs Volk aber zu bauen, ist dasselbe / wie sich an den äußersten Rand eines unterspülten Felsens zu legen.“

388 „Wenn ich die Kinder verliere, verliere ich die Krone, wenn ich sie gewinne, was ist sie ohne die Kinder?"

389 [Radslav:] „Der Kampf war hart, doch das Recht hat gesiegt.“ [Drahomíra:] „Bist Du bereit, mich immer zu verteidigen?" [Radslav:] „Immer, solange das Recht auf deiner Seite ist.“ [Drahomíra:] „Das ist kalt und unbestimmt gesagt.“ [Radslav:] „Das ist klar gesagt und ehrenhaft."

390 [Radslav:] „Was der Sněm gesagt hat, ist vor allem heilig. / Ich bin sein Sprecher, sein Botschafter. / Der Priester Pavel hat aus eigenem Willen / auf eigene Faust angefangen / Deine 
Der Sněm möchte eine Unterordnung unter die Deutschen, wie Ludmila sie vorschlägt, vermeiden. Drahomíra soll daher die politische Vertretung für Vácslav übernehmen, dafür aber auf die Erziehung ihrer Kinder verzichten. Gegenüber der Autorität des Sněm versucht sie auch ihr Recht als Mutter durchzusetzen, das sie als naturgegeben wähnt, welches aber Radslav geringer gilt als der Spruch des Sněm. Er erklärt: „Vlast káže - matka musí ustoupit!"391 (III/8, S. 62) Der Sněm als rechtsetzende Institution ist im Stück aber keine fraglos hingenommene Autorität, Drahomíra meint sogar, die in ihm vertretenen Adeligen würden allein ihre partikularen Interessen verfolgen, hätten aber keinen Sinn für das ganze Land, dessen Stärke und Wohlergehen ihr am Herzen liegen.

Ludmila hat heimlich eine Gesandtschaft zu den Deutschen losgeschickt, welche die Unterwerfung des Landes unter die deutsche Herrschaft bekanntgeben soll, vermöge derer das Christentum in Ruhe weiter verbreitet werden könne. Die Gesandtschaft wurde aber unterwegs abgefangen und Drahomíra muss über sie befinden. Sie ist rasch entschlossen, die in ihren Augen verräterischen Gesandten umgehend töten zu lassen, weiß aber nicht, dass sich auch Vácslav und Boleslav unter diesen befinden. Ob des Fanatismus des heidnischen Priesters Větruš sind Drahomíras Kinder tatsächlich gefährdet.

Mit der Festnahme der Gesandtschaft hat Drahomíra nun drei Motive für den Mord an Ludmila, die alle mit ihrem Verlust an Macht verbunden sind (wegen "Gattenraubs“ - ihr verstorbener Mann Vratislav ist zum Christen geworden, wegen „Kindesraubs“ und Landesverrats). Als sie nach vollbrachter Tat meint, sie habe ihren Machtbereich ausgeweitet bzw. bestätigt, muss sie aber erfahren, dass ihre Kinder, die über den Mord an Ludmila entsetzt sind, sie ablehnen. Der Priester Pavel, den Drahomíra in den Kerker werfen möchte, erklärt im Namen kirchlicher Macht, dass einer mordenden Herrscherin niemand Gefolgschaft leisten müsse. Drahomíra ruft den Sněm zur Entscheidung darüber an, wer die Befehlsgewalt habe. Dieser hat auf Veranlassung Radslav Zlickýs aber schon früher entschieden und ihr die Herrschaftsgewalt entzogen. Radslav verkündet ihre Entmachtung und die Inthronisierung Vácslavs als neuen Herrscher über Böhmen, Drahomíra soll sich aus dem politischen Leben zurückziehen. Diese begeht ob dieser doppelten Ablehnung ihrer Person (durch Kinder und Sněm) Selbstmord.

In Drahomira entscheidet der Sněm somit immer über die Zuteilung der Macht: alles, was er beschließt, gilt als rechtmäßig. Der Sněm als Repräsentation des böhmischen Adels setzt sich auch über "Naturrecht" hinweg, was sich darin zeigt, dass das Recht der Mutter auf Erziehung ihrer Kinder weniger gilt als ein Beschluss des Sněm). Aufgrund des Umstands, dass Drahomíra als Herrscherin den Sněm weitge-

Burg zu belagern / er möchte mit Macht erzwingen, was rechtens ist.“

391 [Radslav:] „Die Heimat befiehlt - die Mutter muss nachgeben!“ 
hend übergeht und seinen Einfluss mindern möchte, beschließt er auch die Übertragung der Macht an Vácslav.

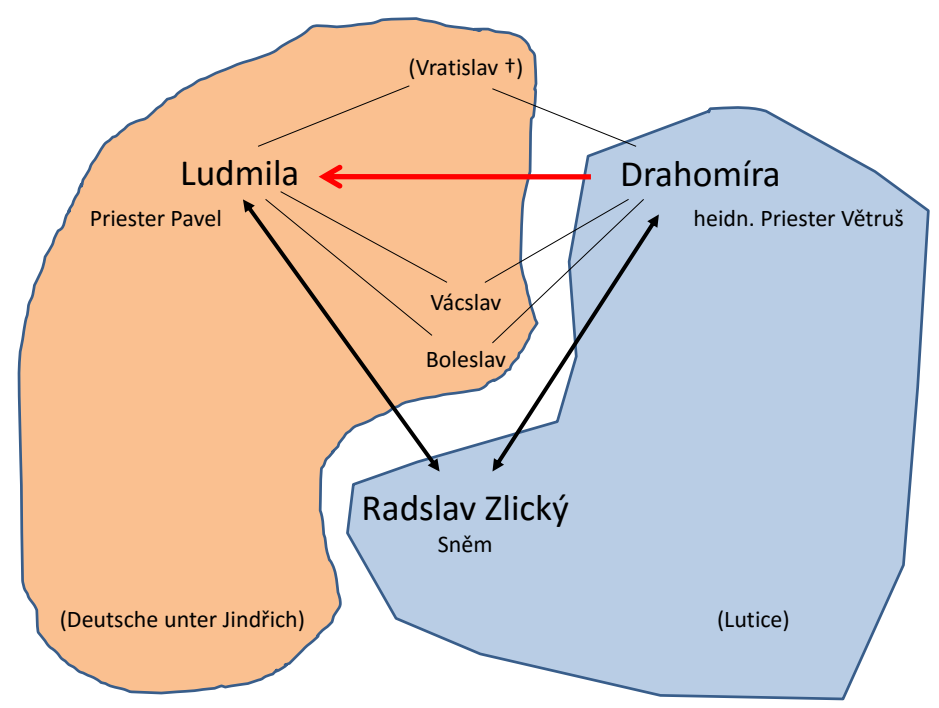

Graphik 32 - Jaroslav Vrchlický: Drahomira (1859)

Die Ansprüche einer Herrscherin auf absolute Macht (im privaten, innen- wie auBenpolitischen Bereich) werden in diesem Stück als unangemessen dargestellt, die Alternative - die Meinungsbildung der Adeligen im Sněm - aber als problematisch, hinter dieser stehen auch partikuläre Interessen. Die christliche Alternative ist zum einen wie bei Tyl mit außenpolitischer Unterordnung verbunden, zum anderen wird angedeutet, dass auch christliche Herrschaft mit Gewalt ihr Recht durchsetzen kann. So sind etwa Ludmila und ihr Priester Pavel durchaus entschlossen, mit militärischen Mitteln die vom Sněm ihnen zur Erziehung zugesprochenen Kinder Vácslav und Boleslav zurückzuholen (vgl. II/7). Ihre politischen Überlegungen sind zwar deutlich vom Interesse geleitet, das Christentum in Böhmen durchzusetzen, sie erscheinen dabei aber in der Einschätzung ihrer Gegner durchaus vernünftig und konsequent in der Forderung nach Durchsetzung der Beschlüsse des Sněm.

Drahomíra zeigt in der Konfliktstruktur nicht zwei Parteien, die gegeneinander stehen, wie es bei Tyl und Dvorský der Fall war, stattdessen sind es deren drei: die christliche Orientierung Ludmilas und ihres Priesters Pavel zum einen, zum zweiten Drahomíras Ansprüche auf möglichst große Macht, um das Land vor einer Unterordnung unter die Deutschen zu bewahren, zum dritten die Institution des Sněm, der zwar als Repräsentation des Adels und des Volkes gilt, gleichwohl aber eigene politische Interessen hat, sich also etwa nicht einer zentralen Fürstengewalt unter- 
ordnen möchte. Die tragische Handlung ist um die Titelfigur Drahomíra konzentriert, die ihre maximalen Ansprüche nicht durchsetzen kann und letztendlich auf politischer Ebene wie auch auf persönlicher Ebene scheitert und Selbstmord verübt.

Mit diesem tragischen Ende schließt die 1882 im Národní divadlo aufgeführte Fassung von Drahomira als selbstständiges, abgeschlossenes Drama. Eine handschriftliche Urfassung unterscheidet sich von dieser auch in der Zeitschrift Kvèty 1882 gedruckten Fassung der Uraufführung darin, dass Drahomíras Selbstmord in der Schlussszene von Vácslav verhindert wird, der ihren Arm zurückhält und ankündigt, als verzeihender Herrscher für ein Klima sorgen zu wollen, welches den Beifall der seligen Ludmila finden würde. Drahomíra beklagt in der Schlussreplik, dass das Herz ihrer Kinder Ludmila gehört. Diese Fassung ist besser mit der Fortsetzung durch das Drama Bratri vereinbar, das Vrchlický als zweiten Teil seiner »Böhmischen Trilogie « verfasst hat (vgl. Haman 2007, 287f).

\section{IV.8.3.2. Bratři. Historické drama o pèti jednánich (1889)}

[Brüder. Historisches Drama in fünf Akten; UA 22.4. 1889, publ. 1889]

Bratři, der zweite Teil der Trilogie, lässt die Krise offenbar werden, die mit der Herrschaft des jungen Václav ${ }^{392}$ beginnt. Während in Drahomíra der Sněm noch als Instanz erscheint, deren Beschlüsse bindend sind, wird gleich zu Beginn von Bratři deutlich, dass der Sněm nicht mehr stark genug für selbstbewusstes Agieren ist. Derselbe Radslav, der in Drahomira die Autorität des Sněm vertreten hat, beklagt sich nun über die Politik Václavs, dem ja vom Sněm die Herrschaft zugesprochen wurde. Václav kann seine deutschfreundliche Politik gegenüber seinen Gegnern durchsetzen, ohne auf großen Widerstand zu stoßen, weil er ein unerklärliches Charisma ausstrahlt, das alle wohlüberlegten Einwände zunichtemacht. Auch als das Prager Volk der deutschen Gesandtschaft mit den Waffen droht, besänftigt Václavs Erscheinen es sofort. Er kann allein durch sein Charisma die Aufhetzung des Volks durch Palhoj unterbinden. Drahomíra und Boleslav sind gegen die Unterzeichnung eines Friedensvertrags mit den Deutschen. Das Charisma von Václav bleibt freilich selbst bei Boleslav nicht ohne Wirkung, denn im Gespräch mit Václav gibt Boleslav klein bei, sobald jener den Arm um seine Schultern legt. Radslav hingegen zieht sich zurück, er verlässt den Sněm, weil er allein keine Möglichkeit sieht, in diesem eine Änderung der Haltung gegenüber den Deutschen durchzusetzen. Václav begründet sein Handeln damit, dass das Land mittels eines Friedensvertrages zu Kräften kommen werde (vgl. I/9).

Die Gegenüberstellung von Václav und Boleslav ist schon durch den Titel indiziert: Václav gilt als der dem Himmel am nächsten stehende Herrscher, Boleslav als

392 Während im ersten Teil der Trilogie der Name „Vácslav“ geschrieben wird, heißt es im zweiten Teil „Václav“. 
der irdische, der noch heidnischen Vorstellungen von Herrschaft nachhängt. Der von Václav mit einer Burg und einem Landstrich bedachte Boleslav, der aber kein richtiges Betätigungsfeld hat, wird als rücksichtslos gezeichnet: adeligen Lechen, die ihm vom Rang her gleichgestellt sind, befiehlt er, eine steinerne Burg zu bauen; als diese sich weigern, ersticht er kurzerhand einen von ihnen, obgleich er dessen Tochter Běla zur Frau begehrt. Als sich diese Boleslav verweigert, lässt er sie an einen Baum binden, was einer schleichenden Tötung gleichkäme, würde Běla nicht von Václav befreit werden. Die Gegenüberstellung der beiden Brüder ist dennoch nicht allein nach einem Schwarzweiß-Schema gezeichnet. Boleslav möchte eine Veränderung erreichen, wofür er bereit ist, seine Mitmenschen zu instrumentalisieren. Durch seine Kompromisslosigkeit verschafft er sich Respekt und erreicht eine Vormachtstellung. Auch wenn Václav durchaus bestrebt ist, seine Vorstellungen von Politik umzusetzen (so muss er, wie erzählt wird, öfters Zwang anwenden, um die Abgaben für die Deutschen eintreiben zu können; er greift auch die Versammlung seiner Gegner an), so erscheinen die irdischen Auswirkungen seiner Herrschaft als weniger glorreich: Die Adeligen sind mit ihm gänzlich unzufrieden, weil sie die im Friedensvertrag vereinbarten Abgaben zu leisten haben. Nur das Charisma Václavs bezwingt sie; selbst erbitterte Gegnerschaft wird dadurch überwunden: Radslav, der sich zuerst entschlossen gegen Václav stellen möchte, muss kleinlaut beigeben. Bei einer zweiten Gegenüberstellung im dritten Akt - also wieder im Zentrum der Tragödie - findet ein Duell statt, das Václav als Repräsentant des Volkes für dieses unternimmt, um unnötiges Blutvergießen zu vermeiden. Radslav erkennt plötzlich beim Duell Václavs Verbindung mit einem transzendenten Sein: er sieht um Václavs Kopf zwei Engel. Radslav verzichtet auf das Duell und beschließt, sich gänzlich aus der Welt zurückzuziehen und Einsiedler zu werden. Auch Boleslav muss eine ähnliche Brechung seines Willens durch Václavs Ausstrahlung erfahren.

Da Boleslav allen Grund hat, hinter Václavs Verhalten gegenüber seiner Frau Běla eine erotische Komponente zu vermuten (immerhin hat Václav sie aus der Erniedrigung durch Boleslav befreit [II/10] und außerdem hat er selbst das Charisma von Václav erfahren), veranlasst er den Mord an seinem Bruder. Wenngleich Boleslav als machtbewusster Herrscher gezeigt wird, der jeden Widerstand brutal zu brechen bereit ist (II/5), ist der Zustand Böhmens nach der Ermordung Václavs durch Boleslav sogar gestärkt. Dabei ist er eine tragische Figur, da er durch Mord das erreicht hat, was er ohnehin bekommen hätte, wäre er nur besonnener gewesen. Er hat vorwiegend aus Eifersucht gehandelt und muss nun mit dem ermordeten Bruder, dessen Gesicht ihn verfolgt, kämpfen. Boleslav erfährt erst im Nachhinein von Radslav, das Václav ihm zuliebe abdanken habe wollen. Er erkennt mit dem Irrtum - vermeinte er doch, es habe ein Liebesverhältnis zwischen seiner Frau und Václav bestanden - seine schwere Schuld und die Inkommensurabilität von weltlicher und geistlicher Größe. Gerührt vom Gesang der tschechischen Kirchenhymne „Svatý Václave, vévodo české země ..." bittet Boleslav um Verzeihung, demütig verbeugt er 
sich vor dem ewigen Fürsten, auf dass dieser schützend seine Hand über Böhmen halte.

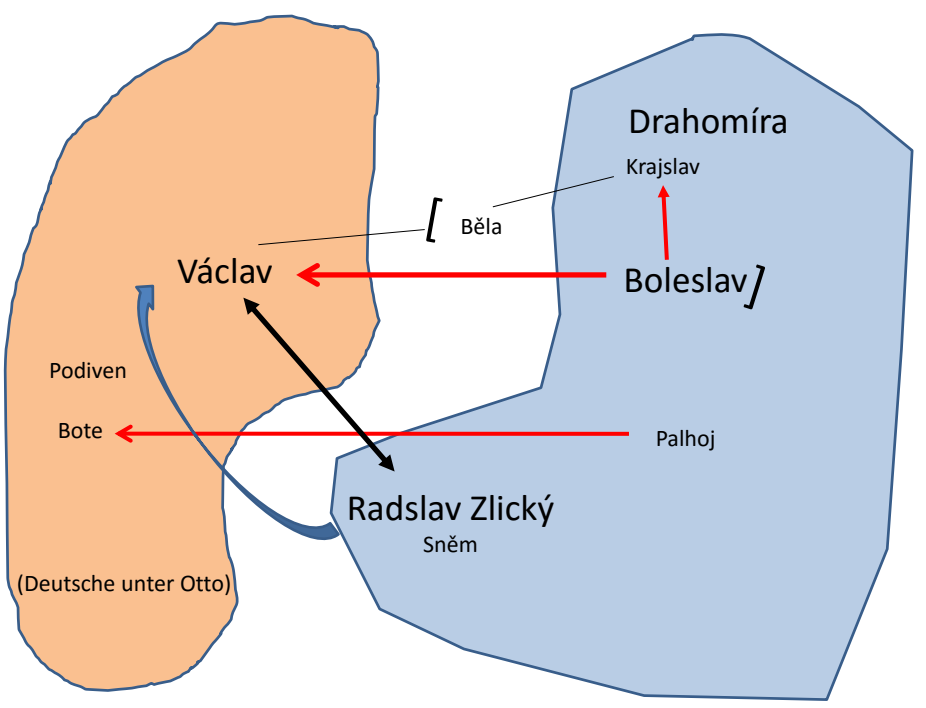

Graphik Nr. 33 - Jaroslav Vrchlický: Bratrí (1889)

Trotz seiner immer wieder unterstrichenen Verbindung zu einem transzendenten Reich, trotz seines Charismas weist Václav als weltlicher Herrscher einige Schwachpunkte auf: Seine Politik findet keineswegs nur Zustimmung, der Vertrag mit den Deutschen bringt Böhmen in eine demütigende Position. Der bereits bei Tyl feststellbare Konflikt zwischen irdischer Herrschaft und den radikalen ethischen Forderungen des Christentums wird von Vrchlický fortgeführt: Václav erklärt seinen Machtverzicht ja auch damit, dass er nicht ganz für die Politik geeignet sei, weil er sich eine Vorstellung vom transzendenten Paradies behalten habe und sich nicht ungeteilt den immanenten Angelegenheiten der Politik zuwenden könne. Er hat schon zeitlebens über die Schwierigkeiten zu regieren geklagt: „Je těžký úkol vladaře,/ na

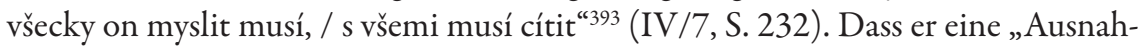
mefigur" ist, kann man schon in der Figurenkonstellation erkennen: abgesehen von seinem Diener Podiven, der eine nur "geringfügige“ Nebenfigur ist, sowie von Běla und Radslav Zlický, die Václav bewundern oder von seiner Heiligkeit affiziert sind, ist er „strukturell“ bzw. „semiosozial“ eine einsame, singuläre Figur. Dass er mit den

393 [Václav:] „Der Herrscher hat eine schwere Aufgabe / er muss an alle denken, / mit allen muss er fühlen." 
Deutschen im Bunde steht, ist diesbezüglich nicht weiter von Belang, weil diese selbst durch keine einzige Figur repräsentiert sind.

Die Alternativen zu Václav - Boleslavs rücksichtsloses Machtstreben, die Institution des Sněm, Radslav als umsichtiger Politiker, der die politische Lage besser zu erkennen glaubt als der durch die Tradition und Erbfolgeregel prädestinierte Václav - erscheinen gegenüber dessen überirdischem Glanz jedoch machtlos. Dies wird besonders im Duell der politischen Rivalen Václav und Radslav deutlich, wo letzterer sich ehrfurchtsvoll unterwirft, nachdem er zwei Engel um die Gestalt Václavs zu sehen glaubte. Radslavs Konsequenz aus dieser Erfahrung einer transzendenten Macht besteht darin, sich als Eremit in die Wälder zurückzuziehen. Diese transzendente Macht Václavs steht gewissermaßen quer zu den realpolitischen Interessen und Erfordernissen, sie ist nicht ganz von dieser Welt.

Bratři baut über den Konflikt zwischen den beiden Brüdern Václav und Boleslav einen Dualismus von irdischer und himmlischer Herrschaft auf. Während die himmlische Herrschaft eine verklärende Apotheose erfährt, werden die schnöden und abstoßenden Aspekte weltlichen Machtstrebens gezeigt. Dennoch kann dieses innenpolitische Erfolge vorweisen. Wenngleich auch Václav als Fürst konsequent seine politischen Vorstellungen verfolgt hat, war seine Herrschaft weniger erfolgreich als diejenige seines Bruders, der es immerhin vermochte, die Abhängigkeit von den Deutschen zu beenden, die Václav begonnen hat. Vergleicht man Bratř́i mit den diskutierten Vorgängerstücken Tyls und Dvorskýs, zeigt sich eine neue Position: Wenn Tyl einen schwer lösbaren Widerspruch zwischen christlicher Ethik und den praktischen Notwendigkeiten politischen Handelns vorgeführt hat, den Dvorský damit auflöste, dass er eine Synthese der beiden Positionen in Boleslav vornimmt, so betont Vrchlický die Inkommensurabilität von Politik und christlicher Ethik. Die Widersprüche stehen aber nicht mehr - wie bei Tyl - gleichsam unaufgelöst einander gegenüber, sie sind deutlich auf zwei verschiedene „Sphären“ - Immanenz und Transzendenz - verteilt. Ähnlich wie Drahomira von Dvorský endet Bratri mit einer gleichsam synthetischen Lösung des Konflikts: Boleslav repräsentiert jedoch nicht idealerweise sowohl die eigenen positiven Eigenschaften wie auch diejenigen seines Bruders, er differenziert vielmehr hierarchisierend und ordnet seine - „nationalpolitisch" erfolgreiche - Politik dem glänzenden Ideal Václavs unter, das allerdings nicht ganz von dieser Welt ist.

In Bratři ist eine „depräsentierende“ Diskussion der „slawischen Wechselseitigkeit" bzw. der Slawophilie zu erkennen, dem von Kollár und Šafařík propagierten Zusammenhang der Slawen, der weiter gestärkt werden soll, wenn die slawischen Völker ihre politische Unselbstständigkeit überwinden wollen. Drahomíra, die vom slawischen Stamm der Luticen nach Böhmen eingeheiratete Fürstin, spricht in der Szene I/9 von ihrer Vision eines slawischen Baumes von gewaltiger Größe, der sich vom Schwarzen Meer weit nach Norden erstrecken würde; durch ihre Heirat 
mit Vratislav habe sie den tschechischen Zweig an diesen binden wollen. Václav korrigiert die Vision seiner Mutter mit den Worten:

Ty žiješ vidinami, matko má.

Žel bohu není slovanstvo ten kmen, jest proutí jenom, jenž se ohýbá

dle silných větrů bouřných nárazů.

Však třeba počítati s tím, co jest.

Kmen musí z kořene růst $\mathrm{v}$ celistvosti.

Být jednou bytostí, jež z různých větví

a proutků nespojišs, a to náš trest

a kletba naše, rozsazení jsme

jak proutí podél břehu cizotí:

ta pere $\mathrm{v}$ nás, zde třeba obstáti

ne odporem, spíš moudrou rozvahou

a dobrou vưlí ukonejšit moře

než po vždy roztrhá nás ze všech stran. ${ }^{394}(\mathrm{I} / 9, \mathrm{~S} .137)$

Auf vergleichbare Weise entgegnet auch Radslav Zlický Drahomíras Überlegungen, dass man nur als Verbund slawischer Völker Bestand haben könne. Das seien nur Träume, die in der Realität um keinen Schritt weiterbrächten. ${ }^{395}$

Das Dilemma der Politik in den beiden ersten Teilen von Vrchlickýs Tragödie besteht wie bei Tyl darin, dass politisches Handeln fatale Implikationen hat und gerade deshalb sein Ziel nicht erreicht. Drahomíras entschlossener Mord an ihrer Schwiegermutter Ludmila hat für sie die politische Isolation zur Folge; Boleslavs Brudermord belastet nicht allein den Mörder, sondern auch nachfolgende Generationen, wie sich in Knižata, dem letzten Teil von Vrchlickýs Böhmischer Trilogie, zeigt, der hier nicht behandelt wird, weil er nicht mehr direkt mit dem Václav-Stoff zusammenhängt. Die von Václav propagierte christliche Politik scheint keine reale,

394 „Du lebst in Träumen, meine Mutter / Leider Gottes ist das Slawentum kein solcher Baum / es besteht nur aus Ruten, / die sich nach dem stürmischen Druck starker Winde bewegen. / Doch muss man mit dem rechnen, was ist./ Ein Baum muss als Gesamtheit aus einer Wurzel entstehen, / ein Wesen sein / das man aus verschiedenen Ruten und Ästen / nicht zusammenfügen kann und das ist unsere Strafe / und unser Fluch. Wir sind auseinander gesetzt / wie Ruten am Gestade der Fremde. / Diese schlägt uns. Hier gilt es zu bestehen / nicht durch Widerstand, eher durch weise Überlegung / und mit gutem Willen das Meer zu beruhigen / bevor es uns auf immer von allen Seiten in Stücke reißt.

395 Vgl. [Radslav:] „Sny, kněžno, pouhé sny a nepřivedou / nás o krok dále. Pouze na sebe / jsme odkázáni. V nás je všecka síla / a všecka mdloba.“ (III/1, S. 185 - „Träume, Fürstin, nur Träume, und diese bringen / uns keinen Schritt weiter. Nur auf uns / sind wir angewiesen. In uns steckt die ganze Kraft / und alle Ohnmacht.") 
sondern bloß eine imaginär-mystische Alternative zu sein. Václavs realpolitische Schwäche - die im Verzicht auf nationale Selbstständigkeit besteht - wird von einer Apotheose Václavs aufgehoben, die seiner Verklärung als Heiliger entspricht.

\section{IV.8.4. František Langer: Svatý Václav. Tragédie ve třech dějstvích (1912)}

[Der heilige Václav. Tragödie in drei Akten; UA 22.11. 1912, publ. 1912]

In seinem ersten Theaterstück, das mit prominenter Besetzung am 22. November 1912 im Národní divadlo eine sehr positiv aufgenommene Premiere feierte, zeichnet František Langer Václav als entschlossenen christlichen Fürsten, der danach strebt, die radikalen Lehren des Evangeliums in der Politik durchzusetzen. Seine entschiedenste Gegnerin findet er dabei in seiner Mutter Drahomíra, die von heidnischen Rachevorstellungen keinesfalls abgehen möchte. Boleslav dagegen wird als Figur gezeichnet, die zwischen der Bindung an die Mutter und der Bewunderung für Václav gespalten ist. Langers Drama ist ein auf die ideell-ethischen Grundmotive reduziertes Stück, dem nationales Pathos fehlt, das stattdessen die unterschiedlichen Positionen politischer Führung anhand der drei Hauptfiguren Drahomíra, Václav und Boleslav darstellt. Der Alexandrinervers von Svatý Václav lässt aufgrund seiner Konnotation mit der Tragödientradition das Drama zwar einerseits feierlich wirken, andererseits ist er prosodisch so gestaltet, dass die Repliken einfach rezipiert werden können (vgl. Wiendl 2010, 206f).

Drahomíra stammt in Langers Version der Fabel von den Stodoranen ab, die von den Deutschen vernichtend geschlagen wurden, obwohl Drahomíra, als sie noch Fürstin war, zu deren Unterstützung auch böhmische Krieger gesandt hatte. Im ersten Akt wird sie von zwei Alten verflucht, die von ihr geblendet wurden, nachdem sie in ihrem Auftrag den Mord an Ludmila ausgeführt hatten. Boleslav hat auf seinem Gebiet zwei Alte köpfen lassen, weil diese sich nur widerwillig am Bau einer steinernen Burg beteiligt hatten. Ein Teil der böhmischen Bevölkerung ist noch in den heidnischen Vorstellungen von Blutrache befangen, was Václav als überzeugter christlicher Fürst unterbinden möchte. Die von Václav propagierte christliche Lebensform findet weitgehend Zustimmung, allein Drahomíra hält an den heidnischen Sitten fest und erwartet, dass Boleslav sich ermannt und diese wiederherstellt. Boleslav hat ein gewisses Verständnis dafür, dass Václav ihn für die Tötung der beiden Alten bestrafen möchte, die er selbst als überstürzt betrachtet. Václav hat Boleslav die Tat verziehen, möchte aber, dass dieser nun Nächstenliebe übe. Da Drahomíra den Stodoranen böhmische Krieger als Waffenhilfe geschickt hatte und diese gemeinsam mit den Stodoranen von den Deutschen schwer geschlagen wurden, erwartet Drahomíra, dass die Verluste gerächt werden. Boleslav soll einen Rachefeldzug beginnen. Sie fühlt sich den Stodoranen verwandtschaftlich tief verbunden und regt in Boleslav dieses Stammesgefühl an: 
„Nebot rod věčný jest a my jen dočasnými, / a každý pro něj čin věčností posvěcen jest. ${ }^{\text {"396 }}$ (I, S. 34)

Václavs Friedenspolitik, die von der Bevölkerung gutgeheißen wird, wird auf eine erste Probe gestellt, als die Deutschen in Böhmen einfallen. Die Alternative zwischen nationaler Freiheit und Souveränität einerseits und Václavs Bemühungen um die Schaffung eines christlichen Landes andererseits wird mit einer Waage verglichen (vgl. I, S. 37f). Václav möchte sich nicht kämpfend verteidigen, sondern den Kampf vermeiden. ${ }^{397}$ Er entschließt sich (Ende des 1. Akts) schließlich doch zur bewaffneten Verteidigung, wobei er seinen eigenen Willen zurückstellt. Er überlegt zuerst sogar, ob er nicht nur sich allein opfern oder vielleicht sogar widerstandslos das Land übergeben soll. Da ein deutscher Fürst über Böhmen aber als „Versklavung" aufgefasst werden würde und weil die Bevölkerung sich Schutz vor Brutalitäten durch die Angreifer erwartet, lässt Václav mobilisieren. Er stellt dabei seine eigenen Überzeugungen hinter das Gemeinwohl zurück, wodurch er sich von den Vladiken unterscheidet, die zuerst nur ihre eigenen Besitzungen sichern möchten. Er erklärt, dass er schweren Herzens seine Überzeugungen aufgibt:

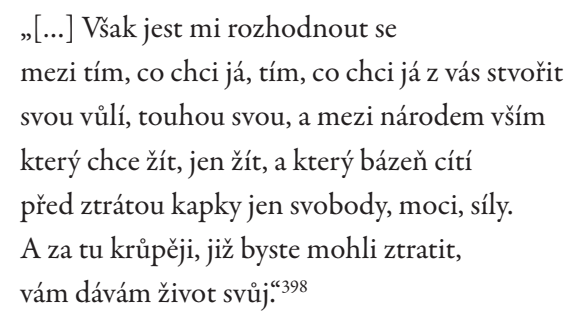

Im Kampf erweist sich Václav als überaus erfolgreich, wie der Beginn des zweiten Aktes zeigt. Statt aber die deutschen Eindringlinge völlig zu vernichten, wie ihm von mehreren Seiten vorgeschlagen wird, entschließt sich Václav zu einem Friedensvertrag, der Böhmen um den Preis von Abgaben dauerhaft Frieden bringen soll. Dies empört Drahomíra über alles, sodass sie daran geht, Boleslav gegen den Bruder aufzubringen. Dieser schätzt seinen Bruder und dessen Politik, wenngleich

396 [Drahomíra:] „Denn der Stamm ist ewig, wir aber nur vergänglich / jede Tat für ihn ist von der Ewigkeit geheiligt."

397 [Václav:] „Ne, nechci boje mít, ne válkou brániti se, / leč válce brániti““ (I, S. 38 - „Ich möchte keine Kämpfe haben, nicht mit Gewalt uns verteidigen / sondern die Gewalt vermeiden.")

398 [Václav:] „[...] Ich muss mich nun aber doch entscheiden / zwischen dem, was ich möchte, was ich aus euch schaffen möchte, / meinem Willen, meinem Streben und dem ganzen Volk, / das leben möchte, bloß leben, und das Furcht empfindet / schon vor dem Verlust nur eines Tropfens Freiheit, Macht, Kraft./ Und für diesen Tropfen, den ihr verlieren könntet / gebe ich euch mein Leben." 
er feststellt, dass es ihn selbst eher zur Rache und zum Kampf drängt. Drahomíra sieht allein in Boleslav eine Fortsetzung ihres „Blutes“, Václavs Verhalten ist in ihren Augen eines Fürstens unwürdig. Sie versucht, ihn zum Mord an Václav zu bewegen.

Václav hat indessen Gewissensbisse wegen seines einmaligen Ablassens von den christlichen Grundsätzen; er meint, dass es möglicherweise eine Strafe für ihn sein soll, wenn Boleslav ,"̈̈ber seine Leiche“ gehen würde, um den Krieg gegen die Deutschen fortzusetzen. Dieser bewundert seinen Bruder für die Stärke, mit der er an seinen Idealen festhält (vgl. II, S. 73).

Boleslav würde den Mord an seinem Bruder nur dann ausführen, wenn dieser kampflos den Tod auf sich nehmen würde, weil damit für ihn erwiesen wäre, dass Václav als Fürst ungeeignet ist, wenn er weder sich noch sein Volk verteidigt.

Wenngleich Václav unbedingt vermeiden möchte, sich mit Gewalt zu verteidigen, so will er letztlich doch nicht widerstandslos sein politisches Werk aufgeben und sich töten lassen. Boleslav versucht alles, um Václav zum Widerstand zu bewegen, denn dann würde er ja keinen Grund haben, den Mord auszuführen. In diesem Zusammenhang kann das Gespräch zwischen Václav und Boleslav, das im Beisein ihrer Mutter Drahomíra erfolgt, zum dramaturgisch interessantesten Teil von Langers Drama gerechnet werden. Boleslav, der seinen Bruder nicht töten möchte, kündigt mit großen Worten seine Tat an, um Václav zu einer Verteidigungsposition zu bewegen. Boleslav, der dieses Gespräch nach seinen Intentionen lenkt, vollzieht hier paradoxe indirekte Sprechakte: Seine Illokution bzw. Drohung „Ich werde dich töten!"3999 soll perlokutiv eine Verteidigungshaltung Václavs auslösen, damit die Drohung nicht umgesetzt werden muss. Zum einen entspricht dies den illokutiven Bedingungen des Sprechaktes Drohung (X möchte, dass Y die Handlung D ausführt. Um dies zu erreichen, droht $X$ damit, dass er widrigenfalls Gewalt an $Y$ ausüben werde. Im konkreten Zusammenhang: Boleslav möchte, dass Václav sich verteidigt), zum anderen aber ist die für die Drohung gewählte Proposition „Ich werde dich töten" genau die Alternative, die Boleslav selbst keinesfalls realisieren möchte. Während die Standardform der Illokution Drohung so aussieht, dass Bewirkungsziel und die angedrohte Alternative durch eine Disjunktion verbunden sind („mach D oder ich werde E tun!), ist die Drohung hier maximal kondensiert: Das Bewirkungsziel D (Václav soll sich verteidigen) ist normalerweise die unmittelbare Reaktion auf dasjenige, was in der Alternative $\mathrm{E}$ angedroht wird.

Diese dramatische Illokution ist allerdings auch aus der Sicht des Adressaten der Drohung ungewöhnlich: Václav hat überhaupt keine Wahl: Er möchte weder getötet werden (weniger aber als Angst vor dem Tod oder aufgrund seines Lebenswillens, sondern weil er sein christliches Missionswerk nicht zerstört sehen möchte), noch möchte er, dass sein Bruder tötet.

399 [Boleslav:] „Dnešního rána chci usmrtit tebe ještě!“ („Heute früh noch möchte ich dich töten!“ - III, S. 82). 
Mithin ist die im dritten Akt geschaffene Konstellation so, dass die beiden Brüder auf das Engst miteinander „verbunden“ sind. Václav hat keine Wahl, er muss sich verteidigen, Boleslav will die Gewalt überhaupt nicht ausüben, die er androht und über welche er verfügt, er will Václav nur aus dem Zustand widerstandsloser Passivität herausführen. In dieser Konstellation ist Boleslav Václav überlegen; er kann diesen zu einem Handeln bewegen, das Václav eigentlich ablehnt, nämlich sich bewaffnet zu verteidigen.

Da Drahomíra die „Manipulationen“ Boleslavs durchschaut und erkennt, dass er damit den von ihr gewünschten Mord nicht ausführen wird, möchte sie mit Listen und Lügen Václav zum Ablegen der Rüstung und zum widerstandslosen Hinnehmen des Todes bewegen. So schlägt sie sich plötzlich ostentativ auf Václavs Seite, was diesen überrascht, weil er ihre Strategie dahinter zuerst nicht erkennt (vgl. III, S. 84). Drahomíra sieht allein Boleslav als ihren Sohn an, da er noch eher eine aggressiv-kämpferische Auffassung von der Fürstenrolle hat.

Václav zeigt sich letztendlich also doch zur Verteidigung seiner Position entschlossen, was Boleslav erfreut: dieser erklärt, nun keinesfalls den Mord an seinem Bruder auszuführen. Drahomíra engagiert daher die Vladiken von Kbely und Suchdol für den Mord, die sich nur gegen das Versprechen einer großzügigen Entlohnung bereiterklären, weil sie die Kampfesstärke Václavs kennen, gegen die sie sich chancenlos wähnen. Drahomíra versucht neuerlich, Václav zum Ablegen der Waffen zu bewegen, um die Wehrlosigkeit zu erreichen, die Boleslav zum Mord bewegen würde. So unternimmt sie alles Mögliche, um die Ermordung Václavs zu provozieren, den sie freilich nicht aus Hass, sondern aufgrund einer gänzlich anderen Vorstellung von politischer Führung durchgeführt sehen möchte; vor allem verfällt sie auf Lüge und Täuschung. Sie kann den beiden von ihr geblendeten Alten, die Václav vor dem Mordanschlag warnen wollen, weismachen, dass sie bereue und nur eine Versöhnung in der Familie erreichen wolle. Václav, der nun in voller Rüstung geht, um einen Anschlag parieren zu können, ist gegenüber den Lügen seiner Mutter viel skeptischer. Auf Drahomíras lügenhaft geäußerten Wunsch, ihre Söhne mögen sich doch versöhnen, geht Václav nur insofern ein, als er gepanzert und bewaffnet Boleslav die Hand entgegenreichen würde. Er erklärt „Zbroj přec je nevinná, když nevinná jest mysl.“400 (III, S. 95) Drahomíra spricht in einer langen Replik exakt die Gedanken und Befürchtungen Václavs aus: Sie erzählt von seinem Streben nach christlicher Perfektion und von den Gewissensbissen, die über ihn gekommen sind, als er entgegen seinen eigenen Grundsätzen in den Kampf gezogen ist. Damit erreicht sie die freiwillige Entwaffnung Václavs. Dieser weiß allerdings, dass seine Mutter damit nur einen einfacheren Vollzug des Mordes bezweckt. Gewissermaßen resigniert Václav vor dem großen Wunsch seiner Mutter: Wenn er schon nicht durch ein mustergültiges Leben zeigen konnte, wie man in

400 [Václav:] „Das Rüstzeug ist wohl unschuldig, wenn die Gesinnung unschuldig ist.“ (III, S. 95) 
der Wahrheit lebt, so wolle er zeigen, wie man sterben sollte. ${ }^{401}$ Als Drahomíra das Schwert Václavs in den Händen hält, frohlockt sie über die so gewonnene Macht über ihn; er allerdings bittet darum, dass sie ihm das Schwert zurückgibt:

Třikrát byl v rukou mých, poprvé za můj národ, podruhé za dobro, jež chtěl jsem zůstaviti, a nyní potřetí jej chci mít ve svých dlaních, bych jemu bránil se, aby on nezabil mne! Jiní at zabijí, by nebyl bratrovrahem! $!^{402}$

Als er erkennt, dass Drahomíra den Mord unbedingt ausgeführt haben möchte, versucht er noch, Boleslav am Brudermord zu hindern, indem er ihm mit bloßen Händen das Schwert aus der Hand reißt und fortwirft. Der Mord wird daher von den Vladiken aus Kbely und Suchdol ausgeführt, die sich sogleich den von Drahomíra versprochenen Lohn sichern wollen.

Nach vollbrachter Tat schränkt Boleslav Drahomíras Einfluss rasch ein. Seinen Anteil am Mord bezeichnet er zutreffend mit „Já bratra zabil jsem, tys vedla na popravu. / Já meč jsem a ty kat. O to jsem tebe lepš́ı “ ${ }^{403}$ (III, S. 103) Wie schon Václav es beabsichtigt hat, verbannt er Drahomíra auf eine Burg. Er ist jetzt aber auch entschlossen, aus Böhmen ein starkes und gefürchtetes Land zu machen: „Nebot by takými jsme jednou mohli býti, / aby nás záhuba nestihla nikdy žádná, / můj bratr

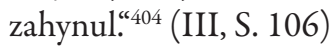

401 Vgl. die Erklärung Václavs: „Když nebylo mi přáno, / abych všem projevil, jak v pravdě nutno žíti, / nuže, chci ukázat, jak nutno umírati!“ (III, S. 98).

402 [Václav:] „Es [das Schwert] war dreimal in meinen Händen, zuerst für mein Volk, / dann für das Gute, das ich hinterlassen wollte / und jetzt möchte ich es zum dritten Mal in den Händen haben / um zu verhindern, dass er [Boleslav] mich ermordet. / Mögen andere mich töten, nur er soll kein Brudermörder sein.“

403 [Boleslav:] „Ich habe den Bruder getötet, du hast ihn zur Hinrichtung geführt. / Ich bin das Schwert und du der Henker. Deswegen bin ich besser als du.

404 [Boleslav:] „Damit wir einmal so sein könnten, / dass uns kein Verderben jemals trifft / dafür ist mein Bruder gestorben." 


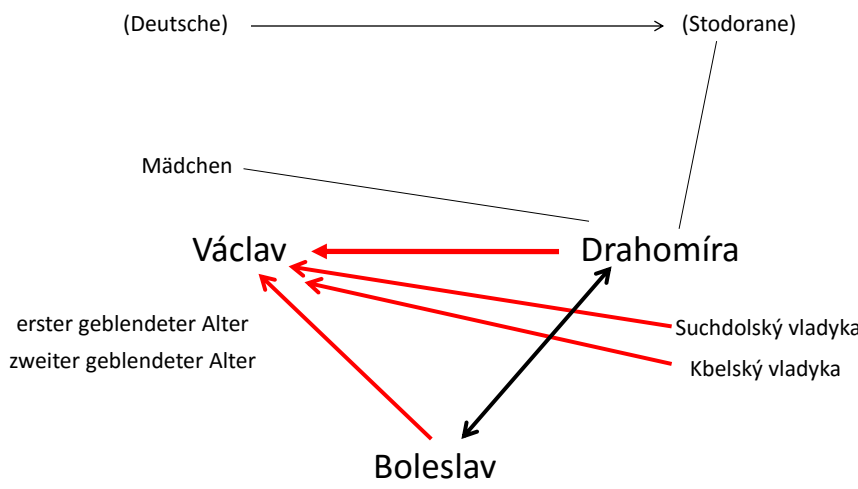

1. vladyka

2. vladyka

Graphik 34 - František Langer: Svatý Václav (1912)

Wenn diese Erklärung Boleslavs einen Zweck der Tötung andeutet, so drückt das eine Logik des Opfers aus, die für eine politische Deutung des Stücks höchst relevant ist. Václav selbst spricht öfters davon, dass er sein Leben gerne opfern wolle, wenn er damit etwas erreichen könne. Seine Einsicht aber, dass ein solches Opfer im Falle des Einfalls der Deutschen niemandem etwas bringen würde, bewegt ihn, zu den Waffen zu greifen und somit seine Grundsätze zu brechen. Dass er in einer zweiten Prüfung aber den Tod widerstandslos hinzunehmen bereit ist, begründet er zum einen mit der Sühne, die für sein Abweichen von den christlichen Prinzipien bei seiner ersten Prüfung als christlicher Fürst nötig sei. „Snad boží vưlí jest, abych již déle nežil, / snad také je to trest, že nepravě jsem jednal, / že svoje svědomí jsem zcela obětoval.“405 (II, S. 73) Zum anderen soll die kampflose Annahme des Todes für das Volk aber Vorbild sein: man soll sterben, ohne die Gewalt in der Welt zu vermehren (vgl. II, S. 78). Sühnebereitschaft und Vorbildwirkung sind mithin die Beweggründe für Václavs Annahme des eigenen Todes. Er kennt alle Warnungen, flieht jedoch nicht. Wird dieser christliche Gedanke durch die Entwicklung des Stücks bestätigt, handelt es sich also um eine Apotheose von Václavs frommer Position?

Das Mädchen beweint zwar den Tod des besten Fürsten am Ende, den letzten Monolog hat freilich Boleslav, der schon zuvor erklärt hat, dass er mit der grausamen Tat zum Mann geworden sei:

405 [Václav:] „Es ist wahrscheinlich der Wille Gottes, dass ich nicht länger lebe / wahrscheinlich ist es auch eine Strafe dafür, dass ich falsch gehandelt habe, / dass ich mein Gewissen ganz aufgegeben habe." 
„Nejsem již dítětem, jak jsem byl před hodinou,
neb čin jsem vykonal. Čin nade všechny krutý,
ale přec velký čin. Zmužněl jsem tímto činem.“ ${ }^{406}$

Das Ergebnis von Václavs neprotivlenie zlu nasiliem ist Boleslavs Herrschaft, die eine Rückkehr zur Machtpolitik darstellt, in der Václavs Idee vom friedliebenden und passiven Fürsten nicht gewahrt ist. Václav konnte mit seinem Tod mithin nicht unmittelbar das bewirken, was er angestrebt hat, die Logik des Opfers funktioniert nicht. Die Hinnahme der von Drahomíra befohlenen Tötung bewirkt allein, dass Boleslav Drahomíras Einfluss eindämmt. Politisch folgt er seiner Mutter: er ist entschlossen, mit großen Taten Böhmen groß und stark zu machen.

Langers Stück macht ideologisch einen durchaus zwiespältigen Eindruck: die radikale Gewaltlosigkeit des tolstoischen neprotivlenie zlu nasiliem, die Václav vertritt, wird im Drama meiner Ansicht nach nicht sanktioniert. Zwar werden die mit dem Prinzip verbundenen hehren Absichten - ein friedliches Gedeihen des Landes als große politische Vision Václavs - gezeigt, gleichzeitig ist das Prinzip im einzigen Fall, wo es angewandt wird, wirkungslos: Es führt zum Tod Václavs, der jedoch anders als der Tod des klassischen Tragödienhelden - nicht gemäß der Opferlogik das erstrebte Resultat mit sich bringt. Der mit seiner Mutter nicht an die Effizienz von Gewaltlosigkeit glaubende Boleslav beginnt ja genau dann zu handeln, als er sieht, dass sich Václav allen Schutzes entledigt. Solange dieser in Waffen geht, um sich und seine Prinzipien zu verteidigen, findet sich Boleslav mit der Rolle des Zweitgeborenen ab. Sobald Václav aber all seine Waffen an die zu allem entschlossene Drahomíra aushändigt, die umgehend über die so erlangte Machtfülle zu frohlocken beginnt, entschließt sich Boleslav zur Mitwirkung an der blutigen Tat. Berücksichtigt man gleichfalls den Umstand, dass Václav von Langer als praktisch unbesiegbarer Kämpfer gezeichnet ist, der freilich seine militärischen Möglichkeiten bewusst ungenutzt lässt und sich lieber einem friedlichen Landesaufbau widmet, so erscheint der Handlungsverlauf als Warnung vor einem „Machtvakuum“. Lässt man wie Václav ein solches entstehen, beschwört man den tödlichen Angriff auf sein Leben herauf. Als er jedwede bewaffnete Verteidigung aufgegeben hat, bereut er dies umgehend und bittet um sein Schwert.

Boleslav erscheint wie gesagt in der Szene, in der er Václav zur Selbstverteidigung zwingt, als Herr der Situation, der den Willen von Drahomíra zurückweist und der bewusst auf die Gewalt gegen Václav verzichtet. Beim zweiten Versuch Drahomíras, Václav zu entwaffnen, weiß Boleslav genau von der Täuschungsstrategie Drahomíras, er schreitet aber nicht ein. Wenngleich sich Boleslav dazu nicht

406 [Boleslav:] „Ich bin nicht mehr das Kind, das ich noch vor einer Stunde war, / denn ich habe eine Tat vollbracht. Eine überaus grausame Tat, / aber dennoch eine große Tat. Durch sie bin ich zum Mann geworden." 
explizit äußert, können dafür zwei Gründe angeführt werden: Zum einen würde der tatendurstige Boleslav tatsächlich gerne Fürst werden, zum anderen kann er aus dem Versteck heraus beobachten, dass ja auch Václav um Drahomíras Verstellung weiß und dennoch die Waffen ablegt und seinen Tod hinnimmt. ${ }^{407}$

Boleslav bewundert zwar wiederholt Václav, nicht allein seine Kampfesstärke, sondern auch die Tapferkeit, mit der er dem Tod entgegentritt, ohne diesen abwehren zu wollen (vgl. II, S. 73f); sein eigener Wille zur Macht und sein Tatendurst geben schließlich aber den Ausschlag dafür, seinen Bruder zu töten und die Herrschaft zu übernehmen. Mithin erscheint die Haltung Václavs auch bei Langer als eine zwar sehr positive, letztlich aber als eine „im Leben“ scheiternde Kraft. Die neprotivlenie zlu nasiliem ist nicht mehr als ein hehres Ideal, das nicht lange dem Drängen und den Erfordernissen profaner politischer Wirklichkeit Paroli bieten kann. Insofern ist der Handlungsverlauf durchaus plausibel; es geht nur darum, Václavs Handeln nicht etwa pauschal als positives zu sehen, wie es Pulicarová (vgl. 2006, 55) macht, die aus diesem Grund auch die Logik des Handlungsverlaufs nicht erkennt und sich irritiert über die zwiespältige Darstellung Václavs zeigt.

\section{IV.8.5. František Zavřel: Boleslav Ukrutný. Tragoedie o třech dějstvích (1919)}

[Boleslav der Grausame. Tragödie in drei Akten; publ. 1919, UA 1920]

Während bei František Langer noch Václavs Vision von christlicher Herrschaft einige Bewunderung hervorruft, letztlich aber am Ideal der Gewaltlosigkeit scheitert, erfolgt in der 1919 veröffentlichten Tragödie von František Zavřel (1884-1947) ${ }^{408}$ eine radikale Distanznahme von den mit Václav und Ludmila verbundenen christlichen Werten. In diesem Drama wird unumwunden der "grausame“ (ukrutný) Boleslav als Titelheld gefeiert, der eine neue Zeit des Übermenschen einleitet, in der sowohl die christlichen also auch die heidnischen Götter überwunden sind. Entsprechend wurde als Motto ein Zitat aus Macbeth vorangestellt: „V boj!“409 Jiří Brabec (vgl. 2010a, 327f) sieht Zavřels Drama als erstes expressionistisches Theaterstück der tschechischen Literatur und seine Inszenierung als Höhepunkt des Theaterjahres 1920.

Die erste Szene des Dreiakters, in der Greise über Sterndeuterei sprechen, nimmt bereits im Wesentlichen die Handlungsentwicklung vorweg: Die Greise

407 Als Drahomíra fragt, ob sich Václav denn nicht fürchte so ganz ohne Waffen, erklärt dieser: „Proto jsem zbraň ti dal, by neteklo víc krve, než mojí musí téct.“ („Ich habe dir deshalb die Waffe gegeben, damit nicht mehr Blut als das meinige fließen muss.").

408 Nicht zu verwechseln mit seinem gleichnamigen Cousin (1879-1915), der als Regisseur nach Aufenthalten in Berlin erfolgreiche expressionistische Inszenierungen an Prager Theatern durchführte (vgl. LčL 4/22, S. 1699).

409 [Boleslav:] „In den Kampf!“ 
unterhalten sich darüber, wie der Kampf der alten heidnischen Götter gegen den neuen Gott ausgehen wird. Man meint, dass dieser bald den alten Göttern in den Tod folgen wird und dass stattdessen ein neuer Mensch auf den Kampf zwischen Drahomíra, der Anhängerin der heidnischen Götter, und dem für manche wahnhaft dem Christentum verfallenen Václav folgen wird. Václav, der von Boleslav für seine Sanftheit und Feindesliebe gerügt wird, rechtfertigt seine Ideen damit, dass Widersprüche und Streit nur „Oberflächenphänomene“ seien, im Wesentlichen sei die Welt harmonisch:

Skutečnost, nejhlubší a nejžhavější skutečnost a nikoli sen je to, co hmatám. Všechny světy jsou jedno. Všechny duše jsou jedno. Hrozivá jednota hltá všechny bytosti a všechny děje. Ona jest život. Ona jest nutnost. Ona jest bůh. Ty jí nežríš. Tvoje zraky odhalují toliko jakýsi náhodný rozbroj, který ji na okamžik láme. Ale tento rozbroj je nejtruchlivějším klamem a nejosudnější kletbou, již nutno sníti. ${ }^{410}(\mathrm{I} / 2, \mathrm{~S} .12)$

Václav aber gilt für die meisten Figuren im Stück als abgehobener Träumer, der keinen Sinn für die anstehenden politischen Aufgaben hat. Es gibt keine Figur, die klar mit seiner Haltung sympathisiert, auch werden die Konsequenzen aus seiner Einstellung von allen Figuren negativ dargestellt. Drahomíra, die neben Boleslav prononcierteste Gegnerin Václavs, formuliert dies folgendermaßen:

Náboženství smrti, zvěčněná nicota, neodpírání zlu to jest po česku sebevražda tváríi ve tvár̆ soku - to je tvůj nový řád. ${ }^{411}$

Boleslav verwirft zwar das Christentum Václavs, er selbst ist aber von inneren Konflikten in Anspruch genommen, die ihn zuerst noch daran hindern, entschlossen gegen Václav vorzugehen. Stattdessen meint er noch, Václav stehe ganz unter dem Einfluss seiner Großmutter Ludmila (vgl. I/5), woraufhin Drahomíra für deren Liquidierung einen Mörder anheuern möchte: Der erste, den sie beauftragt, erklärt jedoch, dass er gegen Ludmila nicht die Hand erheben könne, weil er in ihrem Blick sein ganzes Schicksal habe erkennen können. Drahomíra kommentiert diese Wei-

410 [Václav:] „Wirklichkeit, die tiefste und heißeste Wirklichkeit ist das, was ich erfasse, keineswegs ist es ein Traum. Alle Welten sind eins. Alle Seelen sind eins. Eine mächtige Einheit schluckt alle Wesen und alle Handlungen. Sie ist das Leben. Sie ist die Notwendigkeit. Sie ist Gott. Du siehst sie nicht. Deine Blicke entdecken bloß einen zufälligen Gegensatz, der sie [die Einheit] für einen Augenblick bricht. Dieser Widerstand aber ist eine höchst betrübliche Täuschung und ein verhängnisvoller Fluch, den man auflösen muss.“

411 [Drahomíra:] „Eine Religion des Todes, ein verewigtes Nichts, die Nichtwidersetzung gegen das Böse ist auf tschechisch Selbstmord im Angesicht des Gegners - das ist deine neue Ordnung." 
gerung, den ihrer Ansicht nach notwendigen Mord auszuführen, mit den Worten: „Vsude úpadek a mdloba. Také ve vrazích.“412 (I/8, S. 31)

Boleslav ringt sich nach Überwindung seines inneren Zwistes - dieser wird in Szene II/2 von ihm selbst so dargestellt, dass er sich jeder Geringfügigkeit „kämpfend" genähert, aber dabei die große Einheit aus dem Auge verloren habe - zum Mord an Václav durch, zugleich entschließt sich dazu auch Drahomíra, die noch Zweifel an Boleslavs Tatkraft hat. Ihre Nichte Jitka, die letzte Überlebende der Stodoranen, und ein heidnischer Opferpriester, der den Verfall heidnischer Kultur unter Václavs Führung beklagt, warnen Drahomíra vor diesem Schritt.

Nach der Ermordung Václavs bereut Boleslav seine Tat in keiner Weise, zwar hat er, wie er im Monolog in III/1 erklärt, Visionen vom toten Václav, doch meint er, dass er auch noch dessen Schatten besiegen werde.

Tvé Čechy nejsou více dobrovolnou / kořistí Němce. Probuzeny ze snů,/ kterými jsi je kdysi svázal, sáhly / po tvrdé zbroji. Boj anebo prohra / anebo vítězství jest jejich osud. / [...] Zde je život / a tvrdý zápas, jehož nenáviděls. ${ }^{413}$ (III/1, S. 56)

Drahomíra allerdings wird von heidnischen Rachegeistern (litice) wegen der Morde heimgesucht, in Agonie erklärt sie freilich, dass ihre Taten nicht umsonst waren, wenn sie Boleslav an die Macht gebracht haben, der von ihr den heidnischen Segen erhält, das Land umzuformen und von Sieg zu Sieg zu führen (vgl. III/6).

Zumal Boleslav auch die Deutschen empfindlich geschlagen hat, kann er nun auch die Liebe von Jitka gewinnen, die von ihm erwartet, dass er eine Rückkehr Böhmens ins Heidentum einleitet. Boleslav erklärt jedoch, dass durch seine Taten sowohl die heidnischen Götter der Freude wie auch der christliche Gott des Todes überwunden seien. Mit ihnen sei der Mensch gestorben, an seine Stelle trete der Übermensch: „Nadčlověk, to jest nejsvrchovanější vưle a nejsvrchovanější poznání. Nikoli vůle sama.“ ${ }^{414}$ (III/7, S. 73)

Da nach einem neuen König gerufen wird, wendet sich Boleslav mit einer antichristlichen Apologie souveräner Fürstengewalt an das Volk. Nur vermöge unermüdlichen Kampfes, nicht aber durch Nächstenliebe könne sich das Volk behaupten.

412 [Drahomíra:] „Überall Verfall und Ohnmacht. Sogar unter den Mördern.“

413 [Boleslav:] „Dein Böhmen ist nun keine freiwillige / Beute der Deutschen. Aus dem Schlaf erwacht,/ mit dem du es einst gefesselt hast, griff / es zu harten Waffen. Entweder Kampf oder Niederlage / oder Sieg ist sein Schicksal. / [...] Hier ist das Leben / und der harte Kampf, den Du verabscheutest."

414 [Boleslav:] „Der Übermensch, das ist der souveränste Wille und die souveränste Erkenntnis. Keineswegs der Wille allein.“ 
Rodí se člověk. Teprve nyní se rodí. Spolupracujte na jeho zrození. Bud'te silni. Nemilujte svoje nepřátele, ale pobíjejte je bez oddechu! ${ }^{415}$ (III/8, S. 77)

Dieser Aufruf des zum absoluten Souverän stilisierten Königs Boleslav soll die Tschechen in den Kampf führen, zuallererst seien die „brüderlichen“ Stämme von der Fremdherrschaft zu befreien. Da die Deutschen schon vernichtend geschlagen wurden, geht es am Ende des Dramas gegen die Ungarn als neuen Hauptfeind.

Die meisten Szenen sind in Prosa verfasst, nach dem Mord an Václav spricht Boleslav jedoch einen langen Monolog in reimlosen Jamben und Trochäen, in dem er die errungene Stärke seiner Person sowie Böhmens preist. Kurz darauf erfolgt eine ganze Szene in sehr kurzen, expressiven Stichomythien (III/4), die Gerüchte von einer angeblichen Niederlage Boleslavs sowie Heilungswunder an Václavs Sarg verkünden. Der Einsatz von Stichomythien ist generell für die Dramentechnik Zavřels charakteristisch, da mit ihnen die scharfen Figurenkontraste auch intonatorisch zum Ausdruck kommen.

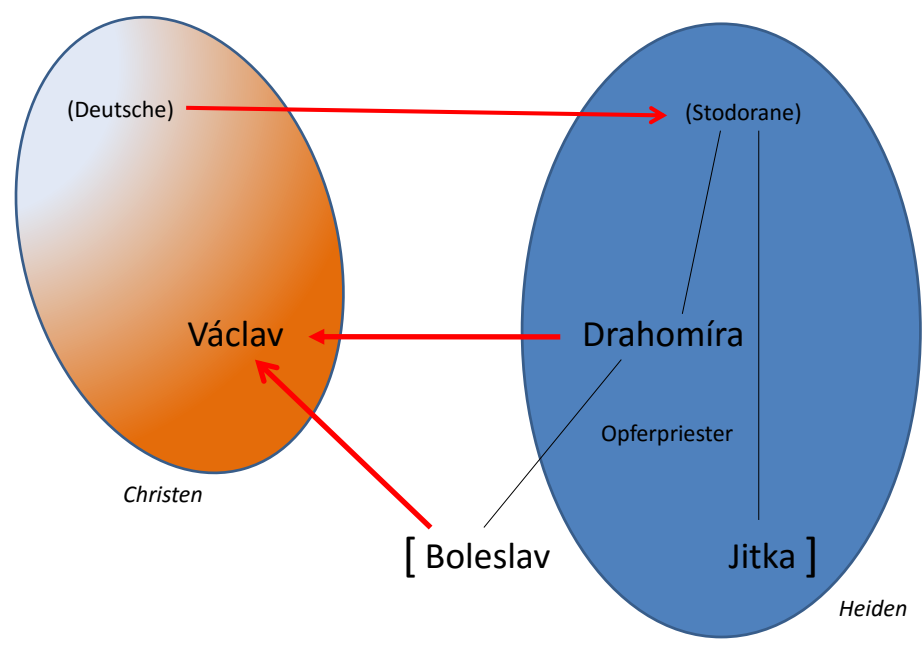

Graphik 35 - František Zavřel: Boleslav Ukrutný (1919)

Zavřels Gestaltung des Václav-Stoffes ist in ihrer Ablehnung der christlichen Position des tschechischen Nationalheiligen von größter Radikalität. Auch wenn diese in der psychischen Verfasstheit des Autors begründet sein mag, ${ }^{416}$ können doch ei-

415 [Boleslav:] „Der Mensch wird geboren. Erst jetzt wird er geboren. Habt Teil an seiner Geburt. Seid stark. Liebt eure Feinde nicht, sondern schlagt sie ohne Unterlass!“

416 Man vergleiche hierzu den Artikel über Zav̌̌el in LčL 4/II, 1699-1702. 
nige klare Bezüge zur Situation der Entstehungszeit des Dramas festgestellt werden. ${ }^{417}$ Depräsentierende allegorische Bezüge auf die ethnopolitische Situation in Böhmen sind wohl in kleinen Details auszumachen: So wirft Boleslav Václav vor, ein Drittel des Landes dem Feind überlassen zu haben (vgl. II/1, S. 32), was dem demographischen Umstand entspricht, dass ein Drittel der Bevölkerung von Böhmen und Mähren von deutscher Nationalität war. Wenn es am Schluss heißt, dass die Deutschen besiegt sind, die Tschechen aber nun gegen den zweiten Hauptfeind, die Ungarn, kämpfen müssen, wird damit von den Zeitgenossen wahrscheinlich in der unmittelbaren Nachkriegszeit der tschechoslowakisch-ungarische Konflikt um die territoriale Zugehörigkeit der Slowakei assoziiert worden sein.

Vor allem das Pathos eines Neubeginns, das vom Dramentext vermittelt ist, entspricht dem Zerfall der Monarchie und der Gründung der Tschechoslowakei. Auffällig ist freilich die Apotheose eines politischen Voluntarismus, die zum einen gegen die christliche Politik Václavs gerichtet ist, zum andern aber zugleich auch wenig Anzeichen für eine demokratische Legitimierung politischer Herrschaft erkennen lässt. Das Volk ruft im dritten Akt lautstark nach einem König, es tritt nicht anders in Erscheinung als durch die Delegierung jeder Entscheidungsgewalt an König Boleslav. Dieser erklärt gegenüber der Menge:

Nazvali jste mne ukrutným, já však budu ještě ukrutnější. Krví a železem vyhladím vřed, který se usadil na vašich duších. Přehnětu vás tak jako jsem přehnětl sama sebe. Učiním vás svými spolubojovníky, nebot' bojem a jedině bojem a nikoli soucitem anebo láskou k bližnímu můžete se zachrániti. ${ }^{418}$ (III/8, S. 76)

Das Volk, das Boleslav nach seiner Fasson umformen möchte (Formen und Ableitungen von prehehnist, umformen, ummodeln' kommen häufig in den Repliken vor), stimmt widerspruchslos diesem Führungsanspruch zu („Ved' nás!“ - III/8, S. 78). Insofern die christlich inspirierte Politik als völlig weltfremd, als irreal und gefährlich dargestellt wird, und die Gegenposition den Mord als äußerstes, aber gerechtfertigtes politisches Mittel einsetzt, um entschlossen eine Führerrolle zu ergreifen, kann Boleslav Ukrutný als Beispiel für eine nationalfaschistische Position im tschechischen historischen Drama gelten.

417 Der Prager Literaturwissenschaftler Eduard Burget, der kürzlich dem Drama einen eigenen Aufsatz gewidmet hat, der im Wesentlichen zu denselben Beobachtungen kommt, meint unumwunden, dass Zavřel mit dem historischen Stoff zur damaligen Gegenwart sprechen wollte (vgl. Burget 2014, 62).

418 [Boleslav:] „Ihr nanntet mich den Grausamen, ich werde freilich noch grausamer werden. Mit Blut und Eisen merze ich die Gefahr aus, die sich in eure Seelen gesetzt hat. Ich forme euch um, wie ich mich selbst umgeformt habe. Ich mache aus euch meine Mitkämpfer, denn allein durch Kampf und wieder durch Kampf, keineswegs aber durch Mitleid oder Liebe zum Nächsten könnt ihr euch retten." 


\section{IV.8.6. Jaroslav Durych: Svatý Václav. Kvas na Boleslavi. Hra o trech dèjstvích}

[Heiliger Václav/Wenzel. Das Fest auf Burg Boleslav; UA 1924, publ. 1924]

Der dem katholischen Lager zugehörige Jaroslav Durych hat ein gleichsam klassisches Drama verfasst, das der Einheit von Zeit (es ist am 27. und 28. September im Todesjahr des heiligen Václav angesetzt), Ort (die Burg Boleslavs) und Handlung in drei Akten entspricht. Die bei Langer und Zavřel auf die Hauptfiguren konzentrierte Handlung erweitert Durych um einige Figuren, von denen entscheidende Handlungen ausgehen.

Der erste Akt wird eröffnet durch einen Dialog des Vladiken Hněvsa mit Boleslavs Priester Pavel, der sich von der Ankündigung irritiert zeigt, dass der zum Besuch angekündigte Václav seinen eigenen Prager Priester Krastej mitbringen werde. Anlass des Besuchs ist die von Boleslav erbaute Kirche für die Reliquien der hl. Kosma und Damian, die zu einem neuen Wallfahrtsziel werden soll. Neben Drahomiř, der Mutter von Václav und Boleslav, soll auch deren Schwester Přibyslava, die Fürstin der Charvaten, zu Boleslav kommen. Hněvsa stichelt Pavels Ehrgeiz an, indem er ihm andeutet, er könne eventuell Bischof in Prag werden, nur stehe dem der Umstand, dass er verheiratet sei und eine Tochter habe, entgegen.

Hněvsa, Česta und Tyra möchten mit Waffengewalt die deutschen Mönche aus Böhmen verjagen, sie müssen aber mit Widerstand rechnen, vor allem von Přibyslava und Václav. Ihrem Herrn Boleslav, der sie durchaus machtbewusst in die Schranken weist, geben sie zu verstehen, dass besser er als Václav der Fürst in Prag sein solle. Boleslav reagiert unwirsch auf diesen Hinweis: die Prager Burg und die Burg von Boleslav sind gleichrangig, Václav könne sich nicht in seine Angelegenheiten mischen und er nicht in diejenigen Václavs. Drahomiř bemerkt die Unbotmäßigkeit und den Übermut der Vladiken und warnt Boleslav vor diesen „Teufeln“ (vgl. I/5, S. 28). Sie erklärt, dass sie nach der Ermordung Ludmilas erkennen musste, dass Mörder zum Kampf nicht fähig sind. All diejenigen, die den von ihr veranlassten Mord gutgeheißen hätten, hätten sich selbst dann rasch mit den Deutschen arrangiert. Boleslav erklärt seiner Mutter:

Matko, nedbej jejich [vladyků] řečí, jako psovod nedbá štěkotu smečky, ale vede ji, kam chce. Muži lačnějí po krvi. A jest to dobře. Ale neumějí držeti jazyk za zuby, což jest ohavné a bude to napravovati můj kat. ${ }^{419}$ (I/4, S. 20)

419 [Boleslav:] „Mutter, achte nicht ihre Reden. Auch der Hundeführer achtet nicht auf das Gebell der Meute, sondern führt sie, wohin er will. Die Männer dürsten nach Blut. Das ist gut so. Sie können aber nicht die Zunge im Zaum halten, was hässlich ist und was mein Henker korrigieren wird." 
Um allfälligen Widerstand gegen eine Vertreibung der Deutschen auszuschalten, treffen Hněvsa, Česta und Tyra Vorkehrungen: So sollen etwa die Charvaten, die Přibyslava begleiten, betrunken gemacht und eingesperrt werden. Drahomiř hat einen Boten zu Radslav Zlický geschickt, der eigentlich mit den Deutschen im Bunde steht, sie aber möchte ihn gegen die Deutschen aufbringen und zum Schutz von Václav gewinnen. Boleslav hingegen möchte Radslav Zlický angreifen, weil er selbst einen Anschlag auf Václav plant, wie Drahomiř befürchtet.

Auf die gemeinsam mit Přibyslava erörterte Frage, was es heißt, jemandes Schwester oder Bruder zu sein, antwortet Boleslav mit einem biologischen Vergleich:

Větve jednoho stromu. Zlomí-li se jedna, druhá roste dále, snad ještě bujněji a ničeho z té ztráty necítí. Tu snad cítí jen kmen. ${ }^{420}$ (I/5, S. 27)

Als Václav unter der Fahne eines Adlers (orlice, f. - im Tschechischen kommen beide grammatischen Geschlechter des Wappentiers in der Heraldik vor) ankommt und Boleslavs Wallfahrtskirche preist, wird er von Česta darauf hingewiesen, dass Boleslav einen Untergebenen getötet hat, der sich weigerte, an der steinernen Burg mitzubauen. Václav zeigt in Durychs Drama sogar Verständnis für Boleslavs Handeln. Den Vorwürfen Boleslavs und der Vladiken, gegenüber den Deutschen unterwürfig sowie kein starker böhmischer Fürst zu sein, weil ihm viele Teilfürsten die Gefolgschaft versagen, entgegnet Václav mit dem Hinweis, dass ihm nicht viel anderes übriggeblieben sei, als mit den Deutschen die Abgaben vertraglich zu verhandeln; allzu viele Landsleute haben ihn im Stich gelassen. Václav kann Boleslav damit durchaus überzeugen, er bittet ihn auch, die Teilfürsten gewinnen zu helfen, um Böhmen zu einem gelobten Land zu machen. Aus Anlass des gemeinsamen Festes legt Václav seine Waffen ab, sein Waffendiener Podiven mahnt mit Verweis auf die Vladiken Boleslavs zur Vorsicht. Václav meint, Boleslav würde für seine Leute bürgen. Sein Vorhaben, Václav zu ermorden, ist durch dessen vertrauliches Verhalten ins Wanken geraten, die Vladiken aber stacheln Boleslav mit aufreizenden Anspielungen auf.

Der Autor lässt die mit den Deutschen vereinbarten Abgaben in einem anderen Licht erscheinen: Nicht als Zeichen der Unterwürfigkeit und der Unselbstständigkeit Böhmens, sondern als notwendiges Unterpfand dafür, dass der Einfluss der Deutschen nicht größer wird. So erklärt etwa Václav, dass er keinesfalls einen Deutschen in Prag zum Bischof haben möchte und er sogar mit dem Schwert den Deutschen den Bischofssitz abringen würde (vgl. II/1, S. 40f). Wie in zwei Repliken erzählt wird, erschienen dem Deutschen Jindřich einst Engel, als er auf dem

420 [Boleslav:] „Äste eines Baumes. Bricht der eine, so wächst der andere weiter, wahrscheinlich sogar stärker, er spürt diesen Verlust wahrscheinlich gar nicht. Diesen spürt wahrscheinlich nur der Stamm." 
Reichstag gegen Václav kämpfen wollte. Ähnlich sei es Radslav Zlický ergangen. Boleslav wendet zwar skeptisch ein, dass die Engel nur Václav wohlgesonnen seien, nicht aber Böhmen; dieser verweist jedoch erneut darauf, dass er von vielen Teilfürsten im Stich gelassen worden sei.

Drahomiř ist erfreut über die sich einstellende Einigkeit zwischen ihren Söhnen. Dass sie aber von keinem ihrer drei Kinder Enkel bekommen hat, bekümmert sie. Die verheiratete Přibyslava gibt zu verstehen, dass sie auch in der Ehe jungfräulich geblieben ist, und Václav erklärt, dass alle Böhmen seine Kinder seien. Boleslav nimmt dies zum Anlass, Václav Vorwürfe zu machen, worauf dieser ihn zu einem Zweikampf im ritterlichen Turnier fordert. Er besiegt Boleslav zweimal und erreicht damit, dass dieser sich und seine Burg ihm unterstellt. Während der Kämpfe versucht Hněvsa weiter, Boleslav als den besseren Fürsten darzustellen. Da Hněvsa von Drahomiř und von Václav als gefährlich angesehen wird, soll Boleslav ihnen diesen übergeben. Er kann jedoch fliehen.

Boten berichten, dass Radslav Zlický an der Grenze angreifende Polen und Ungarn zurückhält. Václav wird von Durych als hartnäckiger und praktisch unbesiegbarer Kämpfer gezeichnet, der militärische Gewalt als nötiges Instrument einsetzt, um Heimat und Glauben zu verteidigen: „Kdo se štítí meče, štítí se i vlasti a Boha!"421 (II/6, S. 62).

Nachdem Přibyslava wieder nach Hause abgereist ist und auch Václav nach Prag zurückkehren möchte, muss Boleslav ihn überreden, doch noch über Nacht zu bleiben. Václav erbittet sich den Schlüssel der Wallfahrtskirche, weil er zeitig aufbrechen möchte und davor noch in der Kirche beten will. Die Intrige geht von Hněvsa aus, der entkommen ist, aber immer wieder kurz auftaucht, um sein Vorhaben voranzutreiben. Drahomiř rät Boleslav, Hněvsa zu töten, aber dieser meint, sie solle noch bis zum nächsten Tag warten. Boleslav erscheint im Dramentext als schwankend bezüglich seines Verhältnisses zu Václav. So gibt es Hinweise auf ein Komplott, das er mit den Vladiken vereinbart hat: Česta etwa hat eine Botschaft Václavs an seine Gefolgsleute zu übermitteln. Statt dies aber unverzüglich auszuführen, erkundigt sich Česta zuerst bei Boleslav, was er dem Gefolge mitteilen soll. Boleslav gibt sich darüber entrüstet: Natürlich soll Česta nur das ausrichten, was Václav ihm mitzuteilen aufgetragen hat. Gleichzeitig lässt Boleslav aber auch anklingen, dass er sich noch keineswegs mit der Vorherrschaft Václavs abgefunden hat (vgl. II/10). Mit seinem Priester, dem feigen Pavel, unterhält sich Boleslav auf eine zweideutige Weise; er fragt ihn etwa, ob jemand auf seiner Burg den Tod verdient. Boleslav folgt weitgehend passiv Hněvsas Plan bzw. macht er ihm nur halbherzige Vorhaltungen (vgl. II/11).

Im abschließenden dritten Akt kommt Boleslav in das Haus Hněvsas und möchte diesen töten oder zumindest festnehmen. Dieser kann sich jedoch mit Un-

421 [Václav:] „Wer das Schwert scheut, scheut auch die Heimat und Gott!“ 
terstützung der dort versammelten Tyra und Česta verteidigen und das Vorhaben der Vladiken erklären: Sie sehen sich als ergebene Diener Boleslavs, die auch dessen geheimste Wunschgedanken kennen. So würden sie Václav töten, damit Boleslav auf den Thron komme; die Verachtung hätten dann sie und Boleslav bliebe der Ruhm. Er könne schlafen gehen, sie würden inzwischen handeln. Freilich gewinnen die Vladiken damit endgültig die Kontrolle über Boleslav, was in seiner Ausdrucksweise heißt, dass die „Hunde“ den „Hundeführer“ führen (entsprechend dem rekurrenten Bild und dem Schmähwort „psi“, das Boleslav gerne gebraucht, vgl. II/10, S. 68, III/3, S. 76 u. S. 80). Boleslav widerstreben die Reden der Vladiken, er kann aber ihrem Treiben nicht mehr Einhalt gebieten bzw. ist er zu feige, um Alarm zu schlagen. Im äußersten Fall drohen die Vladiken ihm auch mit der Ermordung, da sie ja selbst den Tod fürchten müssen, wenn ihr Plan scheitert.

Als Václav im Morgengrauen zur Kirche kommt, holt Boleslav tatsächlich mit dem Schwert zum Schlag aus, Václav überwältigt ihn jedoch mühelos. Aus dem Hinterhalt kommen nun die Vladiken und ermorden Václav vor der verschlossenen Kirchentür. Die entsetzte Drahomiř fordert sofortige Rache an den Tätern, denn zu Recht kann sie Boleslav verdächtigen, zu wenig getan zu haben, um den Mord an Václav zu verhindern. Dieser fordert jedoch, dass sie schweigt. Er trifft alsbald Vorkehrungen, gegen Prag zu ziehen. Er schickt Drahomiř fort, seine Vladiken wollen auch sie töten. Der als neuer Fürst akklamierte Boleslav zeigt ein Schwert und will mit dem Hinweis, dass auf diesem kein Blut klebe, eine Mitschuld am Tod Václavs von sich weisen. Als neu akklamierter Fürst ruft er zur Lynchjustiz an seinen Vladiken auf. In der letzten Szene stellt Boleslav fest, dass einzig Václav ohne Fehler und Schmach in den Tod gegangen ist.

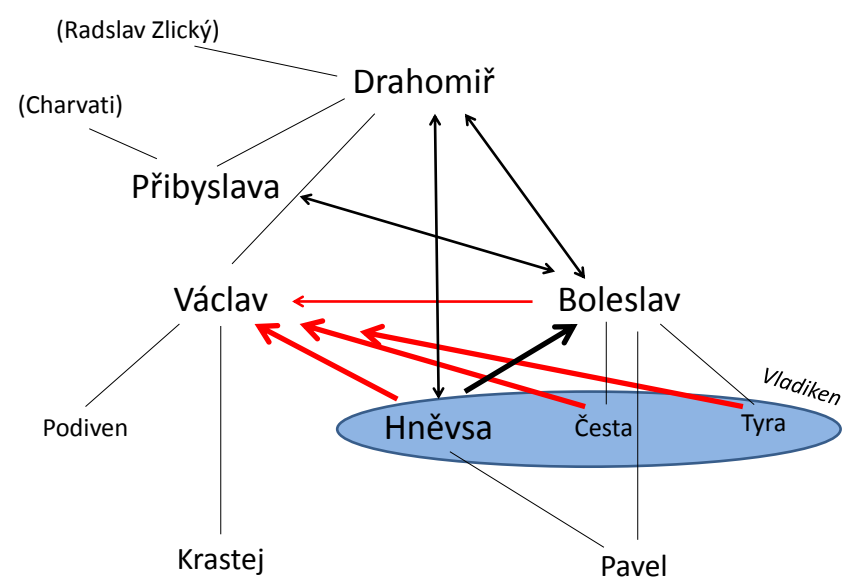

Graphik 36 - Jaroslav Durych: Svatý Václav (1924) 
Das Schema lässt die wichtigste Veränderung erkennen, die Durych in seiner Interpretation der Václav-Legende vorgenommen hat. Während nämlich in den Dramen, die vor Durych entstanden sind, die Vladiken in der Regel eine untergeordnete, ausführende Rolle gespielt haben, sind sie - namentlich Hněvsa - in Durychs Version die Initiatoren von Intrigen, auf welche die „fürstlichen“ Figuren Drahomiř und Boleslav nur reagieren. Es handelt sich gewissermaßen um eine Subversion der Dominanzverhältnisse, die Boleslav im Bild des Hundeführers und der Hundemeute beschreibt: Boleslav tritt im ersten Akt als strenger Teilfürst auf, der seinen Macht- und Herrschaftsanspruch über seine Untergebenen (psi) unterstreicht. Das Stück führt jedoch vor, wie dieser Anspruch unterlaufen wird und der vermeintliche „Hundeführer“ Boleslav letztendlich von den Hunden geführt wird, also zum Werkzeug der Intrige der Vladiken wird.

Durych führt mit Přibyslava als erster eine weitere Hauptfigur aus der Fürstenfamilie ein, die allerdings für den dramatischen Konflikt um Václav und Boleslav weitgehend unbedeutend ist, obwohl auf sie in den ersten beiden Akten ziemlich viele Repliken entfallen. Als Figur scheint Přibyslava Durych vor allem dafür zu dienen, eine mit dem Hauptkonflikt gar nicht im Zusammenhang stehende Apotheose jungfräulicher Reinheit vorzuführen. Sie wird von Hněvsa und Boleslav für ihre bei bestehender Ehe aufrechtgebliebene Jungfräulichkeit verspottet, ihre Mutter ist anfänglich über die Kinderlosigkeit betrübt, letztendlich aber akzeptiert sie zärtlich ihre Tochter, die ihrerseits immer für Václav Partei ergreift.

Darüber hinaus zeichnet Durych Drahomiř und Václav merklich anders als seine Vorgänger. Die Hauptunterschiede bestehen in der Begründung für das Handeln der Figuren. Václav handelt als Fürst durchaus entschieden, er möchte den deutschen Einfluss in Böhmen auf politische Weise einschränken und die Herrschaft an Boleslav abtreten, sobald es ihm gelungen sein wird, ein blühendes Böhmen geschaffen zu haben. Drahomiř ist bei Durych nicht mit dem Heidentum verbunden, sie bereut den politischen Mord an Ludmila und möchte weitere Gewalt in ihrer Sippe vermeiden. Ein Mord aus politischen Gründen zahlt sich ihrer Erfahrung nach nicht aus, weil er nicht die erwarteten Folgen habe. Ludmilas Ermordung, mit der Drahomiř ein Ende der deutschfreundlichen Politik erreichen wollte, habe ein paradoxes Ergebnis gebracht. Diejenigen, die ihren Mord gebilligt haben, seien zu den Deutschen übergelaufen und Böhmen sei deswegen von diesen gelenkt. Drahomiř wird überdies von Schuldgefühlen geplagt. Sie beäugt besorgt das Treiben um Boleslav und erkennt die Gefahr, die von dessen Vladiken ausgeht. Wenngleich sie politische Gewalt „von unten“ ablehnt, rechtfertigt sie eine solche, die von oben kommt: ein Fürst habe das Recht, zu strafen bzw. zu töten, wenn Gefahr drohe sie verlangt daher auch die Tötung von Hněvsa, weil sie dessen Absichten zu kennen glaubt (vgl. II/8).

Boleslav ist zwar neidischer Bruder, doch geht die Initiative zur Tötung von Václav nicht von ihm aus, sondern von seinen Gefolgsleuten Hněvsa, Česta und 
Tyra, die Boleslav manipulieren und ihn so weit in die Enge treiben, dass er ihrem Mordvorhaben an Václav nicht mehr Einhalt gebietet. Boleslav ist dabei als opportunistische Figur gezeichnet, die gerne ihren Gesprächspartnern nachgibt, besonders dann, wenn deren Handeln ihrem eigenen Interesse entgegenkommt. Sie entspricht in dieser Hinsicht dem Priester Pavel, der nicht aus einem christlichen Prinzip heraus handelt, sondern auf seinen eigenen Vorteil bedacht ist: Wenngleich der Mord an Václav von den Mördern unverhohlen angekündigt wird, unternimmt Pavel nichts, um die Tat zu verhindern, sondern gibt sich als unbeteiligte Person, die nichts mit weltlichen Dingen zu tun haben möchte (vgl. III/4). Sein Interesse am Tod Václavs besteht darin, dass er glaubt, zum Bischof von Prag aufsteigen zu können, da Boleslav gerne böhmischer Fürst in Prag sein möchte.

Václav legt großen Wert auf Kampfesstärke und Entschlossenheit; der Waffengewalt ist er nicht abhold, er verbindet das Schwert mit dem Heimatland und mit Gott. Sowohl Václav wie auch Boleslav möchten ihre Macht gegenüber ihren Untergebenen stärken und in diesen „bei sich“ sein, also keinen Widerstand in der Vermittlung ihres Willens verspüren. ${ }^{422}$ Boleslav unterstützt Václav in dessen Machtbegehren, der alleinige Fürst von Böhmen sein zu wollen, Václav seinerseits zeigt Verständnis für die Tötung eines widerspenstigen Untergebenen, der sich weigerte, auf Befehl Boleslavs an der steinernen Burg mitzubauen (vgl. I/6, S. 30f). Die Mannen Boleslavs affirmieren sogar machtbewusstes Verhalten, dabei aber sind sie die eigentlichen - teuflischen, wie Drahomiř es ausdrückt (vgl. I/4, S. 21) - Drahtzieher und Intriganten. Von allen Figuren - die Priester ausgenommen, die behaupten, sich nicht in weltliche Belange einmischen zu wollen - wird Waffengewalt affirmiert, Unterschiede sind lediglich in der Legitimation der Gewalt erkennbar. Hněvsa meint, ein Fürst habe das Recht, mit dem Schwert zu sprechen, weil er ein Fürst sei (I/5, S. 25), Přibyslava hält das Schwert für ein Werkzeug Gottes (ebd.).

Václav fordert Boleslav zum ritterlichen Zweikampf, als dieser ihm wütend erklärt, er wolle ihm am liebsten mit Gewalt den Thron wegnehmen. Der Zweikampf selbst nimmt dann aber keine prominente Position im Stück ein, nur mittels Mauerschau wird von der doppelten Niederlage Boleslavs berichtet, nach welcher er widerwillig die Vorherrschaft Václavs anerkennt. Sein Verhalten gegenüber Václav bleibt zweideutig. Zum einen erklärt er sein Einverständnis mit dessen Oberherrschaft, zum anderen unterbindet er keineswegs die immer deutlicher werdenden Vorbereitungen zu dessen Ermordung. So schiebt er etwa die von Drahomiř und Václav geforderte Festnahme oder Tötung Hněvsas hinaus, er geht nächtens aber doch zu dessen Haus, um ihn zu töten. Dies erfolgt jedoch in angetrunkenem Zustand und ohne Begleitung, sodass sich Hněvsa leicht verteidigen kann. Die Halbherzigkeit

422 Erinnert sei hier an die sehr prägnante Machtdefinition, die Han in Anlehnung an Hegel folgendermaßen formuliert: „Vermittels der Macht ist Ego in Alter bei sich selbst." (Han 2005, 100) 
Boleslavs zeigt sich in der Folge etwa auch darin, dass er keinen Alarm schlägt, obwohl er Drahomiř wecken oder Pavel um Hilfe bitten könnte. Allerdings befindet sich Boleslav da schon in einer von den Vladiken herbeigeführten Double-bind-Situation: Wenn er Alarm schlägt, muss er um sein Leben fürchten (die Vladiken würden ihn töten), unterlässt er die Alarmierung, willigt er in die Ermordung Václavs ein, gegenüber welcher er doch Vorbehalte hegt. Er entscheidet sich schließlich dafür, das Schwert gegen seinen Bruder zu erheben, wird aber auch von diesem überwältigt.

Boleslavs überzogene Machtansprüche werden von den Vladiken umgekehrt. Er betrachtet seine Untergebenen als Teil seiner selbst bzw. als seine Instrumente. Als er Hněvsa für seine Unbotmäßigkeit bestrafen möchte, erklärt er, das Blut seiner Untergebenen gehöre ihm. Hněvsa weist diesen Anspruch zuerst gar nicht zurück, sondern bekräftigt ihn sogar mit der Behauptung, ganz im Interesse von Boleslav zu handeln, weil er dessen geheimste Gedanken kenne, die dieser sich nicht einmal selbst mehr einzugestehen wage („znám věci, o kterých nemluvíš, $[. .$.$] tvoje ta-$ jemství vniklo do našich srdci' ${ }^{\prime 423}$ - III/3, S. 76f).

Gemäß der Auffassung von Macht als Medium zwischen Machthaber und „Unterworfenen" kann man Handeln im Medium der Macht als zweieiniges Handeln sehen: Was der Machthaber will, soll der der Macht Unterworfene ausführen. In der Fabel von Durychs Svatý Václav zeigt sich die fragile Doppelnatur dieser Zweieinigkeit: Boleslav und sogar auch Václav erheben den Anspruch, dass ihr Handeln von den Untergebenen umgesetzt wird. Boleslavs Vladiken affirmieren auch diese Auffassung, letztendlich aber beginnen sie eigen mächtig zu handeln und die Dominanz des Machthabers umzukehren. Sprachlich findet dieses Verhältnis Ausdruck darin, dass sich Boleslav als „vưdce všech těchto věrných zrádcü“ (,Führer all dieser treuen Verräter') bezeichnet. Das Oxymoron „věrný zrádce“ kann dabei gelesen werden als ,oberflächlich treu, in Wahrheit aber ein Verräter', zugleich aber bedeutet es, dass die scheinbaren Verräter an Boleslav in Wahrheit seine treuesten Gefolgsleute sind. Die Genitivkonstruktion „vůdce [...] věrných zrádcü“ entspricht dabei aber auch dem Verhältnis von Boleslav zu Václav. Denn Boleslav folgt nach der zweimaligen Niederlage im ritterlichen Turnier Václavs Wunsch, ihm zu dienen, letztendlich aber wendet sich Boleslav doch mit dem Schwert gegen seinen Bruder. Die Subversion der Machtverkettung lässt sich wie folgt veranschaulichen:

\begin{tabular}{ccccc} 
Machthaber & \multicolumn{3}{c}{ Unterworfener } & Unterworfene \\
Václav & $\rightarrow$ & Boleslav & $\rightarrow$ & Vladiken \\
(Václav) & $\leftarrow$ & Boleslav & $\leftarrow$ & Vladiken \\
(Unterworfener) & & Unterworfener & & Machthaber
\end{tabular}

423 [Hněvsa:] „Ich weiß Dinge, über die du nicht sprichst, [...] dein Geheimnis ist in unsere Herzen gedrungen." 
Das Schema macht deutlich, dass eigentlich Boleslav in der Verkettung der Macht eine Mittlerfigur ist, dass von ihm aber nicht die Macht ausgeht. Er betrachtet sich zuerst noch als gleichrangig mit Václav, dieser fordert jedoch seine Gefolgschaft wie auch diejenige der anderen Teilfürsten. Nach der Niederlage im Turnier und dem abgerungenen Versprechen der Gefolgschaft lässt sich Boleslav aber teilweise in seinem Handeln von den Intrigen seiner Vladiken leiten, womit er Mitschuld trägt an der Ermordung seines Bruders und zum Verräter an ihm wird. ${ }^{424}$ Als Thronfolger weist er allerdings öffentlich jede Schuld von sich. Zuerst lässt er das Volk darüber urteilen, wer Václav getötet hat. Nachdem dieses „Česta, Tyra, Hněvsa“ als Mörder bestimmt hat, ruft Boleslav zur Lynchjustiz an den drei Vladiken auf. Mit dieser finalen Gewalt entledigt er sich letztendlich auch der anderen Rivalen um die Macht, denen er in der voraufgegangenen Handlung folgen musste. In der letzten Szene freilich bekennt Boleslav gegenüber dem dafür völlig unempfänglichen Priester Pavel, dass er schuldig war, während allein Václav würdig - ohne Schande - gestorben sei.

Die im Stück thematisierte Frage von Herrschaft und Gefolgschaft, von Macht und Fügung lässt sich mit Hegels Dialektik der Anerkennung aus der Phänomenologie des Geistes beschreiben. Dort spielt der Zweikampf eine große Rolle, der ja in Durychs Stück die Unterwerfung Boleslavs unter Václav bewirkt. In Hegels Überlegung, die hier nur sehr kursorisch wiedergegeben wird, beweist sich das Selbstbewusstsein durch die Aufhebung alles anderen, im Grenzfall auch der leiblichen Existenz. Im auf sich genommenen Tod aber würde sich das Selbstbewusstsein aufheben. Bei einem Kampf auf Leben und Tod wäre der Tod also der Grenzfall, bei dem sich das Streben nach dem reinen Für-sich-Sein bzw. dem reinen Selbstbewusstsein ad absurdum führt. Hängt das Selbstbewusstsein aber am Leben, fürchtet es den Tod, so wird es zuerst den Kampf aufgeben und damit die Überlegenheit des anderen Selbstbewusstseins anerkennen. In Durychs Drama unterliegt Boleslav zweimal Václav und erkennt in der Folge dessen Oberherrschaft an. Als Václav im letzten Akt zuerst von Boleslav und dann von den Vladiken attackiert wird, verteidigt er sich, unterliegt aber letztendlich und geht in den Tod. Diese Konsequenz hat Václav schon vorher erkannt, denn er erklärt gegenüber Boleslav im ersten Akt:

Srdce knížete není srdce dívky. Dívčině srdci sluší květ, srdci knížecímu sluší rána mečem a někdy mu sluší nejlépe, je-li rozšlápnuto na schodech nebo na nádvoří. ${ }^{425}$ (I/6, S.36)

424 Die Klammer um den „Unterworfenen“ bzw. um „Václav“ in der linken Spalte zeigt nur an, dass es sich mit der Gewalt an Václav eigentlich nicht mehr um ein Machtverhältnis handelt, sondern um die Transgression des von der Macht aufgespannten Handlungsrahmens in den Bereich der Gewalt, der nicht mehr zur Macht gehört, sondern dessen Außengrenze darstellt.

425 [Václav:] „Das Herz eines Fürsten ist nicht das Herz eines Mädchens. Zum Herz eines Mädchens passt eine Blume, zum Herz eines Fürsten passt ein Streich mit dem Schwert und manchmal passt es ihm am besten, wenn es auf der Stiege oder im Hof zertreten wird.“ 
Diese Replik soll keineswegs als bloße Antizipation seines eigenen Todes gesehen werden, sondern auch im Sinne einer fürstlichen Erhabenheit und „heiligen Reinheit “426, die Boleslav in seinen Schlussworten andeutet: Václav hängt nicht verzweifelt an seiner körperlichen Existenz, er nimmt daher seinen Tod auf sich, als dieser nicht mehr vermieden werden kann. Boleslav hingegen handelt weitgehend angstvoll: Er kann weder im ritterlichen Zweikampf noch beim echten Angriff Václav niederringen und gibt schnell auf, ebenso wenig wagt er es, um Hilfe zu rufen, als er weiß, dass die Vladiken den Mordanschlag auf Václav ausführen werden. Hier fürchtet Boleslav wohl auch um sein eigenes Leben. Seine Haltung und seine Position gegenüber Václav kommen dingsymbolisch-metonymisch in dessen Apostrophe seines eigenen Schwerts zum Ausdruck: Nachdem er nämlich Václav im Morgengrauen angreift, von seinem Bruder aber mit bloßen Händen überwältigt wird, schlägt er mit dem Schwert auf den Boden und ruft:

Meči! Kdo na tebe plivl. Kolikrát už jsi mne zradil. Není k boji a nechce se zlomit. Jsi-li už tolikrát potupen, at tě zlomí kat. ${ }^{427}$ (III/4)

Wie das Schwert Boleslav im Stich lässt bzw. ihn „verrät“, so hat sich Boleslav gegenüber Václav verhalten. Er taugt weder zum Kampf noch nimmt er den Tod auf sich. In diesem Augenblick der Krise scheint Boleslav nur kurz zu erkennen, dass sein Verhalten eigentlich vom Henker bestraft werden müsse. Aber schon wenig später ist das Schwert nicht mehr Symbol der Wahrheit, Boleslav setzt es zur Täuschung ein: Da an ihm sichtbar kein Blut klebt, sei er unschuldig.

Durychs Drama zeigt in Václav zum einen einen machtbewussten starken Fürsten, eine Idealgestalt, die für die Schwächen seiner Untergebenen alles auf sich nimmt, zum anderen aber ist im Stück auch zu erkennen, dass die Vorstellung eines vom Fürsten ausgehenden Machtmediums höchst instabil ist: die Untergebenen können das Machtverhältnis umkehren und auch dem vornehmsten Machthaber den Tod bringen.

426 In diesem Zusammenhang ist vielleicht auch die Jungfräulichkeit Přibyslavas zu sehen. Jungfräulichkeit gilt für Durych als deutlichstes weibliches Zeichen einer Erhabenheit über irdisch-körperliche Angelegenheiten. Mit dem tschechischen Wort panenka (,Jungfrau') verband Durych überhaupt das Konzept von spontaner reiner Natürlichkeit, welche in der modernen Kunst abhandengekommen sei (vgl. Brabec 2010b, 390f).

427 [Boleslav:]: „O Schwert! Irgendwer hat auf dich gespuckt. Wie oft hast du mich schon verraten. Es taugt nicht zum Kampf und lässt sich auch nicht brechen. Wenn Du schon so oft besiegt wurdest, soll dich der Henker brechen.“ 


\section{IV.8.7. Gabriela Preissová: Svatý Václav. Hra o pèti dèjstvích (1929)}

[Heiliger Václav/Wenzel. Spiel in fünf Akten; publ. 1929, UA 1929]

Anlässlich des 1000-jährigen Jubiläums der Ermordung von Václav wurden große Feierlichkeiten vorbereitet, die vor allem die konfessionellen Differenzen in der Tschechoslowakei ausgleichen sollten. Die Katholiken - im slowakischen Landesteil die Mehrheit - sahen sich ja im laizistischen Staat unter Masaryks protestantisch gehaltener Führung nur unzureichend repräsentiert. Mit den Jubiläumsfeierlichkeiten, zu welchen auch der Veitsdom fertiggestellt wurde, entstanden auch zwei historische Dramen, die im Národní divadlo (die Erstfassung von Stanislav Loms Drama) bzw. im Městské divadlo na Královských Vinohradech (Preissovás Drama) inszeniert wurden. Auch Jaroslav Durych arbeitete sein Stück von 1924 noch einmal für das Jubiläumsjahr um.

Preissovás Fassung setzt mit einem ritterlichen Turnier ein. Der achtzehnjährige, noch nicht zum Fürsten ausgerufene Václav hat gerade alle Gegner im Zweikampf überlegen besiegt. Von seinem Schild sei man geblendet, meint sein letzter Gegner. Der auf Václavs Thronfolge neidische Boleslav allerdings ätzt, dass die Gegner Václav hätten gewinnen lassen. Er spottet auch über Ludmila und andere Frauen, diese würden allzu viele Gebete für Václav sprechen. Der jugendlich überschwängliche und lebensfrohe Václav kündigt an, dass er als Fürst jedwede Geizigkeit unterbinden wolle, im Fall eines Angriffs auf Böhmen werde er persönlich den gegnerischen Fürsten zum Zweikampf herausfordern, um das Leben junger Untertanen zu schonen, wobei ihm der Erzengel Michael beistehen werde. Als ihn Boleslav zum Kampf auffordert, wird er von Václav umgehend besiegt. Die noch regierende Drahomíra klagt gemeinsam mit Boleslav darüber, dass Ludmila auf Václav und Přibyslava einen großen Einfluss habe; in ihrer Familie sei damit eine Spaltung entstanden: Václav werde von Ludmila begünstigt, nur Boleslav bleibe Drahomíra treu. Auf die scharfe Kritik, dass Ludmila gegenüber fremden Predigern allzu entgegenkommend sei, entgegnet Václav mit der Notwendigkeit der Sicherung des Christentums, für die eben auch ausländische Priester gebraucht würden. Drahomíra ist zwar getauft, sie erklärt aber, an keine Gottheiten mehr zu glauben; besonders fürchtet sie, dass Václavs christliche Nächstenliebe von Feinden ausgenützt werden würde. Immerhin hätten Christen Böhmen überfallen und im Namen des Christentums gemordet. Sie möchte möglichst lange Fürstin bleiben, um die in ihren Augen allzu träumerische Politik Václavs zu verhindern. Auch wenn sie erklärt, hart und unbarmherzig kämpfen zu wollen, erschauert sie bei der Nachricht von der Ermordung Ludmilas, die sie angeordnet hat. Das Volk möchte die Mörder stellen und lynchen sowie Václav zum Fürsten erheben: Dieser ist zutiefst betrübt über die Ermordung und die Reaktion darauf, er nimmt aber das Fürstenamt unter begeisterten Huldigungen an. 
Im zweiten Akt gibt es große Bestürzung über die Heftigkeit des Krieges gegen die Deutschen. Boleslav lässt über den Vladiken Prut das Gerücht verbreiten, dass Václav unterwürfig mit den Deutschen verhandle. Die Tschechen fühlen sich verlassen. Václav kehrt - entsetzt über das allgemeine Morden - früher nach Prag zurück. Der Vladike Horel hat im Kampf seine beiden Söhne verloren, was ihn am versprochenen Beistand des Erzengels Michael zweifeln lässt. Der Vladike Řičanský verteidigt Václav: Er habe äußerst mutig gekämpft, als er aber aufgrund der deutschen Übermacht (es hatten sich Jindřich von Sachsen und Arnulf von Bayern zusammengeschlossen und dabei auch noch Unterstützung von Radslav Zlický, dem Schwager Arnulfs, erfahren, der zu den Deutschen übergelaufen war) erkennen musste, dass die Tschechen chancenlos waren, hat er zur Vermeidung weiteren Blutvergießens ein Friedensangebot gemacht. Als ein Gesandter der Deutschen von christlichem Frieden spricht, halten ihm die Tschechen die deutschen Untaten vor. So spricht etwa Prošek, ein Parteigänger Václavs:

Tam z vaší strany přichází na český lid každý útisk a pohroma. Kdybyste nás jen nechali na pokoji, rájem by se mohla zváti naše vlast. ${ }^{428}$ (II/5, S. 35)

Der deutsche Gesandte entgegnet mit dem Vorwurf, dass der Fürstensohn Boleslav einen Alten wegen dessen Unbotmäßigkeit töten habe lassen. Prošek weist solche Bemerkungen entschieden zurück, immerhin habe Václav Boleslav für die Tötung des Alten damit bestraft, dass er ihn nicht in den Kampf habe ziehen lassen. Der Gesandte meint, die Gottgefälligkeit des deutschen Handelns würde schon allein darin zum Ausdruck kommen, dass sie die Tschechen besiegt hätten, die siegreichen deutschen Fürsten erwarten die symbolische Unterwerfung Václavs. Dieser schätzt die Lage der Tschechen sehr pessimistisch ein; nachdem sie so viel Leid haben hinnehmen müssen, gehe es nun darum, für Frieden und ruhigen Wiederaufbau zu sorgen; es dürfe auch keine Strafexpedition ins Teilfürstentum von Radslav Zlický geben, denn was nütze es, wenn dessen Untertanen für die Vergehen ihres Herrn bitter büßen müssten?

Der Fürst der Chorvaten, Přibyslavas Mann und der Schwager von Václav und Boleslav, ist ebenfalls gefallen. Václav räumt ein, dass die Ausrüstung der eigenen Truppen unzureichend gewesen sei und dass man künftig viel mehr Mittel in die militärische Friedenssicherung stecken müsse. Es wäre naiv gewesen, nur darauf zu bauen, dass die Friedfertigkeit nicht ausgenützt werden würde. Aber eine blutige Rache für die schweren Verluste will Václav keinesfalls zulassen, dies könnte einen noch schlimmeren Gegenschlag der Deutschen nach sich ziehen und somit das Land ganz zerstören.

428 [Prošek:] „Von eurer Seite kommt jedwede Drangsal und Vernichtung über das tschechische Volk. Wenn ihr uns nur in Ruhe ließet, könnte unsere Heimat Paradies genannt werden." 
Máte-li moje rozhodnutí za slabost, zbavte mne vůdcovství i života, ale nedejte zahynouti naší budoucnosti, která vyplyne jednou světlým příkladem mezi národy. ${ }^{429}$ (II/8, S. 44)

Václav lässt seinen Bruder gefangen nehmen und seine Mutter auf die Burg Budeč verbannen, weil diese gegen seine Politik agitieren; während Přibyslava bewusst zu ihrem Bruder Václav hält. Dieser ist bereit, als Fürst für sein Land das schwerste Opfer auf sich zu nehmen: als der Gesandte die deutschen Forderungen nach Unterwerfung vorbringt, willigt er ein in der Hoffnung, dass damit für die Zukunft eine friedliche Grundlage geschaffen werde:

Ale nekonečnou věrností přivtělený $\mathrm{k}$ svému lidu chci věřit nade všecko pomíjitelné, že můj vlastnílid, v mých očích ten nejčistší a nejpřičinlivějš́ lid - stane se jedné chvíle po svých obětech důstojným rozhodčím svých věcí - sám a na věky .... ${ }^{430}$ (II/11, S. 55)

Im dritten Akt, der auf dem Gut des opportunistischen Höflings Tůnek spielt, trifft sich Václav mit den wichtigsten Vertretern des Landes. Tůneks Tochter Bíla ist eine eifrige Anhängerin Václavs, sie interessiert sich nicht für Männer, wie das ihr Vater wünscht, sondern vor allem für die Krankenpflege, für deren Aufwendungen allerdings die Teilfürsten Abgaben leisten müssen. Auf dem Treffen treten die antagonistischen Auffassungen unter den Teilfürsten und Vladiken offen zutage, Boleslav kündigt an, dass letztlich andere Mittel über das Charisma Václavs siegen werden. Dieser appelliert an die nationale Einigkeit unter seiner Prager Führung, nur so könne der Zerfall Böhmens verhindert werden, Radslav Zlický erklärt dem seine Zustimmung, Boleslav und Prut jedoch verweigern sie.

Im vierten Akt, der auf Boleslavs Burg spielt, wo Václav erneut in ritterlichen Turnieren glänzt und jener frustriert seine wenigen Anhänger um sich schart, die sich über die Friedenspolitik, die für wohltätige Zwecke erhöhten Abgaben und die charismatische Wirkung Václavs beklagen, entschließen sich die Gegner zu einem Anschlag auf diesen. Fahrende Sänger geben ein begeistertes Lied über Václav zum Besten und werden dafür von Boleslav verjagt. Drahomíra ist in Preissovás Drama während der Verbannung nach Budeč geläutert worden, sie sieht in Václav einen durchaus erfolgreichen Fürsten, um dessen Leben sie gemeinsam mit Přibyslava besorgt ist. Der von seinen Erfolgen im Turnier hochgestimmte Václav erklärt, dass

429 [Václav:] „Wenn ihr meine Entscheidung für Schwäche haltet, so nehmt mir die Führung und das Leben, lasst aber nicht zu, dass unsere Zukunft stirbt, die einmal als helles Beispiel unter den Völkern aufgehen wird““

430 [Václav:] „Aber als mit grenzenloser Treue mit meinem Volk verbundener möchte ich über alles Vergängliche hinweg glauben, dass mein eigenes Volk, das in meinen Augen reinste und bemühteste, dereinst nach seinen Opfern über seine eigenen Angelegenheiten wird entscheiden können - alleine und dauerhaft." 
Boleslavs Sohn einmal sein Thronfolger werden soll, was dieser kurzfristig von seiner feindseligen Haltung gegenüber seinem Bruder abbringt.

Im fünften Akt kommt es zum Mord an Václav. Boleslav muss jedoch zuvor sein Widerstreben überwinden, er wird aber von Prut zur Ausführung gedrängt, der andernfalls Böhmen untergehen sieht. Václav hatte in der Nacht eine große Vision von einer idyllischen Zukunft für sein Volk:

[...] stojím na stráži všech svých krajů, sloučených jednou dobrou vưlí, jediným věrným tlukotem srdce všech svých obyvatelů, nejpilnějšího a nejčistšího to lidu na širošírém světě $[\ldots]^{431}$ $(\mathrm{V} / 3$, S. 104f)

Der Heide Horel, der aufgrund des Verlustes seiner Söhne lange ein wütender Gegner Václavs war, bittet diesen um Verzeihung, die er selbstverständlich gewährt. Václav ahnt, dass sein Opfergang bald bevorsteht, er spricht auch von Kains Schuld, die immerfort wiederholt werde. Boleslav wirft Václav eine allzu nachgiebige und passive Politik vor, das Land brauche einen Fürsten, der keine Schwäche dulde und die Schwächen anderer ausnutze. Václav kann Boleslavs Attacke leichterhand abwehren; die aus dem Hinterhalt hervorspringenden Tyra und Hněvsa erstechen jedoch Podiven und Václav vor der Kirchentür. Václav bittet sterbend um Verzeihung für seine Mörder und versichert seiner herbeigeeilten Mutter Drahomíra und seiner Schwester, immer über das Land wachen zu wollen. Mit den Klängen des Chorals vom hl. Václav (Svatováclavský chorál) endet das Drama.

Dieser Choral war einer der favorisierten Anwärter für die Staatshymne der neugegründeten Tschechoslowakei. Preissová hat ihr Drama nicht nur mit den Klängen des Chorals enden lassen, sie hat auch Verse des Chorals in Repliken, die meist am Schluss einzelner Akte stehen, in minimal abgewandelter Form integriert: „on je dědic české země“ (I/6, S. 27), „on nedá zahynouti nám ni budoucím“ bzw. „Pane, nedej zahynouti naší lepší budoucnosti!““332 (I/7, S. 26 bzw. III/9, S. 78). Diese Repliken wollen als Anklänge an die Tradition des Heiligenkults um Václav verstanden werden.

431 [Václav:] „[...] ich stehe Wache für alle meine Länder, die durch guten Willen vereint sind, durch einen einheitlichen wahren Schlag all seiner Bewohner, des allerfleißigsten und allerreinsten Volkes auf der großen weiten Welt [...]“.

432 „Er ist der Erbe des böhmischen Landes“, „Er lässt uns und die Nachkommen nicht untergehen“, „Herr, lass unsere bessere Zukunft nicht untergehen!“ 


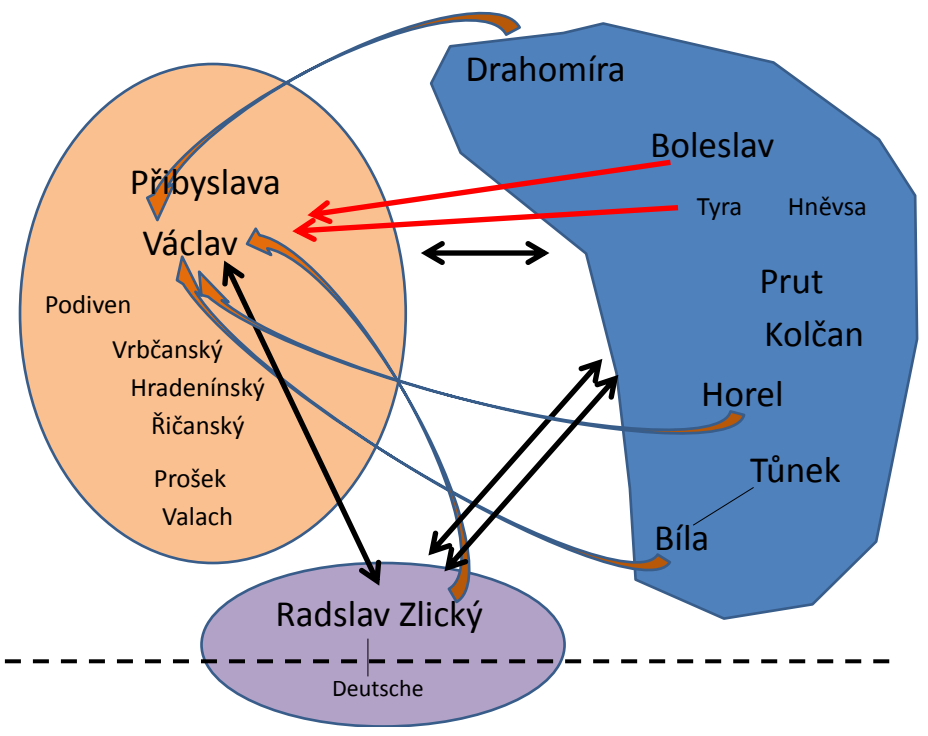

Graphik 37 - Gabriela Preissová: Svatý Václav (1929)

Wie anhand des Schemas erkannt werden kann, gibt es im Wesentlichen drei Konfliktparteien: das Lager Václavs, dasjenige Boleslavs und die Deutschen, die als überhebliche und verblendete Christen erscheinen, die Böhmen unterwerfen möchten. Václav weist seine innenpolitischen Gegner darauf hin, dass die Deutschen deshalb so erfolgreich sind, weil sie zu einer Einigung gefunden haben. Ein solches nationales Einigungsprojekt strebt ja auch Václav selbst an. Er kann dafür sogar Radslav Zlický, den Parteigänger der Deutschen, gewinnen, was freilich von Václavs Gegnern als doppelter Verrat Zlickýs angesehen wird.

Radslav Zlickýs Lagerwechsel ist nur einer von mehreren Lagerwechseln, mit denen aus einstigen Gegnern Václavs dessen Anhänger werden. Auffällig ist dies etwa bei Drahomíra, die zuerst gegen Václavs sanftes Politikverständnis auftritt, letztendlich aber bereits die Früchte des Erfolgs in Václavs nationalem Einigungsprojekt erkennt. Auch Horel, der aufgrund des Verlustes seiner beiden Söhne im Kampf gegen die Deutschen verbitterte Vladike, wechselt letztendlich in Václavs Lager, weil er vom transzendenten Licht, das Václav umgibt, angezogen wird. Dieses Licht ist eindeutig christlich konnotiert, ihm folgt auch Bíla, die Tochter des opportunistischen Hofbeamten Tůnek, die, statt vorteilhaft zu heiraten, wie es sich ihr Vater wünscht, ihrem Vorbild Václav nacheifert und sich gänzlich der Krankenpflege widmet.

Boleslav, der bei Preissová wenig vorteilhaft gezeichnet ist, da er nur ein einziges Mal sich von Václavs Verhalten einnehmen lässt, neidet seinem Bruder nicht 
allein die Thronfolge, sondern auch die Fähigkeit, vermittels Rede und Auftreten für neue politische Ideen - etwa für die nationale Einigung unter christlicher Ausrichtung - zu begeistern. Václav kann also viele Gegner für seine politischen Vorhaben einnehmen, wie vor allem anhand von Radslav Zlický und Drahomíra deutlich wird. Václavs Stärke als Fürst ist mithin nicht ausschließlich einer transzendenten Kraft geschuldet, sie beruht wesentlich auch auf seinem politischen Programm sowie auch auf Kampfesbereitschaft zu Verteidigungszwecken. Václav ist nicht von Anfang an perfekt; er sieht etwa ein, dass sein Vertrauen auf die Friedfertigkeit vom aggressiven deutschen Nachbarn ausgenützt worden war, sodass er später doch dazu auffordert, sich gegenüber Angriffen entsprechend zu wappnen. Nicht also der Waffengebrauch als solcher, wohl aber militärische Angriffskriege und Rachefeldzüge widersprechen seiner christlichen Überzeugung.

In Preissovás Václav-Drama macht Václav eine jähe Reifung durch: Aus dem unter Ludmilas Einfluss christlich erzogenen, zugleich aber lebensfrohen und trinkfreudigen Thronfolger, der zum Fürsten wird, als in Böhmen das Chaos überhandnimmt, wird durch die Erfahrung des Krieges gegen die Deutschen ein sorgenvoller Landeserster, der seine zölibatäre Ehelosigkeit damit begründet, dass Frau und Familie einen Fürsten egoistisch und parteiisch machen würden. Als Fürst möchte Václav jedenfalls ein Vorbild abgeben; von der Bereitschaft, den Tod auf sich zu nehmen, verspricht er sich gemäß christlicher Opferlogik eine Verbesserung der Verhältnisse in Böhmen:

Ta moje stráž na nejvyšším místě musí se vykoupiti větší obětí, než jí může býti pouhá rozvaha nejlepší vůle. Kdybych byl nyní se svými padl v boji, odevzdal v bolesti ten dar života ... to by snad byla již obět českého vojvody, aby jeho lidu zbylo víra v tu jeho věrnou stráž ... i nekonečnou lásku. ${ }^{433}$ (II/10, S. 50f)

Diese Überlegung, eine Opferrolle einzunehmen, leitet Václav auch unmittelbar vor seiner Ermordung, die er voraussieht. Preissová hat den Brudermord naheliegend mit der Geschichte von Kain und Abel verbunden, indem bei ihr Václav schon in seiner Kindheit die alttestamentarische Szene in Zeichnungen festgehalten hat, auf welche im Drama von den Figuren hingewiesen wird. Im Nebentext wird das Bild beschrieben als Darstellung des Opfers von Kain und Abel, dieses wurde in der christlichen Kunst ja mit dem Opfertod Jesu Christi in Verbindung gebracht.

Das Opfermotiv leitet aber nicht allein Václavs Handeln, sogar Boleslav sieht den Umstand, dass er - mit etwas Widerstreben - Václav ermorden soll, als Opfer

433 [Václav:] „Meine Wache am allerhöchsten Rang muss mit einem größeren Opfer als bloß durch Überlegungen mit allerbesten Absichten bezahlt werden. Wenn ich jetzt mit dem Meinen gefallen wäre, hätte ich mit Schmerz dieses Geschenk des Lebens zurückgegeben ... das wäre wohl schon ein Geschenk eines tschechischen Herzogs, damit seinem Volk der Glaube an seine treue Wache ... und seine allergrößte Liebe verbleibe." 
an. In derselben Szene meint Prut, er werde für eine bessere Zukunft seines Vaterlandes diese Opferung durchführen (vgl. V/2, S. 102). In diesem Zusammenhang kann auch die konventionalisierte umgangssprachliche Bedeutung von Opfer (,Verlust, schwere Aufgabe' bzw. ,schwere Lebensumstände'), die im Zusammenhang mit den Belastungen des Volkes durch den Krieg gegen die deutsche Übermacht und die Tributzahlungen geäußert wird (vgl. III/9, S. 75), soweit resemantisiert werden, dass aufgrund eines Opfers eine bessere Zukunft erwartet wird.

Preissovás Drama ist mit der Lobpreisung des Landespatrons und seiner außergewöhnlichen Haltung zugleich ein Preis des „allerreinsten und äußerst bemühten“ („ten nejčistší a nejpřičinlivější lid“ - II/11, S. 55) böhmischen Volkes, über das Václav in den höchsten Tönen spricht:

Bůh dal člověku svobodu vůle, on může dlouho bloudit, ale jednou se může přece přiblížiti k svému určenému, znovu nalezenému ráji, - a náš český člověk se mu přiblíží mezi prvními, protože jeho srdce je už takové od př́rody, že tíhne statečně za pravdou ...(V/6, S. 110) $)^{434}$

Die im historischen Drama verschlungenen Momente von Repräsentation und Depräsentation sind in Preissovás Svatý Václav besonders akzentuiert, da die Millenniumsfeierlichkeiten zum einen an Václav als bedeutende Gestalt der mittelalterlichen Geschichte aktualisierend erinnern, zum andern aber natürlich mit dem Rückgriff auf die Vergangenheit die Gegenwart erreicht werden soll. Man vergleiche etwa das pathetische Ende des dritten Aufzugs, in dem „depräsentierend“ die Millenniumsfeiern angesprochen werden:

Vrbčanský: Náš sjednocený český stát! Přátelé, necht́ ještě po tisíci letech ozve se náš jásot jako dobrý kov všemu našemu lidu na radost a pýchu a tato chvíle je tak štastná a veliká, že je třeba před ní pokleknout. (Sveze se na kolena, po nèm se svezou všichni na kolena, naposledy zlický kniže i Václav.)

Václav (sepne ruce): Pane, nedej zahynouti naší lepší budoucnosti! (III/9, S. 78) 435

In diesem Zitat ist die gattungsspezifische performative Kraft des historischen Dramas in nuce zu erkennen: Der Wunsch Václavs - eine Depräsentation des Wun-

434 [Václav:] „Gott gab den Menschen die Freiheit des Willens, er kann auch lange irren, irgendwann einmal aber muss er an das für ihn bestimmte, wiedergefundene Paradies kommen, und unser tschechischer Mensch nähert sich als einer der ersten [diesem Paradies], weil sein Herz von Natur aus so ist, dass es tapfer nach der Wahrheit strebt ..."

435 [Vrbčanský:] „Unser vereinter tschechischer Staat! Freunde, auf dass noch nach tausend Jahren unser Jubel unser ganzes Volk zu Freude und Stolz zusammenschmiedet. Und dieser Augenblick ist so glücklich und groß, dass man vor ihm niederknien muss. (Lässt sich auf die Knie nieder, nach ihm knien alle anderen nieder, zuletzt der Fürst Radslav und Václav) [Václav: (die Hände erhebend):] „Herr, lass unsere bessere Zukunft nicht untergehen!“. 
sches der Autorin - bezieht sich auf eine Zukunft, die zum einen schon historisch ist (die Zukunft aus der Sicht des sprechenden Václav), die zum anderen aber auch die Gegenwart der Rezeption des Dramas angeht (auch diese ist Zukunft aus der Sicht Václavs), wie eben auch die Zukunft aus der Sicht des Publikums mitgemeint ist. Im äußeren Kommunikationssystem wird ja an das ebenfalls geeinte "Volk“ appelliert, unter dem Banner Václavs aus einer ohnehin schon sehr guten Gegenwart nach einer noch besseren Zukunft zu streben (vgl. V/6, S. 111). Ideologische Vorstellungen von Vergangenheit, Gegenwart und Zukunft erscheinen in solchen Repliken komprimiert und verschlungen, die Aufführung solcher Dramen zu einer großen Jubiläumsangelegenheit strebt nach einer diachronen Integration der tschechischen Gesellschaft.

Die aufgrund des historischen Stoffgehalts bei den Václav-Dramen immer relevante Frage nach dem Verhältnis zu den Deutschen ist bei Preissová zwiespältig: Bei ihr haben Figuren des deutschen Lagers längere Auftritte, in denen sie sich als anmaßende und überhebliche Gegner der Tschechen erweisen, die ihre Forderungen etwa damit rechtfertigen, dass ihr kriegerischer Erfolg über die Tschechen gottgefällig sei (vgl. II/5, S. 36). Da der deutsche Erfolg aber aufgrund nationaler Einigung ermöglicht worden ist, gibt er für Václav das Beispiel ab, dem die Tschechen folgen sollen, wenn sie Bestand haben wollen. Aus diesen beiden Momenten ist freilich noch kein positiver allegorischer Bezug auf die deutsche Bevölkerungsgruppe in der Tschechoslowakei der Zwischenkriegszeit zu erkennen, die doch von den Feiern nicht ausgeschlossen werden sollte. Preissová hat diese allegorisch damit in das unter dem Banner Václavs stehende nationale Einigungsprojekt integriert, dass dieser ausdrücklich die Verbreitung des christlichen Glaubens auch durch fremde bzw. deutsche Priester und Missionare begrüßt. Unter einem wahren Christentum der Nächstenliebe, wie Václav es vertritt, sind nationale Konflikte ja schon theoretisch ausgeschlossen. Der im Drama vorgeführte und für den Handlungsverlauf fundamentale Nationalitätenkonflikt wird als prinzipiell überwindbar dargestellt, wenn das politische Programm Václavs nur entsprechend breit umgesetzt wird.

\section{IV.8.8. Stanislav Lom: Svatý Václav. Tragická bra z českých dějin (1935)}

[Heiliger Václav/Wenzel. Tragisches Spiel aus der böhmischen Geschichte; publ. 1929, UA 28.9. 1929; zweite, veränderte Aufl. 1935, UA 28.6. 1935]

In seinen Überlegungen zum Theater schreibt Stanislav Lom auch über das historische Drama, das seiner Meinung nach bei den Tschechen in der Regel auf eine dramatisierte Darstellung der geschichtlichen Vorgänge beschränkt geblieben sei oder vom engagierten Pathos seiner Autoren seine Wirkung gewonnen habe (vgl. Lom 1942, 174). Diesen dramaturgisch wenig überzeugenden historischen Dramen - 
Lom nimmt nur Jaroslav Hilbert aus - stellt er historische Dramen gegenüber, in denen die Heldenfigur in sich persönliche und nationale Züge vereinige:

Pravý historický hrdina je totiž dovršitelem osobního i národního karakteru. Je nositelem a ukazovatelem národní duše, i když snad jde zdánlivě proti jejím zálibám, náladám a sklonům. ${ }^{436}$ (Lom 1942, 176)

Es darf wohl vermutet werden, dass Lom diese seine Idealvorstellung vom nationalen Helden in seiner Bearbeitung des Václav-Stoffes verwirklicht sehen wollte. Loms Svatý Václav - die Analyse bezieht sich auf die zweite, veränderte Auflage aus dem Jahr 1935 - beginnt nach der von Drahomiř betriebenen Ermordung Ludmilas. Aus deren Tod - so die heidnische Vorstellung - soll Leben für das Land entstehen. Die Hexe weist Drahomiř darauf hin, dass auch zwei Fürstensöhne zu viel sind, einer der Zweige des Stammbaumes soll abgebrochen werden. Václav ist bestürzt über die Ermordung Ludmilas. Er befindet, dass sein Anspruch, ein Fürst des Friedens und des milden Verzeihens zu sein, schamlos ausgenützt wird; es wäre seiner Ansicht nach angemessener, hart zu bestrafen. Gegenüber seinem frommen Erzieher, dem Priester Pavel erklärt er: „Višs, kdo je kniže? / Ten, kdo je nejkrvavější ze všech ostatních!“‘37 (I, S. 16) Seine Mutter, die er der Mitschuld an der Ermordung Ludmilas verdächtigt, verbannt Václav auf die Burg Budeč. Václav wird von Boleslav vorgeworfen, sich zu wenig um das Wohl des Landes zu kümmern; der Tod Ludmilas, an dem Boleslav jede Beteiligung zurückweist, würde vielleicht bewirken, dass eine Veränderung stattfindet. Václav schenkt Boleslav ein Gebiet an der Elbe, Boleslav soll sich dort als Teilfürst beweisen und die Expansionsgelüste Jindřichs von Sachsen [= Heinrich der Vogler] eindämmen. Pavel kommentiert missbilligend, dass Václav Boleslav auf das Schwert schwören lässt, worauf Václav erklärt, die bewaffnete Verteidigung durchaus zu akzeptieren: „Bůh mi dal v ruce meč knížete, / a já ho udržím, / i kdybych mečem měl zahynout!" ${ }^{438}$ Drahomiř ist über diese Wendung hocherfreut.

Bei der böhmischen Landesversammlung auf der Prager Burg werden die Misshelligkeiten unter den Adeligen offenbar. Hněvsa etwa spottet über Václavs Frömmigkeit, man klagt über dessen Freigiebigkeit gegenüber Armen, der Sklavenhändler Tyr darüber, dass keine Sklavenmärkte mehr stattfinden dürfen. Boleslav wird freudig als Teilfürst begrüßt, der für ein höheres Amt geeignet sei. Bei der BegrüBung Václavs kann man deutlich erkennen, wer seine Anhänger sind und wer sich reserviert gegenüber ihm verhält. Václav will eine bessere Rechtssprechung einfüh-

436 „Ein wahrer historischer Held ist nämlich der Vollender des persönlichen und des nationalen Charakters. Er ist der Träger und der Anzeiger der Volksseele, auch wenn er sich augenscheinlich gegen deren Präferenzen, Stimmungen und Geneigtheiten wendet."

437 [Václav:] „Weißt du, wer ein Fürst ist? Derjenige, der blutrünstiger als alle anderen ist.“

438 [Václav:] „Gott gab mir das Fürstenschwert in die Hand, / und ich halte an ihm fest, / auch wenn ich durchs Schwert sterben müsste!“ 
ren, die Angeklagten Homola und Struna, die am Mord Ludmilas beteiligt waren, bezichtigen Boleslav des Mordes an einem Dorfältesten, der sich weigerte, am Bau der steinernen Burg mitzubauen. Václav ist zwar betrübt von dieser Nachricht, er verurteilt Boleslav aber nicht, weil dieser nur nach den Gepflogenheiten seiner Umgebung gehandelt habe. Homola und Struna werden von ihm zum Tode verurteilt.

Als Drahuš z Lucka vorbringt, dass die Deutschen unter Jindřich von Sachsen, der gerne Kaiser werden möchte, in Böhmen für Ordnung sorgen wollen, dafür aber die Oberhoheit beanspruchen, weist Václav dieses Ansinnen klar zurück. Auch die Bayern, denen sich der mächtige böhmische Teilfürst Radislav Zlický angeschlossen hat, sind nach Böhmen gekommen und wollen Unterredungen mit Václav. Die bayrischen Anführer, Fürst Arnolf und Herzog Gero werfen Václav vor, sich nicht wie ein Untergebener zu verhalten, denn er zahle keine Steuern und folge nicht den Vereinbarungen. Václav weist jedes Untertanenverhältnis zurück. Die Bayern hingegen bestehen mit dem Verweis auf die Taufe von 14 Fürsten in Regensburg auf einem Vasallenverhältnis. Václav entgegnet, sein Vater habe aber die Taufe in Mähren empfangen. Er beharrt weiter auf einem freien und christlichen Böhmen. Gero provoziert, indem er die böhmische Fahne packt und symbolisch Bayern unterordnet. Václav gebietet dem entschlossen Einhalt, gewährt aber den Bayern, die mit dem Krieg drohen, freies Geleit. Hněvsa kritisiert die gastfreie Haltung Václavs, auf der anderen Seite kündigt ihm Radislav Zlický die Gefolgschaft. Václav gewinnt begeisterte Zustimmung, als er ganz Böhmen zum Kampf aufruft:

Nad bojem, nad mírem, nad životem české země, my jsme stráž! / Za nový boží svět, za duši člověka, za věčně živou krev, / za všechny rodné své chceme žít! ${ }^{439}$ (II, S. 39)

Im dritten Akt, der im Lager der Prag belagernden Sachsen und Bayern spielt, offenbart zuerst Jindřich von Sachsen seine Machtgelüste im Gespräch mit dem deutschen Bischof Tuto. Jindřich möchte Kaiser werden, er weiß, wie schwierig es ist, die unterworfenen Gebiete zu kontrollieren. Jindřich und Arnolf rivalisieren zwar um die Kaiserkrone, verbünden sich aber gegen Böhmen. Drahuš z Lucka ist zu den Deutschen übergelaufen, seine Andeutung, Václav meuchlings zu ermorden, wird von Jindřich entrüstet zurückgewiesen. Drahuš wird den wüst marodierenden Merseburgern ausgeliefert, die blutrünstig auf eine Schlacht warten, zur Überbrückung aber Drahuš Spießruten laufen lassen. Die bayrischen und sächsischen Fürsten weiden sich an diesen abstoßenden Quälereien. Als Václav - noch dazu unbewaffnet ins Lager tritt, lassen die Merseburger von ihrer Hetze ab und weichen ehrfürchtig zurück. Auch Jindřich und Arnolf sind vom Charisma Václavs überaus beeindruckt

439 [Václav:] „Wir sind Wächter über den Kampf, den Frieden, über das Leben des böhmischen Landes / Für eine neue göttliche Welt, für die Seele des Menschen, für ein immer lebendiges Blut / für all unsere Geschlechter wollen wir leben!“ 
(„Kdo je tak strašně sám, / s tím je Bůh!“440 - III, S. 50). Erst als Václav als Forderung Freundschaft und Friede vorbringt, gewinnen die Deutschen ihre Fassung wieder und zeigen sich entrüstet. Jindřich droht mit der Zerstörung Prags. In einem Disput über die Aufgaben des Fürsten kann aber Václav ihn so sehr beeindrucken, dass dieser ihm einen Platz an seinem Hof anbietet. Da Václav aber mit dem Verweis auf seinen Platz bei seinem Volk ablehnt, das er zu friedlicher Blüte führen will, bietet ihm Jindřich seinen Schutz an und schenkt ihm die Reliquien des heiligen Vít/Veit. Václav soll nicht ein Lehensmann des sächsischen Königs, sondern ein freier Fürst eines freien Landes sein. Die Reliquien waren in Jindřichs Augen bei der Eroberung heidnischer Gebiete hilfreich, und da Václav ihm eine neue Vision von Herrschaft eröffnet habe, soll nun er über diese Reliquien verfügen. Václav gelobt, ihnen die Kirche auf der Prager Burg zu weihen. Die Verbündeten Jindřichs sind über dessen jähen Gesinnungswechsel erbost, Radislav Zlický möchte sich nicht Prag, sondern den Deutschen unterordnen. Jindřich erklärt, dass er mit Václav erstmals einen Menschen getroffen habe, der ein höheres Ziel verfolge als er selbst.

Der vierte Akt beginnt mit einer Szene nach einer Schlacht. Boleslav hat gemeinsam mit seiner Schwester Přibyslava und deren Mann, dem Fürsten der Chorvaten, eine Strafexpedition gegen die abgefallenen Zličanen geführt, deren blutige Folgen Václav jetzt bedauert. Er möchte nicht mittels Gewalt gewinnen, sondern die Herzen erobern. Als ein Verwundeter - es ist der Sohn Radislav Zlickýs - aufwacht und Václav attackiert, kann dieser ihn von seiner Mission überzeugen (auch weil der Verwundete Engel an der Seite Václavs sieht). Radislav Zlický, der Václav ebenfalls schwere Vorwürfe macht, wird von diesem zum Zweikampf herausgefordert, bei dem ermittelt werden soll, wer das vereinte Böhmen führen soll. Auch Radislav sieht Engel um Václav und gelobt Gefolgschaft und Treue. Nur Boleslav hegt Vorbehalte gegen die Politik Václavs, der etwa auch die Kriegsgefangenen sofort wieder in die Freiheit entlässt. Er ist der Auffassung, dass man allein mit Waffengewalt das Leben und den Frieden beschützen könne. Die ihre Taten bereuende Drahomiř spürt die Feindschaft, die Boleslav gegenüber Václav empfindet. Dieser sieht es als sein Schicksal an, Boleslav von seiner Vision zu überzeugen, da dies schwieriger sein würde als die anderen Gegner zu entwaffnen.

Auf Boleslavs Burg sind Gäste anlässlich der bevorstehenden Geburt von dessen Sohn versammelt. Beim üppigen Trinkgelage, mit dem der fünfte Akt beginnt, wird Boleslav nahegelegt, den ebenfalls eingeladenen Václav in dieser Nacht zu töten, um selbst Fürst in Prag zu werden. Boleslav wird insbesondere vom Händler Tyr, bei dem er hoch verschuldet ist, diese Lösung vorgeschlagen. Als Václav ankommt, werden die Spannungen offenbar. Er bringt einen Trinkspruch auf Boleslav aus, dessen Wirkung einige von dessen Anhängern auf die Knie zwingt. Boleslav sieht in Václav den Erzengel Michael mit dem Feuerschwert. Als Tyr Václav mit dem Messer atta-

440 [Jindřich:] „Wer so fürchterlich alleine ist, mit dem ist Gott!“ 
ckieren möchte, fällt ihm dieses unwillkürlich aus der Hand. Václav schlägt entgegen der Warnung seines treuen Gefolges vor, dass alle die Waffen ablegen. Boleslav willigt ein, gibt aber seinen Leuten bereits Anweisung, sie sollen das Gefolge töten, Václav aber am Leben lassen, damit er selbst Fürst in Prag werde. Václav selbst soll in Boleslavs Burg gefangen gehalten werden.

Im sechsten Akt wird der unvorhergesehene Verlauf der Ermordung Václavs gezeigt. Dieser geht nämlich überraschend zum Morgengebet und trifft Boleslav an, der noch sein Schwert trägt. Die Kosma und Damian geweihte Kirche ist verschlossen worden, weil der betrunkene Tyr am Vorplatz randalierte. Als Boleslav zum Schlag mit dem Schwert ausholt, kann Václav seine Hand stoppen, nun sieht auch Boleslav die Engel um Václav. Inzwischen haben Boleslavs Mannen Václavs Gefolge getötet, der tödlich verwundete Mstina warnt noch Václav, der in der Kirche Zuflucht sucht, aber vor der verschlossenen Tür von Tyr erstochen wird. Hněvsa und Česta wollen sich an Václavs Leiche vergehen, etwas aber hält sie zurück. Die heidnische Hexe, die das Geschehen mit seherischen Kommentaren begleitet hat, stürzt sich mit den Worten „Na novém oltáŕi nová obět / na naší zemi / nový svět!“"4411 (VI, S. 101) in den Tod. Als Přibyslava die Geburt von Boleslavs Sohn vermeldet, sieht sie die Getöteten. Drahomiř ist über diese von ihr befürchtete Wendung bestürzt. Boleslav ruft sich zum Fürsten aus, er preist Václav, dessen überirdische Kraft er soeben erfahren hat und bittet ihn um Verzeihung und um Fürbitte. Mit dem Choral vom heiligen Václav, dessen Leichnam vom Licht beschienen ist, endet das Stück.

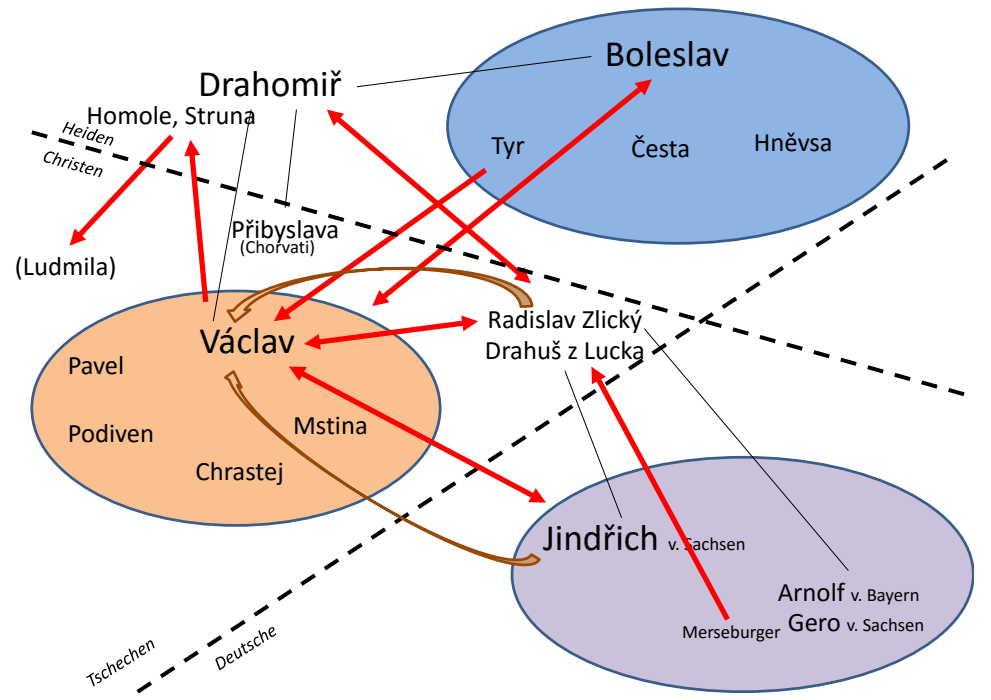

Graphik 38 - Stanislav Lom: Svatý Václav (1935)

441 [Vědma:] „Auf dem neuen Altar ein neues Opfer / auf unserem Land / eine neue Welt!“ 
Zwar knüpft Lom mit Svatý Václav an Tyls Krvavékritiny an, was in einigen intertextuellen Anspielungen zu erkennen ist, doch kann schon an den schematischen Darstellungen der Konflikte erkannt werden, dass es einige entscheidende Differenzen zwischen Tyls Drama aus dem Jahr 1849 und Loms Stück aus dem Jahr 1935 gibt. Während Tyl eine deutlich bipolare Austarierung des Konflikts erreicht, gibt es bei Lom zum einen mehrere konfligierende Parteien und zum anderen auch mehrere Konflikte, die nicht durchwegs konsequent zu einem zentralen Konflikt wie bei Tyl gebündelt werden.

Loms Drama beginnt zwar mit dem für Tyls Konzeption charakteristischen Schwanken zwischen Christentum und Heidentum bzw. zwischen Václav und Boleslav, Drahomiř aber ist nicht mehr die zentrale Figur, in der dieses Schwanken zum Ausdruck kommt. Bei Lom ist nicht sie die Titelheldin, sondern Václav, dessen christliche Politik als hehres und schlechthin bezwingendes Ideal dargestellt wird.

In diesem Zusammenhang sind einige Inkonsequenzen festzustellen, die zum Teil bereits auch in anderen Dramentexten mit dem hl. Václav als Titelfigur aufgetreten sind und dort auf unterschiedliche Weise gelöst wurden: Václavs überirdischer Beistand bzw. sein transzendentes Charisma ist insofern ein sowohl dramaturgisches wie auch ideologisches Problem, als der Widerspruch auftritt, dass Václav zum einen mit einer transzendenten Welt in Berührung zu stehen scheint, zum anderen aber irdische Anforderungen an den Fürsten Václav zu dieser idealen christlichen Welt querliegen. Bei Tyl ist Václavs Charisma vorhanden, dieser verwendet es für einen Ausgleich mit den Deutschen, sodass sich kein Widerspruch zwischen seiner charismatischen Stärke und seiner persönlichen oder politischen Schwäche bzw. Verwundbarkeit ergibt. Bei Vrchlický in Bratři ist das Charisma zwar sehr stark, Václav setzt es aber nicht konsequent für politische Zwecke ein, sondern möchte sich aus der politischen Welt zurückziehen. František Langers Václav ist ebenfalls ein charismatischer Fürst, der Handlungsverlauf unterstreicht aber, dass Charisma allein nicht ausreichend ist, sondern an die Bereitschaft zur Verteidigung gebunden bleibt. In Zav̌rels Negativbild bleibt vom Charisma wenig übrig, sodass Václav als träumerischer Schwächling erscheint. In Durychs Svatý Václav wird kurz auf den Widerspruch aufmerksam gemacht, dass Václavs Ausstrahlung seine Gegner in die Knie zwingt, aber das Land daraus keinen Gewinn zieht. Václav erklärt dies damit, dass er in Böhmen zu wenig politische Unterstützung bekommt. Bei Lom wird der Widerspruch zwischen der überirdischen Stärke Václavs und seiner Niederlage gegen den durchschnittlichen Boleslav aber deswegen besonders deutlich, weil Václav im Verlauf des Stücks ja mehrmals seine Gegner in seinen Bann zieht: Jindřich lässt von seinen Submissionsplänen ab, Radislav Zlický und sein Sohn sehen die Engel um Václav und stellen sich demütig Václav zu Diensten, die als wütende Kampfmaschinen gezeichneten Merseburger ziehen sich beim Auftreten Václavs kleinlaut zurück. Als auf Boleslavs Burg der erste Angriff auf Václav und sein Gefolge passiert, braucht dieser nur wenig, um wie der Erzengel Michael die Angreifer in die Knie 
zu zwingen. Sogar Tyr fällt das Messer aus der Hand, als er gegen Václav anrennt. Letztlich aber sieht er die Engel nicht, die Boleslav entwaffnet haben, und somit kann er Václav doch noch erdolchen.

Der Vergleich der unterschiedlichen Ausgestaltungen von Václavs überirdischer Macht zeigt, dass aus allen Dramen der Widerspruch zwischen der legendären Stärke und seiner finalen Verwundbarkeit herausgelesen werden kann, dass aber Loms Version insofern die Unstimmigkeit verstärkt, als Lom Václav nicht nur als christlichen Fürsten, sondern auch als starken Kämpfer zeigt, der zur Verteidigung seines Landes und seines Vorhabens entschlossen ist. In Loms Svatý Václav wird Václav als Fürst und Politiker auf Kosten von dramaturgischer Plausibilität verklärt. Die Ideologie und ihre „Rhetorik“ (also die diversen Mittel, die das Anliegen umsetzen, Václav als christliche Idealfigur zu zeichnen) bleiben deutlich spürbar, weil Lom die Überhöhung gar nicht zu „motivieren“ versucht.

Der Bezug von Loms Drama auf die großen Millenniumsfeierlichkeiten ist des Weiteren darin zu erkennen, dass im Drama die Reliquien des hl. Veit thematisiert werden, für die Václav verspricht, eine Kirche zu bauen (bekanntlich wurde der Veitsdom auf der Prager Burg ja tatsächlich erst 1929 fertig gestellt). Das Verhältnis zu den Deutschen ist deutlicher ausgestaltet als in den meisten anderen Dramen mit dem Václav-Stoff. Gerade in den Dramen, die im 20. Jahrhundert vor Lom entstanden sind, kommen Vertreter der Deutschen gar nicht als dramatis personae vor, sondern werden nur als im Fabel-Hintergrund Handelnde erwähnt. Lom nun zeichnet die Deutschen zum einen als Eroberer und Aggressoren, die Böhmen nicht allein fest mit dem Deutschen Reich verbinden, sondern dieses auch in ein Vasallenverhältnis zwingen wollen. Zum anderen aber wird Jindřich „Ptáčník“ von Sachsen [= Heinrich der Vogler], der zuerst eher negativ gezeichnet ist, zu dessen Schirmherrn, der Václavs politische Vision bewundernd zur Kenntnis nimmt. Im Verhältnis zu den Deutschen nimmt Václav durchwegs eine entschiedene Position ein: Er akzeptiert nur ein Verhältnis zu diesen, das Böhmen als frei und unabhängig belässt. Tschechische Adelige, die ihre Gebiete deutscher Herrschaft unterstellen und sich von Prag distanzieren, versucht er für ein geeintes Böhmen zu gewinnen, was im vierten Akt bei Radislav Zlický mit der Unterstützung von Engeln gelingt.

Damit ist die Auseinandersetzung mit den Deutschen abgeschlossen, die als personae dramatis überhaupt nur in den ersten drei Akten zugegen sind. Jindřichs Anerkennung von Václav als vorbildhafte Fürstengestalt und die Versicherung, dass er unabhängiger Fürst eines freien Landes ist, lösen den nationalen Konflikt. Die zweite Hälfte von Loms Drama führt also eine innertschechische Konfliktsituation vor, wie sie für die Václav-Dramen seit Vrchlický dominant ist, in denen die Deutschen nur mehr im Hintergrund der Fabel oder als stumme Figuren auftreten. Hierbei ist bemerkenswert, dass die Figuren der Fürstenfamilie (also Drahomiř, Přibyslava und Boleslav) nicht mehr die Auslöser von Handlungen sind. Boleslav selbst wird überhaupt erst von den unzufriedenen Adeligen auf die Idee gebracht, 
die Prager Krone zu beanspruchen; er selbst und sogar seine Mutter Drahomiř weisen zuallererst auf die rechtmäßige Thronfolge hin. Die gegensätzlichen politischen Auffassungen der Brüder werden im vierten Akt virulent, im fünften wird Boleslav aber - ähnlich wie bei Durych - von untergebenen Adeligen angestachelt, sich die Macht von Václav zu nehmen. Als auch noch der - nicht einmal als Adeliger gezeichnete - kaltblütige Sklavenhändler und Geschäftemacher Tyr Boleslav auf die schwer einbringbaren Schulden hinweist (vgl. V, S. 82f), zeigt sich, dass dieser bei weitem nicht allein dafür verantwortlich ist, dass Václav zu Tode kommt. Von den Beeinflussungen seiner Anhängerschaft angestachelt, möchte Boleslav einen Brudermord vermeiden und Václav bloß gefangen setzen (wofür allerdings das Gefolge Václavs sterben muss), aufgrund anderer Umstände kommt es jedoch zu dessen Ermordung, an der Boleslav jedenfalls mitbeteiligt ist. Dennoch kann er aber nicht als Herr der Situation gelten, diese ist ihm vielmehr entglitten.

Stanislav Loms Svatý Václav führt in seinem Titelhelden eine ideale Fürstengestalt vor, die allenthalben - auch bei den deutschen Nachbarn - großen Eindruck hervorruft. Zu Tode kommt sie vor allem aufgrund einer Mischung von Missgunst, Hass, Intrigen und unglücklichen Umständen, die als schwer kontrollierbare Kräfte des politischen Lebens erscheinen. Die transzendente Idealfunktion Václavs soll durch diese Faktoren aber nicht gemindert werden.

\section{IV.9. Zusammenfassung des diachronen Überblicks über die Dramatik um sv. Václav}

Die insgesamt acht Dramen, die den Konflikt zwischen dem Brüderpaar Václav und Boleslav darstellen, bieten aufgrund ihres gemeinsamen stofflichen Fokus eine ideale Möglichkeit, um eine diachrone Achse durch den Untersuchungszeitraum zu bilden und die Veränderungen der politischen Implikationen aufzuzeigen. Ein solcher Vergleich wurde bereits von Pulicarová (2006) vorgenommen, die sich dabei jedoch vor allem auf die Václav-Figur konzentrierte. Aufgrund dieser Schwerpunktsetzung und einer merklich katholischen Beobachterperspektive kommt Pulicarová jedoch bisweilen zu anderen Drameninterpretationen (erkennbar im Fall von Vrchlický, Langer, Durych) als in der von uns gewählten ideologisch-politischen Analyse.

Die beiden Bearbeitungen des Václav-Stoffes in der ersten Hälfte des 19. Jahrhunderts, Máchas Fragment Bratrovrah und Tyls Krvavé křtiny entsprechen auf unterschiedliche Weise der Tendenz ihrer Zeit, Václav nicht mehr allein aus dem Blickwinkel der Verehrung zu zeigen. Mácha war es weniger um Václav zu tun, vielmehr ging es ihm - insoweit die Fragmenthaftigkeit von Bratrourah dies überhaupt erkennen lässt - um den Brudermörder Boleslav und um Drahomíra, deren romantisch-extravaganten dunklen Gemütszuständen Mácha Ausdruck verleiht. Die Analyse von Krvavé kŕrtiny hat gezeigt, dass Tyl mit dem Drama ein sorgfältig konstruiertes Spiel von Gegensätzen - Christentum gegen Heiden, Nächstenliebe gegen 
nationalen Partikularismus - aufgespannt hat. Die beiden ungleichen Brüder Václav und Boleslav - wie analog auch Ludmila und Drahomíra - personifizieren diese Gegensätze, die bei Tyl ausbalanciert bleiben, während etwa Vojáček mit Ludmila eine eindeutige Apologie christlicher Politik entwirft. Damit hat Tyl gegenüber der traditionellen Václav-Verehrung eine Veränderung vorgenommen, weil er Václav mit Drahomíra und Boleslav zumindest politisch ebenbürtige Gegner gegenübergestellt hat.

Beim Vergleich von Vojáčeks Ludmila mit Tyls Krvavé křtiny čili Drahomíra a jeji synové - zwei Dramen, die beide den Übergang vom Heidentum zum Christentum Anfang des 10. Jahrhunderts thematisieren - erweisen sich schnell die dramaturgischen wie auch die ideologischen Unterschiede. Ludmila ist praktisch ein problemloses Stück; das Christentum erscheint als überlegene sittliche Kraft, der gegenüber das Heidentum roh und barbarisch wirkt. Die Antagonisten der Titelheldin sind allesamt Heiden, die in ihrem Rückzugskampf keine Intrige und Bluttat scheuen. In Krvavé kŕtiny dagegen ist der Konflikt viel besser ausbalanciert, weil die moralische Überlegenheit des Christentums mit dem nationalen Problem einhergeht, dass eine christlich geprägte politische Praxis, wie die von Ludmila und ihrem Enkel Václav vertretene, zur nationalen Abhängigkeit oder gar Demütigung der Tschechen führt. Diese Konsequenz aus der Christianisierung wird zwar bereits in Ludmila von den Heiden als Problem angesprochen; die Antwort des Apologeten des Christentums akzentuiert den nationalen Konflikt aber auf eine ganz andere Weise: dem tschechischen Christen zufolge ist das Christentum für die Deutschen gleichfalls eine sittliche Kraft. Der deutsche Nachbar sei eigentlich böse, das Christentum halte ihn aber im Zaum und mäßige ihn. Somit erkennt man in Vojáčeks ziemlich simplem Drama Ludmila unterschwellig eine nationalistische Tendenz, die in den Konflikt zwischen Christen und Heiden hineinspielt: Diese impliziert, dass die tschechischen Christen besser sind als die deutschen Christen, insgesamt aber sind die Christen besser als die Heiden. Bei Tyl gibt es aber keine so eindeutige Wertzuwiesung: In moralischer Hinsicht sind die tschechischen Christen zwar den tschechischen Heiden überlegen, nicht unbedingt aber in nationalpolitischer. Es gibt also keine so vorbehaltlos positive Figur wie Ludmila bei Vojáček, die durch ihren Tod zum Sieg des Christentums beiträgt. Die nationale Auseinandersetzung zwischen Tschechen und Deutschen bildet bei Tyl den Hintergrund, vor dem sich die Ambivalenzen der Konfliktparteien erweisen.

In einer offenen politischen Situation, nach den Aufständen von 1848 und während des österreichischen Reichstags zu Kremsier (Kroměřǐz) in Mähren, bei dem der Dramatiker zugegen war, hat Josef Kajetán Tyl mit Krvavé kŕtiny ein Drama geschrieben, das bis in die Gegenwart immer wieder gespielt wird. Wie soeben in der direkten Gegenüberstellung zu Vojáčeks Ludmila gezeigt wurde, schafft Tyl eine Alternative zwischen nationaler Selbstständigkeit und politisch-ideologischer Bindung an den deutschen Nachbarn, die im Drama nicht aufgelöst wird: Die christ- 
liche Nächstenliebe des Fürsten Václav führt zur nationalen Unselbstständigkeit; der Kampf für eine starke tschechische Nation hingegen nimmt allzu große Blutschuld auf sich. Vergleicht man die allegorischen Aussagen von Jan Hus und $\mathrm{Kr}$ vavé kŕtiny, dem kurz darauf entstandenen Nachfolger, ist eine Zurücknahme des revolutionären Geistes zu erkennen: Während aus der Hinrichtung von Jan Hus die Verheißung eines massiven Aufstandes gegen das Unrecht folgt, führt Krvavé křtiny gleichsam die blutige Konsequenz einer allein auf dem nationalen Prinzip ausgerichteten Politik vor.

Betrachtet man Josef Kajetán Tyls Krvavé kŕtiny als den eigentlichen Beginn der nationalpolitischen Auseinandersetzung um Václav, so ist zuallererst die Ausgewogenheit des ideologischen Kräfteverhältnisses zu erkennen: bei Tyl impliziert Václavs christliche Politik die Gefahr, vom deutschen Nachbarn dominiert zu werden, was Drahomíra und Boleslav mit aller Gewalt zu verhindern suchen. Jan Dvorský hat mit Drahomira dieser Ausgewogenheit eine dialektische Lösung damit gegeben, dass er den seinen Brudermord aufrichtig bereuenden Boleslav zum einen Václavs christliche Politik fortsetzen lässt und zum anderen ihn aber als einen selbstbewussten militärischen Führer zeichnet, der mit dem Kreuz in der linken und dem Schwert in der rechten Hand die tschechische Heimat vor dem deutschen Gegner verteidigt.

Im ersten Teil seiner »Böhmischen Trilogie « zeichnet Jaroslav Vrchlický eine ähnliche Grundsituation wie Tyl, indem er Drahomíra entschlossen gegen die christliche und deutschfreundliche Politik Ludmilas auftreten lässt, mit dem Sněm aber führt er eine dritte Partei ein, die in diesen Konflikt eingreift. Der Sněm ist jedoch kein vermittelnder Dritter (wie es Boleslav gegenüber Drahomíra und Václav bei Dvorský ist), sondern selbst Partei. Als solche weist er die Absolutheitsansprüche Drahomíras zurück und inszeniert sich als eine das Land und den Adel repräsentierende Kraft; zugleich fällt aber auf, dass der Sněm selbst von partikularen Interessen geleitet ist und keineswegs eine dauerhafte Lösung des Konflikts ermöglicht.

Dies erweist sich in Bratřri, dem zweiten Teil der Trilogie, in welchem der Kampf zwischen den beiden Lagern, wie ihn Tyl vorgezeichnet hat, weitergeht - der Sněm bleibt weitgehend machtlos gegenüber der charismatischen Wirkung Václavs. Dieser ist ein entschlossener und edler christlicher Herrscher, politisch aber nicht erfolgreich. Er möchte sogar zugunsten Boleslavs abdanken, der aus Eifersucht Václav töten lässt und trotz seiner negativen Charakterzüge zur Zufriedenheit der Untergebenen regiert. Die Realpolitik erscheint bei Vrchlický unvereinbar mit den hehren Idealen eines christlichen Lebens. Die transzendente Kraft, die von Václav ausgeht, ist zwar bezwingend, sie gibt allerdings insofern kein politisches Muster ab, als die tatsächlichen Erfolge für die Nation ausbleiben. Politisches Handeln ist bei Vrchlický mit Gewalt und Egoismus verbunden, es bezwingt nicht auf eine so unerklärliche Weise wie die transzendente Kraft Václavs, ist aber in der Immanenz der Geschichte erfolgreicher. Boleslav bekennt demütig seine große Schuld gegen- 
über dem himmlischen Herrscher Böhmens, dem jedoch nur in der Transzendenz Idealität zukommt.

Bei František Langers Version des Václav-Stoffes könnte man meinen, dass es sich um eine Apotheose der radikal gewaltlosen Haltung Václavs handle, die er depräsentierend von Lev Tolstoj auf den tschechischen Nationalheiligen zurückprojiziert hat. Langers Stück stellt die Idee von Gewaltlosigkeit allerdings eher in Frage. Wie die Analyse der kunstvoll mehrdeutigen Dialoge im dritten Akt gezeigt hat, ist Boleslav seinem Bruder Václav in einiger Hinsicht überlegen: Er möchte ihn eigentlich gar nicht töten, sondern nur seinen Verteidigungswillen wecken, als er aber sieht, dass dieser bereit ist, den Tod auf sich zu nehmen, um damit ein Beispiel vorbildlichen Sterbens abzugeben, entschließt er sich zur Mitwirkung an der Ermordung seines Bruders. Damit erlangt er die Macht; er handelt sodann aber nicht im Sinne Václavs, sondern als militärisch starker und erfolgreicher Fürst: Boleslav weist jedoch seine Mutter, deren Verhalten ihn dazu gebracht hat, den Brudermord auszuführen, in die Schranken. In dieser Hinsicht ähnelt das Resultat des Dramas demjenigen von Dvorskýs Version: Boleslav ersetzt Václav und korrigiert dessen radikale Vision, um ein Risiko auszuschalten, das dem Land gefährlich wäre. Václav beeindruckt Boleslav zwar in mancher Hinsicht (in seiner Kampfesstärke, seinen moralischen Ansprüchen), wie bei Tyl und Vrchlický aber erscheint die Idee radikaler christlicher Politik als nicht vermittelbar mit der politischen Realität, die Boleslav viel klarer sieht und für welche er bereit ist, den Brudermord auszuführen.

František Zavřel hat mit Boleslav Ukrutný die vehementeste Ablehnung der christlichen Versöhnungspolitik in Dramenform verfasst. Seine protofaschistische Apologie eines kämpferischen Voluntarismus markiert historisch einen extremen Wendepunkt in der Gestaltung des Václav-Stoffes: In allen Dramen der Zeit von 1849 bis 1919 scheint Václavs Verständnis einer christlichen Politik zumindest problematisch zu sein, weil es die nationale Stärke und Selbstständigkeit Böhmens gefährdet. Alle Dramen seit Tyls Krvavé křtiny bringen für die antagonistische Position ein großes Verständnis auf, wobei entweder Drahomíra selbst oder Boleslav für eine Politik einstehen, die die Nation stärkt. Václav wird dabei entweder als verträumt-naiv (bei Tyl und Zavřel) oder als entschlossener Idealist gezeichnet, der sich (so bei Dvorský, Vrchlický oder Langer) nicht ganz in die politische Realität einfinden und adäquat handeln kann.

Erst Jaroslav Durych zeichnet 1925 ein rein positives Bild von Václav. Die Tribute wie überhaupt das Verhältnis zu den Deutschen haben ihren Grund nicht etwa in einer allzu freundlichen - und damit riskanten - Haltung Václavs gegenüber dem schon länger christlichen Nachbarn, sondern verdanken sich praktischen Notwendigkeiten: Václav bekommt zu wenig Unterstützung von den allzu eigensinnigen böhmischen Teilfürsten und kann nur durch Zahlungen und Kompromisse mit den Deutschen Schlimmeres verhindern. Seine Bestrebungen gehen auch dahin, mehr 
Loyalität und Zusammenhalt zu schaffen, damit weitere Zugeständnisse nicht nötig sind. Gegen eine stärkere „Machtvertikale“ - auf diese zielt Václav ab - wenden sich Boleslavs Vladiken, die diesen mit abgefeimten Mitteln dazu treiben, sich an der Ermordung Václavs zu beteiligen. Der ideale Fürst Václav fällt „dunklen“ politischen Kräften zum Opfer.

Gabriela Preissovás für die Millenniumsfeierlichkeiten verfasstes Drama lässt Václav eine politische Reifung durchmachen. Als jugendlicher Fürst ist er allzu gutgläubig und hofft auf ein christliches Verhalten von Seiten der Deutschen. Die Brutalität deren Angriffs auf Böhmen weist Václav auf die Notwendigkeit einer verstärkten militärischen Landesverteidigung hin, die freilich nicht in Rache und Aggression umschlagen dürfe. Václav setzt auf einen friedlichen Aufbau Böhmens; dass er von seinen Gegnern erstochen wird, sieht er voraus. Er deutet seine Ermordung mit Bezugnahme auf den biblischen Mythos von Kain und Abel als Opferung, die der Fürst für sein Volk auf sich nimmt.

Stanislav Lom kreierte ebenfalls eine Václav-Figur, die für ein freies Böhmen auftritt und die sich gegen sächsische bzw. bayrische Ansprüche stellt und sowohl diese wie auch seine innenpolitischen Widersacher mit ungemein starkem Charisma für sich einnimmt. Dass Václav, der deutlich himmlische Unterstützung durch den Erzengel Michael hat, überhaupt bekämpft wird, gründet im Egoismus seiner Gegner. Boleslav, der - ähnlich wie bei Durych - an der Tötung mitschuldig ist, bereut umgehend und bittet um Verzeihung. Anders etwa als bei Vrchlický kann Boleslav keinerlei nennenswerten politischen Erfolg aufweisen, wohl aber Václav, der zur übernationalen, himmlischen Idealgestalt wird.

Der wesentliche Unterschied zwischen den Dramen vor 1918 und danach besteht darin, dass - sieht man von Zavřels Negativbild ab - Václav erst in der Tschechoslowakei zum tragischen Helden wurde. Diesen kennzeichnet ja der Opfertod, mit welchem er der Gemeinschaft, die er mit seinem Tod verlässt, in einen Zustand verhilft, der dem Heil näher ist. Die „Todeskrisis“ des Helden zeigt an, dass der Tod eine Rettung ist (vgl. Benjamin 1974, 286), eine Rettung für die Gemeinschaft, für die der Held in den Tod geht.

An den acht Dramen mit dem Václav-Stoff (vier aus der Zeit vor dem Ersten Weltkrieg, vier aus der Zeit der ersten tschechoslowakischen Republik) lässt sich deutlich der Wandel der Václav-Figur verfolgen: Während der Monarchie - und bei Zavřel unmittelbar nach dem Ersten Weltkrieg - erscheint Václav in den Dramen als Fürst, dessen christliche Politik sein Volk vor das Problem der Unterordnung unter die Deutschen stellt. Seine Antagonisten vertreten andere ideologische Positionen, die sie bis zu seiner Ermordung bewegen. Diese erscheint in diesen Dramen aber als zweckmäßiges Mittel, um die gefährdete böhmische Nation vor deutscher Übermacht zu bewahren.

Die Dramen Durychs, Preissovás und Loms dagegen zeichnen Václav als tragischen Helden, dessen Ermordung durch egoistische Bösewichte als Opfer zu ver- 
stehen ist, mit dem das von der Fürstenfigur repräsentierte Volk heilsgeschichtliche Transzendenz erfahren darf.

Wenn damit in nuce die Hauptdifferenz zwischen den Dramen aus der Zeit der Monarchie und der Unabhängigkeit herausgestrichen wird, so muss freilich in einem zweiten Schritt auch auf die "Verklärung" der Václav-Figur eingegangen werden, die in den früheren Dramen zu beobachten ist. Diese verstellt die hier freigelegten Verhältnisse insofern, als ja die hehre ethische Haltung Václavs dem Verhalten seiner Antagonisten meist weit überlegen ist. Politischer Mord, wie er an Václav verübt wird, gilt in der Regel als so verwerflich, dass auch die ihn motivierenden Positionen desavouiert erscheinen. Erst bei genauerer Betrachtung - und eine solche wurde angestrebt - zeigt sich, dass die Antagonisten, wenn schon nicht in der transzendenten Sphäre ethischer Grundsätze, so doch in den immanenten Niederungen der Politik erfolgreich sind, was heißt, dass sie Böhmen unabhängig halten können. Gewissermaßen können somit Drahomíra bei Tyl, Dvorský und Vrchlický oder Boleslav bei Dvorský und Langer als Tragödienhelden gelten. Der von ihnen (mit-)verantwortete Mord an Václav ist ihr „ethisches“ Opfer, das sie für die Angelegenheit des Volkes bringen.

Rein kulturhistorisch betrachtet, ist Václavs Einsatz für das Christentum in Böhmen gegen den Widerstand der Anhänger des Heidentums ein Kampf des $» N e u e n$ « gegen das »Alte «, wie er ja auch explizit in manchen Repliken - etwa bei Zavřel - thematisiert wird. Dramatisch interessant wird dieser Kampf eben dadurch, dass die Selbstständigkeit Böhmens von den „konservativen“ Heiden vertreten wird, Václav aber diesen Wert nicht allzu hoch ansetzt. Erst die Dramen, die aus der Zeit der souveränen Tschechoslowakei stammen, zeichnen Václav als dazu entschlossen, keine Suzeränität von Deutschen über Böhmen anzuerkennen. Zumal die historischen Dramen in der Regel eine in der realen Welt begründete ideologisch-politische Funktion haben, kann man erkennen, wie sich die Veränderungen der außertheatralischen Umwelt auf die Gattung Drama selbst auswirken: Unter den Bedingungen nationaler Unfreiheit zeigen die Dramen um Václav analytisch die verschiedenen Alternativen, zu denen sich die Repräsentanten des politischen Lebens unterschiedlich verhalten (also entweder kein opferreicher Krieg, dafür aber Unterordnung unter eine fremde Macht, oder ein entschlossener Kampf, der riskant ist und Opfer kostet), während nach erlangter Unabhängigkeit die historischen Dramen zum einen politische Ideale repräsentieren und zum anderen analysieren, warum diese Ideale in ihrer Umsetzung behindert werden oder gefährdet sind. 


\section{Zusammenfassender Überblick über die analysierten Dramen}

\section{V.1. Methodische Vorbemerkung}

Der Umfang des untersuchten Korpus und die Beschaffenheit der dramatischen Literatur, in der zum einen Figurenkonstellationen und Handlungszusammenhänge eine ideologische Tendenz erkennen lassen, zum anderen aber oft auf „mikrotextueller Ebene", also in Nebenhandlungen oder einzelnen Szenen, zusätzliche Akzente gesetzt werden, erschwere Überblicksdarstellungen. In dieser Arbeit wurde nach der Analyse einzelner Dramen des obrozeni eine Zwischenbilanz gezogen, die die wichtigsten Aspekte der Epoche zusammenfasst, in der sich die tschechische Nation kulturpolitisch formiert hat.

An dieser Stelle folgt eine weitere Zusammenfassung, die aber gleich synoptisch eine Überblicksdarstellung des gesamten Zeitraums von ca. 125 Jahren zu leisten versucht, mit der die groben Veränderungen in der ideologischen Tendenz der Dramen nachgezeichnet werden. Unterstützt wird die Überblicksdarstellung durch graphische Veranschaulichungen, in denen die wesentlichen Züge besser ersichtlich sind als in einer rein verbalen Beschreibung. Auf das graphische Hilfsmittel wurde zurückgegriffen, weil der Versuch einer Zusammenschau der ca. 40 untersuchten Dramentexte vor der Schwierigkeit stand, die Mannigfaltigkeit der Dramen vergleichend zu überblicken und dabei Tendenzen für den Gesamtzeitraum zu erkennen. Tatsächlich erwies sich bald, dass der Vergleich nur zwischen einigen wenigen Dramen erfolgen kann, wenn diese Dramen einen gemeinsamen thematischen Fokus - wie etwa die Václav- oder die Falkenštejn-Dramen - aufweisen. Andernfalls ist die Vergleichbarkeit keineswegs selbstverständlich oder einfach, denn man läuft Gefahr, gewisse Aspekte einiger weniger Dramen hervorzuheben, dabei aber andere Aspekte zu übersehen oder zu vernachlässigen. Um diesem Problem zu begegnen, wurde auf ein Hilfsmittel zurückgegriffen, das den Dramen zuerst einige wichtige Parameter nach einer Skala zuordnet und in der Folge eine graphische Darstellung aller Dramen im Untersuchungszeitraum ermöglicht.

Die Auswahl der Parameter erfolgte auf der Basis der Analyse der historischen Dramen des Korpus; es wurden Parameter gewählt, die in einer größeren Zahl der Dramen für eine Analyse von deren ideologischer Tendenz relevant sind. Die $\mathrm{Zu}-$ weisung von Werten für die Dramen erfolgte entweder in einer zehnteiligen Skala mit den Endpunkten > minus $5<$ und > plus $5<$ oder in einer nur fünfteiligen positiven Skala (bei einigen Parametern wie „nationale Einigkeit“, „als Mann verkleidete Frau" erscheinen negative Werte wenig plausibel). Die jeweiligen Werte für die Dramen wurden nach einer rekapitulierenden Lektüre der Inhaltsangaben und Analysen in dieser Arbeit festgelegt. Sie dürfen mithin nicht als „objektive“ Größen 
aufgefasst werden, weil sie ja interpretativ gewonnen wurden, also subjektiv fundiert sind. Wohl aber darf die Zuordnung auf intersubjektive Zustimmung hoffen. Leserinnen und Leser der Analysen oder der jeweiligen historischen Dramen sollten also eine ähnliche Zuordnung von parameterbezogenen Skalenwerten zu den Dramen vornehmen können wie der Verfasser dieser Arbeit. Mitunter freilich ist - dies muss eingeräumt werden - die Zuordnung eines bestimmten Werts nicht wirklich gut quantifizierbar: Ob etwa die moralischen Schwächen einer Fürstenfigur den negativen Wert von -2 oder -3 erhalten (wenn dieser zwar Fehler hat, aber kein ganz finsterer Bösewicht ist), darüber kann nicht nach einem eindeutigen Kriterienkata$\log$ entschieden werden. Hier wurde notgedrungen - aber bewusst - eine spontane Zuordnung vorgenommen. Mitunter ist also entweder die 10-teilige Skala zu fein oder es gibt zu wenig deutliche Anhaltspunkte für die Korrelierung der Skala mit den Merkmalen des Dramas. Insofern aber dennoch den einzelnen Dramen Werte zugeschrieben werden können, lassen sich die Werte gut für eine Überblicksdarstellung verwenden.

Die skalierte Darstellung soll daher nicht als Anmaßung missverstanden werden, den ideologischen Gehalt von historischen Dramen quantifizierend zu „objektivieren", sie ist nicht mehr als ein Versuch, eine verbale Einschätzung von Momenten des Dramas (die etwa Aussagen folgender Art produziert: „Der Fürst ist eher passiv“, „Die Tendenz, die Erbfolgeordnung in Frage zu stellen und stattdessen die politische Führung nach dem jeweiligen Vermögen der Personen zu bestimmen, ist eher stark“, „Ganz deutlich wird die christliche Moral in Frage gestellt"), wie sie bei der ideologieanalytischen Betrachtung erfolgt, vermittels von Zahlenwerten auszudrücken: „eher passiv“ „eher stark“, „ganz deutlich“ entspricht also Zahlenwerten (etwa „-2“, „3“, „5“). Diese Überführung von verbalen Einschätzungen in Zahlenwerte will nicht etwa signalisieren, dass die Beschreibung historischer Dramen durch Zahlen exakter wäre als eine rein verbale Beschreibung, sie wurde nur gewählt, um einen synoptischen Überblick mittels einer Visualisierung zu ermöglichen, der bei einer Anzahl von ungefähr 40 Dramen auf rein verbale Weise kaum nachvollziehbar und alles anderes als anschaulich wäre. In den nachfolgenden graphischen Darstellungen sind nur diejenigen Dramen berücksichtigt, die in der Arbeit ausführlich analysiert wurden, um die prinzipielle Nachvollziehbarkeit für die LeserInnen zu gewährleisten.

In den untenstehenden Graphiken beziehen sich die Jahreszahlen auf die Erscheinungsjahre der Dramen, wie sie in der nebenstehenden Tabelle angeführt sind. Diese enthält auch die Zahlenwerte, die in den Graphiken visualisiert werden. Wenn in der Tabelle bei einem Drama keine Werte für einen bestimmten Parameter eingetragen sind, so zeigt dies an, dass dieser für das Drama nicht sonderlich relevant ist. 


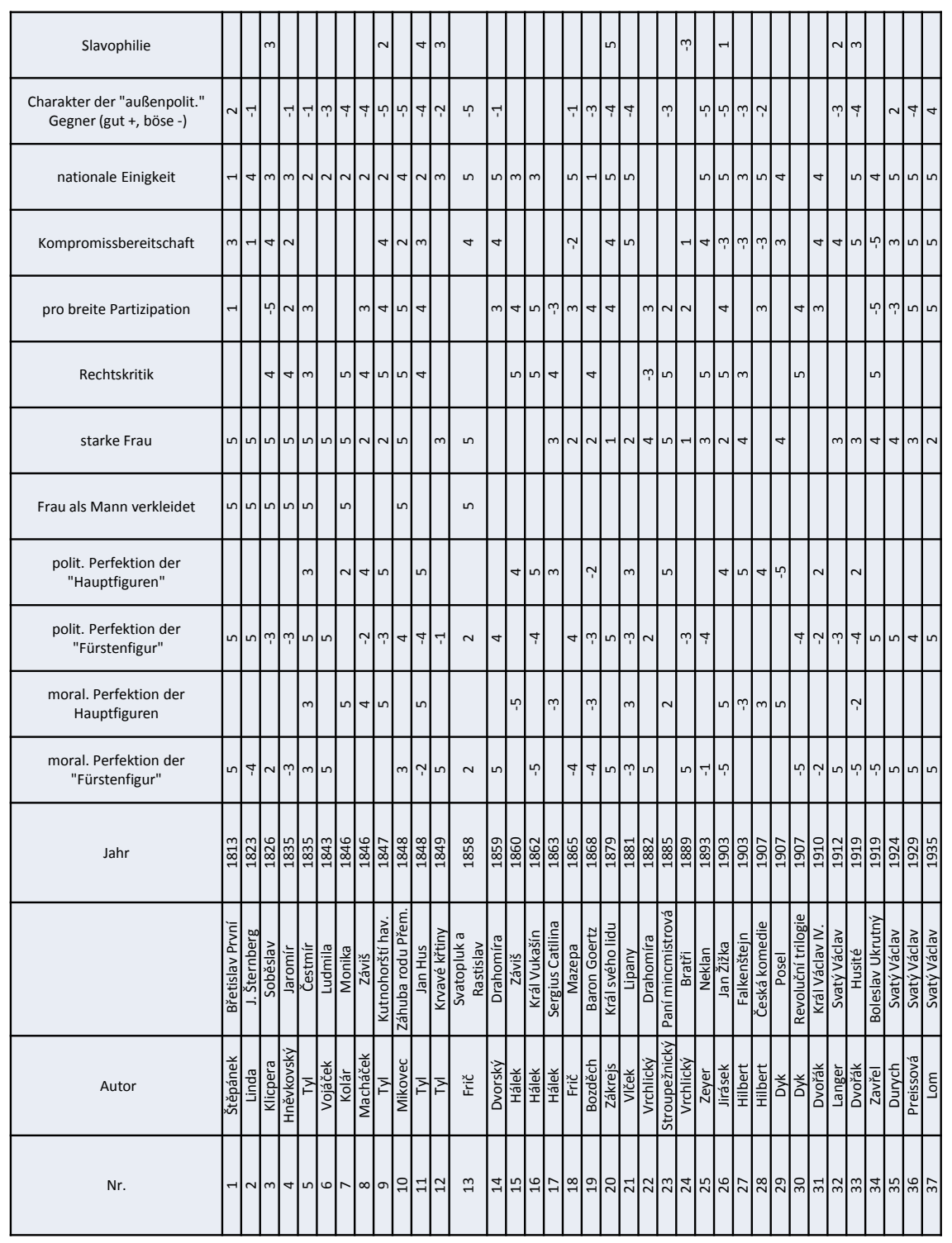

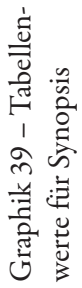



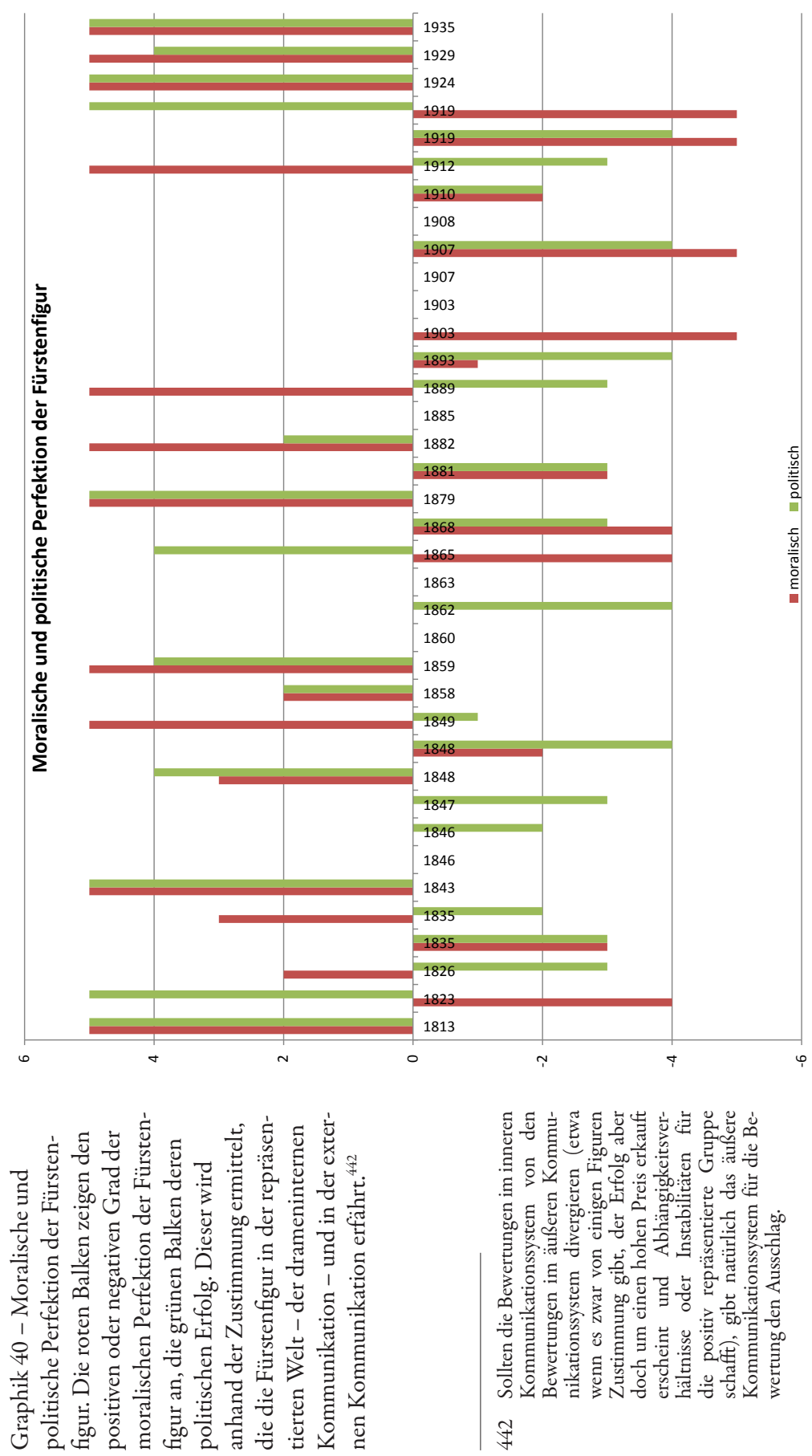


\section{V.2. Erörterungen zu diversen Synopsen}

Die genrespezifische "Retardiertheit" des historischen Dramas, die u.a. von Hegel (vgl. XIII/243), Lukács (vgl. 1965, 126-165) und Lindenberger (vgl. 1975, 56-58) bemerkt wurde, ist in folgendem Umstand angelegt: Die historischen Dramen sind zu einer Zeit entstanden, in der die Entwicklung der Gesellschaften bereits so weit erfolgt ist, dass die für ein Sozium relevanten Entscheidungen bzw. Handlungen nicht mehr vorwiegend von Einzelpersonen getragen werden, sondern eine Agglomeration von Institutionen voraussetzen. In den historischen Dramen erscheinen gattungsbedingt Individuen als Protagonisten von Handlungen, die Komplexität historischer Vorgänge wird mit Rücksicht auf Darstellbarkeit auf eine einigermaßen überschaubare Verkettung von Handlungen der dramatis personae reduziert. Die historiographischen Darstellungen, die den Dramen zugrunde liegen (seien es die Chroniken des späten Mittelalters oder die Ausführungen von Geschichtsschreibern wie Palacký) setzen insofern ein traditionelles Geschichtsverständnis fort, als sie die res gestae der Personen an der Spitze der Gesellschaft darstellen. Da hybride Geschichtsdarstellungen im historischen Drama oder Roman nicht allein an die historiographischen Versionen gebunden sind, sondern die Gattungstradition das historische Drama auch mit der Tragödie assoziiert, die in der vom Klassizismus propagierten Lehre von den genera dicendi dem genus sublime angehört, dessen Protagonisten nur hochgestellte Personen zu sein haben, sind die Fürsten in vielen der hier betrachteten historischen Dramen zentrale Handlungsträger.

Zumal in dieser Arbeit das historische Drama ja nicht bloß als Repräsentation der Vergangenheit gesehen wird, sondern als "allegorischer" Text mit multiplem Referenzpotenzial, soll die Fürstenfigur weniger in Hinblick auf die dargestellte historische Epoche betrachtet werden. Die Repräsentation der Vergangenheit - Ankersmit (2002) hat darauf hingewiesen - kann variieren, sie ist keine de re-Aussage, sondern steht in diskursivem Zusammenhang, von welchem der Gegenstand selbst anders fokussiert wird und damit in unterschiedlicher Hinsicht dargestellt werden kann. Die mitunter frappanten Unterschiede in der Repräsentation ein und derselben historischen Person - etwa des heiligen Fürsten Václav - sind mit Bezugnahme auf die historische Situation der Dramenautoren Indikatoren für unterschiedliche ideologische Haltungen gegenüber dieser Person und den ihr zugeschriebenen Handlungen und Eigenschaften. Die zentralen Fürstenfiguren in den verschiedenen Dramen werden verschieden gezeichnet. Die Graphik Nr. 40 gibt einen Überblick darüber, wie in den Dramen mit „fürstlichen“ Protagonisten der Fürst in moralischer und politischer Hinsicht dargestellt ist.

An der Graphik fällt auf, dass die positiven Werte für beide Aspekte der Fürstenfigur nur in einigen wenigen Dramen konvergieren - es sind dies Štěpáneks Břetislav Prvni (1813), Vojáčeks Ludmila (1843), Dvorskýs Drahomira (1859), Král svého lidu (1879) von František Zákrejs sowie die schon in der tschechoslowaki- 
schen Republik entstandenen Václav-Dramen von Durych (1924), Preissová (1929) und Lom (1935).

In Hněvkovskýs Jaromir (1835), Tyls Jan Hus (1848), Háleks Král Vukašin, Bozděchs Baron Goertz (1868), Václav Vlčeks Lipany (1881), in Viktor Dyks Revolučni trilogie (1907) und Arnošt Dvořáks Král Václav IV. (1910) ist die Fürstenfigur sowohl in moralischer wie auch politischer Hinsicht negativ gezeichnet, wobei sie allerdings in diesen Dramen eine unterschiedlich große Prominenz im Handlungszusammenhang hat.

Während wir sieben Dramen mit einer in beiderlei Hinsicht positiven Fürstenfigur haben und sieben Dramen mit einer weitgehend negativen, so gibt es acht Dramen, in denen die beiden Aspekte der Fürstenfigur divergieren. Es sind dies die Václav-Dramen Tyls (Krvavé kŕtiny, 1849), Vrchlickýs (Bratři, 1889), Langers (1912) sowie Josef Lindas Jaroslav Śternberg v boji proti Tatarim (1823), Klicperas Soběslav (1826), Tyls Čestmir (1835), Mazepa von Josef Václav Frič (1865) sowie František Zavřels Boleslav Ukrutný (1919).

Die positive Darstellung der Fürstenfigur erfolgt also deutlich seltener als die zwiespältige und die negative zusammengenommen. Weiters fällt diesbezüglich auf, dass die positive Darstellung der Václav-Figur nur in der tschechoslowakischen Epoche erfolgt, nicht aber zuvor. In der obigen zusammenfassenden Diskussion der Repräsentationen Václavs wurde dies damit erklärt, dass er in der politisch souveränen Tschechoslowakei als Idealfigur gezeigt wurde, während zuvor unter den Bedingungen der politischen Unselbstständigkeit an der Figur Václavs die Unvereinbarkeit von christlicher Moral und effektivem politischen Handeln demonstriert werden sollte. Gegenüber dem frommen Václav, der politisch wenig erfolgreich ist, stellen Jaroslav Šternberg und Boleslav Ukrutny das erfolgreiche Gegenmodell dar: sie wenden moralisch zweifelhafte Mittel an, sind damit aber in der Auseinandersetzung mit dem Gegner erfolgreich und „befreien“ ihre vom äußeren Feind bedrohte Gemeinde. Die Fürstenfigur funktioniert also während der nationalen Unselbstständigkeit nur selten als Identifikationsfigur; an ihr werden vielmehr die Widersprüche dargestellt, die mit politischem Engagement einhergehen. Vereinfacht gesagt, steht während der politischen Unselbstständigkeit der Tschechen die Fürstenfigur vor dem Dilemma, entweder moralisch gut zu sein, dabei aber politisch keinen Erfolg zu haben, oder politischen Erfolg um den Preis moralisch fragwürdigen Handelns erkaufen zu müssen.

Eine andere Graphik (Nr. 41) veranschaulicht die im obrození beliebte Technik der männlichen Verkleidung weiblicher Figuren, eine Technik, die besonders gerne von Václav Kliment Klicpera (vgl. Haman 2007, 79f) eingesetzt wurde: 

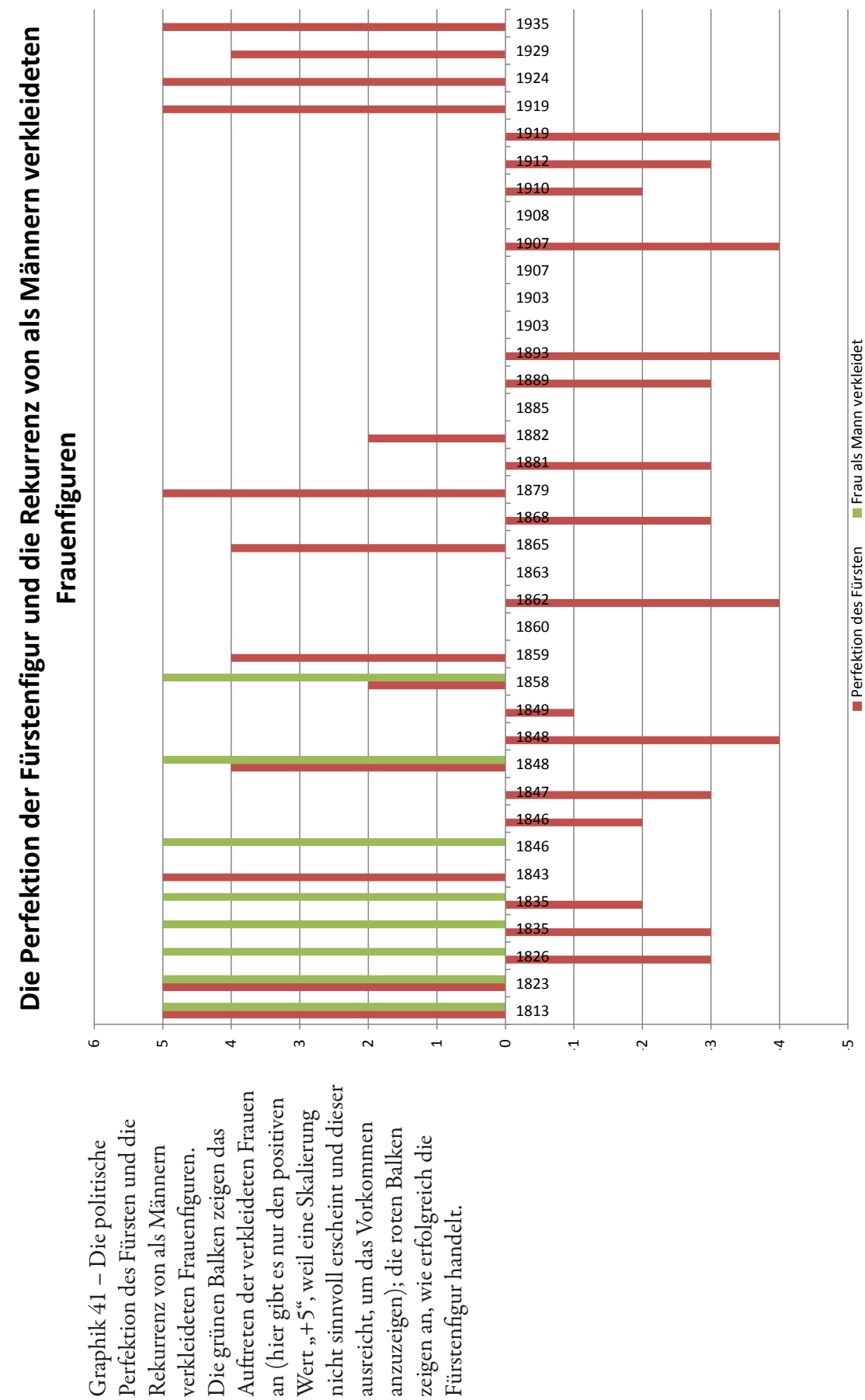

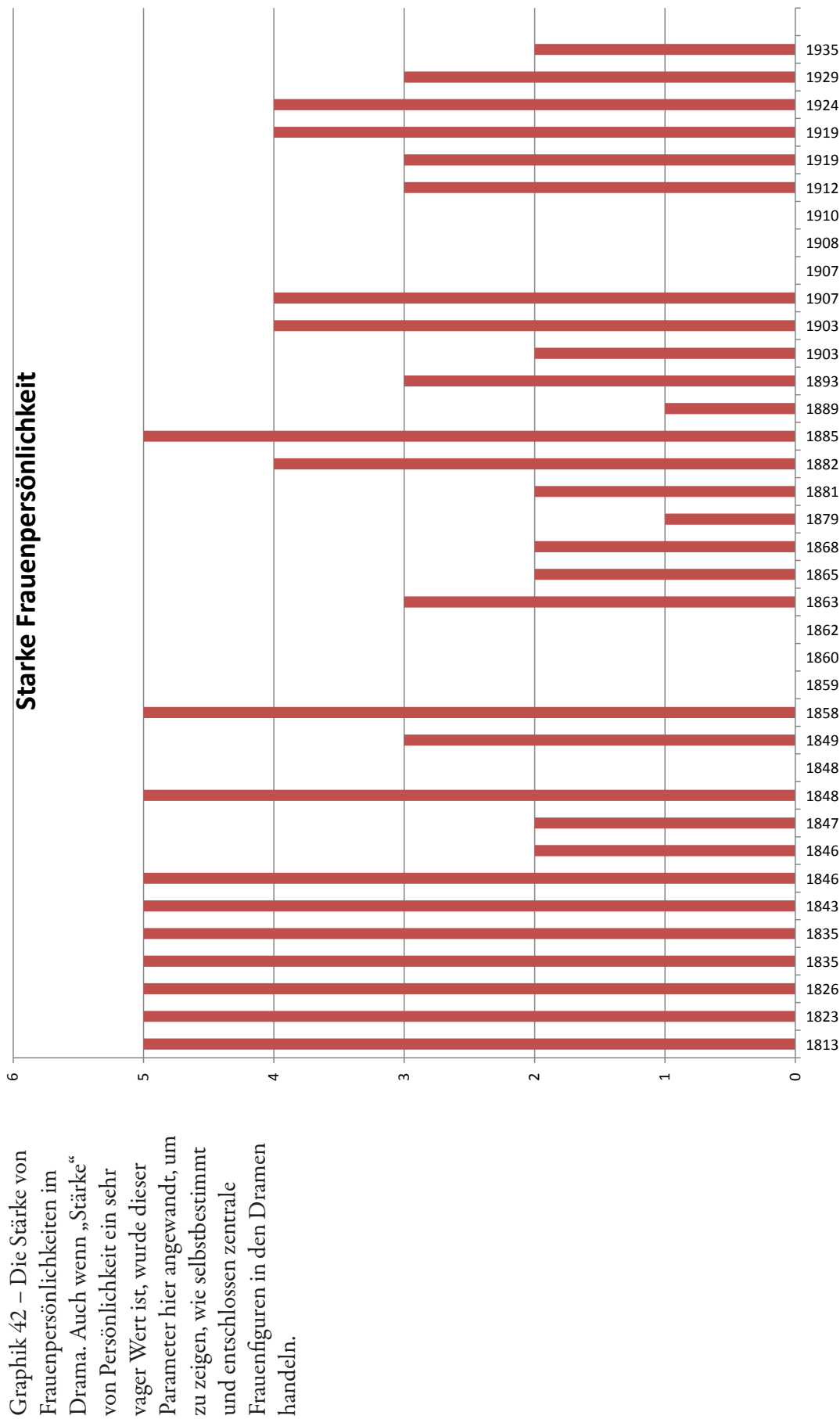
Die semiotische Funktion der als Männer verkleideten Frauen wurde von mir in einem gesondert erschienenen Aufsatz (Deutschmann 2010) untersucht. Das cross-dressing der weiblichen Heldin macht auf eine bedeutsame Handlung aufmerksam, der theatralische Schauwert der Verkleidung unterstreicht gleichsam die Beispielhaftigkeit der Handlung: in Štěpáneks Břetislav Prvni (1813) verkleidet sich die weibliche Hauptfigur als Ritter, um den Titelhelden vor einem heimtückischen Anschlag zu warnen, Linda (1823) lässt die Tochter Jaroslav Šternbergs als Ritter in den Befreiungskampf ziehen, Klicperas Titelheld Soběslav (1826) trifft als Fürst oft falsche Entscheidungen, die aber von seiner als Mann verkleideten Frau „repariert" werden, Hněvkovskýs Jaromír (1835) handelt ebenfalls nicht sonderlich geschickt, in blinder Eifersucht verstößt er seine Frau, die als Mann verkleidet zu seiner Beschützerin wird. In Tyls Čestmir (1835) opfert sich die Frau im Einsatz für das Vaterland, während der Prager Fürst Neklan zu feige für den Kampf ist. Auch in Mikovec' Zábuba rodu Přmyslovského (1848) und in Josef Václav Frič Svatopluk a Rastislav (1858) opfern sich die Frauen in der Verkleidung für die Sache der gerechten Gruppe und sterben tragisch. Ein letztes Nachspiel dieser semiotischen Mode kann man noch in zwei Stücken der 1880er Jahre finden, die in dieser Arbeit nicht gesondert behandelt wurden (und daher auch nicht in der Graphik aufscheinen): Josef Jiří Kolár hat schon in Monika (1846) die Titelheldin in männlicher Verkleidung die Rache für die Schändung ihrer Familie ausführen lassen, während ihr Bruder handlungsunfähig ist und Frauenkleider tragen möchte; in seinem Drama Primátor (1883) ist wieder die weibliche Hauptfigur stark und führt in männlicher Verkleidung die Wende herbei. Und in Jaroslav Vrchlickýs historischer Komödie Noc na Karlštejnè (1884) stellen verkleidete Frauen die von Karl IV. eingeführte Geschlechtersegregation auf der Burg Karlštejn in Frage, womit zugleich auf die Kluft zwischen dem formalen Gesetz und der Mannigfaltigkeit von Konflikten und Tendenzen des Lebens hingewiesen wird (vgl. Strúbrný 1909, 4-7; Haman 2007, 288).

Wie angedeutet wurde, korrespondiert die Verkleidung der Frau als Mann in vielen Fällen mit der Schwäche und Ungeschicklichkeit der männlichen Figuren. Die Verkleidung unterstreicht, dass die Frau „männlich“ handelt, also eine Rolle übernimmt, die die männlichen Figuren in den Dramen mitunter nicht ausführen können.

Die nachfolgende Graphik Nr. 42 zeigt, dass starke Frauenpersönlichkeiten in der Tat eher eine Erscheinung des obrození waren, denn in den Dramen der zweiten Jahrhunderthälfte und im Drama des ersten Drittels des 20. Jahrhunderts kommen starke Frauenpersönlichkeiten nicht in derselben Dichte bzw. Häufigkeit vor wie im obrození.

Diese Darstellung gibt Anlass zur Hypothese, dass mit der Frauendarstellung im $o b$ rození spezifische ideologische Momente verbunden waren. Die nationalen Implikationen dieser Momente lassen sich am deutlichsten in den maskierten Frauenfiguren erkennen - diese markieren die politisch gebotene bzw. notwendige Handlung. 
Abgesehen von den Dramen, die um Fürstenfiguren zentriert sind, gibt es natürlich auch Dramen mit nichtfürstlichen Protagonisten, in denen eine Fürstenfigur nicht als Handlungsträger erscheint bzw. nur eine Nebenfigur ist. Diese sind im Korpus etwas weniger zahlreich als Dramen mit fürstlichem Protagonisten - was wohl auf die für die Analyse achsenbildende Auswahl der Dramen um den hl. Václav zurückzuführen ist. Für die Parameter „moralische“ und „politische“ Perfektion der nichtfürstlichen Protagonisten ergibt sich folgendes Bild (Graphik Nr. 43):

Auffällig an der Graphik Nr. 43 ist vor allem der Umstand, dass es allein im obrozeni eine deutliche Kopräsenz beider Parameter in den Dramen gibt. Kommt diese Kopräsenz später vor, so handelt es sich um Dramen, die deutlich nationalpolitisch ausgerichtet sind, nämlich Václav Vlčeks Lipany, das zur Eröffnung des Nationaltheaters 1881 gegeben wurde, Alois Jiráseks Jan Hus (1911) und Jaroslav Hilberts Einakter Česká komedie (1908). In den anderen Dramen, die nach 1848 entstanden sind, sind die nichtfürstlichen Protagonisten entweder sowohl politisch als auch moralisch deutlich negativ gezeichnet wie der Usurpator Vukašín in Háleks Drama (1862) und die machtgierigen Figuren in Baron Goertz (1868), oder sie sind zwiespältige Figuren, deren moralisch fragwürdiges Handeln aber immerhin politischen Erfolg bringt (Háleks Záviš [1860] und sein Catilina [1863] sowie Jaroslav Hilberts Falkenštejn [1903]). Das entsprechende Gegenstück dazu - moralische Lauterkeit und politische Schwäche - kann man in Viktor Dyks Tomáš Roh erkennen, der es aus moralischen Gründen ablehnt, Widerstand gegen den katholischen Angriff auf den Protestantismus zu leisten (Posel, 1907).

Eine Gegenüberstellung von fürstlichen und nichtfürstlichen Protagonisten wie in Graphik Nr. 44 zeigt ziemlich deutlich zeitbedingte Tendenzen: nichtfürstliche Protagonisten sind in politischer Hinsicht weitaus seltener ohne Erfolg als fürstliche Protagonisten. Die drei grünen Säulen mit negativen Werten in der Graphik beziehen sich auf Háleks Usurpations-Drama Král Vukašin (1862), in dem allerdings dem negativ gezeichneten Usurpator dessen positiv gezeichneter Sohn folgt; auf Baron Goertz (1868), in dem alle Figuren aufgrund ihrer Ruhmsucht eher negativ gezeichnet sind, und auf Dyks Drama Posel (1907), das die negativen Konsequenzen des moralischen Rigorismus darstellt. Betrachtet man die positiven Werte, erkennt man, dass abgesehen von der Zeit nach Erlangung der politischen Selbstständigkeit eher die nichtfürstlichen Protagonisten politisch erfolgreich sind: 13 Dramen haben mehr oder weniger erfolgreiche nicht-fürstliche Protagonisten, 9 Dramen vor 1918 zeigen einen politisch erfolgreichen Fürsten, aber in 16 Dramen ist der Fürst politisch nicht erfolgreich! Die fürstlichen Protagonisten werden also weniger oft für die Demonstration erfolgreicher Politik verwendet; seit Vrchlickýs Drahomíra (1882) bis 1918 gibt es im ausgewählten Korpus praktisch keine Fürstenfigur, deren Handeln als ideal angesehen werden kann.

Ein interessantes Bild ergibt sich gleichfalls anhand des Parameters „Darstellung der außenpolitischen Gegner“ (Graphik Nr. 45), wobei unter „außenpolitische 
Gegner" all diejenigen Gruppierungen gemeint sind, die nicht der "Gruppe“ bzw. der „Nation“ der Protagonisten angehören.

Dass „Gegner" eher negativ als positiv gezeichnet sind, ist freilich trivial. Überdies ist ja gerade für die dramatische Gattung die Konflikthaftigkeit zentral, womit die Negativität der Darstellung von Antagonisten gleichsam gattungslogisch bedingt ist und nicht allein historischen Umständen - der repräsentierten Zeit bzw. der Entstehungszeit - zugerechnet werden kann. Unter Berücksichtigung dieser Überlegungen, welche die Aussagekraft dieser Darstellung freilich mindern, muss dennoch auffallen, dass es vor 1918 immerhin ein einziges Drama gab, in dem außenpolitische Gegner auch vorteilhaft gezeichnet waren. Für Břetislav Prvni (1813) liegt dies wohl im konstatierten Landespatriotismus begründet, Břetislavs Frau Jitka ist eine Deutsche, mit ihr wird das ansonsten häufige Bild der Aggression von deutscher Seite abgemildert. Die beiden Václav-Dramen Durychs (1924) und Loms (1935) zeigen positive Züge bei den Deutschen, was wohl auch mit der zeitpolitischen Aufgabe zu tun hat, in der multinationalen Tschechoslowakei die deutsche Bevölkerungsgruppe nicht zu negativ darzustellen (Dass in Preissovás Version zum Václav-Millennium [1929] die Deutschen so negativ gezeichnet sind, verwundert daher umso mehr; immerhin waren Preissovás und Loms Dramen Auftragswerke für die Millennium-Feiern des Václav-Jubiläums, welche unter Bedachtnahme auf die Sensibilitäten möglichst vieler Bevölkerungsgruppen geplant wurden [vgl. Placák 2002, 57-59]).

Die negative Zeichnung der Gegner erfolgt verstärkt - was nicht wirklich überrascht - in den Jahren um 1848 und der darauf folgenden Repressionsperiode der Ära Bach sowie während des verstärkten Nationalismus um die Jahrhundertwende. Diese Graphik entspricht im Wesentlichen den in einer Einzelstudie (Borová 1995) erarbeiteten Ergebnissen. In dieser wurden belletristische Titel mit historischer Thematik (auch episch-narrative Lyrik) ausgewertet, die im letzten Jahrzehnt des 19. Jahrhunderts, einer von nationalen Zusammenstößen zwischen Tschechen und Deutschen geprägten Zeit, erschienen oder neu aufgelegt wurden. Aufgrund der Berücksichtung von Neuauflagen werden im stattlichen Korpus von 463 Titeln also auch viele Texte vorangegangener Jahrzehnte erfasst. Borová stellt fest, dass von allen Nationen die Deutschen am öftesten in der historischen Belletristik dargestellt werden und dass dabei eine negative Darstellung stereotyp überwiegt; Ausnahmen stellten nur vereinzelte Figuren dar, die einen festen Platz in der Landesgeschichte haben, etwa Rudolf II. (vgl. ebd., 30f). Borová erklärt den Umstand, dass Österreicher selten als national bestimmte Figuren vorkommen, damit, dass sie pauschal den Deutschen subsumiert werden bzw. dass es hier offenbar Zensurrücksichten gab. Wenn etwa die Repressionen gegen die böhmischen Stände nach 1620 geschildert wurden, durften die Habsburger dabei nicht explizit als Verantwortliche genannt werden.

Die Negativität bei der Darstellung der „Deutschen“ entspricht zwar wohl den Zeitumständen, andererseits aber berücksichtigt Borová zu wenig den Umstand, 
dass es die oben angesprochenen gattungslogischen Zwänge gibt, die in verschiedenen literarischen Genres eine Opposition von Konfliktparteien erforderlich machten und eine "Negativzeichnung" der Antagonisten motivierten.

Mit dem Parameter „Rechtskritik“ sollen diejenigen Momente in historischen Dramen erfasst werden, bei denen Zweifel an der bestehenden Rechtsordnung bzw. an den rechtsetzenden Instanzen erkennbar sind (Graphik Nr. 46). Unter „Rechtsordnung" wird in vielen Dramen die Thronfolgeregelung verstanden: wenn Prätendenten auf dem Thron auftauchen, die begründet die Fürstenfiguren angreifen und die selbst oft geschickte Strategen sind, wird dies mit diesem Parameter angezeigt. Die Kritik kann sich aber auch auf die Macht beziehen, die einen bestimmten Zustand der repräsentierten Welt sanktioniert. Auch generelle Zweifel an bestehenden vertraglichen Regelungen, Verpflichtungen, an Traditionen wie etwa dem Gewohnheitsrecht, gehören zu diesem Parameter.

Die graphische Darstellung zeigt, dass es im Vormärz eine größere Dichte an Dramen gab, die an der im Stück repräsentierten Rechtsordnung Kritik üben. Im ersten Drittel des 20. Jahrhunderts ist das Thema in einigen Stücken präsent, es fehlt aber gänzlich in der Zeit politischer Selbstständigkeit, sieht man von Zavřels Boleslav Ukrutny (1919) ab, das freilich ein Einzelfall ist, weil es die Diktatur eines starken Herrschers propagiert, der sich über traditionelle Ordnungen hinwegsetzt. Nicht von der Graphik erfasst ist allerdings Otokar Fischers Drama Přemyslovci (1918), weil es in der Arbeit nicht extensiv genug dargestellt und damit nachvollziehbar gemacht wurde. Wie aber oben im Zusammenhang mit den Usurpationsdramen um Záviš vermerkt wurde, steht gerade in diesem Drama die Thronfolgeordnung und das Gottesgnadentum im thematischen Fokus. Vielleicht könnte man die Graphik auch so interpretieren, dass die Thematik der Legitimierung von Herrschaft in Situationen des Umbruchs - wie um 1848 und 1918 - von größerer Relevanz war. Allerdings müssten zur Überprüfung dieser Hypothese wohl noch weitere Dramen aus gerade diesen Zeiträumen analysiert werden.

Dass nur ein einziges Drama in der Darstellung bei der Rechtskritik einen negativen Wert hat, verlangt gesonderte Erläuterung. In Vrchlickýs Drahomira (1882) erscheint der Sněm als rechtsetzende und richtende Instanz, dessen Entscheidungen die großen Ansprüche von Drahomíra einschränken. Wo die anderen Dramen meist eine Kritik an traditionellen monarchischen Ordnungen ausdrücken, ist bei Vrchlický eine Rechtsinstitution zu erkennen, die „absolutistische“ Ansprüche tatsächlich einschränkt. Zumal diese Instanz affirmiert wird, unterscheidet sich das Drama von den "rechtskritischen“ Dramen in der graphischen Darstellung. Die Institution des sněm ist in Drahomíra allerdings keine problemlos positive: die vom snèm eingeschränkte Drahomíra hält diesem vor, partikularistische Interessen zu vertreten und nicht wirklich das Wohl des Landes zum Ziel zu haben. Berücksichtigt man diesen Umstand, könnte man für Vrchlickýs Drama also gleichfalls die Re- 
levanz von Rechtskritik ansetzen. Und damit wäre es keine so auffällige Ausnahme mehr. $^{442}$

Einige Parameter der Kurzcharakterisierung sind in ihren Implikationen dazu angelegt, sich wechselseitig auszuschließen. So wird beispielsweise ein Drama, in dem die Fürstenfigur positiv gezeichnet ist, nicht zugleich auch Kritik an der Legitimierung der Fürstenrolle beinhalten und umgekehrt: Dramen, in denen die bestehende Rechtsordnung im äußeren Kommunikationssystem in Frage gestellt wird, werden kaum positive Fürstenfiguren haben. Die Parameter sollten also eine gewisse Trennschärfe haben, wie sich an der folgenden Darstellung (Graphik Nr. 47) überprüfen lässt.

Für ein und dasselbe Drama (die roten und grünen Linien liegen auf der $\mathrm{x}$-Achse unmittelbar nebeneinander) sollten also nicht gleichzeitig zwei positive oder zwei negative Werte zu erwarten sein, sehr wohl aber ist es möglich, dass nur ein Parameter vorliegt (weil der andere Parameter im Drama keine große Relevanz besitzt). Die einzige Ausnahme diesbezüglich ist in der obigen Darstellung Mikovec' Drama (1848) um den Untergang der Přemysliden-Dynastie, in dem Václav III. selbst versucht, alte Feindschaften und für den Landesfrieden abträgliche Verträge und Traditionen zu überwinden, aber daran scheitert und Intrigen zum Opfer fällt.

Derlei graphische Darstellungen könnte man noch fortsetzen, jedoch soll deren Erkenntniswert nicht überstrapaziert werden. Die Graphiken sind ja nur Veranschaulichungen, die sich aus konkreten Werkanalysen ergeben haben. Die analysierten Werke ihrerseits bilden das Korpus von ca. 40 historischen Dramen, das für diese Arbeit verwendet wurde. Dieses Korpus umfasst also keineswegs alle historischen Dramen des Untersuchungszeitraums, deren exakte Zahl auch sehr schwer zu bestimmen ist (abgesehen von Zuordnungsfragen zum Genre gibt es auch das praktische Problem der Ermittlung der Dramen selbst: man müsste praktisch alle bibliographischen Angaben des 7-bändigen Lexikon české literatury durchsuchen). ${ }^{443}$ Die so gefundenen Dramen müssten dann aber auch noch allesamt gelesen und auf ähnliche Weise analysiert werden, wie das in dieser Arbeit geschehen ist. Eine derartig umfangreiche Analyse könnte zu einer Änderung der Schlussfolgerungen dieser Arbeit führen, die auf dem genannten Korpus von ca. 40 Dramen beruhen. Solange freilich keine systematische Untersuchung anderer historischer Dramen zum Untersuchungszeitraum vorliegt, können die Ergebnisse dieser Arbeit zumindest ein vorläufiges Bild vom ideologischen Gehalt der historischen Dramen abgeben.

443 Da eine umfassende Bibliographie nicht vorliegt und im Rahmen dieser Arbeit auch nicht geleistet werden sollte, wäre als Schätzung nur eine interpolierende Rechnung möglich. Die Durchsicht der Bibliographie in Janoušek (1989, 225-246) ergab eine Zahl von 32 historischen Dramen, die in den Jahren 1918-1935 publiziert wurden (die Bestimmung der Anzahl erfolgte auf der Grundlage der Kenntnis der Dramen bzw. von Titel und Genrebezeichnung in Janoušeks Bibliographie). Nimmt man vereinfachend an, dass die „Produktivität“ des Genres in diesen 18 Jahren vergleichbar ist mit dem Gesamtzeitraum von 1810 bis 1935, so ergibt sich für diesen eine interpolierte Zahl von 224 historischen Dramen. 


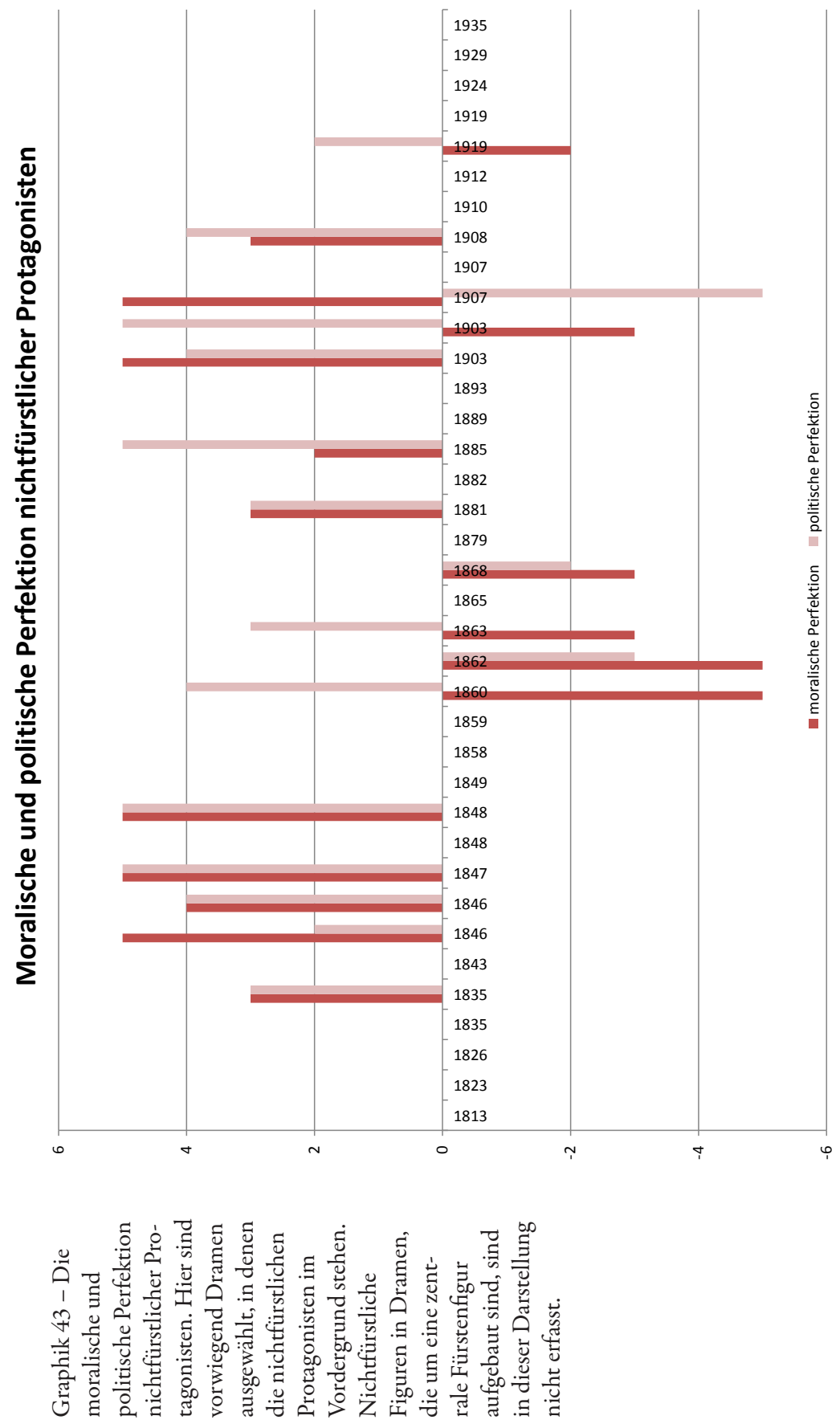




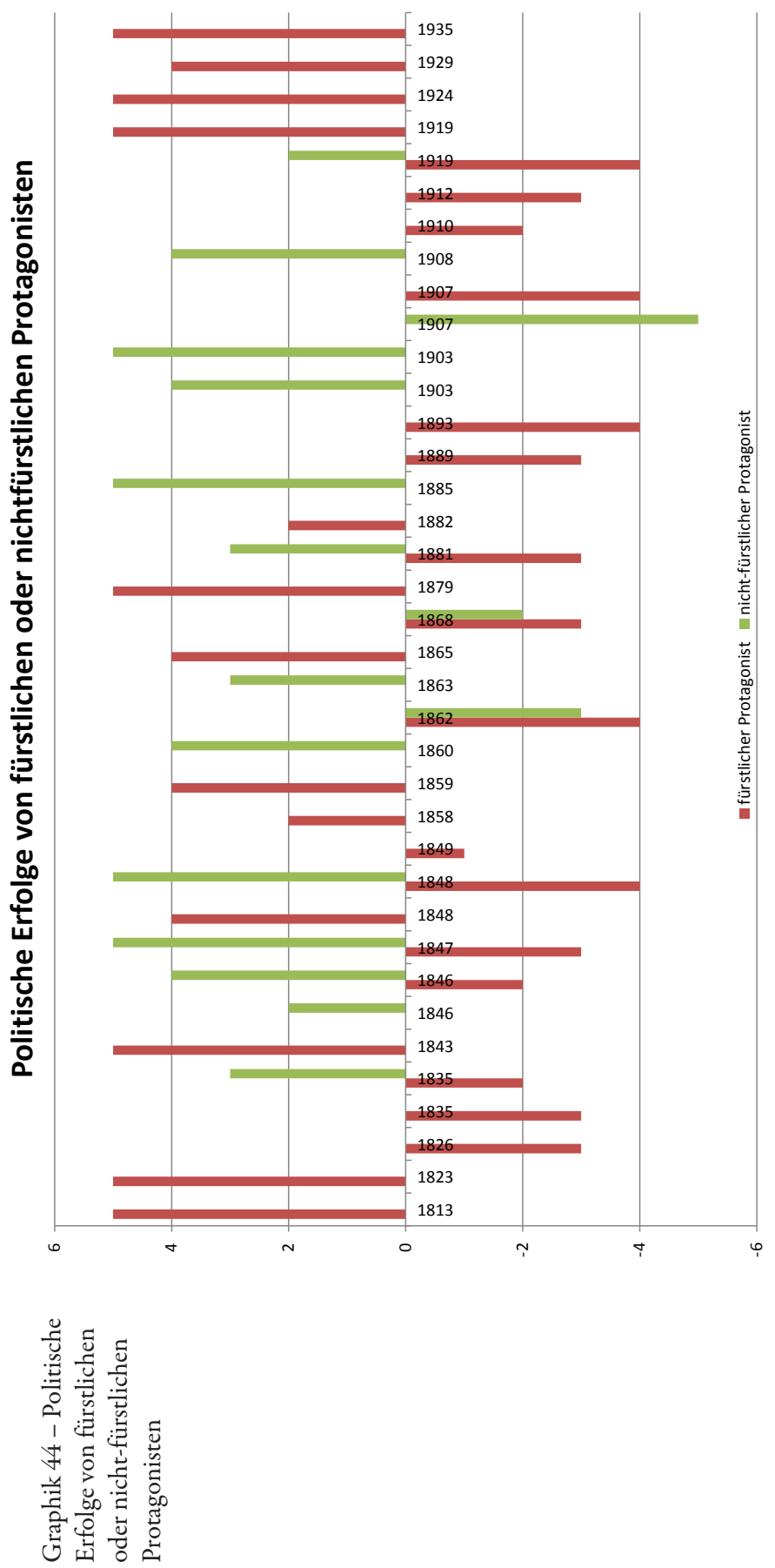




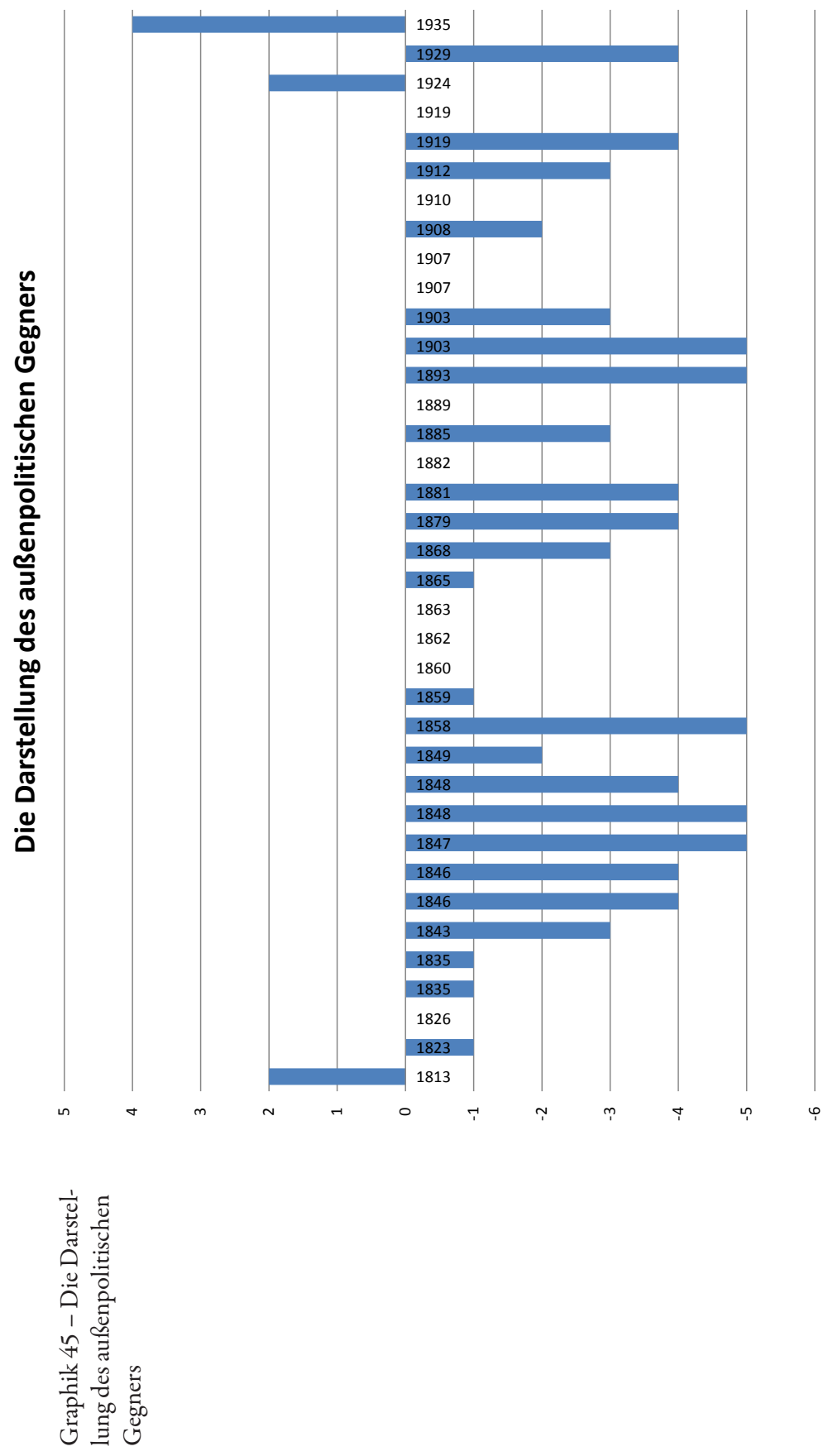



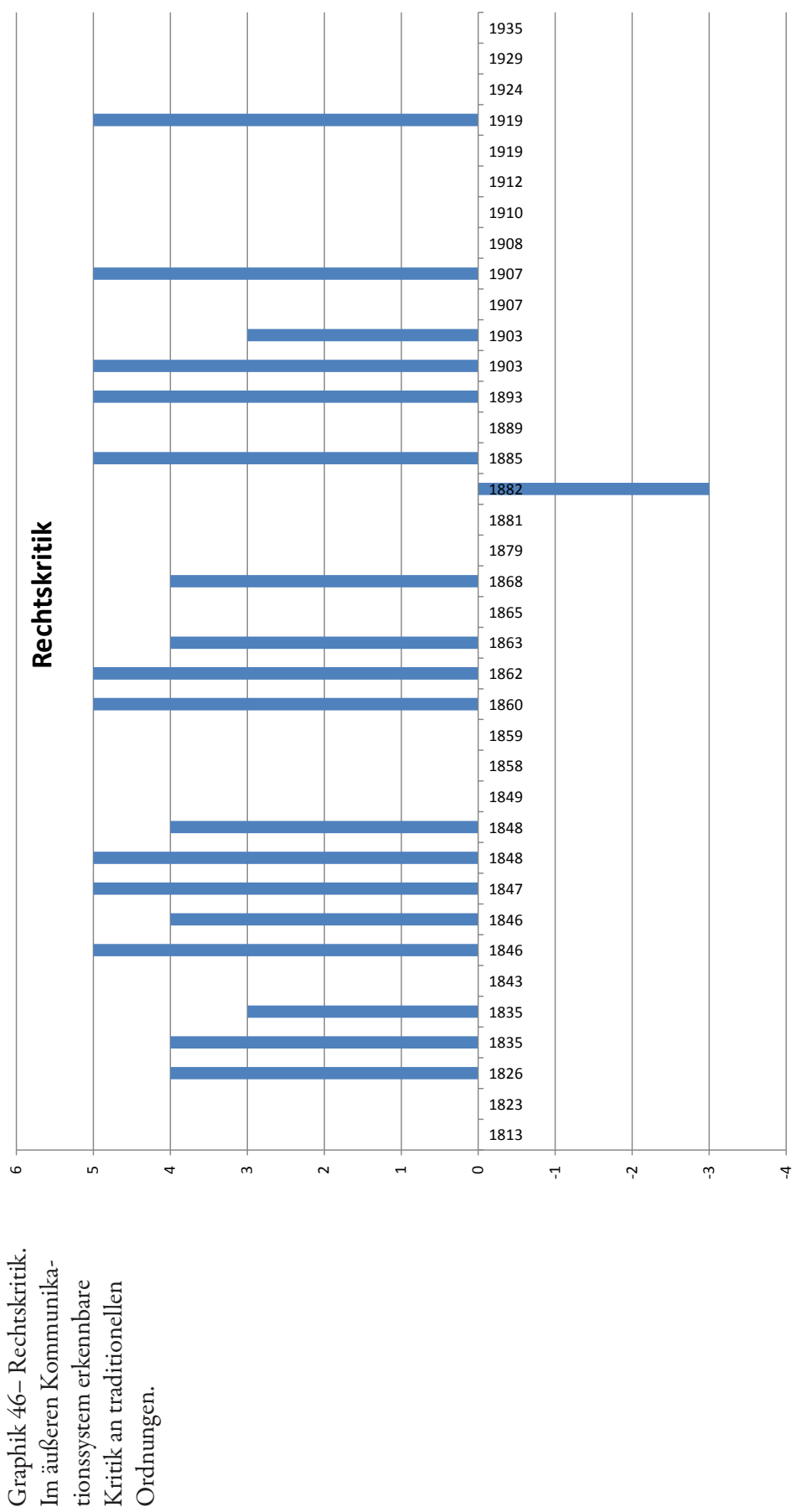

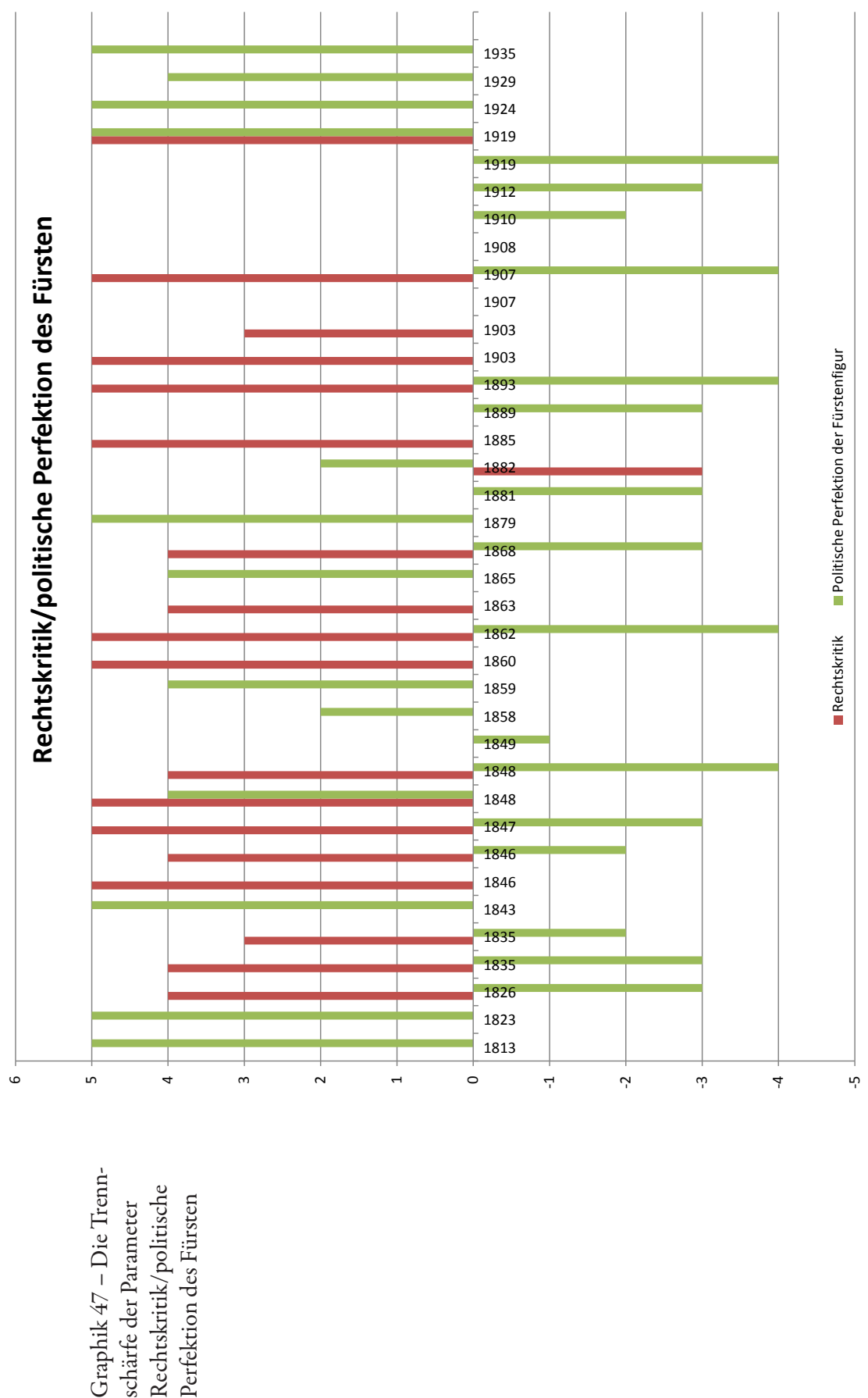


\section{V.3. Schlussbemerkung}

Die mit dem Überblick besser möglich gewordene Hypothesenbildung über Entsprechungen von ideologischen Tendenzen im historischen Drama und geschichtlichen Ereignissen und Veränderungen - man denke etwa an die Idealisierung der Václav-Figur in der Tschechoslowakei, die während der politischen Unselbstständigkeit nicht beobachtet werden kann, oder an die Präferenz für nicht-fürstliche Protagonisten im 19. Jahrhundert - kann freilich an die Doktrin von der Widerspiegelung in der marxistisch-leninistischen Ästhetik erinnern. Hierzu soll nur Folgendes bemerkt werden: Tatsächlich ist es ja ein Ziel der Arbeit, Erscheinungen verschiedener "Reihen“ vergleichend zu untersuchen. Mit „Reihe“ meinen die russischen Formalisten kulturelle Bereiche oder Sphären, die - dem Systembegriff der Luhmann-Schule vergleichbar - zum einen geschlossen gedacht und analysiert werden, zum anderen aber umweltoffen sind, womit Veränderungen auch von außerhalb des Systems möglich werden (vgl. Hansen-Löve 1978, 381-383). Die Arbeit ging der Frage nach, inwieweit Veränderungen in der politischen und sozialen Umwelt Auswirkungen auf das Genre des historischen Dramas haben. Sie versteht sich soweit als empirische Untersuchung, als ja die an einem ausreichend großen Korpus durchgeführten Interpretationen in einem weiteren Abstraktionsschritt mit außerkünstlerischen Veränderungen verglichen wurden. Mit dieser empirisch ausgerichteten Materialorientiertheit unterscheidet sich die Arbeit schon aufgrund ihrer Methode von der marxistischen Widerspiegelungslehre, die deutlich dogmatisch ausgerichtet war und die einen notorischen Mangel an empirischen Untersuchungen hatte. So weisen beispielsweise Georg Lukács' Überlegungen zum historischen Roman und zum historischen Drama (die wohl zum Besten gehören, was die marxistische Ästhetik der Literatur hervorgebracht hat) viele „apriorische“ Überlegungen auf, die man zwar als Postulate anregend finden kann, ${ }^{444}$ die aber doch im Wesentlichen auf spekulativer Kunstbetrachtung beruhen. Ihre „empirische“ Grundlage besteht in der Interpretation ausgewählter Werke der „Höhenkammliteratur“. Diese Methode bedingt wohl auch, dass die marxistische Ästhetik praktisch nicht irre wird an der Vielfalt und Heterogenität der künstlerischen Produktion; sie weiß gleichsam schon im Voraus, wie die Gesetzmäßigkeit von deren Entwicklung beschaffen ist. Auf diese Weise entstehen Thesen wie diejenige vom Zusammenhang von „großen Perioden in der Blüte der Tragödie mit geschichtlichen Umwälzungen“" (Lukács 1965, 116), deren dogmatischer Charakter zwar offensichtlich ist, der

444 Man beachte etwa konstatierende Sätze wie „Das Drama zeichnet die großen historischen Entladungen und Eruptionen des Geschichtsablaufs. Sein Held repräsentiert die weithin leuchtende Spitze dieser großen Krisen. Der Roman stellt mehr das Vorher und das Nachher dieser Krisen dar, in einer breiten Wechselwirkung zwischen Volksbasis und sichtbarer Spitze.“ (Lukács 1965, 181) 
aber auch nur schwer widerlegt werden kann, weil eine Widerlegung die historische Genese einer großen Menge an Texten untersuchen müsste.

Die vorliegende Arbeit kann zwar nicht ohne apriorische Annahmen auskommen, weil diese für initiale Hypothesen wichtig sind, sie begibt sich dann jedoch auf die begrifflich anders gelagerte Ebene der „empirischen“ Interpretation von Dramentexten in einem Korpus. Dabei lässt schon die konkrete Analysepraxis von unterschiedlich bekannten Dramentexten Skepsis gegenüber der Gültigkeit von so allgemeinen Postulaten wie demjenigen vom Zusammenhang zwischen Tragödie und historischen Umbruchszeiten aufkommen.

Abgesehen von der Material- bzw. Textorientiertheit in dieser Arbeit muss des Weiteren dem Vorwurf, die Arbeit sei durch die Postulate der Widerspiegelungsästhetik geprägt, damit entgegnet werden, dass die historischen Dramen hier nicht als „Kunstwerke“, sondern in ihrer politischen bzw. ideologischen Funktion interessieren. Dementsprechend wurden Dramentexte reduktiv auf den in ihnen angelegten politischen „Gehalt" hin gelesen. Die bei der Diskussion der einzelnen Dramen vorgenommene Stratifizierung in Analogie zu Hayden Whites Modell der Historiographie (siehe oben, S. 45f) arbeitet das Stratum der dramatischen „Fabel“ (Fabel $_{2}$ ) heraus, das hinsichtlich seiner politischen Implikationen analysiert wird. Das Erkenntnisinteresse zielt also nicht auf die Ästhetik der Dramentexte ab, sondern aktualisiert die in den Handlungszusammenhängen erkennbaren politischen Ideen. Die gewählte Analyseperspektive wählt also die politische Funktion der historischen Dramen aus und sieht von der expliziten Erörterung von deren ästhetischer Funktion ab (daher wurden sowohl oft gespielte Dramen wie auch unaufgeführte unbekannte Dramen in das Korpus aufgenommen).

Bei der Konzentration auf den ideologischen Gehalt der Dramen werden auch die gängigen Epochenunterschiede des Untersuchungszeitraums (Romantik - Realismus - Moderne) undeutlich: Das historische Drama der Moderne unterscheidet sich in ideologischer Hinsicht nicht substanziell vom Drama der Romantik. Die von Řezníková (vgl. 2004, 65) hervorgehobene Differenz der Dramatik moderner Autoren wie Hilbert, Dyk, Dvořák und anderen soll damit jedoch nicht gleich für unzutreffend erklärt werden: Sie verdankt sich einer anderen Beobachtungsperspektive, die Positionsbestimmungen im damaligen literarischen und literaturkritischen Diskurs fokussiert und damit eher die Unterschiede hervorhebt. Auf der allgemeineren ideologischen Ebene zeigt sich freilich, dass es in den Handlungszusammenhängen keine ganz großen Unterschiede gibt, es sei denn, man möchte veränderte Figurencharakterisierungen (etwa des tschechischen Protestantismus in Dyks Posel, Dvořáks Porträt des scheiternden Václav IV. oder Zavřels Apotheose des grausamen Boleslav) als solche werten. Immerhin gab es ja auch schon vor der Moderne derlei Veränderungen.

Die kulturhistorisch ausgerichtete ideologische Analyse in dieser Arbeit erfolgt mithin auf einer allgemeineren Ebene als eine literaturhistorische Bestimmung, 
die stärker Differenzierungen betont. Sie weist auf eine thematische Kontinuität von Themen und Stoffvorlagen hin, die wiederholt das historische Gedächtnis der tschechischen Kultur beschäftigt haben.

Dass das Genre des historischen Dramas, das seit jeher mit der Sphäre der Politik und der Repräsentation von Macht in der Geschichte verbunden ist, im Untersuchungszeitraum durch diverse politische Ideen geprägt ist, kann angesichts der Veränderungen in der tschechischen Gesellschaft im 19. und 20. Jahrhundert wohl nicht als verwunderlich gelten. Wenn auf die in den Dramen mehr oder weniger deutlich bzw. mehr oder weniger allegorisch erkennbaren politischen Ideen analytisch abgezielt wird, so stellt dies eine Reduktion der ästhetischen Komplexität der Dramen dar. Die Reduktion rechtfertigt sich damit, dass zum einen jedes Drama für sich genommen schon eine gewisse Komplexität besitzt und sein politischer Gehalt nicht immer offenbar ist, und dass zum anderen die Zahl der historischen Dramen im Untersuchungszeitraum den Eindruck eines Sinngestrüpps aus einzelnen Dramen erzeugt. Mit der vorliegenden Arbeit wurde versucht, einen Weg durch dieses Sinngestrüpp zu schlagen. Selbstverständlich wären auch andere Wege möglich, wenn man wie in der vorliegenden Arbeit das kritische Ziel verfolgt, hinter lauter Bäumen einen Wald zu sehen.

Die Arbeit untersucht die Zeitgebundenheit der Dramen - ihr „depräsentierendes" Moment; es wurde gezeigt, dass die Dramenproduktion historische Veränderungen, Gestimmtheiten und Ereignisse im Untersuchungszeitraum reflektiert. Die historische Dramatik der Tschechen ist sehr deutlich von der Sache der Nation geprägt - „Deutsche“ bzw. „Österreicher“ erscheinen, wenn sie als figurae dramatis vorkommen, meist in antagonistischer Rollenfunktion. Anhand der Frauenfiguren und anhand des auffälligen cross-dressing ist ein agitatorisches Moment erkennbar: Im obrození, als die tschechische Nation noch nicht konsolidiert war, werden mit der männlichen Verkleidung der Heldinnen deren mustergültige Handlungen markiert, die dem Ideal von Engagement für die Sache der „nationalen“ Gruppe entsprechen. Mit der vergleichenden Analyse der diversen Václav-Dramen sollte deutlich werden, dass Václav erst mit der unabhängigen Tschechoslowakei zum idealen Fürsten gerät, während vor 1918 immer die der nationalen Selbstständigkeit abträglichen Aspekte von dessen christlicher Politik in den Dramen akzentuiert werden. Die Rechtmäßigkeit der politischen Herrschaft wie sie anhand von Usurpatorfiguren, wie Záviš von Falkenštejn oder Vukašín problematisiert werden kann, ist ein rekurrierendes Dramenthema, das mit dem Untergang der Habsburger Monarchie offenbar seine Aktualität verliert. Dies könnte damit im Zusammenhang stehen, dass sich in einer Demokratie die politische Elite anders legitimiert als in einer Monarchie, in der Usurpatoren zwar als die fähigeren Politiker erscheinen können, deren Machtansprüche aber gegen die geltende Rechtsordnung verstoßen. In der zweiten Hälfte des 19. Jahrhunderts gibt es weitaus mehr zwiespältige Gestalten - auch unter den nicht-fürstlichen Protagonisten - womit man wohl eine Tendenz zum „Re- 
alismus" erkennen darf. Diese Tendenz entspricht möglicherweise der praktischen Einsicht in die Schwierigkeiten politischen Handelns, welche die Tschechen als Nation innerhalb des multinationalen Staates Österreich-Ungarns erkennen mussten.

Derlei Entsprechungen zwischen den Tendenzen des historischen Dramas und den politischen Veränderungen ihrer Entstehungszeit können nur auf der Grundlage einer Dramenanalyse konstatiert werden. Diese beruht auf der Annahme, dass sich politisches Denken in der Literatur manifestiert. Um mit einer Abwandlung des berühmten, oben diskutierten Hegel-Zitats (vgl. S. 42, Fn 38) zu enden, in dem das Verhältnis von Geist/Idee/Ideologie und entsprechender geschichtlicher Manifestation thematisiert wird, das auch der heuristischen Prämisse der Arbeit entspricht: Der Zeitgeist ist auf dem Theater, auf dem wir ihn betrachten, im historischen Drama, in seiner vermittelten Wirklichkeit. Um von dieser Weise seiner vermittelten Wirklichkeit auch das Zeittypische zu fassen, mussten wir einige konkrete Analysen vorausschicken. 


\section{Brief Overview of the Study}

The present monograph ${ }^{445}$ investigates the ways in which the political and ideological content of historical dramas within Czech literature shifted between 1810 and 1935 in a diachronic review covering the period from the beginnings of obrozeni $i^{446}$ dramatic art up to the millennial celebrations of the Václav/Wenceslas Jubilee. In the genre of historical drama, it tends to be the case that the political or ideological function of a given work dominates other more general functions pertaining to linguistic artwork. The central idea governing the current investigation is that historical dramas are built upon the foundations of an allegorical structure which extends beyond the mere portrayal of a story or any underlying "historical interpretation" ${ }^{447}$ : parallel to the portrayal of historical or pseudo-historical events, Czech dramas have an allegorical relationship with the political issues prevailing at the time they were written. In addition to the function of representing the existence of the nation through reference to a very distant past, ${ }^{448}$ the plays also express an ideology that is made more or less obviously manifest in the text or the context of the plot.

The analysis of approximately 40 dramas from a 125 year period traces the ways in which the contemporary political content of the dramas have changed and how the concurrent and ensuing events or changes (such as the strengthening of the nationalist movement, the 1848 revolution, the birth of parliamentarianism, the Austro-Hungarian Compromise, the conflict of nationalities, the First World War and the dissolution of the monarchy, or Czechoslovakian independence) are reflected.

445 The research for this post-doctoral project received very generous support in the form of a MOEL-plus-Stipend from the Austrian Research Association.

446 The period 1810-1935 is a historical approximation insofar as there was not a single theatre performance in Prague in 1810 as a result of the war against Napoleon's army. Jan Nepomuk Štěpánek's patriotic performances, which might be considered to fall under the genre of historical drama, were presented at Prague's Estates Theatre from 1812 on (cf. Miroslav Laiske: Pražská dramaturgie. Česká divadelni predstavení v Praze do otevřeni Prozatímního divadla. Díl 1. Praha: Ústav pro českou literaturu ČSAV 1974, 89f bzw. Aleš Haman: Trvánív proménè. Česká literatura devatenáctého století. Praha: ARSCI 2007, 78).

447 Cf. Elfriede Neubuhr: "Einleitung”, in her (Ed.): Geschichtsdrama, Darmstadt: Wiss. Buchges. 1980, 3-39, here 3f.

448 Cf. Walter Puchner's definition of the particular functions of historical drama, which points towards its polymorphic nature: "Awakening and cultivation of a national self awareness, which accentuates the differences to other nations and people and underlines the nation's autonomy, which re-creates current or developing "we" and "other" images that existed in the (distant) past and offers them to the audience as a means of identification." - Walter Puchner: Historisches Drama und gesellschaftskritische Komödie in den Ländern Südosteuropas im 19. Jahrhundert. Frankfurt u. a.: Lang 1994, 77. 
The question posed here simultaneously proffers an historical overview of the development of a genre which, one the one hand, is imbued with profound significance in the cultural and theatrical history of many European peoples - in this case with specific reference to the Czechs - but, on the other hand, the topic has received little attention in the realms of literary research, most likely due to the emphasis on pronounced ideological functions. Although more than a few single analyses of historical dramas have been conducted, in addition to presentations of the work of individual authors or certain epochs, there is, to date, no large or comprehensive overview of the development of historical drama in $19^{\text {th }}$ century Czech literature or of writing produced in the first half of the $20^{\text {th }}$ century. Considering the sheer mass of theatrical pieces with historical content that were created in the period under study, the current study can necessarily only represent an excerpt. The hope remains, however, that this excerpt has a synecdochic relationship to the totum, which is to say that it is, at least to some extent, representative of a larger body of work. The focus on the political or ideological content of the dramas is established on the basis of a cultural-historical interest in the fact that, ideally, the political or ideological function corresponds better to the historical dramas under study than other functions pertaining to purely literary and theatre analytical perspectives.

\section{Differentiation from Theatre Studies and the History of Theatre}

Before the dissemination of technical media, theatre - the setting for which the historical dramas under study were conceived - was the most significant cultural institution that could serve to attain broad publicity; it reached a wide range of social classes and often addressed issues other than those that predominated in printed media. The genre of historical drama was an ideal means of achieving a wider dissemination of historic imagery and the re-discovery of history at the time.

The relevance of the Czech national theatre movement, whose precursors date back to the late $18^{\text {th }}$ century ${ }^{449}$ and which was formed before 1848 (although this was relatively late when compared to the rest of Europe, with the opening and reopening of the National theatre/ Národní divadlo in 1881 and 1883), to the consolidation of the Czech nation has been described frequently and in detail. Pavla Buzková wrote in 1932 that Czech drama is closely bound to the fate of a "newly born"

449 Prokop Šedivý added the following note to his translation of Schiller's lecture "The Theatre considered as a Moral Institution": "If we eventually had a solid Czech theatre, we would become a nation of people" - cf. Jan Císař: Préhled dějin českého divadla I. Od počátkù do roku 1862, Praha: Akademie múzických umění v Praze, $32 \mathrm{f}$. 
nation and that on the basis of its "ferocious gravity", it could be seen as reminiscent of ancient Greek tragedy. ${ }^{450}$

Whilst the theatre-historical aspects have been studied in encyclopaedic breadth and depth - the four volume portrayal of Déjiny českého divadla (1968-1983) remains, despite its ideological imprint, an indispensable and seminal work -, there has to date been no comparable recent study that describes the history of drama as a genre or historical drama as a sub-genre of Czech literature. Drama that tends to revolve around the nation's own history was seen, at least in the $19^{\text {th }}$ century, as a prestigious genre in the cultural competition between nations. In this sense, it occupied a high position in the hierarchy of genres, as evidenced by various artistic and literary theory texts such as Hegel's Lectures on Aesthetics and Josef Jungmann's Slovesnost as well as by the prize awarded by Ferdinand Fingerhut (Náprstek) for the creation of a dramatic work rooted in Slavic history, which was intended to elevate Czech drama to an international level in the late $1850 \mathrm{~s} .{ }^{451}$ To emphasise the trenchant cultural and political significance of this genre, it is possible to postulate: if the Národní divadlo can be seen as the "hardware" that powers Czech culture, then historical drama is the corresponding "software"; a kind of national and political "programme". Correspondingly, historical dramas were performed to mark the opening of the National Theatre (1881/83) and of the Provisional Theatre (Prozatímní divadlo 1862), which was intended to prepare both the ensembles and the audiences for the development of the National Theatre. ${ }^{452}$

A review of theatre history nonetheless reveals that there were only very few exceptional instances where historical dramas enjoyed broad popularity amongst audiences, who generally preferred contemporary subject matter and less sombre genres, such as comedy, musical works, farce and féeries. ${ }^{453}$

450 Cf. Pavla Buzková: Čské drama, Praha: Melantrich 1932, 27. - The significance accorded to Czech theatre is evident in the great tradition of theatre studies, which even survived the $20^{\text {th }}$ century shift of the political regime fairly unharmed.

451 Cf. Zprávy soudcu o dramatech $z$ dějin slovanských, ježto $k$ dosaženi premie, Pražským městánem, panem Ferdinandem Fingerhutem ustanovené, v letech 1859 a 1860 byly zaslány, Praha: Rivnáč 1860.

452 Vítězslavs Hálek's Král Vukašin opened the Provisonal Theatre in 1862, and Václav Vlček's Lipany opened the National Theatre in 1881 . Vlček's drama is nonetheless admittedly a far less prominent work than Smetana's opera Libuše, which was commissioned as the main opening piece for the National Theatre.

453 The Czech theatre historian František Černý explains this fact by suggesting that the grave connotations of grand tragedies corresponded less to the more comical preferences of the Czechs national character - František Černý: »Znovu o specifikách českého dramatu «, in: Eva Šormová, Michaela Kuklová (Hg.), Miscellanea theatralia, Praha: Divadelní ústav 2005, 63. 


\section{References to Time in Historical Drama}

The simultaneous reference to two distinct periods in a historical drama is describable in terms of the pair of concepts that in this work have been termed "representation" and "depresentation". On the one hand, dramatic texts bring past events into the respective present or receptive context ("representation") and, on the other hand, the choice of subject matter and its dramatic treatment are co-determined by events in the present, whereby current affairs are projected onto the past, which can be described metaphorically as "depresentation". There have been a number of different ways of characterising such double time references as those that are particularly striking in historical dramas ${ }^{454}$ but which can be also applied to descriptions of history in a more general sense (insofar as the historiographic portrayal of the past is led by contemporary interests). Walter Benjamin speaks of a "tiger's leap into the past" ${ }^{155}$, whilst systems theory or cultural studies-based memory research both accentuate the primacy of contemporaneity for the reconstruction of the past. ${ }^{456}$

Although the historical dramas under discussion are often based on historical writing (such as the particularly popular chronicles of Dalimil, the chronicles of Václav Hájek z Libočan, or later František Palackýs The History of the Czech Nation in Bohemia and Moravia), this investigation will nonetheless refrain from detailed comparisons between reference work $(s)$ and individual historical dramas, as the ideological tendency inherent in the dramas is clearly identifiable without such a comparison (which, apart from anything else, would vastly increase the quantity of primary texts in the corpus). Instead, the dramatic texts under study are to be regarded as doubly hybrid texts. They are hybrid not only in the sense of amalgamating past and present but also in the sense of their intermediate position between dramatic pseudo-"event" and textual representation. The playwright creates to some extent a (pseudo-)historical world through his writing, in which certain events take place. At the same time, though, the dramatic events are texts and as such not historical res gestae. The analysis of a dramatic text takes place, according to Hayden White in Metahistory, in strata he describes as event - chronicle - story - mode of emplotment - mode of argument - mode of ideological explanation, ${ }^{457}$ whereas the current investigation only pertains to "story" (qua concise re-telling of dramatic content)

454 Cf. Herbert Lindenberger: Historical Drama. The Relation of Literature and Reality, Chicago, London: Chicago UP 1975, 5.

455 Walter Benjamin: »Über den Begriff der Geschichte «, in ders.: Illuminationen. Ausgewählte Schriften, Frankfurt/M.: Suhrkamp 1977, 251-261, hier 259.

456 Cf. Jan Assmann: Das kulturelle Gedächtnis. Schrift, Erinnerung und politische Identität in frühen Hochkulturen, München: Beck 1992, 41f; Niklas Luhmann: Einführung in die Systemtheorie, Heidelberg: Auer 2009, 102.

457 Cf. Hayden White: Metahistory. The Historical Imagination in Nineteenth-Century Europe. Baltimore, London: John Hopkins UP 1973, 5-29. 
and "explanation". The "explanation" proffers the most important indications of the playwrights' political ideas as embedded in their dramatic writing.

\section{Focus of the Analysis and Corpus}

The analysis of historical dramas is carried out on the basis of their textual form and not of theatre performances, which themselves might be termed "plurimedial" texts. In contrast to performances, dramatic texts can be simply passed on, read and analysed with reference to their political implications. Stage productions and their reception amongst audiences, critics, etc. contribute nothing but background information to the current study. Correspondingly, the focus is not put on the actual communication between the author and audience but rather centres on determining the ideological tendencies that emerge through a close analysis of the message conveyed by the dramatic text. Historical dramas that have never been performed and are only registered in bibliographical lexica or collected in libraries are examined in relation to their inherent political ideas with the same attentiveness and care applied to successful theatre pieces (such as works by Josef Kajetán Tyl, Ladislav Stroupežnický, or Jaroslav Hilbert, amongst others). The selection of the corpus was led by a principle of diversity and scattering: the body of works is not restricted to well known authors or plays; it is not the case that all of a given author's historical dramas are included, nor all the historical dramas of an epoch. ${ }^{458}$ The historical content of the works under study also differs greatly and no strict division has been drawn between historical and pseudo-historical references. Thus, the corpus includes plays which take up stories from renowned Czech fake manuscripts, as well as dramas that present fictitious characters in an otherwise precisely reconstructed historical setting. In these plays, too, there is a clearly recognisable political and ideological expression which is perhaps all the more evident because the authors did not have to pay so much attention to the official, accredited version of historical developments that would have been known to contemporary audiences.

\section{Sketch of the Results}

The scope of the corpus and the aim of arriving at a synoptical review of the political implications and tendencies require a structured overview. This is most easily achievable with reference to historical material that was treated repeatedly in the course of the period under study. Eight plays about Saint Wenceslas/sv. Václav, the Bo-

458 Barbara Topolová: České obrozenecké a poobrozenecké drama, Diss. Praha: Karlova univerzita, Katedra divadelní vědy 1996. 
hemian national patron, ${ }^{459}$ demonstrate that dramas written before 1918 call into question Václavs Christian ethics as a political model, whilst pieces written after 1918 portray Václav as a positive ideal who only fails in the face of confrontations with very negatively drawn antagonists.

The Václav theme follows on from the obrozeni dramas, which touch upon complex topics that continued to occupy playwrights in the ensuing years: the issue of Czech national unity and the question of what type of political situation could be created in this setting of strength and unity that would be capable of defeating a threat from "outside" (Štěpánek, Linda, Klicpera, Mikovec, Vojáček, Kolárs Monika, Tyls Krvavé krttiny/Bloody Baptism); the legitimation of political power (Štěpánek, Klicpera, Hněvkovský, Tyls Čestmirr, Macháček); and the relationship between individual and society (Tyls Čestmirr, in the plays of Vojáček und Kolár). In the second half of the $19^{\text {th }}$ century, Háleks Catilina and Bozděchs Baron Goertz reflect the introduction of limited parliamentarianism in 1861. At the same time, there is a noted "internationalisation" of allegory, whereby authors started to refer to more foreign material in their work: Háleks Král Vukašin, Fričs Ivan Mazepa, Zeyers Doña Šanca. The aggravated antagonism between the Czechs and Germans towards the end of the $19^{\text {th }}$ century is recognisable in Zákrejs, Hilbert and Jirásek (mostly in connection with the question of national cohesion, which tends to be presented at a religious and confessional level with reference to the opposition of Utraquism or Protestantism vs. Catholicism - Dvořák proffers an alternative in Král Václav IV.). Following the formation of Czechoslovakia in 1918, the selected pieces demonstrate a clear shift in the function of historical dramas: the plays move away from analysing historical developments that revealed the problems and difficulties of national political activities and instead, the works start to present Saint Wenceslas/sv. Václav as an ideal role model.

\section{Structure and Framework}

This study is split into two sections. The first section (A) discusses questions pertaining to the theory of theatre and cultural studies in relation to the genre of historical drama. This section is not conceived with reference to a specific language and as such is also intended for readers without any particular interest in the history of Czech theatre. It proffers contributions to some aspects of historical drama that have not received a great deal of attention in academic writing to date (such as the question of the memory function fulfilled by historical drama and their allegorical potential) and some aspects that are more obviously central to dramatic theory

459 The plays in question are Wenceslas pieces by Tyl, Dvorský, Vrchlický, Langer, Zavřel, Preissová, Durych and Lom. 
(such as the question of dramatic communication or the interpretation of dramatic texts).

The second section (B) is culture-specific and constitutes a treatment of Czech historical drama before a backdrop of theatre-historical developments that reached their institutional pinnacle with the opening of the National Theatre in the 1880s. The theatre-analytical section is split into three periods, covering the obrozeni epoch (which is understood here as the first half of the $19^{\text {th }}$ century), the second half of the $19^{\text {th }}$ century and the first third of the $20^{\text {th }}$ century. The individual analysis concludes with a synoptical overview of plays about Saint Wenceslas/sv. Václav, on the basis that the common identity of the historical material offers a good measure of comparison. The summary at the end of the work illustrates the difficulties encountered when trying to address all of the plays analysed in the course of the study in a comprehensive comparison against the backdrop of the historical period and thus includes supporting graphic illustrations. These demonstrate that, despite the diversity of the historical material treated in the works under study, the historical dramas make distinct reference to the political situation at the time they were written. 


\section{Stručná charakteristika díla}

Tato práce zkoumá v diachronním pohledu proměny politicko-ideologického obsahu v českých historických dramatech, která vznikala mezi lety 1810-1935 - tedy od počátků obrozeneckého dramatu až po oslavy svatováclavského milénia v Československé republice. V rámci žánru historického dramatu zpravidla platí, že jeho politická, př́p. ideologická funkce dominuje nad ostatními funkcemi tohoto slovesného uměleckého díla. Vůdčí myšlenkou daného výzkumu je tvrzení, že základ historických dramat tvoří alegorická struktura, která přesahuje pouhé ztvárnění historie nebo její výklad:460 Kromě ztvárnění historických či pseudohistorických událostí česká dramata rovněž alegorickým způsobem tematizují politické otázky, které byly aktuální v době jejich vzniku. Tato dramata v sobě nesou, vedle funkce doložit národní existenci v co možná nejvzdálenější minulosti, ${ }^{461}$ také ideologické sdělení, jež se více či méně explicitně manifestuje v textu nebo dějovém kontextu.

Analýza asi 40 dramat, která vznikala v časovém rozpětí 125 let, demonstruje proměny jejich soudobého politického obsahu a analyzuje, jakým způsobem byly tehdejší aktuální události, př́íp. změny (posilování národního hnutí, revoluce v roce 1848, počátky parlamentarismu, rakousko-uherské vyrovnání, národnostní konflikty, první světová válka, rozpad monarchie a československá státnost) reflektovány.

Daná práce zároveň poskytuje historický přehled o vývoji žánru, kterému byl na jednu stranu v kulturních dějinách a v dějinách divadla mnohých evropských národů - zejména Čechů - připisován velký význam, ale kterému byla na druhou stranu, patrně z důvodu jeho silné ideologické funkce, v literárněvědném zkoumání udílena jen malá pozornost.

Existuje sice několik dílčích analýz historických dramat a zpracování dramatické tvorby jednotlivých autorů nebo určité epochy, avšak práce, která by poskytovala širši souvislý přehled o vývoji historického dramatu v české literatư̌e 19. století nebo první poloviny 20. století, dosud $\mathrm{k}$ dispozici není.

Vzhledem $\mathrm{k}$ velkému počtu dramat $\mathrm{s}$ historickou tematikou, která vznikla ve zkoumaném období, může přehled obsažený v této práci zahrnout pouze část z cel-

460 Srv. Elfriede Neubuhr: „Einleitung“, v kn. Neubuhr (ed.): Geschichtsdrama, Darmstadt: Wiss. Buchges. 1980, 3-39, tady s. 3.

461 Srv. definice funkcí Waltera Puchnera, který také poukazuje na mnohotvárnost historického dramatu: „Probuzení a kultivování národního sebevědomí, které akcentuje rozdíly mezi vlastním národem a ostatními národy a zároveň podtrhuje národní svébytnost; které revitalizuje již existující nebo teprve vznikající představy o „nás“ a „cizincích“ s pomocí (vzdálené) budoucnosti a předkládá je divákovi tak, aby se s nimi mohl identifikovat." - Walter Puchner: Historisches Drama und gesellschaftskritische Komödie in den Ländern Südosteuropas im 19. Jahrhundert. Frankfurt u.a.: Lang 1994, s. 77. 
kového materiálu. Zároveň se ale domníváme, že tento přehled tvoří s celkem synekdochický vztah, a je tedy do značné míry reprezentativní.

Koncentrace na politický, př́íp. ideologický obsah dramat se zakládá na kulturněhistorickém zájmu, který by měl v ideálním případě odpovídat politické, příp. ideologické funkci historických dramat lépe než čistě literárněvědná perspektiva analýzy dramatu.

\section{Vymezení tématu z pohledu teatrologie a dějin dramatu}

V době před rozšířením technických médií bylo divadlo, pro něž byla historická dramata koncipována, nejdůležitějš́ institucí pro formování veřejnosti; mělo možnost proniknout $\mathrm{k}$ širokým vrstvám společnosti a často zpracovávalo jiná témata, než tomu bylo u tradičních tišstěných médií. Žánr historického dramatu byl vhodný pro diseminaci historických námětů stejně jako pro jejich znovuoživení v rámci tehdejší současnosti.

Hnutí, jehož cílem bylo zřízení českého národního divadla a jehož počátky můžeme sledovat již ke konci 18. století, posílilo sice ještě před rokem 1848, ale svého cíle dosáhlo v evropském kontextu relativně pozdě - otevřením Národního divadla v roce 1881, resp. 1883. Téma významu tohoto hnutí pro konsolidaci českého národa bylo již mnohokrát zpracováno. Pavla Buzková píše v roce 1932 o tom, že české drama je úzce spojené s osudy „obrozeného“ " národa a svojí „krvavou vážnosti“ připomíná řecké osudové tragédie z období antiky. ${ }^{462}$

Zatímco z hlediska dějin divadla jsou tyto aspekty zpracovány v encyklopedické šiŕi - čtyřsvazková práce Déjiny českého divadla (1968-1983) představuje přes svoji ideologickou impregnaci dodnes nepostradatelné standardní dílo -, neexistuje zatím žádná srovnatelná mladší studie, která by se věnovala dějinám dramatu či žánru historického dramatu v české literatuře.

Drama, které přednostně zpracovávalo náměty z vlastní národní historie, platilo - přinejmenším v 19. století - za prestižní žánr v rámci kulturní soutěže národů. $V$ žánrové hierarchii zaujímalo velmi vysokou pozici, o čemž svědčí mnohé umělecko- či literárněteoretické spisy, jako např. Hegelovy Vorlesungen zur Ästhetik (Přednásky o estetice) a Slovesnost Josefa Jungmanna, stejně jako cena za vytvoření dramatu s námětem ze slovanských dějin, vypsaná Ferdinandem Fingerhutem (Náprstkem), která si v pozdních padesátých letech 19. století kladla za cíl pozvednout české drama na mezinárodní úroveň. ${ }^{463}$ Abychom zdůraznili kulturněpolitický vý-

462 Srv. Pavla Buzková: České drama, Praha: Melantrich 1932, s. 27. - Význam, který byl českému divadlu připisován, můžeme pozorovat i díky bohaté teatrologické tradici, která relativně bez úhony přečkala dokonce i změny režimů v průběhu 20. století.

463 Srv. Zprávy soudců o dramatech z dèjin slovanských, ježto $k$ dosažení premie, Pražským městáanem, panem Ferdinandem Fingerhutem ustanovené, v letech 1859 a 1860 byly zaslány, Praha: Řivnáč 1860. 
znam tohoto žánru, můžeme použít následující příměr: Pokud může být Národní divadlo pokládáno za nezbytný „hardware“ české kultury, pak je historické drama onen odpovídající „software“ - jistý druh národněpolitického „programu“.

Tomu odpovídá i skutečnost, že jak při slavnostním otevření Národního divadla (1881), tak při otevření Prozatímního divadla (1862), které mělo připravit soubor i veřejnost na vznik Národního divadla, byla uvedena historická dramata. ${ }^{464}$

Při zpětném pohledu na dějiny divadla se ovšem ukazuje, že se historická dramata těšila větší přízně publika jen ve výjimečných případech, nebot toto dávalo zpravidla přednost soudobým námětům a méně závažným žánrům - komediím, zpěvohrám, báchorkám a švankům. ${ }^{465}$

\section{Časové vztahy v historickém dramatu}

Časové vztahy v historickém dramatu mají dvojí charakter, který je možné vyjádřit pojmovou dvojicí „reprezentace“ a „deprezentace“, jež vznikla pro potřeby této práce a která upřesňuje častěji používaný výraz „aktualizace“ (vyjadřující možnost zdůraznit nadčasový význam nějakého historického jevu).

Dramatický text přenáší na jednu stranu události z minulosti do té které současnosti produkce/recepce („reprezentace“), na druhou stranu o výběru námětů a jejich dramatickém ztvárnění spolurozhodují i ty události, které jsou v dané době aktuální. Tyto jsou pak promítány do minulosti, což bychom mohli metaforicky nazvat „deprezentace“. Tento dvojí charakter časových vztahů, který je v př́padě historického dramatu obzvlášt výrazný, ${ }^{466}$ ale který můžeme sledovat i v rámci historiografie (protože i historiografické zpracování minulosti je do jisté míry vedeno aktuálními zájmy), byl již mnohokrát různými způsoby charakterizován: Walter Benjamin hovoří o „tygř́m skoku do minulosti“ ${ }^{467}$, systémová teorie nebo kulturněvědný výzkum lidské paměti akcentují rovněž primát aktuálnosti ve vztahu k rekonstrukci minulosti. ${ }^{468}$

464 Král Vukašin Vítězslava Hálka zahájil v roce 1862 činnost Prozatímního divadla, hrou Lipany Václava Vlčka bylo v roce 1881 otevřeno Národní divadlo. Pochopitelně je Vlčkovo drama méně známé než Smetanova opera Libuše, která byla objednána pro otevření Národního divadla jako centrální dílo.

465 Český divadelní historik František Černý vysvětluje tuto okolnost poněkud zvláštně tím, že vážný charakter konotací velké tragédie by neodpovídal spíše komediantské národní povaze Čechů. - František Černý: »Znovu o specifikách českého dramatu «, in: Eva Šormová, Michaela Kuklová (ed.), Miscellanea theatralia, Praha: Divadelní ústav 2005, s. 63.

466 Srv. Herbert Lindenberger: Historical Drama. The Relation of Literature and Reality, Chicago, London: Chicago UP 1975, s. 5.

467 Walter Benjamin: »Über den Begriff der Geschichte«, in ders.: Illuminationen. Ausgewählte Schriften, Frankfurt/M.: Suhrkamp 1977, 251-261, tady s. 259.

468 Srv. Jan Assmann: Das kulturelle Gedächtnis. Schrift, Erinnerung und politische Identität in frühen Hochkulturen, München: Beck 1992, 41-42; Niklas Luhmann: Einführung in die Systemtheorie, Heidelberg: Auer 2009, s.102. 
Ačkoliv historická dramata zpravidla čerpají z historiografických pramenů (zejména Dalimilovy kroniky nebo z kroniky Václava Hájka z Libočan, později pak z Palackého díla Déjiny národu cesského v Čechách a v Moravé), v rámci našeho výzkumu od detailního srovnávání referenčního díla, př́íp. referenčních děl a jednotlivých historických dramat upouštíme, protože ideologická tendence dramat je i bez takového porovnání zcela zřejmá. To by navíc př́liš navy̌šilo počet primárních textů.

Místo toho je zde na dramatický text pohlíženo jako na text hybridní povahy ze dvou hledisek. Hybridní v něm totiž není jenom vzájemné propojení minulosti a současnosti, ale také pozice dramatické pseudo-události a textové reprezentace. Dramatik vytváŕi svou tvorbou jistý (pseudo-)historický svět, ve kterém se odehrávají určité události. Zároveň jsou ale dramatické události texty, nikoliv tedy z historického hlediska res gestae. Analýza dramatických textů je prováděna na základě modelu popsaného Haydenem Whitem v jeho Metahistory, tj. události - kronika - fabule - výklad, přičemž v textu výzkumu jsou tematizovány pouze „fabule“ (jako stručný popis děje dramatu) a „výklad“. Ten poskytuje přehled nejdůležitějších ideologických bodů, které jsou obsaženy v dramatech.

\section{Těžiště zájmu analýzy a korpus}

Analýza historických dramat se v této práci opírá o jejich tišsěný text, nikoliv o jejich inscenace, které představují text plurimediální. Na rozdíl od divadelních inscenací mohou být tištěné texty dramat jednoduše tradovány, čteny a analyzovány z hlediska jejich politických implikací. Divadelní inscenace a jejich recepce z pohledu publika či kritiky mohou v rámci výzkumu sloužit nanejvýš $\mathrm{k}$ dokreslení pozadí dané tematiky. Je tedy jasné, že se v centru zájmu rovněž nenachází realizovaná komunikace mezi autorem a publikem, nýbrž vyhledávání a pojmenovávání ideologických tendencí, čehož je dosaženo analýzou sdělení (textu dramatu). Historická dramata, která nebyla nikdy uvedena a jsou $\mathrm{k}$ dispozici pouze $\mathrm{v}$ knihovnách, př́p. jsou uvedena v bibliografických lexikonech, jsou v této práci podrobována z hlediska jejich politických implikací stejně důkladnému zkoumání jako úspěšné divadelní kusy (např. dramata Josefa Kajetána Tyla, Ladislava Stroupežnického či Jaroslava Hilberta aj.). Při vytváření korpusu platil princip dekoncentrace: nebyli zohledňováni pouze známí autoři či známá díla. Provedená analýza se nesoustředí ani na veškerá historická dramata z pera jednoho vybraného autora, ani na všechna díla vzniklá v rámci jedné konkrétní epochy. ${ }^{469}$ Historické náměty mohou být rovněž rozdílné. Dále se v práci upouští od striktního rozdělení mezi historickými a pseudohistorickými souvislostmi. Proto byla do korpusu zařazena jak dramata, která tematicky čerpají ze slavných padělaných rukopisů (Rukopisu královédvorského a Rukopisu

469 Barbara Topolová: České obrozenecké a poobrozenecké drama, Dis. Praha: Karlova univerzita, Katedra divadelní vědy 1996. 
zelenohorského), tak i díla, která zpracovávají osudy fiktivních postav v rámci jinak precizně vykreslené historické situace. Také v těchto dramatech můžeme rozpoznat politicko-ideologické sdělení, možná dokonce zřetelněji, protože autoři mohli brát menší ohled na historicky ověřené a publiku známé dějové linie.

\section{Nástin závěrů výzkumné práce}

Rozsah korpusu a cíl prozkoumat politické implikace a tendence ze synoptického hlediska vyžadují jisté vymezení pohledu. Toho je možné nejlépe dosáhnout pomocí analýzy námětu, který byl v námi zkoumaném časovém rozmezí často zpracováván. Na základě analýzy osmi dramat, jejichž tématem je život sv. Václava, českého národního patrona, ${ }^{470}$ se ukazuje, že ta dramata, která vznikla před rokem 1918, zpochybňují Václavovu křestanskou etiku jakožto vhodný politický model, zatímco hry, které byly napsány po roce 1918, zobrazují Václava jako pozitivní ideál, kterému v úspěšném dovršení jeho poslání brání pouze velmi negativně vykreslení antagonisté.

Hry s tematikou života sv. Václava navazují na dramata z období národního obrození, která obsahují tematické prvky, jež se později rovněž vyskytují v historických dramatech. I v pozdější době se toto téma těšilo velké přízni dramatiků. Zpracováván byl problém národní jednoty Čechů a otázka, jaký druh politiky je s to dosáhnout takové jednoty a síly tváří v tvář ohrožení „zvenči““ (Štěpánek, Linda, Klicpera, Mikovec, Vojáček, Kolárova Monika, Tylovy Krvavé kŕtiny), dále pak legitimizace politické moci (Štěpánek, Klicpera, Hněvkovský, Tylův Čestmir, Macháček) a vztah individua vůči společnosti (Tylův Čestmír, u Vojáčka a Kolára). V druhé polovině 19. století je v Hálkově hře Catilina a Bozděchově Baronu Goertzovi reflektováno zavedení omezeného parlamentarismu v roce 1861. Ve stejné době můžeme rovněž pozorovat určitou „internacionalizaci“ alegorie, protože si dramatici vybírají ke zpracování i náměty z historie jiných národů: Hálkův Král Vukašin, Fričův Ivan Mazepa, Zeyerova Doňa Šanca. Vyostření česko-německého antagonismu na konci 19. století reflektují spisovatelé Zákrejs, Hilbert a Jirásek (většinou v souvislosti s otázkou národní jednoty, která je tematizována především na úrovni náboženství a vyznání). Je zde vytvořen protiklad mezi utrakvismem, př́p. protestantismem a katolicismem. Alternativu k tomuto vymezení představuje Dvořákův Král Václav $I V$. Po vzniku Československa v roce 1918 dochází, jak dokazují vybraná díla, k proměně funkce historického dramatu: Toto se nyní zaměřuje méně na analýzu historických procesů, které recipientům přibližují problémy národněpolitické činnosti. Místo toho se díla s tematikou života sv. Václava snaží vytvořit ideál, který má sloužit jako př́klad.

470 Jedná se o hry se svatováclavskou tematikou od Tyla, Dvorského, Vrchlického, Langera, Zavřela, Preissové, Durycha a Loma. 


\section{Formální členění práce}

Tato práce je rozdělena do dvou částí. V první části (A) jsou zpracovány otázky týkající se teorie dramatu a kulturněvědné oblasti, které jsou relevantní pro výzkum žánru historického dramatu. Tato část není jazykově specifická, je tedy možné ji číst i bez zvláštního zájmu o českou dramatickou tvorbu. Dále jsou v této části rozpracovány vybrané aspekty historického dramatu, kterým bud' nebyla v odborné literatư̌e dosud věnována velká pozornost (jako např́klad problematika paměti a její funkce v historickém dramatu nebo jeho alegorický potenciál), nebo které stále představují ožehavá témata $\mathrm{v}$ diskurzu teorie dramatu (nap̌r. problematika komunikace v dramatu nebo interpretace dramatických textů).

Druhá část práce (B) je pojata jako část kulturně specifická. Věnuje se českému historickému dramatu na pozadí vývoje divadelních dějin, za jehož vrchol je možné považovat vznik instituce Národního divadla v osmdesátých letech 19. století. Část, ve které jsou analyzována dramata, je rozdělena do tř́ oblastí: Je v ní zpracována epocha národního obrození (které je zde především chápáno jako období 1. poloviny 19. století), dále druhá polovina 19. století a první třetina 20. století. Analytická část je zakončena synoptickým pohledem na dramata s tematikou života sv. Václava, nebot fakt, že je daný historický námět identický, vytvář́ kvalitní základ pro srovnání. Ve shrnutí na konci práce jsme se pokusili porovnat všechna analyzovaná dramata na základě jejich historického pozadís pomocí grafických znázornění. Díky tomu je možné jasně prokázat politický vztah analyzovaných dramat $\mathrm{k}$ době jejich vzniku bez ohledu na různorodost jejich námětů. 


\section{Literaturverzeichnis}

\section{VIII.1. Abkürzungen und Siglen}

DčD - Černý, František et coll.: Déjiny českého divadla I-IV. Praha 1968-1983.

LčL - Lexikon české literatury. Osobnosti, dilla, instituce. Pod redakcí Vladimíra Forsta. Praha 1985-2008.

SIUD - Procházka, Vladimír et coll. (1988): Národni divadlo a jeho préedchi̊dci. Slovník umélců divadel Vlastenského, Stavovského, Prozatímního a Národního. Praha.

\section{VIII.2. Primärliteratur}

(in chronologischer Ordnung nach dem thematisch relevanten Erstwerk des Autors)

(1) Štěpánek, Jan Nepomuk: Břetislav Prvni, Český Achylles, aneb: Vitězství u Domažlic. Vlastenská piovodní cinohra z jedenáctého století v péti jednáních [UA 22.12. 1812, publ. 1813]. Praha: Jeřábek 1813.

(2) Linda, Josef: Jaroslav Šternberg v boji proti Tatarim. Divadelní bra [publ. 1823]. Praha: Janský 1926.

(3) Klicpera, Václav Kliment: Sobèslav, selský kniže. Truchlohra ve čtveru dèjstvi [entst. 1824, publ. 1826, UA 6.1. 1839]. Spisy Václava Klimenta Klicpery. Díl prvý. Praha: Kober 1862, 59-205.

(4) Hněvkovský, Šebestián: Jaromír. Smutnohra v pateru jednání [publ. 1835]. Praha: Nejedlý 1835.

(5) Tyl, Josef Kajetán: Čestmír. Dramatická báseñ ve dvou oddělenich [UA 3.5. 1835, publ. 1838]. Spisy Josefa Kajetána Tyla. Svazek 17. První dramata. Hrsg. v. Vladimír Štěpánek. Praha: Státní nakl. 1957, 107-240.

(6) Tyl, Josef Kajetán: Krvavý soud aneb Kutnohorští haviři. Činohra v pèti jednánich. [entst. 1847, publ. 1848, UA 24.4. 1848]. Spisy Josefa Kajetána Tyla. Svazek 20. Historická dramata. Praha: Státní nakl. 1954, 7-95.

(7) Tyl, Josef Kajetán: Jan Hus. Dramatická báseñ v 5 oddéleních [UA 26.12. 1848, publ. 1849,]. Spisy Josefa Kajetána Tyla. Svazek 20. Historická dramata. Praha: Státní nakl. 1954, $97-$ 211.

(8) Tyl, Josef Kajetán: Krvavé křtiny, cili, Drahomira a její synové: Romantický obraz z dávných dějin českých ve čtyrech oddèlenich [UA 11.2. 1849, publ. 1868]. Spisy Josefa Kajetána Tyla. Svazek 20. Historická dramata. Praha: Státní nakl. 1954, 213-295.

(9) Vojáček, Václav: Ludmila. Drama ve tréech dèjstvích [publ. 1843]. Praha: Pospiśsil 1843.

(10) Macháček, Simeon Karel: Záviš Vitkovic, pán z Rủže anebo Pokuta za zradu. Smutnohra $v$ pateru jednáni [UA 8.11. 1846, publ. 1846]. Spisy S.K. Macháčka. Svazek první. Praha: Kober 1883, 1-110 (=Národní bibliotéka. 76.)

(11) Kolár, Josef Jiř́: Monika. Tragédie ve třech jednánich [UA 20. 12. 1846, publ. 1847]. Praha: Pospíšil 1847.

(12) Kolár, Josef Jiří: Primátor. Historické drama ve 4 jednáních [UA 6.1. 1883, publ. 1883]. Praha: Nakl. red. »Divadelních listů 1883 (=Divadelní svět. 6.) 
(13) Mikovec, Ferdinand Břetislav: Záhuba rodu Přemyslovského. Tragédie ve čtyřech jednáních [publ. 1851, UA 9. 1. 1848]. Praha: Kober 189?.

(14) Frič, Josef Václav: Svatopluk a Rastislav. Truchlohra v pateru dèjstvích z dějin moravských [UA 29.11. 1857, publ. 1879]. Praha: Eigenverl. 1879.

(15) Frič, Josef Václav: Ivan Mazepa. Tragédie v 5 dèjstvích [publ. 1865, UA 1874]. Praha: Eigenverl. 1865.

(16) Dvorský, Jan: Drahomíra. Dramatický obraz z českých dèjin v třech jednáních [entst. 1859, publ. 1863]. Praha: Bellmann 1863.

(17) Hálek, Vítězslav: Závišz Falkenštejna. Tragédie vpèti jednáních [UA 8.12. 1860, publ. 1861]. Spisy Vítězslava Hálka VII. Dramata I (z let 1859-1861). Praha: Borový 1925, 99-229.

(18) Hálek, Vítězslav: Král Vukašin. Tragédie v pèti jednáních [UA 18.11. 1862, publ. 1881]. Spisy Vítězslava Hálka VIII. Dramata II (z let 1862-1874). Praha: Borový 1925, 145-280.

(19) Hálek, Vítězslav: Sergius Catilina. Tragédie v péti jednáních [UA 1863, publ. 1881]. Spisy Vítězslava Hálka VIII. Dramata II (z let 1862-1874). Praha: Borový 1925, 9-141.

(20) Bozděch, Emanuel: Baron Goertz. Truchlohra v pěti dèjstvich [entst. 1867, UA 1868, publ. 1871]. Praha: Nakl. knihkupectví dra. Grégra \& F. Dattla 1871.

(21) Zákrejs, František: Král svého lidu. Truchlohra v pěti dèjstvich [UA 1879, publ. 1879]. Praha: Eigenverl. bei Kober 1879.

(22) Vlček, Václav: Lipany. Truchlohra v péti jednáních [UA 12.6. 1881, publ. 1881]. Praha: Eigenverl. 1881.

(23) Vrchlický, Jaroslav: Drahomíra. Tragedie v pèti jednáních. České trilogie část prvá. [UA 1882, publ. 1883]. Jaroslav Vrchlický: Soubor dramatických spisů. Sv. 1. Praha: Rodina 1931, 7-103.

(24) Vrchlický, Jaroslav: Noc na Karlštejnè. Veselohra o 3 jednánich [UA 23.5. 1884, publ. 1885]. Jaroslav Vrchlický: Soubor dramatických spisů. Sv. 3. Praha: Rodina 1931, 41-140.

(25) Vrchlický, Jaroslav: Bratři. Historické drama o péti jednáních. České trilogie cást druhá [publ. 1889, UA 22.4. 1889]. Jaroslav Vrchlický: Soubor dramatických spisů. Sv. 1. Praha: Rodina 1931, 105-257.

(26) Vrchlický, Jaroslav: Knižata. Historické drama o šesti jednánich. České trilogie část trètí [entst. Jänner 1903, publ. 1903, UA 29.10.1903]. Jaroslav Vrchlický: Soubor dramatických spisů. Sv. 1. Praha: Rodina 1931, 259-396.

(27) Stroupežnický, Ladislav: Paní mincmistrová. Aktovka [UA 27.4. 1885, publ. 1886]. Ladislav Stroupežnický: Mikuláš Dačický z Heslova. (Zvíkovský rarášek; Paní mincmistrová) Praha $1942,61-146$.

(28) Zeyer, Julius: Neklan. Tragedie o pèti jednánich [publ. 1893, UA 30.3. 1896]. Spisy Julia Zeyera. Svazek XXVII. Dramatická díla. Díl III. Praha: Česká grafická unie 1947, 1-151.

(29) Jirásek, Alois: Jan Žižka. Historická hra o pèti jednánich [publ. 1903, UA 4.7. 1903]. Praha: Otto 1922, 83-188.

(30) Hilbert, Jaroslav: Falkenštejn. Hra o pèti déjstvích [entst. 1901, publ. 1903, UA 24.5. 1903]. Praha: Bursík \& Kohout 1903.

(31) Hilbert, Jaroslav: Česká komedie. Válečná episoda z roku 1866 o jednom dèjství [pub. 1908, UA 28.1. 1909]. Praha: Bursík \& Kohout 1907.

(32) Dyk, Viktor: Posel. Drama o třech dèjstvich [publ. 1907, UA 1907]. Praha: Rosendorf ${ }^{2} 1922$.

(33) Dyk, Viktor: Revolučni trilogie 1907-1909: Ranní ropucha [UA 1908], Figaro [UA 1917], Poraženi [auch Premoženi UA 1911], UA der Trilogie im Gesamten 13.12.1917, publ. 1921] Praha: Rosendorf ${ }^{2} 1921$. 
(34) Dvořák, Arnošt: Král Václav IV. Drama o pèti dějstvich [publ. 1910; UA 2.2. 1911]. Praha: Nová edice 1910.

(35) Dvořák, Arnošt: Husité. Tragedie národa o pěti dèjstvich [UA. 26.11. 1919, publ. 1919]. Praha: Politika 1919.

(36) Langer, František: Svatý Václav. Tragédie v třech dějstvích [UA 22.11. 1912, publ. 1912]. Spisy Františka Langera. Svazek 6. Hry 1. Praha: Divadelní ústav 2000, 5-106.

(37) Fischer, Otokar: Přemyslovci. Hra o pěti dèjstvích [UA 26.4. 1918, publ. 1918]. Praha: Otto 1919.

(38) Zavřel, František: Boleslav Ukrutný. Tragoedie o třech dějstvích [publ. 1919, UA 1920] Praha: Minař́k 1919.

(39) Durych, Jaroslav: Svatý Václav. Kvas na Boleslavi. Hra o třech dèjstvich [publ. 1924, UA 1924, unter dem Titel Kvas na Boleslavi 1929 erneut publ. u. aufgef.]. Praha: Kuncír 1925.

(40) Gabriela Preissová: Svatý Václav. Hra o pèti dèjstvích [publ. 1929, UA 1929] Praha: Otto 1929.

(41) Lom, Stanislav: Svatý Václav. Tragická hra z českých dèjin [publ. 1929, UA 28.9. 1929; zweite, veränderte Aufl. 1935, UA 28.6. 1935] Praha: Mazáč 1935.

\section{VIII.3. Sekundärliteratur}

Anderson, B. 2005. Die Erfindung der Nation. Zur Karriere eines folgenreichen Konzepts [Orig. 1983], Frankfurt/M.

Ankersmit, F. R. 2002. „Vom Nutzen und Nachteil der Literaturwissenschaft für die Geschichtstheorie“, Fulda, D.; Tschopp, S. S. (Hrsg.), Literatur und Geschichte. Ein Kompendium zu ihrem Verhältnis von der Aufklärung bis zur Gegenwart, Berlin, New York, 12-37.

Anonymus 1868. „Popis slavnosti položení základního kamene k velkému Národnímu divadlu“, Kolár, Josef Jiří, Popis slavnosti položeni základního kamene k velkému Národnímu divadlu se slávnou predehrou: Vèstba Libušina, Praha, 89-108.

Aristoteles 1994. Poetik. Griechisch/Deutsch [Orig. ca. 335 v. Chr.], Stuttgart.

Asmuth, B. 1994. Einführung in die Dramenanalyse, Stuttgart.

Assmann, J. 1988. „Kollektives Gedächtnis und kulturelle Identität“, Assmann, J.; Hölscher, T. (Hrsg.), Kultur und Gedächtnis, Frankfurt/M., 9-19.

Assmann, J. 1992. Das kulturelle Gedächtnis. Schrift, Erinnerung und politische Identität in frühen Hochkulturen, München.

Bachtin, M. M. 1996. „Problema teksta“ [Orig. 1976], ders., Sobranie sočinenij, T. 5, Moskva, 306-328.

Bachtin, M.M. 2000. „Problemy poètiki Dostoevskogo“ [Orig. 1972], ders., Sobranie sočinenij, T. 6, Moskva, 5-370.

Bachtin, M. M. 2003. „Avtor i geroj v èstetičeskoj dejatel'nosti“ [Orig. 1923-1927], ders., Sobranie sočinenij, T. 1, Moskva, 69-263.

Bartoš, J.; Procházka, V. 1969. „České divadlo na sklonku napoleonských válek a za utužení feudální reakce. Část o loutkovém divadle“, Černý, F. (Hrsg.), Dějiny českého divadla II. Národní obrození, Praha, 184-194.

Benjamin, W. 1974. „Ursprung des deutschen Trauerspiels“ [Orig. 1928], ders., Gesammelte Schriften, I/I, Frankfurt/M., 203-430.

Benjamin, W. 1977. „Über den Begriff der Geschichte“, Benjamin, W. (Hrsg.), Illuminationen. Ausgewählte Schriften, I, Frankfurt/M., 251-261.

Berwanger, K. 2003. „Jaroslav Vrchlickýs Tschechische Trilogie (Česká trilogie, 1882-1903). Der Geschichtsmythos als Maske“, Schmid, H. (Hrsg.), Kapitel zur Poetik. Vrchlický und der tsche- 
chische Symbolismus. Beiträge des Internationalen Bohemistischen Vrchlicky-Symposiums an der Universität Potsdam 4.-7. Dezember 1997, München, 58-76.

Borová, V. 1995. „Obraz Němců v české historické beletrii 1890-1900“, Obraz druhého v historicképerspektivè, Praha, 11-39.

Borst, A. 1973. „Das historische >Ereignis<“, Koselleck, R.; Stempel, W.-D. (Hrsg.), Geschichte Ereignis und Erzählung, München, 536-540.

Brabec, J. 2004. „Jednota a rozpory slovesného díla Viktora Dyka“, Tomeš, J. (Hrsg.), Básnik a politik. Sbornik z konference k sedmdesátému výroči úmrti Viktora Dyka, Praha, 47-56.

Brabec, J. 2006. „Dvě kapitoly o Masarykově vztahu k literatuře“, Gebhart, J.; Kuklík, J.; Tomeš, J. (Hrsg.), Masarykiov sbornik, 13, Praha, 9-23.

Brabec, J. 2010a. „1920: Neklidný rok“, Papoušek, V. a kolektiv., Déjiny nové moderny. Česká literatura $v$ letech 1905-1923, Praha, 332-349.

Brabec, J. 2010b. „1923: Reinterpretací tradic k novému tvaru“, Papoušek, V. a kolektiv., Dějiny nové moderny. Česká literatura v letech 1905-1923, Praha, 385-395.

Bugge, P. 1994. Czech Nation-Building, National Self-Perception and Politics 1780-1914, Aarhus. Burget, E. 2014. „Ukrutnost knížete Boleslava. Drama Františka Zavřela o počátcích české státnosti“, Divadelni Revue, 25, (1), 57-69.

Buzková, P. 1932. České drama, Praha.

Carlson, M. 1992. „Theater and Dialogism“, Reinelt, J. G.; Roach, J. R. (Hrsg.), Critical Theory and Performance, Ann Arbor, 313-323.

Černý, F. 1969. „České divadlo v předvečer buržoazně demokratické revoluce a za revoluce (1834-1848)“, Černý, F. (Hrsg.), Dějiny českého divadla II. Národni obrození, Praha, 198357.

Černý, F. 2000. Kapitoly z dějin českého divadla, Praha.

Černý, F. 2005a. „Divadlo českého národního obrození“, Vyčichlo, J.; Viktora, V. (Hrsg.), Jeden jazyk naše heslo bud'III: divadlo národního obrozeni a jeho souvislosti, Radnice, Plzeň, $31-37$.

Černý, F. 2005b. „Znovu o specifikách českého dramatu“, Šormová, E.; Kuklová, M. (Hrsg.), Miscellanea theatralia, Praha, 62-72.

Černý, F. 2007. „Slovo na závěr“, Vostrý, J.; Sílová, Z. (Hrsg.), Josef Kajetán Tyl 1808-18562006-2008, Praha, 113-117.

Císař, J. 2004a. Přehled dějin českého divadla I. Od počátků do roku 1862, Praha.

Císař, J. 2004b. Přehled dějin českého divadla II. Od roku 1862 do roku 1945, Praha.

Císař, J. 2011. Česká divadelni tradice: mýtus, nebo živá skutečnost, Praha.

Cobben, P. 2006. „Recht“, Cobben, P. et al. (Hrsg.), Hegel-Lexikon, Darmstadt, 377-381.

Derrida, J. 1966. „Das Theater der Grausamkeit und die Geschlossenheit der Repräsentation“, ders., Die Schrift und die Differenz, Frankfurt/M., 351-379.

Deutschmann, P. 2005. „Texte um die Welt, Welten um den Text. Kritik der semiotischen Fiktionalitätstheorie“, Bernard, J.; Fikfak, J.; Grzybek, P. (Hrsg.), Text \& Reality, Text \& Wirklichkeit, Ljubljana, Wien, Graz, 29-41.

Deutschmann, P. 2008. „Historische Repräsentation im Wandel. Tschechische und russische historische Dramen in der Moderne", Wiener Slavistisches Jahrbuch, 53, 21-46.

Deutschmann, P. 2010. „Žena přestrojená za muže v historickém dramatu národního obrození, Matonoha, J. (Hrsg.), Jiná čská literatura (?). Česká literatura vperspektivách genderu. IV. kongres svètové literárnèvédné bohemistiky, Praha, 45-56. 
Deutschmann, P. 2011. „Zasněná současnost - Zeyerova historická dramata“, Kudrnáč, J. (Hrsg.), Julius Zeyer, lumirovský básnik v duchovnim dèní Evropy, Brno, 205-218.

Dieckmann, J. 2004. Luhmann-Lehrbuch, München.

Dobiáš, D. 2014. „Mezi Rukopisem královédvorským a zelenohorským (1817-1829)“, Dobiáš, D. et al. (Hrsg.), Rukopisy královédvorský a zelenohorský a česká véda (1817-1885), Praha, $17-62$.

Dobiáš, D.; Novák, M. 2014. „Spor o roli Rukopisů královédvorského a zelenohorského v diskursu národa (1829-1840)“, Dobiáš, D. et al. (Hrsg.), Rukopisy královédvorský a zelenohorský a česká véda (1817-1885), Praha, 63-96.

Dolanský, J. 1972. „Dvě varianty Záboje z RK“, Česká literatura, 20, 328-345.

Doležel, L. 1998. Heterocosmica. Fictional and Possible Worlds, Baltimore and London.

Drábek, P. 2012. Česképokusy o Shakespeara. Dějiny českých prekladů Shakespeara doplnèné antologii neznámých a vzácných textů z let 1782-1922, Praha.

Gellner, E. 1996. Nationalismus in Osteuropa, Wien.

Düsing, W. 1998. „Einleitung. Zur Gattung Geschichtsdrama“, Düsing, W. (Hrsg.), Aspekte des Geschichtsdramas. Von Aischylos bis Volker Braun, Tübingen, Basel, 1-10.

Dvorský, J. 1985. „Zahájení [symposia Divadlo v české kultuře 19. století, 10.-12. března 1983]“, Freimanová, M. (Hrsg.), Divadlo v české kultuře 19. století. Sbornik symposia v Plzni, 10.-12. brezna 1983, Praha.

Eco, U. 1977. Das offene Kunstwerk [Orig. 1962], Frankfurt/M.

Engels, F. 1856. „Brief an Karl Marx, 7. März 1856“, Marx, K.; Engels, F., Historisch-kritische Gesamtausgabe. III/2. Der Briefwechsel zwischen Marx und Engels 1854-1860, Berlin 1930, $121-122$.

Fajfr, F. 1934. „Hegel bei den Čechen“ [Orig. 1961], Tschiževkij, D. (Hrsg.), Hegel bei den Slaven, Bad Homburg, 413-459.

Fischer-Lichte, E. 1990. Geschichte des Dramas. Epochen der Identität auf dem Theater von der Antike bis zur Gegenwart. Band 1: Von der Antike bis zur deutschen Klassik, Tübingen.

Fischer, O. 1919. Kdramatu, Praha.

Freise, M. 1993. Michail Bachtins philosophische Ästhetik der Literatur, Frankfurt/M. u.a.

Frič, J. V. 1879. „Přípisek“, Frič, J. V. (Hrsg.), Svatopluk a Rastislav. Truchlohra v pateru dějstvích z dèjin moravských, Praha, 139-146.

Fuchs, P. 1992a. Die Erreichbarkeit der Gesellschaft. Zur Konstruktion und Imagination gesellschaftlicher Einheit, Frankfurt/M.

Fuchs, P. 1992b. „Die moderne Beobachtung kommunikativer Ereignisse: Eine heuristische Vorbereitung“, Balke, F.; Méchoulan, E.; Wagner, B. (Hrsg.), Zeit des Ereignisses - Ende der Geschichte?, München, 111-128.

Gellner, E. 1996. Nationalismus in Osteuropa, Wien.

Goethe, J. W. v.; Schiller, F. 1999. „Über epische und dramatische Dichtung“ [Orig. 1827], Profitlich, U. (Hrsg.), Tragödientheorien. Texte und Kommentare. Vom Barock bis zur Gegenwart, Reinbek, 108-110.

Grob, T. 2005. „Der innere Orient. Mazeppas Ritt durch die Steppe als Passage zum Anderen Europas", Wiener Slawistischer Almanach, 56, 33-86.

Grob, T. 2008. „Mazepa' as a symbolic figure of Ukrainian autonomy“, Wöll, A.; Wydra, H. (Hrsg.), Democracy and Myth in Russia and Eastern Europe, London, New York, 79-97.

Grübel, R. 1979. „Zur Ästhetik des Wortes bei Michail M. Bachtin“, Grübel, R. (Hrsg.), Michail M. Bachtin: Die Ästhetik des Wortes, Frankfurt/M., 29-88. 
Grübel, R. 2001. Literaturaxiologie. Zur Theorie und Geschichte des ästhetischen Wertes in den slavischen Literaturen, Wiesbaden.

Hájek, J. 1951. „Tylova historická dramata z revolučních let 1847-48“, Jedlička, A. (Hrsg.), Jan Hus. Kutnohorští havirí, Praha, 203-208.

Halbwachs, M. 1985. Das Gedächtnis und seine sozialen Bedingungen [Orig. 1925], Frankfurt/M. Haman, A. 2007. Trváni v promènè. Česká literatura devatenáctého století, Praha.

Hampl, F. 1942. „Životem i tvorbou Ladislava Stroupežnického“, Ladislav Stroupežnický: Mikuláš Dačický z Heslova, Treebechovice pod Orebem, 147-178.

Han, B.-C. 2005. Was ist Macht?, Stuttgart.

Hansen-Löve, A. A. 1978. Der russische Formalismus. Methodologische Rekonstruktion seiner Entwicklung aus dem Prinzip der Verfremdung, Wien.

Haverkamp, A.; Menke, B. 2000. „Allegorie“, Barck, K. et al. (Hrsg.), Ästhetische Grundbegriffe. Historisches Wörterbuch in sieben Bänden, Stuttgart, Weimar, 49-104.

Hegel, G. W. F. 1970a. Grundlinien der Philosophie des Rechts [Orig. 1821] (=Werke in 20 Bänden. VII.), Frankfurt/M.

Hegel, G. W. F. 1970b. Phänomenologie des Geistes [Orig. 1807] (=Werke in 20 Bänden. III.), Frankfurt/M.

Hegel, G. W. F. 1970c. Vorlesungen über die Ästhetik I (=Werke in 20 Bänden. XIII.), Frankfurt/M.

Hegel, G. W. F. 1970d. Vorlesungen über die Ästhetik III (=Werke in 20 Bänden. XV.), Frankfurt/M.

Hegel, G. W. F. 1970e. Vorlesungen über die Philosophie der Geschichte (=Werke in 20 Bänden. XII.), Frankfurt/M.

Hejl, P. M. 1996. „Wie Gesellschaften Erfahrungen machen oder Was Gesellschaftstheorie zum Verständnis des Gedächtnisproblems beitragen kann“, Schmidt, S. J. (Hrsg.), Gedächtnis: Probleme und Perspektiven der interdisziplinären Gedächtnisforschung, 900, Frankfurt/M., 293-336.

Hilbert, J. 1941. „O dramatu. Přednáška laikům“ [Orig. 1914], ders., Duch dramatiky, Praha.

Hlavačka, M. 2005. „Formování české novověké společnosti a její interpreti. Úvahy o české historiografii 19. století a o koncepci českých dějin první poloviny 19. století a jejím naplnění, Vyčichlo, J.; Viktora, V. (Hrsg.), Jeden jazyk naše heslo bud'III. Divadlo národního obrození a jeho souvislosti, Radnice, Plzeň, 9-21.

Hobsbawm, E. 1991. Nationen und Nationalismus: Mythos und Realität seit 1780 [Orig. 1990], Frankfurt, New York.

Höhne, S. 2000. „Die literarische Instrumentalisierung der böhmischen Geschichte im Vormärz. Hus und die Hussiten“, Ehlers, K.-H. et al. (Hrsg.), Brücken nach Prag. Deutschsprachige Literatur im kulturellen Kontext der Donaumonarchie und der Tschechoslowakei, Frankfurt/M. u.a., $43-80$.

Höhne, S. 2008. „König Přemysl Ottokar II. Literarische Konstruktionen von Geschichte am Beispiel Böhmens“, brücken. Germanistisches Jahrbuch, NF 16, (1-2), 37-71.

Hoensch, J. K. 1992. Geschichte Böhmens. Von der slavischen Landnabme bis ins 20. Jabrhundert, München.

Hrabák, J.; Jeřábek, D.; Tichá, Z. 1976. Prưvodce po dějinách české literatury, Praha.

Hroch, M. 1999. Na prahu národni existence, Praha.

Hroch, M. 2005. Das Europa der Nationen. Die moderne Nationsbildung im europäischen Vergleich, Göttingen. 
Huizinga, J. 1956. Homo ludens. Vom Ursprung der Kultur im Spiel [Orig. 1938], Reinbek.

Hüttmann, A. 2001. Die Ästhetik der Geschichte. Das zeitgenossische historische Drama Spaniens im Spannungsfeld zwischen Sinn und Spiel, Tübingen, Basel.

Iser, W. 1989. Prospecting: from reader response to literary anthropology, Baltimore, London.

Jahn, M. 1998. „Package Deals, Exklusionen, Randzonen: das Phänomen der Unzuverläßlichkeit in den Erzählsituationen“, Nünning, A. (Hrsg.), Unreliable Narration. Studien zur Theorie und Praxis unglaubwürdigen Erzählens in der englischsprachigen Erzählliteratur, Trier, 83106.

Jakobson, R. 1960. „Closing Statement: Linguistics and Poetics“, Sebeok, T. (Hrsg.), Style in Language, Cambridge/Mass., 350-377.

Jakubcová, A. 2013. „Domácí autoři“, Ludvová, J.; al., e. (Hrsg.), Pražský divadelní almanach: 230 let Stavovského divadla, Praha, 19-23.

Jakubcová, A.; Pernerstorfer, M. J. (Hrsg.) 2013. Theater in Böhmen, Mähren und Schlesien. Von den Anfängen bis zum Ausgang des 18. Jahrhunderts. Ein Lexikon, Wien.

Janoušek, P. 1989. Rozméry dramatu: autorský subjekt a vývojové promény poetiky českého meziválećného dramatu, Praha.

Janský, K. 1948. „Poznámky“, ders. (Hrsg.), Dílo Karla Hynka Máchy. Sv. 1. Básnè. Dramatické zlomky, Praha.

Ježková, P. 2013a. „Jan Nepomuk Štěpánek“, Ludvová, J.; al., e. (Hrsg.), Pražský divadelni almanach: 230 let Stavovského divadla, Praha, 52-56.

Ježková, P. 2013b. „Josef Jiří Kolár“, Ludvová, J.; al., e. (Hrsg.), Pražský divadelni almanach: 230 let Stavovského divadla, Praha, 90-94.

Ježková, P. 2013c. „Josef Kajetán Tyl a myšlenka národního divadla“, Ludvová, J.; al., e. (Hrsg.), Pražský divadelni almanach: 230 let Stavovského divadla, Praha, 76-79.

Ježková, P.; Ludvová, J. 2013. „Ředitel Hoffmann, dramaturg Tyl, revoluce a česká scéna“, Ludvová, J.; al., e. (Hrsg.), Pražský divadelni almanach: 230 let Stavovského divadla, Praha, 80-82.

Jungmann, J. 1820. Slovesnost aneb sbirka príkladi s krátkým pojednáni o slohu, Praha.

Jungmann, J. 1846. Slovesnost aneb Nauka o výmluvnosti básnické i rečnické se sbirkou príkladù vázané a nevázané réri, Praha.

Justl, V. 1960. Václav Kliment Klicpera, Praha.

Kačer, M. 1969. „Počátky českého měštanského divadla (1785-1812)“, Černý, F. (Hrsg.), Déjiny českého divadla II. Národní obrození, Praha, 11-97.

Kantorowicz, E. 1957. The King's Two bodies. A Study in Medieval Political Theology, Princeton.

Kindermann, H. 1966. Theatergeschichte Europas. Band I. Das Theater der Antike und des Mittelalters, Salzburg.

Klosová, L. 1977a. „Pozdní romantismus na profesionálním divadle v období státoprávních bojů a politické stagnace českého měštanstva (1862-1886)“, Černý, F.; Klosová, L. (Hrsg.), Déjiny českého divadla III. Cinohra 1848-1918, Praha, 45-175.

Klosová, L. 1977b. „Proměny romantického divadla za buržoazně demokratické revoluce a za bachovské reakce (1848-1861)“, Černý, F.; Klosová, L. (Hrsg.), Déjiny českého divadla III. Činohra 1848-1918, Praha, 13-45.

Klotz, V. 1969. Geschlossene und offene Form im Drama, München.

Knap, J. 1926. Hilbert. Přpad české dramatiky, Moravský Krumlov.

Koselleck, R.; Stempel, W.-D. (Hrsg.) 1973 Geschichte - Ereignis und Erzählung, München.

Král, J. 1992a. „Falkenštejn, hra o pěti dějstvích od Jaroslava Hilberta“, Jaroslav Hilbert: Falkenštejn [Programmbuch], Praha, 7-11. 
Král, J. 1992b. Jaroslav Hilbert: Falkenštejn. Hra o pèti dějstvích. [Programmbuch], Praha.

Ksandr, K. 2009. Josef Zitek architekt, pedagog a památkár, Praha.

Kutnar, F.; Marek, J. 1997. Přehledné dèjiny českého a slovenského dèjepisectvi. Od počátku národni kultury až do sklonku tríicátých let 20. století, Praha.

Laiske, M. 1974. Pražská dramaturgie I-II. Česká divadelni predstavení v Praze do otevreni Prozatímniho divadla. Díl I 1762/?/-1843, Díl II 1844-1862, Praha.

Lamping, D.; Poppe, S. (Hrsg.) 2009 Handbuch der literarischen Gattungen, Stuttgart.

Lauer, R. 2000. Russische Literatur. Von 1700 bis zur Gegenwart, München.

Lehmann, H.-T. 2013. Tragödie und dramatisches Theater, Berlin.

Lindenberger, H. 1975. Historical Drama. The Relation of Literature and Reality, Chicago, London.

Lom, S. 1942. Svèt na divadle a kolem něho. Záznamy a námèty, Praha.

Lotman, J. M. 1972. Die Struktur literarischer Texte [Orig. 1970], München.

Lotman, J. M.; Uspenskij, B. A. 1986. „Zum semiotischen Mechanismus der Kultur“ [Orig. 1971], Eimermacher, K. (Hrsg.), Semiotica Sovietica 2. Sowjetische Arbeiten der Moskauer und Tartuer Schule zu sekundären modellbildenden Zeichensystemen (1962-1973). Aachen, 853-880.

Loužil, J. 1978. „Bernard Bolzano a rukopisy. Josef Linda“, Česká literatura, 26 (3), 220-234.

Luhmann, N. 2002. Einführung in die Systemtheorie [Orig. 2009], Heidelberg.

Lukács, G. 1965. Der historische Roman [Orig. 1937], Neuwied, Berlin.

Mácha, K. H. 1959. Básné a dramatické zlomky, Praha.

Máchal, J. 1903. „Josef Kajetán Tyl a Prokop Chocholoušek“, Literatura česká devatenáctého století II, Praha, 757-795.

Macura, V. 1983. Znameni zrodu. České národni obrozeníjako kulturni typ, Praha.

Macura, V. 1995. Znameni zrodu. České národni obrození jako kulturni typ, Jinočany.

Macura, V. 1998. Český sen, Praha.

Marinelli-König, G. 2011. Die Böhmischen Länder in den Wiener Zeitschriften des Vormärz (1805-1848). Teil I, Wien.

Martinez, M.; Scheffel, M. 1999. Einführung in die Erzähltheorie, München.

Mašek, P.; Hajšman, V. 2013. „Franz Anton Graf von Nostitz-Rieneck“, Jakubcová, A.; Pernerstorfer, M. J. (Hrsg.), Theater in Böhmen, Mähren und Schlesien. Von den Anfängen bis zum Ausgang des 18. Jahrhunderts. Ein Lexikon, Wien, 489-491.

McCord, O. A. 1993. Nationalism and its expression in architecture: The Czech National Theater and its legacy, Ann Arbor.

Meier, C. 1988. Die politische Kunst der griechischen Tragödie, München.

Menke, B. 2010. Das Trauerspiel-Buch. Der Souverän - das Trauerspiel - Konstellationen - Ruinen, Bielefeld.

Menke, C. 1996. Tragödie im Sittlichen. Gerechtigkeit und Freiheit nach Hegel, Frankfurt/M.

Mezník, J. 1969. „Rukopisy z hlediska historie“, Otruba, M. (Hrsg.), Rukopisy královédvorský a zelenohorský. Dnešni stav poznáni, Praha, 147-178.

Mikovec, F. B. 2010. Pražská Thálie kolem 1850, Praha.

Neubuhr, E. 1980. „Einleitung“, dies. (Hrsg.), Geschichtsdrama, Darmstadt, 1-39.

Neuhäuser, R. 1986. „Puschkin: Boris Godunow“, Zelinsky, B. (Hrsg.), Das russische Drama, Düsseldorf, 51-68.

Novák, A.; Novák, J. V. 1936-1939. Přehledné dějiny literatury české od nejstaršich dob až po naše dny, Olomouc. 
Nünning, A. 1995. Von historischer Fiktion zu historiographischer Metafiktion. Band 1. Theorie, Typologie und Poetik des historischen Romans, Trier.

Obst, M. 1977. „Profesionální divadlo na sklonku rakousko-uherské monarchie (1896-1918)“, Černý, F. (Hrsg.), Déjiny českého divadla III. Činohra 1848-1918, Praha, 282-450.

Obst, M. 1983. „Činoherní divadlo od vzniku Československa do počátku hospodářské krize (1918-1929)“, Černý, F. (Hrsg.), Déjiny českého divadla IV. Činoherní divadlo v Československé republice a za nacistické okupace, Praha, 13-206.

Osolsobě, I. 1993. „Tylova a Škroupova ,operetta aperta - Fidlovačka“, Černý, F. (Hrsg.), Monology o Josefu Kajetánu Tylovi, Praha, 85-113.

Otruba, M.; Kačer, M. 1961. Tvưrč́ cesta Josefa Kajetána Tyla, Praha.

Ottuiv slovnik naučný, Praha 1900.

Palacký, F. 1939. Déjiny národu českého v Čechách a v Moravě. III. Od roku 1403 do roku 1431. [Orig. 1850], Praha.

Papoušek, V. a kolektiv 2010. Déjiny nové moderny. Česká literatura v letech 1905-1923, Praha.

Peřina, J. 2005. „Bouda - vlastenecká scéna Čechů a českých Němcü“, Vyčichlo, J.; Viktora, V. (Hrsg.), Jeden jazyk naše heslo bud'III : Divadlo národního obrození a jeho souvislosti, Radnice, Plzeň, 45-51.

Petrbok, V. 2010. „Kdo byl Ferdinand Břetislav Mikovec?“, Mikovec, F. B. (Hrsg.), Pražská Thálie kolem 1850, Praha, 5-53.

Pfister, M. 2001. Das Drama. Theorie und Analyse [Orig. 1988], München.

Pillau, H. 1981. Die fortgedachte Dissonanz. Hegels Tragödientheorie und Schillers Tragödie. Deutsche Antworten auf die Französische Revolution, München.

Píša, A. M. 1967. Stopami dramatu a divadla, Praha.

Píša, P. 2011. „Dvojí role cenzury při konstituování národního vědomí“, Heeg, D. (Hrsg.), $m^{*}$ OST. Österreichische Studierendentagung für SlawistInnen, München, Berlin, 179-184.

Píša, P. 2015. „V zájmu nevzdělaného čtenáŕe. Literární cenzura v době restaurace a rozmachu národního hnutí", Wögerbauer, M. et al. (Hrsg.), Vobecném zájmu. Cenzura a sociálni regulace literatury v moderni ćeské kultuŕe 1749-2014. Svazek 1: 1749-1938, Praha, 221-285.

Placák, P. 2002. Svatováclavské milenium. Češi, Němci a Slováci v roce 1929, Praha.

Pohorský, M. 1961. „Rozvoj demokratické literatury“, Pohorský, M. (Hrsg.), Dějiny české literatury. Literatura drubépoloviny devatenáctého století, III, Praha, 17-188.

Pokorná, M. 2015. „Část třetí. V zájmu svobody a řádu. Literární cenzura v revoluci a neoabsolutismu“, Wögerbauer, M. et al. (Hrsg.), V obecném zájmu. Cenzura a sociální regulace literatury $v$ moderní české kulture 1749-2014. Svazek 1: 1749-1938, Praha, 345-420.

Posner, R. A. 1998. Law and Literature, Cambridge, Mass. and London.

Procházka, M. 2011. „Shakespeare, Mácha a český romantický historismus“, Piorecký, K. (Hrsg.), Máchovské rezonance. IV. kongres svètové literárnèvédné bohemistiky, Praha, 85-95.

Procházka, V. 1969. „České divadlo na sklonku napoleonských válek a za utužení feudální reakce“, Černý, F. (Hrsg.), Dějiny českého divadla II. Národni obrození, Praha, 98-197.

Procházka, V. et al. (Hrsg.) 1988. Národní divadlo a jeho predchůdci. Slovník umélcu divadel Vlastenského, Stavouského, Prozatímního a Národního, Praha.

Puchner, W. 1994. Historisches Drama und gesellschaftskritische Komödie in den Ländern Südosteuropas im 19. Jahrbundert, Frankfurt/M.

Pulicarová, I. 2005. „Svatý Václav jako dramatický hrdina“, Teologie \& Společnost, (6), 5-10.

Pulicarová, I. 2006. Postava svatého Václava v českém dramatu 19. a 20. století, Dipl. práce, Karlova univerzita, Katedra divadelní vědy, Praha. 
Pynsent, R. B. 1999. „Die Dalimil-Chronik als polymythischer Text (Dalimil - Fichte - Havel)“, Behring, E.; Richter, L.; Schwarz, W. F. (Hrsg.), Geschichtliche Mythen in den Literaturen und Kulturen Ostmittel-und Südosteuropas, 6, Stuttgart, 199-231.

Rak, J. 1994. Bývali Čechové. České historické mýty a stereotypy, Jinočany.

Reitz, B. 2009. „Historisches Drama“, Lamping, D.; Poppe, S. (Hrsg.), Handbuch der literarischen Gattungen, Stuttgart, 370-379.

Revzina, O. G. 1994/95. „Ein systematisch-funktionaler Zugang zur linguistischen Poetik. Teil I:

Die dichterische und die prosaische Redeform", Znakolog, 6/7, 141-162.

Rezníková, L. 2004. Moderna \& Historismus. Historické reprezentace v proménách literatury na prelomu devatenáctého a dvacátého století, Praha.

Sajíc, J. 1942. „»Otec novověké Thalie české«“, Brousil, A. M. (Hrsg.), Od Klicpery k Stroupežnickému. Studie historické, dramaturgické a kritické, Praha, 15-38.

Schadewaldt, W. 1991. Die griechische Tragödie. Tübinger Vorlesungen IV, Frankfurt/M.

Schamschula, W. 1990. Geschichte der tschechischen Literatur. Bd I Von den Anfängen bis zur Aufklärungszeit, Köln, Wien.

Schamschula, W. 1996. Geschichte der tschechischen Literatur. Bd II Von der Romantik bis zum Ersten Weltkrieg, Köln, Weimar, Wien.

Schiller, F. 1962. „Über die tragische Kunst“ [Orig. 1792], Schillers Werke Nationalausgabe, 20, Weimar, 148-170.

Schiller, F. 2005. „Was kann eine gute stehende Schaubühne eigentlich wirken?“, Sämtliche Werke. Berliner Ausgabe Bd 8. Philosophische Schriften, Berlin, 84-97.

Schlegel, A. W. 1966. Vorlesungen über dramatische Kunst und Literatur. Erster Teil [Orig. 1809], Stuttgart, Berlin, Köln, Mainz.

Schlegel, A. W. 1967. Vorlesungen über dramatische Kunst und Literatur. Zweiter Teil [Orig. 1811], Stuttgart, Berlin, Köln, Mainz.

Schmid, H. 1992. „Bachtins Dialogizitätstheorie im Spiegel der dramatisch-theatralischen Gattungen", Schmid, H.; Striedter, J. (Hrsg.), Dramatische und theatralische Kommunikation. Beiträge zur Geschichte und Theorie des Dramas und Theaters im 20. Jahrhundert, Tübingen, 36-90.

Schmid, H. 2006. „Jaroslav Vrchlickýs ,historische Dramen im Streit zwischen Nationalismus und Kosmopolitismus“, Tureček, D.; Zajac, P. (Hrsg.), Mezi texty a metodami. Národní a univerzálni v čské literature 19. století, Olomouc, 287-322.

Schmid, W. 1984. „Bachtins Dialogizität - eine Metapher“ [Orig. 1984], Wilhelmi, B.; Hilbert, H.G. (Hrsg.), Roman und Gesellschaft. Internationales Michail Bachtin-Colloquium, Jena, 70-77.

Schmid, W. 2008. Elemente der Narratologie, Berlin.

Schmidt, S. J. (Hrsg.) 1996a. Gedächtnis: Probleme und Perspektiven der interdisziplinären Gedächtnisforschung, Frankfurt/M.

Schmidt, S. J. 1996b. „Gedächtnisforschungen: Positionen, Probleme, Perspektiven“, ders., Gedächtnis: Probleme und Perspektiven der interdisziplinären Gedächtnisforschung, 900, Frankfurt/M., 9-55.

Schmitz, W.; Udolph, L. (Hrsg.) 2001. »Tripolis Praga«. Die Prager Moderne um 1900. Katalogbuch, Dresden.

Schramm, H. 1990. „Theatralität und Öffentlichkeit. Vorstudien zur Begriffsgeschichte von »Theater «", Weimarer Beiträge, 1990, (2), 223-239.

Schulz, F. 188?. „Život a spisy Vítězslava Hálka“, ders., Vybrané spisy Vitězslava Hálka, Praha, 238-319. 
Seeck, G. A. 2000. Die griechische Tragödie, Stuttgart.

Sengle, F. 1969. Das historische Drama in Deutschland. Geschichte eines literarischen Mythos [Orig. 1952], Stuttgart.

Soukup, D. 2005. „Postava Zatrána v Lindově Jaroslavu Šternbergovi (Památce Prof. A. Sticha)“, Vyčichlo, J.; Viktora, V. (Hrsg.), Jeden jazyk naše heslo bud'III. Divadlo národního obrození a jeho souvislosti, Radnice, Plzeň, 85-89.

Štěpán, V. 2006. „Historický přehled“, Štěpán, V.; Trávníčková, M. (Hrsg.), Prozatímní divadlo 1862-1883, Praha, 11-24.

Štěpán, V.; Trávníčková, M. (Hrsg.)2006 Prozatímni divadlo 1862-1883, Praha.

Štěpánek, V. 1957. „Doslov [k sedmnáctému svazku Spisů Josefa Kajetána Tyla]“, Spisy Josefa Kajetána Tyla, 17, Praha, 461-478.

Štěpánek, V. 1959. Počátky velkého národního dramatu v obrozenské literatuře, Praha.

Štěpánek, V. 1988. Z dějin obrozenské literatury, Praha.

Stich, A. 1993. „Ještě k Máchovi: Velký a silný protivník J.K. Tyl“, Černý, F. (Hrsg.), Monology o Josefu Kajetánu Tylovi, Praha, 65-73.

Stierle, K. 1973. „Geschehen, Geschichte, Text der Geschichte“, Koselleck, R.; Stempel, W.-D. (Hrsg.), Geschichte - Ereignis und Erzählung, München, 530-534.

Strejček, F. 1932. Tylovo drama životni. K 75. výroči básnikovy smrti, Praha.

Stř́ibrný, D. 1908. „Historická dramata J. Vrchlického o látkách českých“, Třetí výroční zpráva c.k. státní čské reálky v Táboŕe za školni rok 1908-1909, 3-23.

Strúbrný, D. 1909. „Historická dramata J. Vrchlického o látkách českých“, Čtvrtá výroční zpráva c.k. státni české reálky v Táboŕe za školni rok 1908-1909, 3-22.

Szondi, P. 1978. „Theorie des modernen Dramas“, ders., Schriften I, Frankfurt/M., 11-148.

Taylor, C. 1978. Hegel [Orig. 1975], Frankfurt/M.

Tetzeli von Rosador, K. 1976. Das englische Geschichtsdrama seit Shaw, Heidelberg.

Ther, P. 2006. In der Mitte der Gesellschaft. Operntheater in Zentraleuropa 1815-1914, Wien, München.

Tökei, É. 2006. „Nationaltheater und Aktualpolitik“, Kakanien revisited, (23. 5. 2006), 1-6. $<w w w . k a k a n i e n . a c . a t / b e i t r / e m e r g / E T o k e i 1 . p d f>$ [zuletzt am 2. 2. 2012]

Topolová, B. 1996. České obrozenecké a poobrozenecké drama, Diss., Karlova univerzita, Katedra divadelní vědy, Praha.

Tschopp, S. S. 2002. „Inszenierte Geschichte. Der Zusammenhang zwischen Dramenform und Geschichtsauffassung als theoretisches und praktisches Problem im 19. Jahrhundert", Fulda, D.; Tschopp, S. S. (Hrsg.), Literatur und Geschichte. Ein Kompendium zu ibrem Verhältnis von der Aufklärung bis zur Gegenwart, Berlin, New York, 367-389.

Tureček, D. 2001. Rozporuplná sounáležitost. Némeckojazyčné kontexty obrozenského dramatu, Praha.

Tureček, D. 2007. „Tylovi Kutnohorští havírii: způsoby existence v rámci kánonu národní kultury“, Vostrý, J.; Sílová, Z. (Hrsg.), Josef Kajetán Tyl 1808 - 1856 - 2006 - 2008, 5, Praha, $51-58$.

Uffelmann, D. 2008. „Palackýs ,Dekonstruktion` Mitteleuropas“, Ressel, G.; Stahl, H. (Hrsg.), Die Slaven und Europa, 8, Frankfurt/M., 345-370.

Urban, O. 1982. Česká společnost 1848-1918, Praha.

Veltruský, J. 1999. Drama jako básnické dílo [Orig. 1942], Brno.

Vlašínová, D. 2003. Julius Zeyer. Dramatik, Brno.

Vlček, R. 2006. „Panslavismus či rusofilství? Pět tezí k otázce reflexe slovanství a panslavismu českou společností 19. století“, Hojda, Z.; Ottlová, M.; Prahl, R. (Hrsg.), „Slavme slavně slávu 
Slávóv slavných". Slovanstvi a česká kultura 19. století. Sbornik prìispèvkio z 25. ročniku symposia k problematice 19. století, Plzeñ 24.-26. února 2005, Praha, 9-20.

Vodička, F. 1937. „Mácha jako dramatik“, Novák, A. (Hrsg.), Karel Hynek Mácha. Osobnost, dílo, oblas, Praha, 133-141.

Vodička, F. 1960a. „Základy obrozenské literatury (Od sedmdesátých let 18. století do roku 1805)“, Dějiny české literatury II. Literatura národního obrození, Praha.

Vodička, F. 1960b. „Zrod obrozenské ideologie v literatuře (1806-1830)“, Déjiny české literatury II. Literatura národního obrození, Praha, 123-281.

Vološinov, V. N. 1975. Marxismus und Sprachphilosophie. Grundlegende Probleme der soziologischen Methode in der Sprachwissenschaft [Orig. 1929], Frankfurt/M., Wien.

Vondráček, J. 1956. Déjiny českého divadla. Doba obrozenská 1771-1824, Praha.

Vondráček, J. 1957. Déjiny českého divadla. Doba prèedbřeznová 1824-1846, Praha.

Weinrich, H. 1973. „Narrative Strukturen in der Geschichtsschreibung“, Koselleck, R.; Stempel, W.-D. (Hrsg.), Geschichte - Ereignis und Erzählung, München, 519-522.

Wellek, R. 1963. „The Two Traditions of Czech Literature“, ders., Essays on Czech Literature, The Hague, 17-31.

Wellek, R. 1980. "Bakhtin's View of Dostoevskij. 'Polyphony' and 'Carnivalesque”, Dostoevskij Studies, 1, 31-39.

Werber, N. 2003. „Repräsentation/repräsentativ“, Barck, K. (Hrsg.), Ästhetische Grundbegriffe, 5 (Postmoderne-Synästhesie), Stuttgart, 264-290.

Werner, G. 1986. „Dionysien“, Träger, C. (Hrsg.), Wörterbuch der Literaturwissenschaft, Leipzig, 108.

White, H. 1973. Meta-History. The historical imagination in nineteenth-century Europe, Baltimore/London.

Wiendl, J. 2010. „1912: Rok sporů, úniků, vizí a katastrof“, Papoušek, V. a kolektiv, Dějiny nové moderny. Ceská literatura v letech 1905-1923, Praha, 191-211.

Wögerbauer, M. 2015. „Část první. 1749-1810. V zájmu rozumu a spásy duše. Literární cenzura mezi protireformací a osvícenstvím“, Wögerbauer, M. et al. (Hrsg.), Vobecném zájmu. Cenzura a sociálni regulace literatury v moderni české kultuŕe 1749-2014. Svazek 1: 1749-1938, Praha, 61-164.

Wögerbauer, M. et al. 2015. V obecném zájmu. Cenzura a sociálni regulace literatury v moderni české kulture 1749-2014. Svazek 1: 1749-1938, Praha.

Žákavec, F. 1918. Chrám znovuzrozeni. O budovatelich a budově Národního divadla v Praze, Praha.

Zeyer, J. 1896. „[Vorwort zu Neklan]“, Spisy Julia Zeyer, Svazek XXVII. Dramatická díla III, Praha, 5-7.

Zimmerhaklová, H. 2005. Stavovské divadlo v letech 1783-1861, Dipl. práce, Karlova univerzita, Katedra divadelní vědy, Praha.

Živý odkaz J.K. Tyla. Sbornik materiálů z konference československých divadelniků o dédictví J.K. Tyla na Dobriši 12.VI.1951, Praha 1952.

Zprávy 1860. Zprávy soudců o dramatech $z$ dějin slovanských, ježto $k$ dosaženi premie, Pražským městanem, panem Ferdinandem Fingerhutem ustanovené, v letech 1859 a 1860 byly zaslány, Praha. 


\section{Namens- und Werkregister}

A

Adam z Veleslavína, Daniel 126

Aischylos 67

Die Perser 120

Alfieri, Vittorio 175

Anderson, Benedict 102

Ankersmit, Frank R. 42-44, 430

Aristoteles 38f, 54, 108, 121

Artaud, Antonin 51

Asmuth, Bernhard 38, 48, 121

Assmann, Jan 18, 26-32, 71, 457

\section{B}

Bach, Alexander von 246

Bachtin, Michail M. 76-80, 83, 85-95, 97f, 100, 106

Bartoš, Jaroslav 135, 140, 156

Bäuerle, Adolf 136 Alína aneb Praha v jiném dilu svèta 136

Benjamin, Walter 18, 52-54, 56, 123, 337, 424, 457

Berwanger, Katrin $376 f$

Beust, Friedrich Ferdinand Graf von 292

Borová, Vladimíra 144, 324, 353, 436

Borst, Arno 48

Bozděch, Emanuel 19, 431

Baron Goertz 19, 289-295, 428, 431,435

Brabec, Jiř́ $5,358,392$

Brachvogel, Albert E. 208

Narziß 208

Bugge, Peter $125 \mathrm{f}$

Burget, Eduard 341, 396

Burka, Antonín 193

Buzková, Pavla 16, 456

Byron, George G. B., Baron 201, 281

C

Calderón de la Barca, Pedro 175

Camus, Albert 90

Carlson, Marvin 86

Čechov, Anton P. $80 f$

Čelakovský, František L. 41, 136f, 147, 154, 156
Černý, František 17, 130, 132-134, 138, 141, 143, 184, 188, 223f, 226, 235, 243 , 245,259

Chamfort, Nicolas 350

Chateaubriand, François-René de 128 Atala 128

Chauer, Josef 252, 260

Císař, Jan 16, 52, 131-133, 135, 137f, 138, $141,147,153,237-239,247-249,252$

Cobben, Paul 208

Corneille, Pierre 123, 175

D

Dačický z Heslova, Mikuláš 312

Dalimil $213 \mathrm{f}$

de Man, Paul 55

Derrida, Jacques 51

Deutschmann, Peter 93, 323, 376, 434

Dieckmann, Johann 122

Dobiáš, Dalibor $156 f$

Dobrovský, Josef 125, 174, 213

Dolanský, Julius 156

Doležel, Lubomír 93, 96,102

Dostoevskij, Fëdor M. 76-79, 87-91, $93 \mathrm{f}$

Drábek, Pavel 127, 155, 247

Drahotín Villani, Karel 201

Durych, Jaroslav 19, 397, 401, 404-406, 418, 420, 423f, 431, 436, 459

Svatý Václav. Kvas na Boleslavi 397-405, 428

Düsing, Wolfgang 35, 107

Dvořák, Arnošt 20, 330, 352, 358, 362-365, 431,445

Husité 358-365, 428

Král Václav IV. 20, 352-358, 428, 431

Dvořák, Antonín 316

Dvorský, Jan 19, 140, 373, 375, 379, 383, 422f, 425, 428, 430, 459

Drahomíra 383, 422, 428, 430

Dyk, Viktor 32, 47, 109, 330, 344, 346, 348f, 431, 435, 445

Revolučni trilogie (Ranni ropucha, Figaro, Poražení [auch Přemoženi]) 350-352, 428,431 
Posel 32, 109, 344-350, 428, 435,445

E

Eberhard, Johann A. 128

Ebert, Karl E. 186

Engels, Friedrich 110, 222, 226

Erben, Karel J. 260

Euripides 67

F

Fajfr, František 58

Fingerhut, Ferdinand siehe Náprstek, Ferdinand

Fischer, Otokar 41, 225, 293, 336-338, 340f, 437

Premyslovci 340f, 428, 437

Fischer-Lichte, Erika 119-121, 123

Franz I./II. 134, $145 f$

Franz Joseph I. 213, 250

Freise, Matthias 79f, 86, 88-90

Freud, Sigmund 63

Frič, Josef V. 20, 235, 244, 247, 252, 281, 285f, 289, 431, 434

Ivan Mazepa 20, 281-289, 428, 431

Svatopluk a Rastislav 252-258, 428, 434

Václav IV., král český 235

Fuchs, Peter 85, 103-106

G

Gebauer, Jan 296

Gellner, Ernest 191, $238 \mathrm{f}$

Goethe, Johann Wolfgang von 24, 127f,

175, 195, 201

Clavigo 201

Egmont 201

Faust I 201, 208

Götz von Berlichingen 201

Hermann und Dorothea 128

Iphigenie auf Tauris 195

Goll, Jaroslav 41

Grillparzer, Franz 338

König Ottokars Glück und Ende 338

Grob, Thomas 286, 288

Grübel, Rainer 86

Grünberger Handschrift siehe Hanka, Václav

\section{H}

Hájek, Jiří 215

Hájek z Libočan, Václav 18, 148, 236, 317, 322

Halbwachs, Maurice 28, 71

Hálek, Vítězslav 17, 19, 47, 110, 261, 263, 270, 274f, 278f, 329, 335, 338-340, 431, 435

Král Vukašin 17, 20, 270-275, 428, 431, 435, 446

Sergius Catilina 19, 275-280, 428, 435

Závišz Falkenštejna 261, 263-270, 330, 428, 435

Haman, Aleš 15, 29, 58, 126, 129, 134, 192, $214,245,247,293,380,431,434$

Hampl, František 312

Hanka, Václav 109, 156f, 214

Grünberger Handschrift 19, 31f, 109f,

156f, 214, 295

Königinhofer Handschrift 19, 31f, 109f, 137, 156f, 160-162, 186, 190, 214, 239, 295

Hansen-Löve, Aage A. 444

Hanuš, Ignác J. 58, 157

Haštalský, Vincenc Vávra 247

Hauptmann, Gerhart 146 Die Weber 146

Haverkamp, Anselm 54

Havlíček Borovský, Karel 139, 245

Hegel, Georg W. F. 17, 32, 36, 39, 41f, 56-74, 82, 108, 120, 185, 201, 208, 212, 242, 262, 335, 404, 430, 447, 456 Phänomenologie des Geistes 208, 404 Vorlesungen über die Ästhetik 32, 36, 42, 57, 59, 61-65, 67-72, 108, 183, 208, 242, 335, 430

Vorlesungen über die Geschichte der Philosophie 120

Hejl, Peter M. 27f, 30, 32-34

Herder, Johann G. 70, 126 Ideen zur Philosophie der Geschichte der Menschbeit 126

Hilar, Karel H. 358

Hilbert, Jaroslav 19f, 23f, 26, 30, 32, 143, 329-344, 414, 435, 445, 458

Česká komedie 342-344, 350, 428, 435

Falkenštejn 23f, 26, 30, 32, 329-343, 428, 435, 446

Psanci 330

Vina 330 
Hlavačka, Milan 125

Hněvkovský, Šebestián 19, 174-180,431, 434 Jaromír 174-179, 428, 431, 434

Hoensch, Jörg K. 125, 133, 148, 164, 231 , 329,337

Hoffmann, Johann 143

Höhne, Steffen 27, 145, 184, 338

Horaz 195

De arte poetica 195

Hostinský, Otakar $262 \mathrm{f}$

Hrabák, Josef 128

Hroch, Miroslav 58, 124f, 130, 133f, 138

Huizinga, Johan 119

Hüttmann, Andrea 41, 108

\section{I}

Iser, Wolfgang $36 \mathrm{f}$

Isidor z Lobkovic, Antonín 147

J

Jahn, Manfred 126

Jakobson, Roman 73

Jakubcová, Alena 131, 134

Janáček, Leoš 316

Janský, Karel 182

Janoušek, Pavel 438

Jeřábek, Dušan 128, 215

Ješín z Bezdězce, Pavel 214

Ježková, Petra 30, 138, 147, 186, 201, 215, 370

Jirásek, Alois 20, 29, 110, 133, 144, 235,

$324,327-329,344,358,435$

Gero 329

Jan Hus 144, 324, 431, 435

Jan Roháć 144, 324

Jan Žižka 144, 324-329, 358, 428

Kolébka 324

M.D. Rettigová 324

Joseph II. 124, 126, 132f, 139, 142, 145, 236

Jungmann, Josef 17, 30, 58, 125-132, 136,

138, 153-155, 164, 195, 240, 456

Dvojí rozmlouváni o jazyku českém 125

Slovesnost aneb Sbirka príkladu s krátkým

pojednánim o slohu 126-128, 130, 164, 195

$\mathbf{K}$

Kačer, Miroslav 142, 147, 186, 190f, 214f, 219 , 222-224, 226f, 231, 233, 366, 369-371
Kainz, Josef 136, 147

Kant, Immanuel 263

Kantorowicz, Ernst 267

Kindermann, Heinz 119-122

Klicpera, Václav K. 19, 135, 137f, 164, 168, 240f, 431, 434, 459

Sobèslav, selskýkniže 163-174,240f, 428, 431, 434

Klosová, Ljuba 184, 208, 210, 246, 258, $270,278,292-294,309,339$

Klotz, Volker 92, 112

Knap, Josef 200, 266, 330, 333f, 336, 338f, 344

Königinhofer Handschrift siehe Hanka, Václav

Kolár, Josef J. 19, 109f, 143, 200f, 230, 241 f, 245, 247, 249f, 261, 459

Císlo 76 anebo Praha pred sto lety 143

Monika 19, 109, 200-209, 241f, 428, 434

Primátor 434

Žižkova smrt 245

Kollár, Jan 200, 262, 301, 383

Slávy dcera 200

Konopásek, Prokop 156

Kosmas von Prag 148

Kotzebue, August von $137 \mathrm{f}$

Král, Jaroslav 24, 336

Kraus, Karl 39

Die letzten Tage der Menschheit 39

Kripke, Saul A. 44

Ksandr, Karel 250

Kutnar, František 213f, 324, 329

L

Laiske, Miroslav 15, 132, 134f, 244

Langer, František 19, 47, 385, 391f, 418, 420, 423, 425, 431, 459

Svatý Václav 385-392, 414, 418-420, 428

Lauer, Reinhard 70

Lehmann, Hans-Thies 7,39, 68

Lessing, Gotthold E. 127, 132, 145

Emilia Galotti 132, 145

Linda, Josef 19, 32, 109, 154f, 162, 164, 239-241, 288, 431, 434

Jaroslav Sternberg $v$ boji proti Tatarim 32, 109f, 154-164, 239, 241, 288, 428, 431,434 
Záre nad pohanstvem 156

Lindenberger, Herbert 26, 49, 64f, 123, 201, 430, 457

Lom, Stanislav 19, 113f, 406, 413f, 418-420, 424, 431, 436, 459

Svatý Václav 19, 406, 413-420, 424, 428, 431, 436

Lope de Vega, Félix 175

Lotman, Jurij M. 28, 46, 54f, 73, 119

Loužil, Jaromír 157

Ludvová, Jitka 30, 215, 370

Luhmann, Niklas 18, 104, 444, 457

Lukács, Georg 70, 74f, 82, 99, 108, 110, $211,226,334,430,444$

M

Mácha, Karel H. 47, 138, 149, 179, 182,

184f, 188, 190, 420

Bratrourah aneb Václav a Boleslav 184f, 420

Bratři 180, 183-185, 380, 383, 418, 422, 431

Máj 184, 190, 247

Macháček, Simeon K. 19, 137, 154, 195 ,

241, 330, 335, 338-340

Záviš Vitkovic, pán z Rưže anebo Pokuta zazradu 195, 241,330

Ženichové 137, 195

Máchal, Jan 215

Machar, Josef S. 329

Macura, Vladimír 125-127, 129, 131, 136, 148, 161f, 316

Marek, Antonín 58

Marek, Jaroslav 213f, 324, 329

Maria Theresia von Österreich 124

Marinelli-König, Gertraud 163, 186

Martinez, Matias 79, 93

Masaryk, Tomáš G. 32, 156, 296, 344, 349f, 365, 406

McCord, Olga A. 30, 140, 246, 250 f

McLuhan, Marshall 127

Meier, Christian 120-122

Menke, Bettine 52-54

Menke, Christoph 31, 60, 65-67

Metternich, Klemens Wenzel Lothar von 184

Metz, Christian 38

Mezník, Jaroslav $156 \mathrm{f}$

Mickiewicz, Adam 126, 184
Dziady 184

Konrad Wallenrod 184

Mikovec, Ferdinand B. 19, 180, 210, 213-215, 242, 260, 434, 438, 459

Zábuba rodu Přmyslovského 180 , 210-214, 242, 428, 434

Milton, John 128

Paradise Lost 128

Mozart, Wolfgang A. 132

Don Giovanni 132

La Clemenza di Tito 132

Mukařovský, Jan 243

Müller, Mikuláš 135

\section{$\mathbf{N}$}

Náprstek, Ferdinand [=Fingerhut,

Ferdinand] 17, 30, 35, 258-263, 317

Náprstek, Vojtěch 259

Nebeský, Jan 41

Nejedlý, Jan 125

Neruda, Jan $247 \mathrm{f}$

Nestroy, Johann 136

Der Affe und der Bräutigam 136

Neubuhr, Elfriede 15, 107, 122, 448

Neuhäuser, Rudolf 49

Nostitz-Rieneck, Franz Anton von 132

Novák, Arne 41, 156, 215

Nünning, Ansgar 41, 47

O

Obst, Milan 146, 329, 358

Osolsobě, Ivo 132

Otruba, Mojmír 142, 186, 190f, 214f, 219 , 222-224, 226f, 231, 233, 366, 369-371

$\mathbf{P}$

Palacký, František 18, 31, 41, 125, 128, 147 , $195,222,227,245,248,250,300,302$,

324, 327, 329, 430

Geschichte von Böhmen / Dějiny národu českého v Čechách a v Moravě 18, 31, 41, 300, 324, 327-329, 357

Počátkové českého básnictví, obzvláště

prosodie 128

Papoušek, Vladimír 364

Pasolini, Pier P. 38

Peisistratos 119 
Pekař, Josef 296

Peřina, Josef 133

Pernerstorfer, Matthias J. 131

Petrbok, Václav 210, 213

Pfister, Manfred 30, 56, 74, 81, 92, 97f, 106

Phrynichos 120

Die Einnahme von Milet 120

Phönikierinnen 120

Pillau, Helmut 62, 70

Píša, Antonín M. 23, 26, 143, 145

Píša, Petr 143f, 184, 324

Placák, Petr 436

Pohorský, Miloš 259

Pokorná, Magdaléna 143, 145, 213, 235, 245

Polawský, Ferdinand 136

Pölitz, Karl H. L. 128

Posner, Richard A. 63

Pražák, Albert 214

Preissová, Gabriela 19, 111, 406, 413, 424, 431, 436

Svatý Václav 19, 406-413, 424, 428, 431, 436

Procházka, Faustin 145

Procházka, Martin 183, 192

Procházka, Vladimír 135, 138, 140, 149, $153-156,163,237,244$

Puchmajer, Antonín J. 174

Puchner, Walter $15,27,455$

Pulicarová, Irena 366, 392, 420

Puškin, Aleksandr S. 49, 93, 281

Boris Godunov 49

Pynsent, Robert B. 214

$\mathbf{R}$

Racine, Jean Baptiste 123,175

Rak, Jiří 366, 368

Reitz, Bernhard 24, 26, 35

Revzina, Ol'ga G. 73

Řezníková, Lenka 329f, 445

Rieger, František L. 139, 248f, 258, 260, 373

Rudolf, Kronprinz von Österreich und

Ungarn 251

Ryleev, Kondratij F. 281

$S$

Sabina, Karel 180, 247, 249

Braniboriv Čechách 249
Sacher-Masoch, Leopold von 213, 246

Šafařík, Pavel J. 41, 128, 383

Poćátkové ceského básnictví, obzvláště prosodie 128

Sajíc, Jan 164

Šalda, František X. 41

Schamschula, Walter $31,41,126,162,174$

Scheffel, Michael 79,93

Schiller, Friedrich 24f, 39, 127f, 132f, 135,

145, 155, 175, 195, 201, 208, 293

Don Carlos, Infant von Spanien 145

Die Jungfrau von Orleans 195

Kabale und Liebe 135, 201

Maria Stuart 145

Die Räuber 132, 135, 145, 201, 208

Die Schaubühne als eine moralische An-

stalt betrachtet 133

Wallensteins Lager 201

Wilhelm Tell 201

Schlegel, August W. 30, 40, 49, 55, 64, 80, 122

Schmid, Herta 80f, 86, 95, 97f, 247, 263, 376

Schmid, Wolf 48,77-79,

Schmidt, Siegfried J. 27, 32

Schmitz, Walter 252

Schramm, Helmar 30, 124

Schulz, Josef 251, 263

Scribe, Eugène 310

Šebor, Karel 249

Šedivý, Prokop F. 16, 127, 133

Seeck, Gustav A. $119 f$

Sengle, Friedrich 107

Shakespeare, William 110, 127f, 155, 175, 182, 201, 210, 219, 247, 262, 266f, 275,

$310,317,339$

Hamlet 110

King Lear 185

Macbeth 392

Richard III. 110

Sládek, Josef V. 41

Sladkovský, Karel 250

Słowacki, Juliusz 281

Mazepa 281

Smetana, Bedřich $17,58,249,251,303$,

316, 457

Braniboŕiv Čechách 249

Dalibor 249

Libuše 251,316 


\section{Prodaná nevěsta 249}

Smetana, Augustin 249

Sophokles 67

Soukup, Daniel 157

Stadion, Franz Seraph von, Graf 30

Štěpán, Václav 51, 131, 245

Štěpánek, Vladimír 129-131, 155, 160f, 163f, 166, 168-171, 186, 190, 191

Štěpánek, Jan N. 15, 19, 135-138, 141, 146-150, 153f, 163f, 175, 179f, 200, 210, 237, 240, 242, 430, 434

Břetislav Pruni, Český Achylles, aneb: Vitèzství u Domažlic 146-154, 175, 179f, 210, 237f, 242, 428, 430, 434, 436 Jaroslav Šternberg aneb porážka Tatarü u Olomouce 163

Obleženi Prahy od Švejdì aneb Vèrnost a udatnost česká 147, 153, 237

Osvobozeni vlasti aneb Korytanév

Cechách 147, 153, 238

Vlastenci aneb Zpráva o vitézství 153

Stich, Alexandr 184f, 189, 206

Stierle, Karlheinz 48, 54

Stöger, Johann A. 138

Štorch, Karel B. 58

Strejček, Ferdinand 139, 192, 201, 225f, 230

Stř́brný, Dominik 434

Stroupežnický, Ladislav 19, 310-312, 316, 324, 458

Pani mincmistrová 310-316

Zvikovský rarášek 311

Štúr, L'udovít 252, 259

Štván, Maximilián 134, 147

Drahomira, ovdovélá kněžna česká, neb

Krvavé boleslavské hody 134

Jiři z Podébrad 134

Oldřich a Božena 134

Svěrák, Eduard 235

Kláster svatého Tomáše 235

Světlá, Karolina 149

Szondi, Peter 55f, 83-85, 101

\section{$\mathbf{T}$}

Tandler, Josef J. 134, 147

Taylor, Charles 59, 61

Tetzeli von Rosador, Kurt $107 \mathrm{f}$

Thám, Karel I. 127, 137
Thám, Václav 127, 134, 147, 154

Bŕetislav a Jitka aneb Únos z klástera 134

Kutnohorský hornici nebo Kdo se vynasnaži, netrpi nouzi 134

Vlasta a Šárka aneb Divcí boj 134

Švédská vojna v Čechách aneb Udatnost pražských městanù a studenti 134

Ther, Philipp 16, 132, 250

Thurn-Taxis, Rudolf von 261

Tichá, Zdeňka 128

Tökei, Éva 250

Tolstoj, Lev N. 40, 94, 391, 423

Topolová, Barbara 19, 130, 147

Trávníčková, Markéta 131

Tschopp, Silvia S. $57 \mathrm{f}$

Tureček, Dalibor 136f, 215, $219 \mathrm{f}$

Turinský, František 154, 164, 339

Angelina 154, 164

Pražanév roku 1648154

Tyl, Josef Kajetán 19, 29f, 32, 47, $109 f$, 130, 137-143, 145, 147, 149, 185f, $188,191,200,214 f, 222 f, 225,233$, 235, 240f, 244f, 247, 324, 366, 369, 371-376, 379, 382-384, 418, 420-423, 425, 431, 434

Čestmir 19, 109, 185-192, 206, 241. 428, 431, 434

Fidlovačka aneb Žádný hnèv a žádná rvacka 132,186

Jan Nepomucký, kanounik pražský 233, 235

Jan Hus 32, 225-235, 244, 366, 372 , 422, 428, 431

Krvavé krtiny, cilli, Drahomira a její synové 19, 30, 225, 366-373, 376, 418, 420-422, 428, 431

Krvavý soud aneb Kutnohorstí haviri

214-225, 242, 324, 372, 428

Rozervanec 190

Strakonickýdudák 225

Turdohlavážena 225

Výhoň Dub 137

Žižka z Trocnova a Bitva u Sudoméric 235

U

Udolph, Ludger 252

Uffelmann, Dirk 227

Urban, Otto 259, 371 
Urbánek, Ferdinand 250

Uspenskij, Boris A. 28

V

Veith, Václav 215

Veltruský, Jiř́i $80,82,86 f$

Vlašínová, Drahomíra 322

Vlček, Václav 17, 295, 302-310, 431, 435

Lipany 303-310, 428, 431, 435

Vocel, Jan E. 155

Harfa 155

Vodička, Felix 126f, 133, 180-182, 185

Vojáček, Václav 19, 193, 366, 368, 421, 430 Ludmila 193-195, 366, 421, 428, 430

Vološinov, Valentin N. 112

Voltaire 281

Vondráček, Jan 131, 136, 145, 153

Vrchlický, Jaroslav 19, 47, 110, 180, 310, $316,324,330,376,380,383 f, 418-420$, 422-425, 431, 434f, 437

Bratri $380-385,418,422,428,431$

Drahomira 376-380, 428, 435, 437

Knižata 180, 376, 384

Noc na Karlštejně 310, 434
Werber, Niels 26, 37

White, Hayden $18,39,42-48,99,113,445$

Wiendl, Jan 385

Wögerbauer, Michael 132-134, $142 \mathrm{f}$

Z

Zahradník, Vincenc 58

Žákavec, František 51

Zákrejs, František 20, 295, 298, 301, 430 Král svého lidu 295-302, 428, 430

Zavřel, František 19, 339, 392, 396, 418, 423-425, 431, 445, 459

Boleslav Ukrutný 392-397, 418, 423-425, 428, 431, 437 Král Premysl Otakar Drubý 339

Zeyer, Julius 20, 47, 155, 316f, 323

Doňa Šanca 20, 323

Neklan 316-323, 428

Libušin hnèv 316

Šárka 316

Zíma, Antonín J. 147, 153, 236

Oldrich a Božena $236 \mathrm{f}$

Zimmerhaklová, Hana $145 f$

Zítek, Josef $250 \mathrm{f}$

W

Weinrich, Harald 48

Wellek, René 78, 142 


\section{BAUSTEINE ZUR SLAVISCHEN PHILOLOGIE UND KULTURGESCHICHTE}

NEUE FOLGE, REIHE A: SLAVISTISCHE FORSCHUNGEN HERAUSGEGEBEN VON DANIEL BUNČIĆ, ROLAND MARTI, PETER THIERGEN, LUDGER UDOLPH UND BODO ZELINSKY

EINE AUSWAHL

BD. 76 | TATIANA G. POPOVA DIE »LEITER ZUM PARADIES« DES JOHANNES KLIMAKOS KATALOG DER SLAVISCHEN HANDSCHRIFTEN

2012. 1073 S. GB. | ISBN 978-3-412-20948-3

BD. 77 | HENRIETTE STÖSSL DIE GEISTLICHE KOMMUNION DER HEILIGEN BORIS UND GLEB EXEMPLARISCHE RHETORIK IN EINEM POLNISCHEN BAROCKDRAMA 2013. 305 S. 15 S/W-ABB. GB. ISBN 978-3-412-20963-6

BD. 78 | PETER SALDEN RUSSISCHE LITERATUR IN POLEN (1864-1904)

2013. 226 S. GB. | ISBN 978-3-412-21022-9

BD. 79 | MAREK NEKULA

TOD UND AUFERSTEHUNG EINER NATION

DER TRAUM VOM PANTHEON IN DER TSCHECHISCHEN LITERATUR UND KULTUR

2017. CA. 740 S. CA. 68 S/W-ABB. GB ISBN 978-3-412-22396-O

BD. 80 | OL'GA LEBEDEVA

\section{ALEKSANDR S. PUŠKIN}

SEIN LITERARISCHES WERK IN RUSSISCHEN UND EUROPÄISCHEN KONTEXTEN

2014. 239 S. GB. | ISBN 978-3-412-22460-8
BD. 81 | DANIEL SCHÜMANN

\section{KAMPF UMS DA(BEI)SEIN}

DARWIN-DISKURSE UND DIE POLNISCHE LITERATUR BIS 1900

2015. 503 S. GB.

ISBN 978-3-412-22504-9

BD. $82 \mid$ CHRISTIAN ZEHNDER AXIOME DER DÄMMERUNG EINE POETIK DES LICHTS BEI BORIS PASTERNAK

2015. 478 S. GB.

ISBN 978-3-412-22503-2

BD. 83 | PETER DEUTSCHMANN

ALLEGORIEN DES POLITISCHEN ZEITGESCHICHTLICHE IMPLIKATIONEN DES TSCHECHISCHEN HISTORISCHEN DRAMAS (1810-1935) 2016. 479 S. 47 GRAFIKEN. GB. ISBN 978-3-412-22510-O

BD. 84 | MICHAELA BÖHMIG, PETER THIERGEN, ANNA-MARIA MEYER (HG.) IVAN A. BUNINS "GOSPODIN IZ SAN-FRANCISKO

TEXT - KONTEXT - INTERPRETATION (1915-2015)

2016. 344 S. UND 16 TAF. MIT 2 S/W- UND 14 FARB. ABB. GB.

ISBN 978-3-412-50142-6

BD. 85 | ANNE HULTSCH (HG.)

IVAN A. GONČAROV

NEUE BEITRÄGE ZU WERK UND WIRKUNG

2016. 256 S. GB. | ISBN 978-3-412-50579-O

BÖHLAU VERLAG, URSULAPLATZ I, D-50668 KÖLN, T:+49 22I 9I3 90-O INFO@BOEHLAU-VERLAG.COM, WWW.BOEHLAU-VERLAG.COM | WIEN KÖLN WEIMAR 
Wie hat sich das historische Drama von der nationalen Wiedergeburt der Tschechen bis zur republikanischen Tschechoslowakei in der Zwischenkriegszeit gewandelt? Die Leitidee dieser Untersuchung ist, dass eine allegorische Struktur in historischen Dramen über bloße Geschichtsdarstellung hinausweist und Bezüge auf die Entstehungszeit der Werke erkennen lässt. Nach allgemeinen dramentheoretischen sowie kulturhistorischen Ausführungen zur Gattung Historisches Drama wird anhand eines Analysekorpus von knapp 50 Dramen nachgezeichnet, welche Spuren politischer Veränderungen in den Texten zu finden sind und wie die historischen Dramen diverse nationale und politische Anliegen reflektieren.

\section{Bausteine zur Slavischen Philologie und Kulturgeschichte}

Reihe A: Slavistische Forschungen, Band 83 